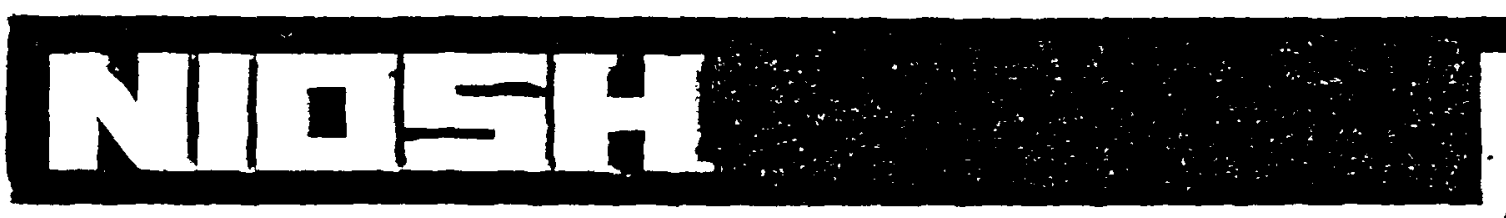

TECHNICAL REPORT

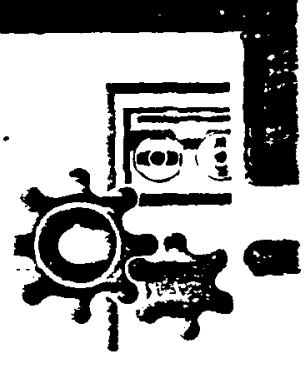

\title{
COMPENDIUM OF MATERIALS FOR NOISE CONTROL
}



COMPENDIUM OF MATERIALS FOR NOISE CONTROL

Robert A. Hedeen.

IIT Research Institute

10 West 35 th Street

Chicago, Illinois 60616

Contract $210-77-00-63$

U.S. DEPARTMENT OF HEALTH, EDUCATION, AND WELFARE

Public Health Service

Center for Disease Control

National Institute for Occupational Safety and Health

Robert A. Taft Laboratories

4676 Columbia Parkway

Cincinnati, Ohio 45226

May 1980

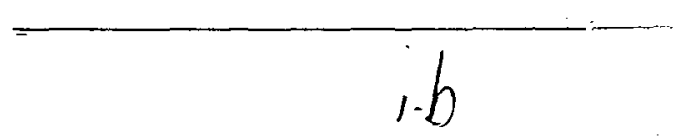


DISCLATMER

The contents of this report are reproduced herein as received from the contractor. The opinions, findings, and conclusions expressed herein are not necessarily those of the National Institute for Occupational Safety and Health, nor does mention of company names or products constitute endorsement by the National Institute for Occupational Safety and Health. NIOSH Project Officer: William McKinnery Principal Investigator: Robert Hedeen

DHEW (NIOSH) Publication No. 80-116 


\section{PREFACE}

The publication of the first edition of the Compendium of Materials for Noise Control (No. 75-165) in 1975 was greeted with enthusiasm by noise control engineers and others interested in aural tranquility. For the first time, a comprehensive listing of noise control materials, with associated technical data, was available in a single source. In the ensuing years, as manufacturers dropped old product lines and added new products, the Compendium began to become obsolete. This second edition has been revised in many ways, but its aim is the same. It is designed for use by those selecting materials and systems for noise control. It will be found useful in determining availability, acoustical performance, and sources of noise control materials and systems, especially those with industrial applications. Data on specific products as well as general information on the uses and limitations of these products are included.

The primary sources of contact with the manufacturers of the products were the list of contributors to the first edition of the Compendium, the "Buyer's Guide" in S/V Sound and Vibration for July and August 1977, and the Riverbank Acoustical Laboratory client list. A total of 627 companies (as well as 21 testing laboratories and manufacturer's associations) derived from these sources were sent letters and questionnaires soliciting descriptions and technical data on their products. Responses generally took the form of product data literature and laboratory test reports, which had to be transcribed into a form suitable for typing in a tabular format. While the greatest pains were taken to ensure the accuracy of the tables, Murphy's Law virtually requires the inclusion of a few minor typographical errors, and for these the authors apologize. The final count of positive responses (those providing usable product information) was 146 , providing a response to contact ratio of 23.3 percent. Remarkably, the ratio for the first edition of the Compendium was an almost identical 23.5 percent, although the contact lists, methods of contact, and numbers contacted were markedly different.

The data tables in this edition of the Compendium are entirely new. Contributors to the previous edition were asked to resubmit their products with the most recent data, and many companies not appearing before are represented. The organization of the data tables and the technical discussion has been revised with the hope of simplifying the use of the volume. The inclusion of eight tables of mufflers, silencers, and ducts is a major improvement to this edition. Data are presented as received from the manufacturers, and have not been verified by IITRI or NIOSH. Some products have been listed with little or no technical data. They have been included to make the user aware that the products exist, and the manufacturer should be contacted for any further required information.

The data tables comprise the principal content of the Compendium. The technical narrative provides highlights of the basic techniques of noise control. 
While not intended as a substitute for the more advanced and detailed books on noise control, it is hoped that it will provide basic reference material for those not already familiar with the subject. This compendium is the authors' contribution to an ultimate goal of a quieter environment. 


\section{ACKNOWLEDGEMENTS}

The preparation of data tables in this document would have been an impossible task without the diligence and patience of John Kopec of IITRI. The assistance of Carol Sessions and Mary Sims, also of IITRI, in preparing the manuscript is appreciated. Pat Wagner, Jill Reed, and Virginia Martin were typists who struggled to interpret the handwritten draft. Special thanks are extended to Dr. Renny S. Norman, IITRI Program Manager, for his understanding of the many problems involved.

Also, NIOSH is grateful to Bruel and Kjaer Instruments for permission to reprint their microphone curves, to EDN Magazine for Figure 1, and to the Acoustical and Insulating Materials Association for providing the absorption data on common building materials in Table 5. The illustrations in the data tables are from the manufacturers' literature and are reprinted with their kind permission. 


\begin{abstract}
This compendium of commercial noise-reduction materials and systems was developed for use by plant engineers, industrial hygenists, acoustical consultants, and others engaged in noise control. It can be used to determine the availability of noise control products, their characteristics and specifications, and their supply sources. Also included is a technical discussion of operating principals, uses, and limitations of the products listed.
\end{abstract}




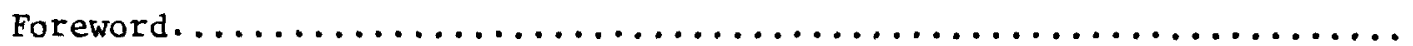
Preface........................................ Acknowledgements ..................................

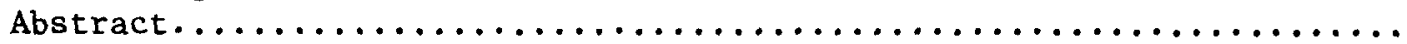
Company Code Numbers and Addresses........................

Other Organizations Supplying Technical Material.............

Categorical Listing of Companies Contributing Data............... Testing Laboratories with Acronyms and Addresses............... Introduction. . . . . . . . . . . . . . . . . . . . . . . . . . . .

Some Basic Concepts...............................

Terminology and Definition..........................

Sound Intensity ..................................

Sound Pressure..................................

Sound Power......................................

Relationship Between Sound Intensity, Pressure, and Power........

Combining Decibels...............................

Directionality...................................

Noise Weighting and Filtering. .......................

Instruments for Noise Measurements....................... 38

Microphones.................................... 38

Sound level Meters.................................. 41

Calibration of Sound Level Meters......................... 43

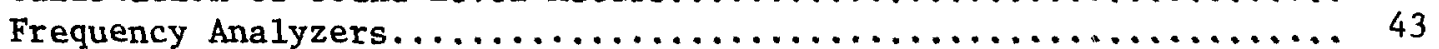

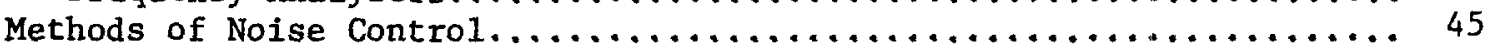

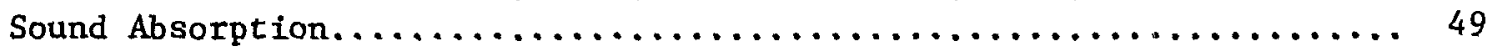

Sound Absorption Measurements (per ASTM C423-77) ............. 50

Absorption Coefficients Exceeding Unity.................. 51

Mountings for Absorption Tests......................... 52

Dependence of Absorption Coefficient on Frequency............ 52

Sound Absorption Measurements (per ASTM C384-58) ............... . . . 54 Relationship Between Random and Normal Incidence Coefficients... 56

Noise Control by Absorption. ............................ 57

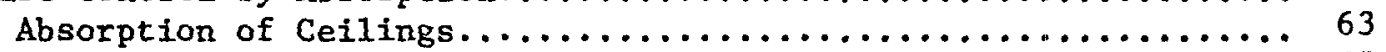

Absorption of Walls.............................. 55

Absorption of Carpets............................ 66

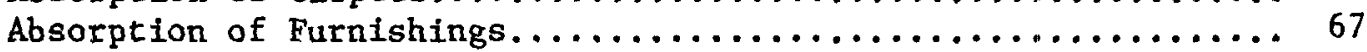

Sound Barriers.....................................68

Sound Transmission Loss Measurements (per ASTM E90-77)........... 69

Dependence of Transmission Loss on Frequency............... 71

Test Facility Requirements........................... 72

Noise Control by Barrier.............................. 73

Walls as Barriers.............................. 77

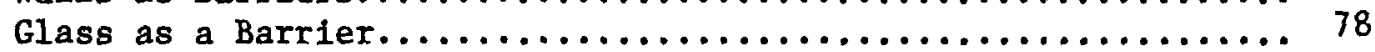




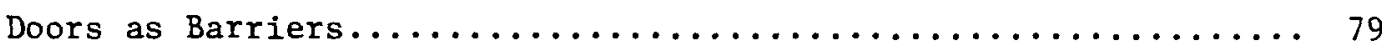

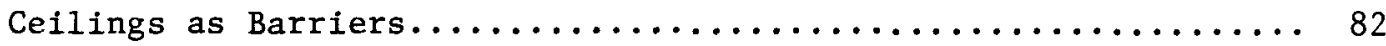

Freestanding Walls as Barriers..................... 82

Noise Reduction and Enclosures....................... 84

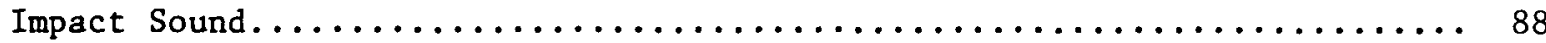

Impact Sound Transmission Measurements (per ASTM E497-77)......... 88

Impact Noise Control.............................. 90

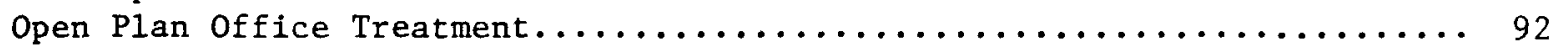

Piping, Ducts, Mufflers and Silencers..................... 94

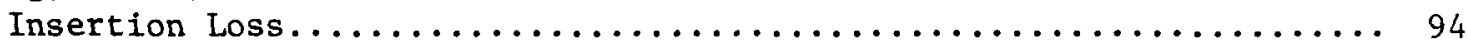

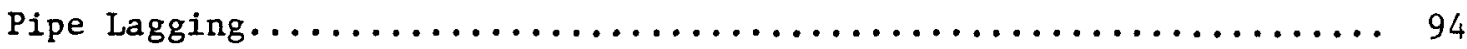

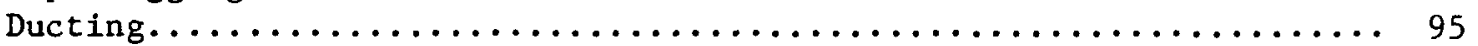

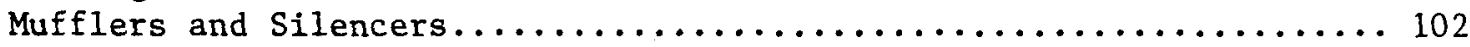

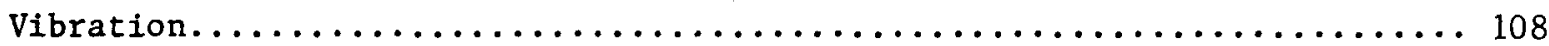

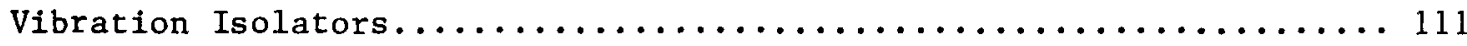

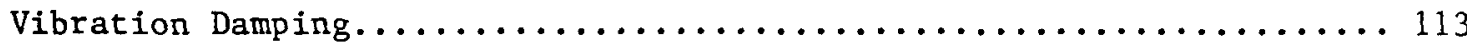

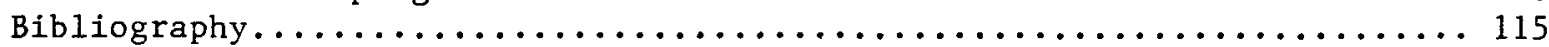

Books on Acoustics and Noise Control................... 115

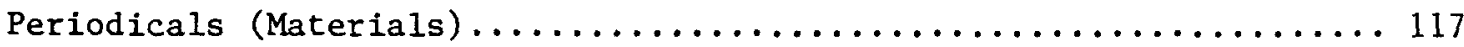

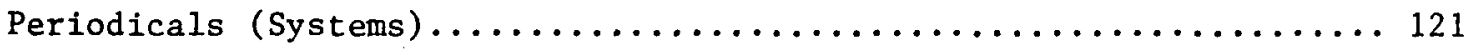

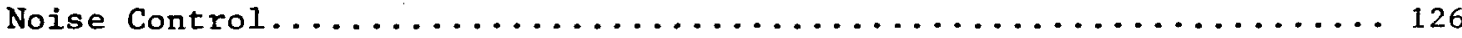

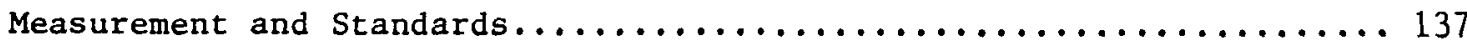

Description of Pertinent Standards............................... 143

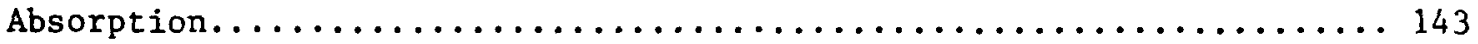

Transmission Loss, Sound Transmission Class, and Impact Isolation.... 145

American National Standards Institute...................... 149

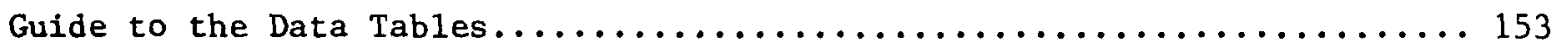

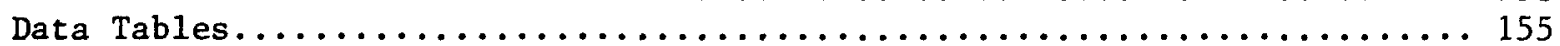

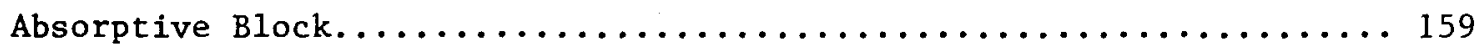

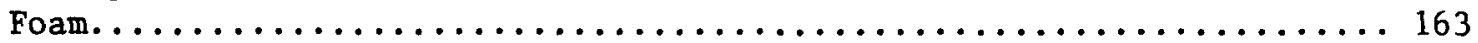

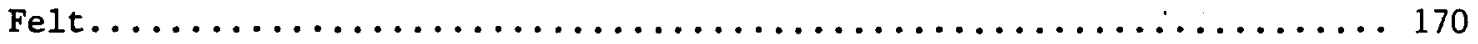

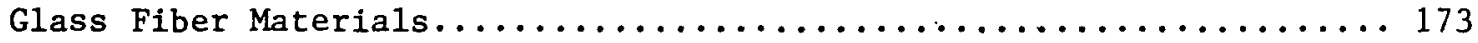

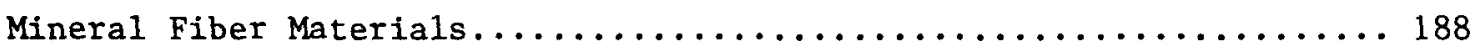

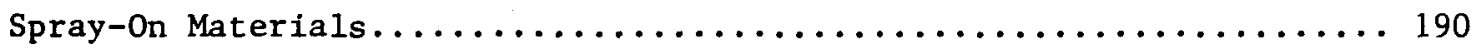

Barrier/Fiberglass Composites........................ 193

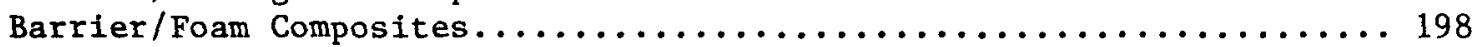

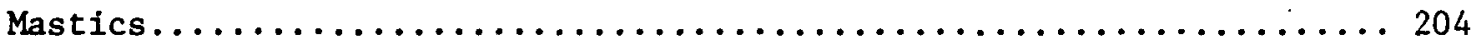

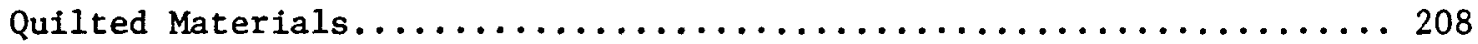

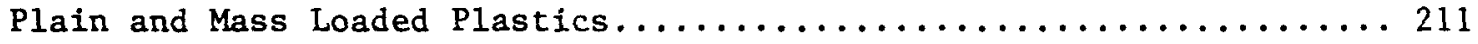

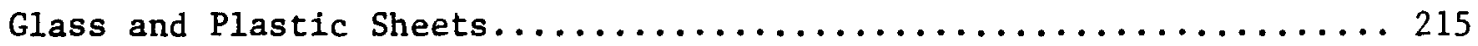

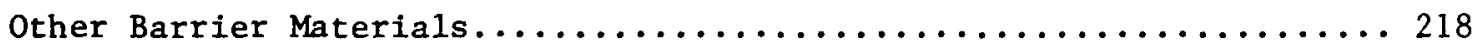

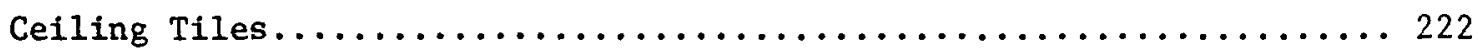

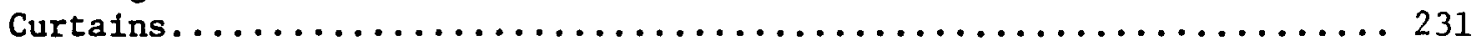

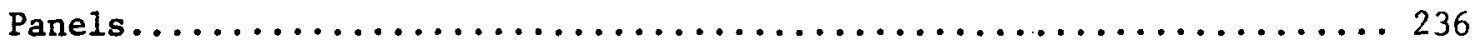

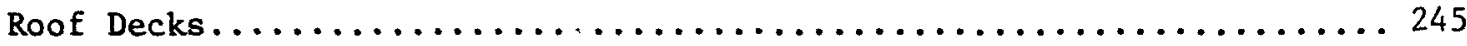

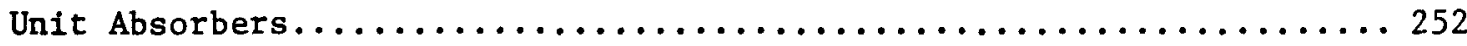

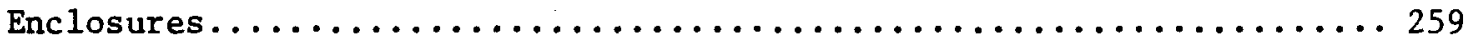

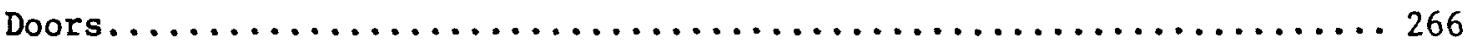

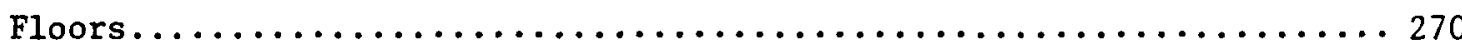

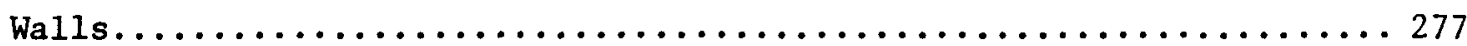


Windows ......................................... 290

Operable Partitions............................... 293

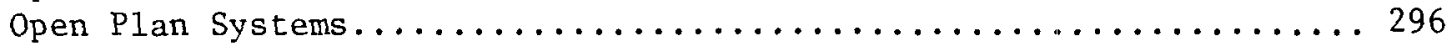

Wall Treatments.................................. 300

Pipe Laggings.................................... 307

General Industrial Silencers............................. 314

High Pressure Discharge Silencers....................... 322

Fan Silencers................................... 327

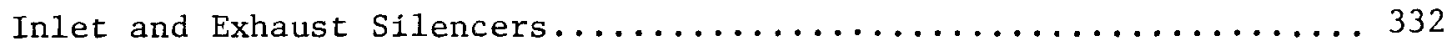

Splitter/Louver Silencers........................... 335

Vehicular Mufflers.................................. 338

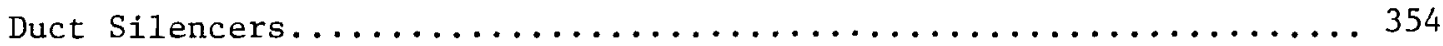

Ducting Materials................................ 359

Seals......................................... 369

Damping Deadeners, and Padding Materials................... 372

Special Applications................................ 375

Index to Data Tables............................... 377

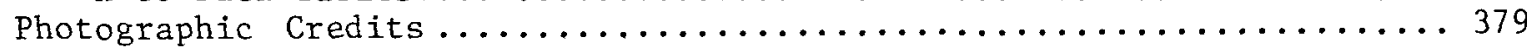

\section{FIGURES}

1. Audible sound frequencies of some musical instruments, voices,

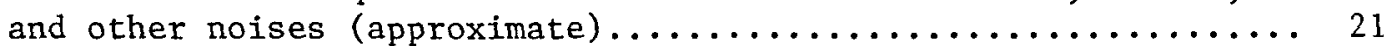

2. Chart for adding or subtracting decibels................. 28

3. Standard A-, B-, and C-weighting curves for sound level meters;

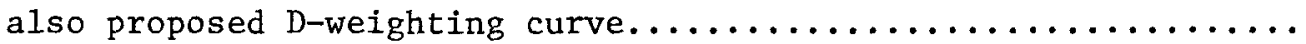

4. Free field correction for microphone with protecting grid......

5. Typica1 directional characteristics for 1-inch microphone with protecting grid.............................440

6. Frequency response curve supplied by $B \& K$ Instruments with 1 -inch pressure microphone type $4144 \ldots \ldots \ldots \ldots \ldots \ldots \ldots \ldots \ldots \ldots \ldots \ldots \ldots$

7. Frequency response curve supplied by $B \& K$ Instruments with 1 -inch

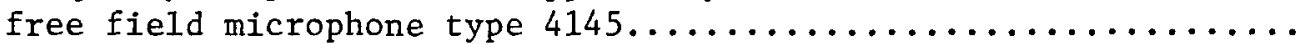

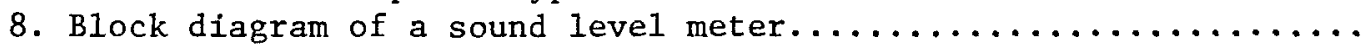

9. Mountings used in sound absorption tests..................

10. Sound absorption coefficients versus frequency for some types of sound absorbing materials.......................

11. Relationship of random to normal incident absorption coefficients

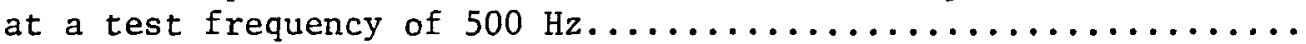

12. Relative sound pressure level versus distance from the source for semireverberant fields.......................

13. Relative distribution of absorption qualities of acoustical ceiling materials............................

14. Typical absorption data for acoustical ceilings.............

15. Typical practical performance of a wall relating to the transmission of sound showing the three separate regions............ 70

16. Determination of sound transmission class.................. 72

17. Possible routes for sound travel from one room to another...... 73

18. Improvement in wall transmission loss by spacing sides, and by adding absorbing material in the cavity................ 
19. Effects of improved sealing of doors on sound transmission class. 80

20. Dependence of sound transmission loss for doors on weight....... 81

21. Geometry for determining sound attenuation by a freestanding wall 83

22. Typical barriers for partial noise control in work areas....... 85

23. Impact insulation class contours..................... 89

24. Interconnections between noise sources, paths, and receivers..... 95

25 . Uses of flexible couplings in ducts................... 96

26. Noise sources and attenuation in a simple duct system......... 97

27. Dependence of noise reduction coefficient of duct lines

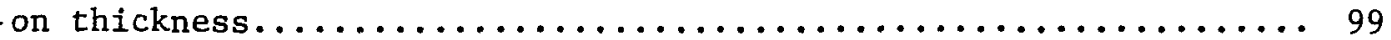

28. Increase of absorbing surface in lined ducts.............. 100

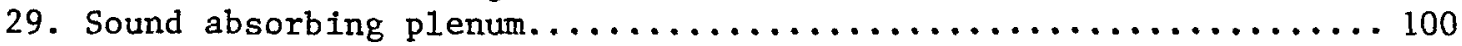

30. Schematic diagram of an expansion chamber................. 103

31. Transmission loss of expansion chamber of length $\ell$ and $s_{2} / s_{1}=m . .104$

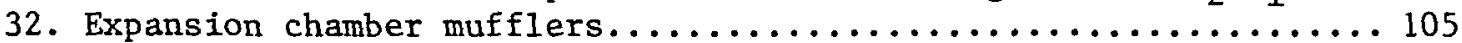

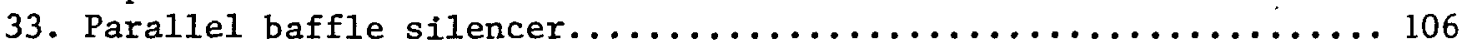

34. Tubular baffle silencer........................... 106

35. Natural frequency of a single degree of freedom vibrating system as a function of static deflection..................... 109

36. Response of a single degree of freedom vibration system with various damping factors......................... 110

37. Vibration isolation of compressor piping................. 112

38. Vibration break in building structure to reduce transmission

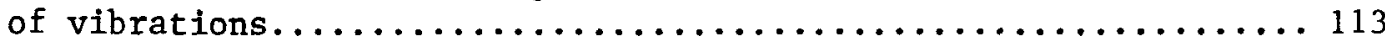

\section{TABLES}

1. Sound intensity level ratios and number of decibels for each..... 24

2. Levels of some common sounds........................ 27

3. $\mathrm{A}-, \mathrm{B}-$, and $\mathrm{C}-$ weighting networks for sound level meters

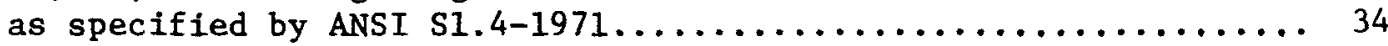

4. Center and cutoff frequencies for preferred series of contiguous octave and one-third octave bands as specified by ANSI S1.6..... 36

5. Absorption coefficients of general building materials

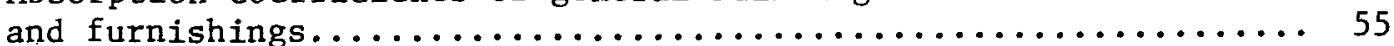

6. Suggested correction factors for large extended areas of the same absorption material..................... 57

7. Air absorption of $20^{\circ} \mathrm{C}$ to be added to average absorption coefficient of room materials......................... 58

8. Noise reduction coefficients for concrete................ 66

9. Effects of padding on carpet noise reduction coefficient....... 67

10. Effects of carpets and pads on impact noise............... 67

11. Sound transmission class of some common building materials..... 71

12. Sound transmission class of monolithic and laminated glass...... 79

13. Sound transmission class of air-spaced glass and monolithic glass of comparable thickness....................... 79

14. Typical improvements with floor and celling treatments......... 90

15. Approximate attenuation in $\mathrm{dB}$ of round elbows.............. 96

16. Duct end reflection loss in $\mathrm{dB} \ldots \ldots \ldots \ldots \ldots \ldots \ldots \ldots \ldots \ldots . \ldots . \ldots . \ldots . \ldots . \ldots$ 
COMPANY CODE NUMBERS AND ADDRESSES

$\underline{\text { Code }}$

Company

$1 \quad$ Accessible Products

2 Acoustex of Canada Ltd.

3 Acoustics Development

4 Acoustiflex Corporation

5 Aeroacoustic Corporation

6 Air Filter Corporation

7 Alcoa (Aluminum Company of America)

$8 \quad$ Allied Steel Products

9 Allied Witan Company

10 Alpha Associates, Inc.
Address

1350 E. 8th St.

Tempe, AZ 85281

(602) $967-8888$

83 Sunrise Ave. Toronto, Ontario M4A1B 1 (416) $751-2380$

1810 Holste Rd. Northbrook, IL 60062 (312) 272-8880

811 Center St. Plainfield, IL 60544 (815) $436-4640$

4876 Victor St. Jacksonville, FL 32207 (904) 731-3577

4554 W. Woolworth Ave. Milwaukee, WI 53218

(414) 353-5800

1501 Alcoa Bldg. Pittsburgh, PA 15219 (412) $553-3770$

7800 N.W. 37 th Ave. Miami, FL 33147 (305) 691-0615

13805 Progress Pkwy. Cleveland, OH 44133 (216) $237-9630$

Two Amboy Ave. Woodbridge, NJ 07095 (201) 634-5700
Pertinent

Data

Table

27

$16,28,29$

38

$2,10,14$, $16,18,25$, 26

$11,14,16$, $19,28,29$, $30,32,34$

31,32

16

20

29

7,16 


\begin{tabular}{|c|c|c|c|}
\hline Code & Company & Address & $\begin{array}{c}\text { Data } \\
\text { Tab1e } \\
\end{array}$ \\
\hline 11 & Alphadyne, Incorporated & $\begin{array}{l}2119 \text { Grand Ave. } \\
\text { St. Paul, MN } 55105 \\
\text { (612) 698-5561 }\end{array}$ & 16,26 \\
\hline 12 & $\begin{array}{l}\text { Alpro } \\
\text { Structural Systems Corporation } \\
\text { (Acoustics Division) }\end{array}$ & $\begin{array}{l}\text { P.0. Box } 50070 \\
\text { New Orleans, LA } 70150 \\
(504) 522-8656\end{array}$ & 5,16 \\
\hline 13 & American Acoustical Products & $\begin{array}{l}9 \text { Cochituate St. } \\
\text { Natick, MA } 01760 \\
(617) 237-4223\end{array}$ & $\begin{array}{l}2,4,7,8 \\
11,13,37\end{array}$ \\
\hline 14 & Amweld Building Products & $\begin{array}{l}100 \text { Plant St. } \\
\text { Niles, OH } 44446 \\
(216) 652-9971\end{array}$ & 20 \\
\hline 15 & Armstrong Cork Company & $\begin{array}{l}\text { W. Liberty St. } \\
\text { Lancaster, PA } 17604 \\
\text { (717) 397-0611 }\end{array}$ & $14,18,26$ \\
\hline 16 & $\begin{array}{l}\text { Arrow Sintered Products } \\
\text { Company }\end{array}$ & $\begin{array}{l}7650 \text { Industrial } \mathrm{Dr} \\
\text { Forest Park, IL } 60130 \\
\text { (312) } 921-7054\end{array}$ & 29 \\
\hline 17 & Atlas Minerals and Chemicals & $\begin{array}{l}\text { Farmington Rd. } \\
\text { Mertztown, PA } 19539 \\
(215) 682-7171\end{array}$ & 29 \\
\hline 18 & Babcock and Wilcox & $\begin{array}{l}\text { P.0. Box } 1260 \\
\text { Lynchburg Research Center } \\
\text { Lynchburg, VA } 24505 \\
(804) 384-5111\end{array}$ & 5,27 \\
\hline 19 & $\begin{array}{l}\text { Barry Wright Corporation } \\
\text { (Vlier Division) }\end{array}$ & $\begin{array}{l}2333 \text { Valley St. } \\
\text { Burbank CA } 91505 \\
\text { (213) } 843-1922\end{array}$ & 29 \\
\hline 20 & BLI Corporation & $\begin{array}{l}33 \text { Parker Ave. } \\
\text { Stamford, CT } 06906 \\
(203) 325-3883\end{array}$ & $\begin{array}{l}4,10,14 \\
16,18,25 \\
26,38\end{array}$ \\
\hline 21 & Bodyguard Inc. & $\begin{array}{l}\text { P.o. Box } 8338 \\
\text { Columbus, OH } 43201 \\
(614) 291-7601\end{array}$ & 16 \\
\hline 22 & Bostik & $\begin{array}{l}\text { Boston St. } \\
\text { Middleton, MA } 01949 \\
(617) 777-0100\end{array}$ & 37 \\
\hline
\end{tabular}


23 Breton Industries Inc.

24 Brunswick Corporation (Technetics Division)

25 Builders Brass Works Corporation

26 The Canada Metal Company Ltd. (Noise Control Division)

27 L. E. Carpenter and Company

28 The Celotex Corporation

29 Certainteed Corporation (Insulation Group)

30 Chemprene Division (The Richardson Company)

31 Chemical Fabrics Corporation

32 Childers Products Corporation

33 Controlled Acoustics Corporation
10 Leonard St.

Amsterdam, NY 12010 (518) 842-3030

2000 Brunswick Ln. Deland, FL 32720 (904) 736-1700

3447 Union Pacific Ave. Los Angeles, CA 90023 (213) 269-8111

721 Eastern Ave. Toronto, Ontario, Canada M4M-1E6 (416) 465-4684

170 N. Main St. Wharton, NJ 08885 (201) 366-2020

P.0. Box 22602

Tampa, FL 33622

(813) $871-4811$

3000 Chrysler Rd. P.0. Box 15080 Kansas City, KS 66115 (913) 342-6624

570 Fishkill Ave. Beac on, NY 12508 (914) 831-2800

P.O. Box 367 108 Northside Dr. Bennington, VT 05201 (802) 442-3122

P.O. Box 22228 23350 Mercantile R.d. Beachwood, $\mathrm{OH} 44122$ (216) $464-8020$

221 E. Hartsdale Ave. Hartsdale, NY 10530 (914) 725-1700
$3,5,9,14$ 7,8

4 $19,27,37$

15

35

36

4

4,35

11,13

$2,7,8,11$, 37 
34 Conwed Corporation (Ceiling Products Division)

35 Curries Manufacturing

36 Daubert Chemical Company

37 DeVac Inc.

38 Dixie Manufacturing Company Inc.

39 Donaldson Company Inc.

40 Doug Biron Associates Inc.

41 H. E. Douglass Engineering Sales Company

42 E. I. DuPont DeNemours and Company Inc.

43 Duracote Corporation

44 Duwe Precast Concrete Products Inc.

45 Eagle-Picher Industries, Inc. (Chemicals and Fibers Division)
332 Minnesota St.

Table

14
(612) 221-1184

2519 th St. S.E.

Mason City, IA 50401

(515) 423-1334

1200 Jorie Blvd.

Oakbrook, IL 60521

(312) 582-1000

10130 State Highway 55

23

Minneapolis, MN 55441

(612) 542-3400

110 Colley Ave.

P.0. Box 59

Norfolk, VA 23501

(804) 625-8251

1400 w. 94 th St.

P.0. Box 1299

Minneapolis, MN 55440

(612) 887-3131

P.0. Box 413

Buford, GA 30518

(404) 945-2929

$2,4,7,8$, $9,11,15$, $16,18,27$, $28,29,37$, 38

10861 Sherman Way

38

Sun Valley, CA 91352

(213) $875-3144$

1007 Market St. Rm. B1216 11

Wilmington, DE 19899

(302) 774-1000

350 N. Diamond St.

8,11

Ravenna, OH 44266

(216) 296-3486

P.0. Box 2068

17

Oshkosh, WI 54901

(414) 231-3980

P.0. Box 1328

5,27

Joplin, MO 64801

(417) $623-8000$ 


\begin{tabular}{|c|c|c|c|}
\hline Code & Company & Address & $\begin{array}{c}\text { Pertinent } \\
\text { Data } \\
\text { Table } \\
\end{array}$ \\
\hline 46 & $\begin{array}{l}\text { Eastman Chemica1 Products, Inc. } \\
\text { (Plastics Products Division) }\end{array}$ & $\begin{array}{l}\text { P.o. Box } 431 \\
\text { Kingsport, TN } 37662 \\
(800) 251-0351\end{array}$ & 12 \\
\hline 47 & $\begin{array}{l}\text { Ecke1 Industries Inc. } \\
\text { (Eckoustic@Division) }\end{array}$ & $\begin{array}{l}155 \text { Fawcett St. } \\
\text { Cambridge, MA } 02138 \\
(617) 491-3221\end{array}$ & $\begin{array}{l}2,4,8,11, \\
15,16,19, \\
37\end{array}$ \\
\hline 48 & Ecology Controls Inc. & $\begin{array}{l}223 \text { Crescent St. } \\
\text { Waltham, MA } 02154 \\
(617) 893-1020\end{array}$ & 38 \\
\hline 49 & Elwin G. Smith Company & $\begin{array}{l}100 \text { Walls St. } \\
\text { Pittsburgh, PA } 15202 \\
\text { (412) } 761-7474\end{array}$ & 16 \\
\hline 50 & $\begin{array}{l}\text { Environmental Elements Corp. } \\
\text { (Sound Control Systems } \\
\text { Group) }\end{array}$ & $\begin{array}{l}\text { P.o. Box } 1318 \\
\text { Baltimore, MD } 21203 \\
(301) 368-7060\end{array}$ & $\begin{array}{l}16,30,31 \\
32,34\end{array}$ \\
\hline 51 & Epic Metals Corporation & $\begin{array}{l}11 \text { Talbot Ave. } \\
\text { Rankin, PA } 15104 \\
\text { (412) 351-3913 }\end{array}$ & 17 \\
\hline 52 & Federated Metals Corporation & $\begin{array}{l}\text { P.o. Box } 2600 \\
270 \text { Foothill Rd. } \\
\text { Somerville, NJ } 08876 \\
(201) 356-2600\end{array}$ & $16,20,22$ \\
\hline 53 & Feeder Corporation of America & $\begin{array}{l}4429 \text { James P1. } \\
\text { Melrose Park, IL } 60160 \\
\text { (312) 343-4900 }\end{array}$ & 38 \\
\hline 54 & Fenestra Company & $\begin{array}{l}4040 \text { W. } 20 \text { th St. } \\
\text { P.0. Box } 8189 \\
\text { Eric, PA } 16505 \\
\text { (814) } 838-2001\end{array}$ & 20 \\
\hline 55 & Fibron Corporation & $\begin{array}{l}\text { P.0. Box } 03061 \\
\text { Portland, OR } 97203 \\
\text { (503) } 286-8315\end{array}$ & $6,21,22$ \\
\hline 56 & Fluid Kinetics Corporation & $\begin{array}{l}\text { P.o. Box C.E. } \\
\text { Ventura, CA } 93001 \\
(805) 644-5587\end{array}$ & 29 \\
\hline 57 & Foamade Industries & $\begin{array}{l}1220 \text { Morse St. } \\
\text { Royal Oak, MI } 48068 \\
\text { (313) 548-5555 }\end{array}$ & 2 \\
\hline
\end{tabular}




\begin{tabular}{|c|c|c|c|}
\hline Code & Company & Address & $\begin{array}{c}\text { Data } \\
\text { Table } \\
\end{array}$ \\
\hline 58 & Foam Design Inc. & $\begin{array}{l}\text { Box } 983 \\
735 \text { Westland Dr. } \\
\text { Lexington, KY } 40501 \\
(606) 252-5671\end{array}$ & 11,15 \\
\hline 59 & Forty-Eight Insulations Inc. & $\begin{array}{l}\text { P.o. Box } 1148 \\
\text { Aurora, IL } 60504 \\
\text { (312) } 896-4800\end{array}$ & 22 \\
\hline 60 & Fromme1t Industries Inc. & $\begin{array}{l}465 \text { Huff St. } \\
\text { Dubuque, IA } 52001 \\
\text { (319) 556-2020 }\end{array}$ & 11 \\
\hline 61 & Gallagher-Kaiser Corporation & $\begin{array}{l}13710 \text { Mt. Elliott Ave. } \\
\text { Detroit, MI } 48212 \\
\text { (313) } 368-3100\end{array}$ & 16 \\
\hline 62 & General Acoustics Corporation & $\begin{array}{l}12248 \text { Santa Monica Blvd. } \\
\text { Los Angeles, CA } 90025 \\
\text { (213) 820-1531 }\end{array}$ & 31 \\
\hline 63 & Glasrock ${ }^{\circledR}$ Products Inc. & $\begin{array}{l}7380 \text { Bohannon Rd. } \\
\text { Fairburn, GA } 30213 \\
\text { (404) } 964-1421\end{array}$ & 29 \\
\hline 64 & Globe-Amerada Glass Company & $\begin{array}{l}2001 \text { Greenleaf Ave. } \\
\text { Elk Grove Village, IL } \\
60007 \\
(312) 439-5200\end{array}$ & 12,23 \\
\hline 65 & Globe Industries Inc. & $\begin{array}{l}2638 \text { E. 126th St. } \\
\text { Chicago, IL } 60633 \\
\text { (312) } 646-1300\end{array}$ & 7,9 \\
\hline 66 & $\begin{array}{l}\text { Goodyear Tire and Rubber } \\
\text { Company }\end{array}$ & $\begin{array}{l}1144 \text { E. Market St. } \\
\text { Akron, OH } 44316 \\
\text { (216) } 794-2616\end{array}$ & $2,8,13,27$ \\
\hline 67. & Haworth Inc. & $\begin{array}{l}545 \text { E. 32nd } \\
\text { Holland, MI } 49423 \\
(616) 392-5961\end{array}$ & 25 \\
\hline 68 & $\begin{array}{l}\text { Holcomb and Hoke } \\
\text { Manufacturing Company Inc. }\end{array}$ & $\begin{array}{l}1545 \text { Van Buren St. } \\
\text { P.0. Box A-33900 } \\
\text { Indianapolis, IN } 46203 \\
\text { (317) } 784-2444\end{array}$ & 24 \\
\hline 69 & Hubert Fiberboard Inc. & $\begin{array}{l}\text { P.o. Box 167, } \\
\text { E. Morgan St. } \\
\text { Boonville, MO } 65233 \\
\text { (816) 882-2704 }\end{array}$ & 22 \\
\hline
\end{tabular}




\begin{tabular}{|c|c|c|c|}
\hline Code & Company & Address & Table \\
\hline 70 & $\begin{array}{l}\text { I.D.E. Processes Corporation } \\
\text { (Noise Control Division) }\end{array}$ & $\begin{array}{l}10681 \text { st Ave. } \\
\text { Kew Gardens, NY } 11415 \\
(212) 544-1177\end{array}$ & $16,19,28$ \\
\hline 71 & Inryco Inc. & $\begin{array}{l}\text { Box } 393 \\
4101 \text { W. Burnham St. } \\
\text { Milwaukee, WI } 53201 \\
\text { (414) } 383-4030\end{array}$ & 16,17 \\
\hline 72 & Insulation Contracting, Inc. & $\begin{array}{l}\text { P.o. Box } 1883 \\
\text { Mobile, AL } 36601 \\
\text { (205) } 456-4561\end{array}$ & 19 \\
\hline 73 & Insul-Coustic Corporation & $\begin{array}{l}\text { Jernee Mill Road } \\
\text { Sayreville, NJ } 08872 \\
(201) 257-6674\end{array}$ & $\begin{array}{l}4,9,10, \\
11,18,26, \\
27,35\end{array}$ \\
\hline 74 & Johns-Manville Corporation & $\begin{array}{l}\text { Ken-Cary1 Ranch } \\
\text { Denver, CO } 80217 \\
(303) 979-1000\end{array}$ & $\begin{array}{l}3,4,14 \\
27,35\end{array}$ \\
\hline 75 & $\begin{array}{l}\text { Kaiser Cement and Gypsum } \\
\text { Corporation }\end{array}$ & $\begin{array}{l}\text { Kaiser Center } \\
300 \text { Lakeside Dr. } \\
\text { Oakland, CA } 94666 \\
\text { (415) 271-2211 }\end{array}$ & 21,22 \\
\hline 76 & Kelley Company, Inc. & $\begin{array}{l}6720 \text { N. Teutonia Ave. } \\
\text { Milwaukee, WI } 53209 \\
\text { (414) 352-1000 }\end{array}$ & 15 \\
\hline 77 & $\begin{array}{l}\text { George Koch Sons Inc. } \\
\text { (Therma1-Acoustics Division) }\end{array}$ & $\begin{array}{l}10 \text { S. 11th Ave. } \\
\text { Evansville, IN } 47744 \\
(812) 425-1321\end{array}$ & $16,19,25$ \\
\hline 78 & Korfund Dynamics Corporation & $\begin{array}{l}\text { P.o. Box } 235 \\
\text { Cantiague Rd. } \\
\text { Westbury, NY } 11590 \\
(516) 33 \cdot 3-7580\end{array}$ & $\begin{array}{l}2,8,11, \\
16,19,34, \\
37\end{array}$ \\
\hline 79 & Laminated Glass Corporation & $\begin{array}{l}355 \text { W. Lancaster Ave. } \\
\text { Haverford, PA } 19041 \\
\text { (215) 642-2344 }\end{array}$ & 12 \\
\hline 80 & Lehigh Fluid Power Inc. & $\begin{array}{l}\text { York Rd., Rt. } 179 \\
\text { Lambertville, NJ } 08530 \\
(609) 397-3487\end{array}$ & 29 \\
\hline 81 & The Logan-Long Company Inc. & $\begin{array}{l}\text { Rt. } 73 \text { and } 25 \\
\text { Franklin, OH } 45005 \\
\text { (513) } 746-4561\end{array}$ & 9,37 \\
\hline
\end{tabular}




\begin{tabular}{|c|c|}
\hline Code & Company \\
\hline 82 & Lord/All Force Acoustics \\
\hline 83 & Maher Engineering Company \\
\hline 84 & $\begin{array}{l}\text { Martin Fireproofing Georgia } \\
\text { Inc. }\end{array}$ \\
\hline
\end{tabular}

85 Metal Building Interior Products Company

86 W. B. McGuire Company Inc.

87 Merco Manufacturing Inc.

88 Modu-Line Window Inc.

89 Monsanto Plastics and Resins Company

90 National Cellulose Corporation

91 National Concrete Masonry Association

92 National Gypsum Company Gold Bond Building Products

93 Noise Control Associates Inc.

2001 Peninsula Dr.

P.0. Box 1067

Erie, PA 16512

(814) $838-7691$

1251 Rand Rd. Des Plaines, IL $60016 \quad 11,13,37$ (312) $824-2124$

P.0. Box 768

17

Elberton, GA 30635

(404) 283-6942

Kane Building

1640 E. 40 th St.

Cleveland, $\mathrm{OH} 44103$

(216) $431-6040$

$4,14,18$, 26

15

Huds on, NY 12534

(518) 828-7652

P.0. Box 4110

17

Dallas, TX 75208

(214) 741-1538

930 Single Ave.

P.0. Box 128

Wausau, WI 54401

(715) 845-9666

800 N. Lindbergh Blvd.

12

St. Louis, MO 63166

(314) 694-1000

12315 Robin Blvd.

Houston, TX 77045

(713) 433-6761

$6,13,18$, 22,27

6845 Elm St.

P.0. Box 135

McLean, VA 22101

(703) $790-8650$

325 Delaware Ave.

Buffalo, NY 14202

14,26

(716) $852-5880$

32 Park St.

Montclair, NJ 07042

(201) 746-5181

Data

Table

$2,15,16$

$18,19,37$,

38

$2,7,8$,

22

8 


\begin{tabular}{|c|c|c|c|}
\hline Code & Company & Address & $\begin{array}{l}\text { Data } \\
\text { Table }\end{array}$ \\
\hline 94 & Noise Reduction Corporation & $\begin{array}{l}\text { Rt. } 1 \text { Box } 3 \\
\text { N. Redwood, MN } 56275 \\
(507) \quad 637-3067\end{array}$ & 38 \\
\hline 95 & Overly Manufacturing Company & $\begin{array}{l}\text { P.0. Box } 70 \\
574 \text { w. Otterman } 5 t . \\
\text { Greensburg, PA } 15601 \\
(412) 834-7300\end{array}$ & 20 \\
\hline 96 & $\begin{array}{l}\text { Owens Corning Fiberglass } \\
\text { Corporation }\end{array}$ & $\begin{array}{l}\text { Sound Laboratory } \\
\text { B1dg. } 300 \\
\text { Grandville, OH } 43023 \\
(614) 587-0610\end{array}$ & $\begin{array}{l}4,11,14 \\
18,25,26 \\
27,35\end{array}$ \\
\hline 97 & Owens Illinois Inc. & $\begin{array}{l}\text { P.o. Box } 1035 \\
\text { Toledo, OH } 43666 \\
\text { (419) } 247-5000\end{array}$ & 13 \\
\hline 98 & Pittsburgh Corning Corporation & $\begin{array}{l}800 \text { Presque Isle } \mathrm{Dr} \\
\text { Pittsburgh, PA } 15239 \\
(412) 327-6100\end{array}$ & $4,18,35$ \\
\hline 99 & Plicoflex Inc. & $\begin{array}{l}1430 \text { E. Davis St. } \\
\text { Arlington Heights, IL } \\
60005 \\
(312) 392-5700\end{array}$ & 24 \\
\hline 100 & Presray Inc. & $\begin{array}{l}159 \text { Maple Blivd. } \\
\text { Pawling, NY } 12564 \\
\text { (914) } 855-1220\end{array}$ & 36 \\
\hline 101 & The Proud Foot Company Inc. & $\begin{array}{l}\text { P.0. Box } 9 \\
\text { Greenwich, CT } 06830 \\
\text { (203) } 869-9031\end{array}$ & 1,18 \\
\hline 102 & Quietflo & $\begin{array}{l}137 \text { S. Middletown Rd. } \\
\text { Nanuet, NY } 10954 \\
\text { (914) 352-8877 }\end{array}$ & 28 \\
\hline 103 & The R.C.A. Rubber Company & $\begin{array}{l}1833 \text { E. Market St. } \\
\text { Akron, OH } 44305 \\
(216) 784-1291\end{array}$ & 21 \\
\hline 104 & $\begin{array}{l}\text { Reeves Brothers Inc. } \\
\text { (Noise Control Materials } \\
\text { Division) }\end{array}$ & $\begin{array}{l}222 \text { Rampart St. } \\
\text { Charlotte, NC } 28203 \\
(704) 333-1131\end{array}$ & 2,15 \\
\hline 105 & $\begin{array}{l}\text { Richards-Wilcox } \\
\text { Manufacturing Company }\end{array}$ & $\begin{array}{l}174 \text { 3rd St. } \\
\text { Aurora, IL } 60507 \\
\text { (312) } 897-6951\end{array}$ & 20,24 \\
\hline
\end{tabular}




\begin{tabular}{|c|c|c|c|}
\hline Code & Company & Address & $\begin{array}{r}\text { Data } \\
\text { Table } \\
\end{array}$ \\
\hline 106 & Robinson Acoustics Ltd. & $\begin{array}{l}313 \text { Enford Rd. } \\
\text { Richmond Hil1, Ontario } \\
\text { L4C3E9 } \\
(416) 889-0218\end{array}$ & 26 \\
\hline 107 & Rohm and Haas Company & $\begin{array}{l}\text { Independence Mall West } \\
\text { Philadelphia, PA } 19105 \\
\text { (215) 592-3000 }\end{array}$ & 12 \\
\hline 108 & Roliform Products, Inc. & $\begin{array}{l}220 \text { Seegers } \\
\text { E1k Grove Village, IL } \\
60007 \\
(312) 640-7760\end{array}$ & 17 \\
\hline 109 & Scientific Applications Inc. & $\begin{array}{l}\text { P.0. Box } 615 \\
\text { Highway } 34 \mathrm{~W} \text {. } \\
\text { Mt. Pleasant, IA } 52641 \\
\text { (319) } 385-9021\end{array}$ & $2,21,22$ \\
\hline 110 & Shatterproof Glass Corporation & $\begin{array}{l}4815 \text { Cabot Ave. } \\
\text { Detroit, MI } 48210 \\
\text { (313) 582-6200 }\end{array}$ & 12 \\
\hline 111 & Shielding, Inc. & $\begin{array}{l}3295 \text { S. Highway } 97 \\
\text { Redmond, OR } 97756 \\
\text { (503) 548-4032 }\end{array}$ & 11 \\
\hline 112 & Singer Safety Products Inc. & $\begin{array}{l}444 \text { N. Lake Shore Dr. } \\
\text { Chicago, IL } 60611 \\
\text { (312) 222-1860 }\end{array}$ & $\begin{array}{l}2,11,15, \\
19\end{array}$ \\
\hline 113 & Span-Deck Incorporated & $\begin{array}{l}\text { Box } 99 \\
\text { Franklin, TN } 37064 \\
(615) 794-4556\end{array}$ & 17,21 \\
\hline 114 & $\begin{array}{l}\text { Sonic Barrier } \\
\text { Sound Products Ltd. }\end{array}$ & $\begin{array}{l}3400 \text { Lysander Ln. } \\
\text { Richmond, } \\
\text { British Columbia V7B1C3 } \\
(604) 273-5722\end{array}$ & 19 \\
\hline 115 & Sonotrol Systems Ltd. & $\begin{array}{l}486 \text { Evans Ave., Unit 非8 } \\
\text { Toronto, Ontario, } \\
\text { Canada M8W2T7 } \\
\text { (416) 252-5979 }\end{array}$ & 18,26 \\
\hline 116 & Sorber Sound Proofing Company & $\begin{array}{l}8 \text { Aaron St. } \\
\text { Framingham, MA } 01701 \\
(617) 879-2140\end{array}$ & 15 \\
\hline
\end{tabular}




\begin{tabular}{|c|c|c|c|}
\hline Code & Company & Address & $\begin{array}{c}\text { Data } \\
\text { Table } \\
\end{array}$ \\
\hline 117 & The Soundcoat Company, Inc. & $\begin{array}{l}175 \text { Pearl St. } \\
\text { Brooklyn, NY } 11201 \\
(212) 858-4100\end{array}$ & $\begin{array}{l}2,7,8,11 \\
13,37\end{array}$ \\
\hline 118 & Sound Control Design & $\begin{array}{l}215 \frac{1}{2} \text { S. County St. } \\
\text { Waukegan, IL } 60085 \\
\text { (312) 623-1317 }\end{array}$ & 25 \\
\hline 119 & Sound Fold Inc. & $\begin{array}{l}\text { P.O. Box } 2125 \\
\text { Dayton, OH } 45429 \\
\text { (513) } 228-3773\end{array}$ & 15 \\
\hline 120 & Sound-Meta1 Engineering Inc. & $\begin{array}{l}\text { P.o. Box 58 } \\
\text { Lawrenceville, IL } 62439 \\
(618) 943-2396\end{array}$ & 16,19 \\
\hline 121 & The Spencer Turbine Company & $\begin{array}{l}600 \text { Dayhill Rd. } \\
\text { Windsor, CT } 06095 \\
\text { (203) 688-8361 }\end{array}$ & 31 \\
\hline 122 & Stanley Door Systems & $\begin{array}{l}2400 \text { E. Lincoln Rd. } \\
\text { Birmingham, MI } 48012 \\
\text { (313) 646-1100 }\end{array}$ & 20 \\
\hline 123 & Stark Ceramics, Inc. & $\begin{array}{l}\text { P.o. Box } 8880 \\
\text { Canton, OH } 44711 \\
\text { (216) } 488-1211\end{array}$ & 1 \\
\hline 124 & Sunnex Corporation & $\begin{array}{l}87 \text { Crescent Rd. } \\
\text { Needham, MA } 02194 \\
\text { (617) 444-4730 }\end{array}$ & 29 \\
\hline 125 & Tempmaster Corporation & $\begin{array}{l}1222 \text { Ozark St. } \\
\text { N. Kansas City, MO } 64116 \\
(816) 421-0723\end{array}$ & 16,19 \\
\hline 126 & Tex-Steel Corporation & $\begin{array}{l}467 \text { Industrial Air Park } \\
\text { P.0. Box } 992 \\
\text { Harlingen, TX } 78550 \\
(512) \text { 423-0912 }\end{array}$ & 20 \\
\hline 127 & Tracoustics Inc. & $\begin{array}{l}415 \text { E. St. Elmo Rd. } \\
\text { P.o. Box } 3610 \\
\text { Austin, TX } 78764 \\
(512) 444-1961\end{array}$ & 19 \\
\hline 128 & Transco Inc. & $\begin{array}{l}55 \text { E. Jackson Blvd. } \\
\text { Chicago, IL } 60604 \\
\text { (312) } 427-2818\end{array}$ & 16 \\
\hline
\end{tabular}


129. Trus Joist Corporation

130 Tube-Lok Products

131 United Sheet Metal Division (McGil1 Corporation)

132 United States Department of Agriculture, Forest Products Lab

133 United States Gypsum Company

134 United Steel Deck, Inc.

135 Universal Silencer Division Nelson Industries Inc.

136 Upstate Precision Manufacturing Inc.

137 Velcro USA Inc.

138 Verco Manufacturing Inc.

139 Vibration and Noise Engineering Corporation

\section{Address}

9777 W. Chinden Blvd. Boise, ID 83702

(208) 375-4450

4644 S.E. 17 th Ave.

Portland, OR 97202

(503) 234-9731

200 E. Broadway

Westerville, OH 43081

(614) 882-7401

P.O. Box 5130

Madison, WI 53705

(608) 257-2211

$101 \mathrm{~S}$. Wacker Dr. Chicago, IL 60606

(312) 321-3865

475 Springfield Ave.

17

P.O. Box 662

Summit, NJ 07901

(201) 277-1617

P.O. Box 411

28

Stoughton, WI 53589

(608) 873-4272

Franklyn Building Rt: 9

Plattsburgh, NY 12901

(518) 563-7440

6815 th Ave. 38

New York City, NY 10022 (212) 751-2144

4340 N. 42nd Ave. Phoenix, AZ 85019 (602) 272-1347

Metro Square

2655 Villa Creek Dr.

Dallas, TX 75234

(214) 243-1951

800 Park Dr.

Pertinent

Data

Table

21

2,8

16,35

22

$18,25,26$

Owatonna, MN 55060

(507) 451-9551
19,28

17 


\begin{tabular}{|c|c|c|c|}
\hline Code & Company & Address & $\begin{array}{c}\text { Data } \\
\text { Table } \\
\end{array}$ \\
\hline 141 & Vogel Peterson & $\begin{array}{l}\text { Rt. } 83 \text { and Madison St. } \\
\text { Elmhurst, IL } 60126 \\
\text { (312) 279-7123 }\end{array}$ & 25 \\
\hline 142 & $\begin{array}{l}\text { VSM Corporation } \\
\text { Environmental Systems Group }\end{array}$ & $\begin{array}{l}7515 \text { Northfield Rd. } \\
\text { Cleveland, OH } 44146 \\
\text { (216) } 439-5400\end{array}$ & 16 \\
\hline 143 & Warren Sales Corporation & $\begin{array}{l}\text { Box } 11849 \\
\text { Knoxville, TN } 37919 \\
(615) 588-6459\end{array}$ & 1 \\
\hline 144 & $\begin{array}{l}\text { Western Conference of Lathing } \\
\text { and Plastering Institutes, } \\
\text { Inc. }\end{array}$ & $\begin{array}{l}\text { P.o. Box } 6468 \\
\text { Santa Anna, CA } 92706 \\
\text { (714) } 531-1278\end{array}$ & 21,22 \\
\hline 145 & Weyerhaeuser Company & $\begin{array}{l}\text { P.o. Box } 188 \\
\text { Longview, WA } 98632 \\
\text { (206) } 425-2150\end{array}$ & $20,21,22$ \\
\hline \multirow[t]{7}{*}{146} & $\begin{array}{l}\text { Zero, Weather Stripping } \\
\text { Company Inc. }\end{array}$ & $\begin{array}{l}415 \text { Concord Ave. } \\
\text { Bronx, NY } 10455 \\
(212) 583-3230\end{array}$ & 36 \\
\hline & \multicolumn{3}{|c|}{ OTHER ORGANIZATIONS SUPPLYING TECHNICAL MATERIAL } \\
\hline & $\begin{array}{l}\text { Association of Home Appliance } \\
\text { Manufacturers (AHAM) }\end{array}$ & $\begin{array}{l}20 \text { N. Wacker Dr. } \\
\text { Chicago, IL } 60606 \\
\text { (312) 236-2921 }\end{array}$ & \\
\hline & $\begin{array}{l}\text { Brick Institute of America } \\
\text { (BIA) }\end{array}$ & $\begin{array}{l}1750 \text { Old Meadow Rd. } \\
\text { McLean, VA } 22101 \\
(703) 893-4010\end{array}$ & \\
\hline & $\begin{array}{l}\text { Hardwood Plywood Manufacturing } \\
\text { Association (HPMA) }\end{array}$ & $\begin{array}{l}\text { P.0. Box } 6246 \\
\text { Arlington, VA } 22206 \\
(703) 671-6262\end{array}$ & \\
\hline & $\begin{array}{l}\text { National Concrete Masonry } \\
\text { Association (NCMA) }\end{array}$ & $\begin{array}{l}6845 \text { Elm St. } \\
\text { P.O. Box } 135 \\
\text { McLean, VA } 22101 \\
(703) 790-8650\end{array}$ & \\
\hline & Portland Cement Association (PCA) & $\begin{array}{l}5420 \text { old Orchard Rd. } \\
\text { Skokie, IL } 60076 \\
\text { (312) } 966-6200\end{array}$ & \\
\hline
\end{tabular}




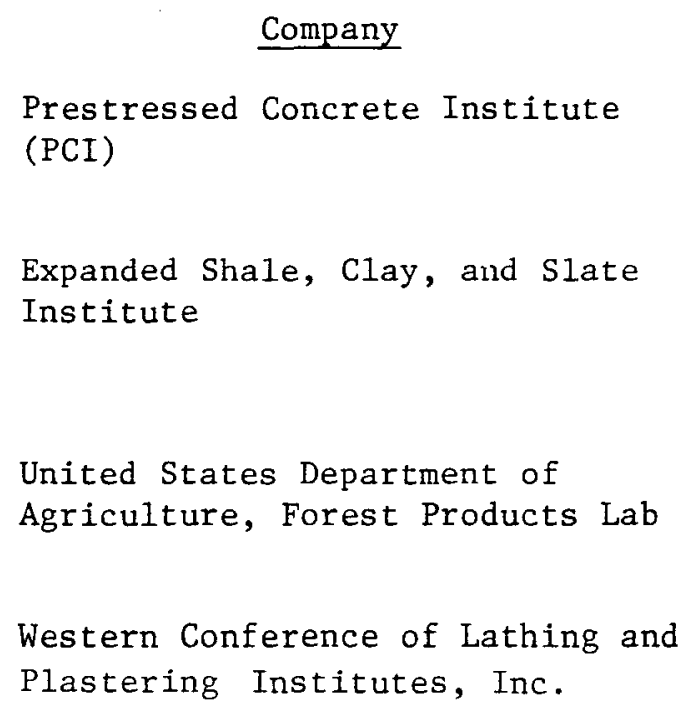

$20 \mathrm{~N}$. Wacker Dr. Chicago, IL 60606 (312) 346-4071

7401 Wisconsin Ave. Suite 414

Bethesda, MD 20014

(301) 654-0140

P.O. Box 5130

Madison, WI 53705

(608) 257-2211

P.0. Box 6468

Santa Anna, CA 92706

(714) 531-1278 


\section{CATEGORICAL LISTINGS OF COMPANIES CONTRIBUTING DATA}

Group A: Noise Control Materials

1 Absorptive Block

2 Foams

$3 \quad$ Felt

4

5

6

7

8

9

10

11

12

17 Roof Decks

18

19

20
Ceiling Tile

Curtains

Panels

Unit Absorbers

Enclosures

Doors
Glass Fiber Material

Mineral Fiber

Spray On

Barrier/Fiberglass

Barrier/Foam

Mastic

Quilted

Plain and Mass Loaded Plastics

Glass/Plastic Sheets

Other Barrier Materials
$101,123,143$

$4,13,33,40,47,57,66,78,82$, $104,109,112,117,130$

28,74

$13,20,27,29,31,40,47,73,74$, $85,96,98$

$12,18,28,45$

55,90

$10,13,26,33,40,65,117$

$13,26,33,40,43,47,66,78,117$, 130

$28,40,65,73,81$

$4,20,73,93$

$5,13,30,33,40,42,43,47,58,60$, $73,78,96,111,112,117$

$46,64,79,89,107,110,140$

$13,30,66,90,97,117$

\section{Group B: Noise Control Systems}

$4,5,15,28,34,74,85,92,96$

$23,40,47,58,76,82,86,104,112$, 116,119

$2,4,5,7,11,12,21,40,47,49$, $50,52,61,70,71,77,78,82,120$, $125,128,131,142$

$44,51,71,84,87,108,113,134,138$ $4,15,20,40,73,82,85,90,96,98$, $101,115,133$

$5,32,47,70,72,77,78,82,112$, $114,120,125,127,139$

$8,14,35,52,54,95,105,122,126$, 145 


\begin{tabular}{|c|c|c|}
\hline Table & Title & Organization Code Numbers \\
\hline 21 & Floors & $55,75,103,109,113,129,144,145$ \\
\hline 22 & Walis & $\begin{array}{l}52,55,59,69,75,90,91,109,132, \\
144,145\end{array}$ \\
\hline 23 & Windows & $37,64,88$ \\
\hline 24 & Operable Partitions & $68,99,105$ \\
\hline 25 & Open Plan & $4,67,77,96,118,133,136,141$ \\
\hline 26 & Wall Treatment & $\begin{array}{l}4,11,15,73,85,92,96,106,115, \\
133\end{array}$ \\
\hline 27 & $\begin{array}{l}\text { Pipe Lagging } \\
\qquad \text { Group C: Muffler, Si }\end{array}$ & $\begin{array}{l}1,18,32,40,45,66,73,74,90,96 \\
\text { ncer, and Duct Systems }\end{array}$ \\
\hline 28 & General Industrial Silencers & $2,5,40,70,102,135,139$ \\
\hline 29 & High Pressure Discharge & $\begin{array}{l}2,5,9,16,17,19,40,56,63,80, \\
124\end{array}$ \\
\hline 30 & Fan Silencers & 5,50 \\
\hline 31 & Inlet and Exhaust Silencers & $6,50,62,121$ \\
\hline 32 & Splitter/Louvers & $5,6,50$ \\
\hline 33 & Vehicular Mufflers & 39 \\
\hline 34 & Duct Silencers & $5,50,78$ \\
\hline 35 & Group D: & $\begin{array}{l}24,29,73,74,96,98,131 \\
\text { scellaneous }\end{array}$ \\
\hline 36 & Seals & $25,100,146$ \\
\hline 37 & Damping, Deadeners, Padding & $\begin{array}{l}13,22,32,33,36,38,40,47,78, \\
81,82,117\end{array}$ \\
\hline 38 & Special Applications & $3,20,40,41,48,53,82,94,137$ \\
\hline
\end{tabular}


Armstrong Acoustical Laboratories........................ AAL West Liberty St.

Lancaster, PA 17604

(717) $397-0611$

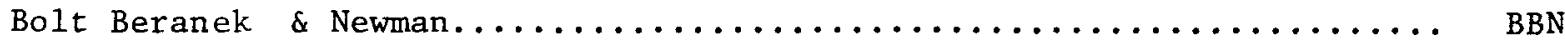
50 Mouiten St.

Cambridge, MA 02138

(617) 491-1850

Cedar Knolls Acoustical Laboratory........................ CKAL 9 Saddle Rd.

Cedar Knolls, NJ 07927

(201) 539-6261

Cominco Product Research Center.......................... CLC Sheridan Park

Mississaqua, Ontario L5K1B4

(416) $822-2022$

Company Reference................................... CR

Company Test.............................. CT

Detroit Testing Laboratory Inc......................... DTL 8720 Northend

Oak Park, MI 48237

(313) $398-2100$

Geiger $\&$ Hamme Labs...................................... G\&H Box 1345

Ann Arbor, MI 48106

(313) $971-3033$

International Acoustics Testing Laboratory Inc. (INTEST)............ INTEST P.0. Box 8049

St. Paul, MN 55113

(612) 645-6699

Jim Walters Testing Laboratories....................... JW Jim Walters Research Corp. 103019 th St. N.

St. Petersburg, FL 33702

(813) $576-4171$ 
Electrical Testing Labs

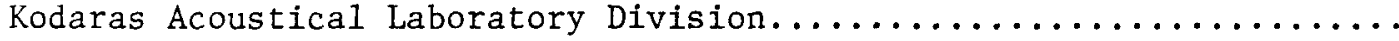
Industrial Park

Cortland, NY 13045

(607) $753-6711$

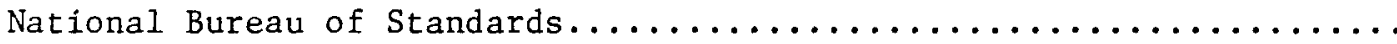

Sound Section

Room B106, B1dg. 233

Washington, D.C. 20234

(301) 921-3607

National Gypsum Company............................. NGC 1650 Military Rd.

Buffalo, NY 14217

(716) $873-9750$

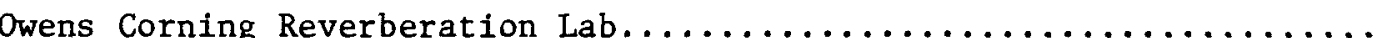

OCRL

Product Testing Laboratory

Technical Center, Owens Corning Fiberglass Corporation

P.0. Box 415

Granville, OH 43023

(614) $587-0610$

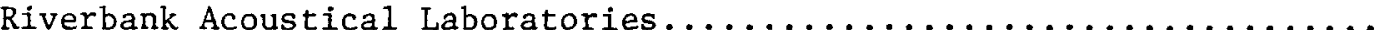

IIT Research Institute

RAL

1512 Batavia Ave.

Geneva, IL 60134

(312) 232-0104

Simpson Timber Company Research Center...................... SRC

3330 Overlake Pkwy.

Redmond, WA 98052

(206) $885-4181$

Wingerter Laboratories Incorporated..................... WLI

1820 N.E. 144 th St.

N. Miami, FL 33161

(305) $944-3401$

These organizatiors are the sources of the technical data presented in the tables. Their acronyms appear in the reference column of all tables. When the data provided by a manufacturer was not associated with a specific test laboratory, the letters $C R$ indicate that the data was derived from a company reference. Following CR, when available, is the identification of the particular company brochure in which the data is published.

CKAL, CLC, G\&H, INTEST, KAL, and RAL are independent acoustical testing laboratories specializing in the testing of noise control materials to the appropriate standards. AAL, JW, NGC, OCRL, and SRC are laboratories owned and operated by the manufacturer for the purpose of testing their own products. They occasionally perform tests for other companies. NBS no longer performs tests of this sort on a routine basis as in the past. BBN is an acoustical consulting firm. DTL and WLI perform a variety of testing services in addition to acoustical tests. 


\section{INTRODUCTION}

The sounds of industry, growing in volume over the years, have heralded not only technical and economic progress but also the threat of an everincreasing incidence of hearing loss and other noise related health hazards to exposed employees. Noise is not a new hazard. Indeed, noise-induced hearing loss was observed centuries ago. Ramazzini in "De Morbis Artificium Distriba" in 1700 described how those hammering copper "have their ears so injured by that perpetual din...that workers of this class became hard of hearing and, if they grow old at this work, completely deaf." Before the Industrial Revolution, however, comparatively few people were exposed to high level workplace noise. It was the advent of steam power in connection with the Industrial Revolution that first brought general attention to noise as an occupational hazard. Workers who fabricated steam boilers were found to develop hearing loss in such numbers that such a malady was dubbed "boilermakers disease". Increasing mechanization in all industries and most trades has since proliferated the noise problem.

Exposures to noise levels found at the workplace, particularly in mechanized industries, are likely to be the most intense and sustained of any experience in daily living. As such, they represent the severest form of acoustic insult to man and therein pose the greatest harm to human function. The effects of occupational noise exposures include:

Temporary and permanent losses in hearing sensitivity

Physical and psychological disorders

Interference with speech communications or the reception of other wanted sounds

Decremental job performance

Engineering controls for the abatement of environmental noise reduce the intensity of the noise either at the source or in the immediate exposure environment. A number of these procedures require considerable expertise, and it is recommended that employers avail themselves of the services of a competent acoustical engineer in development of a noise abatement program. However, many noise control techniques may be implemented directly by company personnel at relatively little expense. (NOTE: The foregoing discussion was excerpted from "Criteria for a Recommended Standard... Occupational Exposure to Noise", DHEW (NIOSH) 1972). 


\section{SOME BASIC CONCEPTS}

\section{TERMINOLOGY AND DEFINITIONS}

Sound consists of pressure waves traveling in an elastic medium, such as air, with propagation occurring in the direction of the wave motion. Noise is a subclass of sound: that sound which is undesirable to its receiver.

A pure tone of sound originates from simple harmonic motion, e.g., the reciprocating motion of a piston in air. The sound wave produced by this motion is a sinusoidal pressure wave whose fluctuation is governed by the displacement and rate at which the piston moves back and forth. Frequency is defined as the number of times this pressure fluctuation passes through a complete cycle in $1 \mathrm{sec}$. The unit of frequency is the hertz ( $1 \mathrm{~Hz}=1$ cycle per sec). The sound frequencies of some common items in air are shown in Figure 1.

The smal1 changes above and below atmospheric pressure resulting from this compression and rarefaction of the air molecules are called "sound pressure". Since sound pressure is a periodic phenomenon, it is invariably expressed in terms of its root mean square (rms) value. Physiologically, the sensation of hearing is produced by this pressure variation. Broadband noise may be defined as a combination of sound waves with differing frequencies and amplitudes as distinct from a pure tone which has a single frequency and amplitude. Thus, broadband noise is a sound wave composed of a number of components combining to yield a resultant complex wave. In noise control work, broadband noise is the most common type of sound. The techniques available for analyzing the components of broadband noise into distinct frequency ranges is referred to as "spectral analysis".

If one were to freeze an oscillating, traveling, pressure fluctuation in time its resultant would be a wavelength defined as the measured distance between the maximum pressure points or any other analogous points on two successive parts of the wave. The Greek letter lambda $(\lambda)$ is the symbol for wavelength, and it is measured in units of feet or meters.

The velocity with which the corresponding pressure points on successive parts of the wave pass a given point is the speed of sound, and the speed of sound is always equal to the product of the wavelength and the frequency, i.e., $c=\lambda f$. This speed is dependent on the equilibrium pressure, ps, of the gas through which the sound wave is traveling and on the equilibrium gas density, $\rho$. The speed of sound (c) is given by the expression

$$
c=\sqrt{\gamma p_{s} / \rho} \quad \mathrm{m} / \mathrm{sec} \text { or } \mathrm{ft} / \mathrm{sec}
$$

where the constant $\gamma$ is the ratio of the specific heat of a gas at constant pressure to its specific heat at constant volume. For air, at most normally 


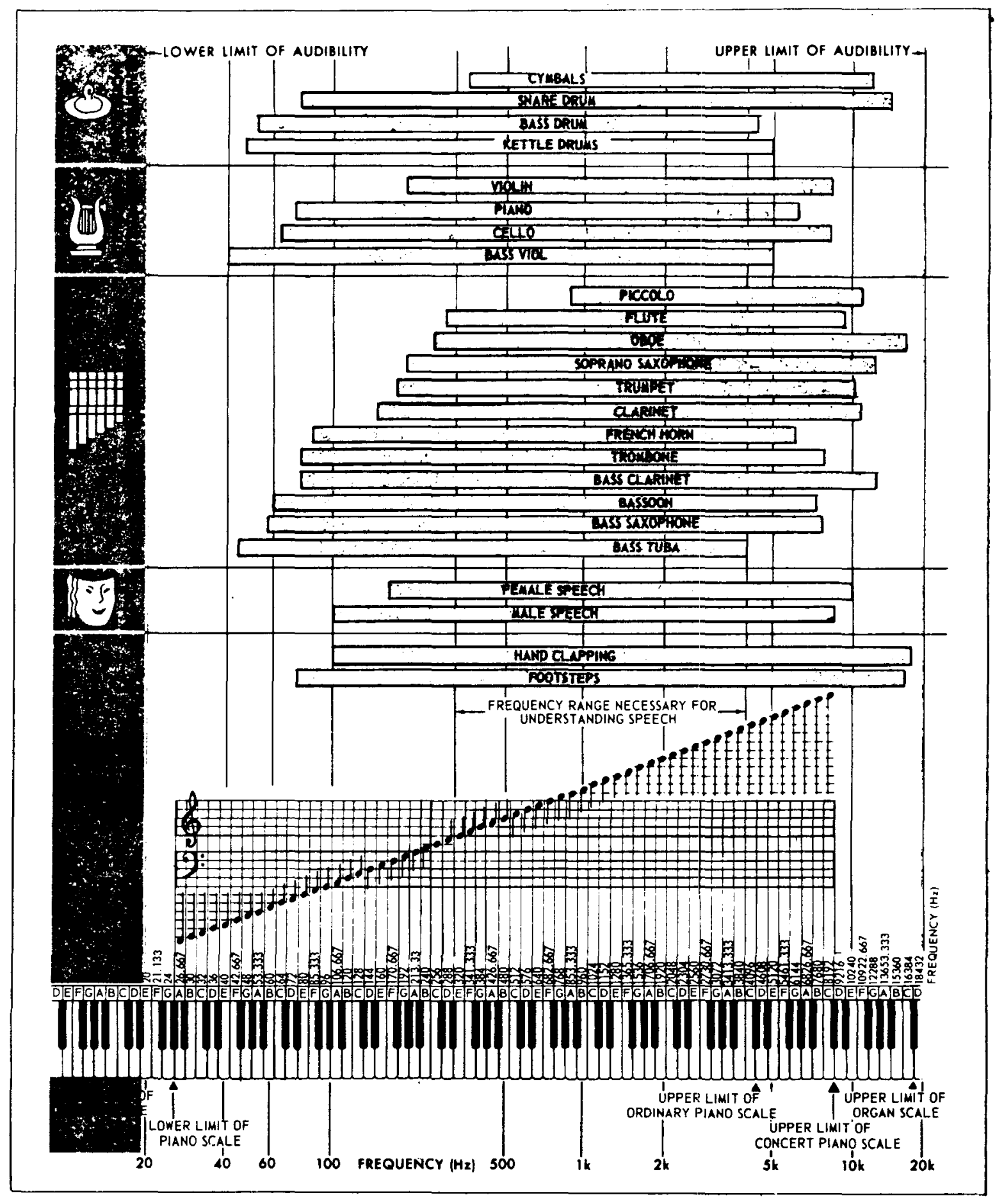

Figure 1. Audible sound frequencies of some musical instruments, voices, and other noises (approximate). (Courtesy of Sonotone Corp., Elmsford, NY. Reprinted by permission of EDN Magazine, April 1967.) 
encountered temperatures, $\gamma$ is equal to 1.4. If the medium may be considered a perfect gas (e.g., air), the speed of sound may also be expressed as

$$
c=\sqrt{\gamma R T}
$$

where $\mathrm{T}$ is the absolute temperature and $\mathrm{R}$ is the ideal gas constant for the appropriate units. Substituting the values of the constants in equation (2), the speed of sound in air at a temperature $t$ of $22^{\circ} \mathrm{C}\left(72^{\circ} \mathrm{F}\right)$ is

or

$$
\begin{array}{ll}
c=20.05 \sqrt{(t+273)}=344 \mathrm{~m} / \mathrm{sec} \quad\left(t \text { in }{ }^{\circ} \mathrm{C}\right) \\
c=49.05 \sqrt{(t+460)}=1131 \mathrm{ft} / \mathrm{sec} \quad\left(t \text { in }{ }^{\circ} \mathrm{F}\right)
\end{array}
$$

The simplest model of acoustic wave propagation is the free field. A free field is a region of space where the medium of wave propagation is considered to be homogeneous and free of obstructions. In a free field the sound from a point source radiates equally in all directions in the form of a spherical wave. As such, the intensity of the wave follows the same inverse square law as light, and the intensity drops to one-fourth its value each time the distance is doubled. The sound pressure drops by one-half when the distance from the source is doubled, since pressure can be shown to be proportional to the square root of intensity. The decrease in intensity or pressure does not hold everywhere within the free field. Near to the sound source (within about two or three wavelengths) the waves behave in a complicated manner requiring special mathematical description; this region is known as the near field. Further out, the inverse square relationship begins to hold; this region, theoretically extending indefinitely, is the far field. The intensity of a spherical wave in a free field at a distance $r$ from the source is represented mathematically by

$$
I=\frac{W}{4 \pi r^{2}}=\frac{p^{2}}{\rho c}
$$

where $I$ is the intensity in watts $/ \mathrm{m}^{2}, \mathrm{~W}$ is the total acoustic power radiated by the source in watts, $p$ is the root mean square sound pressure, and $\rho c$ is the product of the density of the medium and the speed of sound. This product is called the "characteristic impedance" of the medium through which the sound wave is traveling and is the constant of proportionality that relates the squared sound pressure to the sound intensity.

\section{SOUND INTENSITY}

The range of intensity which the human ear can perceive, from the barely discernible to the threshold of pain, is approximately seven orders of magnitude $\left(10^{7}\right)$. The level of sensation is usually measured or reported in a smaller range of numbers by use of the logarithm of the ratio of the measured level to some reference level. For this purpose the unit of the Bel has been borrowed from telephone technology. The loudness of a sound is defined in Bels as

$$
\text { number of Bels }=\log _{10}\left(I / I_{0}\right)
$$


where $I$ is the intensity of sound and $I_{0}$ is the reference intensity, which has an agreed upon value of 1 picowatt/per square meter $\left(\mathrm{pW} / \mathrm{m}^{2}\right)$. Therefore if $I=I_{O}$, the number of Bels is 0 , and if $I=10 I_{O}$, the number of Bels is 1 . The preferred unit for measuring sound has become the minimum difference in loudness that is usually perceptible, one-tenth of a Bel, or 1 decibel (dB); thus

$$
\text { number of } d B=10 \log _{10}\left(I / I_{0}\right)
$$

When any acoustical quantity is expressed in terms of decibels relative to a reference quantity, it is known as a level. Thus the sound intensity level $\left(\mathrm{L}_{\mathrm{I}}\right)$ is

$$
\mathrm{L}_{\mathrm{I}}=10 \log \frac{\mathrm{I}}{\mathrm{I}_{\mathrm{o}}} \mathrm{dB} \text { re } \mathrm{I}_{\mathrm{o}}
$$

It is clear from this expression that for each change in the intensity by one order of magnitude (factor of 10), the number of decibels is changed by 10; or, for each change in the intensity of a factor of 2 , the number of decibels is changed by 3 . Some decibel values for selected intensity ratios are shown in Table 1.

\section{SOUND PRESSURE}

Sound pressure is expressed in decibels for the same reason as intensity; the large range of values commonly encountered. As with sound intensity, there is a reference sound pressure, $\mathrm{p}_{\mathrm{o}}$, equal to 20 micropascals $(\mu \mathrm{Pa})$.

The sound pressure level in decibels is defined as the logarithm of the ratio of the mean squared pressure to the reference pressure squared:

$$
L_{p}=10 \log \frac{p^{2}}{p_{0}^{2}}=20 \log \frac{p}{p_{o}} d B \text { re } p_{o}
$$

Note in the expression that the logarithm of the pressure ratio is multiplied by 20 instead of 10 as for sound intensity level. This is due to the fact that the pressure ratio is squared. Thus there is a $20 \mathrm{~dB}$ change in sound pressure level for an order of magnitude change in the sound pressure, and $40 \mathrm{~dB}$ change for an increase of 100 times; and instead of a $3 \mathrm{~dB}$ change for doubling as in sound intensity, there is a $6 \mathrm{~dB}$ change for doubling of sound pressure.

SOUND POWER

The amount of energy per unit time that radiates from a source in the form of an acoustic wave is sound power. If the source is enclosed by an imaginary surface, then all energy leaving the source must pass through this surface. This relationship can be written as

$$
\mathrm{W}=\mathrm{IS}
$$

where $W$ is the sound power, $S$ is the area of the surface enclosing the source, and $I$ is the average intensity per unit area of the surface. 
Table 1 . Sound intensity level ratios and number of decibels for each.

\begin{tabular}{cc}
\hline $\begin{array}{c}\text { Sound } \\
I / I_{0}\end{array}$ & $\begin{array}{c}\text { Number of decibels } \\
(\mathrm{d} B=10\end{array}$ \\
\hline 1000.0 & 30.0 \\
100.0 & 20.0 \\
10.0 & 10.0 \\
9.0 & 9.5 \\
8.0 & 9.0 \\
& \\
7.0 & 8.5 \\
6.0 & 7.8 \\
5.0 & 7.0 \\
4.0 & 6.0 \\
3.0 & 4.8 \\
& \\
2.0 & 3.0 \\
1.0 & 0.0 \\
0.9 & -0.5 \\
0.8 & -1.0 \\
0.7 & -1.5 \\
0.6 & -2.2 \\
0.5 & -3.0 \\
0.4 & -4.0 \\
0.3 & -5.2 \\
0.2 & -7.0 \\
0.1 & -10.0 \\
0.01 & -20.0 \\
0.001 & -30.0 \\
\hline & \\
\hline
\end{tabular}

If the source is in a free field, and radiates power equally, in all directions, then the sound power can be written from equation (4) as

$$
W=I\left(4 \pi r^{2}\right)
$$

where the enclosing surface is a sphere of radius $r$ chosen for convenience. The expression for sound power level is given by

$$
L_{w}=10 \log _{10}-\frac{W}{W_{0}} d B \text { re } W_{0}
$$

where $W$ is the sound power in watts, and $W_{0}$ is the reference sound power of $10^{-12}$ watt or $1 \mathrm{pW}$. (NOTE: Some earlier texts use $10^{-13}$ watt as the reference value so whenever the power level is reported the reference used must also be stated.) 
For a young person with good hearing, the threshold of hearing at $1000 \mathrm{~Hz}$ (the quietest sound audible) corresponds to approximately a $20 \mu \mathrm{Pa}$ rms pressure. The Pascal $(\mathrm{Pa})$ is the unit of pressure used throughout this volume, and is equal to one Newton per square meter. This value was thus chosen as the reference value for decibels of sound pressure $P_{0}$; a sound pressure of 20 $\mu \mathrm{Pa}$ is $0 \mathrm{~dB}$.

The reference sound intensity $I_{0}$ was chosen to be $1 \mathrm{pW} / \mathrm{m}^{2}$ so that the intensity level and the corresponding sound pressure level would be nearly numerically equal for spherical or plane sound waves in air at room temperature and sea leve1 pressure.

Recalling equation (4), the relationship between $L_{p}$ and $L_{I}$ may be derived as

$$
\begin{aligned}
L_{I} & =10 \log \frac{I}{I_{0}}=10 \log \frac{p^{2}}{\rho c I_{0}}=10 \log \frac{p^{2}}{p_{o}^{2}} \frac{p_{o}^{2}}{\rho c I_{o}} \\
& =L_{p}+10 \log \frac{p_{0}^{2}}{\rho c I_{0}}
\end{aligned}
$$

Substituting the numerical values of the reference quantities, the density of air, and the speed of sound, equation (12) may be simplified to

$$
\begin{aligned}
L_{I} & =L_{p}+10 \log \frac{\left(20 \times 10^{-6}\right)^{2}}{(1.20)(344)\left(10^{-12}\right)} \\
& =L_{p}-0.14 \approx L_{p}
\end{aligned}
$$

Equation (4) may also be developed into a relationship between sound power and sound pressure

$$
\begin{aligned}
I & =\frac{W}{S}=\frac{p^{2}}{\rho c} \\
L_{w} & =10 \log \frac{W}{W_{o}}=10 \log \frac{p^{2} S}{\rho c W_{o}} \\
& =10 \log \left[\frac{p^{2}}{p_{o}^{2}} \frac{p_{o}^{2}}{\rho c W_{o}}\right] \\
& =L_{p}+10 \log s+10 \log \frac{p_{o}^{2}}{\rho c W_{o}}
\end{aligned}
$$

If spherical radiation into a free field is assumed, the power is radiated into a sphere of area $S=4 \pi r^{2}$ where $r$ is the distance from the source to the measuring point. 
Therefore

$$
10 \log S=10 \log 4 \pi+10 \log r^{2}=11+20 \log r
$$

The values of the constants in the third term to the right in equation (13) are the same as in equation (12a) since $W_{0}$ was chosen to equal $I_{0}$. Therefore, the third term is approximately zero and

$$
\mathrm{L}_{\mathrm{w}}=\mathrm{L}_{\mathrm{p}}+10 \log \mathrm{S}=\mathrm{L}_{\mathrm{p}}+20 \log \mathrm{r}+11 \mathrm{~dB} \text { re } 1 \mathrm{pW}
$$

where $r$ is measured in meters. If radiation occurs outdoors over the ground, the power is radiated into a hemisphere. The area $S$ becomes equal to $2 \pi r^{2}$ with the result that

$$
\mathrm{L}_{\mathrm{w}}=\mathrm{L}_{\mathrm{p}}+20 \log \mathrm{r}+8 \mathrm{~dB} \text { re } 1 \mathrm{pW}
$$

with $r$ again measured in meters. If the distance $r$ is to be measured in feet, equations (14) and (15) become respectively

$$
\begin{aligned}
& L_{w}=L_{p}+20 \log \mathrm{r}+0.7 \mathrm{~dB} \text { re } 1 \mathrm{pW} \text { (spherical) } \\
& L_{\mathrm{w}}=\mathrm{L}_{\mathrm{p}}+20 \log \mathrm{r}-2.3 \mathrm{~dB} \text { re } 1 \mathrm{pW} \text { (hemispherical) }
\end{aligned}
$$

Equations (14) and (15) may be inverted to determine the sound pressure level if the sound power level is known. Generally, it is the sound pressure which is measured with microphones or other sensors and the sound power is then calculated. It is often desirable to know the sound power emitted by a source, since the sound power level remains almost constant regardless of the acoustic environment (free field, echos, etc.) the source is placed in. The sound pressure level developed by the same source will vary widely depending on the acoustic environment.

EXAMPLE 1: (a) Determine the sound pressure level at $10 \mathrm{~m}$ for a sound source radiating $116 \mathrm{~dB}$ re $1 \mathrm{pW}$ uniformly into a free field. (b) Also determine the sound pressure level of this source at the same distance over a flat open plane.

SOLUTION: (a) Reversing equation (14) we have

$$
\begin{aligned}
L_{p} & =116-20 \log 10-11 \\
& =116-20-11 \\
& =85 \mathrm{~dB} \text { re } 20 \mu \mathrm{Pa}
\end{aligned}
$$

(b) Using equation (15) for hemispherical radiation

$$
\begin{aligned}
\mathrm{L}_{\mathrm{p}} & =116-20 \log 10-8 \\
& =116-20-8 \\
& =88 \mathrm{~dB} \text { re } 20 \mu \mathrm{Pa}
\end{aligned}
$$


For hemispherical radiation the result is just $3 \mathrm{~dB}$ greater than for spherical or free field radiation. This is borne out by the fact that radiation over a hard plane is like the radiation of a light bulb in front of a mirror. All light radiated into the hemisphere which contains the mirror is reflected into the hemisphere with which we are concerned. Or one may consider optically that there is a true source and an imaginary mirrow image that is also radiating which in effect gives us two identical sources and a $3 \mathrm{~dB}$ increase in sound pressure level.

To relate some of these values to how the human ear responds to sound is a complex process. Generally a change in sound pressure level of $1 \mathrm{~dB}$ can be just barely distinguished under proper conditions. A change of $3 \mathrm{~dB}$ in sound pressure level is readily discernable, and a change of $10 \mathrm{~dB}$ would give the psychological impression of doubling or halving the sound. Some common sounds, their sound pressure levels at a few feet, and sound power levels are listed in Table 2 .

Tab1e 2. Levels of some common sounds.

\begin{tabular}{|c|c|c|c|c|}
\hline $\begin{array}{l}\text { Sound power } \\
\text { watts }\end{array}$ & $\begin{array}{l}\text { Sound power } \\
\text { leve } 1 \\
\mathrm{~dB} \\
\text { re } 10^{-12} \text { watt }\end{array}$ & $\begin{array}{l}\text { Sound } \\
\text { pressure } \\
\text { Pa }\end{array}$ & $\begin{array}{c}\text { Sound } \\
\text { pressure } \\
\text { leve1 } \\
\mathrm{dB} \\
\text { re } 20 \mu \mathrm{Pa}\end{array}$ & Sound source \\
\hline 3000000.0 & $\begin{array}{l}200 \\
185 \\
175\end{array}$ & $\begin{array}{l}1 \text { atmosphere } \\
20000.0\end{array}$ & $\begin{array}{l}194 \\
180 \\
170\end{array}$ & Saturn rocket \\
\hline 30000.0 & $\begin{array}{l}165 \\
155\end{array}$ & 2000.0 & $\begin{array}{l}160 \\
150\end{array}$ & $\begin{array}{l}\text { Ram jet } \\
\text { Turbot jet }\end{array}$ \\
\hline 300.0 & $\begin{array}{l}145 \\
135\end{array}$ & 200.0 & $\begin{array}{l}140 \\
135 \\
130\end{array}$ & $\begin{array}{l}\text { Propeller aircraft } \\
\text { Threshold of pain } \\
\text { Pipe organ }\end{array}$ \\
\hline 3.0 & $\begin{array}{l}125 \\
115\end{array}$ & 20.0 & $\begin{array}{l}120 \\
110\end{array}$ & $\begin{array}{l}\text { Riveter, chipper } \\
\text { Punch press }\end{array}$ \\
\hline 0.03 & $\begin{array}{r}105 \\
95\end{array}$ & 2.0 & $\begin{array}{r}100 \\
90\end{array}$ & $\begin{array}{l}\text { Passing truck } \\
\text { Factory }\end{array}$ \\
\hline 0.0003 & $\begin{array}{l}85 \\
75\end{array}$ & 0.2 & $\begin{array}{l}80 \\
70\end{array}$ & Noisy office \\
\hline 0.000003 & $\begin{array}{l}65 \\
55\end{array}$ & 0.02 & $\begin{array}{l}60 \\
50\end{array}$ & $\begin{array}{l}\text { Conversational speech } \\
\text { Private office }\end{array}$ \\
\hline 0.00000003 & $\begin{array}{l}45 \\
35\end{array}$ & 0.002 & $\begin{array}{l}40 \\
30\end{array}$ & $\begin{array}{l}\text { Average residence } \\
\text { Recording studio }\end{array}$ \\
\hline 0.0000000003 & $\begin{array}{l}25 \\
15\end{array}$ & 0.0002 & $\begin{array}{l}20 \\
10\end{array}$ & $\begin{array}{l}\text { Rustle of leaves } \\
\text { Threshold of good } \\
\text { hearing }\end{array}$ \\
\hline 0.000000000003 & 5 & 0.00002 & 0 & $\begin{array}{l}\text { Threshold of excellent } \\
\text { youthful hearing }\end{array}$ \\
\hline
\end{tabular}


Since decibels represent the logarithm of the ratio of two quantities, they cannot be added directly. The antilogarithm must first be taken before the quantities can be combined arithmetically. This process is included automatically in decibel addition charts such as the one appearing in Figure 2.

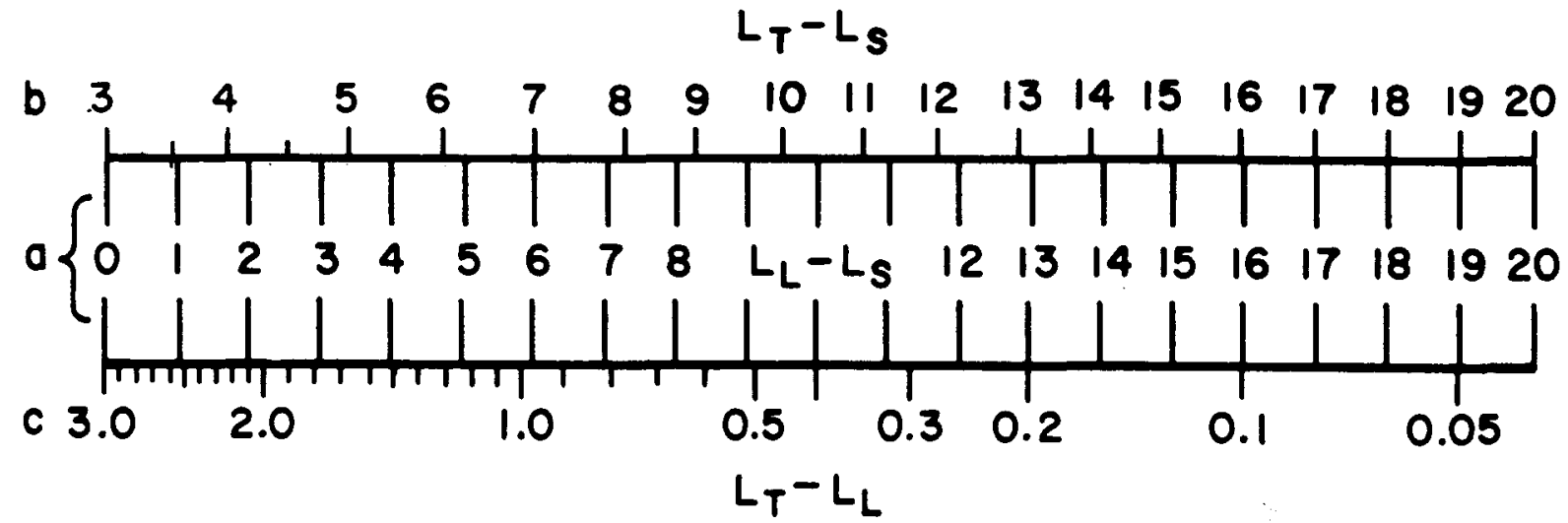

Figure 2. Chart for adding or subtracting decibels. Upper row $b$ shows the difference between the total and smaller values. Bottom row $c$ shows the difference between the total and larger values, and center row a shows the difference between the large and small values. (Chart good for any decibels--pressure, power, or intensity.) Use of this chart is shown in examples 7 and 8 .

EXAMPLE 2: Two sources are radiating noise into a free field. One source has a sound power level of $123 \mathrm{~dB}$ and the other source has a sound power level of $117 \mathrm{~dB}$ re $1 \mathrm{pW}$. What is the combined sound power level of the two sources?

SOLUTION :

$$
\mathrm{L}_{\mathrm{w}}=10 \log \frac{\mathrm{W}}{\mathrm{W}_{\mathrm{o}}}
$$

or

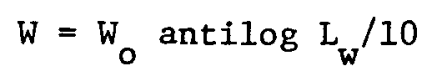

Source 1: $W_{1}=10^{-12}$ antilog $123 / 10$

$$
=10^{-12} \times 1.996 \times 10^{12}=1.996 \text { watt }
$$

Source 2: $\mathrm{W}_{2}=10^{-12}$ antilog $117 / 10$

$$
=10^{-12} \times 5.012 \times 10^{11}=0.5012 \text { watt }
$$




$$
\begin{aligned}
& \mathrm{W}_{\mathrm{T}}=\mathrm{W}_{1}+\mathrm{W}_{2}=2.4972 \text { watt } \\
& \mathrm{L}_{\mathrm{w}}=10 \log \frac{\mathrm{W}_{\mathrm{T}}}{\mathrm{W}_{\mathrm{O}}}=10 \log \frac{2.4972}{10^{-12}} \\
& \mathrm{~L}_{\mathrm{W}}=124 \mathrm{~dB} \text { re } 1 \mathrm{pW}
\end{aligned}
$$

The same process can be used for sound intensity level or sound pressure level. The solution is given to the nearest whole decibel since that was the accuracy implied by the problem statement.

EXAMPLE 3: Suppose the sound pressure level of each of the three individual noise sources is measured at a point such that with only the first source running, the sound pressure level is $86 \mathrm{~dB}$ re $20 \mu \mathrm{Pa}$, with only the second source running it is $84 \mathrm{~dB}$ re $20 \mu \mathrm{Pa}$, and with only the third source it is $89 \mathrm{~dB}$ re $20 \mu \mathrm{Pa}$. What will be the sound pressure level at this point with all three sources running?

SOLUTION :

$$
\begin{aligned}
\mathrm{p}_{\mathrm{T}}^{2} & =\mathrm{p}_{0}^{2}\left[\operatorname{antilog} \frac{\mathrm{L}_{\mathrm{p} 1}}{10}+\operatorname{antilog} \frac{\mathrm{L}_{\mathrm{p} 2}}{10}+\operatorname{antilog} \frac{\mathrm{L}_{\mathrm{p} 3}}{10}\right] \\
& =\mathrm{p}_{0}^{2}[\operatorname{antilog} 8.6+\operatorname{antilog} 8.4+\operatorname{antilog} 8.9] \\
\mathrm{P}_{\mathrm{T}}^{2} & =\mathrm{p}_{\mathrm{o}}^{2}[3.982+2.512+7.944] \times 10^{8} \\
& =\mathrm{p}_{\mathrm{O}}^{2} \times 14.438 \times 10^{8} \\
\mathrm{~L}_{\mathrm{pT}} & =10 \log \frac{\mathrm{p}^{2} \mathrm{~T}}{\mathrm{p}_{\mathrm{o}}}=10 \log \left[14.438 \times 10^{8}\right] \\
& =91.6 \mathrm{~dB} \approx 92 \mathrm{~dB} .
\end{aligned}
$$

Note that it was only necessary to add the pressure-squared values of the decibels, and the constant reference $p_{0}^{2}$ was carried through the calculations and not evaluated.

EXAMPLE 4: Add $85 \mathrm{~dB}$ and $88 \mathrm{~dB}$ using Figure 2.

SOLUTION: $\mathrm{L}_{\mathrm{Z}}-\mathrm{L}_{\mathrm{S}}=88-85=3 \mathrm{~dB}$. Enter row a at 3 and read row $\mathrm{b}$ to get 4.8 to be added to smaller level:

$$
\mathrm{L}_{\mathrm{T}}=85+4.8=89.8 \mathrm{~dB} \approx 90 \mathrm{~dB}
$$

Or, enter row a to 3 and read value of row $c$ to get $1.8 \mathrm{~dB}$ to be added to larger level:

$$
\mathrm{L}_{\mathrm{T}}=88+1.8=89.8 \mathrm{~dB} \approx 90 \mathrm{~dB}
$$


To substract levels enter row $b$ or $c$, whichever corresponds to the difference between the levels, then read value in row a which must be added (subtracted) to (from) the smaller (larger) value to obtain the unknown value.

EXAMPLE 5: Subtract $83 \mathrm{~dB}$ from $87 \mathrm{~dB}$ (see Figure 2).

SOLUTION: $\mathrm{L}_{\mathrm{T}}=\mathrm{L}_{\mathrm{S}}=87-83=4 \mathrm{~dB}$. Enter row $\mathrm{b}$ to 4 and read value in row $\mathrm{a}$ of 1.7 which must be subtracted from the larger value of $87 \mathrm{~dB}$ to obtain the unknown value of $85.3=85$.

EXAMPLE 6: Add the three sound pressure levels of Example 3 using the chart in Figure 2.

SOLUTION:

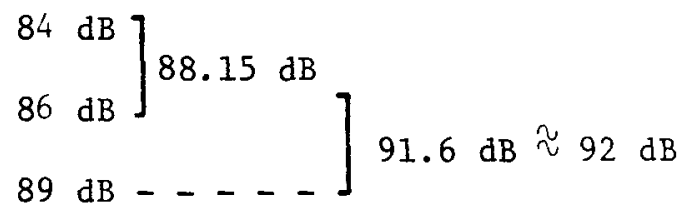

which is the same result obtained with the more lengthy procedure shown in Example 3 .

\section{DIRECTIONALITY}

Now consider another aspect of the noise source; does the sound radiate equally in all directions in a spherical space? Until now it has been assumed that it does. If it does not, then one must be concerned with the directionality of the sound. The directionality of a sound source in a free field is given by the directivity factor $Q_{\theta}$ which will vary with the angle $\theta$ about the source. $Q_{\theta}$ is defined as the ratio between the squared sound pressure measured at an angle $\theta$ and a distance $r$ from the source and the space-average squared sound pressure at the same distance $r$; that is

$$
\begin{aligned}
Q_{\theta}= & \frac{p_{\theta}^{2}}{\bar{p}^{2}}=\operatorname{antilog} \frac{\mathrm{L}_{\theta}-\overline{\mathrm{L}}_{\mathrm{p}}}{10} \\
\mathrm{~L}_{\mathrm{p} \theta}= & \begin{array}{l}
\text { the sound pressure level measured at a distance } \mathrm{r} \text { and } \\
\text { an angle } \theta \text { from the source }
\end{array} \\
\overline{\mathrm{L}}_{\mathrm{p}}= & \begin{array}{l}
\text { the average sound pressure level over the surface of } \\
\text { an imaginary sphere with a radius of } r
\end{array}
\end{aligned}
$$

It is usually more convenient to express the directivity factor in its logarithmic form, the directivity index $\left(\mathrm{DI}_{\theta}\right)$.

$$
D I_{\theta}=10 \log Q_{\theta}=L_{p \theta}-\bar{L}_{p}
$$

with directivity in mind, equation (14) should be modified accordingly:

$$
L_{w}=L_{p \theta}+20 \log r+11-D I_{\theta}
$$


If the source is placed on a hard reflective surface with a free field above, the power directed downward is reflected back up with the result that the intensity increases $3 \mathrm{~dB}$ (double) above that of the same source in a full free field. Equation (17) becomes

$$
D I_{\theta}=L_{p \theta}-\bar{L}_{p}+3
$$

while equation (18) remains the same. The $3 \mathrm{~dB}$ difference between equations (14) and (15) is now accounted for by the $3 \mathrm{~dB}$ in the $\mathrm{DI}_{\theta}$ for hemispherical radiation. Note that if a source radiates uniformly into hemispherical free space, the $\mathrm{DI}_{\theta}$ is equal to 3 and equation (18) reduces to equation (15).

EXAMPLE 7: What is the sound pressure level at $10 \mathrm{~m}$ in the direction of position 1 for a noise source when the free hemispherical field sound pressure levels measured at $3 \mathrm{~m}$ are

\begin{tabular}{crccrr}
\hline Position & $L_{p}$ & Position & $L_{p}$ & Position & $L_{p}$ \\
\hline 1 & 100 & 5 & 89 & 9 & 1.01 \\
2 & 94 & 6 & 90 & 10 & 1.00 \\
3 & 97 & 7 & 93 & 11 & 97 \\
4 & 93 & 8 & 96 & 12 & 95 \\
\hline
\end{tabular}

SOLUTION: We must obtain $\overline{\mathrm{L}}_{\mathrm{p}}$ by averaging the pressures. Thus,

$$
\begin{aligned}
& \mathrm{p}_{1}^{2}=\mathrm{p}_{\mathrm{o}}^{2} \mathrm{x} \text { antilog } \mathrm{L}_{\mathrm{pl}} / 10=\mathrm{p}_{\mathrm{o}}^{2} \times 10 \times 10^{9}(\mathrm{~Pa})^{2} \\
& \mathrm{p}_{2}^{2}=\quad=\mathrm{p}_{\mathrm{o}}^{2} \times 2.512 \times 10^{9} \\
& \mathrm{p}_{3}^{2}=\quad=\mathrm{p}_{\mathrm{o}}^{2} \times 5.012 \times 10^{9} \\
& \mathrm{p}_{4}^{2}= \\
& \mathrm{p}_{5}^{2}= \\
& \mathrm{p}_{6}^{2}= \\
& \mathrm{p}_{7}^{2}= \\
& \mathrm{p}_{8}^{2}= \\
& \mathrm{p}_{9}^{2}= \\
& =\mathrm{p}_{\mathrm{o}}^{2} \times 1.995 \times 10^{9} \\
& =\mathrm{p}_{\mathrm{o}}^{2} \times 0.794 \times 10^{9} \\
& =\mathrm{p}_{\mathrm{o}}^{2} \times 1.0 \times 10^{9} \\
& =\mathrm{p}_{\mathrm{O}}^{2} \times 1.995 \times 10^{9} \\
& =p_{0}^{2} \times 3.981 \times 10^{9} \\
& =p_{0}^{2} \times 12.589 \times 10^{9} \\
& \mathrm{p}_{10}^{2}= \\
& =\mathrm{p}_{\mathrm{o}}^{2} \times 10 \times 10^{9} \\
& \mathrm{p}_{11}^{2}= \\
& \mathrm{p}_{12}^{2}= \\
& =\mathrm{p}_{\mathrm{o}}^{2} \times 5.012 \times 10^{9} \\
& =\mathrm{p}_{\mathrm{o}}^{2} \times 3.162 \times 10^{9} \\
& \text { Total }=\overline{p_{0}^{2} \times 58.052 \times 10^{9}} \\
& \text { Average }=\mathrm{p}_{0}^{2} \times 4.838 \times 10^{9}
\end{aligned}
$$




$$
\begin{aligned}
\overline{\mathrm{L}}_{\mathrm{p}}=10 \log \mathrm{p}_{\mathrm{avg}}^{2} & =10 \log 4.838 \times 10^{9} \\
\mathrm{p}_{\mathrm{o}}^{2} & =96.9 \mathrm{~dB} \text { re } 20 \mu \mathrm{Pa}
\end{aligned}
$$

The average sound power level $\mathrm{L}_{\mathrm{w}}$ is now determined from equation (15) since this radiation is hemispherical.

$$
\begin{aligned}
\mathrm{L}_{\mathrm{W}} & =\overline{\mathrm{L}}_{\mathrm{p}}+20 \log \mathrm{x}+8 \\
& =96.9+9.5+8 \\
& =11.4 \mathrm{~dB} \text { re } 1 \mathrm{pW}
\end{aligned}
$$

Now determine DI for position 1 from equation (17a).

$$
\mathrm{DI}_{1}=100-96.9+3=6.1 \mathrm{~dB}
$$

The sound pressure level at $10 \mathrm{~m}$ in the direction of position 1 can be found by inverting equation (18)

$$
\begin{aligned}
L_{p \theta} & =L_{w}-20 \log r-11+D I_{\theta} \\
& =114.4-20 \log 10-11+6.1 \\
& =80.5 \mathrm{~dB} \approx 81 \mathrm{~dB} \text { re } 20 \mu \mathrm{Pa}
\end{aligned}
$$

To compare the results of averaging mean pressures with averaging sound pressure levels in this case $\overline{\mathrm{p}}^{2}$ gives a value for $\overline{\mathrm{L}}_{\mathrm{p}}$ of $96.9 \mathrm{~dB}$. By simply averaging the decibel values we would have obtained $\overline{\mathrm{L}}_{p}=95.4$ which is about $1.5 \mathrm{~dB}$ low. This example points out the difference in the values obtained between arithmetic averaging of the decibel levels and averaging of the true values. Whenever a set of decibel levels of any sort must be averaged a simple arithmetic averaging process will yield a result that is lower than the true average of the measured value. This holds true for decibel sound power, decibel sound intensity, decibel sound pressure, or any other decibel numbers. However, if the spread of data to be averaged is less than $3 \mathrm{~dB}$, a simple arithmetic average will yield reasonably accurate results.

\section{NOISE WEIGHTING AND FILTERING}

Thus far only the magnitude of sound has been discussed. Sound is generally not composed of a single frequency oscillating wave--sound can be made up of many frequencies, all existing simultaneously. A young, healthy ear is sensitive to the sound frequency range from about 20 to $20,000 \mathrm{~Hz}$. This range narrows with age of the listener plus any possible hearing loss that may have occurred, so that for a nornal adult the upper frequency limit may be approximately $14,000 \mathrm{~Hz}$. Also the ear response varies with different frequencies; the least sensitivity in the lower frequency range and the greatest sensitivity in the range 2000 to $4000 \mathrm{~Hz}$. This difference in sensitivity with frequency tends to become less as the intensity of the sound increases. Consequently, to build an instrument that responds to sound in a manner similar to the human ear, acousticians have developed four frequency weighting networks for measuring sound. These correspond to the $\mathrm{A}-, \mathrm{B}-, \mathrm{C}-$, and $\mathrm{D}$-weighting curves, and 
are electronic filters which attenuate the signal at different frequencies as shown in Figure 3. The specific attenuation versus frequency is shown in Table 3. At most common sound levels, the A-weighting curve corresponds most clearly to the response of the human ear; and consequently the A-weighting network is normally used in noise control work.

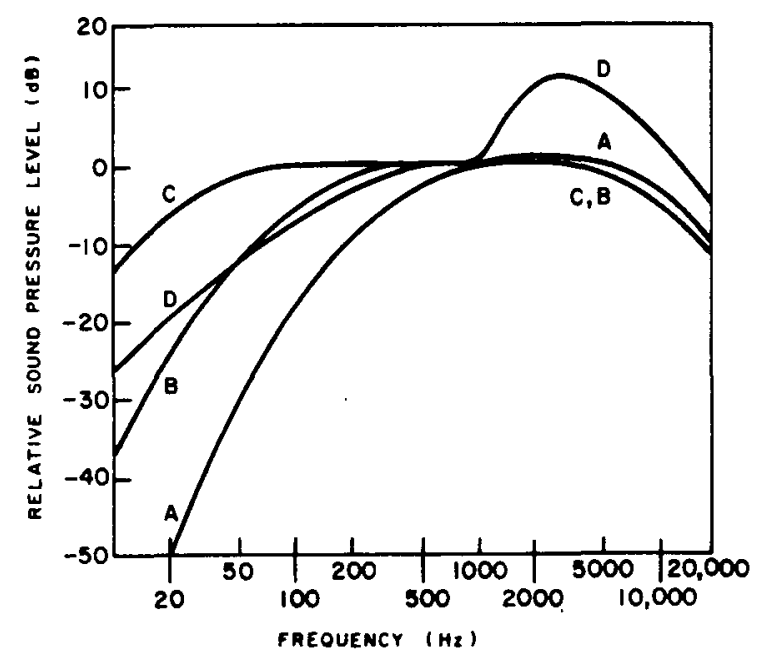

Figure 3. Standard A-, B-, and C-weighting curves for sound level meters; also proposed D-weighting curve for monitoring jet aircraft noise.

Other filters used to analyze acoustic energy pass a narrower range of frequencies than the A-, B-, C-, or D-curves. These filters are of two types--the first a constant bandwidth filter. This type of filter generally has a narrow bandwidth of a few hertz which does not change as the operating frequency changes. The second type of filter is more commonly used in acoustics and is a constant percentage bandwidth filter. The width of the band being utilized is a fixed percent of the frequency at which the instrument is operating.

For example, a 6 percent bandwidth filter would have a bandwidth of $60 \mathrm{~Hz}$ when it is set to operate at $1000 \mathrm{~Hz}$, and a bandwidth of $120 \mathrm{~Hz}$ when operating at $2000 \mathrm{~Hz}$.

The constant percentage filters most often used in acoustics are octave band filters or some submultiple of an octave such as one-half octave, one-third octave, or one-tenth octave. The logarithmic difference between each upper frequency limit, $f_{2}$, and the corresponding lower frequency limit, $f_{1}$, for constant perentage filters is also a constant. For octave band filters, this difference by definition is

$$
\log f_{2}-\log f_{1}=\log \frac{\tilde{f}_{2}}{f_{1}}=\log 2
$$


Table 3. A-, B-, and C-weighting networks for sound level meters as specified by ANSI SI.4-1971

\begin{tabular}{|c|c|c|c|}
\hline $\begin{array}{c}\text { Frequency } \\
\mathrm{Hz}\end{array}$ & $\begin{array}{l}\text { A-weighting } \\
\text { relative } \\
\text { response } \\
\mathrm{dB}\end{array}$ & $\begin{array}{c}\text { B-weighting } \\
\text { relative } \\
\text { response } \\
\text { dB }\end{array}$ & $\begin{array}{l}\text { C-weighting } \\
\text { relative } \\
\text { response } \\
\text { dB }\end{array}$ \\
\hline 10 & -70.4 & -38.2 & -14.3 \\
\hline 12.5 & -63.4 & -33.2 & -11.2 \\
\hline 16 & -56.7 & -28.5 & -8.5 \\
\hline 20 & -50.5 & -24.2 & -6.2 \\
\hline 25 & -44.7 & -20.4 & -4.4 \\
\hline 31.5 & $-39.4 *$ & -17.1 & -3.0 \\
\hline 40 & -34.6 & -14.2 & -2.0 \\
\hline 50 & -30.2 & -11.6 & -1.3 \\
\hline 63 & $-26.2 *$ & -9.3 & -0.8 \\
\hline 80 & -22.5 & -7.4 & -0.5 \\
\hline 100 & -19.1 & -5.6 & -0.3 \\
\hline 125 & $-16.1 *$ & -4.2 & -0.2 \\
\hline 160 & -13.4 & -3.0 & -0.1 \\
\hline 200 & -10.9 & -2.0 & 0 \\
\hline 250 & $-8.6 *$ & -1.3 & 0 \\
\hline 315 & -6.6 & -0.8 & 0 \\
\hline 400 & -4.8 & -0.5 & 0 \\
\hline 500 & $-3.2 *$ & -0.3 & 0 \\
\hline 630 & -1.9 & -0.1 & 0 \\
\hline 800 & -0.8 & 0 & 0 \\
\hline 1000 & $0 \star$ & 0 & 0 \\
\hline 1250 & +0.6 & 0 & 0 \\
\hline 1600 & +1.0 & 0 & -0.1 \\
\hline 2000 & $+1.2 *$ & -0.1 & -0.2 \\
\hline 2500 & +1.3 & -0.2 & -0.3 \\
\hline 3150 & +1.2 & -0.4 & -0.5 \\
\hline 4000 & $+1.0 *$ & -0.7 & -0.8 \\
\hline 5000 & +0.5 & -1.2 & -1.3 \\
\hline 6300 & -0.1 & -1.9 & -2.0 \\
\hline 8000 & $-1.1 *$ & -2.9 & -3.0 \\
\hline 10000 & -2.5 & -4.3 & -4.4 \\
\hline 12500 & -4.3 & -6.1 & -6.2 \\
\hline 16000 & -6.6 & -8.4 & -8.5 \\
\hline 20000 & -9.3 & -11.1 & -11.2 \\
\hline
\end{tabular}

*Values used for converting octave band readings into A-weighted sound levels. 
and

$$
\mathrm{f}_{2}=2 \mathrm{f}_{1}
$$

If each filter has a frequency range equal to a submultiple, $k$, of an octave, then the constant difference is

$$
\log f_{2}-\log f_{1}=\frac{\log 2}{k}=\log 2^{1 / k}
$$

and

$$
\mathrm{f}_{2}=2^{1 / k} \mathrm{f}_{1}
$$

NOTE: In the special case of one-third octave bands $(k=3)$, since $2^{1 / 3}=1.25992$ and $10^{1 / 10}=1.25893, f_{2}=10^{1 / 10} f_{1}$ is used in practice for computational convenience.

The center frequency, $f_{c}$, of a constant percentage filter is the logarithmic or geometric mean of $\mathrm{f}_{1}$ and $\mathrm{f}_{2}$

$$
\begin{aligned}
& f_{c}=\operatorname{antil} \log \frac{\log f_{1}+\log f_{2}}{2}=\left(f_{1} f_{2}\right)^{1 / 2} \\
& f_{c}=\left(2^{1 / k} f_{1} f_{1}\right)^{1 / 2}=2^{1 / 2 k} f_{1}=2^{-1 / 2 k} f_{2}
\end{aligned}
$$

and

$$
\begin{aligned}
& f_{1}=2^{-1 / 2 k} f_{c} \\
& f_{2}=2^{1 / 2 k} f_{c}
\end{aligned}
$$

The constant percentage, $\mathrm{P}_{k}$, for a set of filters is thus

$$
\begin{aligned}
P_{k} & =100 \frac{\left(f_{2}-f_{1}\right)}{f_{c}}=100\left(2^{1 / 2 k}-2^{-1 / 2 k}\right) \\
k & =1,2,3 \ldots
\end{aligned}
$$

The most common constant percentages used are 70.7 percent of the center frequency for octave band filters and 23.2 percent for one-third octave bands.

For a broadband sound the octave band sound pressure level will be just the sum of the three one-third octaves that make up the octave band. Similarly, if measurements are made in one-tenth octaves then 10 of these will add up to the sound pressure level in the octave band. This addition must be made of the mean sound pressures squared and then converted to decibels or the decibels can be added using Figure 2. For example, if the three one-third octave levels are 65,68 , and $70 \mathrm{~dB}$ we get $72.9 \mathrm{~dB}$ for the octave band. The preferred series of octave band and one-third octave band center frequencies, as specified by ANSI S1.6, along with upper and lower frequency limits are shown in Table 4. 
Table 4. Center and cutoff frequencies for preferred series of contiguous octave and one-third octave bands as specified by ANSI $\mathrm{S} 1.6$

\begin{tabular}{|c|c|c|c|c|c|}
\hline \multicolumn{6}{|c|}{ Erequency, $\mathrm{Hz}$} \\
\hline & Octave & & One-t & hird octa & ave \\
\hline $\begin{array}{l}\text { Lower } \\
\text { band } \\
\text { limit }\end{array}$ & Center & $\begin{array}{c}\text { Upper } \\
\text { band } \\
\text { limit }\end{array}$ & $\begin{array}{c}\text { Lower } \\
\text { band } \\
\text { limit }\end{array}$ & Center & $\begin{array}{l}\text { Upper } \\
\text { band } \\
\text { limit }\end{array}$ \\
\hline 11 & 16 & 22 & $\begin{array}{l}11.2 \\
14.1 \\
17.8\end{array}$ & $\begin{array}{l}12.5 \\
16 \\
20\end{array}$ & $\begin{array}{l}14.1 \\
17.8 \\
22.4\end{array}$ \\
\hline 22 & 31.5 & 44 & $\begin{array}{l}22.4 \\
28.2 \\
35.5\end{array}$ & $\begin{array}{l}25 \\
31.5 \\
40\end{array}$ & $\begin{array}{l}28.2 \\
35.5 \\
44.7\end{array}$ \\
\hline 44 & 63 & 88 & $\begin{array}{l}44.7 \\
56.2 \\
70.8\end{array}$ & $\begin{array}{l}50 \\
63 \\
80\end{array}$ & $\begin{array}{l}56.2 \\
70.8 \\
89.1\end{array}$ \\
\hline 88 & 125 & 177 & $\begin{array}{l}89.1 \\
112 \\
141\end{array}$ & $\begin{array}{l}100 \\
125 \\
160\end{array}$ & $\begin{array}{l}112 \\
141 \\
178\end{array}$ \\
\hline 177 & 250 & 354 & $\begin{array}{l}178 \\
224 \\
282\end{array}$ & $\begin{array}{l}200 \\
250 \\
315\end{array}$ & $\begin{array}{l}224 \\
282 \\
354\end{array}$ \\
\hline 354 & 500 & 707 & $\begin{array}{l}354 \\
447 \\
562\end{array}$ & $\begin{array}{l}400 \\
500 \\
630\end{array}$ & $\begin{array}{l}447 \\
562 \\
707\end{array}$ \\
\hline 707 & 1000 & 1414 & $\begin{array}{r}707 \\
891 \\
1122\end{array}$ & $\begin{array}{r}800 \\
1000 \\
1250\end{array}$ & $\begin{array}{r}891 \\
1122 \\
1414\end{array}$ \\
\hline 1414 & 2000 & 2828 & $\begin{array}{l}1414 \\
1778 \\
2239\end{array}$ & $\begin{array}{l}1600 \\
2000 \\
2500\end{array}$ & $\begin{array}{l}1778 \\
2239 \\
2828\end{array}$ \\
\hline 2828 & 4000 & 5656 & $\begin{array}{l}2828 \\
3548 \\
4467\end{array}$ & $\begin{array}{l}3150 \\
4000 \\
5000\end{array}$ & $\begin{array}{l}3548 \\
4467 \\
5656\end{array}$ \\
\hline 5656 & 8000 & 11312 & $\begin{array}{l}5656 \\
7079 \\
8913\end{array}$ & $\begin{array}{r}6300 \\
8000 \\
10000\end{array}$ & $\begin{array}{r}7079 \\
8913 \\
11220\end{array}$ \\
\hline 11312 & 16000 & 22624 & $\begin{array}{l}11220 \\
14130 \\
17780\end{array}$ & $\begin{array}{l}12500 \\
16000 \\
20000\end{array}$ & $\begin{array}{l}14130 \\
17780 \\
22390\end{array}$ \\
\hline
\end{tabular}


EXAMPLE 8: The unweighted octave band sound pressure levels for a particular noise source are as shown below. Determine the A-weighted level of this source.

SOLUTION: The A-weighted correction factors (rounded to the nearest decibel) from Table 3 corresponding to each octave band center frequency are added to the sound pressure levels as shown in the table below.

\begin{tabular}{ccccccccc}
\hline $\begin{array}{c}\text { Octave band } \\
\text { frequency, } \\
\mathrm{Hz}\end{array}$ & 63 & 125 & 250 & 500 & 1000 & 2000 & 4000 & 8000 \\
\hline $\mathrm{SPL}, \mathrm{dB}$ & 71 & 62 & 64 & 68 & 62 & 55 & 52 & 44 \\
\hline $\begin{array}{c}\text { A-weighted } \\
\text { correction, dB }\end{array}$ & -26 & -16 & -9 & -3 & 0 & +1 & +1 & -1 \\
\hline $\mathrm{SPL}, \mathrm{dBA}$ & 45 & 46 & 55 & 65 & 62 & 56 & 53 & 43 \\
\hline
\end{tabular}

The corrected octave band levels in the bottom row are then summed, either mathematically or with the aid of Figure 2 .

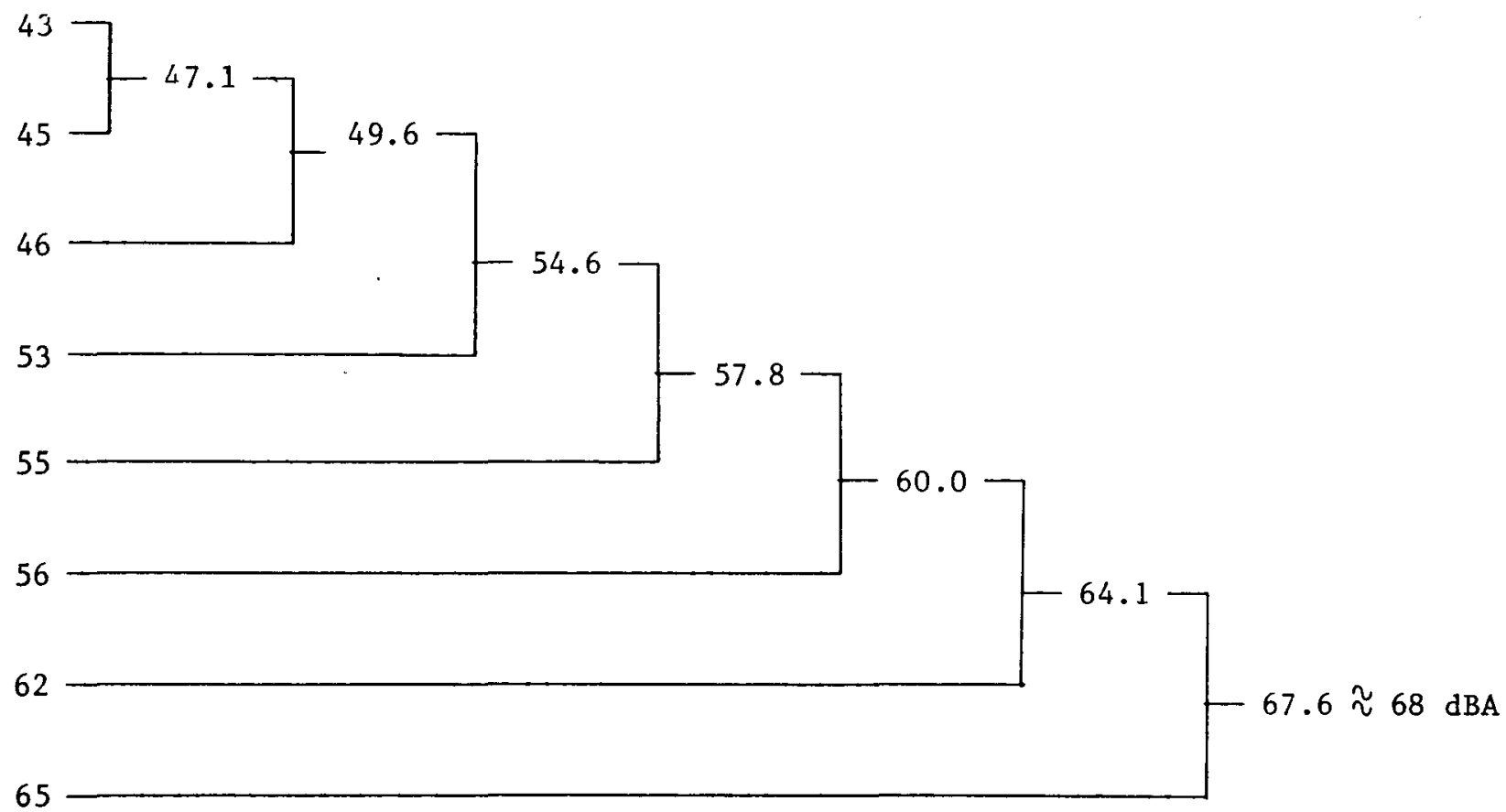




\section{INSTRUMENTS FOR NOISE MEASUREMENTS}

\section{MICROPHONES}

The basic sensing instrument for measuring sound pressure in air is the microphone. These sensors come in a variety of sizes and types but they all have one thing in common. The basic sensor is a diaphragm which is forced to vibrate as the sound wave impinges upon it. This vibratory motion is then converted into an electrical signal in any one of a number of ways.

One of the ways to sense sound is to use the diaphragm as one side of a capacitor to which a large polarizing voltage is applied. Any movement in the diaphragm results in a change in the capacitance and an electrical signal is generated.

A second type of microphone is one in which the diaphragm is attached directly to a piezoceramic material. Motion of the diaphragm causes strain in the ceramic which results in the generation of an electronic signal. These microphones are generally less sensitive than the capacitor types since the diaphragm is mounted directly to the ceramic, although a polarization voltage is not required.

A third type is the dynamic (moving coil) microphone. In this type the diaphragm is attached to a coil which is forced to move through a magnetic field as the diaphragm moves. The movement of the coil through the magnetic field causes a current to flow in the coil. These microphones have a lower electrical impedance than condenser or ceramic microphones. Because of the mass of the coil, however, these microphones are more sensitive to vibration. Additionally, their magnetic operating principle makes them susceptible to external magnetic fields, and their low frequency response is limited due to the large excursions of the coil needed as the frequency is lowered.

A newcomer to the microphone arena is the electret microphone. These are capacitor microphones but the air gap between the capacitor plates is replaced with a prepolarized dielectric. This construction offers the quality of the capacitor microphone but elminates the need for the direct current bias voltage. These microphones are of more simple and rugged construction, and have a higher capacitance which simplifies some of the electrical problems associated with the very small capacitance of the capacitor type microphones.

The sensitivity of a microphone is generally dependent on the frequency and direction of the incident sound wave, and size of the diaphragm. The sensitivity at a given frequency is defined as the ratio of the root mean square output voltage to the root mean square sound pressure and is given in units of volts per pascal or other similar units. 
If the sensitivity is measured by applying the sound pressure uniformly over the surface of the diaphragm with an electrostatic actuator the response is called pressure response.

The free field response at a given frequency is defined as the ratio of the root mean square output voltage to the root mean square sound pressure that existed at the microphone location prior to the insertion of the microphone.

These two definitions are identical for a microphone with negligible dimensions. However, when the wavelength of the sound wave becomes comparable to the dimensions of the diaphragm, the microphone acts as a reflector which causes an increase in pressure on the diaphragm and a corresponding increase in output voltage. This reflection effect also depends on the angle of incidence of the sound wave on the diaphragm.

Since it is impossible to make a microphone with zero dimensions there will always be some effect on the sound field when the microphone is inserted. Therefore, to obtain the pressure that exists at that point before the microphone is inserted one must apply correction to the sensitivity of the microphone. In Figure 4 some corrections are shown that must be applied to the microphone sensitivity as a function of frequency in kilohertz $(\mathrm{kHz})$ and angle of incidence on the diaphragm.

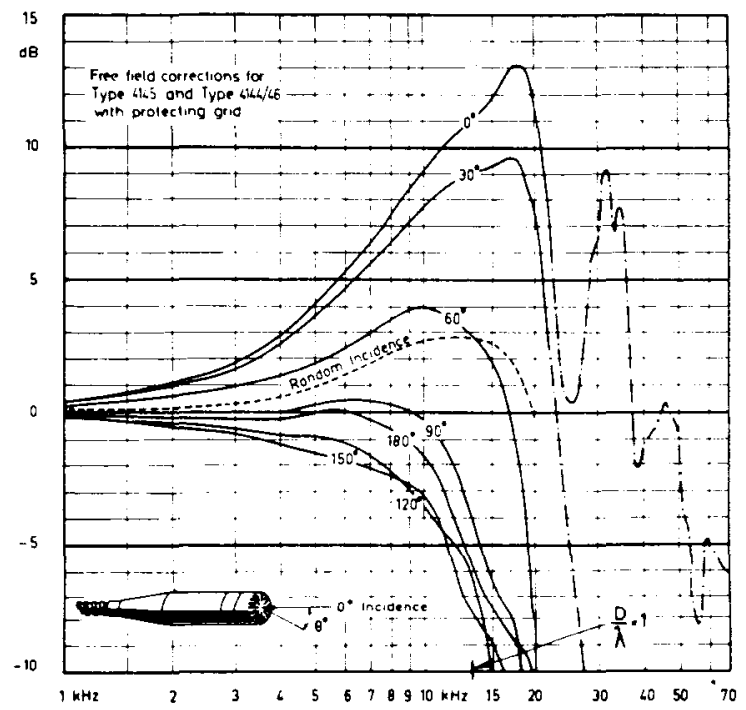

Figure 4. Free field correction for microphone with protecting grid (electrostatic actuator method of pressure calibration). (Courtesy Bruel $\&$ Kjaer Instruments Inc.)

As previous1y mentioned the increase in pressure at the diaphragm for wavelengths comparable to the dimensions of the diaphragm shows up very clearly in the sensitivity correction that must be applied when the sound wave is incident normally on the diaphragm. Note how close the peak in the zero incidence correction curve comes to the frequency where the wavelength equals the diameter of the diaphragm (shown in this figure as $\mathrm{D} / \lambda=1$ ). 
Another view of the dependence of sensitivity on frequency and angle of incidence is shown in Figure 5. In this figure the relative response for five frequencies through the full $360 \mathrm{deg}$ of possible incidence are shown. For the microphone shown, the circular symmetry makes the response symmetric about the axis of the diaphragm.

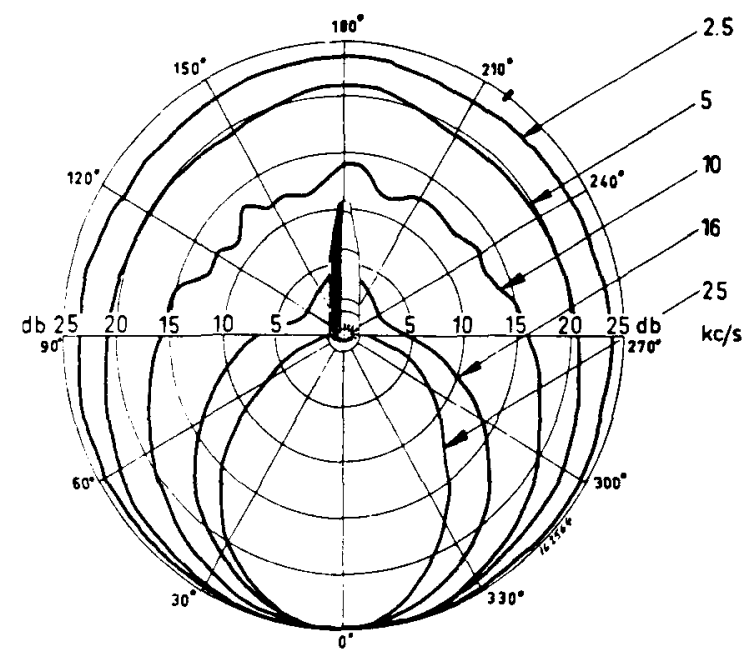

Figure 5. Typical directional characteristics for 1-inch microphone with protecting grid. (Courtesy Bruel \& Kjaer Instruments Inc.)

To reduce the complexity of applying these corrections when using a microphone the manufacturers have designed microphones with proper tension and damping on the diaphragm so that either a free field response may be obtained directly or a pressure response will result. Figure 6 shows the response of a typical "pressure" microphone (Bruel \& Kjaer $2.54 \mathrm{~cm}$ (1-inch) microphone). This type of microphone should be pointed at $90 \mathrm{deg}$ to the source of the sound to obtain the proper flat frequency response. A flat frequency response is one in which the microphone sensitivity is independent of frequency.

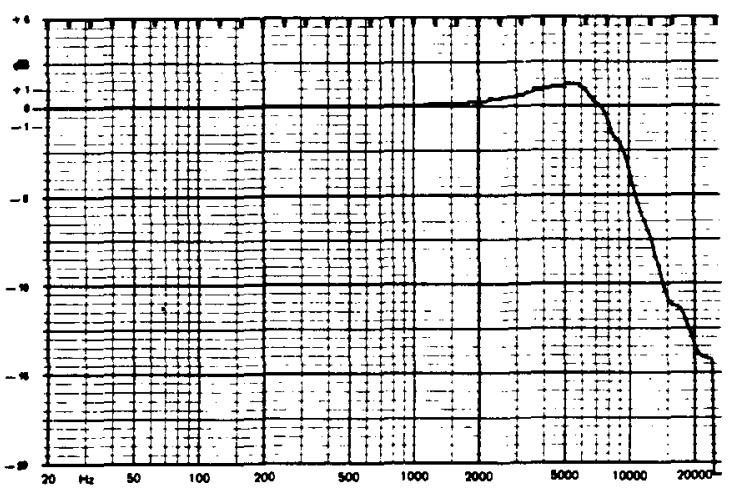

Figure 6. Frequency response curve supplied by B\&K Instruments with 1-inch pressure microphone type 4144. (Courtesy Bruel \& Kjaer Instruments Inc.) 
To produce a so-called free field microphone, this manufacturer has constructed the diaphragm so that the pressure response is as shown in the lower curve in Figure 7. If the microphone is pointed at the sound source ( 0 deg incidence) the correction factor for 0 deg shown in Figure 4 must be applied. As an example, observe that the lower response curve in Figure 7 is $-9 \mathrm{~dB}$ at $10,000 \mathrm{~Hz}$. The 0 deg incidence correction curve at $10,000 \mathrm{~Hz}$ in Figure 4 is $+9 \mathrm{~dB}$. Adding the two curves at this frequency brings the free field response up to $0 \mathrm{~dB}--$ the frequency response becomes flat.

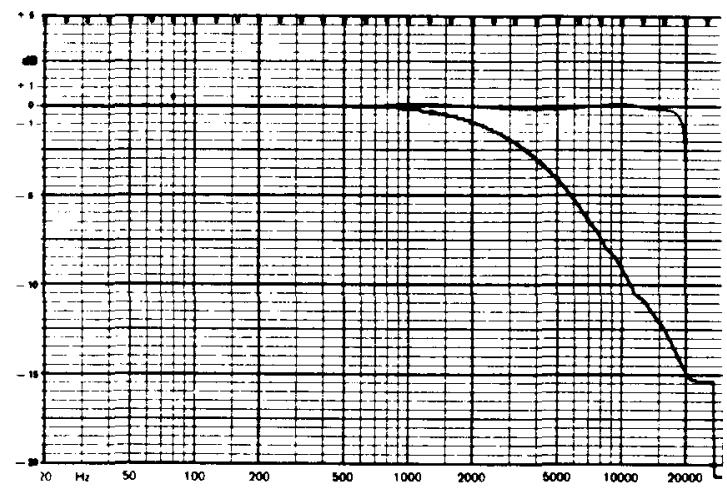

Figure 7. Frequency response curve supplied by B\&K Instruments with 1-inch free field microphone type 4145. (Courtesy Bruel \& Kjaer Instruments Inc.) Lower curve: microphone pressure response. Upper curve: microphone pressure response with correction added for zero angle of incidence giving the free field response.

These general characteristics hold for most microphones. If one desired to use a microphone which qualifies as a precision instrument he can take assurance in the fact that standards for the performance of such microphones are published by the American National Standards Institute (ANSI), for example, ANSI S1.12-1967, "Specifications for Laboratory Standard Microphones." When purchasing such a microphone the manufacturer will supply the buyer with a calibration curve, stating to which appropriate standard the microphone complies and this calibration will be traceable to the National Bureau of Standards (refer to standard ANSI S1.10-1966, "Method for the Calibration of Microphones").

\section{SOUND LEVEL METERS}

In its basic form a sound level meter (SLM) is simply a microphone mounted on an amplifier with a meter to indicate the level of the sound pressure at the microphone. While construction details may vary, all SLM should read the same value when exposed to the same sound pressure. Consequently, ANSI has another standard for sound level meters - ANSI S1.4-1971, "Specification for Sound Level Meters". This standard clearly points out the tolerances within which the meter must be able to measure sound pressure levels. NIOSH maintains a certification program for industrial sound level meter sets. The certified meters are essentially those meeting the ANSI S1.4-1971 standard for a type 2 sound level meter set to A-weighting and slow response. A list of certified meters is available in the NIOSH Certified Equipment List. 
As previously discussed, sound is composed of both amplitude and frequency, and the A-, B-, C-, and D-weighting curves were introduced along with band pass filters. A typical SIM may incorporate some or all of these filters such as shown in the block diagram of Figure 8. The "typical" SLM has the microphone mounted on the front and the output is amplified and fed to one of the filter circuits as selected by a switch. Band pass filters are usually of the constant percentage or fractional octave type. Constant bandwidth filters are not usually provided on portable meters.

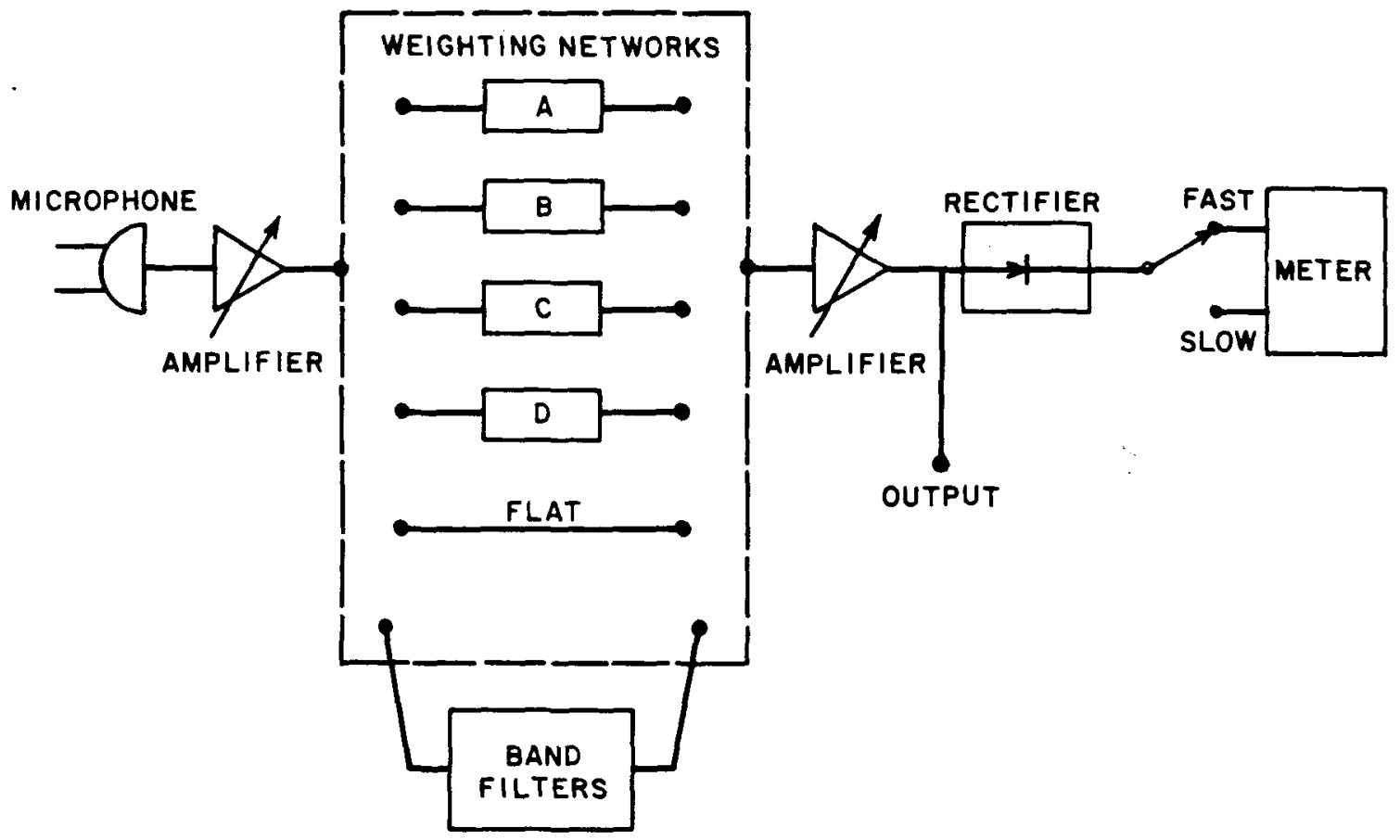

Figure 8. Block diagram of a sound level meter.

After passing through the selected filter network the signal is again amplified. At this point an output jack is provided so that the signal may be recorded on tape or fed to some other signal analyzing device. After being amplified the signal goes to a mean square rectifier and the value is displayed on a meter in decibel units. Note here that the meter may have either a fast or slow response which is switch selectable. The fast response provides an averaging time of 200 to $250 \mathrm{~ms}$. The slow response position averages the signal for a greater period of time.

Each of the blocks shown in Figure 8 is covered in the specifications of ANSI S1.4-1971, including the response time of the meter. While this standard does not specify which of the filter circuits a SLM must have it does specify how accurately the weighting curves must correspond to the attenuations shown in Table 3 . The accuracy requirements are divided into four groups:

$$
\begin{aligned}
& \text { Type } 0 \text { - Laboratory standard SLM (proposed) } \\
& \text { Type } 1 \text { - Precision SLM (most stringent) }
\end{aligned}
$$


Type 2 - General purpose SLM

Type 3 - Survey SLM (least stringent)

A fifth type called special purpose SLM includes those which have only a portion of the variations possible. These special purpose meters must meet the standard for those features they do incorporate.

Only sound levels that are reasonably steady in time have been considered thus far. Another noise type which must be considered is the so-called "impulse" noise. This is a sound of short duration such as a gunshot or the noise produced by a hammer striking an object. To measure such sounds the SLM described is not very well equipped because the meter simply cannot respond fast enough. These sounds can best be measured by connecting the SLM output to a storage oscilloscope and reading the peak amplitude from the dispilay. However, there are some instruments available which incorporate a "peak hold" feature. This is an instrument that has a very fast response electrical circuit which measures the peak of the sound pressure pulse and holds the value long enough for the meter to display the value that is held. The meter then holds this value until the operator resets the instrument.

Current1y being considered by international standards groups is another meter response time called "impulse" response. This impulse measurement is between the meter fast response time and the true peak measurement. (see S/V Sound and Vibration, March 1974).

\section{CALIBRATION OF SOUND LEVEL METERS}

Although a SLM comes from the factory calibrated and is provided with the appropriate traceability to the National Bureau of Standards, its performance must be checked on a regular basis. Several devices are available for this purpose. The most common of these is a calibrator which fits directly over the microphone and generates a known pressure level within the closed volume by the motion of a piston back and forth or with a small loudspeaker. It is recommended that a sound level meter be calibrated with a compatible acoustical calibrator before and after a measurement period. The manufacturer's instructions should be followed for procedures and corrections for environmental conditions such as temperature and atmospheric pressure. A complete recalibration of the sound level meter and acoustical calibrator is recommended on a periodic basis.

\section{FREQUENCY ANALYZERS}

Since a SLM is a small portable device it cannot incorporate all of the capabilities to analyze sounds which an engineer may desire. For this reason an output jack is often provided. With this output the engineer can either record the sounds on tape or he may connect the SLM directly to some other signal analysis device.

Some of the devices which find particular use in acoustics are frequency analyzers which can produce frequency spectra in real time in almost any desired bandwidth or type. These "real time analyzers" are generally of two types. The first is the multiple filter in which the electronic signal is fed to many 
filters simultaneously and the output of each is displayed in suitable fashion. The second type uses a time compression technique and feeds the signal through a single variable filter at such a speed that the signal appears to have been run through many filters at once. Of increasing importance in recent years have been analyzers which employ the same techniques in a digital manner. These analyzers are rather large expensive devices and are therefore not on the equipment list of the average individual or small company. The types of analysis that can be performed with these or other even more sophisticated instruments are many and varied. 


\section{METHODS OF NOISE CONTROL}

The basic idea behind the techniques for limiting a person's exposure to noise is very simple and straightforward. The reference frame dealt with in noise reduction is composed of a sound source, the sound wave path, and a sound wave receiver which, in common circumstances, is an ear or a microphone that is used for measurement.

The best and most satisfying means of reducing noise levels is to reduce the source sound output. This approach may require major modifications, including better quality control, closer tolerances on moving parts, better balancing of rotating parts, and sometimes even a complete redesign of the technique utilized to perform the job for which this machine is intended. Since something vibrating causes compression and rarefaction of the air which is observed as sound, the above mentioned and many other modifications to a sound source are all aimed toward reducing the vibration of any part to the lowest possible level. Normally these modifications are not within the capability of the user and therefore must be left to the equipment manufacturers. Fortunately for those directly affected, manufacturers are beginning to make these changes.

At the other end of the noise control path is the receiver. The method of controlling noise exposure at the receiving end usually means removing the affected person from the sound field. When this cannot be done the alternative is to have the person wear ear muffs or ear plugs. This procedure is actually a control on the path of the noise but since it is incorporated directly with the receiver it is considered a receiver application.

The middle course of action is modification to the path the sound takes from the source to the receiver. It is with controls on the sound path that most of the items listed in this document are concerned.

Sound can reach a listener's ears by several different routes. The most obvious for internal noise sources is the direct path, a straight line through the air from source to receiver. In a given room, reflections from walls, ceiling, floor, or any solid objects may contribute as much or more to the sound pressure level than the direct path. As sound travels through solids and air, it may travel an indirect route through floors and walls and arrive at the receiver after reradiation.

Paths for external sound include penetration through and/or around open or closed doors, partitions, walls, windows, roofs, ceilings and floors. The effectiveness of a well-designed acoustical wall can be largely destroyed by relatively small openings.

Basically the two different acoustic environments that are employed in evaluating noise sources or the effectiveness of acoustic insulation are the free field and diffuse field. As previously mentioned a free field is defined as a homogenous, isotropic medium, free from boundaries. 
A reverberant field exists when sound from the suurce bounces back and forth from the hard surfaces of the room such that the sound pressure level at any point is composed of many such reflected waves. In an ideal reverberant field the sound waves are perfectly reflected with no loss in intensity and a diffuse condition exists where the sound pressure level is equal everywhere. In real life, a perfect free or reverberant field is rarely found. Sound almost always propagates in an environment between these two extremes. Only in laboratories may approximations to these ideal fields be found. An anechoic (echo free) room has its walls, floors, and ceilings lined with material which absorbs the sound waves which reach it. The absence of reflections produces a sound field which is essentially free at most frequencies. A reverberation room on the other hand has walls, floor, and ceiling constructed of hard, solid materials to reflect as much of the sound waves as possible. The reflections in the sound field, along with the presence of irregularities in the surfaces and large rotating vanes produce a reverberant field. Most test procedures for acoustic materials have evolved around the use of a reverberation room.

In actual conditions when a sound wave strikes a surface it is partially reflected, partially transmitted through the surface, and partially absorbed. These interactions of sound waves and surfaces will be examined in turn.

The practical approach to noise control takes into account the noise sources, paths, and receivers. The following items must be determined successively to accomplish noise control:

1. Noise criteria for each occupied space.

2. Sound power level of the noise produced by each source.

3. Noise levels at typical employee positions in that space.

4. Attenuation of the noise by walls, ducts, etc., between each source and the space in question.

5. Required additional attenuation (item 3 minus item 1 ).

6. Identify major noise sources and select noise control treatment.

7. Any special mountings of the devices necessary to control flanking noise.

8. Any vibrating elements whose vibrations may be transmitted to some other member causing it to become a noise radiator.

Criteria: The first of these items, criteria for the space, is not part of the scope of this compendium. In a factory the criteria are determined by some federal agency such as the Occupational Safety and Health Administration (OSHA). In an office environment or concert hall the factors determining acoustic criteria are more numerous and complex than just a requirement for reduction of the sound pressure level to conserve hearing.

Sound Power: The second item is more straightforward. If at all possible one should obtain from the manufacturer of a noisy device the sound power levels that have been measured in the laboratory. Fortunately, more and more manufacturers are taking such measurements and data are becoming available. Barring this course one must make his own measurements of sound power, which can be 
very difficult if not completely impossible on a large piece of machinery in a factory environment. One usually is forced to make sound pressure level measurements at many locations around the noise source and attempt to estimate the sound power. The effects of other machinery, the room itself, background noises, etc., can preclude a very accurate determination.

The procedure for determining sound power is basically simple. Make enough measurements on a hemisphere around the source in a quiet anechoic space above a hard floor. If one is careful to choose his points on this hemisphere such that each measurement represents an equal area of the surface, then the sound power is computed with the aid of equations (14) or (18). It is important to realize that this procedure only produces accurate results if the measurements are made in a free field environment. When performed in a factory the results are far from accurate but provide an estimate of the sound power.

Noise Levels: The sound pressure levels must be measured at all locations where it is desirable to reduce the noise. These measurements must include an A-weighted sound pressure level, $\mathrm{dBA}$, and they should also include measurements in each of the octave bands. For engineering analysis of machine noise sources a narrow band analysis of the noise can also be of value if the presence of pure tones is observed. This frequency analysis is an aid in determining the source of the noise as well as being necessary to make a proper selection of the noise control item. The best choice of noise control item is made by obtaining the closest fit possible between the noise spectrum and the noise reduction spectrum of the noise control device.

Noise Attenuation: Having measured the sound pressure levels and knowing the criteria that must be met, the noise level now must be reduced by the required amount. The fourth and fifth items can best be handled at the same time. When attempting to reduce the noise levels one is faced with the fact that the presently existing attenuation is not sufficient and more must be done. If the attenuation is sufficient this will be evident when the noise levels are measured at the desired locations.

Noise Control Devices: This item concerns the selection and use of noise reducing devices, and because this is the subject that occupies most of the latter portion of the compendium, it is only defined at this point.

Mountings: When the goal is to keep noise from traveling, any possible path should not be overlooked. Normally one thinks of sound traveling through the air but this certainly is not the only medium that will support sound waves. In fact, sound travels very well in most solids.

Therefore when one deals with flanking and transmission problems it must be remembered that the hard materials are very good conductors of sound. An aid in reducing sound transmitted through these objects is the mismatch of mechanical impedances at boundary surfaces such as from air to steel, or steel to wood. Just as with electrical power transmission, the greater the mismatch of impedances the more reflection of energy and loss in power transfer results. As in electronics, the optimum power is transferred when the impedances of the two items are equal. The same holds true for acoustics. Therefore, flanking paths can be greatly reduced by introducing materials in the path of the sound 
which have poorly matching mechanical impedance. For example, place pieces of rubber or cork between structural steel members, mount items on a material different from the main support, etc.

The most commonly occurring flanking path is an actual opening in the partition. A direct leak such as this can completely destroy the effectiveness of any sound barrier.

Vibration: Noise from vibrating elements may be considered as another aspect of the flanking problem. Vibrations in a solid structure may be radiated as sound. The use of vibration isolation devices causes a mechanical impedance mismatch between a vibrating machine and the surrounding structures, preventing vibrational energy from reaching any elements which may prove to be good sound radiators. 


\section{SOUND ABSORPTION}

The sound absorbing quality of a material is described by an absorption coefficient, $\alpha$, which is defined as the ratio of the total energy incident on a surface minus the energy reflected from the surface, to the energy incident upon the surface. As such the absorption coefficient can vary between zero and one. When the energy is perfectly reflected the ratio is zero and when the energy is completely absorbed this ratio is one. The absorption coefficient of a surface depends on the frequency of the sound impinging on it. To completely specify the absorption properties of a material, a table or curve of $\alpha$ versus frequency must be obtained.

The mechanism of sound absorption is that the acoustic energy of the wave is converted to some other form of energy, usually heat. Three major means of converting the acoustic energy are by using porous absorptive materials, diaphragmatic absorbers, and resonant or reactive absorbers.

Porous absorptive materials are the best known of the acoustical absorbers. These are usually fuzzy, fibrous materials, perforated board, foams, fabrics, carpets, and cushions, etc. In these materials the sound wave causes motion of the air in the spaces surrounding the fibers or granules, the frictional energy losses occur as heat, and the acoustic energy is reduced. Because this is the mechanism by which these materials absorb sound, it is easy to see that a "too loose" material will not cause enough frictional energy loss and will be a poor absorber. On the other hand, a material which is too dense will not permit enough air motion to generate sufficient friction and will also be a poor absorber. The latter type of material is more of a reflector than an absorber.

In a diaphragmatic absorber the panel oscillates at the same frequency as the sound wave impinging upon it (or at some harmonic). Since no material is perfect1y elastic, the natural damping will absorb some of the incident energy. This type of absorber is usually more effective at lower frequencies since the higher frequencies tend to be reflected. Since the absorption coefficient of this absorber type is very dependent on mass, rigidity, size, shape, and mounting methods, it is difficult to forecast how any particular panel will operate in practice. Usually it is necessary to test prototypes for each specific application.

Resonant or reactive absorbers (often called Helmholtz resonators) are cavities which confine a volume of air which is connected to the atmosphere by a small hole or channel in the cavity. If the cavity is very small compared with the wavelength of the incident sound wave, the air in the connecting channel is forced to oscillate into and out of the cavity. The air inside the cavity acts as a spring and the kinetic energy of the vibration is essentially that of the air in the channel moving as an incompressible and frictionless fluid. This 
type of absorber has a very narrow frequency band where absorption takes place and as such its use is somewhat limited. This narrow band of absorption can be broadened by insertion of a porous type of absorber into the cavity. Also, the absorption peak is usually in the lower frequencies and as such this principle is useful for increasing the low frequency performance of common porous type absorbers.

Commercial panels are available which have many small holes in the face and the appropriate dimensions of absorber and air gap behind the faces to increase the low frequency absorption. This principle requires that the face plate have an opening of approximately 5 percent or less to effect any tuning. Common perforated absorption panels usually have a much higher open area, since the large closed surface acts to reflect the higher frequencies.

\section{SOUND ABSORPTION MEASUREMENTS (PER ASTM C423-77)}

The absorption coefficient of a material may be observed to vary with the frequency of the incident sound and with the angle of incidence between the sound waves and the materials. By testing the absorption properties of the material in a reverberation room, the dependence of absorption on direction may be averaged since in the diffuse sound field produced in a reverberation room the sound waves arrive from all directions with equal probability. Absorption coefficients measured in a reverberation room are called random incidence absorption coefficients. The presence of absorption removes energy from a sound field, and this energy loss can be measured by the rate at which the sound intensity in a room decays after the sound source is removed. The rate of decay of a sound field in a reverberation room is expressed as the "reverberation time" which is the time required for the sound pressure level to drop $60 \mathrm{~dB}$ after the source is removed.

The test procedure for the measurement of random incidence absorption coefficients is specified by and described in ASTM Standard C423-77, "Standard Method of Test for Sound Absorption of Acoustical Materials in Reverberation Rooms."

Often, instead of the absorption coefficient of a material, which is a nondimentional quantity, the total absorption of an area is considered. One sabin is $1 \mathrm{sq} \mathrm{ft}$ of perfect absorption; similarly, $2 \mathrm{sq} \mathrm{ft}$ of material with an absorption coefficient of 0.5 is also 1 sabin of total absorption. The total absorption of a patch of material is the product of the absorption coefficient and the surface area of the material. The units of total absorption are square feet. A metric sabin is used when dealing with metric quantities. Its definition is the same but the basic unit is a square meter. One metric sabin is equal to 10.76 English sabins.

The total absorption in the room is first measured without the specimen by turning on a sound source long enough to come to a steady state level and then measuring the rate of decay of the sound pressure level when the sound source is suddenly turned off. The total absorption of the room is then given by the Sabine equation

$$
A=0.9210 \frac{V d}{c}
$$


where
$\mathrm{V}$ is the volume of the room; cu $\mathrm{ft}$
$d$ is the rate of decay of the sound field; $d B / s e c$
$c$ is the speed of sound; $\mathrm{ft} / \mathrm{sec}$
$A$ is the total absorption in sabins; sq $\mathrm{ft}$

If the volume used is expressed in cubic meters and the speed of sound is in meters per second, then the absorption will be given in metric sabins. After measuring the total absorption in the room the specimen is brought into the room and the total absorption is again measured in the same manner. The absorption added to the room by the test specimen is then determined by taking the difference, thus

$$
\begin{aligned}
A_{\text {specimen only }} & =A_{\text {with specimen }}-A_{\text {without specimen }} \\
& =0.9210 \mathrm{~V}\left(\mathrm{~d}_{\text {with }}-\mathrm{d}_{\text {without }}\right) / \mathrm{c}
\end{aligned}
$$

The absorption coefficient is then determined by dividing the total absorption by the area of the specimen

$$
\alpha=\mathrm{A} / \mathrm{S}
$$

where $\alpha$ is the absorption coefficient and $S$ is the area of the specimen in either square meters or square feet as required.

There are several important factors to note about this standard laboratory procedure. First, the room must be very hard and be able to support a reverberant (diffuse) sound field very close to the ideal. Also, the room must be sufficiently large so that the introduction of a highly absorbing specimen will not destroy this diffuse field. Because of the second limitation the specimen must be small enough to not interfere with the diffuseness of the sound field but it must also be large enough so that accurate data may be obtained. The size of the specimen also introduces other effects such as the fact that smaller specimens will generally measure higher values of absorption coefficient than a larger area of the same material. To avoid variations from different laboratories the standard specifies that the specimen size is to be at least $21.95 \mathrm{sq} \mathrm{m}$ (72 sq ft), which is the customary size.

Absorption Coefficients Exceeding Unity

In this method of testing the diffuse sound field measures absorption for all angles of incidence and not just for normal incidence. The method of measuring absorption coefficients using the decay rate of the sound field can yield absorption coefficients as high as 1.2 to 1.3 (the absorption coefficient by definition must be between zero and 1 ). These higher values do not cause problems in practice.

The principal reasons that the measured values of absorption coefficients sometimes exceed unity are diffraction effects and the size of the specimen. Diffraction probably accounts for most of the difference in the lower frequencies 
while specimen size is more responsible for the effects at higher frequencies, since the theory which relates absorption to the decay rate of the sound field is based on an infinite size sample in a diffuse field.

An additional factor affecting the absorption in a reverberation room is that the air is also an absorber, the extent of which is dependent on temperature and relative humidity, especially at the higher frequencies. To control this dependency, the laboratory measurement of absorption is usually made in a room where these values are maintained within narrow limits. (Temperature and humidity values should be included in the laboratory report of a test.)

\section{Mountings for Absorption Tests}

Another item that affects the absorption properties of a material is the method of mounting. For a porous type absorber the space between it and the wall will increase the absorption somewhat as the space is increased. Consequently, to maintain standard mountings for testing, the Acoustical and Insulating Materials Association (AIMA) specifies seven standard mountings which should be used for testing sound absorbing materials. These mountings are shown in Figure 9. Laboratories making absorpiton tests will always include in their report which of these mountings were used for the test.

Since the standard mountings are based on actual methods of installing absorbing material, the mountings reported in tests made in recent years are predominantly numbers four and seven as these represent the most popular methods of mounting modern acoustical material. While no standard mounting exists for landscape screens or absorbent partitions, they are commonly tested in pairs in an upright position, arranged nonparallel to each other, and separated by

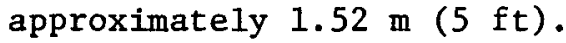

\section{Dependence of Absorption Coefficient on Frequency}

Only the magnitude of sound absorption has been discussed but as with the other properties of sound the absorption also depends on frequency. Some typical sound absorption coefficlents versus frequency are shown in Figure 10. Notice the increase in absorption coefficient with increasing frequency and increasing thickness.

The frequency dependence of the absorption coefficient is obtained by measuring the absorption as described above in six one-third octave bands centered at $125,250,500,1000,2000$ and $4000 \mathrm{~Hz}$. The laboratory report will therefore show six absorption coefficients and the frequencies at which they were measured. Note that these numbers are rounded to the nearest integral multiple of 0.01 as specified in the standard. Table 5 lists the average absorption coefficients of some typical building materials. 


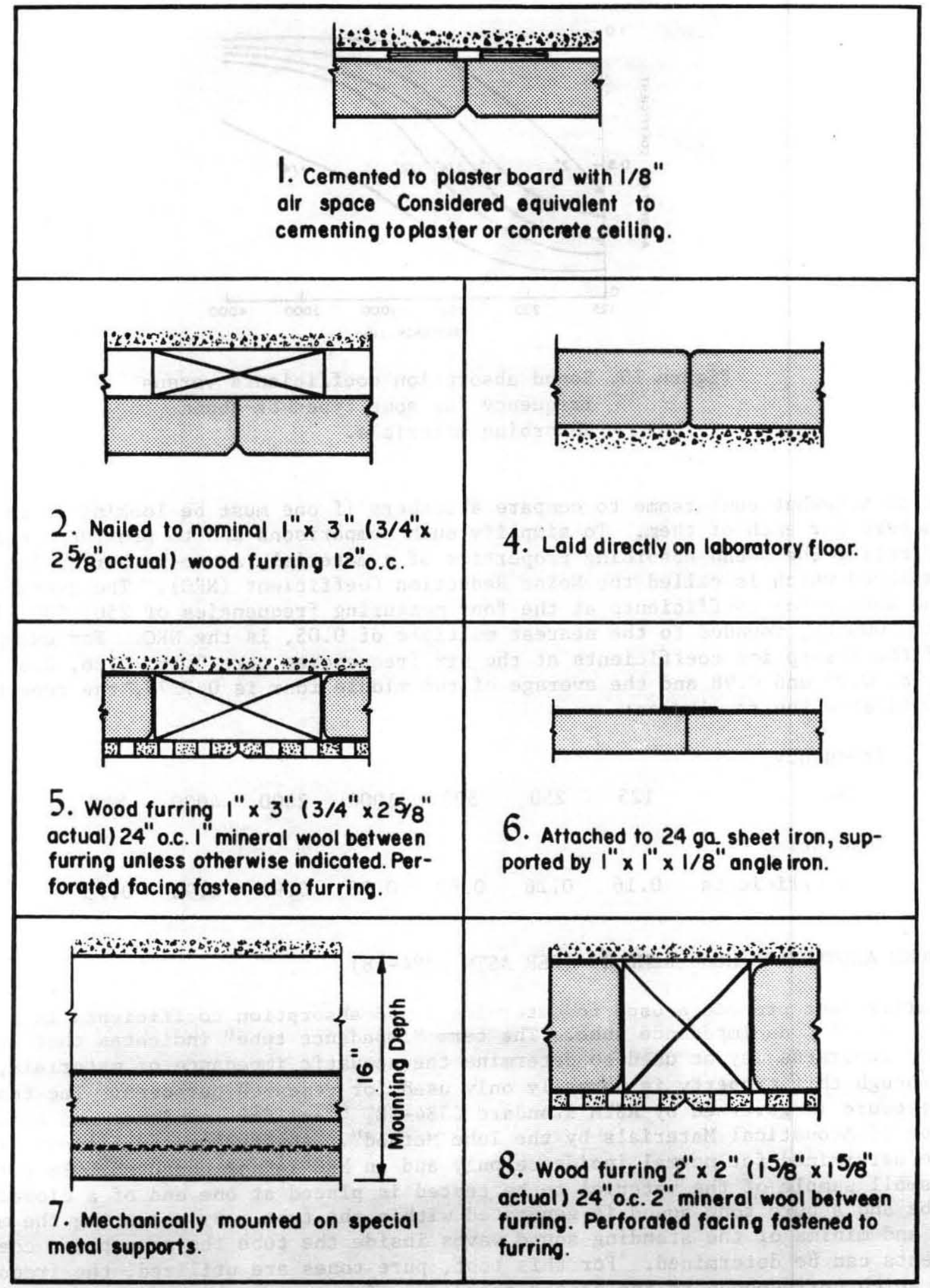

Figure 9. Mountings used in sound absorption tests. (from AIMA Bulletin, "Performance Data, Architectural Acoustical Material") 


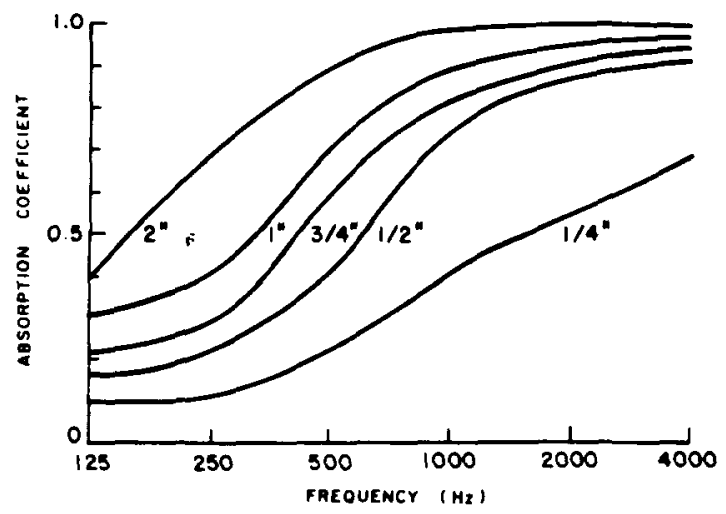

Figure 10. Sound absorption coefficients versus frequency for some types of sound absorbing materials.

It is somewhat cumbersome to compare absorbers if one must be looking at six numbers for each of them. To simplify such comparisons and to provide a means of rating the sound absorbing properties of a material, a one-number rating is employed which is called the Noise Reduction Coefficient (NRC). The average of the absorption coefficients at the four measuring frequencies of 250, 500, 1000, and $2000 \mathrm{~Hz}$, rounded to the nearest multiple of 0.05 , is the NRC. For example, if the absorption coefficients at the six frequencies were $0.16,0.26,0.68$, $0.98,0.99$ and 0.98 and the average of the middle four is 0.7275 , the report would show the results as:

Frequency,

$\mathrm{Hz}$

125

250

500

1000

2000

4000

NRC

Absorption

Coefficients

0.16

0.26

0.69

0.98

0.99

0.98

0.75

\section{SOUND ABSORPTION MEASUREMENTS (PER ASTM C384-58)}

Another test procedure used to determine sound absorption coefficients is performed using an impedance tube. The term "impedance tube" indicates that the same apparatus may be used to determine the acoustic impedance of materials, although this property is normally only used for research purposes. The test procedure is governed by ASTM standard C384-58, "Test for Impedance and Absorption of Acoustical Materials by the Tube Method". Absorption coefficients $\left(\alpha_{n}\right)$ are determined for normal incidence only and an NRC is not computed. In effect, a small sample of the material to be tested is placed at one end of a closed tube and a pure tone sound is generated within the tube. By measuring the maxima and minima of the standing sound waves inside the tube the absorption coefficients can be determined. For this test, pure tones are utilized, the frequency of which corresponds to the center frequency of an octave band (i.e., 125, 250, $500,1000,2000$ or $4000 \mathrm{~Hz}$ ). 
Table 5. Absorption Coefficients of general building materials and furnishings. Complete tables of coefficients of the various materials that normally constitute the interior finish of rooms may be found in the various books on architectural acoustics. The following short list will be useful in making simple calculations of the reverberation in rooms.

\begin{tabular}{|c|c|c|c|c|c|c|}
\hline \multirow[t]{2}{*}{ MATERIALS } & \multicolumn{6}{|c|}{ COEFFICIENTS. $\mathrm{Hz}$} \\
\hline & 125 & 250 & 500 & 1.000 & 2.000 & 4.000 \\
\hline Brick, unglazed & 0.03 & 0.03 & 0.03 & 0.04 & 0.05 & 0.07 \\
\hline Brick, unglazed, painted & .01 & .01 & .02 & .02 & .02 & .03 \\
\hline $\begin{array}{l}\text { Carpet, heavy, on concrete } \\
\text { Same, on } 40 \text { oz hairfelt or foam }\end{array}$ & .02 & .06 & .14 & .37 & .60 & .65 \\
\hline rubber & .08 & .24 & .57 & .69 & .71 & .73 \\
\hline $\begin{array}{l}\text { Same, with impermeable latex } \\
\text { backing on } 40 \text { oz hairfelt or } \\
\text { foam rubber }\end{array}$ & .08 & .27 & .39 & .34 & .48 & .63 \\
\hline Concrete Block, coarse …..................... & .36 & .44 & .31 & .29 & .39 & .25 \\
\hline 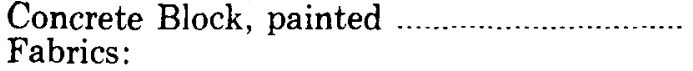 & .10 & .05 & .06 & .07 & .09 & .08 \\
\hline $\begin{array}{l}\text { Light velour, } 10 \mathrm{oz} \text { per sq yd, } \\
\text { hung straight, in contact with wall } \\
\text { Medium velour, } 14 \mathrm{oz} \text { per sq yd. }\end{array}$ & .03 & .04 & .11 & .17 & .24 & .35 \\
\hline $\begin{array}{l}\text { Medium velour, } 14 \text { oz per sq yd, } \\
\text { draped to half area }\end{array}$ & .07 & .31 & .49 & .75 & .70 & .60 \\
\hline $\begin{array}{l}\text { Heavy velour, } 18 \text { oz per sq yd, } \\
\text { draped to half area }\end{array}$ & 14 & .35 & .55 & .72 & .70 & .65 \\
\hline Floors: & & & & & & \\
\hline $\begin{array}{l}\text { Concrete or terrazzo } \\
\text { Linoleum, asphalt, rubber or cork }\end{array}$ & .01 & .01 & .015 & .02 & .02 & .02 \\
\hline tile on concrete. & .02 & .03 & .03 & .03 & .03 & .02 \\
\hline Wood & .15 & 11 & .10 & .07 & .06 & .07 \\
\hline Wood parquet in asphalt on concrete.... & .04 & .04 & .07 & .06 & .06 & .07 \\
\hline $\begin{array}{l}\text { Glass: } \\
\text { Large panes of heavy plate glass }\end{array}$ & & & & & & \\
\hline $\begin{array}{l}\text { Large panes of heavy plate glass } \ldots . . . . . . . \\
\text { Ordinary window glass }\end{array}$ & $\begin{array}{l}.18 \\
.35\end{array}$ & $\begin{array}{l}.06 \\
.25\end{array}$ & $\begin{array}{l}.04 \\
.18\end{array}$ & .03 & $\begin{array}{l}.02 \\
.07\end{array}$ & $\begin{array}{l}.02 \\
.04\end{array}$ \\
\hline Gypsum Board, $1 / 2$ " nailed to $2 \times 4$ 's & & & & & & \\
\hline $16^{\prime \prime}$ o.c. $\ldots$. & .29 & .10 & .05 & .04 & .07 & .09 \\
\hline $\begin{array}{l}\text { Marble or Glazed Tile } \\
\text { Openings: }\end{array}$ & .01 & .01 & .01 & .01 & .02 & .02 \\
\hline $\begin{array}{l}\text { Stage, depending on furnishings } \\
\text { Deep balcony, upholstered seats } \\
\text { Grills, ventilating }\end{array}$ & & & $\begin{array}{l}.25 \\
.50 \\
.15\end{array}$ & $\begin{array}{l}.75 \\
1.00 \\
.50\end{array}$ & & \\
\hline $\begin{array}{l}\text { Plaster, gypsum or lime, smooth } \\
\text { finish on tile or brick }\end{array}$ & .013 & .015 & .02 & .03 & .04 & .05 \\
\hline Plaster, gypsum or lime, rough finish & & & & & & \\
\hline on lath & .14 & .10 & .06 & .05 & .04 & .03 \\
\hline $\begin{array}{l}\text { Same, with smooth finish } \\
\text { Plywod Paneling } 3 \text { " thick }\end{array}$ & .14 & .10 & .06 & .04 & .04 & .03 \\
\hline Plywood Paneling, 3/8" thick .............. & 28 & .22 & .17 & .09 & .10 & .11 \\
\hline $\begin{array}{l}\text { Water Surface, as in a swimming pool } \\
\text { Air, Sabins per } 1000 \text { cubic feet }(1150 \%\end{array}$ & .008 & .008 & .013 & .015 & .020 & .025 \\
\hline Air, Sabins per 1000 cubic feet & & & & .9 & 2.3 & 7.2 \\
\hline
\end{tabular}

Air, Sabins per 1000 cubic feet $\pi 50 \% \mathrm{RH}$

ABSORPTION OF SEATS AND AUDIENCE, sabins per square foot of seating area or per unit

\begin{tabular}{|c|c|c|c|c|c|c|}
\hline $\begin{array}{l}\text { Audience, seated in upholstered seats, } \\
\text { per sq ft of floor area }\end{array}$ & 0.60 & 0.74 & 0.88 & 0.96 & 0.93 & 0.85 \\
\hline $\begin{array}{l}\text { Unoccupied cloth-covered upholstered } \\
\text { seats, per sq ft of floor area }\end{array}$ & .49 & .66 & .80 & .88 & .82 & .70 \\
\hline $\begin{array}{l}\text { Unoccupied leather-covered upholstered } \\
\text { seats, per sq } \mathrm{ft} \text { of floor area......... }\end{array}$ & .44 & .54 & .60 & .62 & .58 & .50 \\
\hline $\begin{array}{l}\text { Wooden Pews, occupied, per sq } \mathrm{ft} \text { of } \\
\text { floor area }\end{array}$ & .57 & .61 & .75 & .86 & .91 & .86 \\
\hline $\begin{array}{l}\text { Chairs, metal or wood seats, } \\
\text { each, unoccupied }\end{array}$ & .15 & .19 & .22 & .39 & .38 & .30 \\
\hline
\end{tabular}


Often a laboratory or the manufacturer will measure the normal incidence absorption coefficients in an impedance tube and then estimate a value for the NRC.

Relationship between Random and Normal Incidence Coefficients

It is important to realize that a concrete theoretical relationship has not yet been developed to relate $\alpha_{n}$ to $\alpha$, and that any estimate made is based on empirical relationships. A rule of thumb for relating $\alpha_{n}$ to $\alpha$ (Section V-1, ASTM C384) is that $\alpha_{n}$ is about one-half of $\alpha$ for small values of $\alpha$ and as $\alpha$ becomes large $\alpha$ becomes almost equal to $\alpha$. The maximum difference occurs for intermediate values and can be as large as 0.25 to 0.35 . In general $\alpha_{n}$ is always smaller than $\alpha$ (see Figure 11).

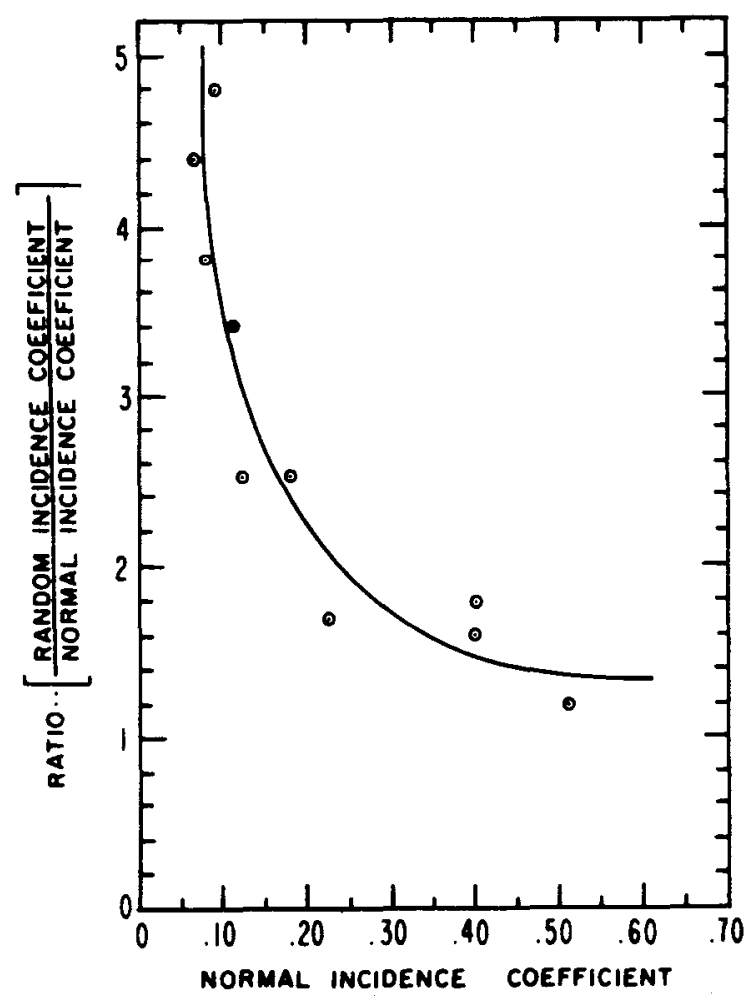

Figure 11. Relationship of random to normal incidence absorption coefficients at a test frequency of $500 \mathrm{~Hz}$. (A. London, JASA, 1950) 
If different surfaces of a room are comprised of different materials (the usual case), the average absorption coefficient is determined by the sum of the coefficients of each area:

$$
\bar{\alpha}=\frac{\sum S_{i} \alpha_{i}}{\sum S_{i}}
$$

where

$$
\begin{aligned}
& \alpha_{i}=\text { random incidence coefficient of the } i \text { th surface } \\
& s_{i}=\text { area of that surface }
\end{aligned}
$$

Another method which can be used to determine the average absorption coefficient of a room is due to Fitzroy (JASA, 1959)

$$
\bar{\alpha}=s\left[\frac{x}{\bar{\alpha}_{\mathrm{x}}}+\frac{\mathrm{y}}{\bar{\alpha}_{\mathrm{y}}}+\frac{z}{\bar{\alpha}_{z}}\right]^{-1}
$$

where

$$
\begin{aligned}
& x=\text { total floor-ceiling areas with average absorption coefficient } \bar{\alpha}_{x} \\
& y=\text { total side wall areas with average absorption coefficient } \bar{\alpha}_{y} \\
& z=\text { total end wall areas with average absorption coefficient } \bar{\alpha}_{z}
\end{aligned}
$$

This equation is especially useful for areas where the absorption material is not evently distributed.

When large extended areas of the same absorption material are used, the absorption coefficients may not be the same as observed in laboratory-sized samples. Table 6 presents suggested correction factors from Faulkner, Handbook of Industrial Noise Control (Industrial Press, NY 1976).

Table 6. Suggested correction factors for large extended areas of the same absorption material. Multiply the laboratory absorption coefficients by the factors given for each octave band.

\begin{tabular}{cccccccc}
\hline & \multicolumn{6}{c}{ Frequency, Hz } \\
\cline { 3 - 7 } Common sample sizes, ft & 125 & 250 & 500 & 1000 & 2000 & 4000 \\
\cline { 2 - 7 } & \multicolumn{5}{c}{ Absorption Coefficient } & Multipliers \\
\hline 8 by 9 & 0.49 & 0.66 & 0.79 & 0.88 & 0.94 & 0.97 \\
6 by 8 & 0.43 & 0.60 & 0.75 & 0.86 & 0.92 & 0.96 \\
\hline
\end{tabular}


At higher frequencies, the air within a room will absorb a fraction of the acoustic energy. An accurate determination of the absorption of the room requires the addition of this air absorption to the average absorption coefficient of the materials. This additional absorption is listed in Table 7.

Table 7. Air absorption at $20^{\circ} \mathrm{C}$ to be added to average absorption coefficient $\bar{\alpha}$ of room materials. $V=$ volume of room in cu ft. $S=$ surface area of room in $\mathrm{sq} \mathrm{ft}$.

\begin{tabular}{ccccc}
\hline $\begin{array}{l}\text { Relative } \\
\text { Humidity }\end{array}$ & $2000 \mathrm{~Hz}$ & $4000 \mathrm{~Hz}$ & $6300 \mathrm{~Hz}$ & $8000 \mathrm{~Hz}$ \\
\hline $30 \%$ & $0.0144 \mathrm{~V} / \mathrm{S}$ & $0.0464 \mathrm{~V} / \mathrm{S}$ & $0.1024 \mathrm{~V} / \mathrm{s}$ & $0.1640 \mathrm{~V} / \mathrm{S}$ \\
$50 \%$ & $0.0116 \mathrm{~V} / \mathrm{S}$ & $0.0296 \mathrm{~V} / \mathrm{S}$ & $0.0612 \mathrm{~V} / \mathrm{s}$ & $0.1040 \mathrm{~V} / \mathrm{s}$ \\
$70 \%$ & $0.0104 \mathrm{~V} / \mathrm{S}$ & $0.0260 \mathrm{~V} / \mathrm{S}$ & $0.0488 \mathrm{~V} / \mathrm{s}$ & $0.0736 \mathrm{~V} / \mathrm{S}$ \\
\hline
\end{tabular}

When the average absorption coefficients are known, the total room absorption in sabins is given by

$$
A=\bar{\alpha} S
$$

where

$$
S=\text { total area of the room. }
$$

Another useful quantity is the room constant

$$
R=S\left(e^{\bar{\alpha}}-1\right)
$$

Frequently it is impractical or even impossible to determine the room constant by directly calculating $\bar{\alpha}$. In this case the room constant can be determined by first measuring the reverberation time of the room. This is a rather complicated procedure best left to a professional acoustician or noise consultant. The average absorption coefficient can then be derived from equation (28) such that

$$
\bar{\alpha}=\frac{0.049 \mathrm{~V}}{\text { TS }}
$$

Here, $T$ is the reverberation time in seconds. Note that the numerical value of the speed of sound in English units and the $60 \mathrm{~dB}$ decay (i.e., decay rate, $d=60 / T$ ) appearing in equation (28) have been incorporated into equation (35).

The effect of the room absorption and distance from the noise source on the sound pressure level can be seen in Figure 12 where the relative sound pressure level in decibels is plotted versus distance from a noise source of sound power level $\mathrm{L}_{\mathrm{w}}$ for several values of the room constant. If the room constant is near zero (perfectly reflecting surfaces) the sound pressure level differs very little throughout the room and a reverberating field exists. On the other hand as the 
room constant becomes very large the sound pressure field approaches that of a free field. This information can be very important when considering sound

treatment for a room.

In many cases, the operator of a piece of machinery is probably affected more by the direct field of the noise source rather than the reverberant field. Consequently, absorption treatment on the walls and ceiling will not reduce the noise of this machine at the operator's position. It can be seen in Figure 12 that the sound pressure level can never be below the straight line corresponding to the free field $1 / \mathrm{r}^{2}$ decrease.

Employees a little further from the machine will probably be in a region that can be called a semireverberant field, i.e., where the sound pressure level is made up of some combination of the direct and reflected sound. Figure 12 can be used as a quick guide to determine if sound absorption treatment reduces the noise level at a given location.

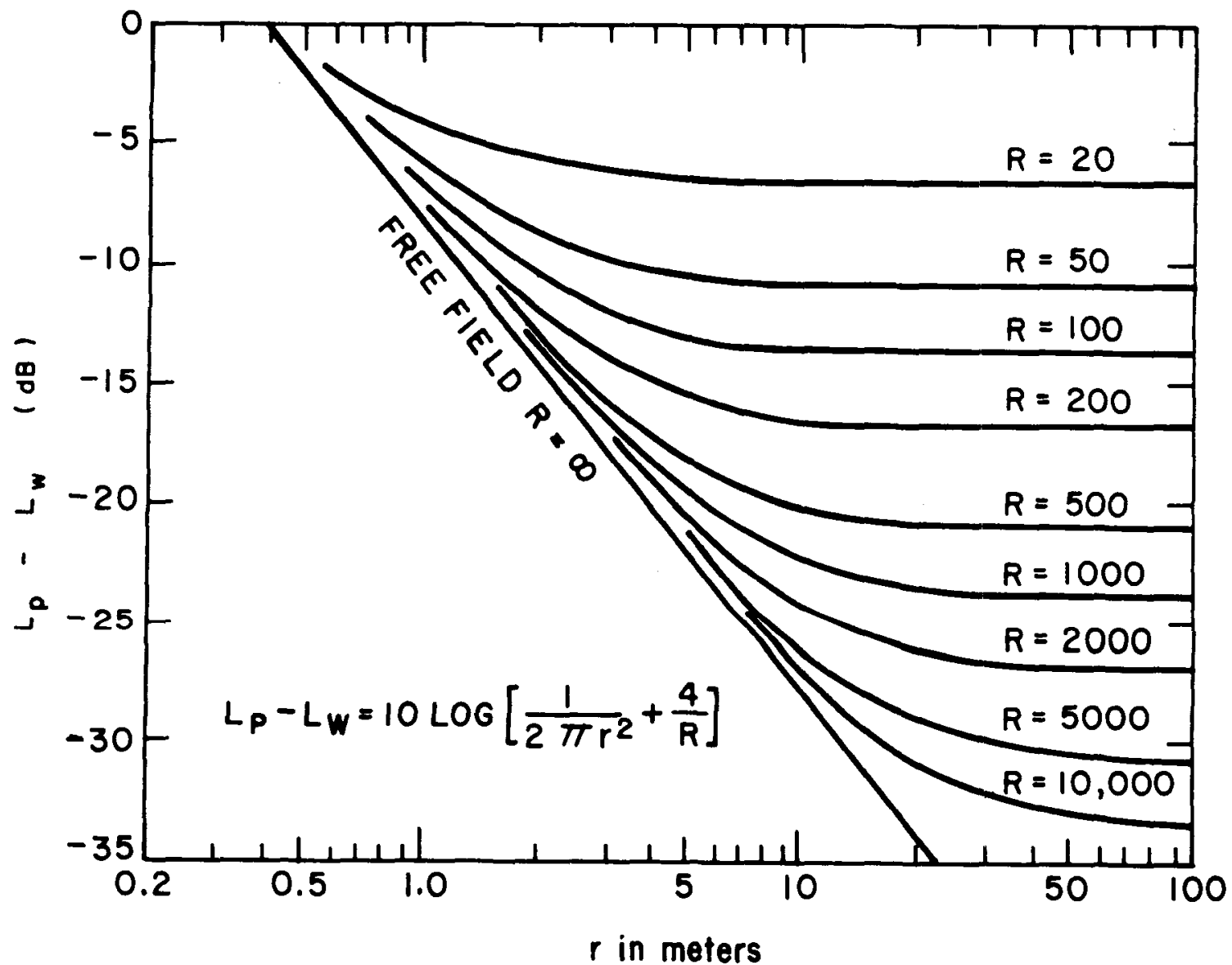

Figure 12. Relative sound pressure level versus distance from the source for semireverberant fields. $r=$ distance from acoustic center; $\mathrm{R}=$ room constant. 
Suppose it is desired to reduce the sound pressure level at a particular operator's position which is $8 \mathrm{~m}$ from the sound source with a sound power level of $\mathrm{L}_{\mathrm{w}}$. If the room constant is determined to be about 1000 , any absorbent material on the walls will have a negligible effect on the sound pressure level at this position.

If however, the room constant is significantly below 1000, an absorption treatment of the surfaces of the room (e.g., $R=1000$ after treatment) can have an appreciable effect which would be equal to

$$
\left[\left(L_{p}-L_{w}\right)_{R}<1000\right]-\left[\left(L_{p}-L_{w}\right)_{R}=1000\right]
$$

Thus in practice, one must first determine when absorption treatment will be useful. Figure 12 is based on the relationship

$$
L_{p}=L_{w}+10 \log \left(\frac{1}{2 \pi r^{2}}+\frac{4}{R}\right)
$$

for the usual case of a noise source resting on a hard surface. If the source were suspended above the floor of a large room, equation (36a) would become

$$
L_{p}=L_{w}+10 \log \left(\frac{1}{4 \pi r^{2}}+\frac{4}{R}\right)
$$

The more general form of this expression includes the directivity factor $Q$ such that

$$
L_{p}=L_{w}+10 \log \left(\frac{Q}{4 \pi r^{2}}+\frac{4}{R}\right)
$$

Note that equations $(36 a, 36 b$, and $36 c$ ) are identical except for the first term in the argument of the logarithm. Equations (36a) and (36b) can be obtained readily from (36c) if one notes that for a nondirectional source in a free field $Q=1$ and for the same nondirectional source in a free field over a reflecting plane $Q=2$. (See Beranek, "Acoustics", pp 311-322, 1957, for the development and discussion of equation (36).)

Clearly the larger $R$ becomes, the lower the sound pressure level at a given distance from the source. To determine the decrease in sound pressure level when absorption is added to a room, which increases the room constant $R$, one could calculate the value of $L_{p}$ from equation (36) for $R_{1}$ before treatment and again for $R_{2}$, the room constant after treatment, or by the equivalent relation

$$
\begin{aligned}
& \text { Reduction in } d B=\left(L_{p 1}-L_{w}\right)-\left(L_{p 2}-L_{w}\right) \\
& L_{p 1}-L_{p 2}=10 \log \left[\left(\frac{Q}{4 \pi r^{2}}+\frac{4}{R_{1}}\right) /\left(\frac{Q}{4 \pi r^{2}}+\frac{4}{R_{2}}\right)\right]
\end{aligned}
$$

where $L_{p 1}$ is the sound pressure level before acoustic treatment and $L_{p 2}$ is the sound pressure level after treatment, both levels measured at the same point in the room. The use of this equation is illustrated by the following example. 
EXAMPLE 9: The dimensions of a room are $15.24 \mathrm{~m}$ (50 ft) (length), $7.62 \mathrm{~m}$ (25 ft) (width), and $3.66 \mathrm{~m}$ (12 ft) (height). The absorption in the room is shown below using absorption coefficients provided by AIMA in Table 5.

\begin{tabular}{lcc}
\hline \multicolumn{1}{c}{ Room component } & $\begin{array}{c}\mathrm{s}_{\mathbf{i}} \\
(\mathbf{s q} \mathrm{ft})\end{array}$ & $\begin{array}{c}\mathrm{a}_{i} \\
(@ 500 \mathrm{~Hz})\end{array}$ \\
\hline Floor; 1inoleum & 1150 & 0.03 \\
10 occupants seated at desks & 100 & 0.55 \\
Ceiling; plaster & 1250 & 0.06 \\
Side walls; gypsum board & 1000 & 0.05 \\
windows & 100 & 0.10 \\
End walls; gypsum board & 450 & 0.05 \\
& 150 & 0.18 \\
\hline
\end{tabular}

Given these initial room conditions:

1. Can absorption treatment be effective in reducing the $500 \mathrm{~Hz}$ octave band sound level of a newly installed machine at a position $8 \mathrm{~m}$ from an observer?

2. How much reduction of the sound level from this source will be achieved using absorption treatment?

SOLUTION: Since the absorption present in the room is fairly evenly distributed, the average absorption coefficient may be calculated from equation (31).

$$
\begin{aligned}
\bar{\alpha} & =\frac{\sum S_{i} \alpha_{i}}{\sum S_{i}}= \\
& =\frac{(1150)(.03)+(100)(.55)+(1250)(.06)+(1000)(.05)+(100)(.10)+(450)(.05)+(150)(.18)}{4200} \\
& =0.065
\end{aligned}
$$

and thus, the room constant from equation (33) before treatment

$$
\begin{aligned}
R_{1}=S\left(e^{\bar{\alpha}}-1\right)=4200\left(e^{0.065}-1\right) & =283 \mathrm{sq} \mathrm{ft} \\
& =26.3 \mathrm{sq} \mathrm{m}
\end{aligned}
$$

Observing Figure 12, a room constant corresponding to about $26 \mathrm{sq} \mathrm{m}$ is well above the free field curve at $r=8 \mathrm{~m}$. Absorption can thus be effective for this position. However, for a given room constant, absorption treatment will have less of an effect as the distance from the machine, or $r$, decreases. Also the use of 
absorber materials can never reduce the sound to a level below that of the free field radiation. At best, a sound absorber can reduce the reflections to zero which is the same as removing the surface entirely (i.e., no surface = no reflection $=$ perfect absorber .

From the data tables, an acoustical wall treatment with an absorption coefficient of 0.95 at $500 \mathrm{~Hz}$ is selected to cover all four walls, and a type of mineral fiber ceiling panel with an absorption coefficient of 0.90 at $500 \mathrm{~Hz}$ is selected to cover the ceiling. With these treatments in place, the new absorption characteristics of the room are as shown:

\begin{tabular}{lcc}
\hline Room component & $\begin{array}{c}\mathrm{s}_{\mathbf{i}} \\
\left(\mathrm{sq}_{\mathrm{ft}}\right)\end{array}$ & $\begin{array}{c}\mathrm{a}_{\mathbf{i}} \\
(@ 500 \mathrm{~Hz})\end{array}$ \\
\hline Floor; linoleum & 1150 & 0.03 \\
10 occupants seated at desks & 100 & 0.55 \\
Ceiling; mineral fiber panels & 1250 & 0.90 \\
Side walls; wall treatment & 1000 & 0.95 \\
& 100 & 0.10 \\
End walls; wall treatment & 450 & 0.95 \\
& 150 & 0.18 \\
\hline
\end{tabular}

$\bar{\alpha}=\frac{(1150)(.03)+(100)(.55)+(1250)(.90)+(1000)(.95)+(100)(.10)+(450)(.95)+(150)(.18)}{4200}$

$=0.626$

$$
\begin{aligned}
R_{2}=4200\left(e^{0.626)}-1\right) & =3654 \mathrm{sq} \mathrm{ft} \\
& =339.8 \mathrm{sq} \mathrm{m}
\end{aligned}
$$

The reduction in sound level at a distance $r=8 \mathrm{~m}$ from the source for application of the absorption material is calculated for the $500 \mathrm{~Hz}$ band using equation (37) with $Q=2$ which assumes the noise source in the room will be sitting on the floor (hemispherical radiation)

$$
\begin{aligned}
\Delta L_{p} & =10 \log \left[\left(\frac{Q}{4 \pi r^{2}}+\frac{4}{R_{1}}\right) /\left(\frac{Q}{4 \pi r^{2}}+\frac{R}{R_{2}}\right)\right] \\
& =10 \log \left[\left(0.0025+\frac{4}{26.3}\right) /\left(0.0025+\frac{4}{339.8}\right)\right] \\
& =10.3 \mathrm{~dB}
\end{aligned}
$$

A drop of about $10 \mathrm{~dB}$ in the $500 \mathrm{~Hz}$ octave band at a point $8 \mathrm{~m}$ from the source would be expected after the described treatment had been applied to this room. 
For the complete noise reduction expected, a similar analysis of absorption coefficients and room constants before and after treatment must be carried out for the remaining octave bands. The decibel sum of noise reduction in all bands is then calculated to arrive at the total noise reduction expected from the treatment. The appropriate A-weighting corrections (see Table 3) must be included in each octave band before decibel addition if the total noise reduction in $\mathrm{dBA}$ is desired.

Absorption of Ceilings

The main purpose of acoustical ceilings is for the absorption of sound. In the previous example, it was shown how the absorption added to a room can reduce the sound pressure level in the reverberant sound field region of a room.

There are many types of acoustical ceilings, ranging from the attractive tiles seen in homes and offices to the thicker sturdier panels that can be used in an industrial atmosphere. The range of absorption ability of modern acoustical ceilings extends from an NRC of about 0.30 to over 0.90 . The ceiling used in the example had an NRC of 0.90. From a sampling of the tests performed at one acoustical testing laboratory the most common value for NRC is about 0.55 to 0.70 as can be seen in Figure 13. This sampling includes ceilings made of wood fiber, glass fiber, and other mineral fibers. It also includes the full range of densities and thicknesses that are common to ceilings. This figure shows the relative number of ceiling materials whose NRC lies in the indicated range. Since a mean value is about $\mathrm{NRC}=0.60$ one can say that typical noise reduction effects will be obtained with $\mathrm{NRC}=0.60$ items, not with $\mathrm{NRC}=0.90$ items.

Note that ceilings are usually tested with the number 7 mounting $(40.64 \mathrm{~cm}$ (16 inch) plenum behind material). The effect of this mounting is to increase the absorption in the lower frequency range over what would be obtained if the material were mounted directly to the surface. The typical shape of the curve of sound absorption coefficient versus frequency can be seen in Figure 14. In this figure, three "typical" absorption coefficient versus frequency curves are shown. Note the increase in low frequency absorption, and reduction in high requency absorption for the absorbing material covered with a perforated metal facing tested using mounting number 7 . Note also that while the thicker material will usually have a better low frequency absorption the two shown here for mounting number 4 appear to contradict this. However the thicker one does have an overall higher absorption level and this further points out that there is no such thing as "typical". These data once again reemphasize that the NRC should not be used as the basis for selecting any acoustical treatment. The full set of frequency data should be utilized and the chosen product matched to the noise spectrum in the space where it is to be used.

One note of caution on ceilings should be heeded. Since acoustic absorption takes place when the sound penetrates into the pores or openings in the material, care should be taken when the ceiling is painted. If the paint is not applied properly, it can plug the openings so that sound cannot enter into the material. The result is that sound is reflected from the surface, and the absorbent capability is completely destroyed. If it becomes necessary to paint an acoustical ceiling the manufacturer should be contacted for his recommended 
method which will preserve the acoustical qualities. If it is known before purchasing a ceiling that painting will be required in the future, the "paintability" of the ceiling should be considered, as some ceiling materials are better able to withstand painting than others. Again, check with the manufacturer for his recommendations.

\section{MOUNTING NUMBER 7 CEILING BOARD \\ EOZA PERFORATED \\ QX8Q FISSURED \\ DIV FISSURED AND PERFORATED}

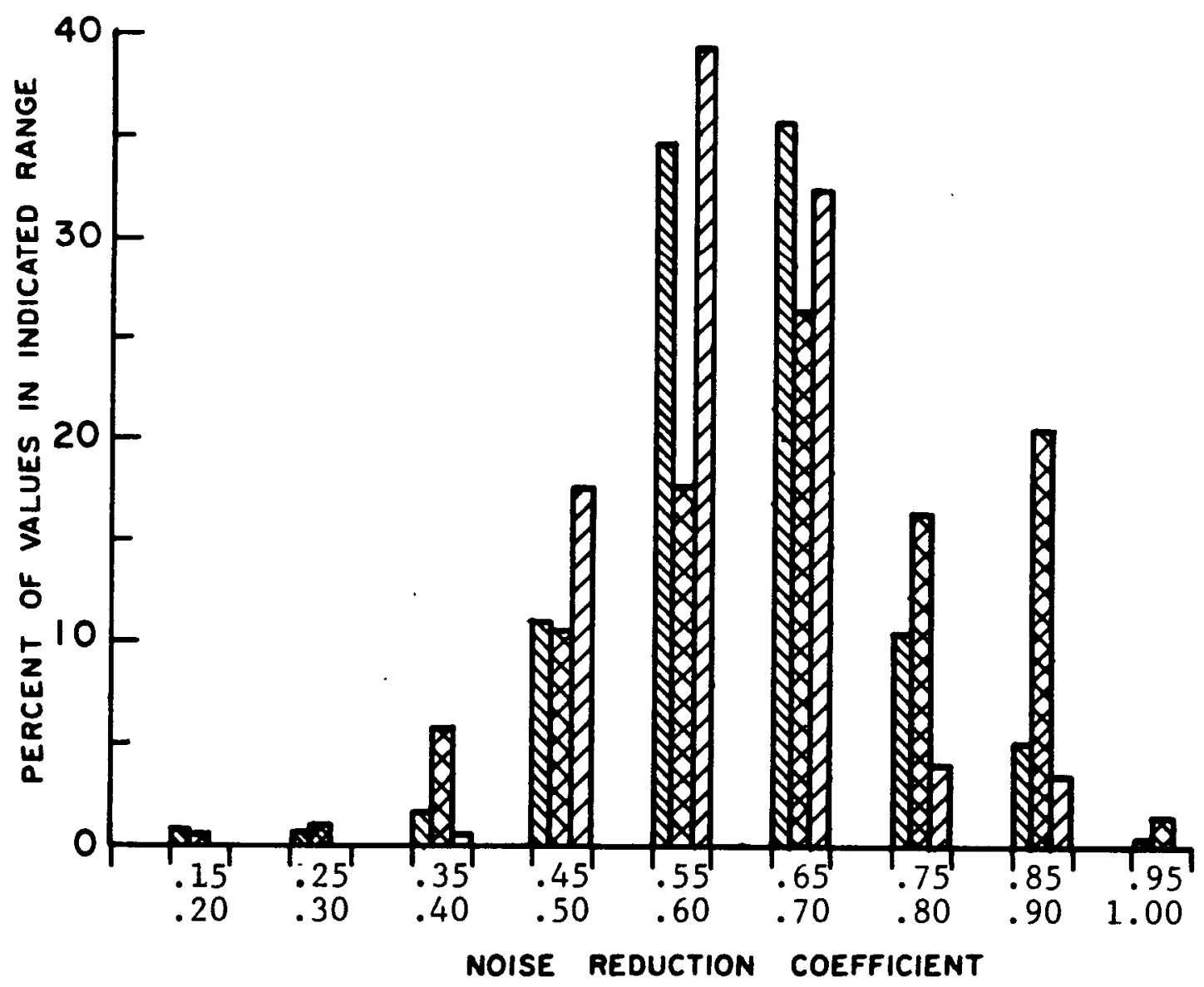

Figure 13. Relative distribution of absorption qualities of acoustical ceiling materials. 


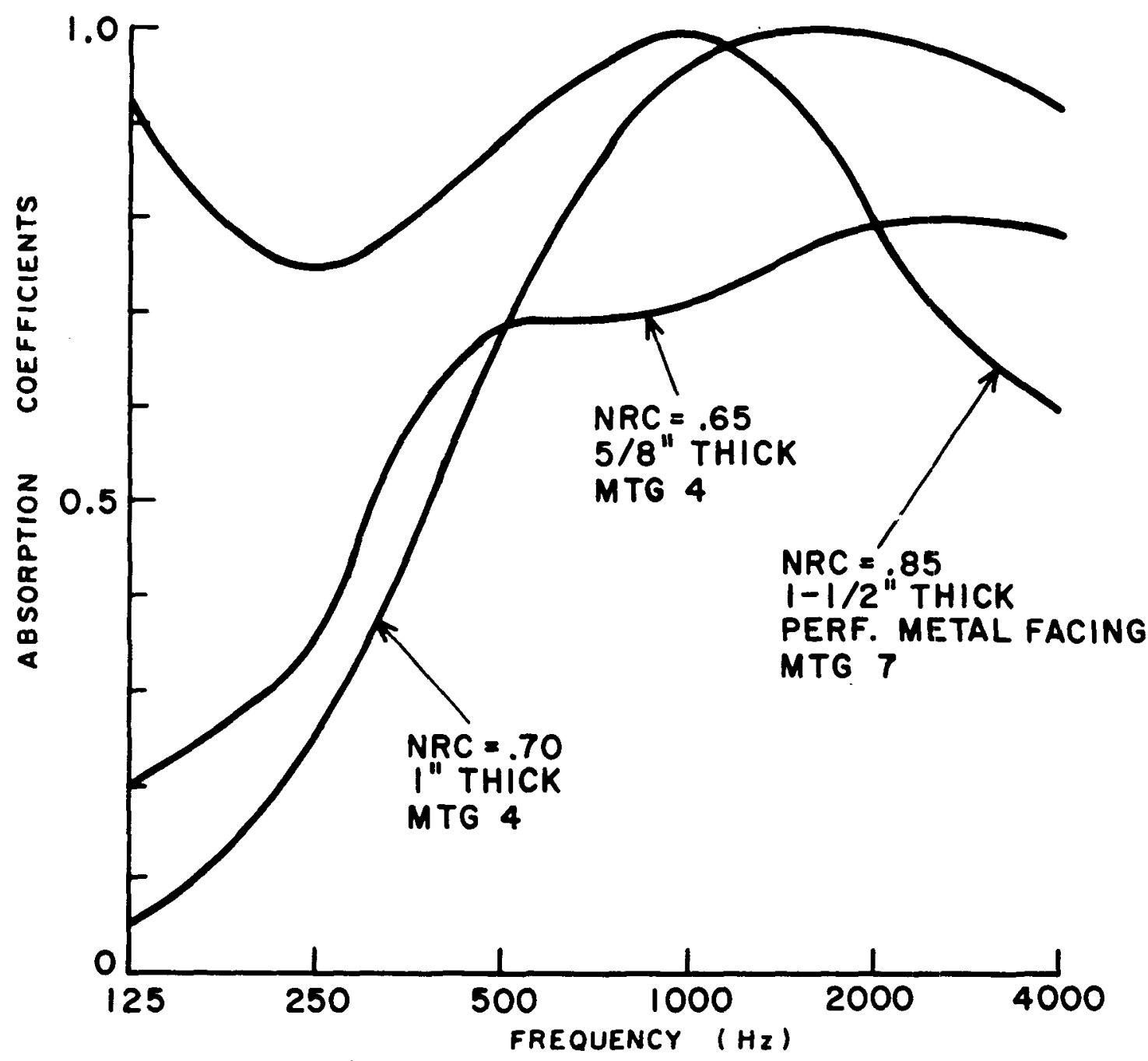

Figure 14. Typical absorption data for acoustical ceilings.

Absorption of Wa1ls

Normally walls are considered to be sound barriers, but as seen in the example, the applications of absorbent materials to the walls of a room aid in the reduction of noise levels in a noisy space. While almost any absorption material may be used with success on walls, there is a certain class of material called wall facing or treatment specifically designed for this purpose. These generally have a fiberglass or mineral fiber core covered with fabric. They may be attached directly to the wall or attached by a system of furring strips to create an air gap between the treatment and the wall. As in the case of ceilings, this air gap would serve to decrease the low frequency absorption of the treatment. 
Standard unpainted concrete block can also exhibit reasonable absorption characteristics, especially if they have a coarse texture. Noise reduction coefficients for concrete block are shown in Table 8.

Table 8. Noise reduction coefficients for concrete.

\begin{tabular}{|c|c|c|c|c|}
\hline \multirow{2}{*}{$\begin{array}{l}\text { Material, } \\
\text { medium texture, } \\
\text { unpainted }\end{array}$} & \multirow{2}{*}{$\begin{array}{c}\text { Approximate } \\
\text { NRC }\end{array}$} & \multicolumn{3}{|c|}{ Adjustment, percent } \\
\hline & & \multicolumn{2}{|c|}{$\begin{array}{l}\text { Coarse } \\
\text { texture }\end{array}$} & $\begin{array}{c}\text { Fine } \\
\text { texture }\end{array}$ \\
\hline Expanded shale block & 0.45 & Add & 10 & Deduct 10 \\
\hline Heavy aggregate block & 0.27 & Add & 5 & Deduct 5 \\
\hline \multicolumn{5}{|c|}{ Deductions from NRC for painted block, percent } \\
\hline Paint type & Application & $\begin{array}{l}\text { One } \\
\text { coat }\end{array}$ & $\begin{array}{l}\text { Two } \\
\text { coats }\end{array}$ & $\begin{array}{l}\text { Three } \\
\text { coats }\end{array}$ \\
\hline Any & Spray & 10 & 20 & 70 \\
\hline Oil base & Brushed & 20 & 55 & 75 \\
\hline Latex or resin base & Brushed & 30 & 55 & 90 \\
\hline Cement base & Brushed & 60 & 90 & -- \\
\hline
\end{tabular}

(Courtesy Expanded Shale and Slate Institute)

A particular kind of block is constructed with internal cavities with slots or openings in the surface connecting the cavities to the outside. This configuration makes each block a Helmholtz resonator tuned to a particular frequency. Such blocks are generally most effective as absorbers at low frequencies and near the frequency for which they are tuned.

Absorption of Carpets

Carpets serve the dual purposes of floor covering and noise reduction. Noise reduction is achieved in two ways; carpets absorb the incident sound energy; and sliding and shuffling movements on carpets produce less noise than on bare floors. The Carpet and Rug Institute has published a report on "Sound Conditioning with Carpet" and some of their findings are:

1. NRC of carpets laid directly on bare concrete floor ranged from 0.25 to 0.55 ;

2. fiber type has virtually no influence on sound absorption;

3. cut pile provides greater noise reduction than loop pile;

4. the NRC increased as pile weight and/or pile heights were increased;

5. carpet pads have considerable effects on sound absorption as shown in Table 9; 
6. permeability of backing results in higher NRC. In one test a carpet with a coated backing had an NRC of 0.40 and the same carpet with an uncoated backing had an NRC of 0.60 ; and

7. carpets and pads provide significant improvements in impact noise ratings of floors. Table 10 shows the results of tests made on a concrete slab using a woven, 44 oz wool carpet with various pads.

Table 9. Effects of padding on carpet noise reduction coefficient.

\begin{tabular}{lll}
\hline $\begin{array}{c}\text { Pad } \\
\text { weight } \\
\text { oz }\end{array}$ & \multicolumn{1}{c}{ Pad material } & NRC \\
\hline-- & None & 0.35 \\
32 & Hair & 0.50 \\
40 & Hair & 0.55 \\
86 & Hair & 0.60 \\
32 & Hair jute & 0.55 \\
40 & Hair jute & 0.60 \\
86 & Hair jute & 0.65 \\
31 & Foam rubber, 3/8 inch & 0.60 \\
44 & Sponge rubber & 0.45 \\
\hline
\end{tabular}

Table 10. Effects of carpets and pads on impact noise.

\begin{tabular}{lccc}
\hline & Floor covering & INR & IIC \\
\hline None & -17 & 34 \\
Carpet on1y & +14 & 65 \\
Carpet with 40 oz hairfelt pad & +21 & 72 \\
Carpet with urethane foam pad & +24 & 75 \\
Carpet with 44 oz sponge rubber & +25 & 76 \\
Carpet with 31 oz 3/8 inch form rubber & +28 & 79 \\
Carpet with 80 oz sponge rubber & +29 & 80 \\
\hline
\end{tabular}

\section{Absorption of Furnishings}

The use of general furnishings, such as chairs, draperies, carpets, etc., can provide absorption of the sound in the room. For offices, homes, schools, etc., the noise control should also be attractive. Modern sound absorption wall and ceiling treatments are available in many colors and patterns. But just using these is not quite enough. If the wall and ceiling treatment is selected for good sound absorption and the effect of general furnishings is overlooked, the finished area may be too dead and unpleasant. Some absorption data on these items are given in Table 5. The absorption of curtains and draperies depends on spacing from the wall, how close and deep the pleats are, size, and the material used. Some coefficients for these items can be found in the data tables. 


\section{SOUND BARRIERS}

The portion of the sound wave that is not absorbed or reflected when the sound wave strikes a surface is transmitted through to the other side. The fraction of the incident energy that is transmitted through the partition is defined to be the transmission coefficient $(\tau)$. That portion of the energy which is "lost" upon transmission through a material is the difference between the incident energy and the transmitted energy. Expressed in decibel terms, the sound transmission loss is

$$
T L=10 \log \frac{W_{i}}{W_{0}}-10 \log \frac{W_{t}}{W_{o}}=10 \log \frac{W_{i}}{W_{t}}=10 \log \frac{1}{\tau}
$$

Just as with the absorption coefficient the transmission coefficient depends on frequency and equation (38) indicates the transmission loss is also frequency dependent.

The mechanism of transmission loss is similar to that of a diaphragmatic absorber. The incident sound wave causes the partition to vibrate. This vibration in turn causes the air on the other side of the partition to be set into motion and sound is radiated as though this partition were now a sound source. However, this new sound field will be much lower in energy since much of the energy of the incident wave was spent in forcing the partition to vibrate.

It can be shown that for a "limp" panel, (a limp panel is an idealized panel without flexural stiffness), the transmission loss should theoretically increase by $6 \mathrm{~dB}$ each time the mass of the panel is doubled. This, however, does not hold strictly true in practice. In the real world a doubling of the mass of the wall will increase the transmission loss only by about 4 or $5 \mathrm{~dB}$. The real world mass law, which is obtained from empirical results can be stated as

$$
\mathrm{TL}=23+14.5 \log \mathrm{m} \mathrm{dB}
$$

where $\mathrm{m}$ is expressed in $\mathrm{lb} / \mathrm{sq} \mathrm{ft}$ or

$$
\mathrm{TL}=13+14.5 \log \mathrm{m} \mathrm{dB}
$$

where $\mathrm{m}$ is expressed in $\mathrm{kg} / \mathrm{sq} \mathrm{m}$. The increase predicted from this expression for a doubling of the mass is about $4.4 \mathrm{~dB}$. Generally the transmission loss increases more slowly than $4.4 \mathrm{~dB}$ per octave of frequency below $1000 \mathrm{~Hz}$, and approximately at the rate of $4.4 \mathrm{~dB}$ per octave above this frequency. Some notable exceptions to this are due to stiffness, resonances, and coincidence effects.

Resonance occurs when the frequency of the incident sound wave corresponds to 
a natural frequency of the partition. At this frequency very little energy is required to force the panel to vibrate, and the high amplitude of this vibration produces a correspondingly high sound pressure level on the opposite side of the panel. In some instances the sound wave passes through the panel almost as if it were not there. To avoid the effects of resonance it is desirable to have the lowest natural frequency possible. This condition can best be met by using panels which are as limp and as massive as possible.

A condition similar to resonance can occur when sound waves are incident on a panel at an oblique angle. At certain frequencies the phases of the incident wave will coincide with the phase of the panel's flexural waves. Under these conditions the intensity of the transmitted wave may nearly equal that of the incident wave. Wave coincidence can only occur when the wavelength of the sound in air is less than the wavelength of sound in the panel. Thus, coincidence can only occur at a frequency above a certain critical frequency which is determined by the material and thickness of the panel. For a single homogeneous panel, this frequency is given by

$$
f_{c}=\frac{C^{2}}{1.8 t} \sqrt{\frac{P}{E}}
$$

where $C=$ speed of sound

$t=$ thickness of panel

$\mathrm{p}=$ mass density of panel

$E=$ modulus of elasticity of panel material

In practice the sound wave is usually not incident from a single direction but is more omnidirectional. A typical panel will have studs, braces, discontinuities, etc., and the effect of coincidence can usually be neglected. If, however, this effect is encountered it can usually be reduced by using very stiff and thick walls or by heavy walls with small stiffness. In general, the transmission properties of a wall behave more like the typical performance shown in Figure 15.

It should be emphasized that sound absorbent materials; due to their soft, porous structure, offer only low resistance to a sound wave and permit the passage of the wave through to the other side relatively unattenuated. Only when these materials are very dense or very thick will they appreciably reduce the amplitide of a sound wave as it passes through. Thus, a sound absorbing material is a poor sound barrier. Remember that if air can pass through the material, so can sound.

On the other hand, typical sound barrier materials are hard, heavy, and very reflective. These materials generally follow the mass law and as such offer a high resistance to the passage of a sound wave. A sound barrier material is a poor absorber and an absorbent material is a poor barrier.

\section{SOUND TRANSMISSION LOSS MEASUREMENTS (per ASTM E90-77)}

The test procedure for measurement of transmission loss of materials is specified by, and described in, ASTM Standard E90-77, "Standard Recommended Practice for Laboratory Measurement of Airborne Sound Transmission Loss of Building Partitions". Unlike the absorption coefficient, the transmission 
coefficient is rarely measured in practice. Instead the transmission loss is calculated in a more roundabout manner from sound pressure levels. To measure the transmission loss of a specimen it is simply mounted in the connecting opening between two reverberation rooms. Care is taken to assure that the only sound path between the two rooms is through the specimen. A sound source is operated in the source room and sound pressure levels in the source room and the receiving room are then measured in each of 16 contiguous onethird octave bands from 125 through $4000 \mathrm{~Hz}$. The transmission loss is then computed from the relationship

$$
\mathrm{TL}=\mathrm{NR}+10 \log \mathrm{S}-10 \log \mathrm{A}
$$

where $T L$ is the transmission loss in decibels, $S$ is the total area of the sound transmitting surface of the test specimen, $A$ is the total absorption in the receiving room (expressed in units consistent with $S$ ), and

$$
N R=L_{p_{S}}-L_{p_{r}}
$$

is the noise reduction between the two reverberation rooms. Average sound pressure level in the source room is $\mathrm{L}_{\mathrm{p}_{\mathrm{S}}}$. Average sound pressure level in the receiving room is $\mathrm{L}_{\mathrm{p}_{\mathrm{r}}}$.

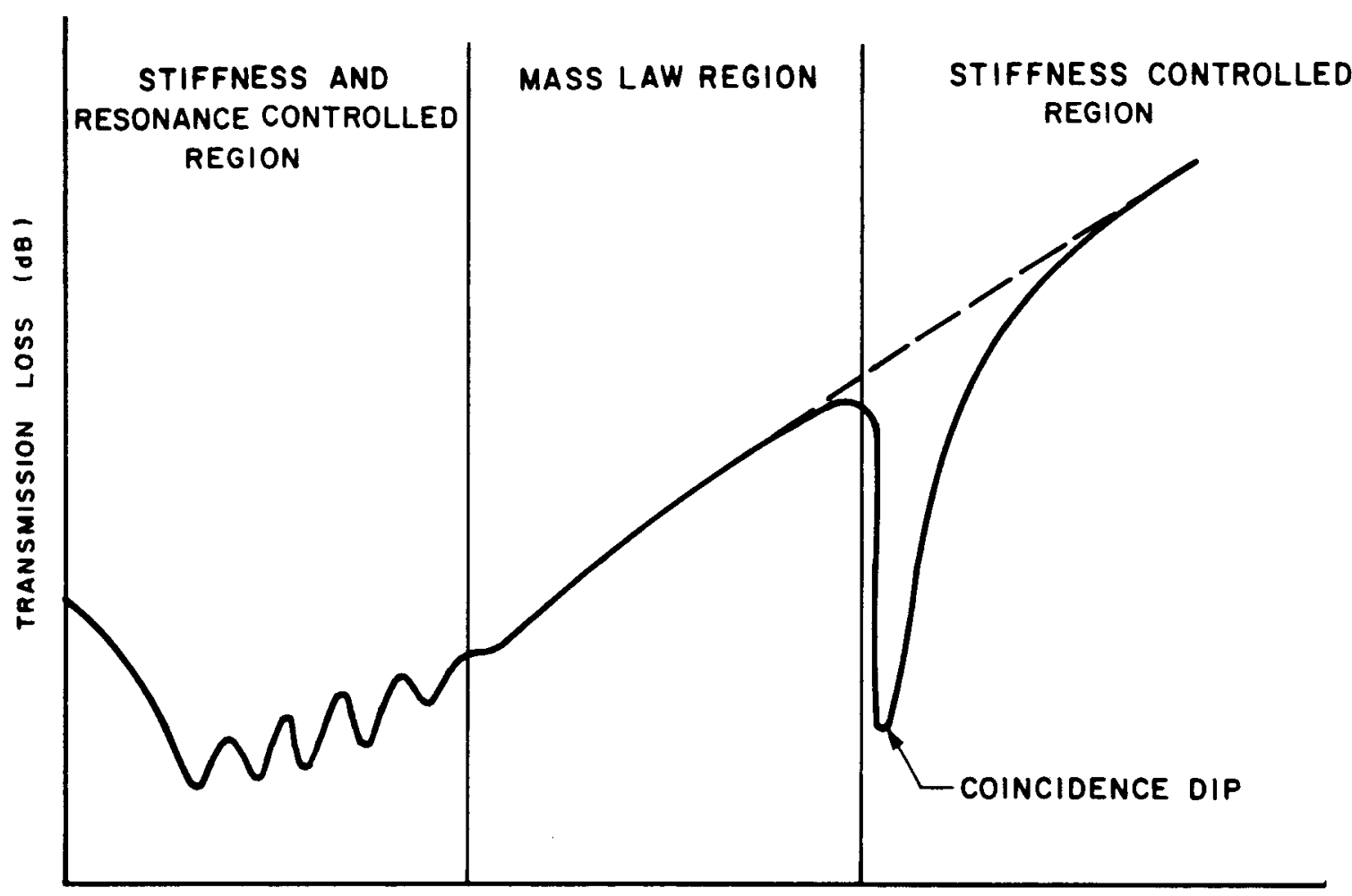

FREQUENCY (Hz)

Figure 15. Typical practical performance of a wall relating to the transmission of sound showing the three separate regions. 
The variation in sound pressure level over a large portion of each room must be carefully measured to ensure accuracy in determining the average level.

The term for the absorption of the receiving room is necessary to account for the fact that the sound pressure level developed in the receiving room will depend upon the amount of absorption in the room. Equation (41) may be derived from the basic principles of equation (38) by noting that the power incident on a panel is equal to intensity times the area of the panel, and that decibels of intensity are approximately equal to decibels of pressure.

Dependence of Transmission Loss on Frequency

Since once again there is a situation where the acoustical properties of an item are frequency dependent and there are 16 numbers to describe these properties it is desirable to reduce this amount of data to a single number. In the case of TL properties this single-number rating is called Sound Transmission Class (STC). The STC is determined by comparing the set of transmission losses at all 16 frequencies to a set of standard STC contours as described in ASTM Standard E413-70T, "Tentative Classification for Determination of Sound Transmission Class". Briefly stated, the STC contour must be chosen which fits the TL curve in such a way that in no event is the TL curve more than $8 \mathrm{~dB}$ below the STC contour at any frequency, and the sum of the deviations of the TL values which are below the contour shall not exceed $32 \mathrm{~dB}$. The highest contour to which the specimen TL curve can satisfy these requirements is used as the STC curve. The value of this curve at $500 \mathrm{~Hz}$ is then chosen as the STC of the specimen.

The STC values of some common materials are shown in Table 11 . The values shown in Table 11 are representative because the weights and densities of these materials vary and some of the items are porous even though they are heavy.

Table 11. Sound transmission class of some common building materials.

\begin{tabular}{lc}
\hline Material & STC \\
\hline 24-gauge steel & 26 \\
1/8-inch plate glass & 28 \\
1/4-inch plate glass & 30 \\
3/16-inch steel plate & 35 \\
4-inch two-cell concrete block & 41 \\
4-inch two-cell concrete block & \\
$\quad$ (filled with sand) & 43 \\
Two layers of 5/8-inch gypsum & \\
board on 2x4-inch studs 16 & \\
inches on center & 43 \\
8-inch lightweight hollow & 46 \\
concrete block & \\
8-inch hollow core concrete block & 50 \\
4-inch brick wall with 1/2-inch & \\
plaster & 50 \\
8-inch brick wall & 52 \\
6-inch dense concrete & 54 \\
12-inch brick wall & 59 \\
\hline
\end{tabular}


In general these curves provide a good comparison between specimens, but due to the way deviations from the standard curve are handled poor comparisons can be made as shown in Figure 16. The partition shown by the solid line has TL values that are higher than those for the dashed curve except between about 600 to $2000 \mathrm{~Hz}$ and yet has a STC $5 \mathrm{~dB}$ lower than for the dashed curve. This only points out that STC is a convenience and should be used with care in selection of any particular item.

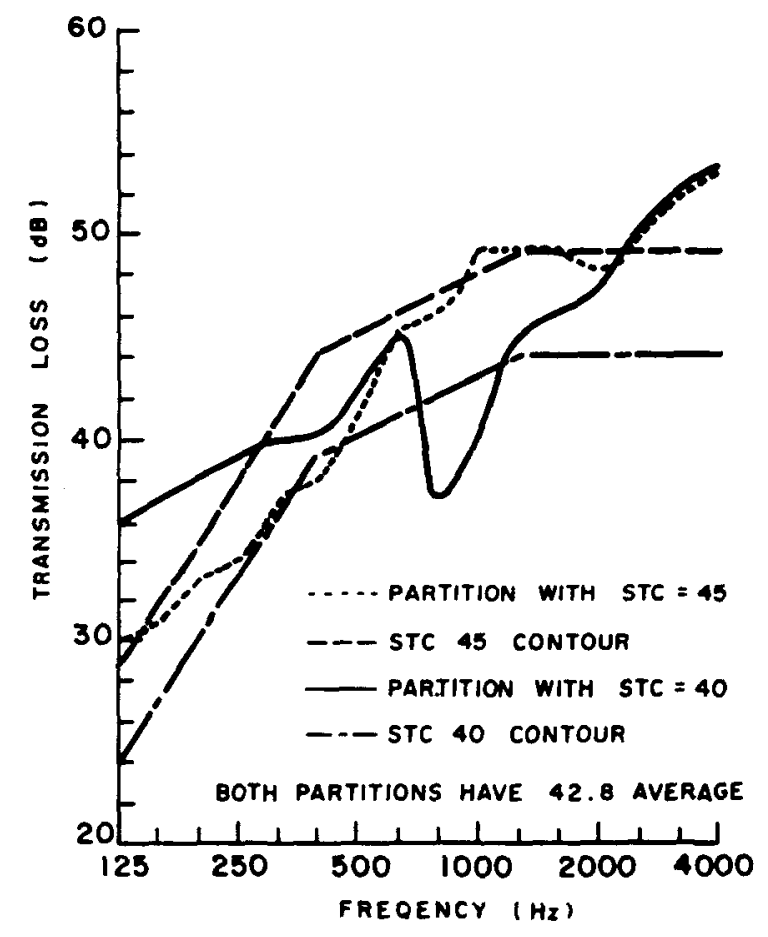

Figure 16. Determination of sound transmission class.

\section{Test Facility Requirements}

A few comments are in order at this point about the characteristics of the reverberation rooms used for testing partitions for transmission loss. One of these is that the rooms should be large enough to support a diffuse field in the lower frequencies. The size should be such that

$$
V=4 \lambda^{3}
$$

where $\mathrm{V}$ is the room volume and $\lambda$ is the wavelength of the lowest frequency of interest in units consistent with $\mathrm{V}$. For example if a room has a volume $178.3958 \mathrm{cu} \mathrm{m}(6300 \mathrm{cu} \mathrm{ft})$ it should not be used for measurements below about $97 \mathrm{~Hz}$.

A second requirement is that the sound field in the two reverberation rooms be 
sufficiently diffuse so that measurements can be made such as to ensure that the mean value of the noise reduction can be known to within $1 \mathrm{~dB}$ with 90 percent confidence. To accomplish this, laboratories use special, very hard rooms, with both fixed and rotating panels (vanes) to increase the diffuseness of the sound field.

A further requirement on the laboratory is the reduction of flanking path transmission to the point where it no longer interferes with the measurements. Flanking transmission occurs when the sound travels from the source room to the receiving room by some route other than through the test specimen. Some of these paths are through cracks or gaps around the specimen, into the floor or wall in the source room, through the connecting floor and wall, or any other route the sound may take as shown in Figure 17. Flanking path transmission is considered to have negligible effect on measurements when the sound pressure level transmitted by flanking is more than $10 \mathrm{~dB}$ below the level transmitted by the specimen.

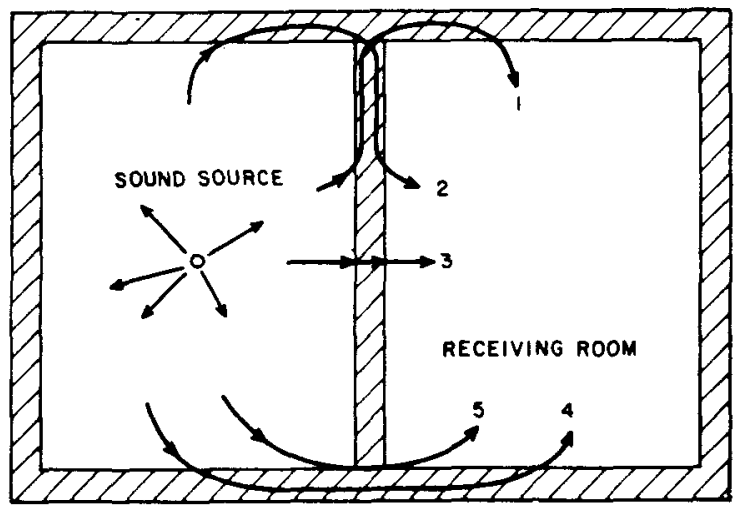

Figure 17. Possible routes for sound travel from one room to another. For paths 1 through 4 the sound travels some portion of the path in solid material. Path 5 represents transmission through any crack, gap, or other opening in the wall.

Finally, the ASTM standard for measuring transmission loss recommends that the minimum dimensions of the test specimen be at least 2.44 by $3.66 \mathrm{~m}$ ( 8 by $12 \mathrm{ft}$ ), with the exception that doors, windows, and other smaller items should be their normal size. This is because the full effects of stiffness, resonances, etc., will be different if the specimen is different from what will be constructed in actual use.

NOISE CONTROL BY BARRIER

Controlling noise by barrier is simply a matter of providing some form of wall or other heavy dense object between the source of the sound and the receiver, i.e., its path is blocked. 
One of the most inexpensive and easiest to accomplish methods providing a barrier is to locate a source or a receiver behind an already existing barrier. For example, if a new apartment is to be constructed near an expressway and the landscape is hilly, the hill between the apartment and expressway can be used as a barrier. When this is not possible, bedrooms or other spaces where quiet is desired should be on the far side of the building. Hallways, elevators, etc., should be on the side facing the noise. In this way a great deal of special acoustical treatment can be eliminated.

In a factory the noisy machinery should not be in the same room with quieter objects. If noisy equipment is to be located outdoors, it should be placed on the side away from the area where quiet is desired. If the plant is located near a residential neighborhood the noisy activities such as loading docks should be on the side away from the homes. A little thought before the installation of some noise source can save a lot of time and money later.

To determine what the sound level in a room would be after a barrier wall has been erected, equation (41) can be reversed to obtain

$$
\mathrm{NR}=\mathrm{TL}-10 \log \mathrm{S} / \mathrm{A}
$$

and it can then be seen that the noise reduction is dependent on the total absorption in the receiving room. This is understandable if one remembers what reverberation does to the sound field. The noise that comes through the wall bounces around in the receiving room so the level is not what it would be if a free field existed on the receiving side.

EXAMPLE 10: The sound pressure level on one side of a 3.05 by $4.27 \mathrm{~m}$ (10 by $14 \mathrm{ft}$ ) wall is measured $95 \mathrm{~dB}$ in the $500 \mathrm{~Hz}$ octave band. If the transmission loss of the wall is $47 \mathrm{~dB}$ in this band and the absorption in the receiving room is 1000 sabins, what will the sound pressure level be in the receiving room?

SOLUTION:

$$
N R=L_{P_{S}}-L_{P_{r}}=T L-10 \log \mathrm{S} / \mathrm{A}
$$

or

$$
\begin{aligned}
\mathrm{L}_{\mathrm{P}_{\mathrm{r}}} & =\mathrm{L}_{\mathrm{P}_{\mathrm{S}}}-\mathrm{TL}+10 \log \mathrm{S} / \mathrm{A} \\
& =95-47+10 \log \frac{10 \times 14}{1000} \\
& =39.5 \mathrm{~dB} \text { re } 20 \mu \mathrm{Pa}
\end{aligned}
$$

and the absorption in the receiving room has reduced the sound level by 8.5 $d B$ more than what is predicted by simply subtracting the TL value from the sound level in the source room. Note that if the receiving room is very hard such that $\mathrm{S}>\mathrm{A}$, then the opposite is true.

In the general case of using a partition as a sound barrier, the partition may be a wall with a door and windows and may even be built in several sections 
each with a different transmission loss. It is necessary to know the average transmission loss of the entire assembly. This is found by first determining an average transmission coefficient $\bar{\tau}$ in a manner similar to finding the average absorption coefficient.

$$
\bar{\tau}=\frac{\sum \tau_{i} S_{i}}{\sum S_{i}}
$$

and

$$
\overline{\mathrm{TL}}=10 \log 1 / \bar{\tau}
$$

where $S_{i}$ and $T_{i}$ are the area and transmission coefficient of the $i$ th section of the partition. $\tau_{i}$ for each section may be determined by inverting equation (38):

$$
\tau_{i}=\operatorname{antilog}\left(-\frac{\mathrm{TL}_{i}}{10}\right)
$$

Now the noise reduction of this partition can be determined by combining equation (46) with equation (41) as

$$
\mathrm{NR}=\overline{\mathrm{TL}}-10 \log \mathrm{S} / \mathrm{A}
$$

EXAMPLE 11: A partition consists of a concrete wall ( $T L=50) 3.66 \mathrm{~m}(12 \mathrm{ft}$ ) high by $30.5 \mathrm{~m}(100 \mathrm{ft})$ long with a window $(\mathrm{TL}=25)$, a door $(\mathrm{TL}=30)$, and an open area (leak) under the door. Determine the noise reduction through this wall in the $500 \mathrm{~Hz}$ band. The total absorption of the room on the receiving side of the wall is 300 sabins. The areas and transmission coefficients of each element of the partition are

\begin{tabular}{lcrrr}
\hline ITEM & DIMENSION & AREA & \multicolumn{1}{c}{ TL } & \multicolumn{1}{c}{$\tau$} \\
\hline wall & $12 \times 100$ & 1151.4 & 50 & 0.00001 \\
window & $4 \times 6$ & 24.0 & 25 & 0.00316 \\
door & $7 \times 3.5$ & 24.5 & 30 & 0.00100 \\
leak & 0.5 inch $\times 3.5 \mathrm{ft}$ & 0.15 & 0 & 1.00000 \\
\hline
\end{tabular}

SOLUTION: Note that the area of the concrete wall is 1200 sq $\mathrm{ft}$ minus the area of the window, door, and leak, and that the TL of an open area such as a leak is zero. The noise reduction of the wall is determined using equations (46), (47), and (48) 


$$
\begin{gathered}
\bar{\tau}=\frac{(0.00001)(1151.4)+(0.00316)(24)+(0.001)(24.5)+(1)(0.15)}{1200}=0.0002 \\
\overline{\mathrm{TL}}=10 \log \frac{1}{0.0002}=37 \mathrm{~dB} \\
\mathrm{NR}=37-1010 \mathrm{l} \frac{1200}{300}=31 \mathrm{~dB}
\end{gathered}
$$

Due to the sections with lower TL values (especially the leak) and the hardness of the receiving room, the $50 \mathrm{~dB}$ wall results in a noise reduction of only $31 \mathrm{~dB}$.

If absorption treatment is added to bring the absorption of the receiving room up to 2000 sabins, we will have a noise reduction of

$$
\mathrm{NR}=37-10 \log \frac{1200}{2000}=39 \mathrm{~dB}
$$

Observe that the increased absorption in the receiving room works together with the wall to produce a noise reduction greater than predicted from the wall alone.

If the leak is blocked with a seal that provides a transmission loss of $50 \mathrm{~dB}$, the transmission coefficient $\tau$ of the leak drops from 1 to 0.00001 . Considering the leak blocked while retaining the original receiving room absorption of 300 sabins, the noise reduction across the wall becomes

$$
\begin{gathered}
\vec{\tau}=\frac{(0.00001)(1151.4)+(0.00316)(24)+(0.001)(24.5)+(0.00001)(0.15)}{1200}=0.00009 \\
\overline{\mathrm{TL}}=10 \log \frac{1}{0.00009}=40 \mathrm{~dB} \\
\mathrm{NR}=40-10 \log \frac{1200}{300}=34 \mathrm{~dB}
\end{gathered}
$$

The whole job, sealing the leak and providing 2000 sabins of absorption in the receiving room, results in a noise reduction of

$$
\mathrm{NR}=40-10 \log \frac{1200}{2000}=42 \mathrm{~dB}
$$

which represents an improvement of $11 \mathrm{~dB}$ over the original case. To improve this even more, it can be seen from the calculated transmittances that the door and the window are still the weakest links. This example also shows how a barrier and an absorbing material work together to improve the transmission loss. For this reason, many noise control materials are a composite of barrier with absorber bonded to it. Lead-loaded vinyl with absorbing plastic foam on one side is a popular combination. The example only considered the noise reduction at one frequency band, $500 \mathrm{~Hz}$. A complete analysis would include similar computations for all significant frequency bands. 
In general, walls can be classified as nonload-bearing partition type walls, load-bearing, and masonry type walls. Masonry walls are made up of bricks, or various types of concrete and may be plastered or painted.

Plasterboard walls are relatively light, inexpensive, and easy to erect. A typical plasterboard wall consists of two plasterboard leaves, separated by an air space and a system of studs or framing members. The sound transmission loss of such a wall depends on the transmission losses of the individual leaves and on the degree of coupling introduced by the intervening air space and stud system. The studs can sometimes act as vibration conductors and thus may degrade the performance of a wall assembly. If the studs have low torsional rigidity (e.g., steel channels.) transmission via the studs appears to be neg1igible. If proper construction techniques are used, it is possible to get a transmission loss greater than that predicted by the mass law. The main factor in achieving this enhanced performance is to construct what is referred to as a "double wall". In a double wall arrangement the two sides of the wall are independent of each other (there are no connecting braces, and each side uses its own set of studs).

Figure 18 shows the transmission losses of three wall assemblies as functions of frequencies. Wall assembly number 1 has the lowest STC even though its density is slightly higher than the other two assemblies. It can be seen from the figure that a significant increase ( $14 \mathrm{~dB}$ in this case) in transmission loss can be achieved by separating the two leaves of a wall and putting a sound absorbent batt in the wall cavity.

Load-bearing walls made from concrete or bricks are heavier than the plasterboard wall and consequently they can provide increased sound attenuation. For instance, the Brick Institute reports STC from 39 to 59 for specific walls made from structural clay tiles or bricks, with their weights ranging from 107.41 to $566.36 \mathrm{~kg} / \mathrm{sq} \mathrm{m}$ (22 to $116 \mathrm{lb} / \mathrm{sq} \mathrm{ft}$ ). Concrete walls also provide similar attenuation and in general the dense, heavyweight concrete walls perform better than the lightweight concrete walls - particularly at low frequencies.

In addition to plasterboard and masonry many other types of wall materials are used and the wall construction also ranges from a simple brick wall to walls with a complex stud system combined with acoustical and thermal batts. Plywood, hardboard, steel, etc., are other commonly used wall materials. In all cases it can be said that increased mass and decreased coupling between different components along the path of sound result in high transmission loss. 


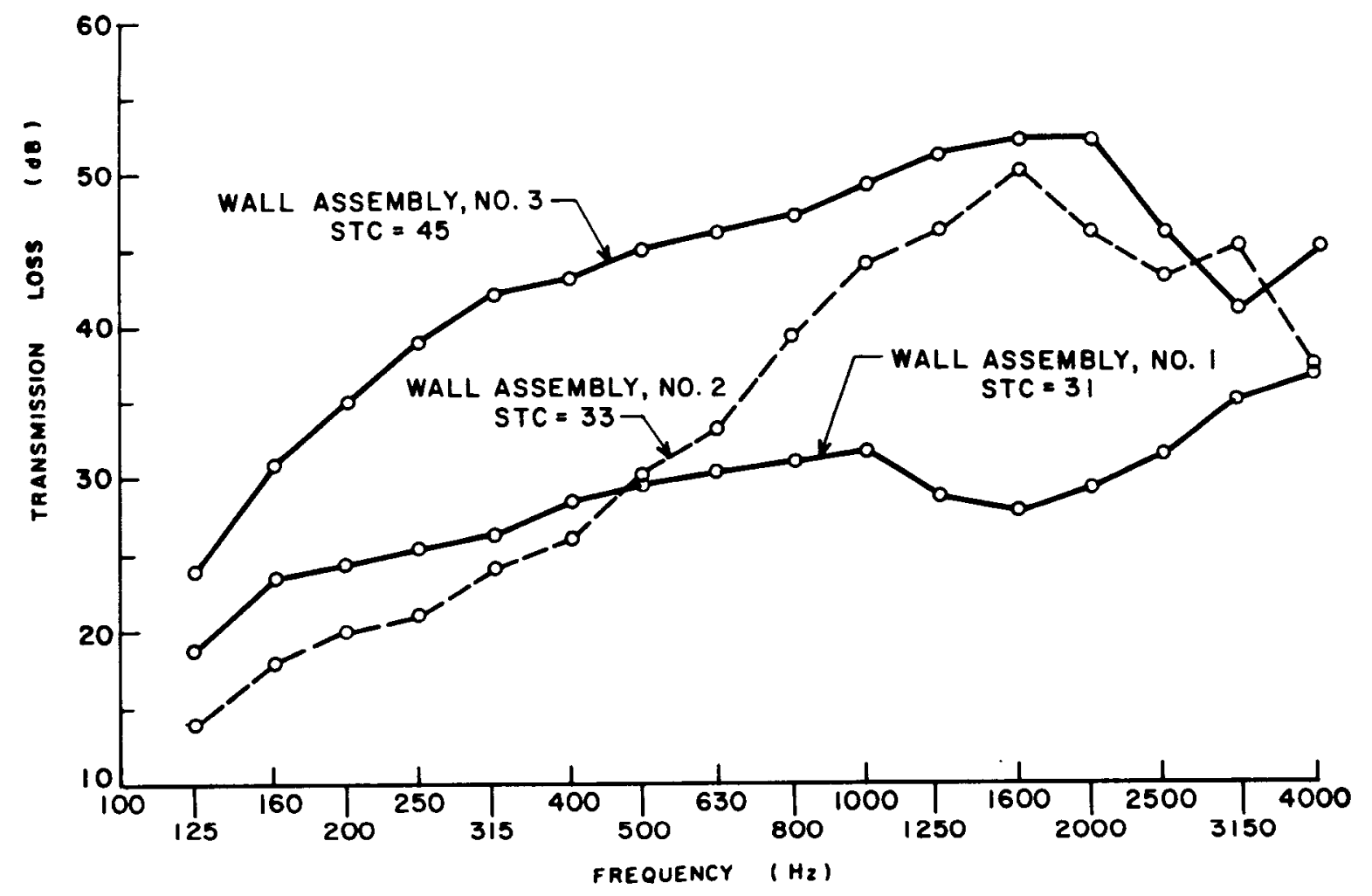

Figure 18. Improvement in wall transmission loss by spacing sides, and by adding absorbing material in the cavity. (Data courtesy National Research Council of Canada)

Wall Assembly No. 1: Two layers of 1/2-inch plasterboard with joint compound. Weight $-4.6 \mathrm{lb} / \mathrm{sq} \mathrm{ft}$.

Wall Assembly No. 2: Two 1/2-inch plasterboard leaves with 3-5/8inch space, no studs. Weight $-4.2 \mathrm{Ib} / \mathrm{sq} \mathrm{ft}$.

Wall Assembly No. 3: Two 1/2-inch plasterboard leaves with 3-5/8inch space, 2-inch thick absorption. Weight $-4.2 \mathrm{lb} / \mathrm{sq} \mathrm{ft}$.

Glass as a Barrier

Glass windows are often the weak link in an otherwise good sound barrier. Acceptable sound transmission loss can be achieved in most cases by a proper selection of glass. Mounting of the glass in its frame should be done with care to eliminate noise leaks and to reduce the glass plate vibrations.

Acoustical performance of glass is often improved by a plastic inner layer or an.air gap. Table 12 shows the comparison of STC values for glass and laminated glass of various thicknesses. Table 13 compares the monolithic glass plate with air-spaced glass of equal thicknesses. 
Table 12. Sound transmission class of monolithic and laminated glass.

\begin{tabular}{lcc}
\hline $\begin{array}{c}\text { Overal1 } \\
\begin{array}{c}\text { Thickness } \\
\text { inch }\end{array}\end{array}$ & $\begin{array}{c}\text { Monolithic } \\
\text { Glass } \\
\text { STC }\end{array}$ & $\begin{array}{l}\text { Two equally thick layers } \\
\text { glass with 0.030-inch } \\
\text { plastic inner layer } \\
\text { STC }\end{array}$ \\
\hline 0.125 & 23 & - \\
0.25 & 28 & 34 \\
0.5 & 31 & 37 \\
0.75 & 36 & 41 \\
1.00 & 37 & - \\
\hline
\end{tabular}

Table 13. Sound transmission class of air-spaced glass and monolithic glass of comparable thickness.

\begin{tabular}{clcc}
\hline $\begin{array}{c}\text { Overal1 } \\
\text { Thickness } \\
\text { inch }\end{array}$ & \multicolumn{1}{c}{$\begin{array}{c}\text { Air-spaced } \\
\text { Glass } \\
\text { Construction }\end{array}$} & STC & $\begin{array}{c}\text { Comparably } \\
\text { Thick Glass } \\
\text { without } \\
\text { Air Space } \\
\text { STC }\end{array}$ \\
\hline 1.0 & $\begin{array}{l}\text { Two 0.25-inch plates } \\
\text { with } 0.50 \text {-inch air space }\end{array}$ & 32 & 31 \\
1.5 & $\begin{array}{l}\text { Two 0.25-inch plates } \\
\text { with 1-inch air space }\end{array}$ & 35 & 31 \\
4.75 & $\begin{array}{l}0.25-\text { and } 0.5-8 \text { inch } \\
\text { with 2-inch air space }\end{array}$ & 39 & 36 \\
6.75 & $\begin{array}{l}0.25 \text { - and } 0.5 \text {-inch plates } \\
\text { with 4-inch air space } \\
0.25-\text { and } 0.5 \text {-inch plates } \\
\text { with 6-inch air space }\end{array}$ & 40 & 36 \\
\hline
\end{tabular}

Doors As Barriers

Sound transmission loss of a door depends upon its material and construction, and the sealing between the door and the frame. Most doors are of wood or steel construction with various stiffnesses and barrier batts added to the hollow cavity inside the door if one exists. It is usually difficult to specify the STC of a door because the sealing between the door and the frame is not a precisely controlled variable. The variations in STC of two doors as the sealing was improved by increasing the deflection of gaskets, by adding extra gaskets, and by changing the gasket materials, are shown in Figure 19. In each case the improved sealing improves the performance such that the STC approaches its maximum possible value shown by the completely sealed case.

This figure points out improvements that can be made by attacking the weakest link. If better sealing does not offer sufficient improvement selecting 


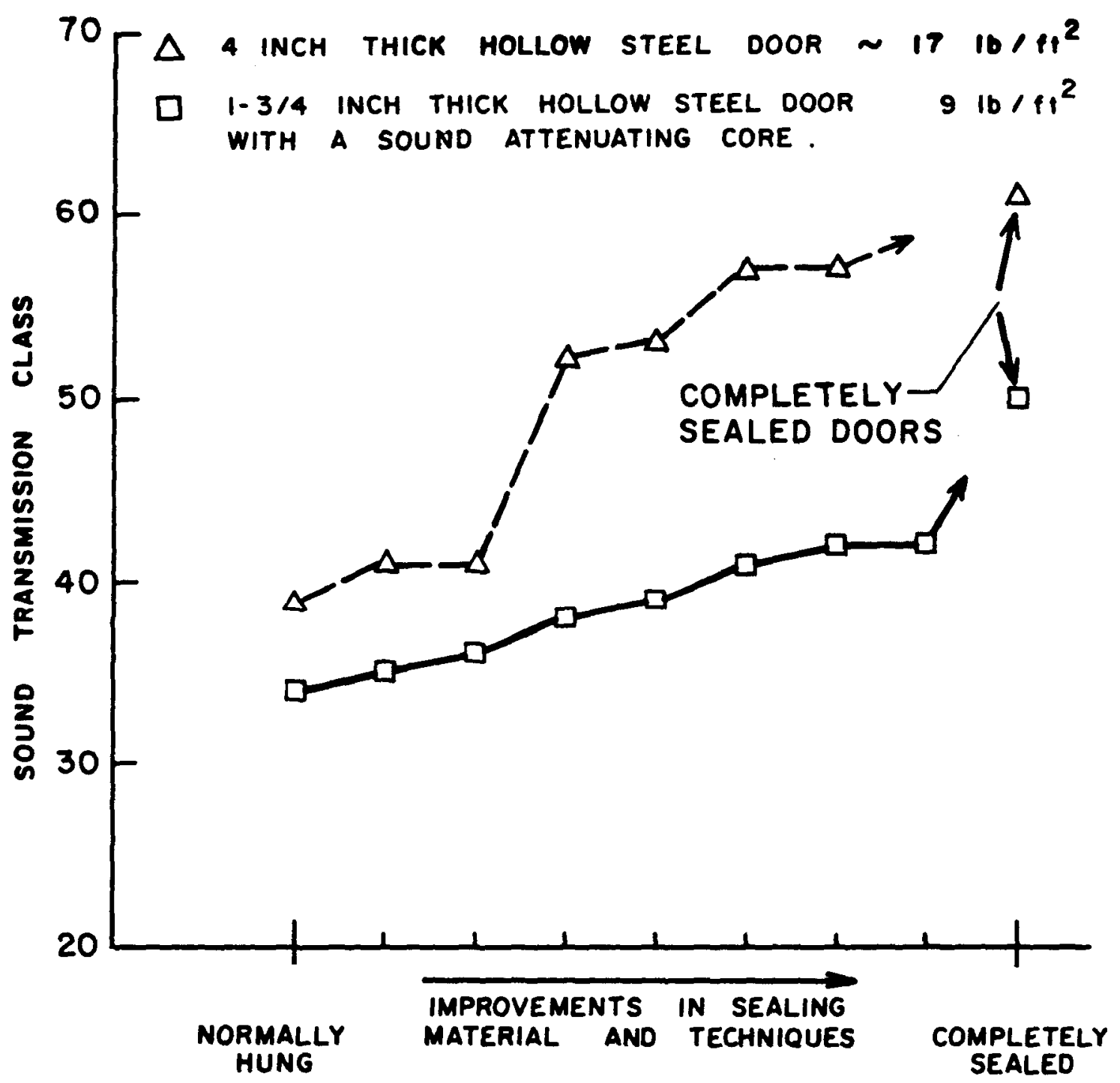

Figure 19. Effects of improved sealing of doors on sound transmission class. (Based on a series of tests on two different types of door.) 
a better door design becomes necessary. Generally the heavier doors provide increased attenuation. Wood and steel doors behave essentially in a similar manner as shown in Figure 20 which shows a form of the mass law dependence of STC on weight (in $1 \mathrm{~b} / \mathrm{sq} \mathrm{ft}$ ) for wood and steel doors. These data which are based on many tests conducted in an acoustical laboratory, indicate an increase of 8 to $9 \mathrm{~dB}$ in STC for a doubling of the weight. NOTE: That effects of better design, better sealing, etc., are also reflected in this figure. The approximate relationships are

$$
\begin{array}{ll}
\text { For steel doors: } & \text { STC }=15+27 \log \mathrm{W} \\
\text { For wood doors: } & \text { STC }=12+32 \log \mathrm{W}
\end{array}
$$

where $W=$ weight of the door in $1 \mathrm{~b} / \mathrm{sq} \mathrm{ft}$. It should be emphasized that these relationships are purely empirical and that large deviations may be possible for any given door.

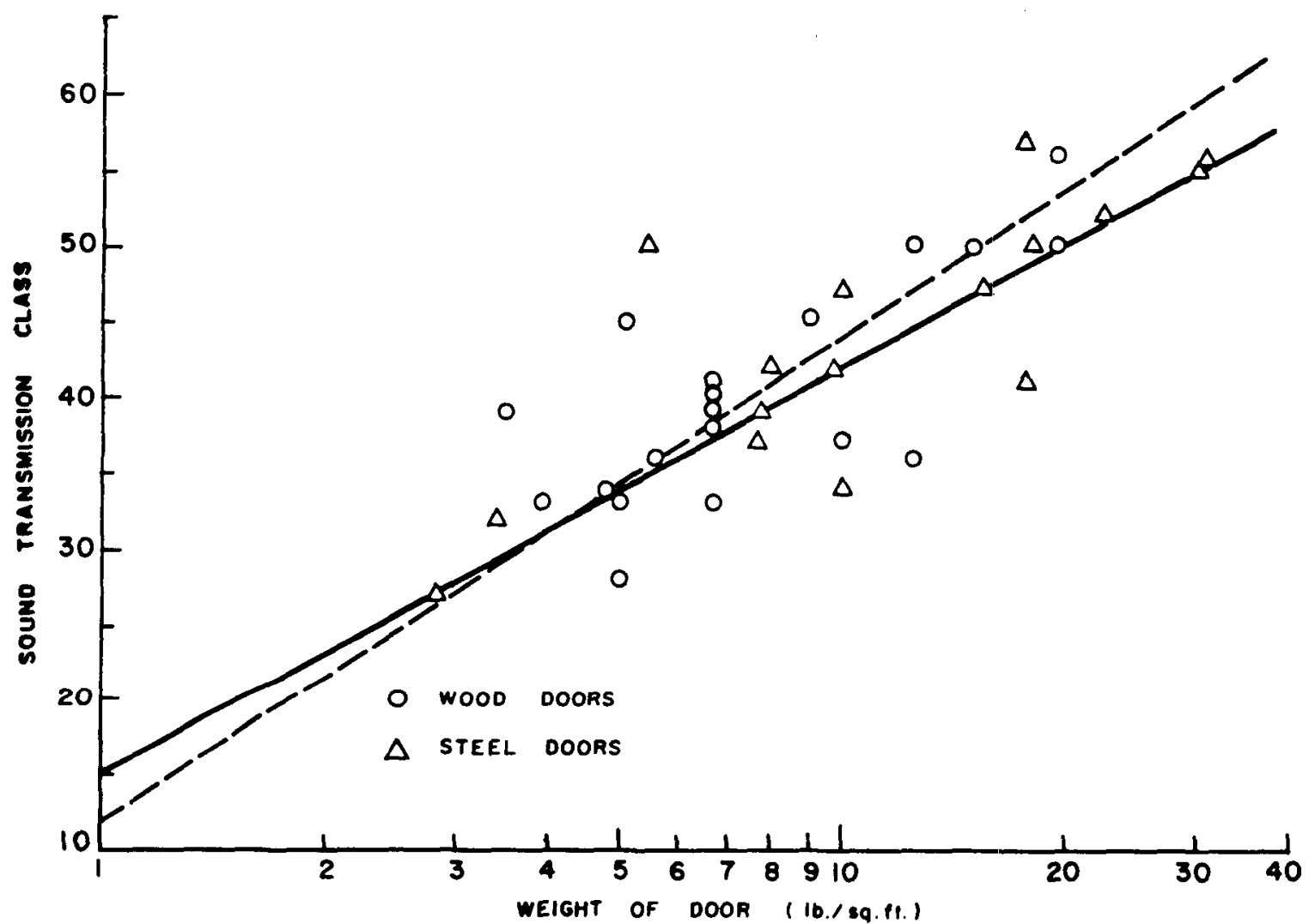

Figure 20. Dependence of sound transmission loss for doors on weight. Approximate STC for wood door, STC $=12+32 \log \mathrm{W}$; approximate STC for steel door, $\mathrm{STC}=15+27 \log \mathrm{W}$; where W=weight of the door in $1 \mathrm{~b} / \mathrm{sq} \mathrm{ft}$. 


\section{Ceilings As Barriers}

The use of ceilings as sound barriers is not a normal application. Yet it is frequently through the ceiling and the open plenum above into the next room and down through the ceiling of the adjoining room that sound travels. This is just one flanking path that can seriously degrade the sound isolation between rooms.

There are several alternatives for reducing the noise transmitted in this way. One method is to place a barrier in the ceiling plenum between the two rooms. This may be difficult sometimes due' to the piping, wiring, ductwork, etc., that is probably in this space.

A second way is to place some barrier material such as gypsum board on top of the ceilings. However, one must be careful because enclosing the space above the ceiling may decrease the absorption coefficient of the ceiling and reduce the absorption of the room below.

The third method is to use a ceiling that has both the proper absorption and sound transmission loss properties. For this reason ceilings are tested for their transmission from one room to another as well as for sound absorption. This test provides a sound attenuation factor for the ceiling. A two-room test procedure has been developed for this purpose. Basically, the procedure involves the construction within a room of a partition which does not quite reach the ceiling. The suspended panel ceiling to be tested is installed in the room on both sides of the partition so as to simulate a plenum above the suspended ceiling extending between both halves of the test room. The transmission loss of sound passing up through the suspended ceiling, through the plenum, and back down through the ceiling into the other half of the room is then measured. The transmission loss of the partition should be considerably greater than that of the test ceiling. A drawing illustrating this procedure appears in the text before data table 14.

Freestanding Walls As Barriers

A freestanding wall is defined here as a solid fence, with no bounding surface above the wall so that sound waves can pass freely over the wall.

As with all sound control systems the amount of attenuation provided by a freestanding wall depends on the frequency as well as many other factors. For low frequencies where the sound wavelength is of the same order of magnitude as the wall dimensions, the sound diffracts around the edges and over the top of the wall with very little attenuation (zero to $5 \mathrm{~dB}$ ) on the other side. The higher frequencies can be very effectively attenuated with reductions of $20 \mathrm{~dB}$ being quite possible.

The attenuation of an infinitely long, freestanding wall can be determined from Figure 21 and the relationship

$$
\text { Attenuation }(\mathrm{dB})=20 \log (2.5 \mathrm{~N})+5 \mathrm{~dB}
$$




$$
\begin{aligned}
N & =1, \text { for where } \\
N & =\left[\frac{2}{\lambda}(A+B-d)\right]^{\frac{1}{2}} \\
\lambda & =\text { wavelength of sound, meters } \\
d & =\text { straight line distance from source to receiver in meters, } \\
A+B= & \text { shortest path length of wave travel over the wall between } \\
& \text { source and receiver. }
\end{aligned}
$$

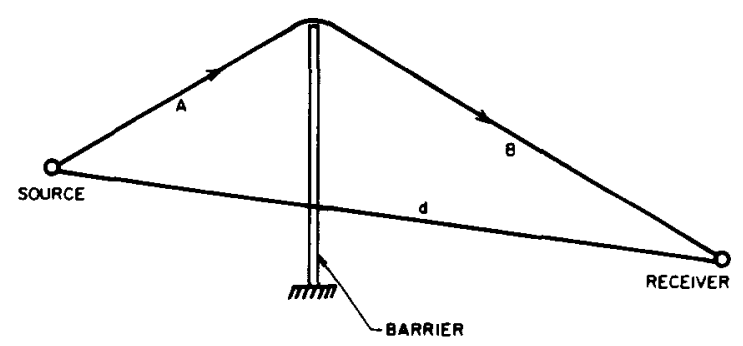

Figure 21. Geometry for determining sound attenuation by a freestanding wall.

Attenuations range from a low of about $5 \mathrm{~dB}$ to a maximum of about $24 \mathrm{~dB}$. This attenuation can then be subtracted from the sound pressure level that would exist at the point of the receiver if the wall were not there.

The maximum attenuation occurs when $A+B \gg d$ and/or when $\lambda$ is very small (high frequency).

EXAMPLE 12: Determine the attenuation at $1000 \mathrm{~Hz}$ for a freestanding wall $4 \mathrm{~m}$ high.

SOLUTION: The wavelength of sound at $1000 \mathrm{~Hz}$ is $0.344 \mathrm{~m}$. Assume that the wall is long enough so that the sound diffracting around the ends can be neglected. Also assume the point noise source is $1.7 \mathrm{~m}$ from the ground and the receiver is a human ear also $1.7 \mathrm{~m}$ from the ground. Locate the wall such that the source is $3 \mathrm{~m}$ from the wall and the receiver $6 \mathrm{~m}$ from the wall. Then

$$
\begin{aligned}
& \mathrm{N}=\left[\frac{2}{.344}(3.78+6.43-9)\right]^{\frac{1}{2}}=2.65 \\
& \text { Attenuation }=20 \log [(2.5)(2.65)]+5=21.4 \mathrm{~dB}
\end{aligned}
$$

On the other hand, how high must the wall be built to obtain a specified attenuation? For example, for the same case as above, how high must the wall be to obtain $15 \mathrm{~dB}$ attenuation at $125 \mathrm{~Hz}$, where the wavelength is $2.75 \mathrm{~m}$ ? 
By rearranging equation (50),

$$
N=0.4 \text { antilog } \frac{\mathrm{dB}-5}{20} \text {. }
$$

The value of $A+B$ can be derived from equation (51) as

$$
A+B=N^{2} \lambda / 2+d .
$$

The wall height can then be determined on a trial and error basis or graphically; in this case, $A+B$ is $11.2 \mathrm{~m}$, which corresponds to a wall height of 5.m. (Further discussion of the attenuation of sound by freestanding walls can be found in the Journal of the Acoustical Society of America, 55(3), pp 504-518, March 1974).

The wall should be constructed of such a material that transmission of sound through the wall does not degrade its performance since the above equations assume no transmission through the wall. This can be readily accomplished if the surface density of the wall is at least about $9.76 \mathrm{~kg} / \mathrm{sq} \mathrm{m}(2 \mathrm{lb} / \mathrm{sq} \mathrm{ft})$.

One final note on the use of a freestanding wall is that the noise from the source will reflect off the wall so that to an observer on the same side of the wall, the sound pressure level will be higher than if the wall were not there.

Noise Reduction And Enclosures

A barrier may be characterized by its noise reduction (NR) alone. For example, the sound pressure level inside an enclosure, $L_{1}$, and the sound pressure level outside the enclosure, $\mathrm{L}_{2}$, may be measured simultaneously. The difference in these two levels is the NR value. If the noise source is inside the enclosure the NR is given by $\mathrm{L}_{1}-\mathrm{L}_{2}$, or $N R$ is $\mathrm{L}_{2}-\mathrm{L}_{1}$ if the noise source is outside the enclosure.

The NR can differ significantly from the transmission loss for a specimen since the absorption in the two regions where the measurements are made is not included in the calculation. Whenever this value is presented in the data tables it is pointed out so the user will be aware of the difference.

The measurement of NR is not only used for enclosures, but for any case where the difference in two sound pressure levels is determined. One should also be aware that the NR of a specimen bears no relation to the noise reduction class (NRC) of an absorber material. The NR relates to the ability of a specimen to block sound whereas the NRC is a sound absorption property.

In many cases the purpose of an acoustic enclosure is to keep the noise from getting inside. Examples are soundproof booths for machine operators and audiometric test booths for testing the hearing of employees. It is relatively straightforward to calculate the noise reduction by employing the principles of transmission loss, since the enclosure may simply be regarded as a small room, and its walls as partitions. More often, however, an enclosure, or box, is placed around a noise source to keep the noise from getting outside. Several common designs of enclosures and barriers are illustrated in Figure 22. 
In predicting the noise reduction for this case there are some subtleties which warrant further discussion.

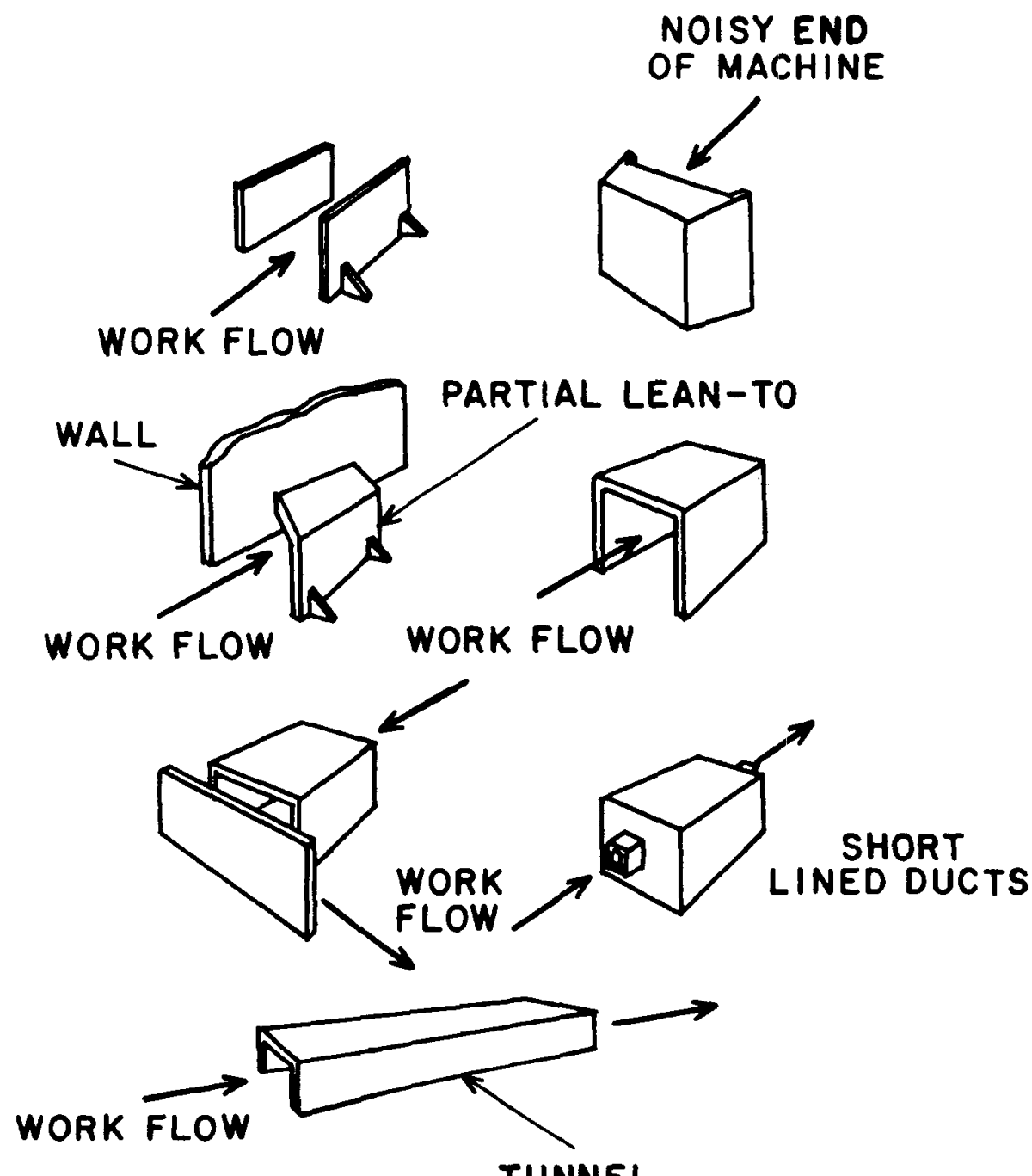

Figure 22. Typical barriers for partial noise control in work areas.

To predict the NR of an enclosure the procedure is the same as with a barrier wall. One first determines the transmittance of the total surface area and then, including the absorption of the space outside the enclosure, determines the noise reduction of the box. 
EXAMPLE: A noisy machine sits in a room in a factory. The room has been found to have a total absorption of 3000 sabins at $250 \mathrm{~Hz}$. It is desired to build a $3.05 \mathrm{~m}$ by $3.05 \mathrm{~m}$ by $3.05 \mathrm{~m}$ (10 ft by $10 \mathrm{ft}$ by $10 \mathrm{ft}$ ) enclosure about the machine, made of partitions with a TL in the $250 \mathrm{~Hz}$ band of $50 \mathrm{~dB}$. There will be a $1.07 \mathrm{~m}$ by $2.13 \mathrm{~m}$ ( $3.5 \mathrm{ft}$ by $7 \mathrm{ft}$ ) door in the enclosure. The TL of the door at $250 \mathrm{~Hz}$ is $25 \mathrm{~dB}$. What noise reduction can we expect to achieve from the use of the enclosure?

SOLUTION: As in example 11, we must calculate the average transmission loss, this time for four walls and a ceiling.

\begin{tabular}{lccc}
\hline ITEM & $\begin{array}{c}\text { AREA } \\
(\mathrm{sq} \mathrm{ft})\end{array}$ & $\begin{array}{c}\mathrm{TL} \\
(\mathrm{dB})\end{array}$ & $\tau$ \\
\hline $\begin{array}{l}\text { Four walls } \\
\text { (less door) }\end{array}$ & 375.5 & 50 & 0.00001 \\
Ceiling & 100 & 50 & 0.00001 \\
Door & 24.5 & 25 & 0.00316 \\
\hline $\bar{\tau}=\frac{(475.5)(0.00001)+(24.5)(0.00316)}{500}=0.00016$ \\
$\overline{\mathrm{TL}}=10 \log \frac{1}{0.00016}=38 \mathrm{~dB}$ \\
$\mathrm{NR}=38-10 \log \frac{500}{3000}=46 \mathrm{~dB}$
\end{tabular}

The NR computed above is the difference between noise levels inside and outside the box, and represent what one would most likely be concerned with in practice. However, what is the noise level inside the box? An interesting phenomenon occurs in a complete enclosure. If there is some source of sound power and a box is built around it, the sound energy density, or the intensity, will increase until the amount of power absorbed by the walls is equal to the power emitted by the source. This phenomenon is referred to as "sound build-up". To illustrate, suppose that the machine being enclosed has been found by prior testing, to produce $105 \mathrm{~dB}$ of sound power at $250 \mathrm{~Hz}$. If the room constant $\mathrm{R}$ is $350 \mathrm{sq} \mathrm{m}$, the sound pressure level of the machine at a distance of $1.5 \mathrm{~m}$ (5 ft) is

$$
\begin{aligned}
L_{P} & =L_{w}+10 \log \left[\frac{1}{2 \pi r^{2}}+\frac{4}{R}\right] \\
& =105-11=94 \mathrm{~dB} \text { re } 20 \mu \mathrm{Pa}
\end{aligned}
$$

The enclosure is now placed around the machine. It is made of steel with an absorption coefficient of 0.2 . The concrete floor it rests on also has an absorption coefficient of 0.2 . 
The room constant in the enclosure is

$$
\begin{aligned}
R=S\left(e^{\bar{\alpha}}-1\right)=600\left(e^{.02}-1\right) & =12 \mathrm{sq} \mathrm{ft} \\
& =1.1 \mathrm{sq} \mathrm{m}
\end{aligned}
$$

(Note that the surface area inside the enclosure used in determining $\mathrm{R}$ includes the area of the floor). The sound pressure level at $1.5 \mathrm{~m}$ ( $5 \mathrm{ft}$ ), (now just inside the enclosure wall) is

$$
L_{p}=105+10 \log \left[\frac{1}{2 \Pi(1.5)^{2}}+\frac{4}{1.1}\right]=111 \mathrm{~dB} \text { re } 20 \mu \mathrm{Pa}
$$

Recalling that the NR of the enclosure was found to be $46 \mathrm{~dB}$, the sound pressure level just outside the enclosure will be $111-46=65 \mathrm{~dB}$, compared with $94 \mathrm{~dB}$ at the same location before construction of the enclosure. The effect of building the enclosure has been a reduction of the noise by $29 \mathrm{~dB}$. While this is a good improvement, it is a long way from the $46 \mathrm{~dB}$ predicted by the barrier properties of the enclosure alone.

This problem is not insurmountable. The solution is to add absorption to the lining of the walls of the enclosure. If the job is good enough, the level at the inside of the wall can be very nearly what it would be in a free field. In the above example, the external room constant was so large that the sound pressure at $1.5 \mathrm{~m}(5 \mathrm{ft})$ from the source was essentially that of a free field. As can be seen from Figure 12. Note that not in any case can the use of acoustical treatment inside a room reduce the sound pressure level at a point below that of the direct path transmitted wave. This wave is the free field wave which represents the minimum achievable sound pressure level that can be obtained without using a sound barrier between the source and the receiver.

Another factor that must be considered is resonance. If the dimensions of the box result in resonance due to one of the modes of the sound, the box can be driven to high levels of vibration and become a new radiator of these components of the sound. When this occurs the sound pressure level outside the box can be higher than it was even before the box was installed. This effect is significantly reduced when the noise source occupies a sufficient fraction of the room volume, by the use of absorbent lining on the interior surfaces of the enclosure, damping treatment on the panels, and stiffening of the panels. 


\section{IMPACT SOUND}

The term impact sound as used here should not be confused with hazardous impact noise as defined by OSHA regulations. The tests described herein are used to measure transmission of footsteps and similar sounds and have little relevance to control of industrial impact noise.

A knowledge of sound transmission loss is useful for many objects such as walls, floors, doors, windows, specialized panels, or any other item that may be used to block a sound path. In the case of floors, however, not all noise in the space below the floor is due to airborne sound transmission through the floor. Some of the noise below the floor is due to sliding objects across the floor, footsteps, dropping objects, etc. These occurrences induce structural vibrations in the floor assembly which are reradiated as sound waves into the rooms above and below the floor.

\section{IMPACT SOUND TRANSMISSION MEASUREMENTS (PER ASTM E497-77)}

The recommended method for this test procedure has been published by ASTM as E492-77 "Method of Laboratory Measurement of Impact Sound Transmission through Floor-Ceiling Assemblies Using the Tapping Machine".

This test utilizes a standard impact source which is known as a tapping machine. With this machine making fixed amplitude impacts on the floor the sound pressure level produced in the room below is measured in 16 contiguous one-third octave bands from $100 \mathrm{~Hz}$ through $3150 \mathrm{~Hz}$. The sound pressure levels thus measured are affected by the absorption in the receiving room. In order to compare results from different receiving rooms, these values are normalized to a reference room which has an absorption of 108 sabins or 10 metric sabins. This normalization is obtained through the relationship

$$
L_{N}=L_{p}-10 \log \left(A_{o} / A_{2}\right) \text { dB re } 20 \mu \mathrm{Pa}
$$

where

$L_{N}$ is the normalized sound pressure level,

$I_{p}$ is the mean square measured sound pressure level,

$A_{2}$ is the measured absorption in the receiving room measured as described for absorption tests, and

$A_{0}$ is the reference absorption in the same units as $A_{2}$.

There is still much debate over the use of the tapping machine as an impact source. Many feel that this excitation is not representative of footsteps, sliding furniture, etc. 
Just as with absorption and transmission data the impact data make comparisons between products difficult. There is another one-number rating called the Impact Insulation Class (IIC), which is obtained by comparing the normalized sound pressure levels at each of the 16 one-third octave bands to a set of standard contours as in the case of the STC for transmission loss. These contours however have a different shape from the STC contours. The normalized sound pressure level curve in this case must fit the standard contour in such a way that in no event is the $L_{N}$ curve more then $8 \mathrm{~dB}$ above the IIC contour at any frequency, and the sum of the deviations of the $L_{N}$ values which are above the IIC contour shall not exceed $32 \mathrm{~dB}$. The lowest contour to which the specimen $L_{N}$ curve can satisfy these requirements is the proper IIC contour and the value of this curve at $500 \mathrm{~Hz}$ is then chosen as the IIC number of the specimen. The standard contour is shown in Figure 23.

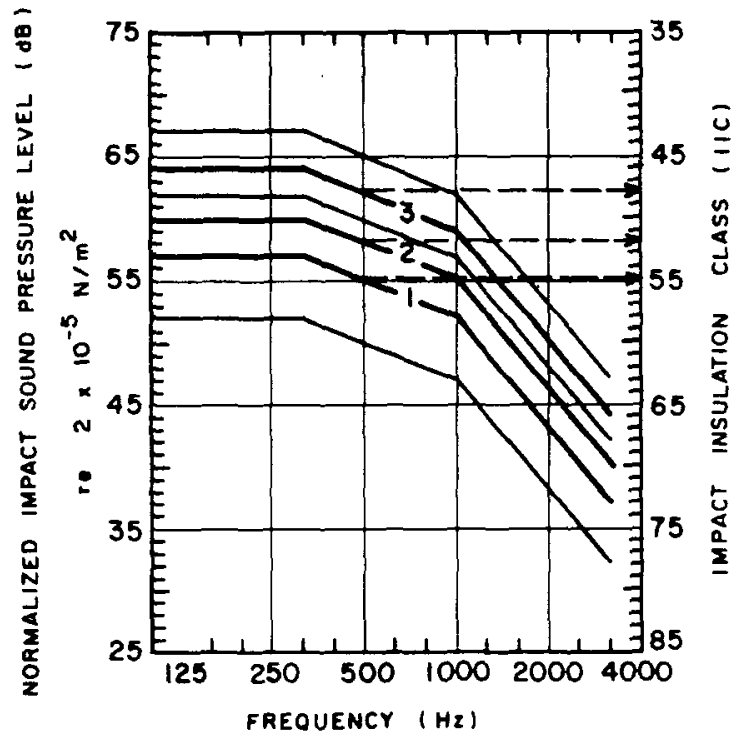

Figure 23. Impact insulation class contours. Contour 1, IIC $=55$; Contour 2, $I I C=52 ;$ Contour 3 , IIC $=48$.

An older single-number rating for impact insulation which was used by the Federal Housing Administration is known as the Impact Noise Rating (INR). This rating is based on the same contours, but a standardized floor was given an $I N R=0$. Thus, the first contour above this had a rating of -1 (higher sound pressure level $=$ poorer floor) and the first contour below had a rating of +1 . Consequently the INR can take on positive and negative values. This standard floor compares to the IIC contour which has a value of 51 at $500 \mathrm{~Hz}$; thus, any value of IIC can be obtained from the INR by adding 51. That is

$I I C=I N R+51$ 
The use of floors as barriers of sound in the path between two rooms is exactly as with walls plus a few additional considerations. First consider the STC of the floor. Generally, floors have good STC since their structural requirements are such that the floors are sufficient mass. However, this is not always true, especially in some of the modern apartment constructions.

One of the main problems with floors is that they are located in the direction of gravity for footsteps, falling objects, support of furniture and equipment of all sorts, etc. These falling objects produce impact noises both in the spaces above and below the floor. Because of these impacts, many floors are now tested for impact insulation.

Sound transmission of a floor can be decreased by increasing the weight of the floor or by designing a more complex floor system using acoustical batts, cavities, etc. The goal of these complexities is to decouple the bottom of the floor assembly from structural vibrations set up in the top part of the assembly.

The IIC of a floor cannot be significantly increased by increasing its weight, but a carpet on the floor, or even better, a carpet placed on a pad, can greatly increase the IIC. The effects of various floor treatments on STC and IIC are shown in Tables 10 and 14 .

Table 14. Typical improvements with floor and ceiling treatments.

\begin{tabular}{|c|c|c|c|}
\hline \multirow{2}{*}{ Type of treatment } & \multicolumn{3}{|c|}{ Change in ratings } \\
\hline & $\begin{array}{l}\text { Airborne, } \\
\text { STC }\end{array}$ & $\operatorname{Im}$ & $\begin{array}{l}\text { apact, } \\
\text { or IIC }\end{array}$ \\
\hline 2-inch concrete topping, 24 psf & 3 & & 0 \\
\hline Standard $44 \mathrm{oz}$ carpet and $40 \mathrm{oz}$ pad & 0 & & 48 \\
\hline Other carpets and pads & 0 & 44 & to 56 \\
\hline Vinyl tile & 0 & & 3 \\
\hline 0.5 inch wood block adhered to concrete & 0 & & 20 \\
\hline $\begin{array}{l}0.5 \text { inch wood block and resilient fiber underlay adhered } \\
\text { to concrete }\end{array}$ & 4 & & 26 \\
\hline Floating concrete floor on fiberboard & 7 & & 15 \\
\hline Wood floor, sleepers on concrete & 5 & & 15 \\
\hline Wood floor on fiberboard & 10 & & 20 \\
\hline Acoustical ceiling resiliently mounted & 5 & & 27 \\
\hline Acoustical ceiling added to floor with carpet & 5 & & 10 \\
\hline $\begin{array}{l}\text { Plaster or gypsum board ceiling resiliently mounted } \\
\text { Plaster or gypsum board ceiling with insulation }\end{array}$ & 10 & & 8 \\
\hline in space above ceiling & 13 & & 13 \\
\hline Plaster direct to concrete & 0 & & 0 \\
\hline
\end{tabular}


Consideration must be given to what happens when a piece of vibrating machinery is mounted on the floor. At the moment no particular test procedure exists to predict what noise this type of installation will have. What can be said is that if the floor is driven to a sufficiently high level of vibration it will become an acoustic radiator of noise into the spaces both above and below. To prevent such problems one must mount machinery on proper vibration isolation mounts.

It cannot be said that the real noises produced by objects hitting the floor above will resemble the noises of the tapping machine. Since the machine is portable, it cannot simulate the shifting of weight distributions that occur as a human walks across the floor, nor does it produce the sort of structural vibrations set up as furniture slides on the floor. These actions produce creaking and squeaking noises, especially in wood construction floors, which are not accounted for by the IIC values and the ASTM test method. The use of a tapping machine is only of value as a standard in comparing the performance of a floor to other floors similarly tested.

There is no definite way one can predict the sound pressure levels in the room below any particular floor without first measuring the noise of the specific impact of interest. The only handle that is available is that the higher the IIC the lower the sound level in the space below for most, but not all, types of impact noises. Of course, just as with STC, the true shape of the sound spectrum must be considered in its entirety.

With regard to airborne sound transmission, it was shown earlier that a good IIC floor probably has a good STC as well. It should not be overlooked, however, that flanking paths such as into the walls of the upper room, down through the wall, and out into the space of the room below, can contribute a good portion of the noise in the space below. Also, any impact on the floor will send vibrations into the walls which can become airborne sound in the room below.

Laboratories that measure impact insulation provide a good test floor in terms of isolation. Any good installation of a floor that must have a high insulation. against impact noises should be equal to the laboratory setup. There are numerous ways and materials that can be used to increase the isolation of the floor from the wall and even from the subfloor. The interested reader should consult the relevant data tables of this volume as well as one of the many good books on architectural acoustics for the many designs presently used.

Of additional benefit to the sound barrier properties of a floor is the fact that if there is a space below there is probably some kind of ceiling also. Consequently, a floor should not be considered alone but as a floor-ceiling system. Well designed floor-ceiling systems can significantly improve the acoustic environment by reducing impact sound generation, increasing the sound absorption, and attenuating the airborne sound that passes through the floor. 
OPEN PLAN OFFICE TREATMENT

In response to the growing popularity of open plan office architecture, a growing number of manufacturers are producing a variety of decorative wall treatments and freestanding landscape screens to divide a large office area into smaller work areas. Speech privacy bewteen work areas is a major concern of such treatments. The landscape screens provide sound absorption and act as a freestanding barrier to noise.

Such screens are generally constructed of an absorbent core held in a wood or metal frame and covered with fabric. The units may be attached together at their ends to enclose or delineate areas. They may have an open area at the bottom or they may extend to the floor, although the units which extend to the floor are more effective barriers. Since the screens are obviously sold as a preformed unit and the size of the specimen will affect the absorption, the measured absorption is reported directly in sabins per unit and is usually not reduced to a coefficient. Transmission of sound through the screens is described by normal transmission loss values. To reduce transmission, some screens contain an impermeable septum in the core.

Sound may still diffract over the tops of the screens as discussed in the section of freestanding barriers, and reflections off the ceiling may travel from one side of a screen to the other. For this reason, most open plan office designs incorporate a combination of landscape screens and sound absorbent ceilings. Electronic noise masking systems may also be employed to diminish the intelligibility of speech diffracting over the tops of the screens.

The Public Buildings Service of the Government Services Administration has published a test method to quantify the acoustic privacy of open plan office systems (PBS-C.2 "Test Method for the Sufficient Verification of Speech Privacy Potential Based on Objective Measurements"). This method defines interzone attenuation as the difference in decibels, at a given frequency, between the sound pressure level on one side of a screen and the level on the other side. Measurements are taken $0.914 \mathrm{~m}$ ( $3 \mathrm{ft}$ ) from a sound source on one side and at specified points on the other side. The distance between the source and the measuring point is called the interzone distance. Functional Interzone Attenuation at each frequency is defined as the average of individual interzone attenuation values over a specified range of interzone distances, typically 2.743 to $3.657 \mathrm{~m}$ ( 9 to $12 \mathrm{ft}$ ) from the source (the screen is usually $1.828 \mathrm{~m}(6 \mathrm{ft}$ ) from the source). The averages are "functional" because they represent interzone distances typical of actual office layouts.

The functional interzone attenuation in each one-third octave band between $400 \mathrm{~Hz}$ and $2000 \mathrm{~Hz}$ (representative of speech frequencies) are compared to the STC contours within the same frequency range and a single number descriptor is derived in a manner similar to the STC except that the allowable deficiencies are cut 
in half ( 4 at any one frequency and 16 total). This descriptor is called the NIC'. An open-plan office layout with an NIC' equal to or exceeding 20 is considered to provide adequate privacy between areas. Both screens and ceilings may be evaluated by this method by using them in conjunction with a standardized ceiling or screen, respectively. 
PIPING, DUCTS, MUFFLERS AND SILENCERS

\section{INSERTION LOSS}

The tests previously described do not apply to such items as ducts, mufflers, pipe lagging, etc. The measurement procedure for these is simply to measure the noise radiating from some pipe or duct work, and then apply (insert) the specimen and measure the sound pressure levels again. The difference in sound pressure levels is due to the insertion of the device under test and is called the "insertion loss". This is a before-and-after type measurement as opposed to the simultaneous measurement on two sides of a partition for noise reduction and transmission loss. The concept of insertion loss may also apply to enclosures as was illustrated in example 13.

\section{PIPE LAGGING}

The covering of a pipe or duct with some sound barrier material is normally referred to as "lagging". Lagging amounts to wrapping the pipe with a flexible sound barrier material in such a way that no seams exist to permit an acoustic leak. This is accomplished by overlapping the barrier material at the places where one piece ends and another begins, also overlapping the two ends of each piece at the point where they wrap back on each other. These seams should then be secured with duct tape so that the barrier remains properly in place.

To realize the full benefit of the lagging, the barrier must not touch the pipe it is covering. Any direct connection between the lagging and the pipe will cause the lagging to vibrate as well, and reduce its effectiveness as a sound barrier. This incidently also holds for any enclosure around a noise source. The lagging can be effectively "floated" away from the pipe wall by first wrapping the pipe with a layer of foam, fiberglass, or other porous material that acts both as a vibration isolator, and sound absorber, and even increases the transmission loss in the higher frequencies. The outer layer of barrier material can be made of any limp impermeable membrane such as thin sheet metal, asphalted paper, rubber, lead loaded vinyl, lead sheet, etc. The heavier and limper the better, just as with any barrier application.

The means of determining how much reduction in sound level can be achieved by such treatment is a little more difficult to determine than for a wall or enclosure because of the different types of acoustical data that are encountered. Some items that are useful as lagging materials such as leaded vinyl may also be useful as a hanging curtain or as a plug to close some opening. Consequent$1 \mathrm{y}$, the manufacturer of these items may have them tested for transmission loss in the usual way between two reverberation rooms. This provides a good measure of the sound barrier capability of the material, but requires that one knows the sound pressure level very close to the pipe along its length and the absorption in the surrounding space. Some manufacturers actually mount their material on a piece of test pipe and determine the noise reduction of the covering 
by measuring the sound pressure level inside the pipe and in the space outside the lagging. To use these data requires that the sound pressure level inside the pipe, the sound pressure level produced by the pipe vibrations, and the absorption in the surrounding space be known.

Insertion loss measurements are made with a test pipe in a reverberation room with a noise source of some kind inside the pipe. Measurements are made in the room with only the bare pipe and again after the pipe is lagged. Insertion loss data are the most meaningful and easiest to use.

\section{DUCTING}

Sound may propagate through the ductwork which often connects spaces which would otherwise be sound isolated from each other. In particular, the noise of a fan or blower can travel great distances along the duct work and be heard in many areas of a building.

Figure 24 illustrates interconnection through ducts. The fan in room A produces vibrations which enter room $B$ through the floor and it produces noise which may enter room $B$ through the air diffuser or by vibration of the duct walls. The noise may travel to all other rooms through the duct. The men talking in room $C$ produce noise in room $B$. Noise from the shop $D$ may travel through the ducts to rooms $B, C$ and $E$.

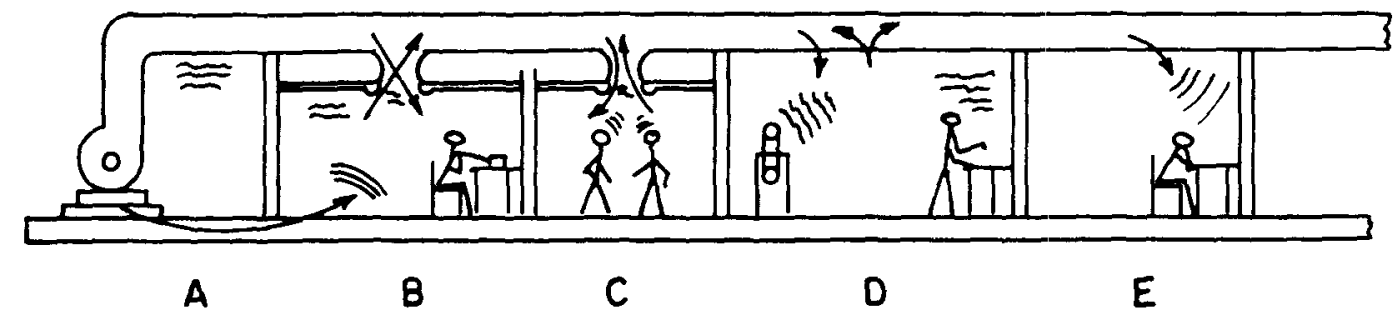

Figure 24. Interconnections between noise sources, paths, and receivers.

Figure 25 shows the use of flexible couplings between ducts and blower and between ducts and a noise attenuation package, as well as the use of vibrationisolating hangers. Figure 26 shows the noise sources in a simple duct system with the spectra of the sources and the attenuation of a lined duct, an attenuation package, a bend, and the end reflection losses.

A very good description of the propagation of sound as related to ductwork can be found in the "ASHRAE 1973 systems Handbook". The following discussion presents some of the pertinent information taken from Chapter 35 of the book.

Normally occurring features of a duct system such as bends and abrupt changes in cross section can provide sound attenuations without the need for special silencing components. Elbows and bends, because they block the line-of-sight transmission of the waves, produce attenuations at the higher frequencies as shown in Table 15. 


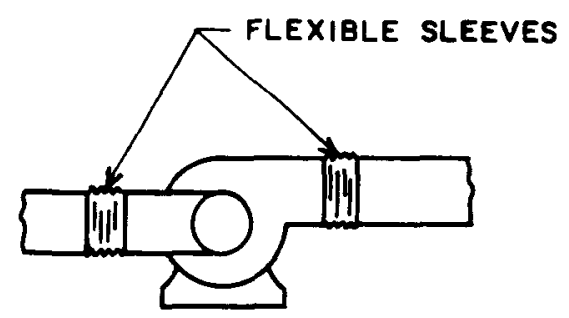

(a)

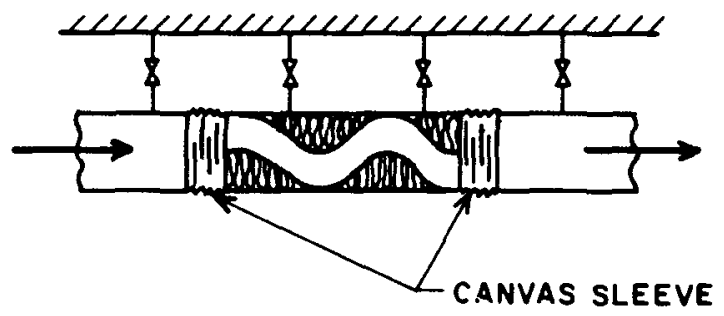

(b)

Figure 25. Uses of flexible couplings in ducts. (a) Canvas or flexible molded rubber and fabric sleeves serve as vibration breaks between fan and connecting ductwork. (b) Canvas or molded rubber connectors between ductwork and high-attenuation devices such as aircoustat package sound attenuators prevent short-circuiting of noise through duct walls. Vibration-isolating hangers should be used where objectionable amounts of noise may short-circuit through supports and building structure.

Table 15. Approximate attenuation in $d B$ of round elbows,

\begin{tabular}{lccccccccc}
\hline $\begin{array}{l}\text { Diameter or } \\
\text { dimensions, } \\
\text { (inch) }\end{array}$ & 63 & 125 & 250 & 500 & 1000 & 2000 & 4000 & 8000 \\
\cline { 2 - 9 } & 0 & 0 & 0 & 0 & 1 & 2 & 3 & 3 \\
$5-10$ & 0 & 0 & 0 & 1 & 2 & 3 & 3 & 3 \\
$11-20$ & 0 & 0 & 1 & 2 & 3 & 3 & 3 & 3 \\
$21-40$ & 0 & 1 & 2 & 3 & 3 & 3 & 3 & 3 \\
$41-80$ & & &
\end{tabular}




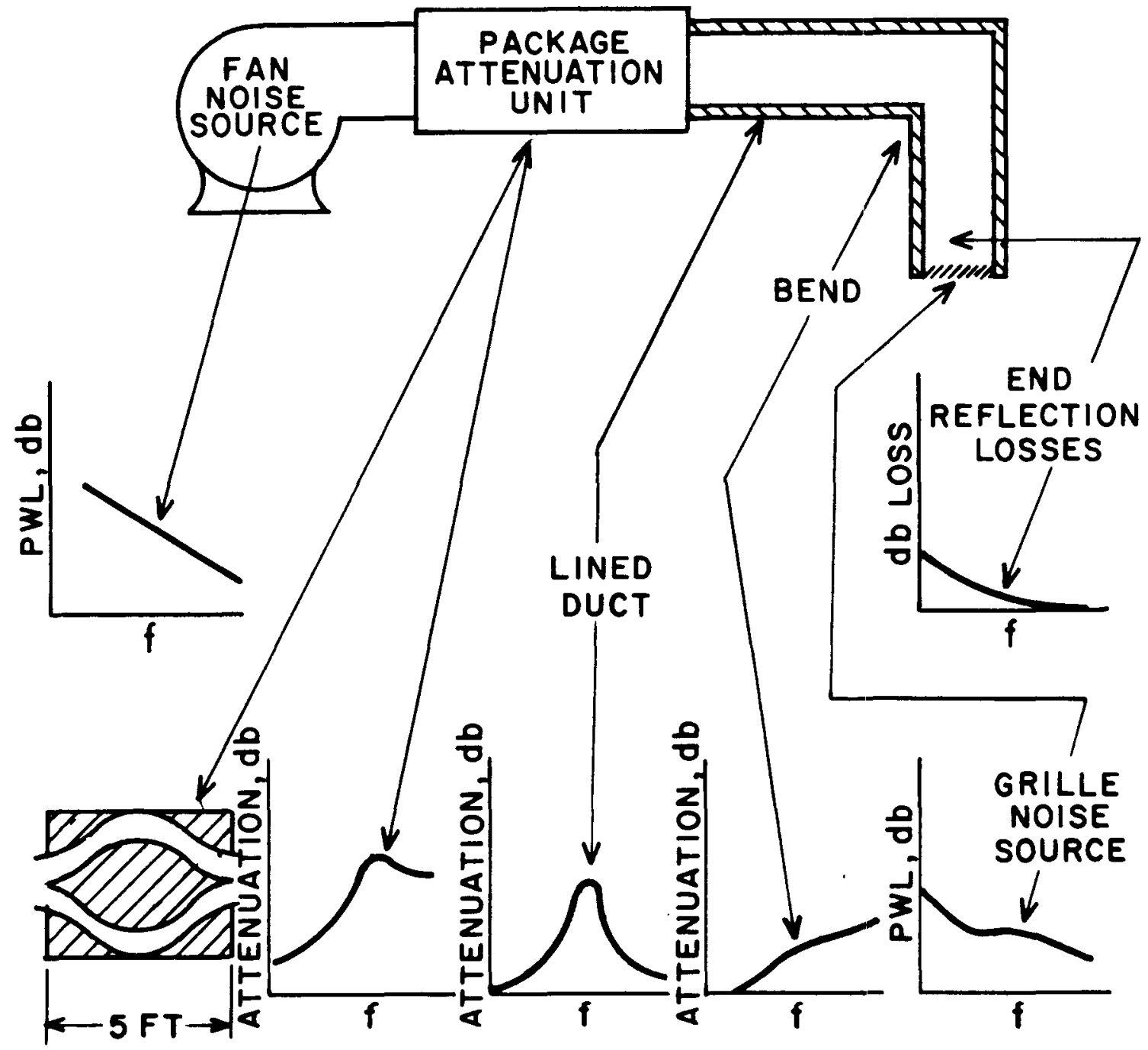

Figure 26. Noise sources and attenuation in a simple duct system. The sources are the fan and the grille. Attenuation is provided by a package attenuation unit, a lined duct, a bend, and by reflection of lowfrequency waves backward at the end of the duct. 
When a duct abruptly changes its cross section, as when it empties into a room, a portion of the wave will be reflected back down the duct because of a mismatch of acoustic impedance at the boundary of the two regions. Table 16 illustrates this. Note that the attenuation is best at the frequencies where the wavelength is much larger than the lateral dimension of the duct.

Table 16. Duct end reflection loss in $\mathrm{dB}^{*}$.

\begin{tabular}{|c|c|c|c|c|c|c|}
\hline \multirow{2}{*}{$\begin{array}{c}\text { Duct } \\
\text { diameter, } \\
\text { (inch) }\end{array}$} & \multicolumn{6}{|c|}{ Octave band center frequency, $\mathrm{Hz}$} \\
\hline & 63 & 125 & 250 & 500 & 1000 & 2000 \\
\hline 5 & 17 & 12 & 8 & 4 & 1 & 0 \\
\hline 10 & 12 & 8 & 4 & 1 & 0 & 0 \\
\hline 20 & 8 & 4 & 1 & 0 & 0 & 0 \\
\hline 40 & 4 & 1 & 0 & 0 & 0 & 0 \\
\hline 80 & 1 & 0 & 0 & 0 & 0 & 0 \\
\hline
\end{tabular}

The following points should be considered when lining a duct with absorptive material.

1. For absorption of frequencies below $500 \mathrm{~Hz}$, the material should be at least $5.08 \mathrm{~cm}$ ( 2 inches) thick. Thin materials, particularly when mounted on hard surfaces, will absorb only the high frequencies.

2. Increased absorption at frequencies below $700 \mathrm{~Hz}$ may be obtained by using a perforated facing in which the area of the perforation is from 3 to 10 percent of the surface area. Such facings, however, decrease the absorption at high frequencies.

3. Any air space behind the material has considerable effect. Absorption coefficients should be based on the particular mounting method intended.

The dependence of absorption NRC on thickness is shown in Figure 27 . This figure shows the range of typical NRC for any given thickness. The frequency dependence varies as with any absorbing material on the type and spacing of the pores, any covering such as mylar, perforated metal, etc. Again the specific product and thickness should be selected on the basis of the full range of frequency data and not just on NRC. If the entire duct cannot be lined, some improvement may be gained by lining two duct widths before and after bends and the last five duct widths before an outlet. 


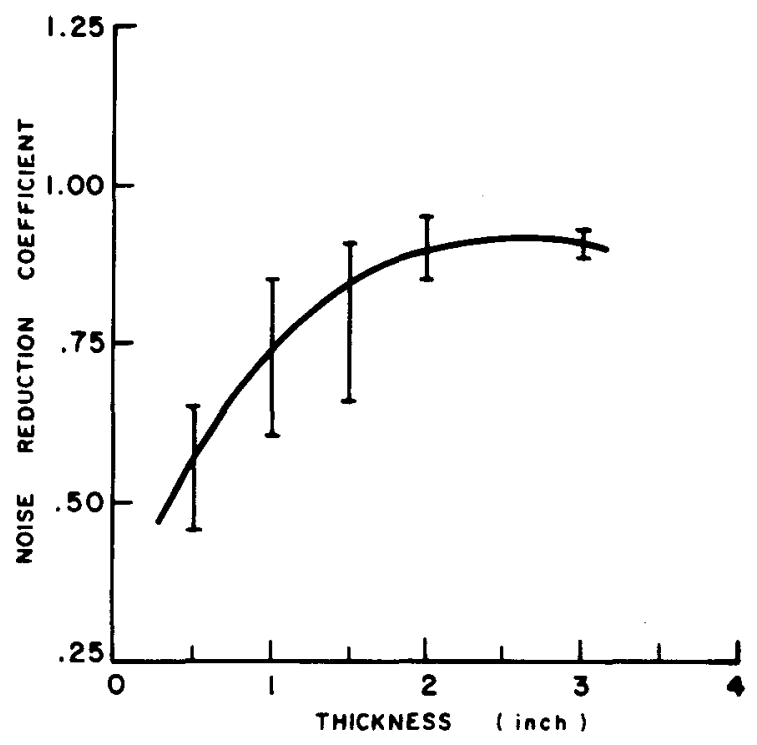

Figure 27. Dependence of noise reduction coefficient of duct lines on thickness.

Although the exact mathematics of sound attenuations in a lined duct is rather complicated, theoretically the following empirical relation can be used to estimate the sound attenuation if the proper limitations on its use are observed.

$$
\text { Attenuation }(\mathrm{dB})=12.61 \frac{\mathrm{P}}{\mathrm{S}} \alpha^{1.4}
$$

where $I=$ length of lined duct in feet; $p=$ perimeter of the duct inside the lining, inches; $S=$ cross-sectional area of the duct inside the lining, square inches; and $\alpha=$ absorption coefficient of the lining (frequency dependent). Some limitations on the use of equation (54) are:

1. smallest side of the duct should be between 15.24 and $45.72 \mathrm{~cm}$ (6 and 18 inches);

2. duct width to height ratio should be less than 2;

3. the equation should not be used where airflow velocities are greater than $1219 \mathrm{~m} / \mathrm{min}(4000 \mathrm{ft} / \mathrm{min})$; and

4. line of sight propagation of the higher frequencies is not accounted for by this equation. (In a straight $3.048 \mathrm{~cm}$ (12 inch) duct the attenuation in the $8000 \mathrm{~Hz}$ octave band will be only about $10 \mathrm{~dB}$ for any lining length over $0.914 \mathrm{~m}$ $(3 \mathrm{ft})$. The attenuation in the next lower octave band, $4000 \mathrm{~Hz}$, will be about midway between $10 \mathrm{~dB}$ and the value calculated from equation (54). The frequency above which the $10 \mathrm{~dB}$ limit applies is inversely proportional to the shortest dimension of the duct.) 
Some actual measurements have indicated that the sound level drops much faster than predicted by equation (54) for the first $1.524 \mathrm{~m}$ (5 ft) of the duct. After that the rate of sound level dropoff is much slower than predicted by equation (54). This is mainly due to flanking transmissions where the sound enters the duct wall and is transmitted along the wall itself. This flanking appears to be the limiting factor in any instance where the predicted sound attenuation exceeds $2 \mathrm{~dB} / \mathrm{ft}$. To reduce this flanking it is therefore recommended that flexible vibration couplings be inserted in the ductwork for every $25 \mathrm{~dB}$ of lining attenuation required in any frequency band.

If additional attenuation is still required then the attenuation can be increased by increasing the absorbing surface in the lined duct as shown, for example, in Figure 28. Another means of reducing the noise in a duct is by using a sound absorption plenum, shown in Figure 29, which is sometimes the most economical arrangement.

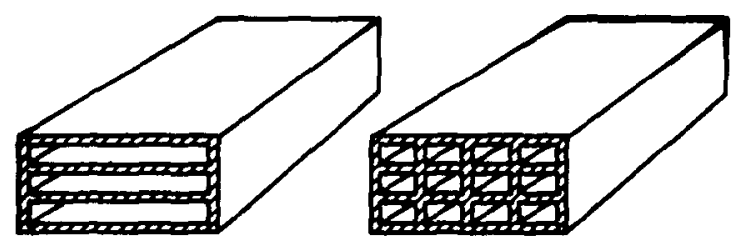

Figure 28. Increase of absorbing surface in lined ducts.

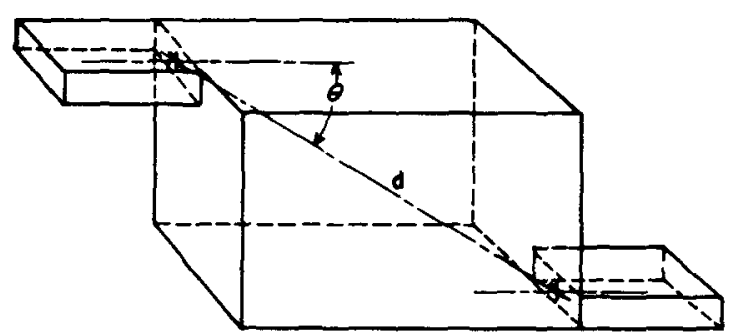

Figure 29. Sound absorbing plenum.

The attenuation provided by such a plenum can be determined by the empirical expression

where

$$
\text { Attenuation }(d B)=10 \log \left[\frac{1}{S_{e}\left(\frac{\cos \theta}{2 \pi d^{2}}+\frac{1-\alpha}{\alpha S_{w}}\right)}\right]
$$

$$
\begin{aligned}
\alpha & =\text { absorption coefficient of the lining (frequency dependent) } \\
S_{e} & =\text { plenum exit area } \\
S_{w} & =\text { plenum wall area }
\end{aligned}
$$




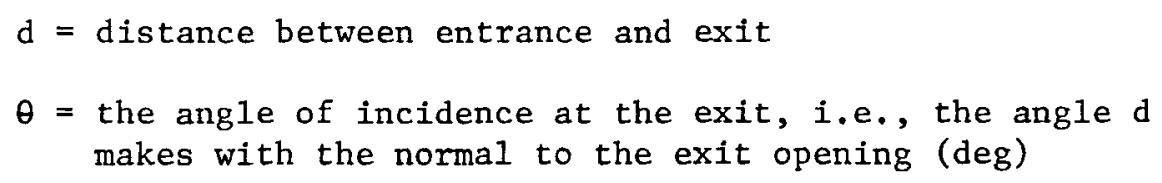

English or metric units may be used, as long as they are consistent.

EXAMPLE 14: As an example of the attenuation a plenum can provide, suppose we build a box $3048 \mathrm{~m}(10 \mathrm{ft})$ on a side which attaches to a $0.6096 \mathrm{~m}$ ( $2 \mathrm{ft})$ square duct in the manner shown in Figure 29. Now line the plenum with a sound absorbing liner such as foam or fiberglass, which has an absorption coefficient in the $1000 \mathrm{~Hz}$ octave band of 0.6 . What attenuation may we expect in the $1000 \mathrm{~Hz}$ band from this plenum?

SOLUTION: For the $1000 \mathrm{~Hz}$ band,

$$
\begin{aligned}
& \alpha=0.6 \\
& \mathrm{~s}_{\mathrm{e}}=4 \mathrm{ft}^{2} \\
& \mathrm{~S}_{\mathrm{w}}=6 \times\left(10^{2}\right)-4=596 \mathrm{sq} \mathrm{ft} \\
& \mathrm{d}=\sqrt{8^{2}+10^{2}}=12.8 \mathrm{ft} \\
& \theta=\tan ^{-1}(8 / 10)=38.7 \mathrm{deg} \\
& \text { Attenuation }(\mathrm{dB})=10 \log \left[\frac{1}{4\left(\frac{\cos 38.7}{2 \pi(12.8)^{2}}+\frac{1-0.6}{0.6 \times 596}\right)}\right]=21.2 \mathrm{~dB}
\end{aligned}
$$

This result is fairly accurate as the predictions obtained with equation (55) normally are within a few decibels for frequencies where the wavelength is less than the plenum dimensions (in this case the wavelength is just over a foot). For the lower frequencies this equation can be conservative by 5 to $10 \mathrm{~dB}$ since the abrupt change in the duct dimensions acts to reflect these longer wavelengths.

It may be necessary to purchase a prepackaged silencer, which can be installed as part of the ductwork, and acoustically treated grills where the ducts terminate in rooms. The attenuation of these devices as with airflow silencing application is dependent on the flow rate, the pressure drop, and the noise frequency content, etc. Specific data for each application should be obtained directly from the manufacturer of these items.

Another concern in duct noise is with sound that propagates through the duct wall, into and out of the duct. As the primary concern in this case is keeping the sound from getting out of the duct, it should be remembered that ducts make good acoustical connections between rooms. One does not want to have sound enter the duct where it passes through a noisy. room to be transmitted to another room, especially if a great deal of time, money, and effort have been expended to reduce the noise (e.g., from fans, blowers, etc.) by installing plenums or silencers. In either case if barrier treatment is applied on the outside of the ductwork or the piping it should reduce the transmission of sound through the walls. 


\section{MUFFLERS AND SILENCERS}

A muffler or silencer is a section of pipe or duct which has been designed to reduce the transmission of sound along its length while allowing free flow of gas. Noisy gas flow through a duct consists of alternating pressure waves superimposed on a steady flow, analogous, to an alternating current superimposed on a direct current in an electrical transmission line. Continuing this ana1ogy, a muffler serves as a low-pass filter, removing or attenuating the alternating component while passing the steady component.

The performance of mufflers may be described in several ways. Insertion loss is defined as the difference in decibels between the sound pressure measured at a point before and after the muffler is placed between the source and the measurement point. Transmission loss is defined as 10 times the logarithm of the ratio of the sound power entering the muffler to the sound power transmitted through the muffler. Noise reduction is the difference between sound levels measured at the input of a muffler and its output. Attenuation is the decrease in sound power between two points in a system. It is usually determined by measuring the decrease in sound pressure per unit length of a duct or pipe. In practical terms, insertion loss is generally regarded as the most useful descriptor of performance and the most convenient to measure.

Mufflers are generally =lassified into three types: reactive, dissipative, and dispersive. Reactive mufflers consist of chambers, resonators, and finite sections of pipe which work to create a mismatch of acoustic impedance between the inlet and outlet of the muffler. Upon meeting a change in acoustic impedance, a portion of the energy in the sound wave is reflected, either to travel back to the source or to be reflected back and forth within the muffler. If the impedance relationships are correct- there will also be some amount of destructive interference with the oncoming wave, canceling out the pressure variations. The simplest kind of reactive muffler is the expansion chamber, where the duct opens into a large volume, creating an abrupt change in cross-sectional area at each end of the volume (Figure 30 ).

A mathematical analysis of the reflection and expansion of sound waves as they pass through the chamber leads to a theoretical expression for the transmission loss through such a muffler:

$$
\mathrm{TL}=10 \log \left[1+\frac{1}{4}\left(\mathrm{~m}-\frac{1}{\mathrm{~m}}\right)^{2} \sin ^{2} \mathrm{k} l\right]
$$

where

$$
\begin{aligned}
& \mathrm{m}=\frac{\text { cross-sectional area of chamber }}{\text { cross-sectional area of duct }} \\
& \mathrm{k}=\text { wave number }=2 \pi / \lambda \\
& \lambda=\text { wavelength of the sound } \\
& l=\text { length of expansion chamber }
\end{aligned}
$$

It can be seen from this theoretical relationship that the transmission loss of a muffler is a maximum at those frequencies where the length of the muffler is an odd multiple of a quarter-wavelength; $\lambda / 4,3 \lambda / 4$, etc. 


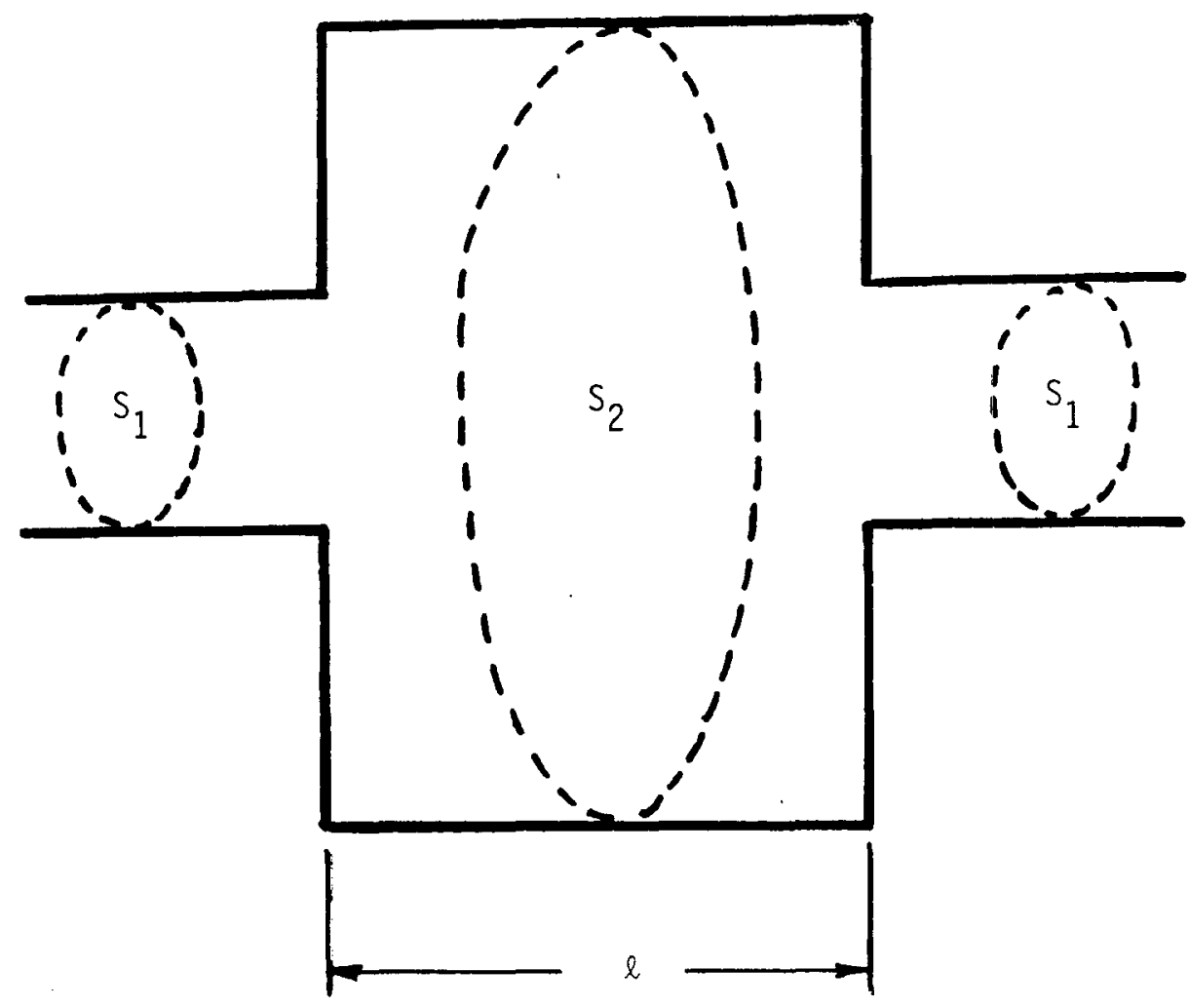

Figure 30. Schematic diagram of an expansion chamber

Figure 31 illustrates curves of TL versus the parameter $k \ell$ for various values of the area ratio $\mathrm{m}$. The performance of expansion chamber mufflers is not affected by steady flow through it, at least for reasonable gas velocities. At very high speeds, noise from turbulence in the flow itself may make the muffler ineffective. Side-branch resonators work in a manner similar to expansion chambers. Openings in a through pipe lead to a chamber to the side of the main flow. The chamber and the openings form a Helmholtz resonator which attenuates noise at the frequency the resonator is tuned to.

EXAMPLE 15: It is desired to reduce the sound power output of a compressor by $10 \mathrm{~dB}$. Design an expansion chamber for the exhaust which will accomplish this. The predominate frequency of the exhaust noise is $250 \mathrm{~Hz}$, the exhaust port has a diameter of $7.62 \mathrm{~cm}$ ( 3 inches), and the temperature of the exhaust is $175^{\circ} \mathrm{F}$.

SOLUTION: At this elevated temperature, the speed of sound and hence the wavelength at $250 \mathrm{~Hz}$ is significantly different from its value at room temperature: from equation (36)

$$
c=49.05 \sqrt{175+460}=1236 \mathrm{ft} / \mathrm{sec}
$$




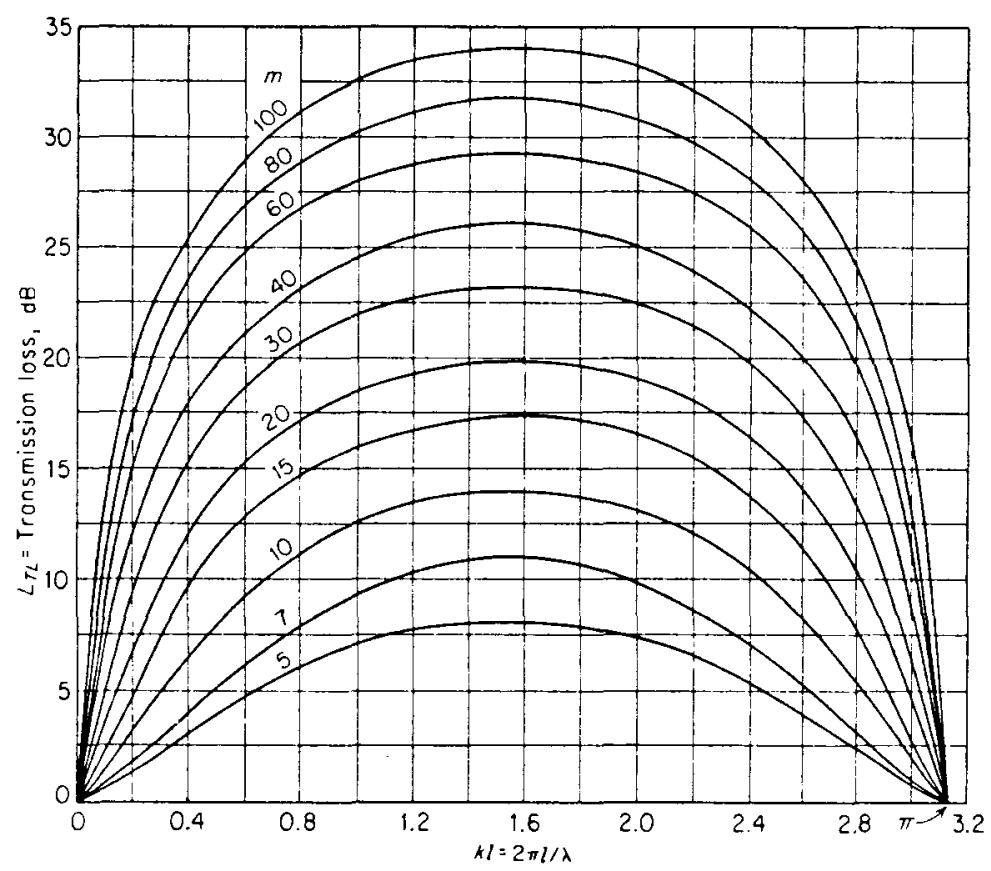

Figure 31. Transmission loss of expansion chamber of length $\ell$ and $S_{2} / s_{1}=m$.

$$
\begin{aligned}
& \lambda=\frac{c}{f}=\frac{1236}{250}=4.94 \mathrm{ft} \\
& k=\frac{2 \pi}{\lambda}=1.27
\end{aligned}
$$

Figure 31 indicates that a chamber area to pipe area of $m=7$ will be sufficient to produce a transmission loss of $10 \mathrm{~dB}$. Substituting these values into equation (56) allows us to solve for the length of the expansion chamber (note that the argument of the sine is in radians).

$$
\begin{aligned}
10 & =10 \log \left[1+\frac{1}{4}\left(7-\frac{1}{7}\right)^{2} \sin ^{2} 1.27 \ell\right] \\
\ell & =0.839 \mathrm{ft}
\end{aligned}
$$

About $25.4 \mathrm{~cm}$ ( 10 inches). Assuming the expansion chamber is to be cylindrical the ratio of the areas of chamber to pipe is equal to the ratio of the diameters squared.

$$
\begin{aligned}
& \mathrm{m}=\mathrm{D}^{2} / \mathrm{d}^{2} \\
& 7=\mathrm{D}^{2} / 9 \\
& \mathrm{D}=7.9 \text { inches }
\end{aligned}
$$

A cylindrical expansion chamber $20.06 \mathrm{~cm}$ ( 7.9 inches) in diameter and $25.4 \mathrm{~cm}$ (10 inches) long will provide a $\mathrm{TL}$ of $10 \mathrm{~dB}$ in this case. 
By observing that the abscissa of Figure 31 is proportional to frequency, one may see the major drawback to reactive mufflers--the attenuation they provide is only effective over a narrow frequency range. Since exhaust noise is of ten broadband, simple expansion chambers of the type illustrated in Figure 30 are rarely used. Most manufacturers of reactive mufflers produce units which contain a combination of differently tuned expansion chambers in series or parallel, with and without side-branch resonators. Some common examples are shown in Figure 32 .
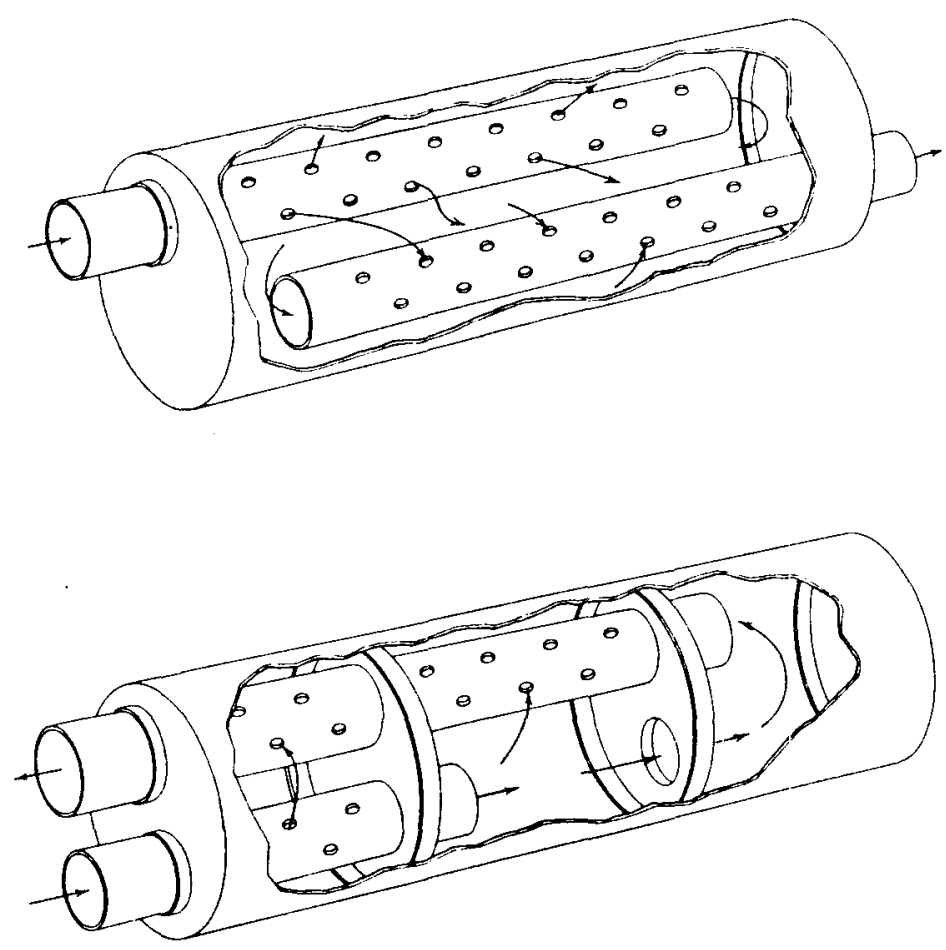

Figure 32. Expansion chamber mufflers.

Dissipative silencers employ a sound absorbing material to attenuate the sound waves. Fiberglass and stranded metal are common materials for this purpose. The incident sound energy is partially converted to heat by causing motion in the fibers during its passage through the material. The simplest form of dissipative silencers incorporate parallel baffles running lengthwise of a fibrous material often covered with plastic or perforated sheet metal to protect the fibers and prevent them from entering the airstream. The acoustical performance depends on the thickness, spacing, and length of the baffles as well as the absorption coefficients of the material.

Decreasing the thickness of each baffle and the parallel spacing between them, and increasing the length of the baffles will increase the performance of the system, particularly at frequencies above $500 \mathrm{~Hz}$. Additional noise attenuation may be achieved by staggering sets of parallel baffles, thereby blocking lineof-sight transmission of the sound waves down the duct. Commercially manufactured parallel baffle units are often produced in modular form enabling them to be stacked and combined by the user to fit any size or performance requirements. 
A commonly encountered form of parallel baffle is the tubular silencer. In this configuration, the baffle has the form of a slug or cylinder of absorbing material, often protected by plastic or perforated metal, suspended along the axis of a circular outer shell. The inner surface of the shell may also be lined with acoustic material. The performance of these units is similar to rectangular parallel baffle silencers--good high frequency attenuation with somewhat lesser performance at lower frequencies. Figures 33 and 34 illustrate some typical parallel and tubular baffle silencers.

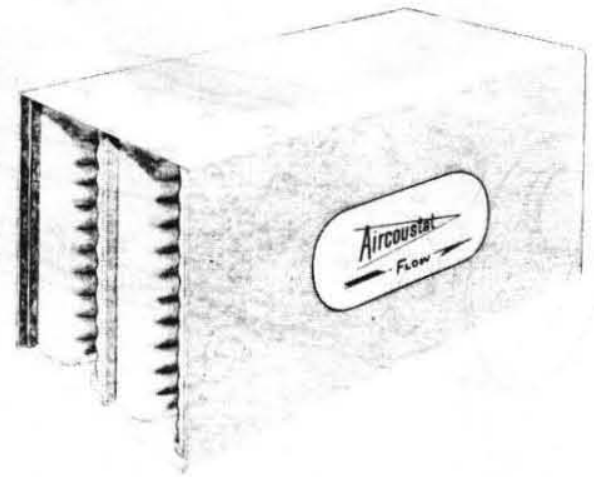

Figure 33. Parallel baffle silencer.

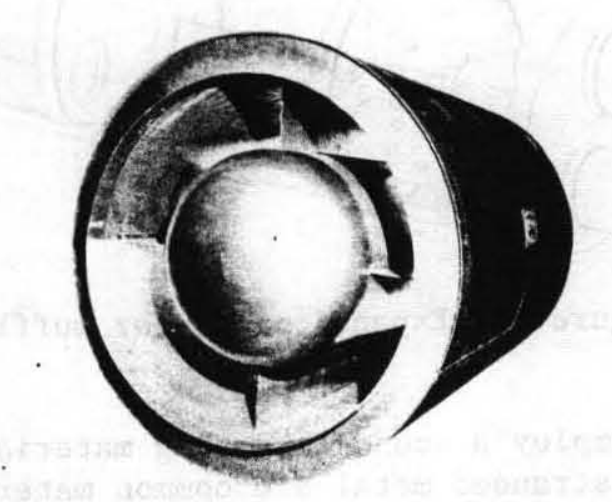

Figure 34. Tubular baffle silencer.

Dispersive mufflers are pressure reducing devices that fit downstream of an orifice or a constriction in a piping system. They act to drop the gas pressure, hence reducing the velocity, and to straighten the flow, reducing the turbulence. Gas velocity and turbulence are prime causes of aerodynamically induced noise. They may be used to reduce noise from control valves, outlet nozzles, blow-off lines, and in ducting.

Aerodynamic noise tends to be relatively broad band in nature, the spectrum rolling off slightly on either side of a frequency peak. This peak may be approximated by the relationship

$$
f_{\text {max }}=s v / d
$$


where

$$
\begin{aligned}
& \mathrm{S}=\text { Strouhal number }(=0.2, \text { approximately constant }) \\
& \mathrm{V}=\text { flow velocity } \\
& \mathrm{d}=\text { exit diameter }
\end{aligned}
$$

It can be shown that the sound power radiated by a gas jet is proportional to the eighth power of the jet speed. Such a strong dependence means that even a small reduction in velocity can effect substantial reductions in noise levels.

Dispersive silencers usually have the form of a slotted or perforated metal cage or a covering of porous material around the exit of an air line. The velocity of the jet is reduced by these devices by making the path of jet to the ambient atmosphere more complicated.

The muffler designs most effective over a broad range of frequencies are generally the combination designs. Designs employing a combination of elements enable use of the advantages of each type. Since reactive silencers are usually most effective over a narrow range of frequencies, such a device will often be lined with acoustical materials to broaden the absorption characteristics as well as flow straighteners to reduce turbulence. Likewise, since a parallel baffle silencer is most effective at higher frequencies, it might be combined with a series of reactive elements tuned to lower frequencies to provide broad band attenuation. Commercial silencers are readily available in a wide variety of types and sizes. Although applications can vary, reactive silencers are considered best for reciprocating exhausts or other pulsing gas flows; dissipative silencers are useful in large air handling ducts and flues; and dispersive silencers find most use in high speed, high pressure systems.

The pressure drop through a silencer can often be a critical factor in the selection process. All silencers create a line pressure drop to some degree. Care must be taken to choose a unit which will not materially affect the performance of the system it is attached to. Many manufacturers produce silencers with standard, medium, and low pressure drop characteristics. Also several silencers may often be installed in parallel to reduce pressure drop while retaining silencing performance. Dispersive-type silencers tend to introduce the most extreme pressure drop while straight-through dissipative units cause little pressure drop.

The performance of many silencers is proportional to the gas flow rate through them and to the size of the piping in the system. A thorough understanding of the operational characteristics of the problem system is necessary before a wise choice of silencer can be made. Most important is knowledge of the frequency spectrum of the noise. The goal is to choose a silencer whose attenuation curve most nearly matches the spectrum of the noise source while meeting other design parameters such as pressure drop, construction adequate for the operating climate, mountability, and cost. 


\section{VIBRATION}

An understanding of mechanical vibration is essential to noise control since all sound begins as a vibration of something. Noise radiating from vibrating machines can reach excessive levels, especially if the machine has large, thin panels. A more common problem is the coupling of vibration to structural elements of the building such as floors, walls, and piping. This kind of vibration problem can be effectively reduced by the proper use of isolation or damping treatment. While the emphasis of this document is on noise control through modification of the sound path, a short discussion of basic vibration control will aid in a better understanding of noise control modifications to the source.

The simplest vibrating system is the undamped single degree of freedom system. In its most elementary form, it consists of a mass which is displaced and a spring which restores the displacement, such as a vibrating machine on a single isolator mount. The term single degree of freedom indicates that the system can only move along one dimension, i.e., up and down. While consideration of such a simple system moves us quite some distance from real world vibrating systems, the basic principles behind its behavior also govern the much more complicated systems normally encountered.

When the system is given an initial motion, it will vibrate at its natural frequency, that frequency which causes the change of the kinetic energy of mass into potential energy in the spring at the most efficient rate. The natural frequency is strictly a function of the mass and stiffness of the system. Also a function of mass and stiffness is the static deflection, the amount the spring deforms when the mass is applied. The natural frequency may most easily be predicted by the relationship

$$
\mathrm{f}_{\mathrm{n}}=\frac{3.13}{\sqrt{\mathrm{d}}} \mathrm{Hz}
$$

where $\mathrm{d}=$ static deflection in inches, or

$$
\mathrm{f}_{\mathrm{n}}=\frac{4.98}{\sqrt{\mathrm{d}}} \mathrm{Hz}
$$

where $\mathrm{d}=$ static deflection in centimeters.

Figure 35 shows a chart of natural frequency versus static deflection. When the system is excited by a time-varying force (as in an out-of-balance machine), it will vibrate at the frequency of the force.

The effectiveness of the isolation provided by the spring can be characterized 
by the transmissibility (TR); the ratio of the force transmitted through the spring to the exciting force due to the mass. The transmissibility of a simple spring-mass system is given theoretically by

$$
T R=\frac{1}{\left(f / f_{n}\right)^{2}-1}
$$

where $\mathrm{f}=$ forcing frequency

$\mathrm{f}_{\mathrm{n}}=$ natural frequency

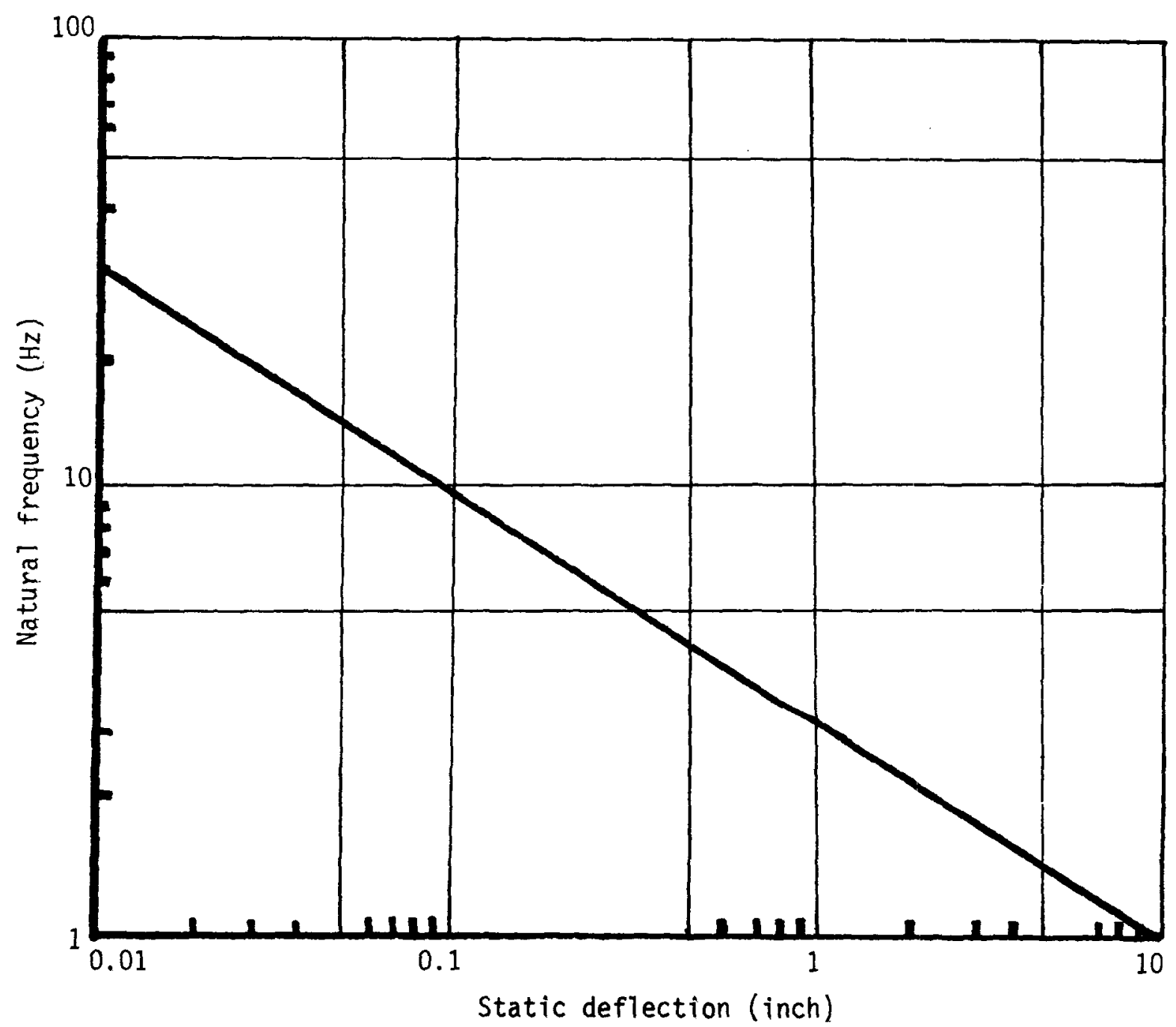

Figure 35. Natural frequency of a single degree of freedom vibrating system as a function of static deflection, 
This relationship is illustrated by the solid curve in Figure 36 . Note that the curve goes, theoretically at least, to infinity when the forcing frequency is equal to the natural frequency of the system. This indicates that the transmitted force becomes infinite at this point. In actual use, the presence of a property called damping limits the response of the natural frequency, but it is still an operating frequency to be avoided.

Damping is an element of vibrating systems analogous to absorption in noise control - it dissipates the tnergy of the system. All materials have some amount of internal damping, and specific damping elements may be added to a vibrating system. Damping produces the broken lines in Figure 36, lowering the response at resonance.

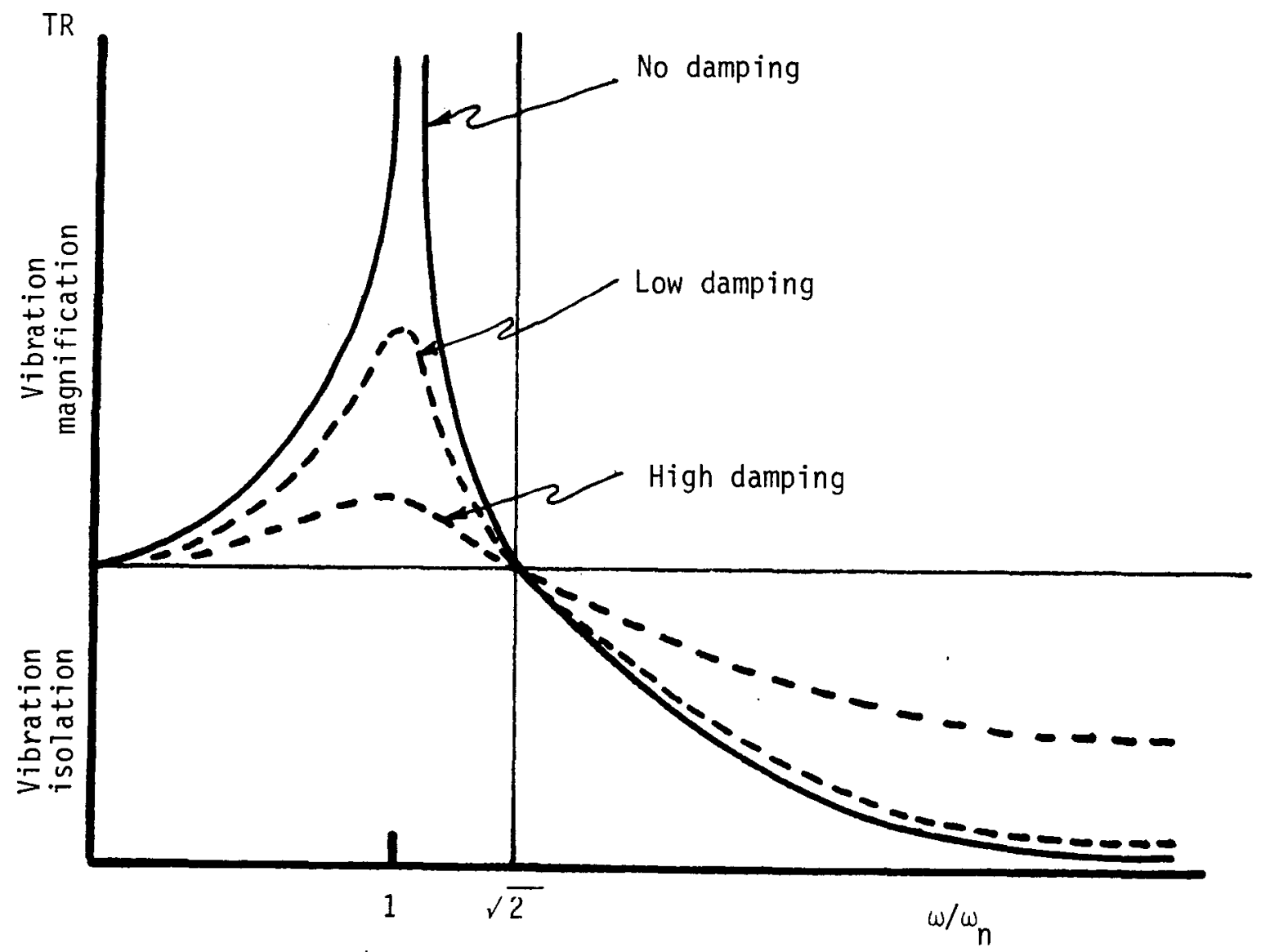

Figure 36. Response of a single degree of freedom vibration system with various damping factors.

From the definition of transmissibility, it is apparent that when TR is greater than one, the forces transmitted will be magnified. A glance at Figure 36 will show that no isolation is possible unless the ratio of forcing frequency to natural frequency is greater than the square root of two. Consequently, 
the basic approach to vibration isolation is to lower the natural frequency of the system as much as possible. The lower the natural frequency is relative to the forcing frequency, the more isolation is theoretically realizable. The natural frequency is lowered by increasing the static deflection, i.e., by making the springs softer or by increasing the mass, or both.

It is interesting to note from Figure 36 that the addition of damping to a system actually decreases the isolation at a given frequency ratio. Damping tends to stiffen the system and allow easier transmission of forces. In a vibration isolation scheme, damping is primarily useful in smoothing out the peak at resonance. Since an isolated machine operates above its natural frequency, it must pass through resonance as it is turned on or off. The presence of damping in the isolators prevents excessive vibration levels at this point.

A more common use of damping is on vibrating machines or structures which have large thin panels. These panels can shake like a drumhead, radiating considerable acoustic energy. Viscoelastic materials with high internal damping may be applied to panels to substantially reduce the vibration levels and hence reduce the radiated noise. The damping properties of materials may be characterized in many ways. Two of the more common are the material loss factor $(n)$ and the decay rate.

The loss factor is a dimensionless ratio of the amount of energy lost in each vibratory cycle to total energy stored in the material. It may be considered analogous to the absorption coefficient of acoustical materials. The loss factor generally varies with both frequency and temperature, and can range from $1 \times 10^{-4}$ in a material such as steel, with poor damping, to as high as 0.5 in especially formulated viscoelastic materials.

The decay rate is analogous to a reverberation time measurement. The damping material is applied to a loosely supported steel plate. The plate is made to vibrate by a magnetic exciter and the vibration level is monitored by a microphone in the near field. When the excitation is removed, the damping rate is measured in decibels per second. The more effective damping materials cause the vibration to decay at a faster rate.

\section{VIBRATION ISOLATORS}

Anything which has resiliency may be used for vibration isolation. Steel springs are perhaps most common, especially for large heavy machinery. Rubber and other elastomeric materials with metal support housings are commercially available in a wide range of models and applications. Care must be taken that the deflection of the vibrating source on its isolators does not become so great that the stability of the source is affected. For small sources or less serious vibrations where small static deflections are indicated, pads of flexible material such as neoprene, cork, felt, etc., which fit under the entire base of the source present the most economical solutions. When large deflections are needed, pneumatic mounts resembling innertubes are available which lower the natural frequency without requiring excessive deflection.

In piping and ducting in which there is some fluid flowing, vibrations from the pump, blower, or fan may transmit far from the source. It is recommended 
that flexible pipe connections be inserted every so of ten in the pipe to prevent the passage of the pipe wall vibration to the next section of pipe. Prevention of such vibration paths, or short circuits, can be very helpful in reducing the amount of attenuation required in the succeeding section of piping.

Piping connected to vibrating machinery such as a compressor should be isolated by flexible couplings, or isolation hangers as shown in Figure 37 . The use of additional mass to further reduce vibrations is also shown. The compressor itself is mounted on vibration isolators. Where this is insufficient, the floor itself should be isolated from adjacent building structures as shown in Figure 38. Other isolation may also be used for offices adjacent to production areas.

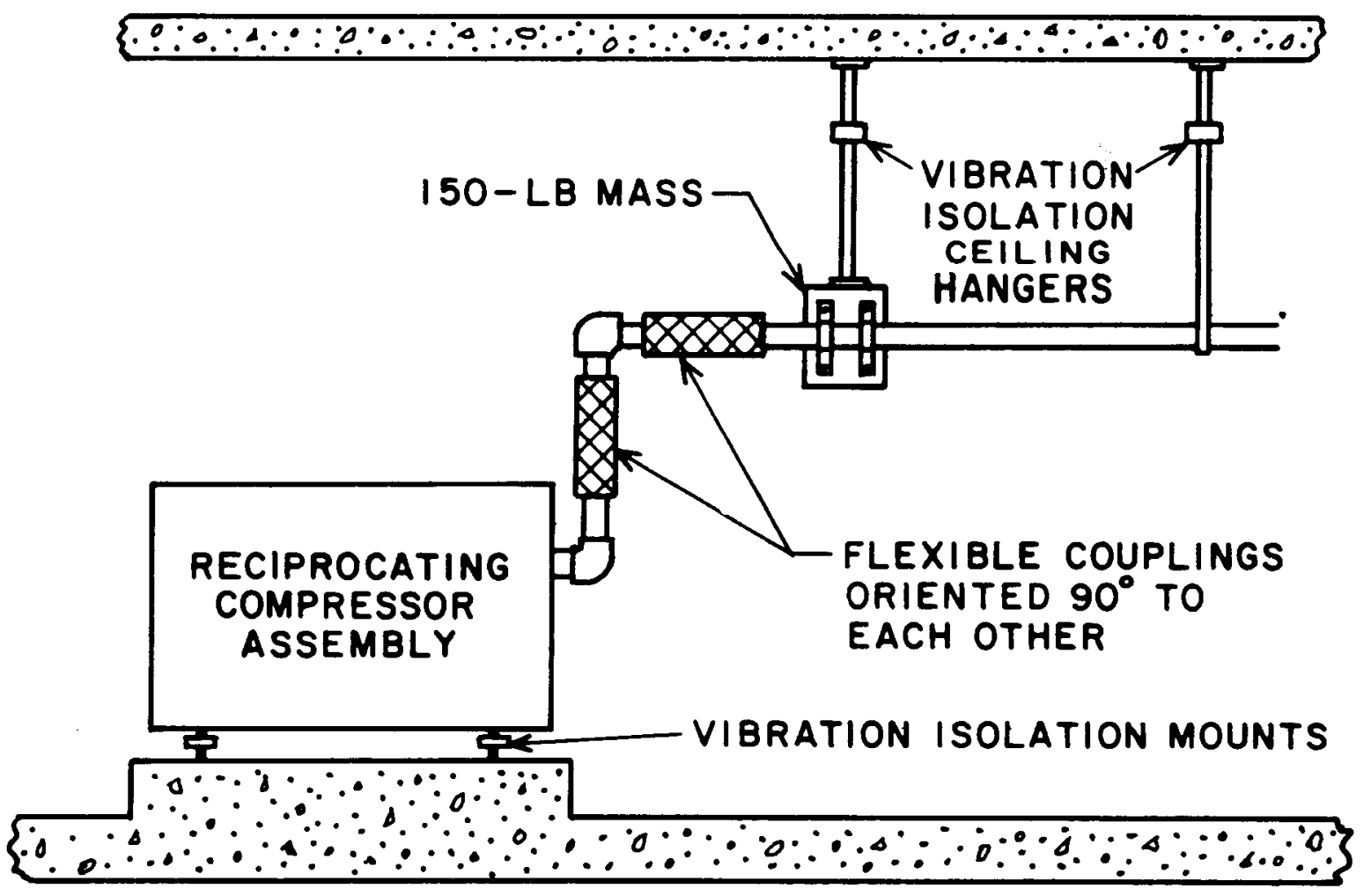

Figure 37. Vibration isolation of compressor piping 


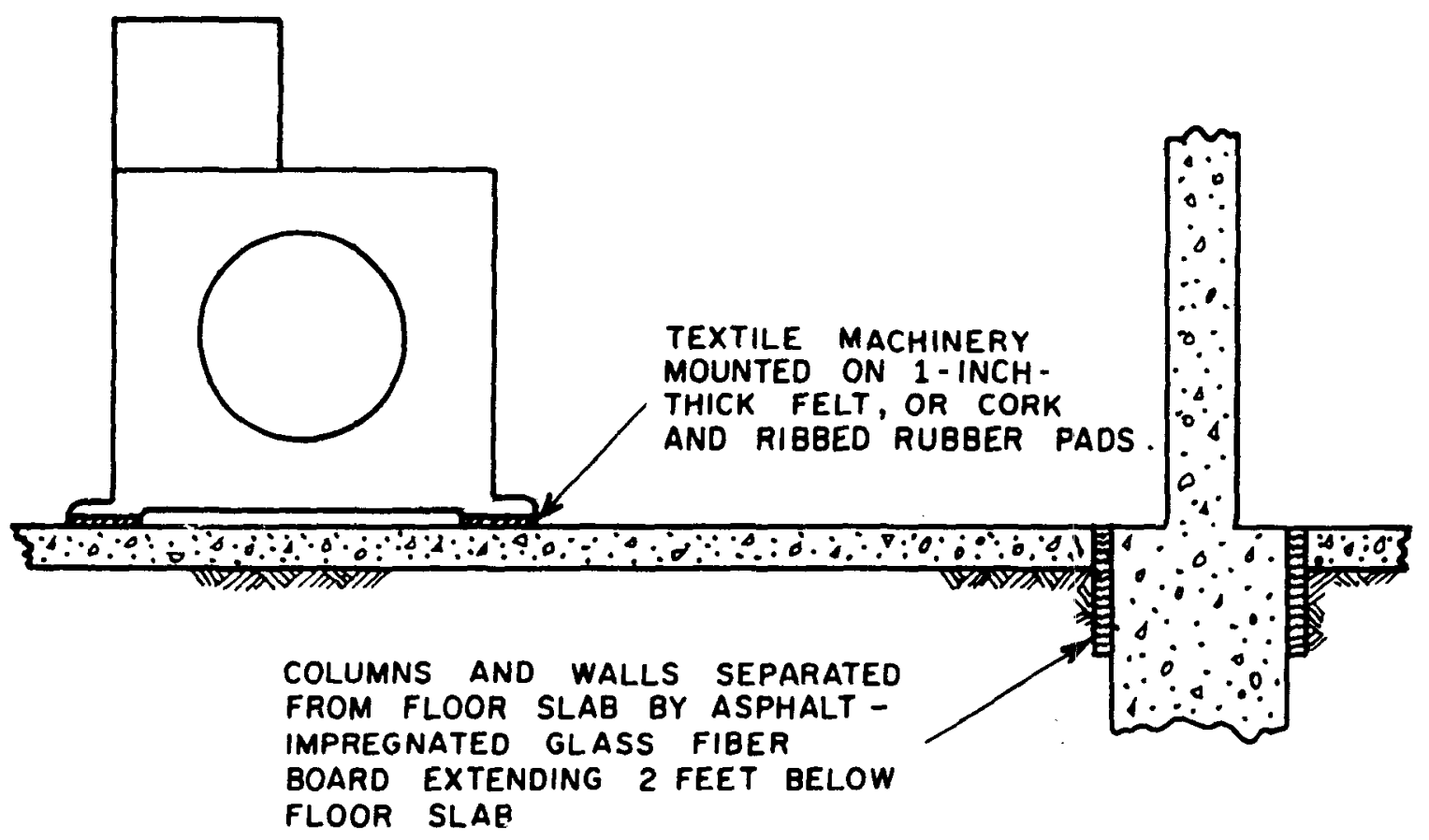

Figure 38. Vibration break in building structure to reduce transmission of vibrations.

\section{VIBRATION DAMPING}

The application of damping material to large panels can substantially reduce vibration-induced radiated noise. Polymer plastic materials are widely used today, although the older asphalt-based mastic materials are also common. The materials are typically available either as sheets which may be applied to panels with adhesive (some have adhesive backing) or as compound intended for trowel or spray application. The thicknesses required are usually about $1.5240 \mathrm{~mm}(0.0625 \mathrm{inch})$ and rarely over $3.048 \mathrm{~mm}(0.125 \mathrm{inch})$, It is rarely necessary to cover the entire surface of a panel with damping material. Usually, a few strategically placed sheets on a panel will reduce the vibration levels sufficiently. The proper location of the sheets may be determined by trial-and-error or by extensive modal analysis. Modal analysis, the determination of the vibration geometry of a unit, is a complicated procedure best left to experts. Since the viscoelastic materials commonly appearing in dampers may change their characteristics radically at different frequencies and temperatures, it is essential to obtain knowledge of the frequency and temperature conditions associated with a specific problem before choosing a damping material. The choice boils down to selecting the material which provides the maximum loss factor or decay rate at the frequency and temperature of interest. The predominant vibration frequency of a panel may best be measured with accelerometers feeding through an octave or one-third octave filter, but useful data can be obtained by placing a microphone or sound level meter near to the surface of the panel while it is vibrating. 
Constrained-layer damping materials can be very useful. These are typically sandwich panels consisting of a layer of damping material between two sheets of metal. Constraining the damping material in this manner places different and more efficient strain patterns in the material than simply affixing it to the outside of panel. These constructions form and work much like normal sheet metal, and may be considered as replacements for more common sheet material in particularly severe problems. Alternately, an existing panel may be made into a constrained-layer type by applying a layer of damping compound and adhering or bolting an outer layer of sheet metal over it. 
BIBLIOGRAPHY

BOOKS ON ACOUSTICS AND NOISE CONTROL

American Society of Heating, Refrigeration, and Air Conditioning Engineers (ASHRAE). Guide and Data Book, Systems Chapter 35, Sound and Vibration (1973)

Beranek, L. L. Noise and Vibration Contro1 McGraw-Hil1, New York (1971)

Beranek, L. L. Noise Reduction McGraw-Hill, New York (1960)

Beranek, L. L. Acoustics McGraw-Hill, New York (1957)

Beranek, L. L. Acoustic Measurements McGraw-Hil1, New York (1949)

Berendt, R. D. et a1. Quieting: A Practical Guide to Noise Control National Bureau of Standards, Washington, DC (1976)

Berendt, R. D., Winzer, G. E. and Burroughs, C. B. A Guide to Airborne, Impact, and Structure-Borne Noise Control in Multifamily Housing prepared by National Bureau of Standards for Federal Housing Administration, U.S. Govt. Printing Office, Washington, DC (1967)

Berendt, R. D. and Winzer, G. E. Sound Insulation of Wall, Floor, and Door Constructions National Bureau of Standards Monograph 77 (Nov 1964)

Bolt, R. H., Lukasik, S. J., Nolle, A. W. and Frost, A. D. Handbook of Acoustic Noise Control WADC Technical Report 52-204 Vo1. 1. USAF Wright Air Development Center, OH (Dec 1952)

Bolt, R. H., Lukasik, S. J., Nolle, A. W. and Frost, A. D. Handbook of Acoustic Noise Control WADC Technical Report 52-204 Vol. 1, Supplement 1. USAF Wright Air Development Center, OH (1955)

Broch, J. T. The Application of the Brüel and Kjaer Measuring Systems to Acoustic Noise Measurements Brüel and Kjaer Instruments (Jan 1971)

Bruel, P. V. Sound Insulation and Room Acoustics Chapman and Hall Ltd, London (1951)

Cheremisinoff, P. N. and Cheremisinoff, P. Industrial Noise Control Handbook Air Arbor Science, Ann Arbor, MI (1977)

Close, P. D. Sound Control and Thermal Insulation of Buildings Reinhold Publishing Corp, New York (1966)

Cremer, L., Heck1, M. and Ungar, E. E. Structure-Borne Sound Springer-Verlag, New York (1973)

Crocker, M. J. (ed.) Reduction of Machinery Noise (revised edition) Purdue Univ. West Lafayette, IN (1976)

Crocker, M. J. and Price, A. J. Noise and Noise Control CRC Press, Cleveland, $\mathrm{OH}$ (1975) 
Egan. Concepts in Architectural Acoustics McGraw-Hill, New York

Faulkner, L. L. (ed.) Handbook of Industrial Noise Control Industrial Press, New York (1976)

Grundy, N. A. et al. Practical Building Acoustics Halstead Press, New York (1976)

Harris, C. M. (ed.) Dictionary of Architecture and Construction McGraw-Hill, New York (1975)

Harris, C. M. Handbook on Noise Control McGraw-Hill, New York (1957)

Harris, R. W. and Ledwidge, T. J. Introduction to Noise Analysis Academic

Press, New York (1974)

Hunter. Acoustics Prentice-Hall, Englewood Cliffs, NJ (1962)

Industrial Noise Control Manual, DHEW Publication (NIOSH) 75-183, U.S. Government Printing Office

Industrial Noise Public Health Service Bulletin 1572, U.S. Government Printing Office (1967)

Ingerslev. Acoustics in Modern Building Practice Architectural Press, London (1952)

Kinsey, B. Y. Environmental Technologies in Architecture Prentice-Ha11 (1965)

Kinsler, L. E. and Frey, A. R. Fundamentals of Acoustics (second edition) Wiley (1962)

Knudsen, V. O. Architectural Acoustics Wiley, London (1947)

Kryter, K. D. Effects of Noise on Man Academic Press, New York (1970)

Kuttruff, H. Room Acoustics Halstead Press, New York (1974)

Meyer, H. B. and Goodfriend, L. S. Acoustics for the Architect Reinhold, New York (1957)

Miller, R. K. Handbook of Industrial Noise Management Fairmont Press, Atlanta, GA (1976)

NBS Sound Section Staff. Sound Insulation of Wall and Floor Constructions Building Materials and Structures Report 144, National Bureau of Standards (Feb 1955)

Northwood, T. D. (ed.) Architectural Acoustics Dowden, Hutchinson, and Ross, Stroudsburg, PA (1977)

Olsen, H. F. Acoustical Engineering D. Van Nostrand, New Jersey (1957)

Parkin, P. H. and Humphreys, H. R. Acoustics, Noise and Buildings F. A. Praeger Publishers, New York (1958)

Parkin, P. H., Purkis, H. J. and Scholes, W. E. Field Measurements of Sound Insulation Between Dwellings Her Majesty's Stationery Office, London (1960)

Peterson, A.P.G. and Gross, E. E. Jr. Handbook of Noise Measurement General Radio Company (1972)

Petrusewicz, S. A. and Longmore, D. K. (ed.) Noise and Vibration Control for Industrialists American Elsevier, New York (1974) 
Purkis, H. J. Building Physics: Acoustics Pergammon Press (1966)

Putnam, A. A. Combustion Driven Oscillations in Industry American Elsevier

Publishing, New York (1971)

Rettinger, M. Acoustics, Room Design and Noise Control Chemical Pub1ishing Company, New York (1968)

Richardson, E. G. (ed.) Technical Aspects of Sound Vol. 1, Elsevier Publishing Company, New York (1953)

Sabine, H. J. et al. Acoustical and Thermal Performance of Exterior Residential Walls and Windows National Bureau of Standards, Building Science Series

77, Washington, DC (1975)

Sabine, H. J. Less Noise, Better Hearing The Celotex Corporation

Schaudinischky, L. H. Sound, Man, and Building Applied Science, Barking, England (1976)

Smith. Acoustics E1sevier, Amsterdam, New York

Stevens and Bates Acoustics and Vibrational Physics Edward Arnold Ltd, London (1966)

Thumann, A. and Miller, R. K. Secrets of Noise Contro1 Fairmont Press, Atlanta, GA (1974)

Webb, J. D. (ed.) Noise Control in Industry Halstead Press; New York (1976)

Woods, R. I. (ed.) Noise Control in Mechanical Services Halstead Press, New York (1977)

Yerges, L. F. Sound, Noise and Vibration Control Van Nostrand Reinhold, New York (1969)

PERIODICALS (MATERIALS)

Wood

Godshall, W. D. and Davis, J. H. "Acoustical Absorption Properties of WoodBase Panel Materials" Forest Products Journal 104, p 8 (1969)

Heebink, T. B. and Grantham, J. B. "Field/Laboratory STC Ratings of WoodFramed Partitions" S/V Sound and Vibration 5(10), pp 12-16 (Oct 1971)

Fabric

"Acoustical Drapery" J. Acoust. Soc. Amer. 47(4), pp 971-972 (1970)

Kingsbury, H. F. and Wallace, W. J. "Acoustic Absorption Characteristics of People" S/V Sound and Vibration 2(12), pp 15-16 (Dec 1968)

Lebedeva, I. A. and Nesterov, V. S. "Acoustical Parameters of a Lightweight Perforated Membrane" Soviet Physics-Acoustics 10(3), pp 269-275 (1964)

Fe1t

Tyzzer, F. G. and Hardy, H. C. "The Properties of Felt in the Reduction of Noise and Vibration" J.Acoust. Soc. Amer. 19(5), pp 872-877 (Sept 1947) 
Utley, W. A. et al. "The Use of Absorbent Material in Double-Leaf Wall

Constructions" J. Sound and Vib. 9(1), pp 90-96 (Jan 1969)

Foam

"Acoustical Foams for Sound Absorption Applications" S/V Sound and Vibration $11(7)$, pp 12-16 (July 1970)

"Effect of Surface Films on Acoustical Foam Performance" S/V Sound and Vibration 8(7), pp 24-29 (July 1974)

Gardinier, R. E., et al. "Acoustical Foams for Sound Absorption Applications" S/V Sound and Vibration 4 (7) pp 12-16 (JuIy 1970)

"S/V Observer; Noise Control in the F-111" S/V Sound and Vibration 2(8), p 4 (Aug 1968)

Concrete

Kihlman, T. "Sound Transmission in Building Structures of Concrete" J. Sound and Vib. 11(4), pp 435-455 (April 1970)

Ward, F. L. and Randall, K. E. "Investigation of Sound Isolation of Concrete Slab Floors" J. Sound and Vib. 3(2), pp 205-215 (March 1966)

Kohasi, Y. "Sound Absorption Characteristics of a Hollow Concrete Block With a Slotted Face" Report in the 6th Intl Congr on Acoustics, Tokyo, Vol. III Paper E-3-5 (1968)

Lead

Holub, R. "Controlling Punch Press Noise with Lead/Vinyl Curtains" NOISEXPO, Nat1 Noise and Vibration Control Conf Proceedings, pp 58-66 (Apr 30-May 2, 1975)

"Lead-Viny1 Fabric Shuts out Noise" Materials in Design Engineering 64 (4), pp 27-29 (Oct 1966)

Martin, E. D. "Specifying Lead for Noise Control" Constr Specifier 28(7), pp 34-41 (Ju1y 1975)

Meier, A. V. "Application of Lead for Sound Insulating Partitions" S/V Sound and Vibration 1(5), pp 14-19 (May 1967)

Meteer, C. L. "Application of Lead-Vinyl Noise Barriers in Transportation Equipment" SAE Paper 720222, pp 1-7

Ostergaard, P. B., Cardinell, R. L. and Goodfriend, L. S. "Transmission Loss of Leaded Building Materials" J.Acoust. Soc. Amer. 35(6), pp 837-843 (June 1963)

Powe11, M. "Uses of Lead Sheet in Noise Reduction" Noise Control Vib Insul 6 (11), pp 357-361 (Nov 1975)

Schmidt, B. R. "Lead Sheet Sound Barrier: A Valuable in Noise Control" Constr Specifier 30(10), pp 44-48, 50-53 (Oct 1977)

Schmidt, B. R. "Use Lead to Block Noise" Hydrocarbon Process 55(10), pp 112-115 (Oct 1976) 
Metal Fiber

Cimerol, J. J., Erickson, A. R. and Fisher, J. I. Investigation of the Properties of Fiber Metal Acoustical Materials, Report NASA-CR-6643, $177 \mathrm{pp} \mathrm{(Sept}$ 1968)

Karplus, H. B. et al. "Noise and Vibration Control with Fiber Metallurgy" J. Soc. Japan 10 (5) pp 209-217 (Nov 1964)

Composites

Braunisch, Von H. "Vibration Damping by Three-Layered Sandwich Systems" Acustica 22(5), pp 136-144 (1969)

Burns, J. J. "The Use of Asphalt-Mastics for Acoustical Damping" S/V Sound and Vibration 6(10), pp 4,6,8 (Oct 1972)

Chen, Y. N. "Influence of the Space in the Acoustic Sandwich Sheet 'Rockwool, Foil, Perforated Plate' on the Sound Absorption Capacity" 7th Intl. Congr. on Acoustics, Budapest, p 241 (1971)

Cook, R. L. and Lovejoy, R. E. "Acoustic Properties of Epoxy-Fiberglass and Epoxy-Fiberglass-Pb Plates in the Frequency Range 100-700 KHz" JASA 57, pp 1554-1558 (1975)

Emme, J. H. "Composite Materials for Noise and Vibration Control" S/V Sound and Vibration 4(7), pp 17-21 (July 1970)

Ganesan, N. "Composites for Noise Control" SAE preprint 730339, (April 3-6, 1973)

Higgs, R. W., Eriksson, L. J. "Acoustic Attenuation in Composite Materials" J. Acoust. Soc. Amer. 50(1), pp 306-309 (July 1971)

Miska, K. H. "Consider Composites to Cut and Control Cacophony" Material Engr 82 (3), pp 82-84 (Sept 1975)

Profit, J. "Composites for Noise Control Sound-Deadened Steel." Sheet Metal Indus 51 (1), pp 44-50 (Jan 1974)

Toyoda, H. and Hayek, S. "Attenuation of Acoustic Waves by Composite Plates" J. Sound and Vib. pp 103-133 (Jan 1971)

General

Arctander, C. "Sound Absorptive Materials for Aircraft Noise Control" Sound and Vibration 5(8), pp 12-16 (Aug 1971)

Borisov, L. A. "Experimental Investigation of the Effectiveness of SoundAbsorbent Coatings" Soviet Phys Acoust 11(4), pp 366-372 (1966)

Brown, S. M. "Development and Testing of Vibration-Damping Materials" S/V Sound and Vibration 11(4), pp 28-33 (April 1977)

Callaway, D. B. and Ramer, L. G. "The Use of Perforated Facings in Designing Low Frequency Resonant Absorbers" J. Acoust. Soc. Amer. 24(3), pp 309-312

(May 1952) 
Cheremisinoff, P. N. "Noise Control Materials" Pollution Engr 7 (11), pp 22-28 (Nov 1975)

Duggar, B. C. "Special Sound Absorptive Materials in Noise Control" Amer. Industrial Hygiene Assn. J. 20, pp 447-452 (Dec 1959)

Dunn, R. L. (ed.) "Specifications Chart for Noise Control Products" Plant Engr (Barrington, Ill.) 26 (25), pp 82-89 (Dec 14, 1972)

"Grass Makes a Good Sound Absorber" S/V Sound and Vibration 3(5), p 10 (May 1969)

"How to Select Acoustical Materials" Acoustical Materials Assn. 7, pp 187-188 (July 1965)

Hyer, W. G. "Acoustic Materials" RD Research Development 28(2), pp 74-76, 78-79 (Feb 1977)

Mangiante, G. A. "Active Sound Absorption" JASA 61(6), pp 1516-1523 (June 1977)

Morris, A. J. "Flexible Noise Control Materials and Fire Safety" NOISEXPO, Natl Noise and Vib Control Conf Proceedings, pp 49-53 (April 30-May 2, 1975)

Myles, M. M., Ver, I. L. and Henderson, H. R. "Effects of Outdoor Exposure on Sound Absorption Materials" S/V Sound Vib 11(6), pp 24-27 (June 1977)

Pancholy, M. and Bindal, V. N. "Transmission Loss Studies in Granular Materials" Acustica 17(1), pp 51-55 (1966)

Purcell, W. E. "Materials for Noise and Vibration Control" S/V Sound and Vibration 11(7), pp 4-29 (July 1977)

Purcell, W. E. "Materials for Noise and Vibration Control" S/V Sound and Vibration 10(7), pp 6-33 (July 1976)

Scott, H. L. "The Performance of Sound Absorbers in a Radial Diffuser Configuration" J. Sound and Vib. 19(4), pp 445-451 (Dec 1971)

Stahovic, S. J. and Stone, E. W. "Use of Absorber/Barrier Materials for Noise Control Enclosures" S/V Sound and Vibration 10(9), pp 20-23 (Sept 1976)

Wakefield, B. D. "Materials That Build a Box Around Noise" Iron Age 214(3), pp 53-54, 58-59 (July 15, 1974)

Wald, B. "Right Materials for Wrong Noises" Design Engr 19(6), pp 40-41 (June 1973)

Wald, B. "Choosing the Right Material for Noise Control" ASME Paper 73-DE-40, 4 pp (April 9-12, 1973)

Waller, R. A. "The Performance and Economics of Noise and Vibration Reducing Materials in the Construction Industry" J. Sound and Vib. 8 (2), pp 177-185 (Sept 1968)

Wirt, L. S. "Sound-Absorptive Materials to Meet Special Requirements" JASA 57, pp 1.26-143 (1975)

Yerges, L. F. "The Use of Acoustical Absorbents in Industrial Noise Control"

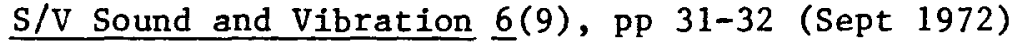




\section{PERIODICALS (SYSTEMS)}

Houses and Buildings

"A Pitch for the Noiseless Home" Business Week, pp 87-88 (May 1971)

Bender, E. K. "Noise Source Impact in Construction/Buildings/Homes" S/V Sound and Vibration 7(5), pp 33-41 (May 1973)

Bishop, D. E. "Reduction of Aircraft Noise Measured in Several Schools, Motel, and Residential Rooms" J. Acoust. Soc. Amer. 39(5), pp 907-913 (1966)

Eijk, J.V.D. "The New Dutch Code on Noise Control and Sound Insulation in Dwelllings and Its Background" J. Sound and Vib. 3(1), pp 7-19 (Jan 1966)

"Engineering Outline 113; Sound Insulation in Buildings" Anon. Engineering 205(5314), pp 307-310 (1968)

Fricke, F. R. "Protection of Buildings Against Traffice Noise" Noise Control Eng $\underline{8}(1)$, pp 27-32 (Jan-Feb 1977)

Hardy, A. D. and Lewis, P. T. "Sound Insulation Standards for Buildings Adjacent to Urban Motorways" J. Sound and Vib. 15(1), pp 53-59 (Mar 1971)

Ingemansson, S.P.N. "The Calculation of Sound Insulation in a Building" Reports of the 6th Int1 Congr on Acoustics, Vol. III, Paper E-4-7, Tokyo (1968)

Kihlman, T. "Transmission of Structure-Borne Sound in Buildings" Natl Swedish Inst of Building Research, Box 27163, Stockholm 27, Report 9-1967

Kumar, S. "Analysis of Structural-Vibration Related Noise" S/V Sound and Vibration 11(4), pp 22-26 (April 1977)

Pretlove, A. J. "The Transmission of Outdoor Noises into Buildings" Environmental Engineers 43, pp 7-10 (March 1970)

Quirt, J. D. "Insulating Buildings from Aircraft Noise" JASA $\underline{63}(3)$, p 823 (June 1978)

Sato, H. "On the Outdoor Noise Insulation of Dwellings Particularly on the Results of Field Measurements" Reports of the 6th Intl Congr on Acoustics, Vol. IV, Paper F-5-16, Tokyo (1968)

Siekman, W., Jr. "Architectural Acoustics (A Problem of Measurement)" Frontier 3, pp 16-21 (Autumn 1966)

Walker, K. W. "Estimating Indoor Sound Levels Produced by Outdoor Sources" S/V Sound and Vibration $9(6)$, pp 20-22 (June 1975)

Waller, R. A. "Building on Springs" $S / V$ Sound and Vibration $9(7)$, pp 20-26 (July 1975)

Young, J. R. "Attenuation of Aircraft Noise by Wood-Sided and Brick-Veneered Frame Houses" Stanford Research Inst., NASA CR-1637 
Rooms

"Acoustical Drapery" J. Acoust. Soc. Amer. 47(4), pp 971-972 (1970)

Banks, D. "Noise Reduction by the Use of Suspended Noise Absorbers and Acoustical Treatment" Noise Control Vibration Insul 6 (10), pp 305-308 (Oct 1975)

Barron, M. "Growth and Decay of Sound Intensity in Room According to Some Formulae of Geometric Acoustics Theory" J. Sound and Vib. 27(2), pp 183-196 (March 1973)

Beranek, L. L. "Acoustics and the Concert Ha11" JASA 57, pp 1258-1262 (1975)

Berman, J. M. "Behavior of Sound in a Bounded Space" JASA 57, pp 1275-1291 (1975)

Benasutti, R. "Noise Control in School Auditoriums, Gymnasiums and Multipurpose Rooms" JASA 57, p 517 (A) (1975)

Bhandari, P. S., Balachandran, C. G. and Krishnan, P. V. "Functiona1 Sound Absorbers and Noise Reduction in a Cafeteria" Indian J. Technol. 3(11), pp 345-350 (1965)

Eijk, J. van Den "The New Dutch Code on Noise Control and Sound Insulation in Dwellings and its Background" J. Sound and Vib. 3(1), pp 7-19 (Jan 1966)

Harris, C. M. "Acoustical Design of the John F. Kennedy Center for the Performing Arts" J. Acoust. Soc. Amer. 51(4), pp 1113-1126 (April 1972)

Joyce, W. B. "Sabine's Reverberation Time and Ergodic Auditoriums" JASA 58, pp 643-655 (1975)

Kihlman, T. "Sound Radiation into a Rectangular Room. Applications to Airborne Sound Transmission in Buildings" Acustica 18(1), pp 11-20 (1967)

Killery, P. "Acoustic Screens for Office Landscaping" Noise Control Vibration Insul 6(12), pp 370-371 (1975)

Plenge, G. Lehmann, P., Wehschureck, R. and Wilkens, H. "New Methods in Architectural Investigations to Evaluate the Acoustic Qualities of Concert Halls" JASA 57, pp 1292-1299 (1975)

Simpson, M. A. and Bishop, D. E. "Measurement of Classroom Noise Environments" JASA 57, pp 514 (A) (1975)

Warnock, A.C.C. "Studies of Acoustical Parameters in Open Plan Offices" JASA $63(3)$, p 832 (June 1978)

Yerges, L. F. "Open-P1an School Revisited" Noise Control Engr 6 (1), pp 22-29 (Jan-Feb 1976)

Walls and Partitions

Banuls-Terol, V. "Composed Airborne Sound Isolation of Partitions under Suspended Ceilings" Reports of the 6th Int1 Congr on Acoustics, Tokyo, Vol. III, Paper E-4-5 (1968)

Brown, S. U., Niedzielski, J. and Spalding, G. R. "Effect of Sound Absorptic Facings on Partition Airborne Sound Transmission Loss" JASA 63(6), p 1851

(June 1978) 
Donato, R. J. "Sound Transmission Through a Double-Leaf Wall" J. Acous. Soc. Amer. 51(3), pp 807-815 (March 1972)

Ellwood, E. "The Anatomy of a Wall" S/V Sound and Vibration $6(6)$, pp 14-18 (June 1972)

Fader, B. "Mass-Air Mass Resonance Monograph" S/V Sound and Vibration 4(8), p 25 (Aug 1970)

Flynn, D. R. and Pallet, D. S. "Simplified Methods for Calculating the Transmission Loss of Two-Element Partitions" JASA 58, pp 1341-1342 (1975)

Harris, C. H. "Reduction of Noise by Walls or Fences" Handbook of Noise Contro1, p 7, New York (1975)

Heebink, T. B. "Sound Reduction of Windows in Exterior Wood-Framed Walls" S/V Sound and Vibration 9(6), pp 14-18 (June 1975)

Heebink, T. B. and Grantham, J. B. "Field/Laboratory STC Ratings of WoodFramed Partitions" S/V Sound and Vibration 5(10), pp 12-16 (Oct 1971)

Hudson, R. R. and Mulholland, K. A. "The Measurement of High Transmission Loss (The Brick Wall Experiment)" Acustica 24(5), pp 251-261 (May 1971)

Ingemanson, S. "Sound Insulation of Light Walls" 5th Int1 Congr on Acoustics Proceedings, Liege (Sept 1965)

Jones, R. E. "How to Accurately Predict the Sound Insulation of Partitions" S/V Sound and Vibration 10(6), pp 14-25 (June 1976)

Jones, R. E. "Effects of Flanking and Test Environment on Lab-Field Correlations of Airborne Sound Insulation" JASA 57, pP 1138-1149 (1975)

Junger, M. C. "Helmholtz Resonators in Load-Bearing Walls" Noise Control Engr 4(1), pp 17-25 (Jan-Feb 1975)

Kihlman, T. "Sound Transmission in Building Structures of Concrete" J. Sound and Vib. 11(4), pp 435-445 (Apri1 1970)

Koval, L. R. "Effect of Airflow Panel Curvature, and Internal Pressurization on Field Incidence Transmission Loss" JASA 59, pp 1379-1385 (1976)

Lindah1, R. "The Use of Insulation Board in Wa11s of Gypsum and Wood Studs to Improve Airborne Sound Insulation" 5th Int 1 Congr on Acoustics Proceedings, Liege (Sept 1965)

Lord, P. "Improved Sound Insulation of Double Leaf Partitions Using Absorbent Cavity Linings" Insulation 10(3), pp 122-123 (1966)

Nilsson, A. C. "Reduction Index and Boundary Conditions for a Wall Between Two Rectangular Rooms. Part I: Theoretical Results" Acustica 26(1), pp 1-8 (Jan 1972)

Nilsson, A. C. "Reduction Index and Boundary Conditions for a Wall Between Two Rectangular Rooms. Part II: Experimental Results" Acustica 26(1), pp 19-23 (1972)

Rettinger, M. "Acoustic, Room Design and Noise Control" New York, p 386 (1968)

Siekman, W. "STC's and Room Dividers" Construction Specifier pp 51-54 (Dec 1971)

Tseo, G. G. "Estimating the Noise Reduction of Wall Structures of Enclosures" J. Acoust. Soc. Amer. 52(6), Part 1, pp 1573-1578 (Dec 1972) 
Utley, W. A., Cummings, A. and Parbrook, H. D. "The Use of Absorbent Materia1 in Double-Leaf Wall Constructions" J. Sound and Vib. 9(1), pp 90-96 (Jan 1969)

Velizhanina, K. A. et al. "Impedance Investigation of Sound Absorbing Systems in Oblique Sound Incidence" Soviet Physics-Acoustics 17(2), pp 193-197 (Oct/ Dec 1971)

Von Meier, A. "Sound Insulation of Stiff Lightweight Partitions" Reports of the 6th Intl Congr on Acoustics, Tokyo, Vol. III, Paper E-4-4 (1968)

Zaborov, V. I. "Normalization of the Acoustic Reduction in Buildings" Soviet Physics-Acoustics 16(1), pp 43-45 (July/Sept 1970)

Panels

Alers, G. A., Thomson, R. B., Thomson, D. 0. and Tennison, M. A. "Dispersion of Flexural Elastic Waves in Honeycomb Sandwich Panels" JASA 57, pp 1119-1127 (1975)

Awaya, K. and Miyazaki, Y. "A New Theory on the Edge Effect of Sound Absorbing Panels" 7th Intl Congr on Acoustics Proceedings 4, Budapest, p 245 (1971)

Brilloin, J. "Sound Absorption by Structures with Perforated Panels" S/V Sound and Vibration 2(7), pp 6-22 (July 1968)

Dym, C. L., Ventres, C. S. and Lang, M. A. "Transmission of Sound Through Sandwich Panels: A Reconsideration" JASA 59, pp 364-367 (1976)

Fang, G. T. "Influence of Internal and Boundary Damping on Response of Panels to Random Excitations" Reports of the 6th Intl Congr of Acoustics, Tokyo, Vol. IV, Paper F-4-9 (1968)

Ford, R. D., Lord, P. and Walker, A. W. "Sound Transmission Through Sandwich Constructions" J. Sound and Vib. 5(1), pp 9-21 (Jan 1967)

"Functional Panels Control Noise" S/V Sound and Vibration 3(7), pp 4, 6 (July 1969)

Kuga, S. "On the Sound Transmission Loss of Sandwich Panels" Reports of the 6 th Int1 Congr on Acoustics, Tokyo, Vol. III, Paper E-4-6 (1968)

Lang, M. A. and Dym, C. L. "Optimal Acoustic Design of Sandwich Panels" JASA 57, pp 1481-1487 (1975)

Nordby, K. S. "Measurement and Evaluation of the Insertion Loss of Panels" Noise Control Engr 10(1), pp 22-32 (Jan-Feb 1978)

Floors

Allen, D. L. and Swallow, J. C. "Annoying Floor Vibrations-Diagnosis and Therapy" S/V Sound and Vibration 9 (3), pp 12-17 (March 1975)

Budds, D. E. "Engineered Floating Floor for Airborne and Impact Noise Control" Insulation (Lond) 18(2), pp 17-18 (Mar-Apr 1974)

Choudhury, N.K.D. and Bhandari, P. S. "Impact Noise Rating of Resilient Floors" Acustica 26 (3), pp 135-140 (March 1972)

Choudhury, N.K.D. "Impact Noise Transmission Through Floors" Indian J. Technol. $\underline{6}(7)$, pp 213-216 (1968) 
Eijk, J.V.D. and Bitter, C. "Neighbour's Footsteps" 7 th Intl Congr on Acoustics, Budapest (1971)

Ford, E. "Floating Floor-A Versatile Noise Control Technique" Noise Control Vibration Reduction 5(4), pp 145-148 (June 1974)

Heebink, T. B. "Upgrading the Sound-Insulating Efficiency of Wood Joist Floor-Ceiling Systems" S/V Sound and Vibration 11(6), pp 16-18 (June 1977)

Lindblad, S. "Impact Sound Characteristics of Resilient Floor Coverings with Linear and Nonlinear Dissipative Compliance" 7th Intl Congr on Acoustics, Budapest (1971)

Nelson, F. C. "Subjective Rating of Building Floor Vibration" S/V Sound and Vibration 8(10), pp 34-37 (Oct 1974)

Northwood, T. D. and Clark, D. M. "Frequency Considerations in the Subjective Assessment of Sound Insulation" Reports of the 6th Intl Congr on Acoustics, Tokyo, Vo1. III, Paper E-3-8 (1968)

Svensson, J. "Impact Noise Reduction Predicted from Samples on Flooring Materials" 7th Intl Congr on Acoustics, Budapest, p 60 (1971)

Ungar, E. E. "Design of Floated Slabs to Avoid Stiffness Effect of Entrapped Air" Noise Control Engr 5(1), pp 12-16 (July-Aug 1975)

Ver, I. L. "Relation Between the Normalized Impact Sound Level and Sound Transmission Loss" J. Acoust. Soc. Amer. 50(6), pp 1414-1417 (Dec 1971)

Ver, I. L. "Impact Noise Isolation of Composite Floors" J. Acoust. Soc. Amer. 50(4), pp 1043-1050 (Oct 1971)

Ward, F. L. and Randadal1, K. E. "Investigation of the Sound Isolation of Concrete Slab Floors" J. Sound and Vib. 3(2), pp 205-215 (March 1966)

Wegscheid, E. L. and Smith, W. F. "Structure-Borne Noise of Concrete Floors on Grade" S/V Sound and Vibration 10(11), pp 30-36 (Nov 1976)

Zaborov, V. I. "On the Transmission of Impact Noise Through Single-Layer Floors" Akust. ZH 14(1), pp 127-128 (1968)

Zaborov, V. I. et al. "Reduction of Impact Noise by Flooring Materials" Soviet Physics-Acoustics 12(3), pp 263-265 (1967)

Ceilings

"Acoustical Ceilings" Constr. Spec. Inst. Monograph 09M531 (June 1970)

Matsui, M. et al. "Sound Absorption Characteristics on an Acoustic Ceramic Tile" Reports of the 6th Intl Congr on Acoustics, Tokyo, Vol. III, Paper E-3-7 (1968)

Windows

Yerges, L. F. "Windows, The Weak Link" S/V Sound and Vibration $\underline{5}(6)$, pp 19-21 (June 1971) 
Doors

Larsen, J. "Transmission Loss of Double Door Constructions" Reports of the 6th Int1 Congr on Acoustics, Tokyo, Vo1. III, Paper P-0-14 (1968)

Fences and Other Noise Barriers

Ayeor, D. E. and Marks, L. E. "Perception of Noise Transmitted Through Barriers" JASA 59, pp 397-400 (1976)

DeJons, R. and Stusnick, E. "Scale Model Studies of the Effects of Wind on Acoustic Barrier Performance" Noise Control Engr $\underline{6}$ (3), pp 101-109 (May-June 1976)

Fujiwara, K., Ando, Y. and Maekawa, Z. "Noise Contro1 by Barriers-2. Noise Reduction by an Absorptive Barrier" Applied Acoust 10(3), pp 167-179 (July 1977)

Harris, C. H. "Reduction of Noise by Walls or Fences" Handbook of Noise Control, New York (1957)

Jones, P. E. and Royle, P. "Use of Plasterboard and Wood Wool in Industrial Noise Control" Noise Control Vibration Insul 8(4), pp 117-119 (Apri1 1977)

Maekawa, Z. "Shielding Highway Noise" Noise Control Engr 9(1), pp 38-44 (Ju1y-Aug 1977)

Rettinger, M. "Fences and Other Noise Barriers", New York (1968)

Scholes, W. E., Salvidge, A. C. and Sargent, J. W. "Field Performance of a Noise Barrier" J. Sound and Vib. 16(4), pp 627-642 (June 1971)

Stahovic, S. J. and Stone, E. W. "Use of Absorber/Barrier Materials for Noise Control Enclosures" S/V Sound and Vibration 10(9), pp 20-23 (Sept 1976)

NOISE CONTROL

General Plant Noise

Barger, J. E. "Noise Path Diagnostics in Dispersive Structural Systems Using Crosscorrelation Analysis" Noise Control Eng 6(3), pp 122-129 (May-June 1976)

Bijl, L. A. "Noise Emission of Forced-Draft Refinery Furnaces" Noise Control Eng 5(3), pp 116-123 (Nov-Dec 1975)

Bonvallet, G. L. "Noise Sources in Modern Industry" Noise Contro1 1 (3), pp 30-33 (May 1955)

Bonvallet, G. I. "The Measurement of Industrial Noise" Amer. Indus. Hygiene Assoc. Quart., Technical Guide Number 5 (Sept 1952)

Buecher, J. P. and Thompson, E. P. "Noise Control Techniques for Existing Power Plants" IEEE Trans Power Appar Syst PAS-96(3), pp 1021-1026 (May-June 1977)

Burkhardt, T. H., Roley, D. G. and O'Brien, M. "Investigating Isolated Noise Sources in Canneries" ASAE Pao Annual Meeting 67th, Okla State Univ, Stillwater, (June 23-26 1974) and Winter Meeting, Chicago, IL (Dec 10-13 1974) Paper $74-6002,18 \mathrm{pp}$ 
Copley, L. G. "Engineering Approaches to Plant Noise Control" ASME Paper 73-DET-88 for Meeting (Sept 9-12 1973) 16 pp

DeBiase, J. L. "Criteria and Design Specifications for Plant Noise Control" S/V Sound and Vibration 6 (9), pp 26-30 (Sept 1972)

Dennison, E. E. Maier, R. E., McGaughey, J. W. and Ying, S. P. "Environmental Noise-Study for a Nuclear Power Plant" Noise Control Eng 10(1) pp 33-39, (Jan-Feb 1978)

DiRita, R. A. and George, D. L. "How to Estimate Sound Levels in Industrial Environments" S/V Sound and Vibration 6(9), pp 33-36 (Sept 1972)

Dove, R. A. "Basic Principles of Noise Control" Plast Rubber Int $3(1)$, pp 23-26 (Jan-Feb 1978)

Dym, C. L. "Sources of Industrial Impact/Impulsive Noise" Noise Control Eng 8(2), pp 81-89 (Mar-Apr 1977)

Edwards, R. G., Hauser, W. P., Moiseev, N. A., Broderson, A. B. and Green, W. W. "Effectiveness of Earplugs as Worn in the Workplace" S/V Sound and Vibration 12(1), pp 12-20, 22 (Jan 1978)

Giardino, D. A. and Seiler, J. P. "Noise Dosimeters-Past, Present and Future" S/V Sound and Vibration 10(10), pp 26-30 (Oct 1976)

Goodfriend, L. S. "Noise Control Program for a Large Power Station" IEEE Trans Power Appar Syst PAS-96 (3), pp 1036-1038 (May-June 1977)

Grabkowski, S. E., Sirota, S. R., Jenkins, S. III and Buechler, J. P.

"Controlling Noise in a Large Steam Turbine-Generator Room" IEEE Trans Power Appar Syst PAS-97 (2), pp 504-512 (Mar-Apr 1978)

Hall, W. E. and Saporita, R. "Design to Minimize Olefin-Plant Noise" Oil Gas J 76(14), pp 84, 86, 91-92 (Apr 3 1978)

Headon, D. "Coping with Noise Problems in the Gas Industry" Gas Eng Manage 14(9), pp 263-270 (Sept 1974)

Heitner, I. "How to Estimate Plant Noises" Hydrocarbon Processing 47(12), pp 67-74 (Dec 1968)

Hersh, A. S., Kessler, R. A. and Seebold, J. G. "Refinery Auxiliary Stack Redesign to Eliminate Fluid Induced Resonance Tone" Noise Control Eng 4(1), pp 30-33 (Jan-Feb 1975)

Hillier, A. J. "Noise and Its Control in the Textile Industry" Noise Control Cent Ltd Text Mon, pp 52, 54 (June 1976)

Hoover, R. M. "Study of Community Noise Complaints Caused by Electric Power Plant Operations" Noise Control Eng 6 (2), pp 74-80 (Mar-Apr 1976)

Hosey, A. D., et al. "Industrial Noise: A Guide to its Evaluation and Control" U.S. Dept. of Health, Education and Welfare, Publication 1572

Jacks, R. L. "Sound Suppression" Chemical Process Industries, pp 127-134 (Feb 1961)

Jenson, J. E., Evenson, H. A., Lord, H. W. and Hendrickson, A. A. "IndustryUniversity Approach to Forging Noise Control" S/V Sound and Vibration $8(11)$, pp 32-37 (Nov 1974) 
Karplus, H. B. and Bonvallet, G. L. "A Noise Survey of Manufacturing Industries" Amer. Indus. Hygiene Assoc. Quart. 14(4), pp 235-263 (Dec 1953)

Kessler, F. M. "Acoustic Impact Assessment Procedure Used in Industrial PlantSite Selection" Noise Control Eng 6 (1), pp 35-39 (Jan-Feb 1976)

Lowery, R. L. "Noise Control: A Common-Sense Approach" Mech Eng 95(6), pp 26-31 (June 1973)

Lyon, R. H., Cann, R. G. and Carpenter, G. D. "Application of Acoustical Modeling to Plant Noise Problems" $\mathrm{S} / \mathrm{V}$ Sound and Vibration 10(5), pp 14-18 (May 1976)

Mazoh, M. "Practical Noise Control Methods" Warner \& Swasey Res Center, SME Tech Pap Ser MM for Annual Conf - Book 2, Cleveland, OH, (Apr 26-29 1976) Paper MM76-291, 13 pp

Meteer, C. L. "Stop Plant Noise... At the Source or Along the Way" Ferro Corp, Norwalk, CT, Automation (Cleve) 21(7), pp 58-61 (July 1974)

Miska, K. H. "Where to Turn for Help in Solving Noise Pollution Problems" Mater Eng 87(3), pp 19-23 (Mar 1978)

"Noise Control of Metal Stamping Operations" S/V Sound and Vibration $\underline{5}(11)$, pp 41-45 (Nov 1971)

Padilla, M. "Ear Plug Performance in Industrial Field Conditions" S/V Sound and Vibration 10(5), pp 33-36 (May 1976)

Putnam, A. A. "Combustion Noise in Industrial Burners" Noise Control Eng $\underline{7}(1)$, pp 24-34 (Ju1-Aug 1976)

Seebold, J. G. "Source of Refinery Noise Key to Control Technique" Oil Gas J. 74(26), pp 146-148 (June 28 1976)

Seebold, J. G. "Process Plant Noise Control at the Design Engineering Stage" ASME J. Engr Industry, pp 779-784 (Nov 1970)

"Standards and Codes" $S / V$ Sound and Vibration $\underline{5}$ (2), pp 4-5 (Feb 1971)

Storment, J. W. and Pelton, H. K. "Practical Noise Control in a Large Manufacturing Plant" S/V Sound and Vibration 10(5), pp 22-24, 26-32 (May 1976)

Tatge, R. B. "Noise Control of Gas Turbine Power Plants" S/V Sound and Vibration ?(6), pp 23-27 (June 1973)

Teplitzky, A. M. "Electric Power Plant Noise Emission Controls" S/V Sound and Vibration 10(9), pp 24-30 (Sept 1976)

"Typical Factory and Office Noise Problems in an Aircraft Plant" Noise Control $\underline{2}$ (2), pp 22-25, 90 (March 1956)

Tyzzer, F. G. "Reducing Industrial Noise, General Principles" Amer. Indus. Hygiene Assoc. Quart. 14(4), pp 1-22 (Dec 1953)

Wang, J. S. "Induced Draft Cooling Tower Noise and Its Control" Cool Tower Inst Annual Meeting, Houston, TX (Jan 31-Feb 2 1977) Sponsored by Cool Tower Inst, Houston, TX, 1977 Paper TP 161A, 23 pp

Yerges, J. R. and Morris, A. J. "Machine Enclosures Versus Personnel Shelters" S/V Sound and Vibration 9 (5), pp 36-38 (May 1975) 
Machinery and Equipment

Applegate, S. L. and Crocker, M. J. "Reducing the Noise of a Rotary Lawn Mower Blade" Noise Control Eng 6 (1), pp 30-34 (Jan-Feb 1976)

Badgley, R. H. "Mechanical Aspects of Gear-Induced Noise in Complete Power Train Systems", ASME Paper 70-WA/DGP-1

Bailey, J. R., Daggerhart, J. A. and Stewart, N. D. "Systems Approach for Control of Punch Press Noise" NC State Univ, Raleigh, ASME Paper 75-DET-49 for Meeting (Sept 17-19 1975) $8 \mathrm{p}$

Bernhagen, J. R. "Noise Control on a Heavy-Duty Mobile Crane" Harnischfeger Corp, Milwaukee, WI, SAE Preprint 760601 for Meeting (Aug 9-12 1976) 12 pp

Bourne, J. C. "Noise Control Hood for the Davenport Automatic" $\underline{S} / \mathrm{V}$ Sound and Vibration 8(11), pp 22-24 (Nov 1974)

Brammer, A. J. and Muster, D. "Noise Radiated by Internal Combustion Engines" JASA 58, pp 11-21 (1975)

Callaway, D. B. "Reducing Noise in Machines" Machine Design, pp 1-8 (Dec 1951)

Carlson, D. R. and Evans, K. W. "Noise Control in Bevel Gears" Gleason Works, Rochester, NY, SAE Preprint 770563 for Meeting (Apr 18-20 1977) 11 pP

Cashmore, D. H., and Menzies, J. E. "Sound Level Prediction for Installed Rotating Electrical Machines" Westinghouse Electric Corp, Buffalo, NY, TAPPI 57(12), pp 130-133 (Dec 1974)

Chanaud, R. C., Kong, N. and Sitterding, R. B. "Experiments on Porous Blades as a Means of Reducing Fan Noise" JASA 59, pp 564-575 (1976)

"Circular Saw Noise Control" S/V Sound and Vibration 3(7), p 6 (July 1969)

Cook, G. C. "Noise Control for Power Presses" Sheet Met Ind 52(11), pp 653-656 (Nov 1975)

"Cost/Effectiveness Approach to Machinery Noise Contro1" S/V Sound and Vibration 8(7), pp 30-32 (July 1974)

Dennisen, E. E. "Sound Power Level Measurement of Small Fans" S/V Sound and Vibration 10(3), pp 44-45 (Mar 1976)

Diehl, G. M. "Comparison of Calculated and Measured Sound Power Levels of Large Machinery and Small Hand Held Tools" JASA 62(51) (Dec 1977)

Fried, K. Rheinhausen, Germany "Noise Abatement of Stranding Equipment Hulak WH" Wire J. 3(7), pp 37-41 (July 1970)

Halvorsen, W. G. and Bendat, J. S: "Noise Source Identification Using Coherent Output Power Spectra" S/V Sound and Vibration 9(8), pp 15, 18-24 (Aug 1975)

Hardy, H. C. and Biship, D. E. "Evaluation of Equipment Noise" ASHRAE Journal Section Heating, Piping \& Air Conditioning, pp 137-141 (Sept 1955)

Hillier, A. J. "Loom Noise and Its Control" R. S. Allsopp \& Assoc Ltd, Noise Contro1 Vib Reduct 5(8), pp 312-317 (Nov 1974)

Hirschorn, M. "Noise Control for Portable Air Compressors" S/V Sound and Vibration 9 (8), pp 12-14 (Aug 1975) 
Holdsworth, T. M. and Morris, R. D. "Use of Induction Motors as Vibration Generators" S/V Sound and Vibration 10(11), pp 24-28 (Nov 1976)

Holub, R. "Controlling Punch Press Noise with Lead/Viny1 Curtains" Singer Part Inc., Chicago, IL, NOISEXPO: Natl Noise and Vib Control Conf. Proc of the Tech Program, Atlanta, GA (Apr 30-May 2 1975) pp 58-61, Acoust Publ. Inc. Bay Village, OH (1975)

Ige, M. T. and Finner, M. F. "Reduction of the Aerodynamic Noise Generated by Crop Drying Fans" Univ of Wis. Madison, Trans Am Soc Agric Eng (Gen Ed) 17(6), pp 1177-1181 (Nov-Dec 1974)

Jensen, J. W. and Visnapuu, A. "Pneumatic Rock Drill Noise can be Reduced" Noise Contro1 Eng 4(2), pp 54-63 (Mar-Apr 1975)

Keller, A. C. "Real-Time Spectrum Analysis of Machinery Dynamics" S/V Sound and Vibration $9(4)$, pp 40-48 (Apr 1975)

Koss, L. L. "Punch Press Load-Radiation Characteristics" Noise Control Eng 8(1), pp 33-39 (Jan-Feb 1977)

Lance, H. "Noise Reductions in Motors" Am Filter Co., Pulsco Div, Water Sewage Works 123 (2), pp 76-77 (Feb 1977)

Marraccini, L. C. "Noise Control of Strip Mine Vehicles" Mine Enforcement \& Saf Adm, Pittsburgh, PA, U.S. Bur of Mines Inf Circ 8686 1975, for Technol Transfer Semin, Pittsburgh, PA, pp 79-85 (Jan 22 1975)

Mellin, R. C. "Selection of Minimum Noise Fans for a Given Pumping Requirement" Noise Control Eng 4(1), pp 35-45 (Jan-Feb 1975)

Miller, T. D. and Fader, B. "Industrial Noise Control $\$$ and Sense" $S / V$ Sound and Vibration 11(9), pp 16-19 (Sept 1977)

Miller, T. D. "Industrial Noise Control: Putting it All Together" Noise Control Eng 9(1), pp 24-31 (Ju1-Aug 1977)

Niemiec, K. "Metal Sawing Noise: Potential Noise Controls" Bolt Beranek \& Newman, Inc., Light Met Age 33 (9-10), pp 13-16 (Oct 1976)

Ostergaard, P. B. "Machine Too1 Noise Measurements" S/V Sound and Vibration $\underline{10}(10)$, pp 22-24 (Oct 1976)

Page, J. D. "Textile Machine Noise Control" Saco-Lowe11, Clemson, SC, IEEE Trans Ind Appl IA-8(4), pp 472-476 (Jul-Aug 1972)

Patsora, A. V., Mikhailov, V. V. and Scarton, H. A. "Diagnostic Technique for S1ip Ring Failure Detection" S/V Sound and Vibration 9(11), pp 36-39 (Nov 1975)

Patterson, W. N. "Quieting Portable Air Compressors" Noise Control Eng 5 (1), pp 41-47 (Jul-Aug 1975)

Pleeck, G. "Noise Control in the Turbine Room of a Power Station" Noise Control Eng 8 (3), pp 131-136 (May-June 1977)

Potter, S. M. and Hardy, H. C. "General Principles of Reducing Noise in Machinery" Noise Control 1(5), pp 43-48 (Sept 1955)

Reethof, G. "Control Valve and Regulator Noise Generation, Propagation and Reduction" Noise Control Eng 9(2), pp 74-85 (Sept-Oct 1977) 
Reid, I. Y. "Some Factors in the Estimation and Measurement of Airborne Noise from Centrifugal Pumps" Weir Pumps Ltd, Glasgow, Scotland, Vib and Noise in Pump, Fan, and Compressor Install. Conf. Proc. Univ of Southampton Engl. Sept 16-18 1975 PP 183-189, Pub1 for Inst of Mech Eng (CP9-1975), London, Engl by Mech Eng Publ Ltd, New York, NY 1975

Sanders, G. J. and Lawrie, W. E. "Low Frequency Combustion Noise in Oilburning Equipment" ASHRAE Journal, Section Heating, Piping and Air Conditioning

(Oct 1958)

Sanders, G. J. "Noise Reduction in Machinery" Noise Control 3(6), pp 29-37 (Nov 1957)

Scherr, R. C., Ostendorf, R. G. and Shuler, B. F. "Noise Reduction Techniques for Paper Converting Machinery" Procter \& Gamble Co. Jackson, TN, TAPPI 56(6), pp 65-68 (June 1973)

Small, D. J. and Davies, P.O.A.L. "Computerized Valve Noise Prediction System" Noise Control Eng 4 (3), pp 124-128 (May-June 1975)

Sperry, W. C. and Sanders, G. J. "Quiet Blades for 18-inch Rotary Type Power Lawn Mowers" Noise Control 5(3), pp 26-31 (May 1959)

Stewart, J. S. and Hart, F. D. "Control Industrial Wood Planer Noise Through Improved Cutterhead Design" Noise Control Eng 7(1), pp 4-9 (Ju1-Aug 1976)

Stewart, N. D., Bailey, J. R. and Daggerhart, J. A. "Study of Parameters Influencing Punch Press Noise" Noise Control Eng 5(2), pp 80-86 (Sept-0ct 1975)

"Taming Noisy Feeders" Automation (Cleveland) 18(7), pp 55-56 (July 1971)

"The First Quiet Portable Compressor" $\underline{S / V}$ Sound and Vibration $3(5)$, pp 6-8 (May 1969)

Thompson, M. P. "Noise Control Techniques for Both New and Existing Stationary Engines and Compressors" White Mot Corp, Springfield, OH, ASME Paper 74-DGP-6 for Meeting (Apr 28-May 2 1974) $11 \mathrm{pp}$

Torpey, P. J. "Noise Reduction of a $115 \mathrm{kw}$ Generator Set" $\mathrm{S} / \mathrm{V}$ Sound and Vibration 1(11), pp 16-22 (Nov 1967)

Tree, D. R. and Hamilton, J. F. "Noise Analysis of Fractional Horsepower Compressors" Noise Control Eng 5 (3), pp 100-107 (Nov-Dec 1975)

Tree, D. R. and Uffman, W. P. "Noise Reduction of a Household Vacuum Cleaner" S/V Sound and Vibration 7(3), pp 27-30 (March 1973)

Tsao, M.C.C. and Musa, R. S. "Noise Control in Home Appliances" S/V Sound and Vibration 7(3), pp 31-33 (March 1973)

Wilson, R. J. "Compressor Noise Control in Applications" Tecumseh Prod Co Purdue Compressor Technol Conf, Proc, Purdue Univ, West Lafayette, IN (Jul 10-12 1974) pp 208-213

Yerges, L. F. "Noise Reduction in Metal Cutting Operations" Yerges Consult Eng, Downers Grove, IL, Natl Saf News 115(5), pp 59-62 (May 1977) 
Piping, Ducts, and Silencers

Audette, R. R. and McCormick, R. J. "Silencers for Corrosive Applications" $\underline{S} / \mathrm{V}$ Sound and Vibration $\underline{5}$ (2), pp 10-11 (Feb 1971)

Baade, P. K. "Effects of Acoustic Loading on Axial Flow Fan Noise Generation" Noise Control Eng 8 (1), pp 5-15 (Jan-Feb 1977)

Bartenwerfer, M., Gikadi, T. Neise, W. and Agnon, R. "Noise Reduction in Centrifugal Fans by Means of an Acoustically Lined Casing" Noise Control Eng 8(3), pp 100-107 (May-June 1977)

Beckenmeyer, R. J. and Sawdy D. T. "Analytical and Experimental Studies of Folded Cavity Duct Acoustic Liners" JASA 60, pp 5-123 (Dec 1976)

Bokor, J. "A Comparison of Some Acoustic Duct Lining Materials According to Scott's Theory" J. Sound and Vib. 14(3), pp 367-373 (Feb 1973)

Callaway, D. B., Tyzzer, F. G., and Hardy, H. C. "Techniques for Evaluation of Noise-Reducing Piping Components" J. Acoust. Soc. Amer. 24(6), pp 725-730 (Nov 1952)

Callaway, D. B., Tyzzer, F. G. and Hardy, H. C. "Resonant Vibrations in a Water-Filled Piping System" J. Acoust. Soc. Amer. 23(5), pp 550-553 (Sept 1951)

Chanaud, R. C. "Basic Mechanisms of Noise Generation by Fluids" Dyna-Syst, Inc. Denver, $\mathrm{CO}$, Noise and Fluids Eng, Presented at the Winter Annual Meeting of ASME, Atlanta, GA (Nov 27-Dec 2, 1977) Publ by ASME, New York, NY 1977 pp 45-55

Cheng, I., Young, J. and Crocker, M. J. "Acoustical Analysis, Testing and Design of Flow-Reversing Muffler Chambers" JASA 60, pp 1111-1118 (Dec 1976)

Cheng, I., Young, J. and Crocker, M. J. "Prediction of Transmission Loss in Mufflers by the Finite-Element Method" JASA 57, pp 144-148 (1975)

"Coping with Control-Valve Noise" Chemical Engineering, pp 149-153 (Oct 1970)

Daggerhart, J. A. and Berger, E. "Evaluation of Mufflers to Reduce Punch Press Air Exhaust Noise" Noise Control Eng 4(3), pp 120-123 (May-June 1975)

Davies, H. G. and Williams, J.E.F. "Aerodynamic Sound Generation in a Pipe" J. Fluid Mech $32(4)$, pp 765-778 (1968)

Diboll. "The Measurement and Prediction of Exhaust Frequencies in Large Internal Combustion Engines" ASME Paper 72-DGP-2

Doak, P. E. "Fundamentals of Aerodynamic Sound Theory and Flow Duct Acoustics" J. Sound and Vib. 28(3), pp 527-562 (June 1973)

Hale, M. E. and Kugler, B. A. "Acoustic Performance of Pipe Lagging Systems" Bolk Beranek \& Newman, Inc. Canoga Park, CA, ASME Paper 75-WA/Pet-2 for Meeting (Nov 30-Dec 4, 1975) 8 pp

Hall, H. H. "Laboratory Evaluation of Field Measurements of the Truck Exhaust Noise" J. Acoust. Soc. Amer. 26(2), pp 216-220 (March 1954)

Hirata, Y. et al. "Influence of Airflow on the Attenuation Characteristics of Resonator Type Mufflers" Acustica 28(2), pp 115-120 (Feb 1973)

Johnsen, G. E. "How to Select Effective Lagging Configurations" S/V Sound and Vibration 11(4), pp 34-35 (Apr 1977) 
Kennedy, W. C. and Young, F. J. "Chart for Estimating the Efficiency of the Broadband Sound-Power Radiation by Randomly Vibrating Pipe Walls" JASA 61(5), pp 1209-1212 (June 1977)

Lord, H. W., Evensen, H. A. and Stein, R. J. "Pneumatic Silencers for Exhaust Valves and Parts Ejectors" S/V Sound and Vibration 11(5), pp 26-34 (May 1977)

Sanders, G. J. "Silencers: Their Design and Application" S/V Sound and Vibration 2(2), pp 6-13 (Feb 1968)

Scott, H. L. "The Performance of Sound Absorbers in a Radial Diffuser Configuration" J. Sound and Vib. 19(4), pp 445-451 (Dec 1971)

Scott, H. L. "Optimization of Sound Absorbers in Circular Ducts" Simon-Carves Ltd, Cheshire, England, J. Sound and Vib. 16(2), pp 189-222 (May 22 1971)

Sparks, C. R. and Lindgren, D. E. "Design and Performance of High-Pressure Blowoff Silencers" ASME Paper 70-WA-PET-1

Strumpft, F. M. "Water Piping Systems and Noise Control" S/V Sound and Vibration 3 (5), pp 23-25 (May 1969)

Young, C. I. and Crocker, M. J. "Finite Element Acoustical Analysis of Complex Muffler Systems With and Without Wall Vibrations" Noise Control Eng 9 (2), pp 86-93 (Sept-Oct 1977)

Vibration Control

"Aircraft Noise and Structural Vibration" $\mathrm{S} / \mathrm{V}$ Sound and Vibration 12(2), pp 24-28 (Feb 1978)

Allen, D. L. and Swallow, J. C. "Annoying Floor Vibrations - Diagnosis and Therapy" S/V Sound and Vibration 9(3), pp 12-17 (Mar 1975)

Bannister, R. L. "Structural Models for Vibration Control" Noise Control Eng 4(2), pp 84-92 (Mar-Apr 1975)

"Design and Application of Pneumatic Vibration-Isolators" S/V Sound and Vibration 8 (8), pp 24-27 (Aug 1974)

Dym, C. L. "Attenuation of Ground Vibration" S/V Sound and Vibration 10(4), pp 32-34 (Apr 1976)

Harbarger, W. B. "Vibration Signature Surveillance of Axial Flow Compressors" S/V Sound and Vibration 10(3), pp 38-43 (Mar 1976)

"How to Select Vibration Isolators for OEM Machinery and Equi.pment" S/V Sound and Vibration 8 (8), pp 14-23 (Aug 1974)

Jones, D.I.G. "Damping Treatments for Noise and Vibration Control" $\mathrm{S} / \mathrm{V}$ Sound and Vibration 6(7), pp 25-31 (July 1972)

Junger, M. C. "Effectiveness of Resilient Elements for Noise Versus Vibration Control" Cambridge Acoust Assoc, Inc., MA, ASME AMD V 11973 for Meeting Cincinnati, OH, pp 173-191 (Sept 1973)

Lang, G. F. "Understanding Vibration Measurements" S/V Sound and Vibration $\underline{10}(3)$, pp 26-37 (Mar 1976)

Liu, T. K., Kinner, E. B. and Yegian, M. K. "Ground Vibrations" S/V Sound and Vibration $\underline{8}(10)$, pp 26-32 (Oct 1974) 
Morrow, C. T. "Noise Control Versus Shock and Vibration Engineering" J. Acoust. Soc. Amer. 55(4), pp 695-699 (Apr 1974)

Nelson, F. C. "Subjective Rating of Building Floor Vibration" S/V Sound and Vibration 8(10), pp 34-37 (Oct 1974)

Russe11, R. H. "New Excitation Sources Simplify Dynamic Testing of Large Structures" S/V Sound and Vibration 8(10), pp 4-10 (Oct 1974)

Turner, A. E. "Development of Visco-Elastic Damping Materials for Applications Involving Large Temperature Fluctuations" ICI Ltd., Paints Div., Hyde, Cheshire, England, Environmental Engineering (49) pp 13-16 (June 1971)

Turner, A. E. "Use of Damping Materials for Noise Reduction on Passenger Ship" Petrochemical and Polymer Lab, Cheshire, England J. Sound and Vib. 10(2), pp 187-197 (Sept 1969)

Community Noise and Noise Effects on Humans

"Acceptable Noise Exposures" S/V Sound and Vibration 1(11), pp 4, 6 (Nov 1967) Adams, J. V. et al. "S/V Status Report: 3 Community-Noise Programs" S/V Sound and Vibration I(5), pp 42-44 (May 1973)

Attenborough, K. et al. "Large-Scale Noise Surveys: An Educational Experiment" Acustica 28(5), pp 290-295 (March 1973)

Berglund, B., Burglund, J. and Linduall, T. "Scaling Loudness, Noisiness, and Annoyance of Community Noises" JASA 60, pp 1119-1125 (Dec 1976)

Bragdon, C. R. "Environmental Noise Control Programs in the United States" S/V Sound and Vibration 11(12), pp 12-16 (Dec 1977)

Bragdon, C. R. "City Noise Ordinances-A Status Report" S/V Sound and Vibration 7(5), pp 45-48 (May 1973)

Bragdon, C. R. "Urban Planning and Noise Control" S/V Sound and Vibration $\underline{7}(5)$, pp 26-32 (May 1973)

Bullen, R. "Sound Scattering in an Urban Street" Noise Control Eng 9 (2), pp 54-59 (Sept-Oct 1977)

Caccavari, C., and Schechter, H. "Background Noise Study in Chicago" Air Pollution Contro1 Journal 24(3) (1974)

Carlson, J. P. "Impact of Noise Control Regulations on Electric Utilities" S/V Sound and Vibration 11(9), pp 20-23 (Sept 1977)

Cohen, A., Anticaglia, J. R. and Carpenter, P. L. "Temporary Threshold Shift in Hearing From Exposure to Different Noise Spectra at Equal dBA Levels" 51(2), pp 503-507 (Feb 1972)

Connor, W. K. "Behavior of Noise Exposure Variables in an Urban Noise Survey Sample" Noise Contro1 Eng 10(1), pp 14-21 (Jan-Feb 1978)

Donley, R. "Community Noise Regulation" $\underline{S} / \mathrm{V}$ Sound and Vibration 3 (2), pp 12-21 (Feb 1969)

Fidel, S. "Nationwide Urban Noise Survey" JASA 64(1), p 198 (1978)

Finkelman, J. M. "Effects of Noise on Human Performance" S/V Sound and Vibration 10(9), pP 26-28 (Sept 1975) 
Galloway, W. J. "Assessment of the Relative Importance of Sources of Urban Noise" Noise Contro1 Eng 9(2), pp 68-73 (Sept-Oct 1977)

Guinter, J. M. "Action Plan for Product Noise Reduction" S/V Sound and Vibration 6(12), pp 18-22 (Dec 1972)

Hardy, H. C. "Tentative Estimate of a Hearing Damage Risk Criterion for SteadyState Noise" J.Acoust. Soc. Amer. 24(6), pp 756-761 (Nov 1952)

Jones, H. H. and Cohen, A. "Noise as a Health Hazard at Work, in the Community, and in the Home" 95th Annual Meeting of the American Public Health Assoc 83(7), pp 533-536 (July 1968)

Karplus, H. B. "Mechanism of a Correlation Theory of Hearing" from Bionics Symp. 1962, J. Acoust. Soc. Amer. 35, p 809 (1963)

LaBreche, R. M., Mendias, M. L. and Putnicki, G. J. "Inexpensive Community Noise Assessments for Medium and Small Cities" S/V Sound and Vibration 10(12), Pp 12-14 (Dec 1976)

McFadden, D., Russe11, W. E. and Pulliam, K. A. "Monaural and Binaural Masking Patterns for a Low-Frequency Tone" J. Acoust. Soc. Amer. 51(2), pp 534-543 (1972)

Mintz, F. and Tyzzer, F. G. "A Loudness Chart for Octave-Band on Complex Sounds" J. Acoust. Soc. Amer. 24(1), pp 80-82 (Jan 1952)

"New Housing and Airport Noise (A Supplement to the Site Planning Handbook)" Central Mortgage and Housing Corporation, Ottawa, K1A, OP7, Canada

Northwood, T. D. and Clark, D. M. "Frequency Considerations in the Subjective Assessment on Sound Insulation" Reports of the 6th Intl Congr on Acoustics, Tokyo, Vol. III, Paper E-3-8 (1968)

Rice, C. G. and Marton, A. M. "Impulse Noise Damage Risk Criteria" J. Sound and Vib. 28(3), pp 359-368 (June 1973)

Safeer, H. B. "Community Noise Levels-A Statistical Phenomenon" J. Sound and Vib. 26 (4), pp 489-502 (Feb 1973)

Schechter, H. "Creating Noise Level Limits Using Baseline Survey Results", Proceedings NOISEXPO 1974

Schechter, H. "Statistical Methodologies for Community Noise Sampling", Proceedings NOISEXPO 1974

Schechter, H. "Economic Solutions to Noise Control Programs", Proceedings NOISEXPO 1976

Schultz, T. J. "Synthesis of Social Surveys on Noise Annoyance" JASA 64(2), p 377 (1979)

Schultz, T. J. "Comments of the Paper 'Errors Due to Sampling in Community Noise Level Distributions'" J. Sound and Vib. 27(2), p 261 (March 1973)

Schultz, T. J. "Some Sources of Error in Community Noise Measurement" S/V Sound and Vibration $6(2)$, pp 18-27 (Feb 1972)

Stempler, S., Sanders, H. Watkins, H. and Boronow, E. "Development of Environmental Noise Codes for the City of New York" S/V Sound and Vibration 11(12), pp 18-22 (Dec 1977)

Teplitzky, A. M. "Community Noise Emissions from Enclosed Electric Power Plants" Noise Control Eng 6(1), pp 4-9 (Jan-Feb 1976) 
Thiessen, G. J. and OIson, N. "Community Noise-Surface Transportation" S/V Sound and Vibration 2(4), pp 10-16 (April 1968)

Von Gierke, H. E. "Noise-How Much is Too Much?" Noise Control Eng 5 (1), pp 24-34 (July-Aug 1975)

Traffic Noise

Brasch, J. K. "Vehicular Traffic Noise Near High Speed Highways" S/V Sound and Vibration 1 (12), pp 10-27 (Dec 1967)

Campbell, R. A. "A Survey of Passby Noise for Boats" S/V Sound and Vibration 3 (9), pp 24-26 (Sept 1969)

Chalupnik, J. D. and Harper, C. R. "Can Correlation Techniques be Used for the Measurement of Vehicle Noise?" Noise Contro1 Eng 8(1), pp 16-23 (Jan-Feb 1977)

Close, W. H. "Should There be Truck Tire Noise Regulations" S/V Sound and Vibration 9(2), pp 24-27 (Feb 1975)

Commins, D. E. "Directivity of Truck Noise in the Normal Plane" JASA 57, pp 121-125 (1975)

Fricke, F. R. "Protection of Buildings Against Traffic Noise" Noise Control Eng 8(1), pp 27-32 (Jan-Feb 1977)

Harris, C. M. and Aitken, B. H. "Noise in Subway Cars" S/V Sound and Vibration 5 (2), pp 12-14 (Feb 1971)

Kugler, B. A., Commins, D. E. and Galloway, W. J. "Highway Noise-A Design Guide for Prediction and Control" Bolt Beranek \& Newman, Los Angeles, CA, Nat1 Coop Highw Res Program Rep 174 (1976) 194 p

Leasure, W. A. "Tire Noise Regulations: Technical and Economic Implications" Noise Control Eng 7 (3), pp 140-147 (Nov-Dec 1976)

Maekawa, Z. "Shielding Highway Noise" Noise Control Eng 9 (1), pp 38-44 (July-Aug 1977)

"Noise in Mass Transit Systems" SRI Journal 16(1), pp 2-7 (Sept 1967)

"Objective and Subjective Measurement of Truck Noise" S/V Sound and Vibration 1(4), pp 8-13 (April 1967)

Peterson, A. G. "Motor Vehicle Noise Measurement" $\underline{S / V}$ Sound and Vibration 9(4), pp 26-33 (April 1975)

Roberts, J. E. and Borthwick, J. D. "Florida's Approach to Motor Vehicle Noise Control" S/V Sound and Vibration 9(12), pp 18-22 (Dec 1975)

Skeiber, S. C., Mason, R. L. and Potter, R. C. "Effectiveness of Audible Warning Devices on Emergency Vehicles" S/V Sound and Vibration 12 (2), pp 14-22 (Feb 1978)

Spencer, R. H. "Noise Control of the Standard Light Rail Vehicle" Noise Control Eng 10 (1), pp 4-13 (Jan-Feb 1978)

Thompson, J. W. "Engineering Approach to Diesel Truck Noise Reduction" White Motor Corp, SAE Prepr Paper 730713 for Meeting (Aug 20-23 1973) 13 pp

Wesler, J. E. "Highway Traffic Noise Prediction: A State of the Art Review" S/V Sound and Vibration 11(2), pp 12-15 (Feb 1977) 
MEASUREMENT AND STANDARDS

Standards

"AGMA Standard Specification for Measurement of Lateral Vibration on High Speed Helical and Herringbone Gear Units" S/V Sound and Vibration $\underline{7}(6)$, p 20 (June 1973)

Guinter, J. M. "Action Plan for Product Noise Reduction" S/V Sound and Vibration 6(12), pp 18-22 (Dec 1972)

Heebink, T. B. and Granthan, J. B. "Field/Laboratory STC Ratings of WoodFramed Partitions" S/V Sound and Vibration 5(10), pp 12-16 (Oct 1971)

Heymann, R. W. and Sachs, F. Z. "Standards for Noise Measurement" S/V Sound and Vibration 10(10), pp 14-20 (Oct 1976)

Keighley, E. C. "Acceptability Criteria for Noise in Large Offices" J. Sound and Vib. 11(1), pp 83-93 (Jan 1970)

Kopec, J. W. and Williams, L. D. "Laboratory Reverberation Time Measurements" Proceedings of the Technical Program (NOISEXPO) National Noise and Vibration Control Conference, Chicago (1978)

Kryter, K. D. "Acoustical Society of America Policy on Noise Standards" J. Acoust. Soc. Amer. 51(3), pp 803-806 (March 1972)

Lang, W. W. "Status of Noise Control Regulations in the USA" Noise Control Eng 5. (3), pp 108-115 (Nov-Dec 1975)

Meyer, A. F. "EPA's Implementation of the Noise Control Act of 1972" S/V Sound and Vibration 9(12), pp 10-17 (Dec 1975)

Meyer, A. F. "The Need for Standards on Noise" J. Acoust. Soc. Amer. 51(3), pp 800-802 (March 1972)

Norman, R. S. and Williams, L. D. "Measurement of Absorptive Properties of Landscape Screens in a $10,300 \mathrm{ft}^{3}\left(292 \mathrm{~m}^{3}\right)$ Reverberation Room" Proceeding of the Technical Program (NOISEXPO) National Noise and Vibration Control Conference, Chicago (1978)

Pallet, D. S. and Cadoff, M. A. "National Measurement System for Acoustics" S/V Sound and Vibration 11(10), pp 20-25, 27-31 (Oct 1977)

Siekman, W. "STC's and Room Dividers" Construction Specifier, pp 51-54 (Dec 1971)

Thoma, F. A. "Vibration Limits for High-Speed Gear Units" $S / V$ Sound and Vibration Z(6), p 20 (June 1973)

Van Houten, J. J. "California's Noise Insulation Standards" Noise Control Eng $\underline{5}(2)$, pp 52-59 (Sept-Oct 1975)

Test Facilities

Applegate, S. L. and Nelson, D. K. "Qualification of Two 180-Cubic Metre Reverberation Rooms with Microphone Traversing and Low Frequency Absorbers" Noise Control Eng $\underline{7}(2)$, pp 105-109 (Sept-Oct 1976) 
Bies, D. A. "Uses of Anechoic and Reverberant Rooms for the Investigation of Noise Sources" Noise Control Eng I(3), pp 154-163 (Nov-Dec 1976)

Blake, W. K. and Maga, L. J. "Chamber for Reverberant Acoustic Power Measurements in Air and in Water" JASA 57, pp 380-384 (1975)

Duda, J. "Basic Design Considerations for Anechoic Chambers" Noise Control Eng 9 (2), pp 60-67 (Sept-Oct 1977)

Dykstra, R. A., Baxa, D. E. and Stein, R. J. "Semi-Anechoic Testing Rooms: Some Sound Advice" S/V Sound and Vibration 11(5), pp 35-38 (May 1977)

Hirschorn, M. and Singer, E. "The Effect of Ambient Noise on Audiometric Room Selection" S/V Sound and Vibration $\underline{7}$ (2), pp 18-22 (Feb 1973)

Holmer, C. I. and Lubman, D. "Comparison of Microphone Traverse and Microphone Array for Determining Space Average Sound Pressure Level in a Reverberation Room" Noise Control Eng 7(2), pp 64-70 (Sept-Oct 1976)

Ingerslev, F., Pedersen, O. J., Moller, P. K. and Kristensen, J. "New Rooms for Acoustic Measurements at the Danish Technical University" Acustica 19(4), pp 185-199 (1968)

Kolmer, F. and Wagner, G. "Several Physical Conditions at Measurements in Reverberation Rooms" Reports of the 6th Intl Congr on Acoustics, Tokyo, Vol. III, Papers E-5-6 (1968)

McAuliffe, D. R. "Design and Performance of a New Reverberation Room at Armor Research Foundation" J.Acoust. Soc. Amer. 29(12), pp 1270-1273 (Dec 1957)

Parking, P. H. and Stacy, E. F. "The Anechoic and Reverberant Rooms at the Building Research Station" J. Sound and Vib. 19(3), pp 277-286 (Dec 1971)

Schultz, T. J. "New Acoustical Test Facilities of the National Gypsum Company" J. Acoust. Soc. Amer. 45 (1), pp 20-36 (Jan 1969)

"Test Room for Vocoder Research" S/V Sound and Vibration 2(7), p 4 (July 1968)

Tichy, J. "Effects of Source Position, Wall Absorption, and Rotating Diffuser on the Qualification of Reverberation Rooms" Noise Control Eng 7(2), pp 57-63 (Sept-Oct 1976)

Testing Techniques

"AGMA Standard Specification for Measurement of Lateral Vibration on High Speed Helical and Herringbone Gear Units" S/V Sound and Vibration $\underline{Z}(6)$, pp 20-22 (June 1973)

Anderson, A. L. and Hampton, L. D. "Use of Tubes for Measurement of Acoustical Properties of Materials" JASA $\underline{57}$ 530(A), (1975)

Bies, D. A. and Hansen, C. H. "Impedance Tube Calibration of a Reverberant Room for the Measurement of Sound Power in Tones" JASA 59, PP 1393-1398 (1976)

Bruel, P. V. "Do We Measure Damaging Noise Correctly?" Noise Control Eng 8 (2), pp 52-60 (Mar-Apr 1977)

Burd, A. N. "The Measurement of Sound Insulation in the Presence of Flanking Paths" J. Sound and Vib. $\underline{7}$ (1), pp 13-26 (Jan 1968) 
Chien, C. S., Waterhouse, R. and Lubman, D. "Sperical Averaging in a Diffuse Sound Field" JASA 57, pp 972-975 (1975)

Chu, W. T. "Comparison of Reverberation Measurements Using Schroeder's Impulse Method and Decay Curve Averaging Method" JASA 63(5), p 1444 (June 1978)

Diehl, G. M. "Sound-Power Measurements on Large Machinery Installed Indoors: Two-Surface Method" JASA 61(2), pp 449-455 (1977)

Donovan, J. "Noise Measurement Techniques" ASTM Stand News 2(5), pp 17-31, 61 (May 1974)

Dowe11, E. H. "Reverberation Time, Absorption, and Impedance" JASA 64(1), p 181 (1978)

Enochson, L. "Digital Techniques in Data Analysis" Noise Control Eng 9(3), pp 138-154 (Nov-Dec 1977)

Fahy, F. J. "Technique for Measuring Sound Intensity with a Sound Level Meter" Noise Control Eng 9(3), pp 155-162 (Nov-Dec 1977)

Fearn, R. W. "Some Reverberation Time Measurements in English and Spanish Churches" J. Sound and Vib. 27(1), pp 134-135 (March 1973)

Francois, P. "Characteristics and Calibration of Reference Sound Sources" Noise Control Eng 9(1), pp 6-15 (July-Aug 1977)

Galaitsu, A. G. and Patterson W. N. "Prediction of Noise Distribution in Various Enclosures from Free-Field Measurements" JASA 60, pp 848-856 (Dec 1976)

Halvorsen, W. G. and Brown, D. L. "Impulse Technique for Structural Frequency Response Testing" S/V Sound and Vibration 11(11), pp 8-21 (Nov 1977)

Heebink, T. B. "The Field Measurement of Sound Insulation" S/V Sound and Vibration 3(5), pp 18-22 (May 1969)

Higginson, R. F. "A Study of Measuring Techniques for Airborne Sound Insulation in Buildings" J. Sound and Vib. 21 (4), pp 405-429 (April 1972)

Hruska, G. R., Magrab, E. B. and Penzes, W. B. "Environmental Effects on Microphones of Various Constructions" JASA 61(1), pp 206-210 (June 1977)

Huber, W. C. and Sikora, R. "Spectrum Analyzer Simplifies Operator Controls" S/V Sound and Vibration 11(12), pp 4, 6 (Dec 1977)

Huntley, R. "The Effect of Room Characteristics on Sound-Power Measurements" Noise Control 5(1), pp 59-63, 77 (Jan 1959)

James, R. R. and Thompson, K. L. "Computer Assisted Acoustical Engineering Techniques" Total Environ Syst Inc. East Lansing, MI, NOISEXPO: Natl Noise and Vib Control Conf, Proc of the Tech Program, Atlanta, GA, pp 82-84 (Apr 30May 2 1975)

Jorgen, G. 0. "Technical Problems in Impact Noise Testing" 5th Int1 Congr on Acoustics, Liege (Sept 1965)

Kamperman, G. W. and Moore, M. "Real Time Frequency Analyzers for Noise Control" Noise Control Eng 9(3), PP 131-136 (Nov-Dec 1977)

Karplus, H. B. "Environment for Measuring Noise" Noise Control 3(2), pp 19-22 (March 1957) 
Kartr, T. S. and King, D. B. "Noise Control Design Using Scale Model Tests" S/V Sound and Vibration I(1), pp 14-21 (Jan 1973)

Kasteleijn, M. L. "The Statistical Spread of Measured Airborne and Impact Sound Insulation in the Field" J. Sound and Vib. 3(1), pp 36-45 (Jan 1966)

Kodaras, M. J. and Hansen, R. A. "Measurement Sound-Transmission Loss in the Field" J.Acoust. Soc. Amer. 36 (3), pp 565-569 (March 1964)

Koyasu, M. "Investigations into the Precision of Measurement of Sound Absorption Coefficients in a Reverberation Room" Reports of the 6th Intl Congr on Acoustics, Tokyo, Vol. III, Paper E-5-8 (1968)

Kundert, W. R. "Sound Level Meters: The State of the Art" Noise Control Eng $\underline{9}$ (3), pp 120-130 (Nov-Dec 1977)

"Laboratory Measurements of Sound Transmission Through Suspended Ceiling Systems" J. Acoust. Soc. Amer. 33(11), pp 1523-1530 (Nov 1961)

Lavender, D. C. "Interpretation of Noise Measurements" J. Sound and Vib. $15(1)$, pp 1-9 (March 1971)

Maling, G. C. "Guidelines for Determination of the Average Sound Power Radiated by Discrete-Frequency Sources in a Reverberation Room" J.Acoust. Soc. Amer. 53(4), pp 1064-1069 (April 1973)

Marraccini, L. C. and Giardino, G. A. "Predicting Sound Levels from Sound Power Data" S/V Sound and Vibration 8(11), pp 28-30 (Nov 1974)

Moreland, J. B. "Measurement of Sound Absorption in Rooms" JASA 61 (2), pp 476483 (June 1977)

Powers, W. R. and Rudinoff, C. D. "Noise Box Test: A Novel Method for Evaluating Sound Absorbers" Spec Compos Corp, SAE Prepr 750777 for Meeting (Sept 8-11 1975) $9 \mathrm{p}$

Rasmussen, G. "Measurement Microphones" Noise Contro1 Eng 9(3), pp 109-119 (Nov-Dec 1977)

Raymond, R. W. "Automatic Measurement of Sound Power Level" S/V Sound and Vibration 8 (11), pp 12-16 (Nov 1974)

"Research Project on Impact Noise" S/V Sound and Vibration 2(3), p 4 (March 1968)

Russel, R. H. and Deel, J. C. "Modal Analysis: Trouble-Shooting to Product Design" S/V Sound and Vibration 11(11), pp 22-38 (Nov 1977)

Scholes, W. E. "A Note on the Repeatability of Field Measurements of Airborne Sound Insulation" J. Sound and Vib. 10(1), pp 1-6 (July 1969)

Schneider, A. J. "Noise Measuring Instruments and Surveying Techniques" Light Met Age 33 (9-10), pp 23-24 (Oct 1976)

Schultz, T. J. "Alternative Test Method for Evaluating Impact Noise" JASA 60 , pp 645-655 (Dec 1976)

Sepmeyer, L. W. "Effect of Filter Bandwidth and Attenuation Characteristics on Sound-Transmission Loss Measurements" J. Acoust. Soc. Amer. 39(2), pp 399401 (Feb 1966)

Siekman, W., Yerges, J. F. and Yerges, L. F. "A Simplified Field Sound Trans-

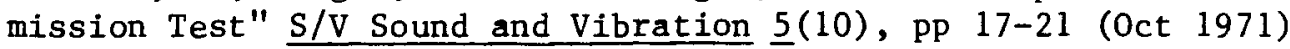


Siekman, W., Jr. "Architectural Acoustics (A Problem of Measurement)" Frontier, pp 16-21 (Autumn 1966)

Starr, E. A. and Beranek, L. L. "Noise Measurements, 1977" Noise Control Eng 9(3), pp 100-108 (Nov-Dec 1977)

Steele, J. M. "Time/Accuracy Tradeoffs in the Analysis of Random Signals" S/V Sound and Vibration 6 (12), pp 23-27 (Dec 1972)

Svensson, J. "Impact Noise Reduction Predicted from Samples of Flooring" 7 th Intl Congr on Acoustics, Budapest (1971)

Ten Wolde, T. "Reciprocity Measurement of Acoustical Source Strength in an Arbitrary Surrounding" Noise Control Eng 7(1), pp 16-23 (July-Aug 1976)

Tyzzer, F. G. and Hall, H. H. "An Evaluation Technique for Impact-Type Noises" Noise Control 2(2), pp 38-41, 98 (March 1956)

Utley, W. A., Cummings, A. and Parbrook, H. D. "The Accuracy of Laboratory Measurements of Transmission Loss" J. Sound and Vib. 16(4), pp 643-644 (June 1971)

Van Zy1, B. G. and Anderson, F. "Evaluation of the Intensity Method of Sound Power Determination" JASA 57, pp 682-686 (1975)

Walker, B. and Delsasso, L. P. "Integrated Pulse Technique for the Measurement of Acoustical Absorption Techniques" 7th Intl Congr on Acoustics, Budapest (1971)

Wilkerson, R. B. "Sound Level Meter and Dosimeter Response to Unsteady Noise Levels" Noise Control Eng 4(2), pp 68-75 (Mar-Apr 1975)

Zaveri, K. "Estimation of Sound Pressure Leve1s at a Distance from a Noise Source" Testing Technique, pp 24-29

Zwieback, E. L. "Recording Aircraft Flyover Noise" S/V Sound and Vibration 1(9), pp 17-24 (Sept 1967) 

DESCRIPTION OF PERTINENT STANDARDS

The published standards that pertain to the many types of noise measurements are too numerous to be included here. While ASTM is by no means the only organization publishing standards, it is these standards which cover almost all of the tests reported in the data tables. It is therefore pointed out that since through the years standards have been changed, data obtained using older standards are somewhat different than they are today.

A user knows the year of the standard because the ASTM designation shows the year as the last digits of the code number. For example, for the present absorption test the code designation is C423-66 indicating standard number C423 first appeared as a standard in 1966. This does not necessarily mean that 1966 is the first year ASTM had a standard for absorption testing but that this form of the standard was published in 1966.

It should also be noted here that there are standards covering the measurement of these values under field rather than laboratory conditions. The procedures are basically the same in principle, but generally, tests performed in the field will yield poorer results than tests performed under controlled laboratory conditions. However if careful attention is given to detail during construction and good measurement practice is maintained, the field test can give values approaching the laboratory values.

\section{ABSORPTION}

The absorption standards are given, followed by a brief description of each.

ANSI/ASTM C423-77: American Society for Testing and Materials, plus American National Standards Institute Standard Test Method for Sound Absorption and Sound Absorption Coefficients by the Reverberation Room Method.

This method covers the measurement of sound absorption in a diffuse reverberant sound field by measuring the decay rate. Included in the specifications are the test methods, room and specimen requirements, sound source and detection limits. See text page 49.

There are primarily two methodologies of reporting data. If the specimen is an extended flat surface, then the data are usually reported as random incidence absorption coefficients (i.e., absorption per unit area). This is found by measuring the difference of the time decay of the empty room (without specimen) and of the room with the specimen. The absorption coefficients are given in sabins per square foot and/or metric sabins per square meter. This method sometimes requires a one-number rating called the noise reduction coefficient (NRC). The NRC is an average of the values of the absorption coefficients at $250,500,1000$, and $2000 \mathrm{~Hz}$. These are the center frequencies of octave bands 
having equal power per constant proportional bandwidth, called pink noise. Also, the 125 and $4000 \mathrm{~Hz}$ octave bands are recorded. The second technique is used when the specimen is a specific size or shape (unit absorbers, chairs, landscape screens). Then, the results are reported as sabins per object or metric sabins per object. The size, shape, number, and spacing of the objects used during the test must be stated exactly.

This test method allows the NRC to be reported above 1.0 but is still rounded off to the nearest 0.05 . Techniques for calculating 95 percent confidence limits and percent of uncertainty are slightly revised from previous test methods. Also a proposed change in filtering techniques is pending as a requirement for this standard.

ASTM C423-66: American Society for Testing and Materials Standard Method of Test for Sound Absorption of Acoustical Materials in Reverberation Rooms.

This method follows the same procedures as. ASTM C423-77 except that the maximum NRC value is limited to 0.95 . This was the recommended procedure even in cases where the NRC exceeded unity. However, the exact data were also reported.

ASTM C423-65T: American Society for Testing and Materials Standard Method of Test for Sound Absorption of Acoustical Materials in Reverberation Rooms.

This test method and ASTM C423-66 are exactly alike. The number is different because the method was accepted tentatively in 1965, and then adopted officially in 1966.

ASTM C423-60T: American Society for Testing and Materials Standard Method of Test for Sound Absorption of Acoustical Materials in Reverberation Rooms.

This standard covers the same tests as ASTM C423-66 but allows a choice of three different sound sources. The other portions of the test procedure are essentially the same and results obtained in accordance with either form are equivalent.

The current standard states that the test signals shall be one-third octave bands of random noise with a continuous frequency spectrum and with either equal energy per constant bandwidth, called white noise, or equal energy per constant proportional bandwidth, called pink noise.

This earlier version of the standard permitted swept frequency tones or "warble" tones. The tone was warbled at a rate of 5 to 10 times per second through a range of +11 percent to -11 percent of the center frequency giving a bandwidth of approximately one-third octave. In lieu of warbling the tone signal this standard also permitted the use of suitable multitones centered on the standard test frequencies with a bandwidth of one-third octave. Finally, it also permitted the use of white noise of one-third octave bands centered on the standard test frequencies.

One of the main reasons for rewriting the absorption standard was to eliminate the differences in test signals between testing laboratories. The newer standard specifies only the one type of test signal that may be used. While the 
test signals are quite different in these two test procedures, no problems are encountered when using the earlier data since the values obtained according to each standard compare well with each other.

ASTM C423-58: American Society for Testing and Materials Standard Method of Test for Sound Absorption of Acoustical Materials in Reverberation Rooms.

This standard preceded and is similar to C423-60T. It was one of the first modern standards dealing with the properties of absorption as measured in the reverberation room.

ASTM C384-58: American Society for Testing and Materials Standard Method of Test for Impedance and Absorption of Acoustical Materials by the Tube Method.

The methodology for computing normal incidence absorption coefficients is specified. The method uses a closed tube with the specimen mounted in one end. A pure tone of sound is generated within the tube and the maxima and minima of the sound pressure inside the tube are measured.

Normal incidence absorption coefficients, which this method determines are always lower than random incidence coefficients determined in a reverberation room. There is no simple way of relating these two values, especially since the relationship depends on the material itself.

TRANSMISSION LOSS, SOUND TRANSMISSION CLASS, AND IMPACT ISOLATION

The standards of transmission loss, determination of sound transmission class, and impact isolation are given, followed by a brief description of each.

ASTM E90-75: Standard Method for Laboratory Measurement of Airborne Sound Transmission Loss of Building Partitions.

This method covers the laboratory measurement of airborne sound transmission loss of building partitions such as walls, floor-ceiling assemblies, doors, windows, and other space dividing elements. Refer to text (page 69). Basically, the procedure calls for mounting the specimen between two reverberation rooms. One room contains a calibrated noise source (source room) where its sound pressure level is measured at 16 frequencies. Then similar sound pressure levels are measured in the receiving room. The noise reduction qualities of the barrier are determined by the differences in sound levels. Special care in laboratory preparation is required, such as elimination of gaps and flanking paths.

Specific room qualifications are required. Sizing, conditioning, mounting and construction of the specimens are considered in the standard. Measurement precision requires a 95 percent confidence limit.

ASTM E90-70: American Society for Testing and Materials Standard Recommended Practice for Laboratory Measurement of Airborne Sound Transmission Loss of Building Partitions.

The same procedures as mentioned in E90-75 except fewer limits on room qualifications and a 90 percent confidence limit on measurements. 
ASTM E90-66T: American Society for Testing and Materials Standard Recommended Practice for Laboratory Measurement of Airborne Sound Transmission Loss of Building Partitions.

This standard which covers testing of sound barrier properties is the same as E90-70. It was in this standard that the test frequencies were fixed at one-third octave of either pink or white noise. Prior to this the transmission loss standard permitted the testing laboratory a choice of one of three different sound source signals.

ASTM E90-61T: American Society for Testing and Materials Standard Recommended Practice for Laboratory Measurement of Airborne Sound Transmission Loss of Building Partitions.

The same testing as in E90-66T and E90-70 is covered by this standard. However, the sound source is not as completely specified in this standard. Because of the different sound sources used, the data obtained under this standard sometimes showed values a few decibels higher in the lower frequencies. Also, this standard had provision for determining two different one-number ratings of the specimen.

One of these ratings is called the "Nine-Frequency Average". This number is simply the average decibel value of the transmission losses at the nine test frequencies of $125,175,250,350,500,700,1000,2000$, and $4000 \mathrm{~Hz}$. It should be noted that the test frequencies, while they are approximately onethird octave wide, they are centered on the one-half octaves and are not the series used in today's test standards.

The other one-number rating was called the Sound Transmission Class (STC). STC obtained by this method are equivalent to STC computed by E413-70T to within the accuracy of the measurements, however the methods of computation are different.

The change made in 1966 for transmission loss testing was the same as the change made in the absorption standard. The choice of one-third octave wide warble tone bands, or multitone bands, as in absorption testing, were replaced with a continuous spectrum source, either white or pink noise in shape, and filtered with a one-third octave band filter. Whereas this change produced little effect in absorption coefficients, the values of transmission loss tested with the newer sound source showed values 2 to $3 \mathrm{~dB}$ lower in the first few bands leaving the higher frequency bands relatively unchanged. Normally, a 2 to 3 $\mathrm{dB}$ change would not be a matter of major concern, although this 2 or $3 \mathrm{~dB}$ could result in a lower value of STC for a particular product.

ASTM E90-55: American Society for Testing and Materials Standard Recommended Practice for Laboratory Measurement of Airborne Sound Transmission Loss of Building Partitions.

This standard preceded and is similar to E90-61T. It was one of the first modern standards dealing with the properties of transmission loss of industrial materials. 
ASTM E336-71: American Society for Testing and Materials Standard Method of Test for the Measurement of Airborne Sound Insulation in Buildings.

This standard establishes uniform procedures for the determination of field transmission loss, i.e., the airborne sound insulation provided by a partition already installed in a building. It also establishes a standard method for the measurement of the noise reduction between two rooms in a building. If the test structure is a complete enclosure out-of-doors, neither the field transmission loss nor the noise reduction is appropriate; instead, a method for determining the insertion loss is established.

Results from this method may then be reported in three ways: Field Sound Transmission Class (FSTC), which provides an evaluation of the performance of a partition in certain common sound insulation problems; Noise Isolation Class (NIC), which provides an evaluation of the sound isolation between two enclosed spaces which are acoustically connected by one or more paths; or Field Insertion Loss (FIL), which is a measure of the sound isolation between two locations, one of which is not enclosed.

ASTM E336-67T: American Society for Testing and Materials Standard Method of Test for the Measurement of Airborne Sound Insulation in Buildings.

This test method and ASTM E336-71 are exactly alike. The numbers are different because it was accepted as a tentative method in 1967 before the offical adoption in 1971 .

AMA-I-II-1967: Acoustical Materials Association Ceiling Sound Transmission Test by the Two-Room Method for Measurement of Normalized Attenuation Factors.

The method of test is intended for the direct measurement of sound transmission through a suspended ceiling. This is a performance test for a configurational property of ceiling construction, without explicit reference to the sound absorption coefficients or sound transmission loss (TL) of ceiling materials. Performance is rendered independent of the total in situ absorption contribution of the receiving-room ceiling under test conditions by normalizing results with respect to separate measurements and thereby focusing attention upon the relative energy transmission of the ceiling configuration. The method of test is designed to reflect field conditions of ceiling erection under laboratory conditions of measurement control.

ASTM E413-70T: American Society for Testing and Materials Tentative Classification for Determination of Sound Transmission Class.

The purpose of this classification is to provide a standard method for determining the one-number rating of sound barrier items. The original intention of STC was to correlate measured sound reduction properties with subjective impressions of the specimen performance when used as a barrier against such sounds as speech, music, radio, television, etc., because these are the types of sounds that exist in most homes, apartments, offices, and schools. Consequent1y, the sounds of a factory, or of jet aircraft, or other transportation systems, whose noise spectrum is quite different from music or speech are not well treated by the STC value. It is therefore necessary to use the complete 
set of TL values to determine the performance of a partition against such noises.

Prior to the publication of E413 in 1970 the procedure for determining STC was published by ASTM as a recommended method (RM14-2) in 1966. This procedure is the same as $\mathrm{E} 413$ and first appeared in 1966 when E90 was revised. The procedure for determining STC before 1966 was a part of E90-61T and was different from the present method (see discussion of E90-61T).

This standard specifies the technique for comparing the TL values at each of the 16 one-third octave bands to the STC contours and the determination of the STC. The highest contour to which the specimen TL curve meets the requirements (see page 71) is the STC curve. The value of this curve at $500 \mathrm{~Hz}$ is the STC rating of the specimen. The numerical values for this set of standard contours are shown in Table 16 .

ASTM E492-77: American Society for Testing and Materials Tentative Method of Laboratory Measurement of Impact Sound Transmission Through Floor-Ceiling Assemblies Using the Tapping Machine.

ASTM E492-73T (RM14-4): American Society for Testing and Materials Impact Sound Transmission Through Floor-Ceiling Assemblies Using the Tapping Machine.

These procedures were originally published in 1971 as a recommended method only (RM14-4). The method uses a standard tapping machine to produce impacts on a floor-ceiling assembly and the sound pressure levels produced by these impacts are measured in the room below the assembly. There is still much debate over the use of the tapping machine as to impact source because many feel that these impacts are not representative of noises produced by such occurrences as dropping objects on the floor, sliding objects across the floor, and in particular, the noises due to footfalls. Prior to the publication in 1971 of RM14-4 there was no American standard to cover impact testing. There is, however, an international standard which is very much the same which is published by the International Standards Organization (ISO) as R140. This standard does not provide.for an IIC value but did specify normalization to 10 metric sabins (meter ${ }^{2}$ ) absorption.

FHA 750: Federal Housing Administration Guide to Impact Noise Control in Multifamily Dwellings.

This authority establishes a method of testing which makes it possible to evaluate the ability of different floors to impede the transmission of impact noise to the space below.

A tapping machine, which generates the impact noise, is set into operation on the floor. Sound pressure levels are then taken in the space below. These levels are normalized to a receiving room with a reverberation time of 0.5 second. The normalized levels are then compared to the standard FHA impact noise curve, allowing a single number, the Impact Noise Rating. (INR), to be determined. INR numbers which are zero or greater meet the recommended FHA specifications; those less than zero do not. The higher the INR the better the impact isolation. 


\section{AMERICAN NATIONAL STANDARDS INSTITUTE}

For the many other types of acoustic test data there is probably some type of standard which governs the procedure. While the above test standards and the many other standards that relate to specific types of items provide for the measurement of particular items, there is another series of standards that specifies general acoustic measurement methods, values for references, etc. These are the standards published by the American National Standards Institute (ANSI).

This institute was originally known as the American Standards Association and the published standards have the prefix ASA. In 1966 the name was changed to United States of America Standards Institute (USASI) and standards published by this group are prefixed with USAS. Again in 1969 the nane of this organization was changed. Since American National Standards Institute is the current name, the following standards are shown with the prefix ANSI regardless of the year of publication. While some copies of earlier standards may bear the title of ASA standard or USAS standard, all of these have been adopted as ANSI standards. These standards specify how to make acoustic measurements, the characteristics of laboratory microphones, how calibrations shall be performed on these, test room characteristics, etc. This organization does not concern itself with the special procedures which must be followed when making these measurements on any special class of items.

ASA 224.19-1957: Laboratory Measurement of Airborne Sound Transmission Loss of Building Floors and Walls

This recommended practice is intended to cover the random incidence or reverberant sound method for the laboratory measurement of airborne sound transmission loss of floors, walls, windows, doors, etc. It gives specifications for the test facility and testing equipment including the signal requirements of random noise or warble tone, sound sources, position of microphones, and format for the report. It also gives minimum conditions of the sample.

ANSI S1.1-1960: American National Standard Acoustical Terminology (Including Mechanical Shock and Vibration).

The purpose of this standard is to establish and define standard acoustical terminology.

ANSI S1.2-1962: American National Standard Method for the Physical Measurement of Sound.

Methods for measuring and reporting the sound pressure levels and sound power generated by a source of sound are established. This standard applies primarily to airborne sound produced by apparatus which normally operates in air. These sounds must not be impulsive and must be of sufficient duration to be within the dynamic measuring capabilities of the instruments used. 
The purpose of this standard is to maintain maximum possible accuracy of sound level measuring instruments and to maintain uniformity between instrument measured quantities.

Characteristics of sound level meters starting with the amplitude, frequency response, and directional properties of the microphone are specified. The frequency weighting filters are standardized both to shape of the weighting function and tolerances on these shapes. The tolerances are divided into three groups with Type I (Precision) the most stringent, then Type II (General Purpose) and Type III (Survey) the least stringent. Meter response time and output requirements are also covered.

ANSI S1.6-1967: American National Standard Preferred Frequencies for Acoustical Measurements.

To maintain uniformity and comparability among measurements this standard specifies which series of frequencies shall be used as the preferred octave, one-half octave, and one-third octave bandwidths. It is in this standard that the one-third octave series is modified so that they are actually one-tenth decade. This modification changes the bandwidths less than 0.1 percent and provides a series of frequencies where 10 successive one-third octave bands are in the ratio of $10: 1$ in center frequency.

ANSI S1.8-1969: American National Standard Preferred Reference Quantities for Acoustical Levels.

Values to be used as reference when acoustic quantities such as power, pressure, intensity, etc., are stated in the form of levels are specified. This standard does not specify that level shall be used but provides the reference to a convenient magnitude for any physical quantity that may be used in acoustics.

ANSI S1.10-1966: American National Standard Method for the Calibration of Microphones.

Techniques and principles involved for performing absolute calibration of microphones are described. Experimental procedures for determining pressure, free field, and diffuse field calibrations are standardized. These procedures provide for either absolute calibration based on the reciprocity principle or calibration by comparison with another microphone.

ANSI S1.11-1966: American National Standard Specification for Octave, Ha1fOctave, and One-Third Octave Band Filter Sets.

Just as ANSI S1.4 specifies the characteristics and tolerances on sound level meters, this standard specifies the characteristics of band pass filters for acoustical measurements. Some of the items specified are the features of the pass band and the slope and width of the skirts of the band. This standard assures the user of acoustic band pass filter sets that measurements made with one filter set will agree with those made with any other filter set providing each set conforms to the standard. 
ANSI S1.12-1967: American National Standard Specification for Laboratory Standard Microphones.

The physical, electrical, and acoustical properties of microphones that are suitable for calibration by an absolute method, such as the reciprocity technique described in ANSI S1.10, are described. These microphones are intended to be used for acoustical standards or as comparison microphones for calibrating other microphones by the comparison technique.

ANSI S1.13-1971: American National Standard Method for the Measurement of Sound Pressure Levels.

This standard is a partial revision of ANSI S1.12-1962 and contains recommendations pertaining to the techniques of the physical measurement of sound. These techniques are applicable to a variety of environment conditions but are not intended to include measurements made for the purpose of determining the sound power level radiated from a source. This standard is applicable to the many different types of sound pressure level measurements that may be encountered in practice and is intended to provide assistance to those persons responsible for the preparation of test codes, ordinances, acoustical criteria, and effects of noise on people, etc.

ANSI S1.21-1972: American National Standard Method for the Determination of Sound Power Levels of Small Sources in Reverberation Rooms.

While the main purpose of this standard is to describe in detail the procedures for the measurement of sound power levels, its pertinence here is due to the lengthy and complete discussion of the quality and characteristics of the reverberation room for making the measurements. This standard describes both a direct method for determining sound power level and a comparison method which uses a calibrated reference sound source. 

GUIDE TO THE DATA TABLES

While almost any porous material will absorb some sound energy, and any dense impermeable material will block sound transmission, the products listed in the following tables have been designed specifically to perform these functions efficiently and economically. While it is probably impossible to organize a listing such as this without categories, categorization implies a certain rigidity of purpose for a product which may be misleading. Within most of the tables, there are products with other potential uses which would place them in another category. Each product has been placed in the table corresponding to its prime function, and on occasion the same product is listed in more than one table. For each entry in the tables, contact with the manufacturer is recommended for information on other uses of the products, as well as for additional required data which are not included in this document.

The tables are divided into four broad groups: materials, systems, silencers, and miscellaneous. Materials are defined as single component products which may be composites of different substances. Systems are more complicated products of many components which often must be assembled by the end user.

- Within the first two broad groups, the tables are arranged in a progression from strictly absorbing products, through products with both absorptive and barrier properties, to strictly barrier products. Where materials or systems have several types of properties, the appropriate table is divided into subtables.

- Products are arranged within a table in order of increasing single number descriptor (NRC, STC, NIC'). When no descriptor was provided, it was calculated from the data where possible. Such calculated descriptors are identified by (c). The most recent ASTM standard allows values of NRC equal to 1.0 whereas previously the highest allowed NRC was 0.95 . The NRC of materials tested under older standards was not recalculated. This points out the necessity of examining the frequency band absorption coefficients and not choosing a material on the basis of NRC alone.

- Many products were tested for properties such as noise reduction, where there is no standard single number descriptor. In these cases, the data values were arithmetically averaged and arranged in order of increasing average value. This was done solely to provide a logical scheme for arranging the entries in the table. A product position in such a table says very little about the product acoustical properties. Again, refer to the frequency-dependent data. 
- The weight or density of a product may be in terms of $1 \mathrm{~b} / \mathrm{ft}^{3}, 1 \mathrm{~b} / \mathrm{ft}^{2}$, or $1 \mathrm{~b} / \mathrm{unit}$. The column headings show the units used in each table.

- Due to space limitations, the manufacturer of each product is denoted by a code number. The code numbers are identified in a list at the beginning of the book.

- The reference column identifies the laboratory where the acoustic test was performed and the test report number. The laboratory acronyms are explained in a list at the beginning of this book. Where no laboratory data were provided, the letters CR (company reference) appear, followed by the identifying number of the company publication from which the data were derived.

- Some products did not fit well into the format of the tables. The descriptive paragraph associated with each entry indicates any deviations from the table format. 
DATA TABLES 


\section{CATEGORY 1. ABSORPTIVE BLOCK}
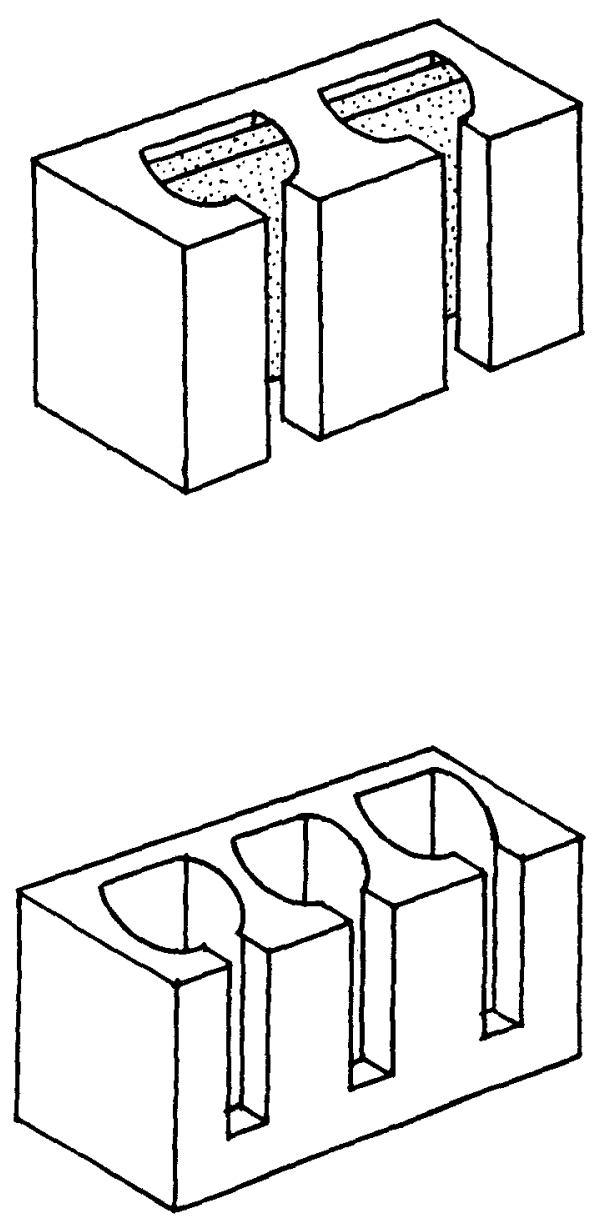


\section{CATEGORY 1. ABSORPTIVE BLOCK}

The sound absorption of concrete blocks with built-in cavities are listed. The absorption techniques of plain and damped Helmholtz resonators are used.

A block can be tuned for high absorption around a given frequency by the proper sizing of cavities and openings (slots, cuts, holes), as shown in the illustrations. The addition of absorptive material (fiberglass, mineral wool, foam, etc.) to the interior of the cavity, can provide a wider frequency range of absorption. The block also acts as a sound barrier. Additional provisions to enhance barrier performance are available. A properly balanced block offers a composite absorptive-barrier system. Organfzations contributing data to this table are: 101, 123, and 143.

\section{CAUTION}

1. ABSORPTION COEFFICIENTS MAY EXCEED 1.0. FOR A COMPLETE DISCUSSION OF THESE VALUES SEE PAGE 51.

2. THE NUMBERS LISTED UNDER THE "MOUNTING" COLUMN REFER TO THE AIMA STANDARD MOUNTINGS DESCRIBED ON PAGE 53. 
Table 1. Absorptive block.

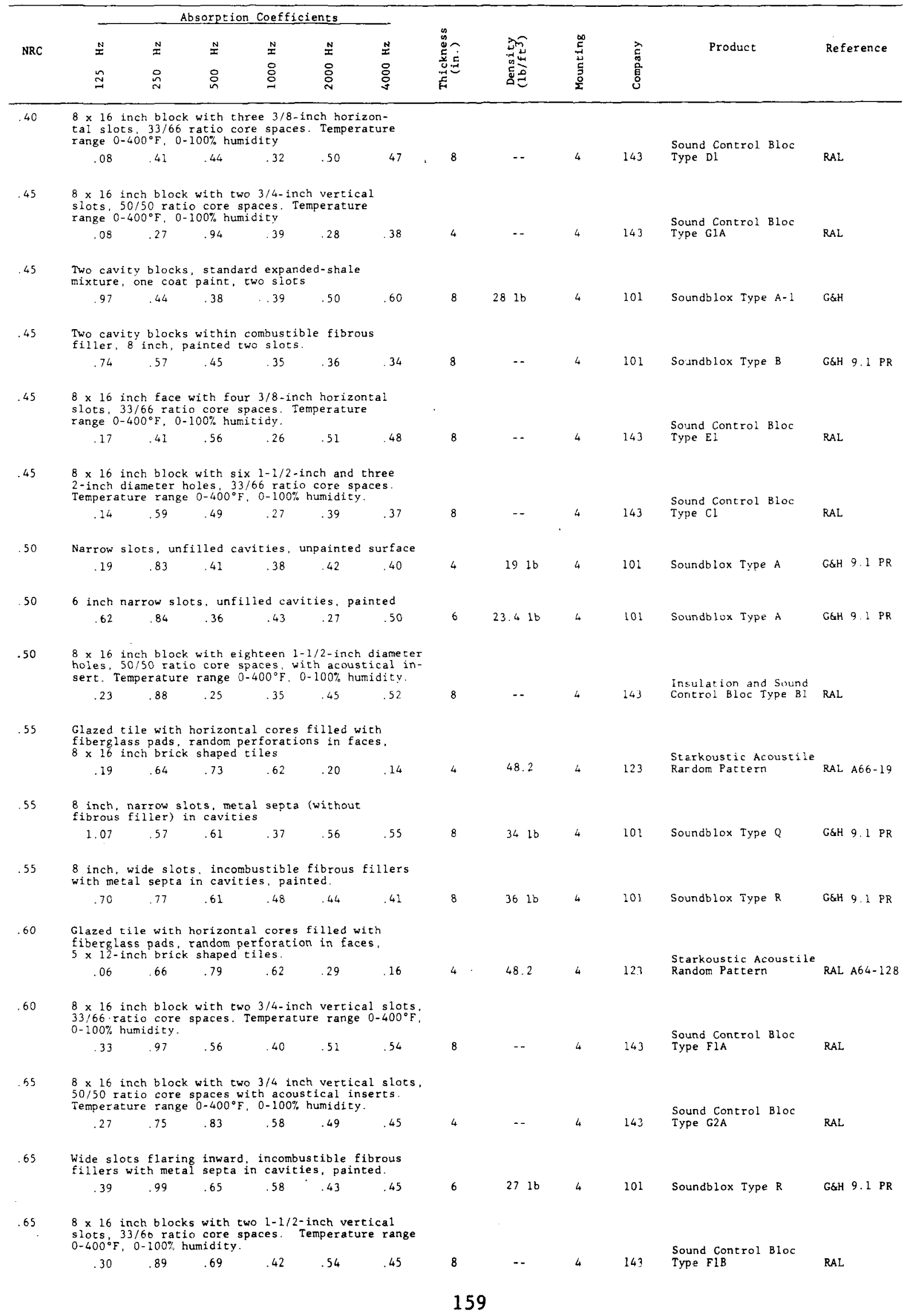


Table 1. Absorptive block concluded.

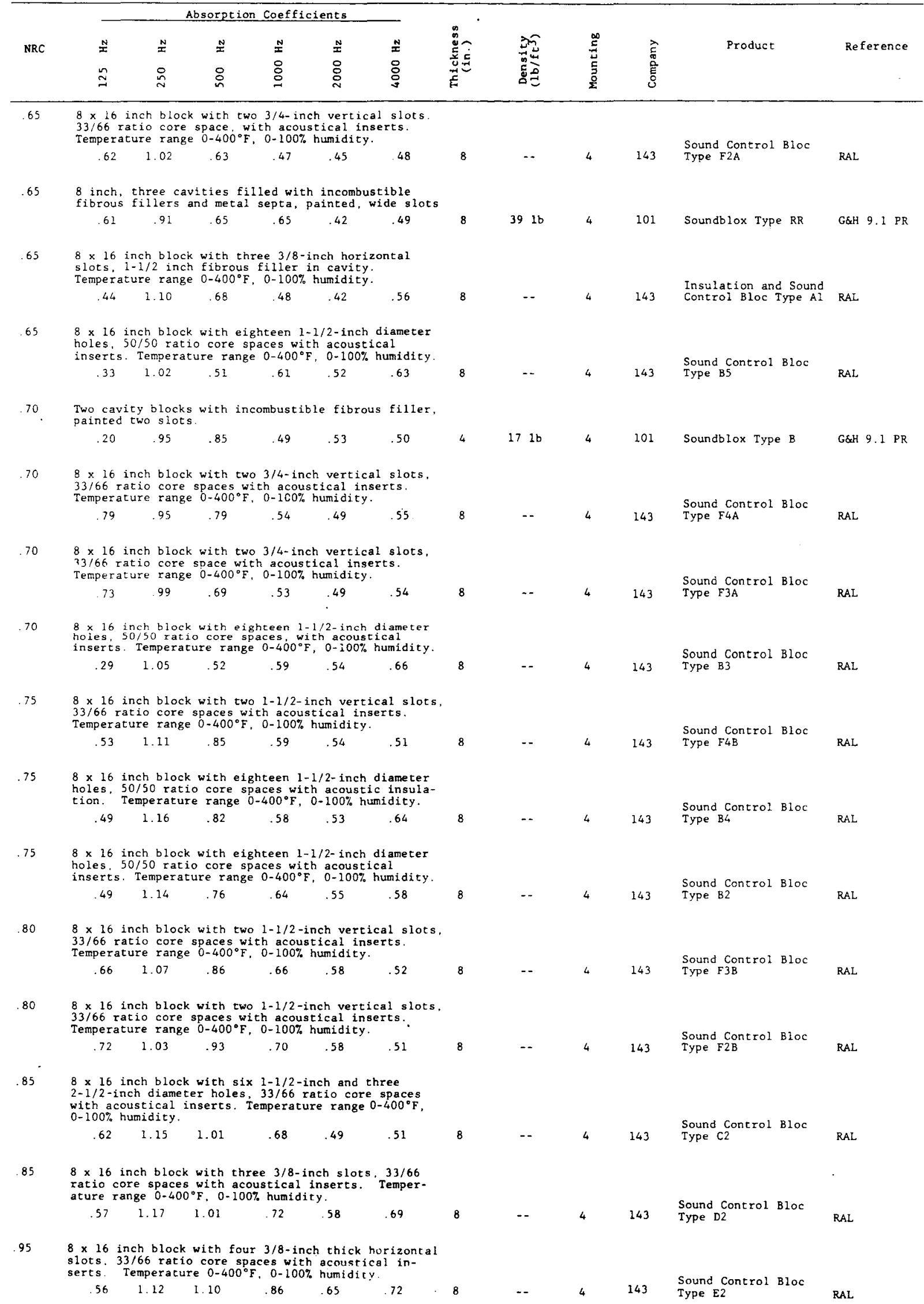




\section{CATEGORY 2, FOAM}
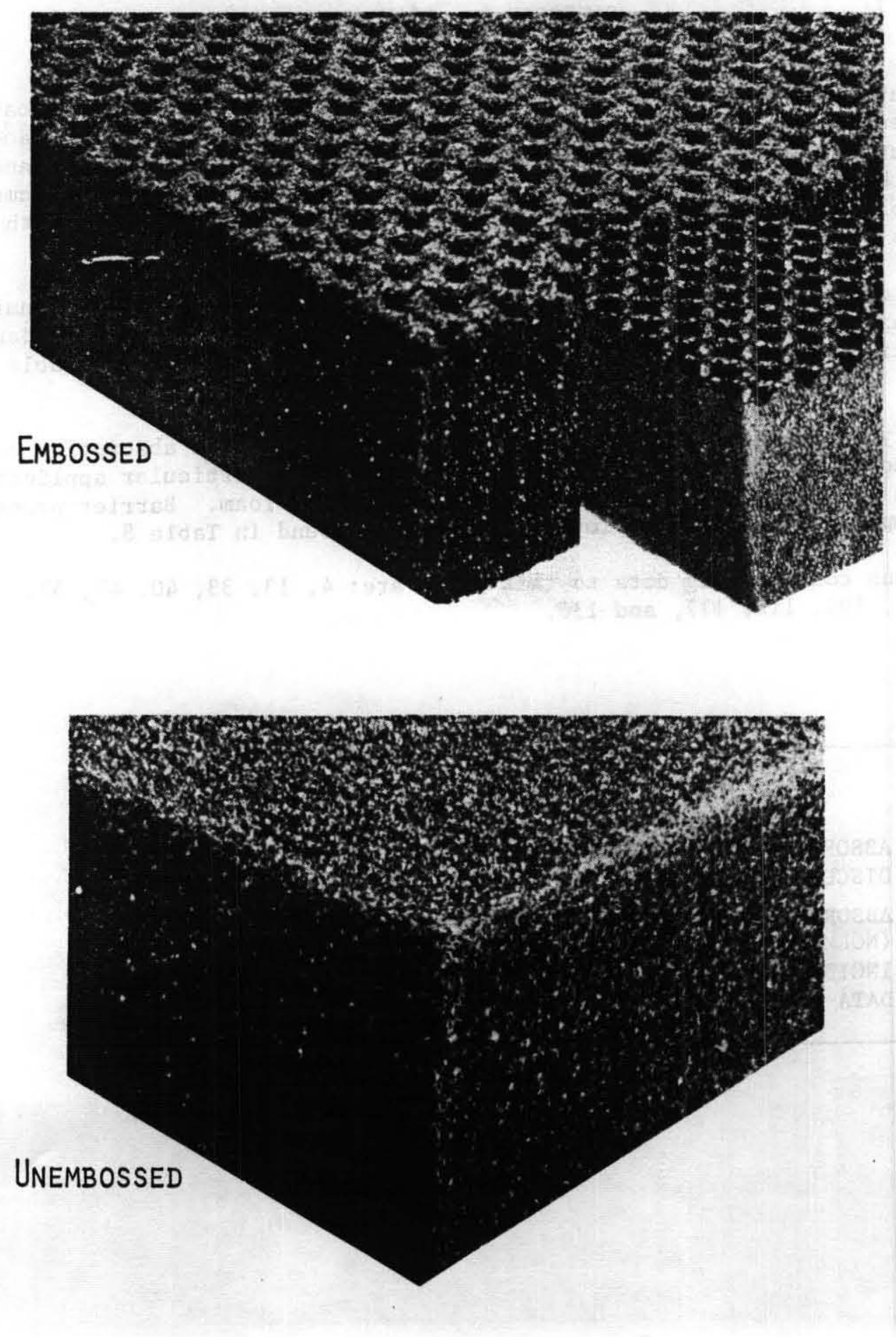
CATEGORY 2. FOAM

The sound absorption properties of various types of foams are listed. Foam has excellent absorption, provides a fair amount of vibration isolation and damping, but is a poor sound barrier material. Ester types of polyurethane foams are the most commonly used for noise reduction. These flexible foams are available in reticulated open-pore construction or nonreticulated with a microporous integral skin left intact.

Foams with convoluted surfaces and compressed feltlike foams are also manufactured to maximize absorption in specific frequency regions. Flame retardants and protective films for dirty or oily environments are commonly available options.

The porosity, thickness, and surface of a foam as well as its absorption coefficients should be considered in selecting a foam for a particular application. The data in this section are absorption coefficents of foam. Barrier properties of composite materials employing foam may be found in Table 8.

Organizations contributing data to this table are: $4,13,33,40,47,57,66$, $78,82,104,109,112,117$, and 130 .

\section{CAUTION}

1. ABSORPTION COEFFICIENTS MAY EXCEED 1.0. FOR A COMPLETE DISCUSSION OF THESE VALUES SEE PAGE 51.

2. ABSORPTION COEFFICIENTS. ARE SHOWN EITHER AS PERCENTAGES (NORMAL INCIDENCE DATA) OR AS DECIMAL FRACTIONS (RANDOM INCIDENCE DATA). THE DIFFERENCES BETWEEN THESE TWO DATA ARE DISCUSSED ON PAGE 56. 
Table 2. Foam.

Reproduced from

best available copy.

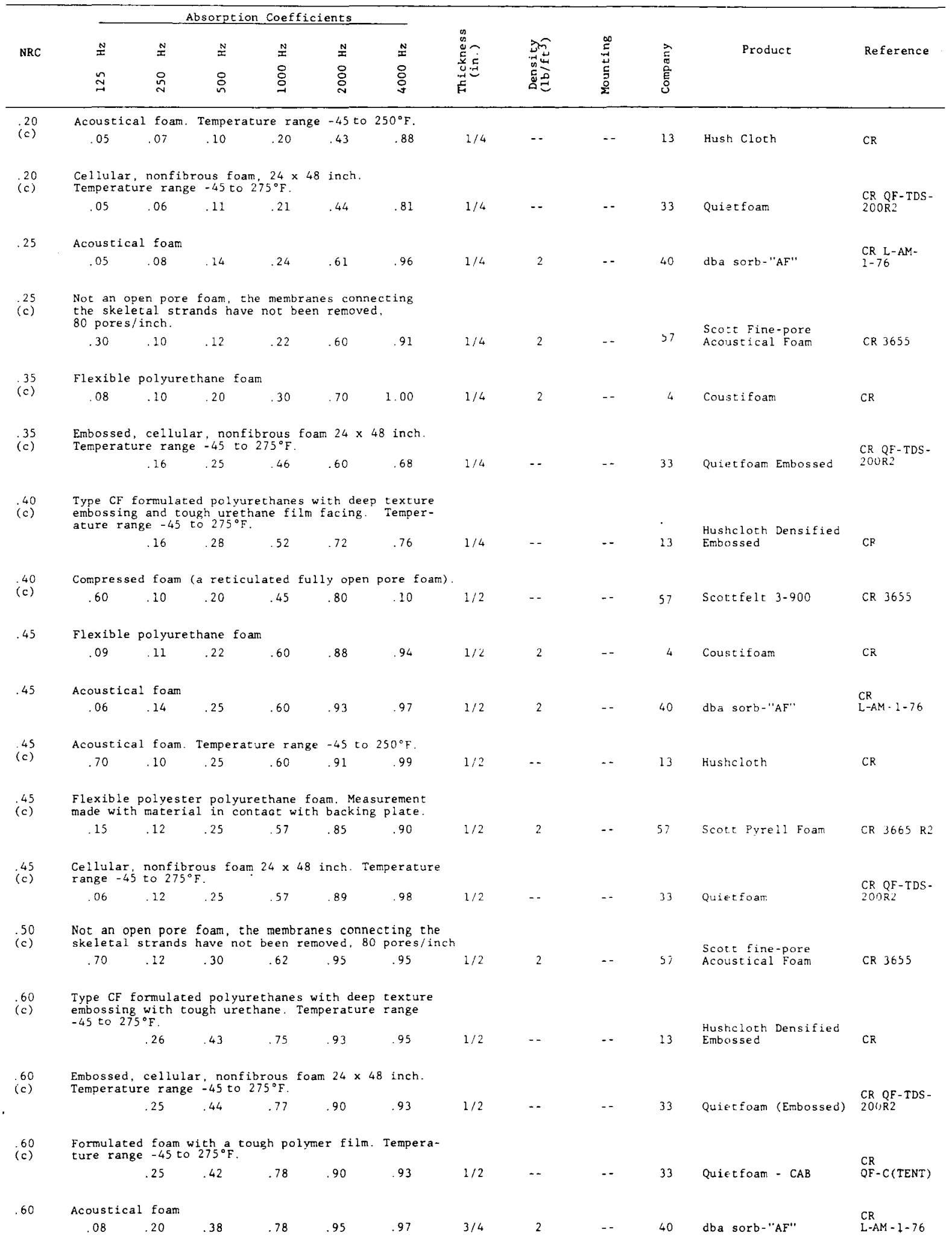


Table 2. Foam continued.

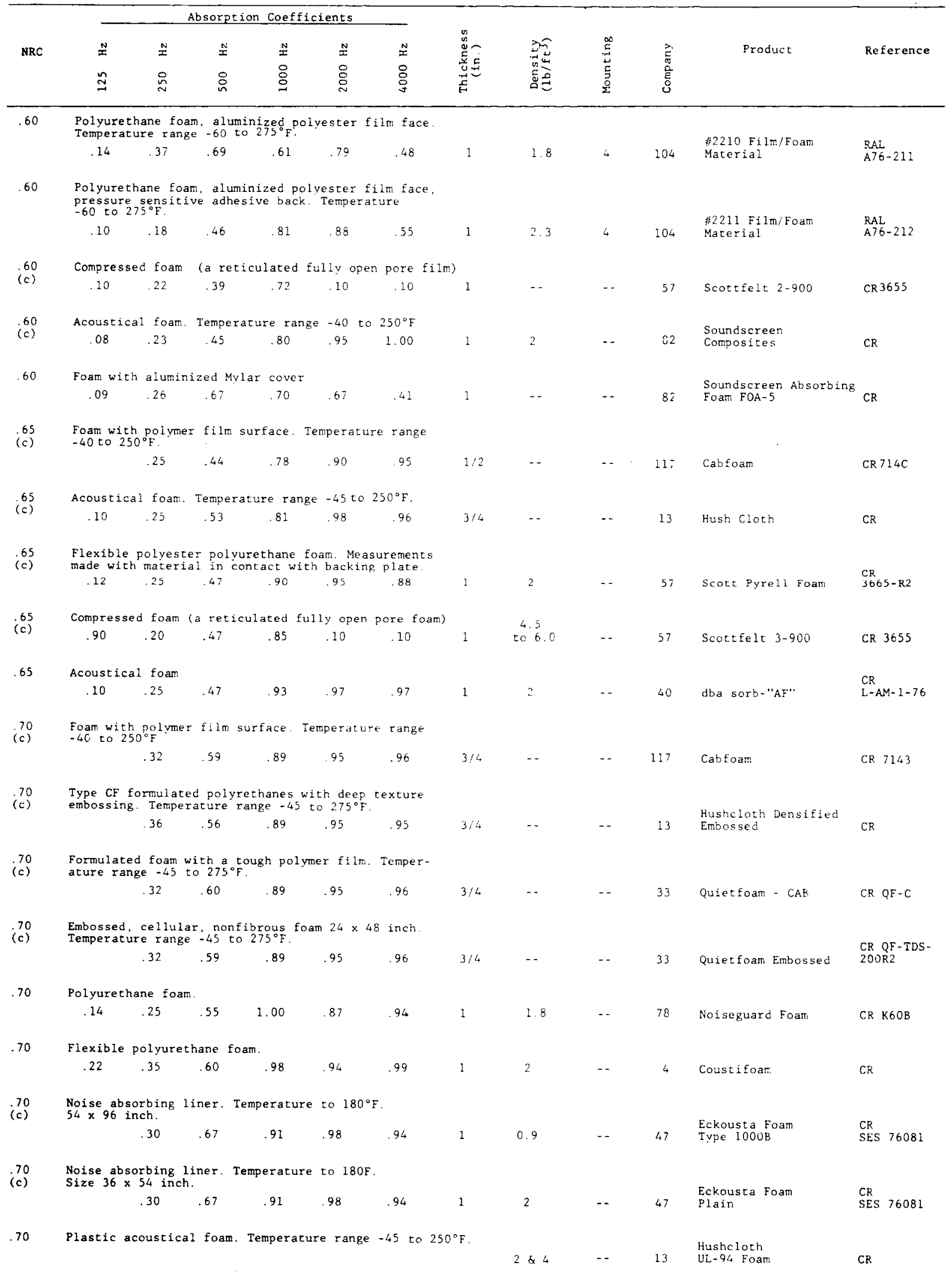


Table 2. Foam continued.

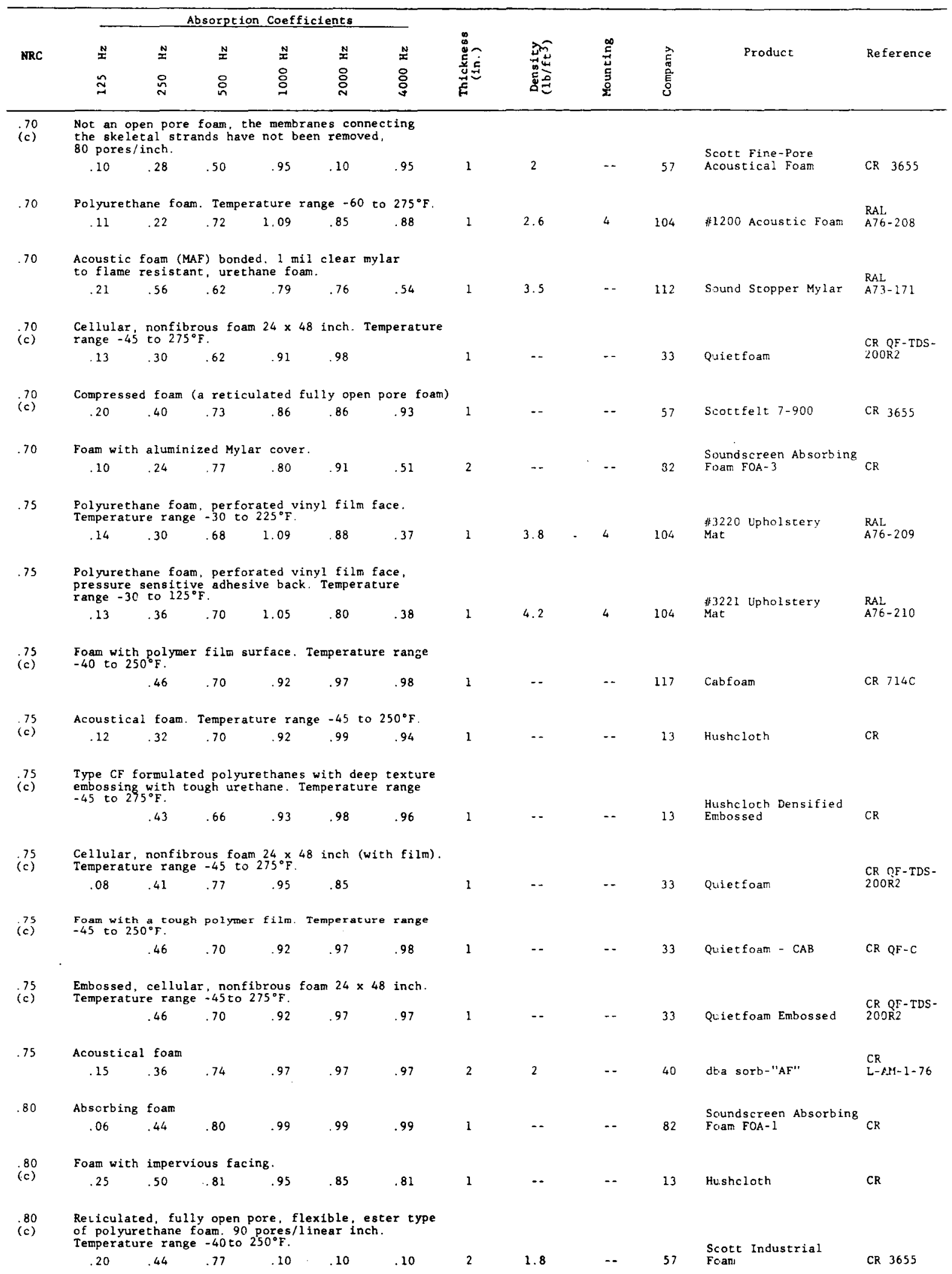


Table 2. Foam continued.

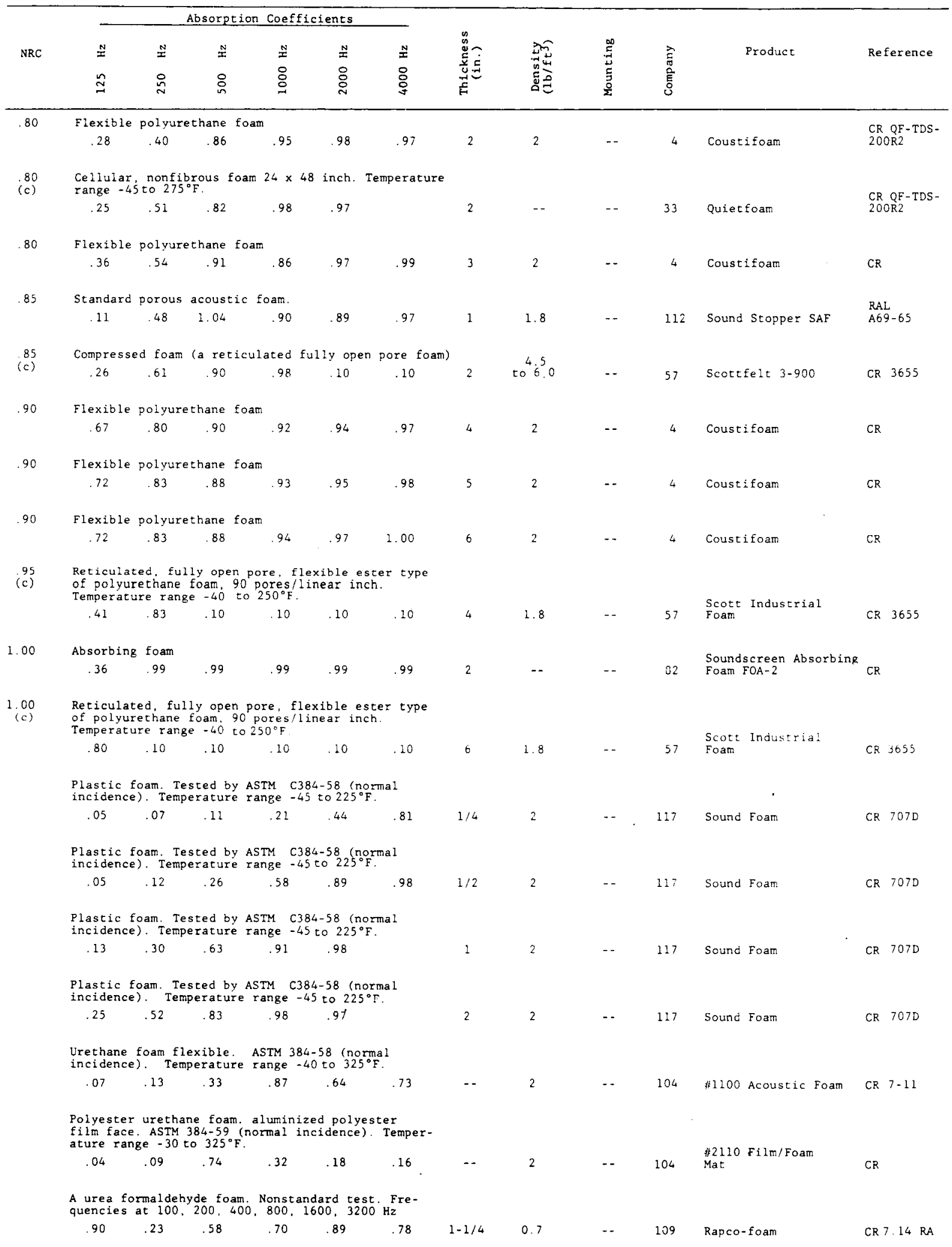


Table 2. Foam concluded.

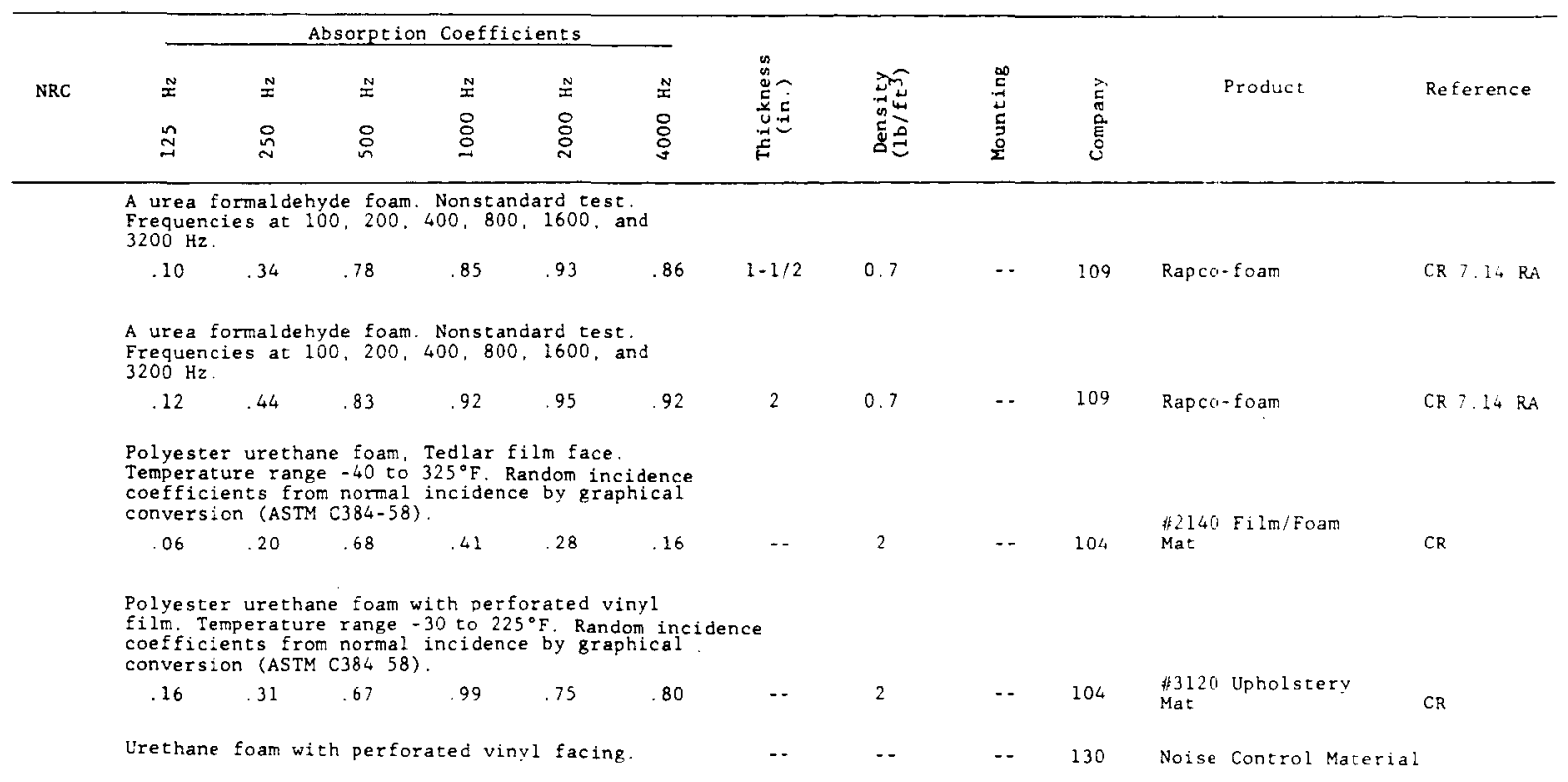


CATEGORY 3， FELT

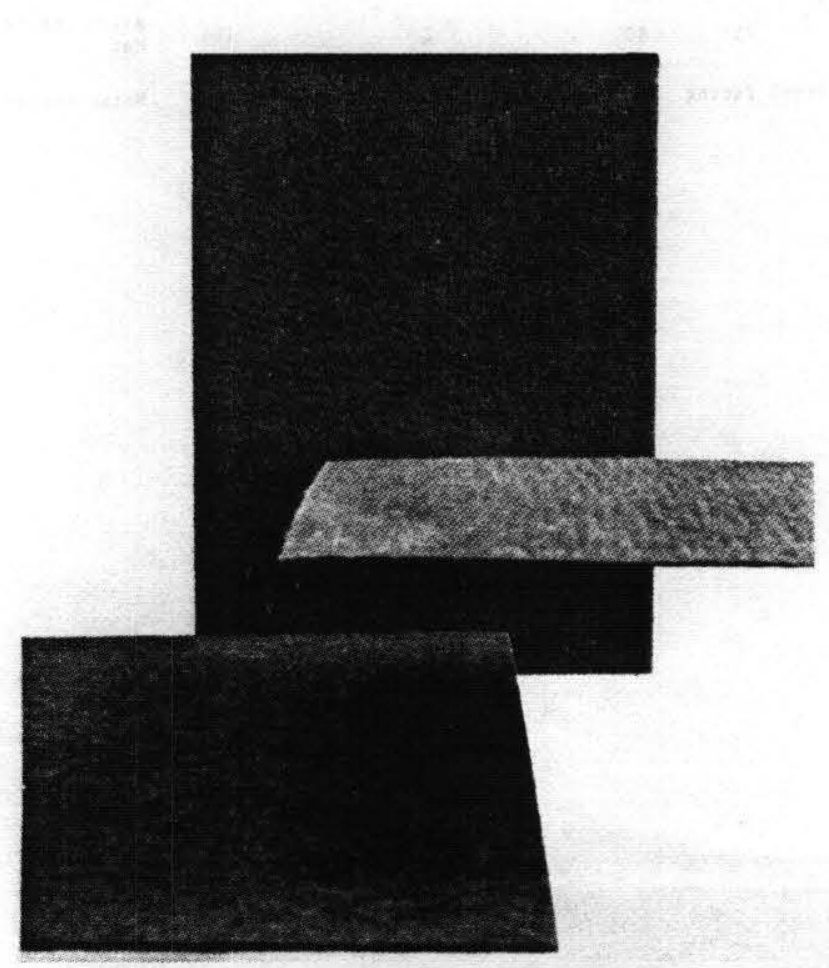


Felt is made of various fibers formulated together by pressure, heat, chemical action, etc., without weaving or knitting. In some cases felt is saturated with a massive substance such as asphalt, alumina, or silica. This offers a more moisture resistant product, with better thermo characteristics and some barrier properties.

Table 3 is divided into two parts:

3A Absorption Properties of Felt

3B Barrier Properties of Felt

Organizations contributing data to this table are: 28 and 74.

\section{CAUTION}

THE NUMBERS LISTED UNDER THE "MOUNTING" COLUMN REFER TO THE AIMA STANDARD MOUNTINGS DESCRIBED ON PAGE 53. 
Table 3A. Absorption properties of felt.

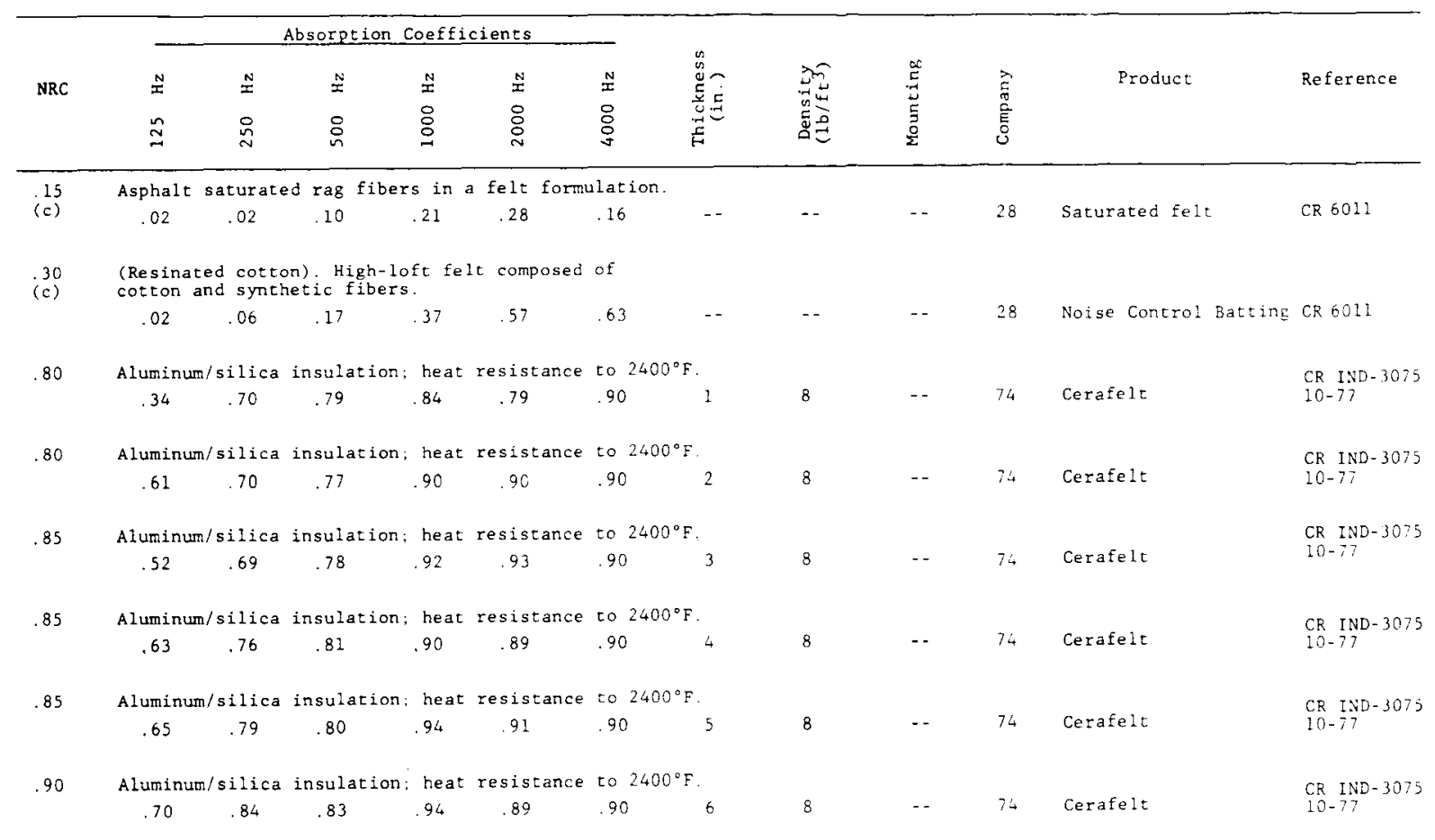

Table 3B. Barrier properties of felt.

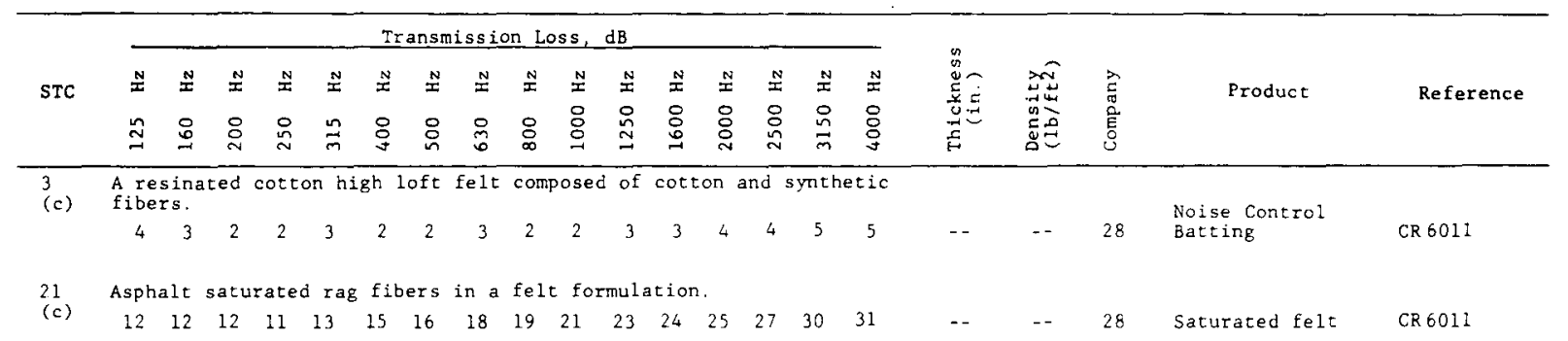




\section{CATEGORY 4. GLASS FIBER MATERIALS}

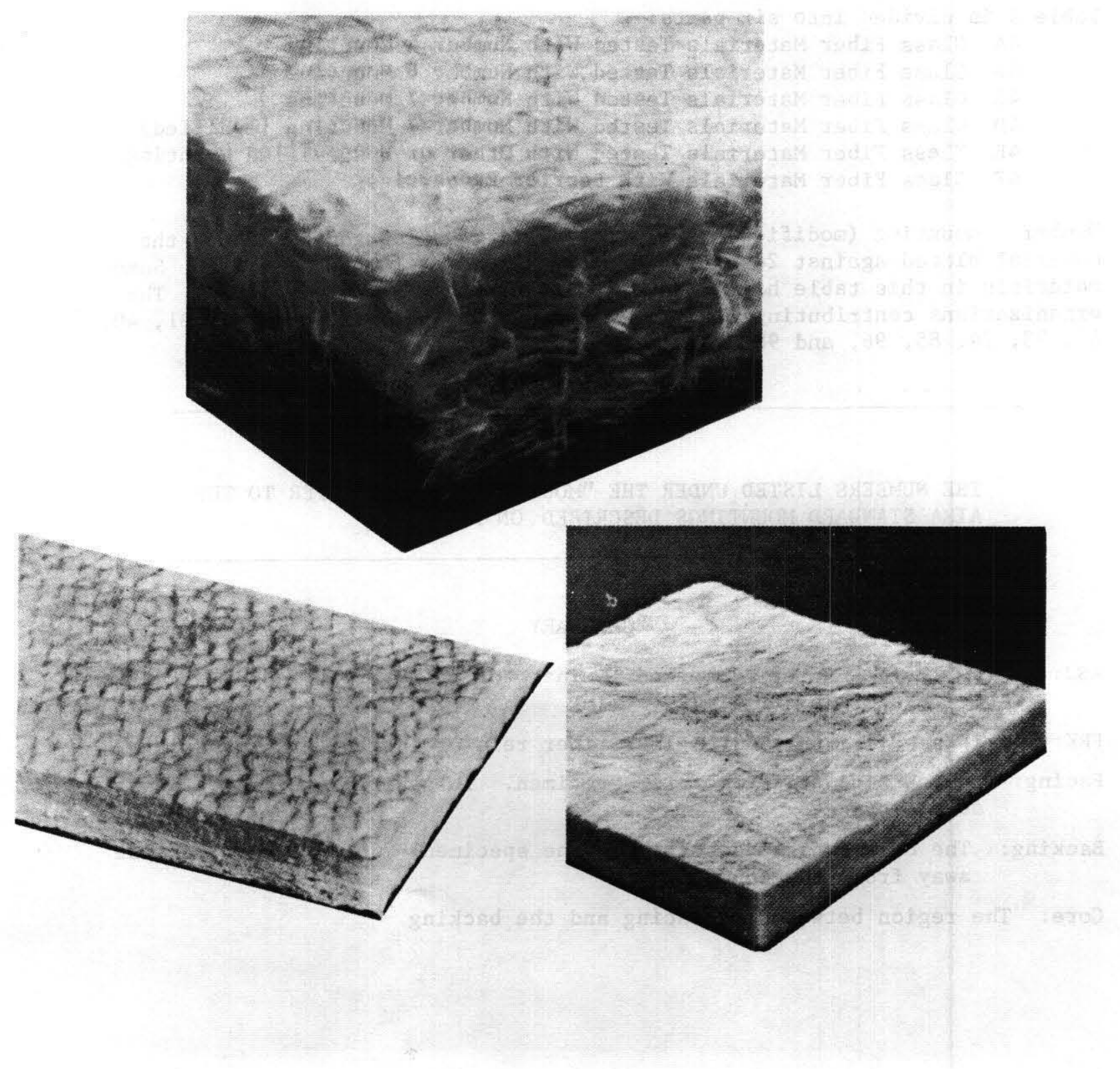


CATEGORY 4. GLASS FIBER MATERIALS

Long glass fibers when bonded with resins or other bonding materials convert acoustic energy into heat through air friction within the porous body of the material. However, glass fiber products are rather poor sound barrier materials.

Table 4 is divided into six parts:

4A Glass Fiber Materials Tested With Number 4 Mounting

4B Glass Fiber Materials Tested With Number 6 Mounting

4C Glass Fiber Materials Tested With Number 7 Mounting

4D Glass Fiber Materials Tested With Number 7 Mounting (modified)

4E Glass Fiber Materials Tested With Other or Unspecified Mounting

4F Glass Fiber Materials With Barrier Properties

Number 7 mounting (modified) is a nonstandard mounting consisting of the material placed against 24 gauge sheet metal over a 16 inch air gap. Some materials in this table have data associated with several mountings. The organizations contributing data to this table are: $13,20,27,29,31,40$, $47,73,74,85,96$, and 98 .

\section{CAUTION}

THE NUMBERS LISTED UNDER THE "MOUNTTNG" COLUMN REFER TO THE AIMA STANDARD MOUNTINGS DESCRTBED ON PAGE 53.

\section{GLOSSARY}

ASJ: (Al1-Service Jacket) Embossed laminate of white kraft facing with glass fiber reinforcing and foil backing

FRK: Foil-faced laminate with glass fiber reinforcing and kraft backing

Facing: The outside surface of the specimen. In general, the side facing the sound source

Backing: The other outside surface of the specimen. In general, the side away from the sound source.

Core: The region between the facing and the backing 
Table 4A. Glass fiber materials tested with number 4 mounting.

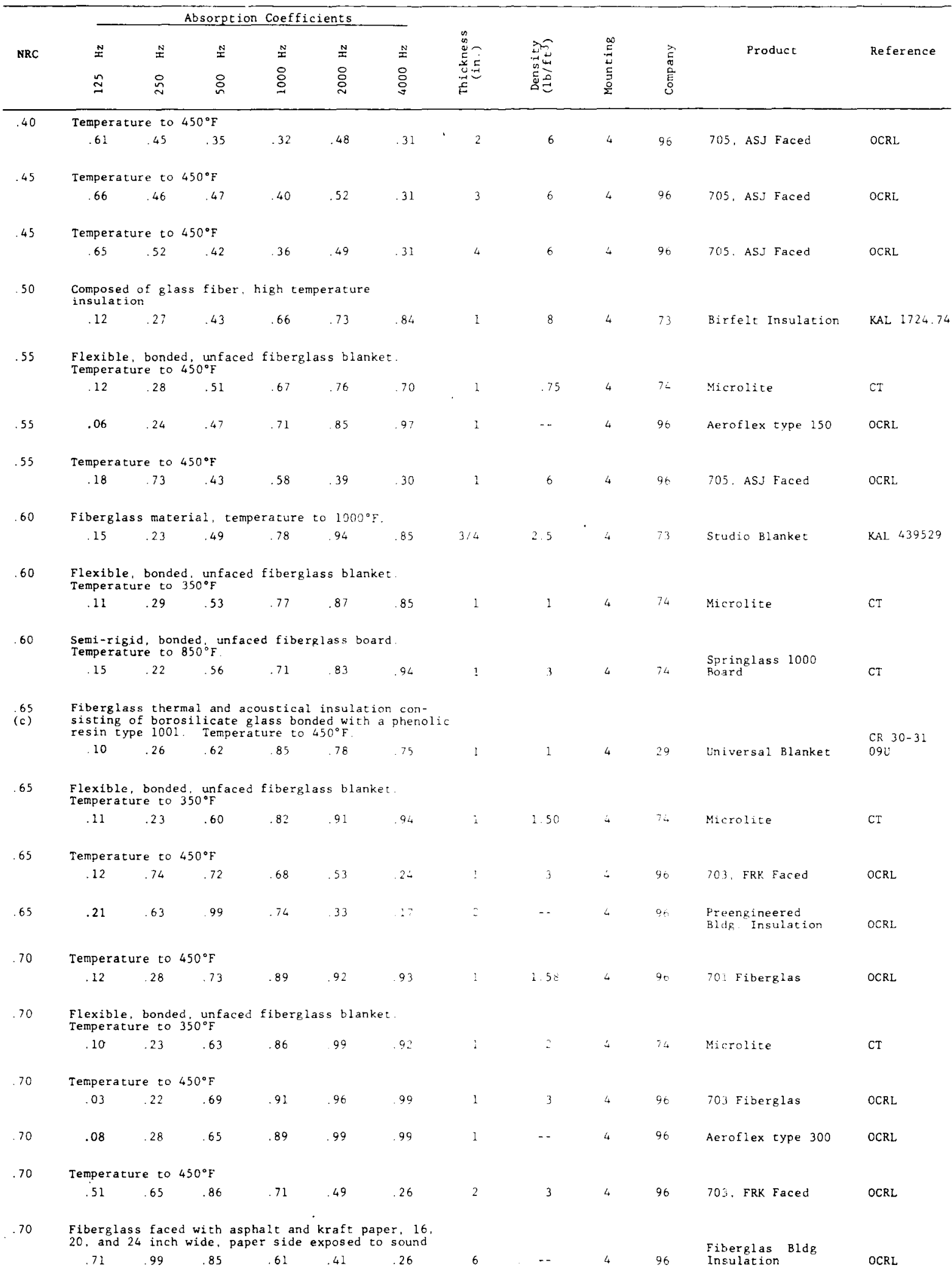


Table 4A. Glass fiber materials tested with number 4 mounting continued.

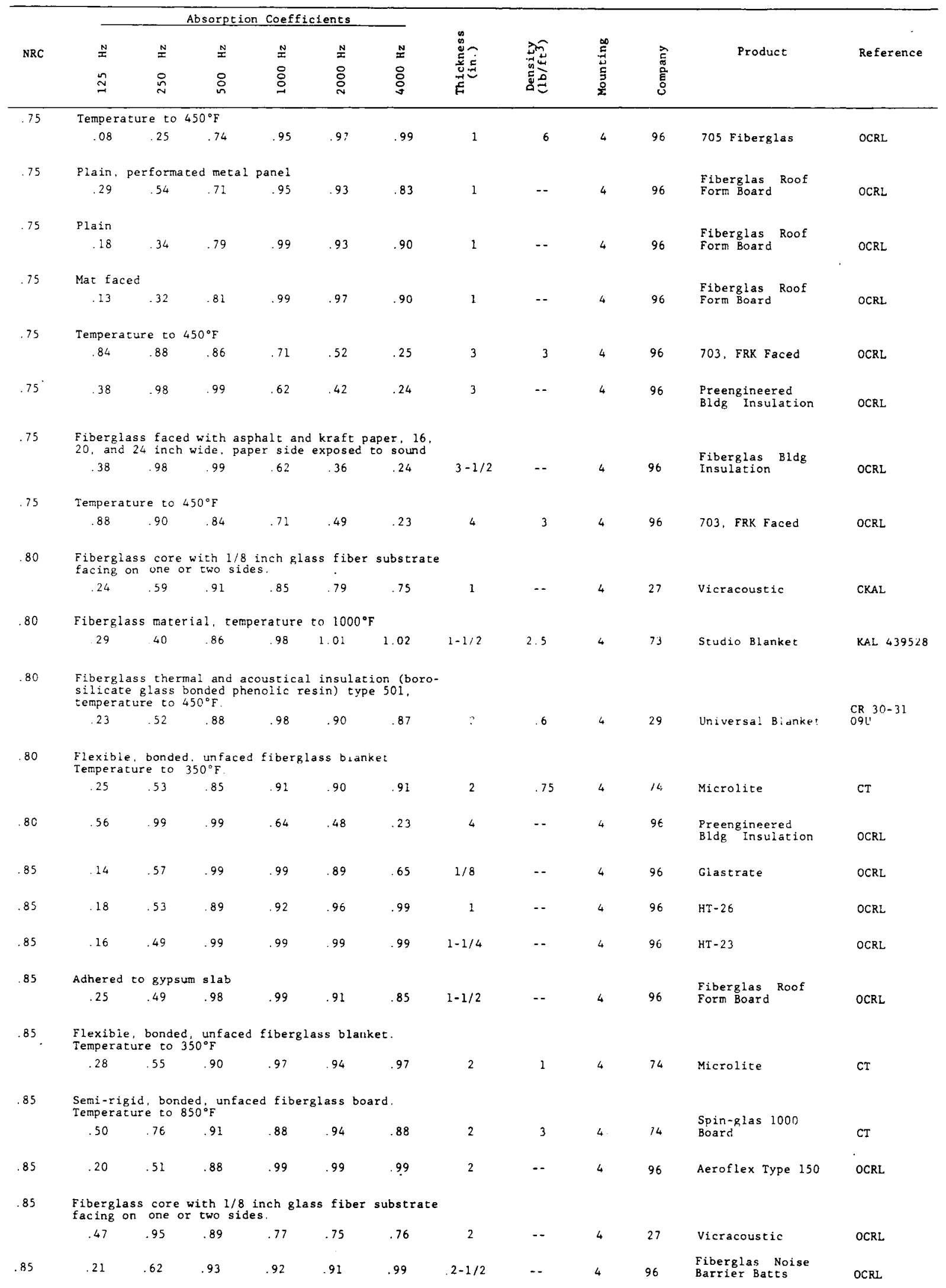


Table 4A. Glass fiber materials tested with number 4 mounting concluded.

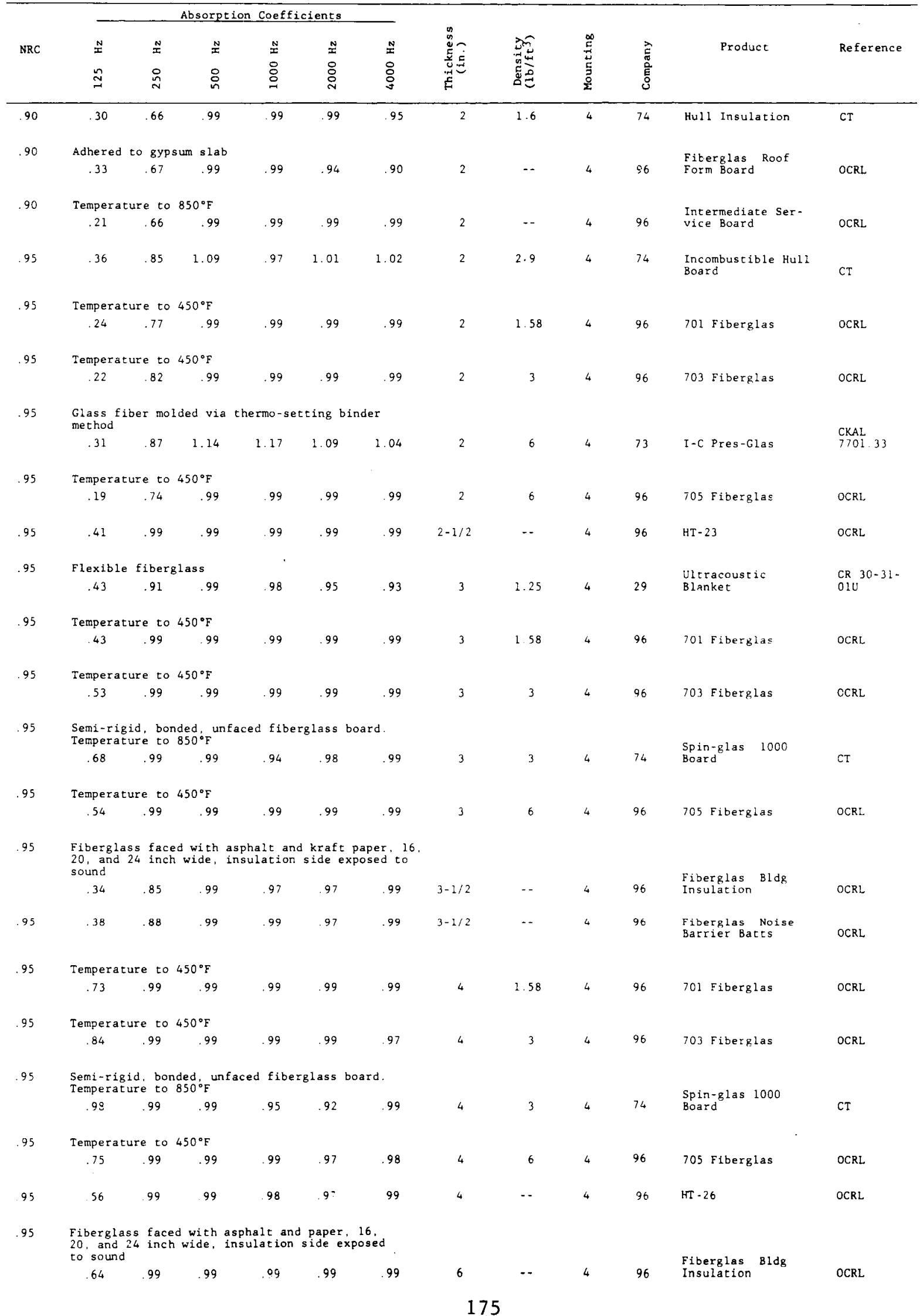


Table 4B. Glass fiber materials tested with number 6 mounting.

\begin{tabular}{|c|c|c|c|c|c|c|c|c|c|c|c|c|}
\hline \multirow{3}{*}{ NRC } & \multicolumn{6}{|c|}{ Absorption Coefficients } & \multirow{3}{*}{ 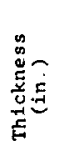 } & \multirow{3}{*}{ 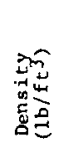 } & \multirow{3}{*}{ 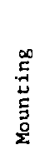 } & \multirow{3}{*}{$\begin{array}{l}\overrightarrow{\mathrm{E}} \\
\overrightarrow{0} \\
\mathrm{0} \\
\overline{\mathrm{E}} \\
\mathrm{U}\end{array}$} & \multirow{3}{*}{ Product } & \multirow{3}{*}{ Reference } \\
\hline & $\stackrel{N}{2}$ & $\stackrel{N}{x}$ & $\stackrel{N}{I}$ & $\stackrel{N}{ \pm}$ & $\stackrel{N}{x}$ & $\stackrel{N}{ \pm}$ & & & & & & \\
\hline & $\approx$ & $\stackrel{0}{i}$ & 8 & 号 & $\stackrel{\circ}{\circ}$ & 离 & & & & & & \\
\hline \multirow[t]{2}{*}{.20} & \multicolumn{3}{|c|}{ Temperature to $350^{\circ} \mathrm{F}$} & & & & & & & & & \\
\hline & .15 & .32 & .13 & .13 & .29 & .51 & $1 / 8$ & 6 & 6 & 74 & Exact-0-Board & CT \\
\hline \multirow[t]{2}{*}{.35} & \multicolumn{3}{|c|}{ Temperature to $250^{\circ} \mathrm{F}$} & & & & & & & & & \\
\hline & .16 & .37 & .25 & .34 & .51 & .73 & $1 / 4$ & 3 & 6 & 74 & Exact-0-Mat & CT \\
\hline \multirow[t]{2}{*}{.40} & \multirow{2}{*}{\multicolumn{3}{|c|}{ 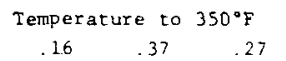 }} & & & & & & & & & \\
\hline & & .37 & & .40 & .54 & .59 & $1 / 4$ & 3 & 6 & 74 & Exact-O-Board & CT \\
\hline \multirow[t]{2}{*}{.45} & \multicolumn{3}{|c|}{ Temperature to $250^{\circ} \mathrm{F}$} & & & & & & & & & \\
\hline & .14 & .37 & .30 & .45 & .61 & .74 & $3 / 8$ & 2 & 6 & 74 & Exact-0-Mat & $\mathrm{CT}$ \\
\hline \multirow[t]{2}{*}{.45} & \multicolumn{3}{|c|}{ Temperature to $350^{\circ} \mathrm{F}$} & & & & & & & & & \\
\hline & .17 & .40 & .32 & .49 & .59 & .68 & $3 / 8$ & 2 & 6 & 74 & Exact-0-Board & CT \\
\hline \multirow[t]{2}{*}{.45} & \multicolumn{2}{|c|}{ Temperature to } & $250^{\circ} \mathrm{F}$ & & & & & & & & & \\
\hline & .17 & 39 & .36 & .50 & .64 & .78 & $1 / 2$ & 1.5 & 6 & 74 & Exact-0-Mat & CT \\
\hline .50 & Temper & e to & $350^{\circ} \mathrm{F}$ & & & & & & & & & \\
\hline & .18 & .43 & .40 & .53 & .67 & $: 78$ & $1 / 2$ & 1 & 6 & 74 & Microlite B & CT \\
\hline .55 & Temper & re to & $450^{\circ} \mathrm{F}$ & & & & & & & & & \\
\hline & .16 & .36 & .23 & .57 & .96 & .90 & $3 / 8$ & 1.5 & 6 & 74 & Microlite AA & CT \\
\hline .55 & Temper & ce to & $250^{\circ} \mathrm{F}$ & & & & & & & & & \\
\hline & .23 & 41 & 41 & .58 & .72 & .85 & $1 / 2$ & 1.9 & 6 & 74 & Tuf-Skin Microlite & CT \\
\hline .60 & Temper & te to & $450^{\circ} \mathrm{F}$ & & & & & & & & & \\
\hline & .18 & .39 & 37 & .72 & .95 & 99 & I & 42 & $b$ & 74 & Microlite AA & $\mathrm{CT}$ \\
\hline .60 & Temper & e to & $350^{\circ} \mathrm{F}$ & & & & & & & & & \\
\hline & .22 & .46 & .51 & .64 & .74 & .78 & 1 & .5 & 6 & 74 & Microlite B & $\mathrm{CT}$ \\
\hline .65 & Temper & e to & $350^{\circ} \mathrm{F}$ & & & & & & & & & \\
\hline & 26 & .50 & .55 & .69 & .79 & .86 & 1 & .6 & 6 & 74 & Microlite B & $\mathrm{CT}$ \\
\hline .65 & Temper & e to & $250^{\circ} \mathrm{F}$ & & & & & & & & & \\
\hline & .26 & .51 & .56 & .67 & .77 & .79 & 1 & .75 & 6 & 74 & Exact-0-Mat & $C T$ \\
\hline .65 & Temper & e to & $350^{\circ} \mathrm{F}$ & & & & & & & & & \\
\hline & 32 & .56 & .58 & .67 & .73 & .76 & 1 & .8 & 6 & 74 & Spin-Glass SG-28 & CT \\
\hline .65 & Temper & e to & $250^{\circ} \mathrm{F}$ & & & & & & & & & \\
\hline & .24 & .53 & .59 & .71 & .81 & .86 & 1 & 1 & 6 & 74 & Exact-0-Mat & CT \\
\hline .70 & Temper & re to & $250^{\circ} \mathrm{F}$ & & & & & & & & & \\
\hline & .26 & .51 & .63 & .83 & .91 & .94 & 1 & 1.75 & 6 & 74 & Tuf-Skin Microlite & CT \\
\hline .70 & Temper & re to & $450^{\circ} \bar{F}$ & & & & & & & & & \\
\hline & .18 & .41 & .50 & .92 & .99 & .9 .6 & 1 & 60 & 6 & 74 & Microlite AA & $\mathrm{CT}$ \\
\hline .70 & Temper & re to & $350^{\circ} \mathrm{F}$ & & & & & & & & & \\
\hline & .31 & .52 & .59 & .79 & .81 & .92 & 1 & I & 6 & 74 & Spin-Giass SG-26 & CT \\
\hline .70 & Temper & to to & $350^{\circ} \mathrm{F}$ & & & & & & & & & \\
\hline & .26 & .53 & .59 & .77 & .88 & .94 & 1 & 1 & 6 & 74 & Microlite B & CT \\
\hline .70 & Temper & ee to & $350^{\circ} \mathrm{F}$ & & & & & & & & & \\
\hline & .26 & .53 & .60 & .77 & .84 & .87 & 1 & 1.2 & 6 & 74 & Spin-Glas SG-25 & CT \\
\hline .70 & Temper & e to & $350^{\circ} \mathrm{F}$ & & & & & & & & & \\
\hline & 23 & 54 & 64 & .81 & .89 & .91 & 1 & 1.5 & 6 & 74 & Spin-Glas SG-24 & CT \\
\hline
\end{tabular}


Table 4B. Glass fiber materials tested with number 6 mounting continued.

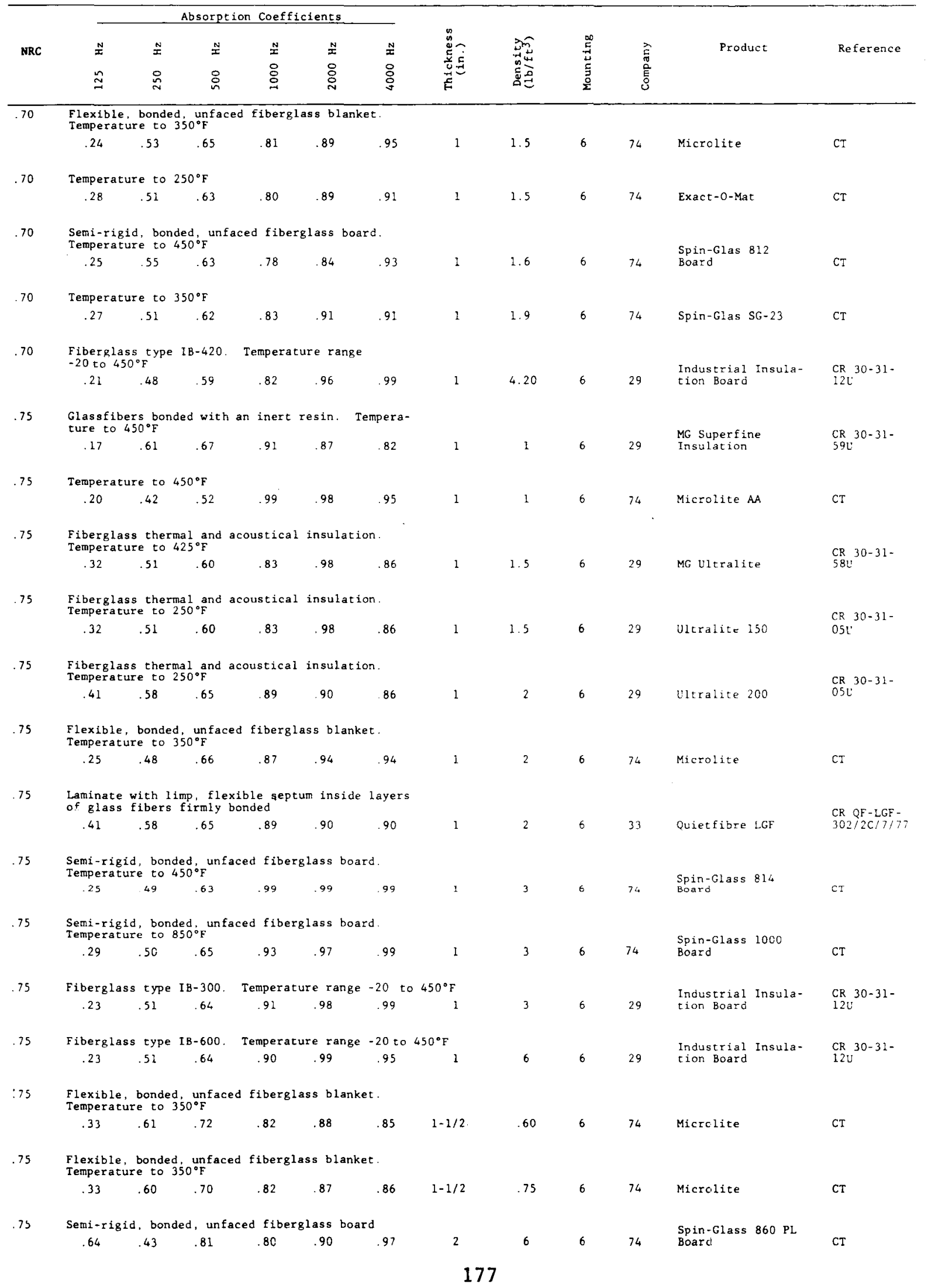


Table 4B. Glass fiber materials tested with number 6 mounting continued.

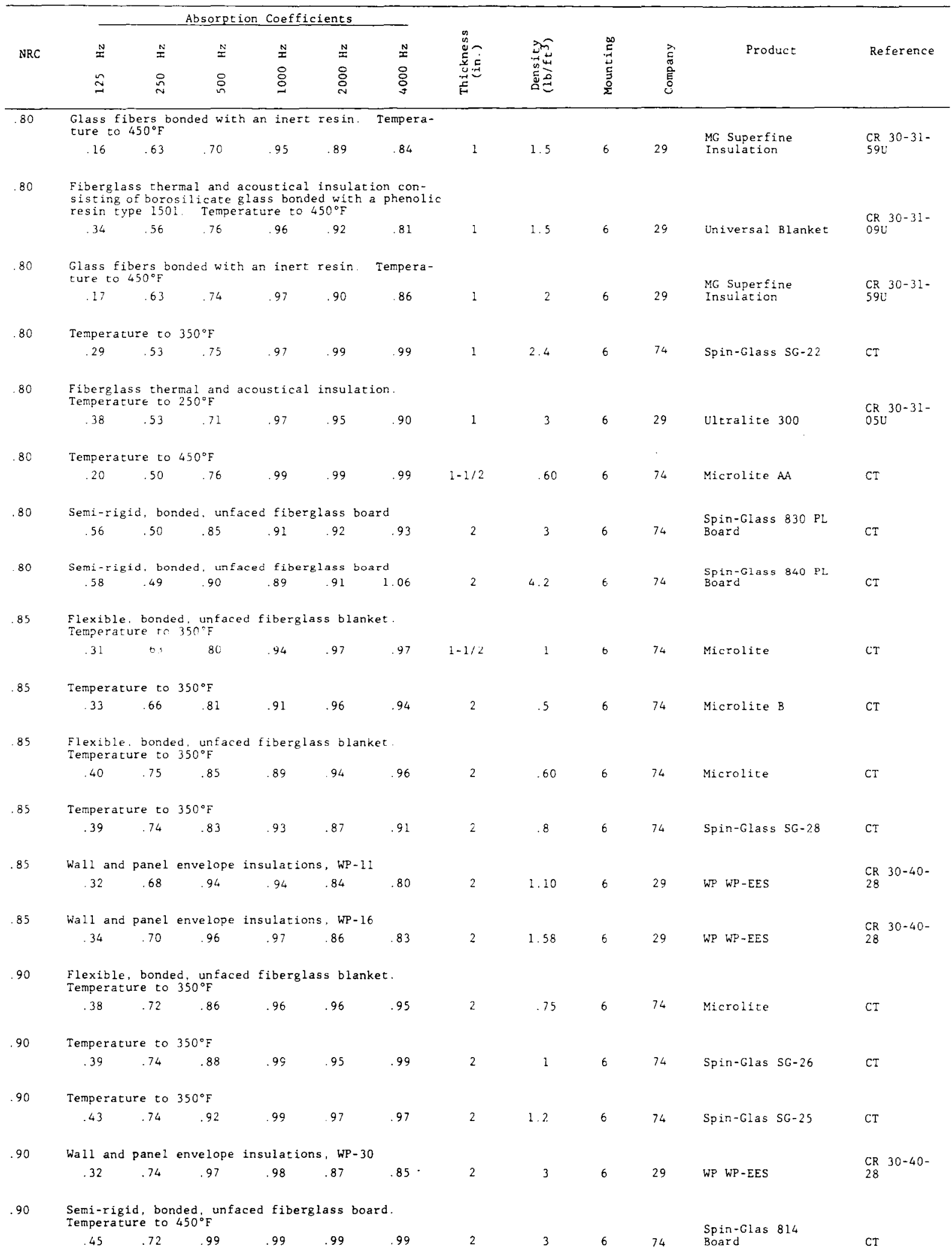


Table 4B. Glass fiber materials tested with number 6 mounting concluded.

\begin{tabular}{|c|c|c|c|c|c|c|c|c|c|c|c|}
\hline \multirow{3}{*}{ NRC } & \multicolumn{5}{|c|}{ Absorption Coefficients } & \multirow{3}{*}{ 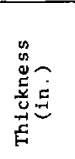 } & \multirow{3}{*}{ 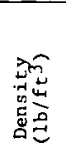 } & \multirow{3}{*}{ 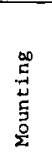 } & \multirow{3}{*}{$\begin{array}{l}\overrightarrow{\hat{\pi}} \\
\hat{\tilde{0}} \\
\overline{\tilde{\delta}} \\
0\end{array}$} & \multirow{3}{*}{ Product } & \multirow{3}{*}{ Reference } \\
\hline & $\stackrel{N}{I}$ & $\stackrel{N}{工}$ & $\stackrel{N}{x}$ & $\stackrel{N}{x}$ & $\stackrel{N}{I}$ & & & & & & \\
\hline & $\stackrel{\circ}{i}$ & $\stackrel{8}{\circ}$ & $\stackrel{8}{9}$ & 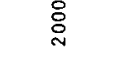 & 号 & & & & & & \\
\hline \multirow{2}{*}{.90} & Wall and panel & envelope $i$ & insula & Dns, WP -40 & & & & & & & CR 30-40= \\
\hline & $.27 \quad .79$ & .98 & .99 & .88 & .86 & 2 & 4 & 6 & 29 & WP WP-EES & 22 \\
\hline \multirow[t]{2}{*}{.90} & Wall and panel & envelope $i$ & insula & ons. WP-60 & & & & & & & \\
\hline & $.48 \quad .82$ & .97 & .99 & .90 & .86 & 2 & 6 & 6 & 29 & WP WP-EES & 28 \\
\hline \multirow[t]{2}{*}{.95} & Temperature to & $250^{\circ} \mathrm{F}$ & & & & & & & & & \\
\hline & $.48 \quad .85$ & .99 & .99 & .99 & .99 & 2 & 1.5 & 6 & $7 / 6$ & Tuf-Skin Microlite & $\mathrm{CT}$ \\
\hline \multirow[t]{2}{*}{.95} & Temperature to & $350^{\circ} \mathrm{F}$ & & & & & & & & & \\
\hline & $.48 \quad .75$ & .97 & .99 & 99 & 99 & 2 & 1.5 & 6 & 74 & Spin-G1as SG-24 & $\mathrm{CT}$ \\
\hline \multirow[t]{2}{*}{.95} & $\begin{array}{l}\text { Semi-rigid, bon } \\
\text { Temperature to }\end{array}$ & 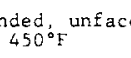 & & glass boar & & & & & & & \\
\hline & $.47 \quad .77$ & .96 & .99 & .99 & .99 & 2 & 1.6 & 6 & 74 & Board & $\mathrm{CT}$ \\
\hline \multirow[t]{2}{*}{.95} & Temperature to & $350^{\circ} \mathrm{F}$ & & & & & & & & & \\
\hline & $.43 \quad .76$ & .99 & .99 & .99 & 99 & 2 & 1.9 & 6 & 74 & Spin-Glas SG-23 & $\mathrm{CT}$ \\
\hline \multirow[t]{2}{*}{.95} & Temperature to & $350^{\circ} \mathrm{F}$ & & & & & & & & & \\
\hline & .87 & .99 & .99 & .99 & .99 & 2 & $2-4$ & 6 & 74 & Spin-Glas SG-22 & $\mathrm{CT}$ \\
\hline \multirow[t]{2}{*}{.95} & Temperature to & $350^{\circ} \mathrm{F}$ & & & & & & & & & \\
\hline & .92 & .99 & .99 & .99 & 99 & 3 & .8 & 6 & 74 & Spin-Glas SG-28 & $\mathrm{CT}$ \\
\hline \multirow[t]{2}{*}{.95} & Temperature to & $350^{\circ} \mathrm{F}$ & & & & & & & & & \\
\hline & .91 & .99 & .99 & .99 & .99 & 3 & 1 & 6 & 74 & Spin-Glas SG-26 & CT \\
\hline \multirow[t]{2}{*}{.95} & Temperature to & $350^{\circ} \mathrm{F}$ & & & & & & & & & \\
\hline & .94 & .99 & 99 & .39 & .99 & 3 & $1-2$ & 6 & 74 & Spin-G1as SG-25 & $\mathrm{CT}$ \\
\hline \multirow[t]{2}{*}{.95} & Temperature to & $350^{\circ} \mathrm{F}$ & & & & & & & & & \\
\hline & .94 & .99 & .99 & 99 & .99 & 3 & 1.5 & 6 & 74 & Spin-Glas SG-24 & CT \\
\hline \multirow[t]{2}{*}{.95} & Temperature to & $350^{\circ} \mathrm{F}$ & & & & & & & & & \\
\hline & .99 & .99 & .99 & .99 & .99 & 3 & 2.9 & 6 & 74 & Spin-Glas SG-23 & $\mathrm{CT}$ \\
\hline \multirow[t]{2}{*}{.95} & $\begin{array}{l}\text { Semi-rigid, bon } \\
\text { Temperature to }\end{array}$ & $\begin{array}{l}\text { nded, }{ }^{\circ} \text { unfac } \\
850^{\circ} \mathrm{F}\end{array}$ & & glass board & & & & & & Spin-Glas 1000 & \\
\hline & $.71 \quad .99$ & .99 & .99 & .99 & .99 & 3 & 3 & 6 & 74 & Board & CT \\
\hline \multirow[t]{2}{*}{95} & $\begin{array}{l}\text { Semi-rigid, bon } \\
\text { Temperature to }\end{array}$ & $\begin{array}{l}\text { nded, unfac } \\
850^{\circ} \mathrm{F}\end{array}$ & & glass board & & & & & & & \\
\hline & $.48 \quad .74$ & .99 & .99 & 99 & .99 & 2 & 3 & 6 & 74 & $\begin{array}{l}\text { Spin-Glas } 1000 \\
\text { Board }\end{array}$ & CI \\
\hline \multirow[t]{2}{*}{.95} & Temperature to & $350^{\circ} \mathrm{F}$ & & & & & & & & & \\
\hline & $.72 \quad .99$ & .99 & .99 & .99 & .99 & 4 & 8 & 6 & 74 & Spin-G1as SG-28 & CT \\
\hline \multirow[t]{2}{*}{.95} & Temperature to & $350^{\circ} \mathrm{F}$ & & & & & & & & & \\
\hline & $.74 \quad .99$ & .99 & 99 & .99 & 99 & 4 & 1 & 6 & 74 & Spin-Glas SG-26 & CI \\
\hline \multirow[t]{2}{*}{95} & $\begin{array}{l}\text { Semi-rigid, bon } \\
\text { Temperature to }\end{array}$ & $\begin{array}{l}\text { nded, unfac } \\
850^{\circ} \mathrm{F}\end{array}$ & & glass board & & & & & & Spin-Glas 1000 & \\
\hline & .89 & 99 & .99 & .99 & .99 & 4 & 3 & 6 & 74 & Board & CT \\
\hline
\end{tabular}


Table 4C. Glass fiber materials tested with number 7 mounting.

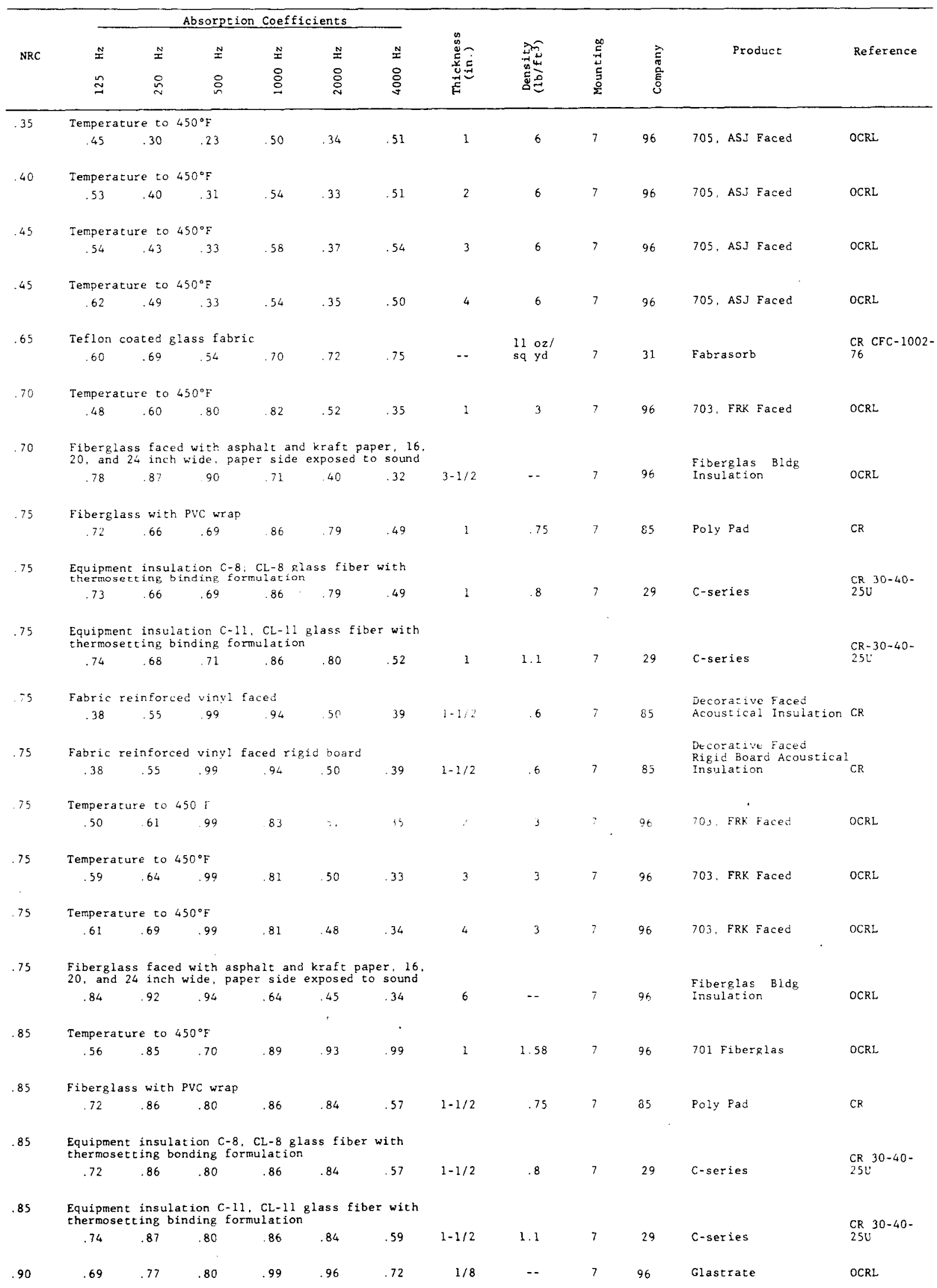


Table 4C. Glass fiber materials tested with number 7 mounting continued.

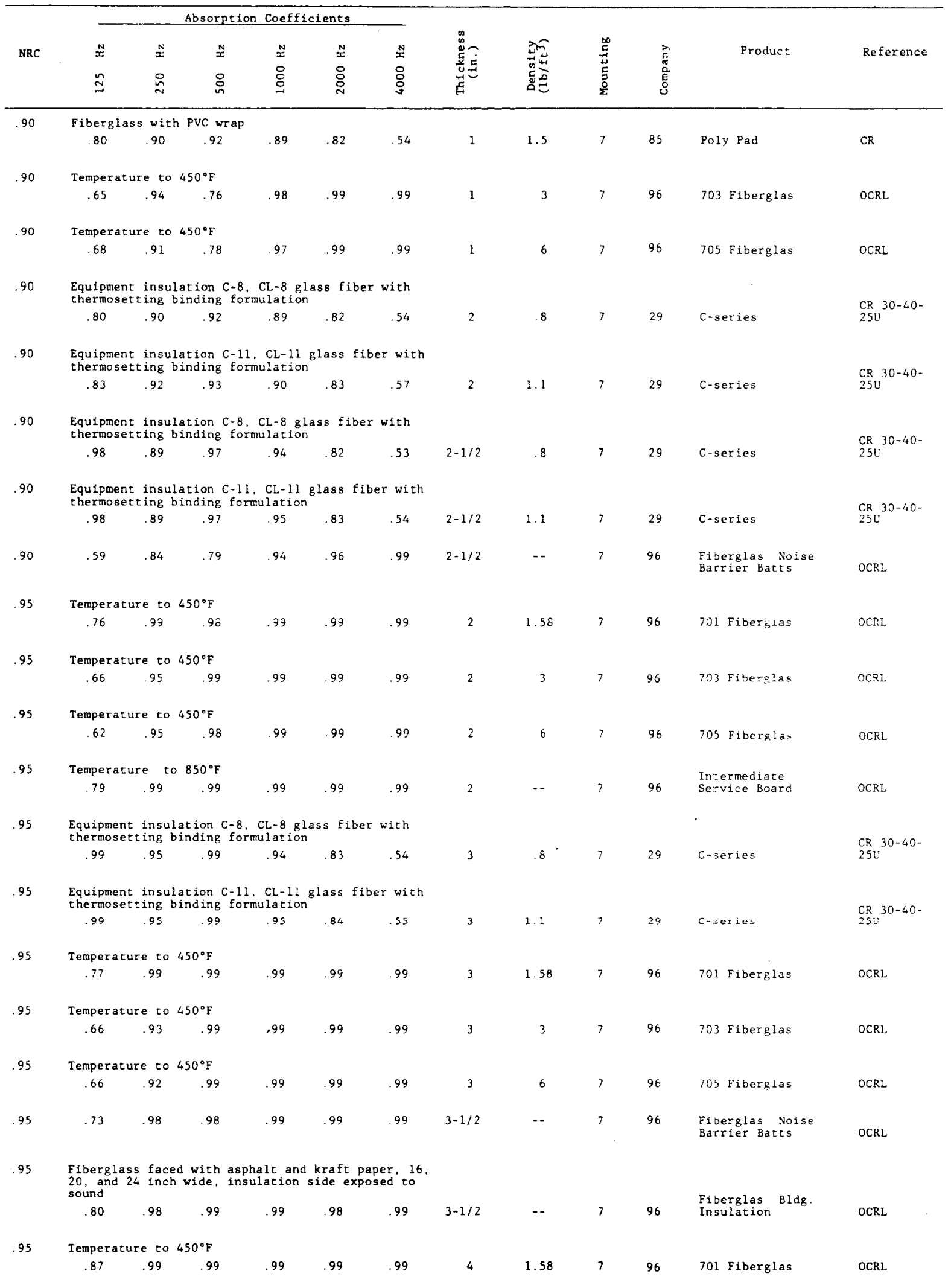


Table 4C. Glass fiber materials tested with number 7 mounting concluded.

\begin{tabular}{|c|c|c|c|c|c|c|c|c|c|c|c|c|}
\hline \multirow{3}{*}{ NRC } & \multicolumn{6}{|c|}{ Absorption Coefficients } & \multirow{3}{*}{ 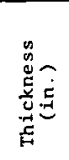 } & \multirow{3}{*}{ 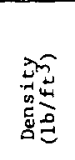 } & \multirow{3}{*}{$\begin{array}{l}\stackrel{\infty}{E} \\
\stackrel{D}{E} \\
\frac{0}{2}\end{array}$} & \multirow{3}{*}{$\begin{array}{l}\overrightarrow{\vec{\sigma}} \\
\text { O. } \\
\text { 言 } \\
\text { o }\end{array}$} & \multirow{3}{*}{ Product } & \multirow{3}{*}{ Reference } \\
\hline & $\stackrel{N}{x}$ & $\stackrel{N}{=}$ & $\stackrel{N}{I}$ & $\stackrel{N}{I}$ & $\stackrel{N}{x}$ & $\stackrel{N}{I}$ & & & & & & \\
\hline & $\cong$ & $\stackrel{D}{\sim}$ & 品 & $\stackrel{8}{\circ}$ & : & 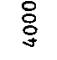 & & & & & & \\
\hline \multirow[t]{2}{*}{95} & \multicolumn{12}{|c|}{ Temperature to $450^{\circ} \mathrm{F}$} \\
\hline & .65 & .99 & .99 & .99 & .99 & .99 & 4 & 3 & 7 & 96 & 703 Fiberglas & OCRL \\
\hline \multirow[t]{2}{*}{.95} & \multicolumn{12}{|c|}{ Temperature to $450^{\circ} \mathrm{F}$} \\
\hline & .59 & .91 & .99 & .99 & .99 & .99 & 4 & 6 & 7 & 96 & 705 Fiberglas & OCRL \\
\hline \multirow[t]{2}{*}{$95^{\circ}$} & \multicolumn{12}{|c|}{ Temperature to $450^{\circ} \mathrm{F}$} \\
\hline & .61 & .99 & .99 & .99 & .99 & .99 & 4 & 1.58 & 7 & 96 & 701 Fiberglas & OCRL \\
\hline \multirow[t]{2}{*}{ 95 } & \multicolumn{12}{|c|}{ Temperature to $450^{\circ} \mathrm{F}$} \\
\hline & .62 & .99 & 99 & .99 & .99 & .99 & 4 & 3 & 7 & 96 & 703 Fiberglas & OCRL \\
\hline \multirow[t]{2}{*}{.95} & \multicolumn{12}{|c|}{ Temperature to $450^{\circ} \mathrm{F}$} \\
\hline & .57 & .99 & .99 & .99 & 99 & .99 & 4 & 6 & 7 & 96 & 705 Fiberglas & OCRL \\
\hline \multirow[t]{2}{*}{95} & \multicolumn{12}{|c|}{$\begin{array}{l}\text { Fiberglass faced with asphalt and kraft paper, } 26 . \\
20 \text {, and } 24 \text { inch wide, insulation side exposed to } \\
\text { sound }\end{array}$} \\
\hline & $\begin{array}{r}\text { sound } \\
.86\end{array}$ & .99 & .99 & .99 & .99 & .99 & 6 & -- & 7 & 96 & $\begin{array}{l}\text { Fiberglas Bldg } \\
\text { Insulation }\end{array}$ & OCRL \\
\hline
\end{tabular}


Table 4D. Glass fiber materials tested with number 7 mounting (modified).

\begin{tabular}{|c|c|c|c|c|c|c|c|c|c|c|c|c|}
\hline \multirow{3}{*}{$\mathrm{NRC}$} & \multicolumn{6}{|c|}{ Absorption Coefficients } & \multirow{3}{*}{ 总 } & \multirow{3}{*}{ 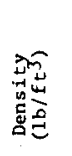 } & \multirow{3}{*}{$\begin{array}{l}\text { D. } \\
\stackrel{D}{ \pm} \\
\frac{5}{5} \\
\frac{0}{2}\end{array}$} & \multirow{3}{*}{ 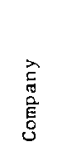 } & \multirow{3}{*}{ Product } & \multirow{3}{*}{ Reference } \\
\hline & N & $\stackrel{N}{x}$ & $\stackrel{n}{x}$ & $\stackrel{N}{x}$ & $\stackrel{N}{x}$ & $\stackrel{N}{x}$ & & & & & & \\
\hline & $\cong$ & $\stackrel{\sim}{\approx}$ & $\stackrel{\circ}{\circ}$ & @ & 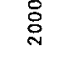 & 品 & & & & & & \\
\hline \multirow[t]{2}{*}{.35} & \multicolumn{12}{|c|}{ Temperature to $450^{\circ} \mathrm{F}$} \\
\hline & .60 & .39 & .34 & 29 & 47 & .30 & 4 & 6 & $7 \bmod$ & 96 & 705, ASJ Faced & OCRL \\
\hline \multirow[t]{2}{*}{.40} & \multicolumn{12}{|c|}{ Temperature to $450^{\circ} \mathrm{F}$} \\
\hline & .38 & .36 & .39 & .37 & 56 & .38 & 2 & 6 & $7 \bmod$ & 96 & 705, ASJ Faced & OCRL \\
\hline \multirow[t]{2}{*}{.40} & \multirow{2}{*}{\multicolumn{3}{|c|}{$\begin{array}{c}\text { Temperature to } 450^{\circ} \mathbf{F} \\
.48 \quad .44 \quad .40\end{array}$}} & & & & & & & & & \\
\hline & & & & .31 & .52 & .29 & 3 & 6 & $7 \bmod$ & 96 & 705, ASJ Faced & OCRL \\
\hline \multirow[t]{2}{*}{45} & \multicolumn{3}{|c|}{ Temperature to $450^{\circ} \mathrm{F}$} & & & & & & & & & \\
\hline & .25 & .48 & .28 & .57 & .39 & .30 & 1 & 6 & $7 \mathrm{mod}$ & 96 & 705, ASJ Faced & OCRL \\
\hline \multirow[t]{2}{*}{55} & \multicolumn{3}{|c|}{ Temperature to $450^{\circ} \mathrm{F}$} & & & & & & & & & \\
\hline & .31 & .45 & .62 & .65 & .51 & .28 & 1 & 3 & 7 mod & 96 & 703, FRK Faced & OCRL \\
\hline \multirow[t]{2}{*}{.65} & \multicolumn{3}{|c|}{ Temperature to $450^{\circ} \mathrm{F}$} & & & & & & & & & \\
\hline & .38 & .51 & .83 & .73 & .53 & .37 & 2 & 3 & $7 \bmod$ & 96 & 703, FRK Faced & OCRL \\
\hline \multirow[t]{2}{*}{.65} & \multicolumn{3}{|c|}{ Temperature to $450^{\circ} \mathrm{F}$} & & & & & & & & & \\
\hline & .56 & .74 & .74 & .67 & .48 & .23 & 3 & 3 & $7 \bmod$ & 96 & 703. FRK Faced & OCRL \\
\hline \multirow[t]{2}{*}{.65} & Temper & e to & $450^{\circ} \mathrm{F}$ & & & & & & & & & \\
\hline & .70 & .78 & .73 & .67 & 46 & .24 & 4 & 3 & 7 mod & 96 & 703. FRK Faced & OCRL \\
\hline .70 & Temper & e to & $450^{\circ} \mathrm{F}$ & & & & & & & & & \\
\hline & 38 & .34 & .68 & .82 & 87 & .96 & 1 & 1.58 & 7 mod & 96 & 701 Fiberglas & CCRL \\
\hline .70 & Temper & e to & $450^{\circ} \mathrm{F}$ & & & & & & & & & \\
\hline & .33 & .28 & .62 & .88 & .96 & .99 & 1 & 3 & $7 \bmod$ & 96 & 703 Eiberplas & OCRL \\
\hline .70 & Temper & e to & $450^{\circ} \mathrm{F}$ & & & & & & & & & \\
\hline & .32 & .30 & .66 & .90 & .95 & .99 & 1 & 6 & $7 \bmod$ & 96 & 705 Fiberglas & OCRL \\
\hline .90 & Temper & e to & $450^{\circ} \mathrm{F}$ & & & & & & & & & \\
\hline & .38 & .63 & .99 & .99 & .99 & .99 & 2 & 3 & $7 \bmod$ & 96 & 703 Fiberglas & OCRL \\
\hline .90 & Temper & e to & $450^{\circ} \mathrm{F}$ & & & & & & & & & \\
\hline & .39 & .59 & 99 & .99 & .99 & .99 & 2 & 6 & 7 nod & 96 & 705 Fiberglas & OCRL \\
\hline 90 & Temper & e to & $850^{\circ} \mathrm{F}$ & & & & & & & & Intermediate & \\
\hline & 33 & .57 & .99 & .99 & .99 & .99 & 2 & $\cdots$ & $7 \bmod$ & 96 & Service Board & OCRL \\
\hline .90 & Temper & e to & $450^{\circ} \mathrm{F}$ & & & & & & & & & \\
\hline & .44 & .66 & 99 & .99 & .99 & .99 & 2 & 1.58 & 7 r.od & 96 & 701 Fiberglas & OCRL \\
\hline .95 & Temper & e to & $450^{\circ} \mathrm{F}$ & & & & & & & & & \\
\hline & .53 & .96 & 99 & .99 & .99 & .99 & 3 & 1.58 & 7 mod & 96 & 701 Fiberglas & OCRL \\
\hline .95 & Temper & e to & $450^{\circ} \mathrm{F}$ & & & & & & & & & \\
\hline & 45 & .98 & 99 & .99 & .99 & .99 & 3 & 3 & 7 mod & 96 & 703 Fiberglas & OCRL \\
\hline .95 & Temper & e to & $450^{\circ} \mathrm{F}$ & & & & & & & & & \\
\hline & .49 & .93 & .99 & .99 & 99 & .99 & 3 & 6 & 7 mod & 96 & 705 Fíberglas & OCRL \\
\hline
\end{tabular}


Table 4E. Glass fiber materials tested with other or unspecified mounting.

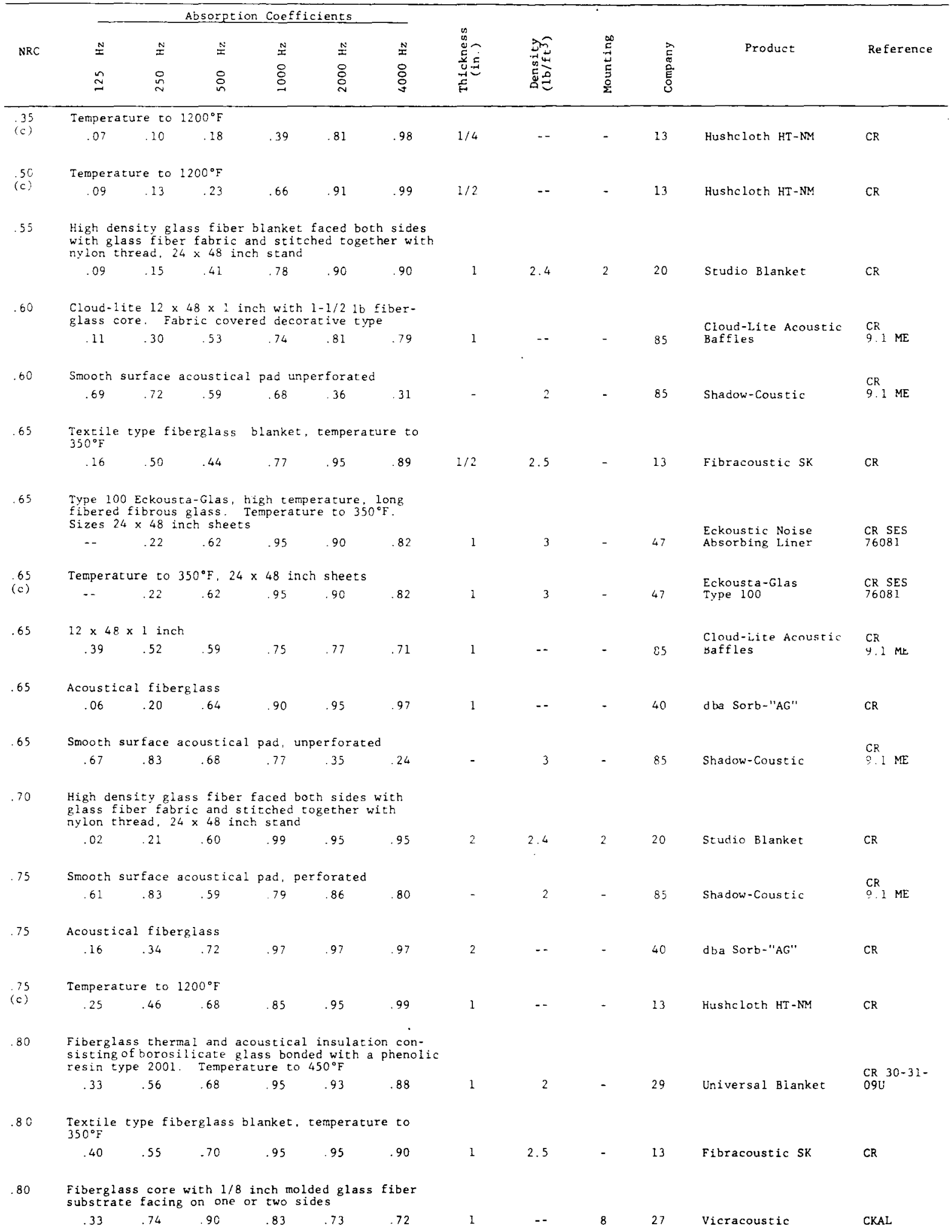


Table 4E. Glass fiber materials tested with other or unspecified mounting concluded. Absorption Coefficient

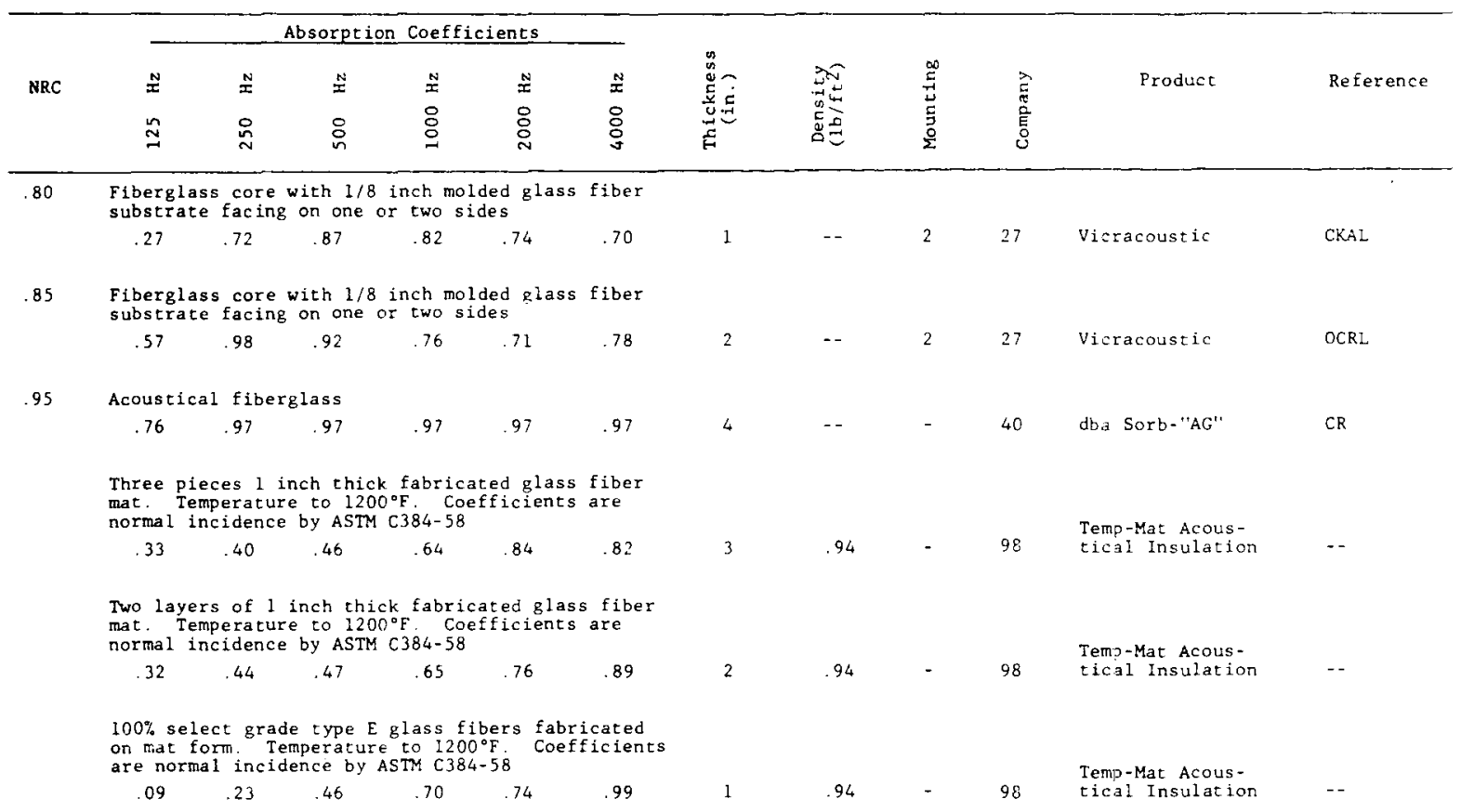

Table 4F. Glass fiber materials with barrier properties.

\begin{tabular}{|c|c|c|c|c|c|c|c|c|c|c|c|c|c|c|c|c|c|c|c|c|c|}
\hline \multirow[b]{2}{*}{ sTc } & \multicolumn{16}{|c|}{ Transmission Loss, $d B$} & \multirow[b]{2}{*}{ 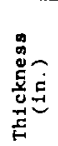 } & \multirow[b]{2}{*}{ 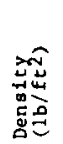 } & \multirow[b]{2}{*}{ 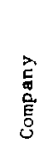 } & \multirow[b]{2}{*}{ Product } & \multirow[b]{2}{*}{ Reference } \\
\hline & $\begin{array}{l}\mathbb{N} \\
\underset{N}{N}\end{array}$ & $\begin{array}{l}\mathbf{N} \\
8 \\
8\end{array}$ & $\begin{array}{l}\underset{X}{X} \\
\stackrel{N}{D}\end{array}$ & 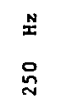 & $\begin{array}{l}\stackrel{N}{x} \\
\stackrel{n}{m}\end{array}$ & $\begin{array}{l}\text { N } \\
\stackrel{9}{\mathbf{X}}\end{array}$ & $\begin{array}{l}\text { N } \\
8 \\
8\end{array}$ & $\begin{array}{l}\text { N } \\
0 \\
0\end{array}$ & $\begin{array}{l}\stackrel{N}{x} \\
8 \\
\stackrel{0}{\infty}\end{array}$ & $\begin{array}{l}\text { Nㅗ } \\
8 \\
8 \\
\end{array}$ & $\begin{array}{l}\mathbf{N} \\
\stackrel{9}{\mathbf{N}} \\
\end{array}$ & $\begin{array}{l}\mathbf{N} \\
8 \\
0 \\
0\end{array}$ & $\begin{array}{l}\stackrel{N}{\mathbf{x}} \\
\stackrel{8}{8} \\
\stackrel{D}{N}\end{array}$ & $\begin{array}{l}\text { N } \\
8 \\
\stackrel{D}{N}\end{array}$ & 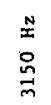 & $\begin{array}{l}N \\
: \\
8 \\
8 \\
\end{array}$ & & & & & \\
\hline 17 & $\begin{array}{r}\text { Glass } \\
7\end{array}$ & $\begin{array}{c}\text { fibe } \\
12\end{array}$ & $\begin{array}{l}x \text { mo } \\
11\end{array}$ & $\begin{array}{l}1 \text { ded } \\
10\end{array}$ & $\begin{array}{l}\text { via } \\
10\end{array}$ & $\begin{array}{c}\text { ther } \\
9\end{array}$ & $\begin{array}{c}\text { mose } \\
10\end{array}$ & $\begin{array}{c}t t \text { in } \\
13\end{array}$ & $\begin{array}{l}16 \text { me } \\
16\end{array}$ & $\begin{array}{c}\text { thod } \\
17\end{array}$ & 19 & 22 & 24 & 27 & 28 & 31 & 1 & 18 & 73 & IC Pres-Glas & $\begin{array}{l}\text { KAL } \\
439294\end{array}$ \\
\hline 20 & $\begin{array}{r}\text { Glass } \\
14\end{array}$ & $\begin{array}{c}\text { fibe } \\
13\end{array}$ & $\begin{array}{l}\text { mo } \\
11\end{array}$ & $\begin{array}{l}\text { Ided } \\
12\end{array}$ & $\begin{array}{l}\text { via } \\
13\end{array}$ & $\begin{array}{c}\text { then } \\
13\end{array}$ & $\begin{array}{c}\text { mose } \\
13\end{array}$ & $\begin{array}{c}\text { tein } \\
13\end{array}$ & $\begin{array}{l}18 \text { bir } \\
19\end{array}$ & $\begin{array}{c}\text { nder } \\
22\end{array}$ & $\begin{array}{l}\text { met } \\
24\end{array}$ & $\begin{array}{r}\text { hod } \\
27\end{array}$ & 29 & 32 & 34 & 36 & 1 & .35 & 73 & IC Pres-Glas & $\begin{array}{l}\text { KAL } \\
439293\end{array}$ \\
\hline
\end{tabular}




\section{CATEGORY 5, MINERAL FIBER MATERIALS}

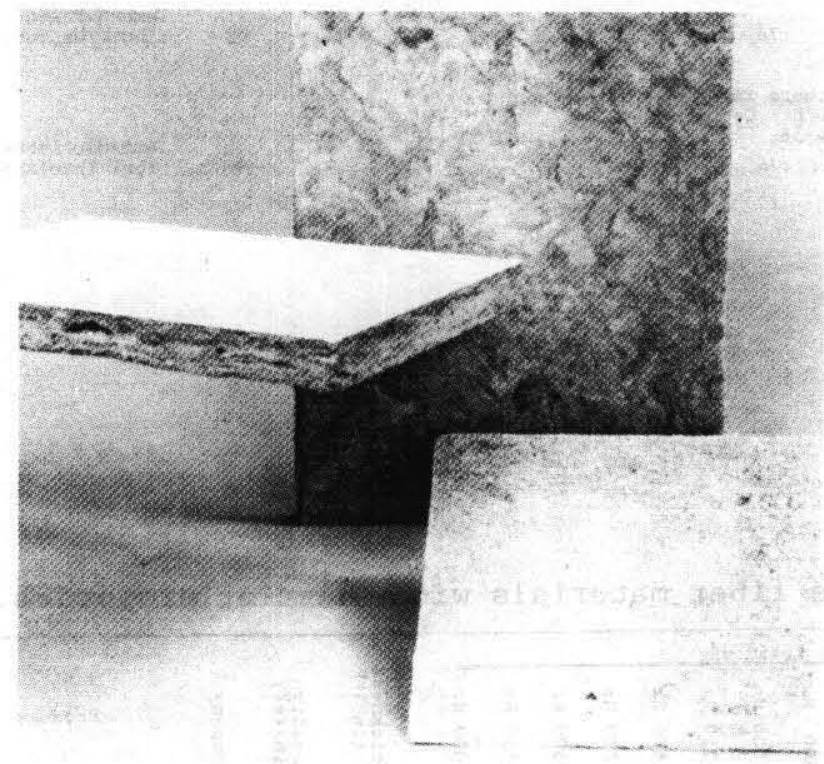




\begin{abstract}
Open-cell absorptive materials can be divided into three classes: methane foams, glass fibers, and mineral fibers. Materials in the latter class are generally low density, flexible products which are available in sheet or roll geometries. Mineral fiber products are used as absorptive fillers for acoustic panels, enclosures, or partition walls.

Organizations contributing data to this category are: $12,18,28$, and 45 .
\end{abstract}

\title{
CAUTION
}

1. ABSORPTION COEFFICIENTS MAY EXCEED 1.0. FOR A COMPLETE DISCUSSION OF THESE VALUES SEE PAGE 51.

2. THE NUMBERS LISTED UNDER THE "MOUNTING" COLUMN REFER TO THE AIMA STANDARD MOUNTINGS DESCRIBED ON PAGE 53. 
Table 5A. Absorption properties of mineral fiber.

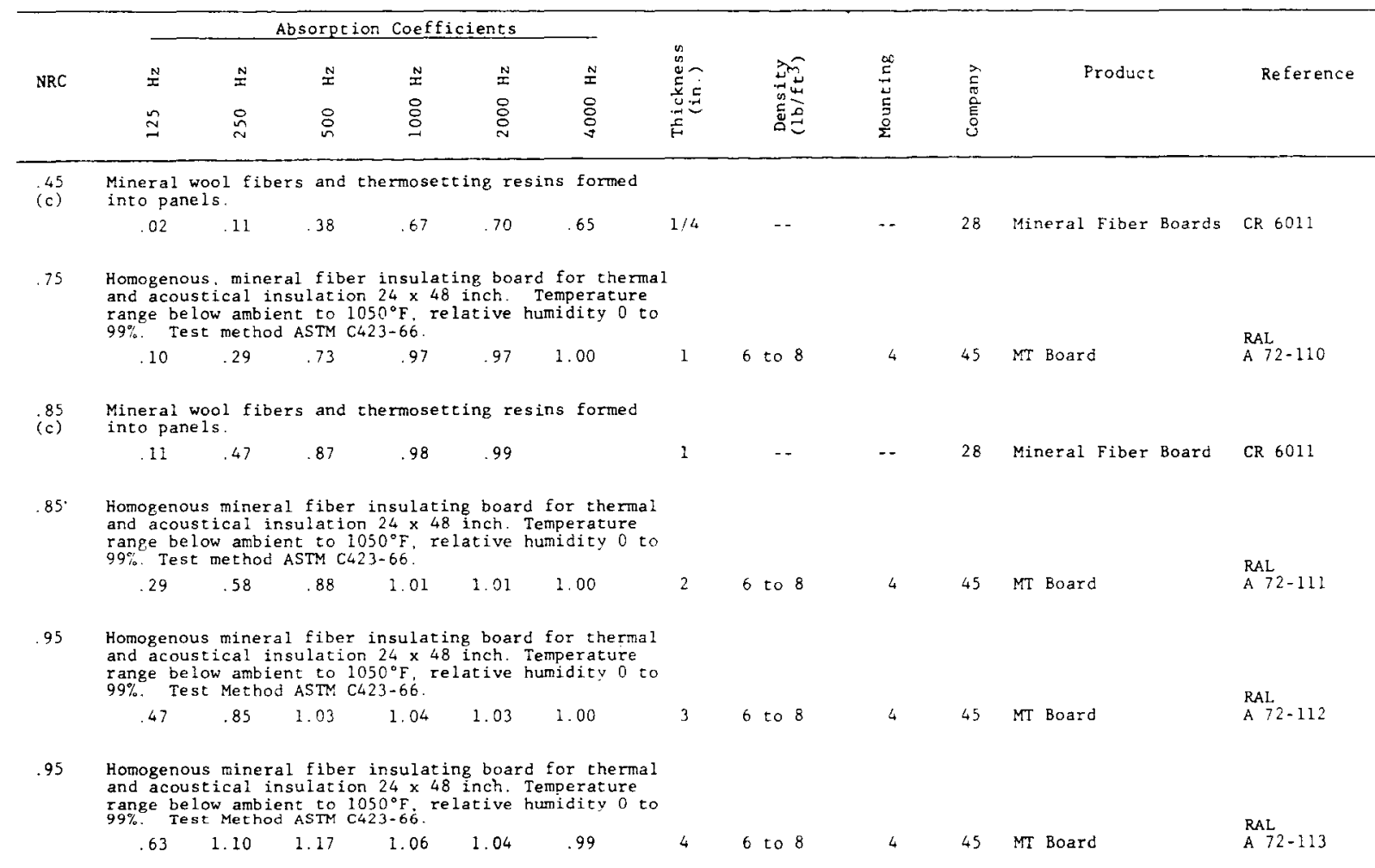

Table 5B. Barrier properties of mineral fiber.

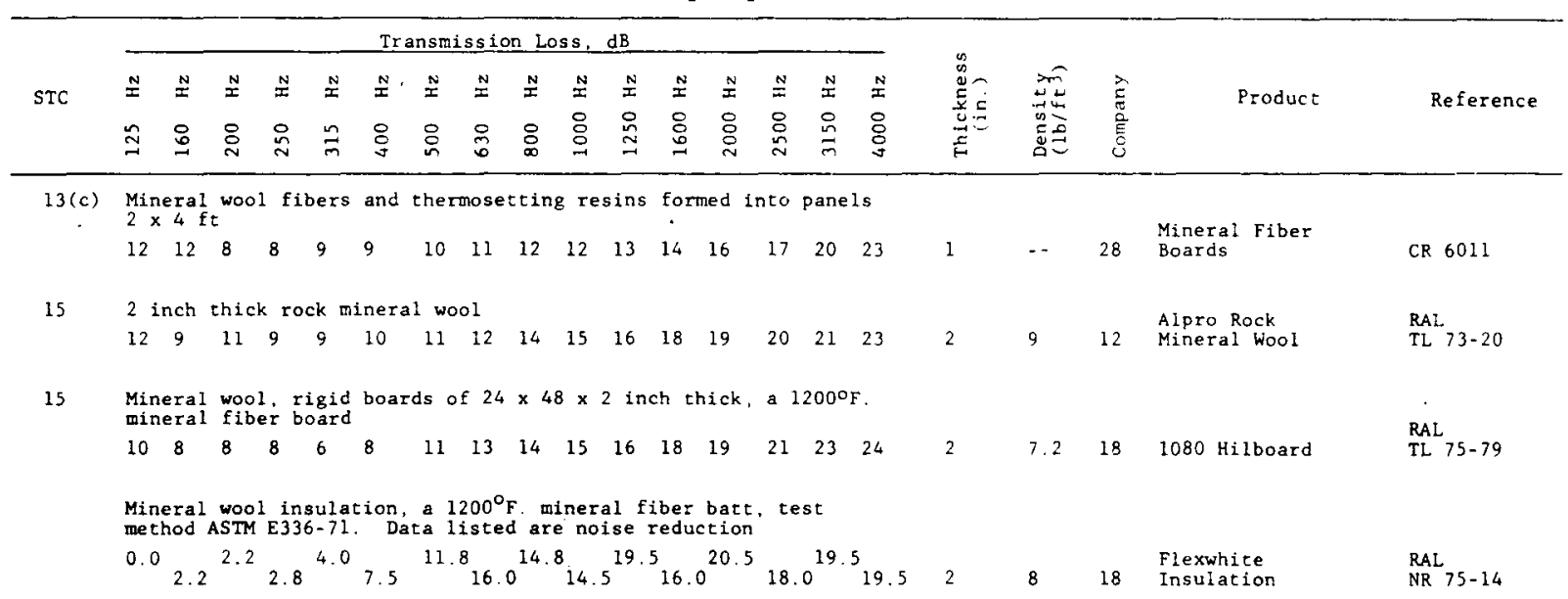


Sound absorption provided by spray-on coatings depends on the type of material used, thickness, and the substrate material. Different spraying techniques are usually centered around a nozzle-type delivery system. The data presented in this category relate to different spray-on materials applied to different base materials. Thus, direct comparisons are limited by base material corrections.

When a spray-on material is appropriately applied to a good barrier material, a composite absorptive/barrier system can be created. For related barrier data, see walls. Organizations contributing data are: 55, 90, and 91.

\section{CAUTION}

1. ABSORPTION COEFFICIENTS MAY EXCEED 1.0. FOR A COMPLETE DISCUSSION OF THESE VALUES SEE PAGE 51.

2. THE NUMBERS LISTED UNDER THE "MOUNTING" COLUMN REFER TO THE AIMA STANDARD MOUNTINGS DESCRIBED ON PAGE 53.

\section{GLOSSARY}

Lath: Thin, lightweight structure used as groundwork for plastering, tiles, etc. It may be in a form of perforated metal, wire cloth, thin wood strips, etc. 
Table 6. Spray-on materials.

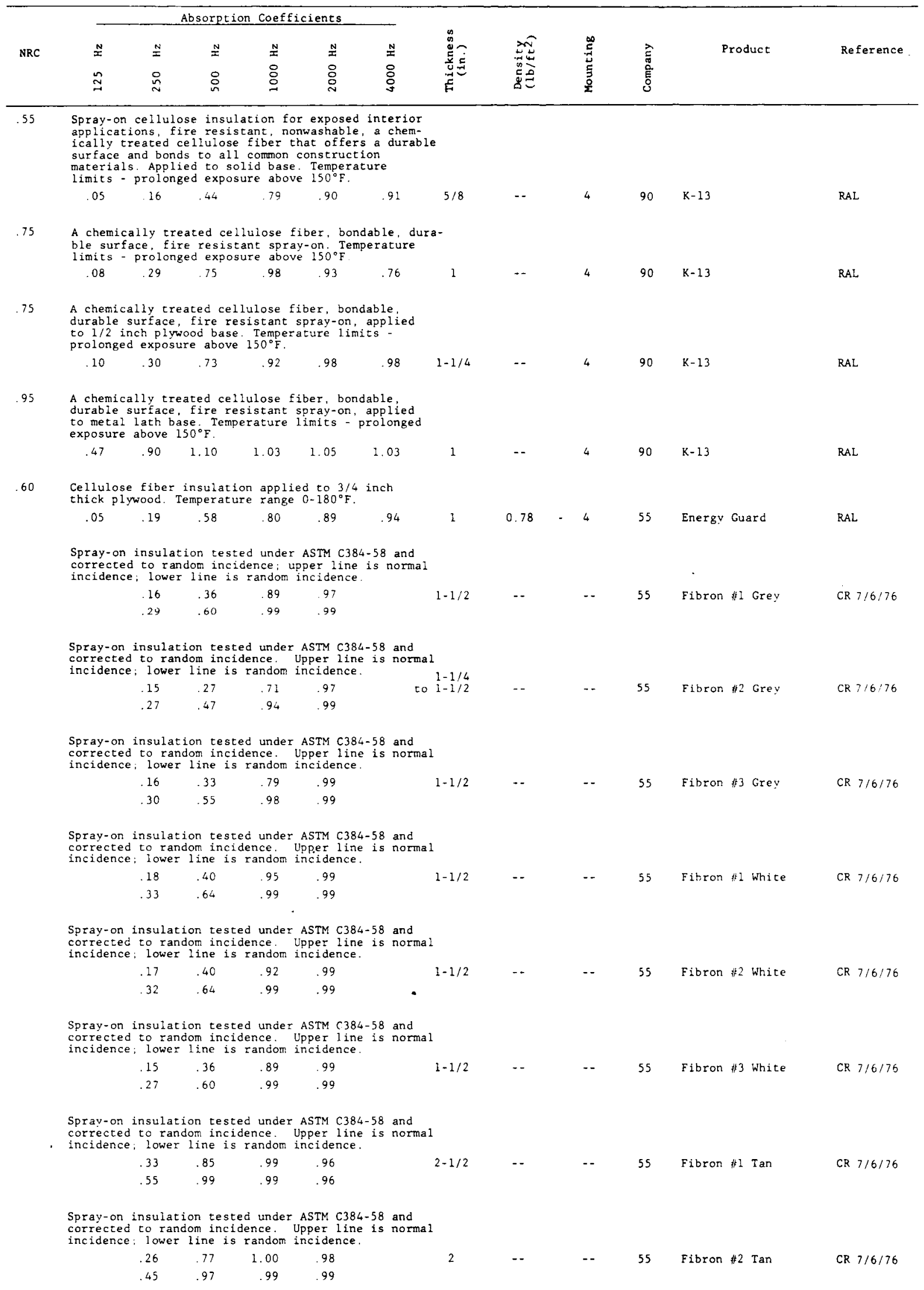




\section{CATEGORY 7. BARRIER/FIBERGLASS COMPOSITES}

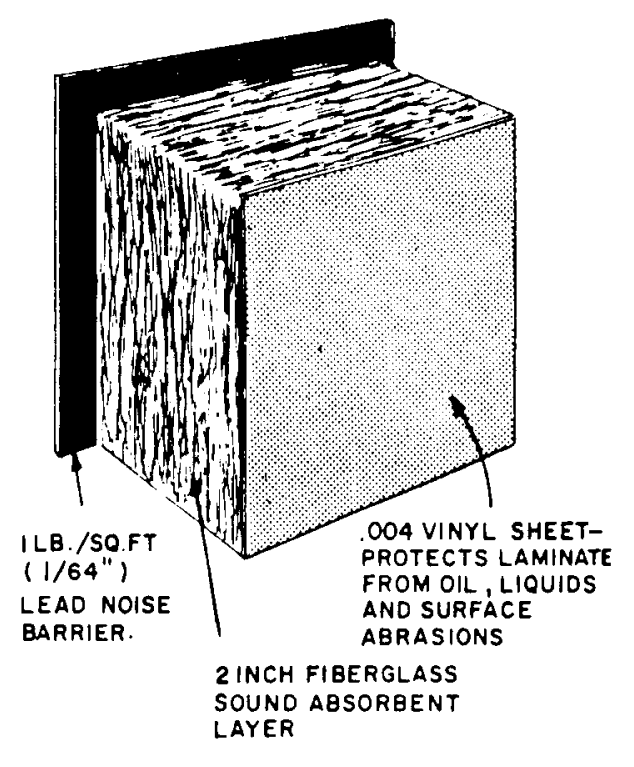

COMPOSITE LEAD/FibergLASS With a Protective Facing

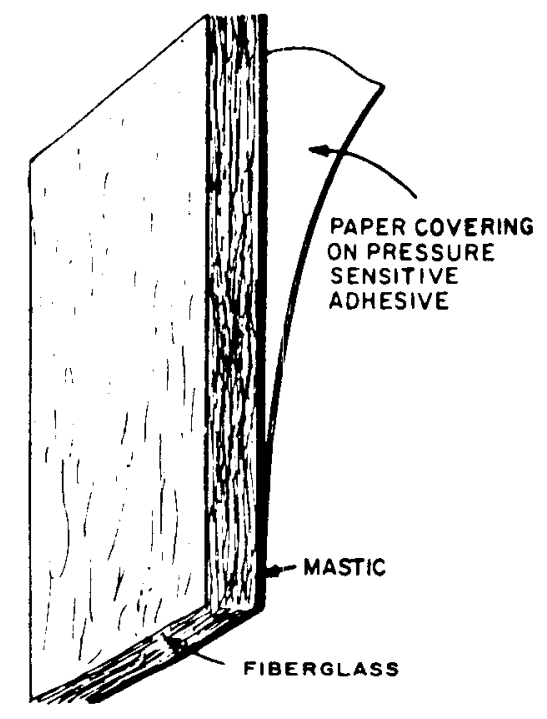

Composite Mastic/Fiberglass With Pressure Sensititive Adhesive 
Composite products consisting of fiberglass (absorption) and a dense backing material (barrier) mostly lead, asbestos, felt, mastic, etc, are listed. The absorption parameters are dependent upon the type, thickness, density, and surface characteristics of the fiberglass. The transmission loss is dependent upon the mass and rigidity of the barrier material. The absorptive barrier can also offer good thermal properties. Precautionary measures to control problems of moisture and soiling are also available in various forms (wraps, coatings, encapsulations, chemical treatments, etc).

The composite absorptive barrier can be adapted for a variety of uses such as machine and room enclosures, vehicle and heavy equipment quieting, pipe and duct wrapping, or as space absorbers. Organizations contributing data are: $10,13,26,33,40,55$, and 117 .

\section{CAUTION}

NOISE REDUCTION AND TRANSMISSION LOSS VALUES MAY HAVE BEEN SUBSTANTIALLY INCREASED DUE TO THE MATERIAL ON WHICH THE PRODUCT WAS MOUNTED.

\section{GLOSSARY}

Facing: The outside surface of the specimen. In general the side facing the sound source

Backing: The other outside surface of the specimen. In general the side not facing the sound source

Core: The region between the facing and the backing

Mastic: Any of various quick-drying pasting cements. For sound barrier application this is usually a dense flexible asphalted product.

Scrim: A light, loosely woven cotton or woolen cloth. 
Table 7A. Absorption properties of barrier/fiberglass composites.

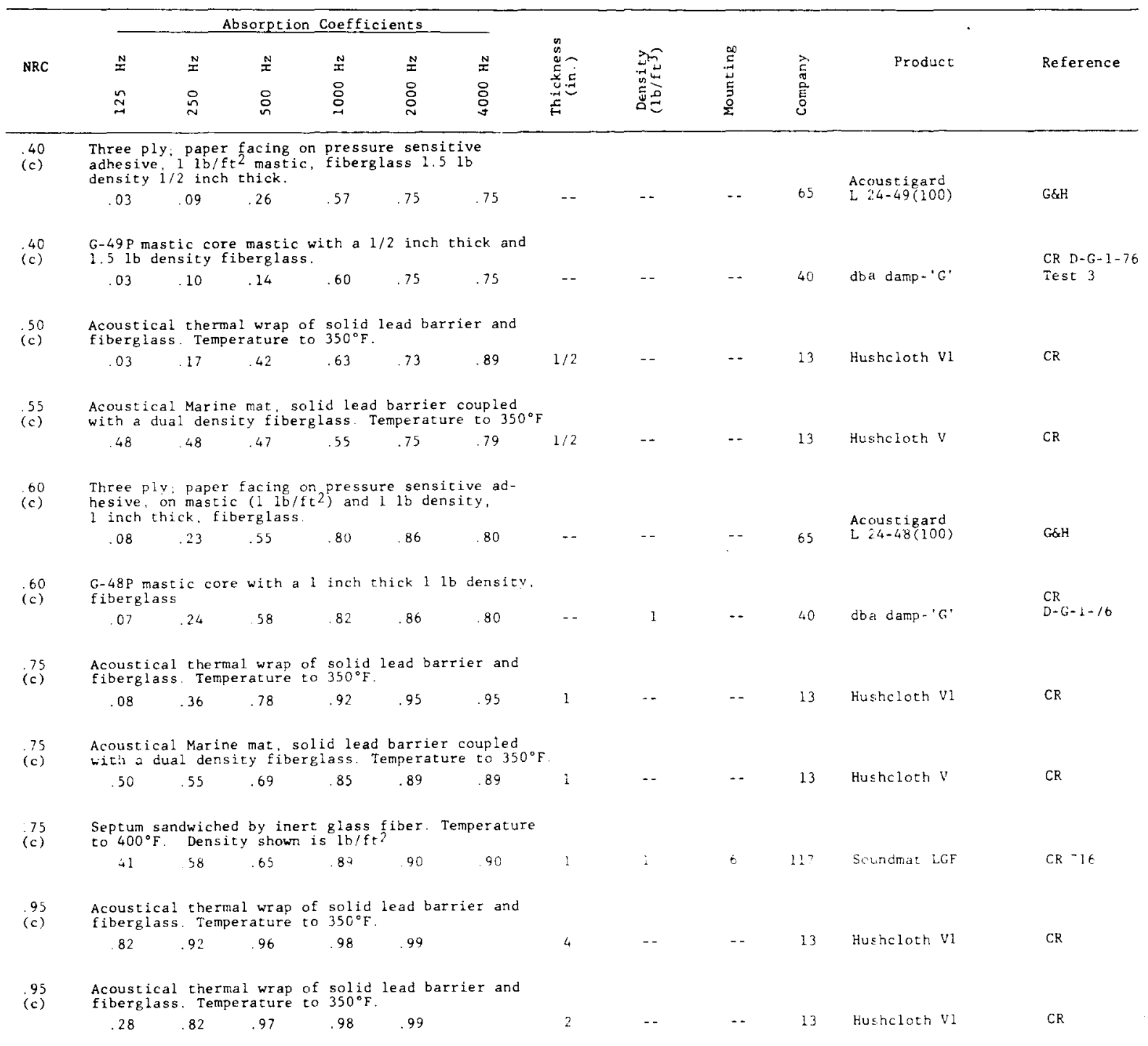


Table 7B. Barrier properties of barrier/fiberglass composites.

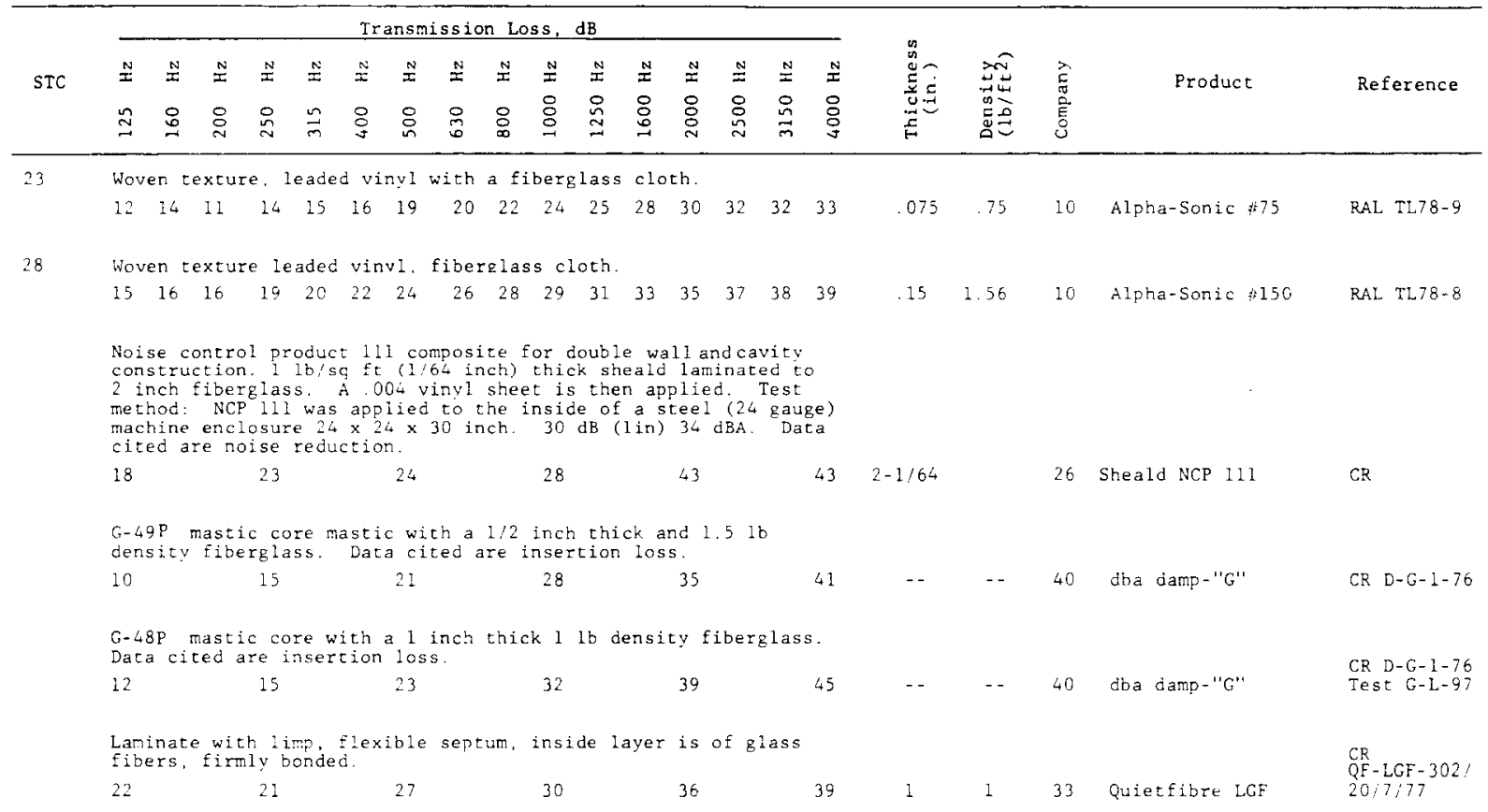




\section{CATEGORY 8. BARRIER/FOAM COMPOSITES}
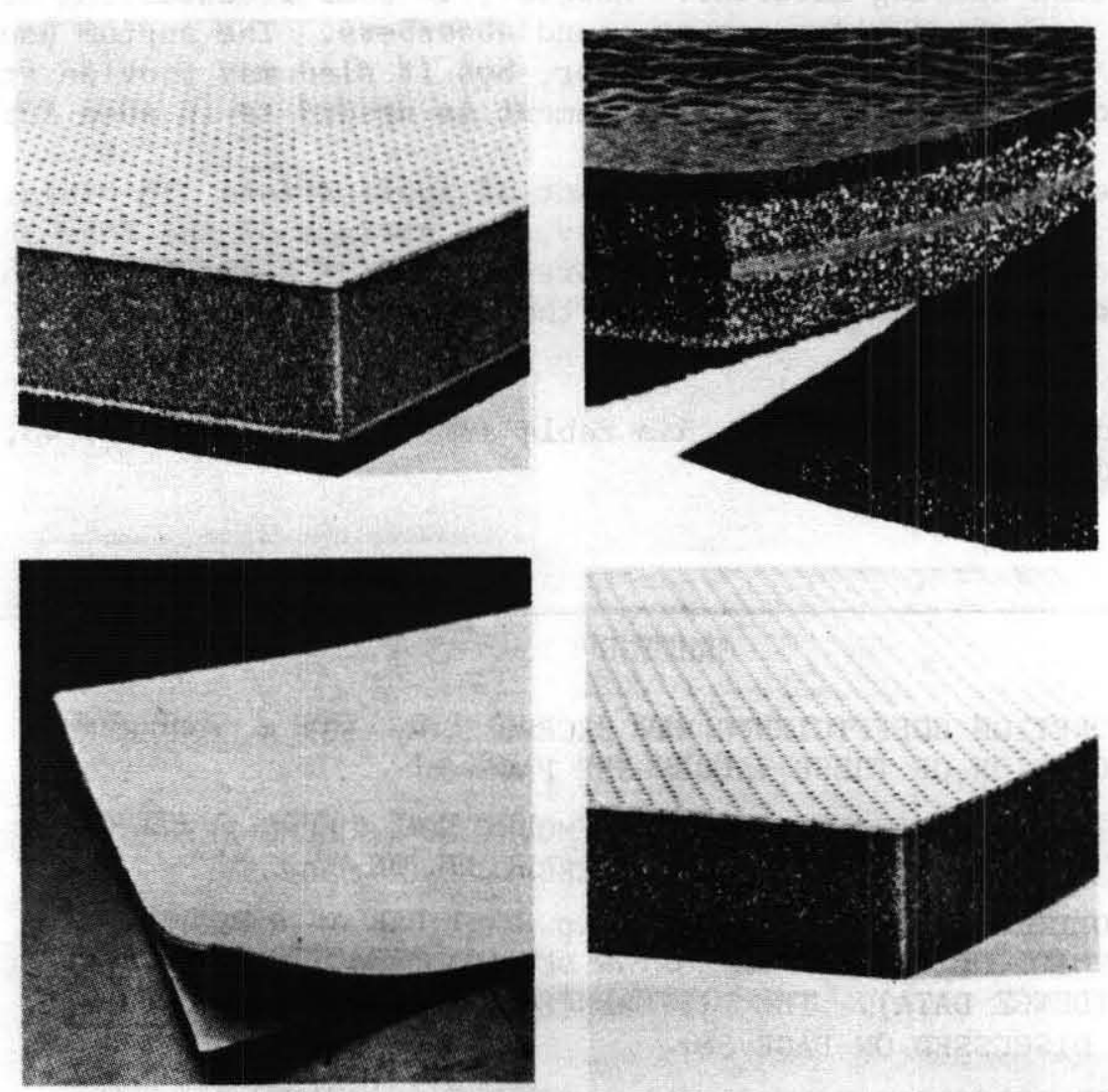


\section{CATEGORY 8. BARRIER/FOAM COMPOSITES}

Composite materials utilizing an acoustical foam (absorption) combined with a barrier (septum) material such as lead, vinyl, barium, steel, wood, etc., are listed. These materials may be formulated into a sandwich type array (foam/ barrier-septum/foam) with the septum position varying. Usually in this type of array, one side of the foam acts as a sound absorber and the other side acts as a vibration damping material. However, in some freestanding acoustical barriers, both foam sides act as sound absorbers. The septum usually acts as a sound (transmission loss) barrier, but it also may provide strength. In some cases, only a barrier/foam arrangement is needed as in some enclosures.

Variations in design offer a wide assortment of applications in vibration and sound control. The type thickness, density, and surface of the foam should be considered for specific purposes of vibration and/or absorption. The thickness, rigidity and mass qualities of the septum influence barrier performance.

Organizations contributing data to this table are: $13,26,33,40,43,47$, $66,73,117$, and 130 .

\section{CAUTION}

1. ABSORPTION COEFFICIENTS MAY EXCEED 1.0. FOR A COMPLETE DISCUSSION OF THESE VALUES SEE PAGE 51.

2. THE NUMBERS LISTED UNDER THE "MOUNTING" COLUMN REFER TO THE AIMA STANDARD MOUNTINGS DESCRIBED ON PAGE 53.

3. ABSORPTION COEFFICIENTS ARE SHOWN EITHER AS PERCENTAGES (NORMAL INCIDENCE DATA) OR AS DECIMAL FRACTIONS (RANDOM INCIDENCE DATA). THE DIFFERENCES BETWEEN THESE TWO DATA ARE DISCUSSED ON PAGE 56.

4. NOISE REDUCTION VALUES MAY HAVE BEEN SUBSTANTIALLY INCREASED DUE TO THE MATERIAL ON WHICH THE PRODUCT WAS MOUNTED.

5. VALUES PRESENTED ON PAGE 199 ARE NOISE REDUCTIONS; ON PAGE 200, INSERTION LOSSES; ON PAGE 201, NOISE REDUCTIONS. SEE PAGES 70 AND 94 FOR EXPLANATION OF DIFFERENCES. 


\section{GLOSSARY}

Facing: The outside surface of the specimen. In general the side facing the sound source

Backing: The other outside surface of the specimen. In general the side not facing the sound source

Core: The region between the facing and the backing

Loaded: A foreign substance added to the base material. In noise control materials this usually means addition of a dense material to a fabric type material to increase sound transmission loss.

Lead loaded: Lead added to a base material such as vinyl to increase sound transmission loss. 
Table 8A. Absorption properties of barrier/foam composites.

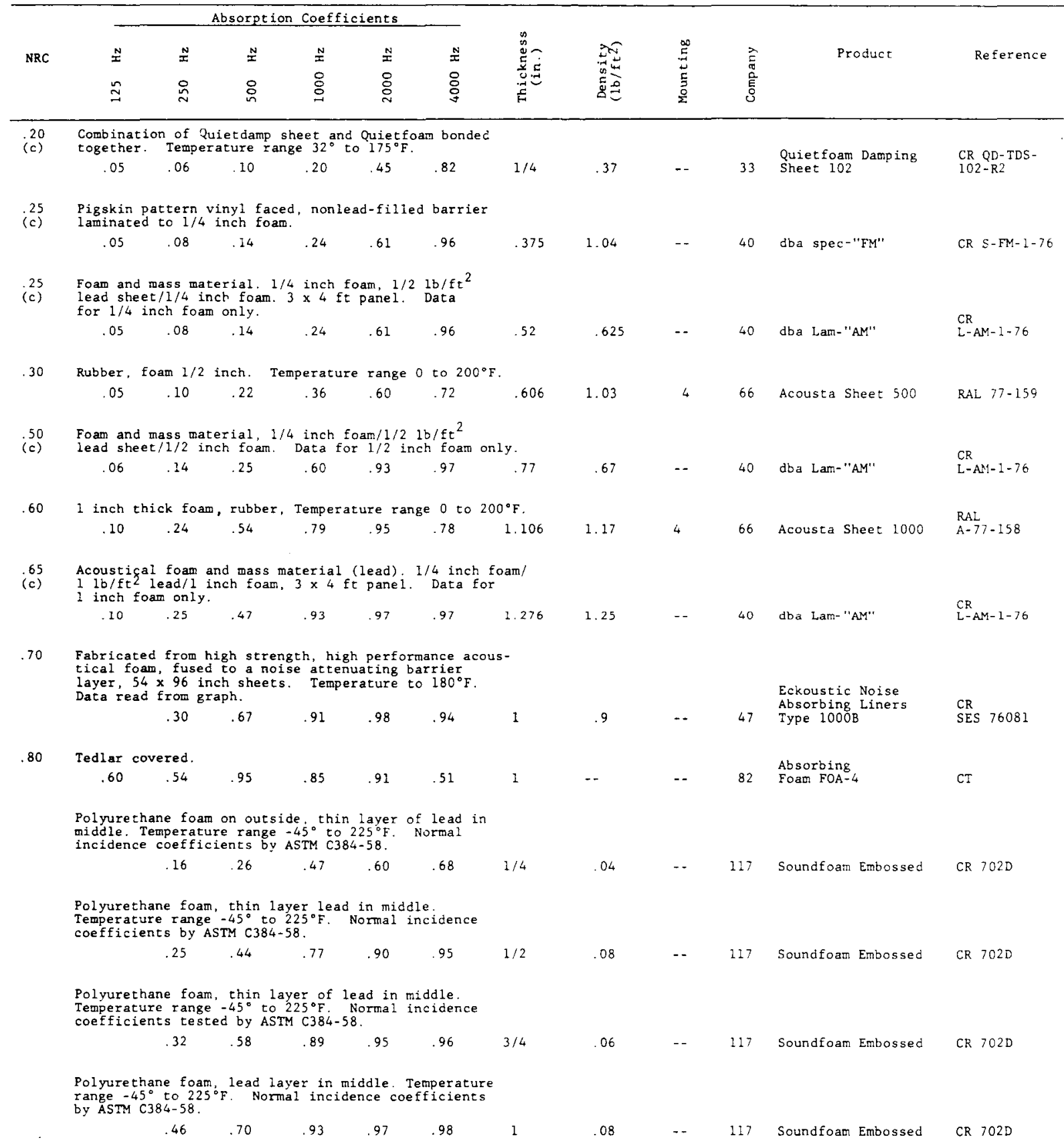


Table 8B. Barrier properties of barrier/foam composites (transmission loss). Transmission Loss, dB

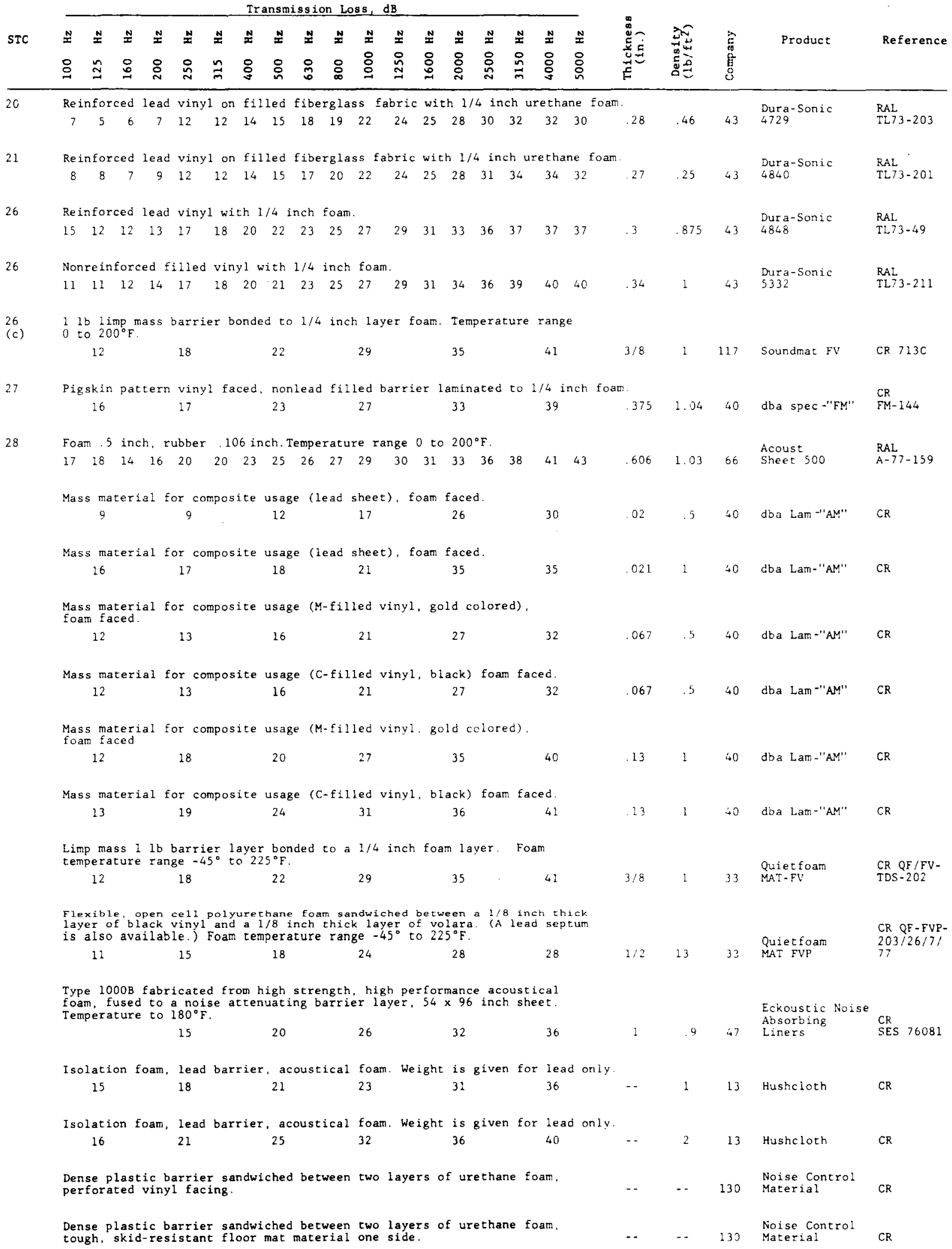


Table 8C. Barrier properties of barrier/foam composites (insertion loss).

Insertion Loss, $d B$

\begin{tabular}{|c|c|c|c|c|c|c|c|c|c|c|c|c|c|c|c|}
\hline STC & 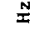 & $\stackrel{N}{\Sigma}$ & $\stackrel{N}{I}$ & I & $\stackrel{N}{\geq}$ & $\stackrel{N}{I}$ & $\stackrel{N}{I}$ & $\stackrel{N}{ \pm}$ & $\stackrel{N}{=}$ & $\stackrel{N}{I}$ & $\stackrel{N}{I}$ & $\stackrel{N}{x}$ & 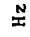 & $\stackrel{N}{ \pm}$ & $\stackrel{N}{\mathbf{N}}$ \\
\hline & -7 & $\stackrel{8}{\circ}$ & $\stackrel{8}{\stackrel{N}{*}}$ & 윢 & $\cong$ & 0 & 5 & & & 8 & 品 & 8 & ㅇ & : & $c$ \\
\hline
\end{tabular}

Flexible, barium-loaded vinyls on $1 / 4$ inch plywood enclosure.'

Temperature range (foam) $-40^{\circ}$ to $300^{\circ} \mathrm{F}$

15

18

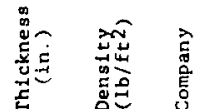

Product

Reference

Flexible, barium-loaded vinyls on 18 gauge steel enclosure.
20
12
$19 \quad 22$
26

$25 \quad-$

78 Noiseguard Laminates

CR R60B

Flexible, tedlas film with acoustical foam on $1 / 4$ inch $p$ lywood

enclosure. Foam temperature range $-40^{\circ}$ to $300^{\circ} \mathrm{F}$. Weight is

$\begin{array}{llllllllllll}29 & 21 & 24 & 23 & 25 & 26 & 1-1 / 4 & \text { to. } 23 & 78 & \text { Noiseguard Laminates } & \text { CR K60B }\end{array}$

Flexible, acoustical foam on $1 / 4$ inch plywood enclosure. Foam

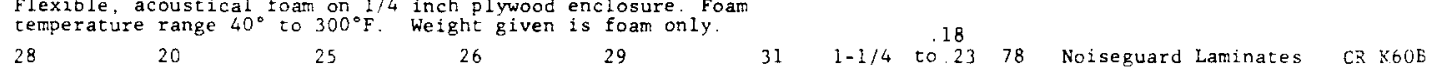

Flexible, acoustical foars with tedlar film on 18 gauge steel

enclosure. Temperature range $-40^{\circ}$ to $300^{\circ} \mathrm{F}$. Weight is

foam only.

16

18

28

$31 \quad 34$

$42 \quad 1 \quad \begin{array}{ll}.18 \\ \text { to. }\end{array}$

CR K60E

Flexible, acoustical foam on 18 gauge steel enclosure. Foam cem-
perature range $-40^{\circ}$ to $300^{\circ} \mathrm{F}$. Weight is foam only.

$15 \quad 28 \quad 33$

$45 \quad 1$ to $18,23,78$ Noiseguard Laminates $\mathrm{CR}$ K'60R

Flexible, barium-loaded vinyls with acoustical foam. Foam temper-

ature range $-40^{\circ}$ to $300^{\circ} \mathrm{F}$. Weight is foam only.

Flexible, barium-loaded vinyis with acoustical foam on 18 gauge steel enclosure. Foam temperature range $-40^{\circ}$ to $300^{\circ} \mathrm{F}$. Weight is foam oniy.

18

$20 \quad 32$

$32 \quad 38$

36

$45 \quad 1 \quad .18$

$41 \quad 1 \quad 0.18078$ Noiseguard Laminates CR K60B

Flexible, barium-loaded vinyls with acoustical foams (1 inch foam-vinyl-1/4 inch foam) on $1 / 4$ inch plywood enclosure

Foan temperature range $-40^{\circ}$ to $300^{\circ} \mathrm{F}$. Weight is foam only

30

26

$29 \quad 28$

36

$45 \quad-\quad .18$

.18

Noiseguard Laminates

CR. $\mathrm{K} 60 \mathrm{~B}$

Flexible, barium-loaded vinyls with acoustical foam (I inch foam-vinyl-1/2 inch foam) on $1 / 4$ inch plywood enclosure. Temperature range foam $-40^{\circ}$ to $300^{\circ} \mathrm{F}$. Weight is foam only

30

$$
27
$$

$28 \quad 27$

41

$49 \quad-\quad+0.18$

18

Noiseguard Laminates

CR $k 608$

Flexible, barium-loaded vinyls with acoustical foams (1 inch

foam-vinyl-1/4 inch foam) on 18 gauge steel enclosure.
Temperature range $-40^{\circ}$ to $300^{\circ} \mathrm{F}$. Weight is foam only.

$\begin{array}{llcccccccccc}18 & 21 & 32 & 31 & 47 & 54 & 1-1 / 4 & \text { to.23 } & 78 & \text { Noiseguard Laminates } & \text { CR K6UB }\end{array}$

Flexible, barium-loaded vinyls with acoustical foams ( 1 inch foam-vinyl-1/2 inch foam) on 18 gauge steel enclosure.

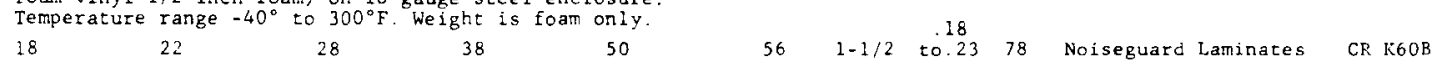


Table 8D. Barrier properties of barrier/foam composites (noise reduction).

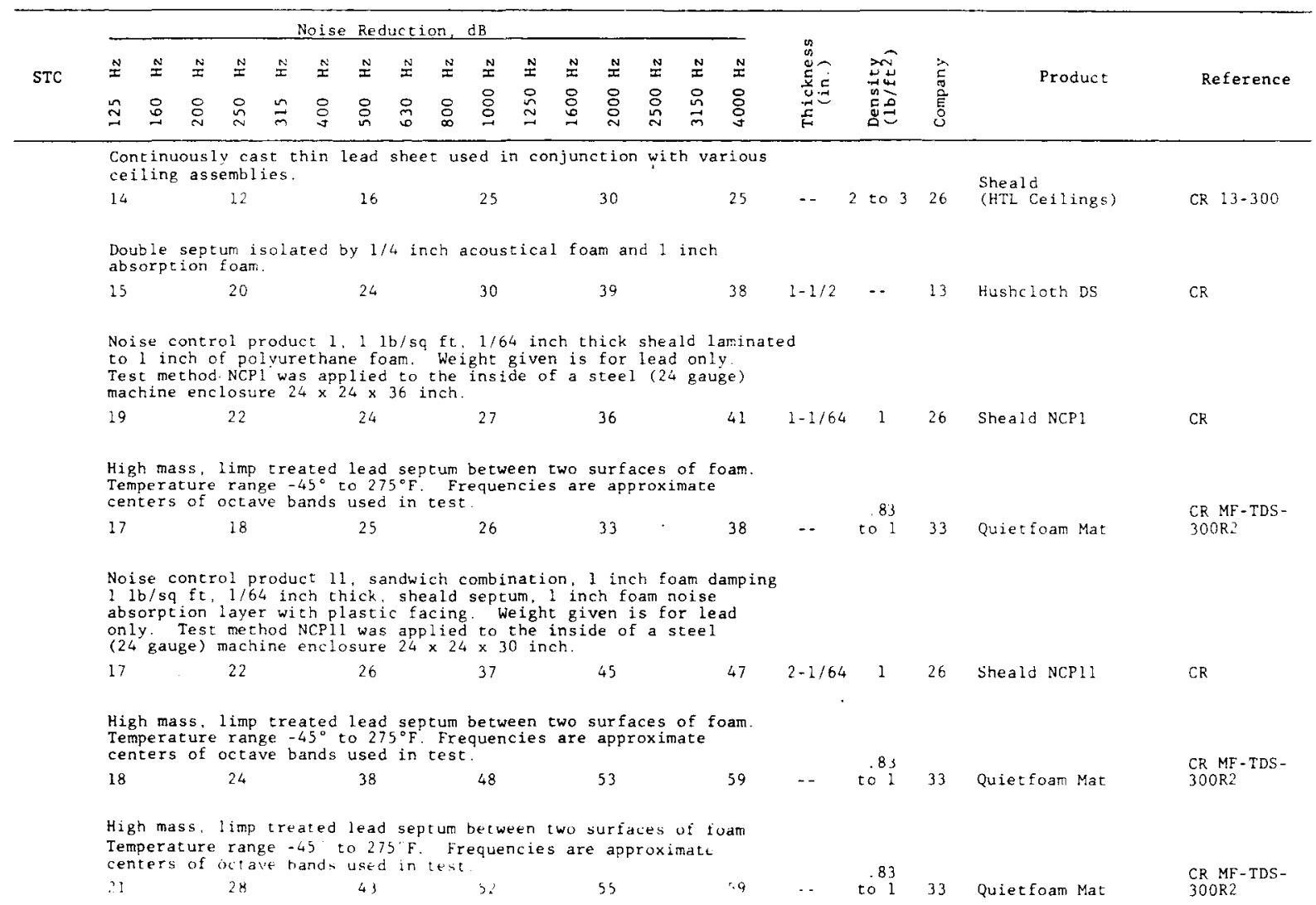




\section{CATEGORY 9. MASTICS}
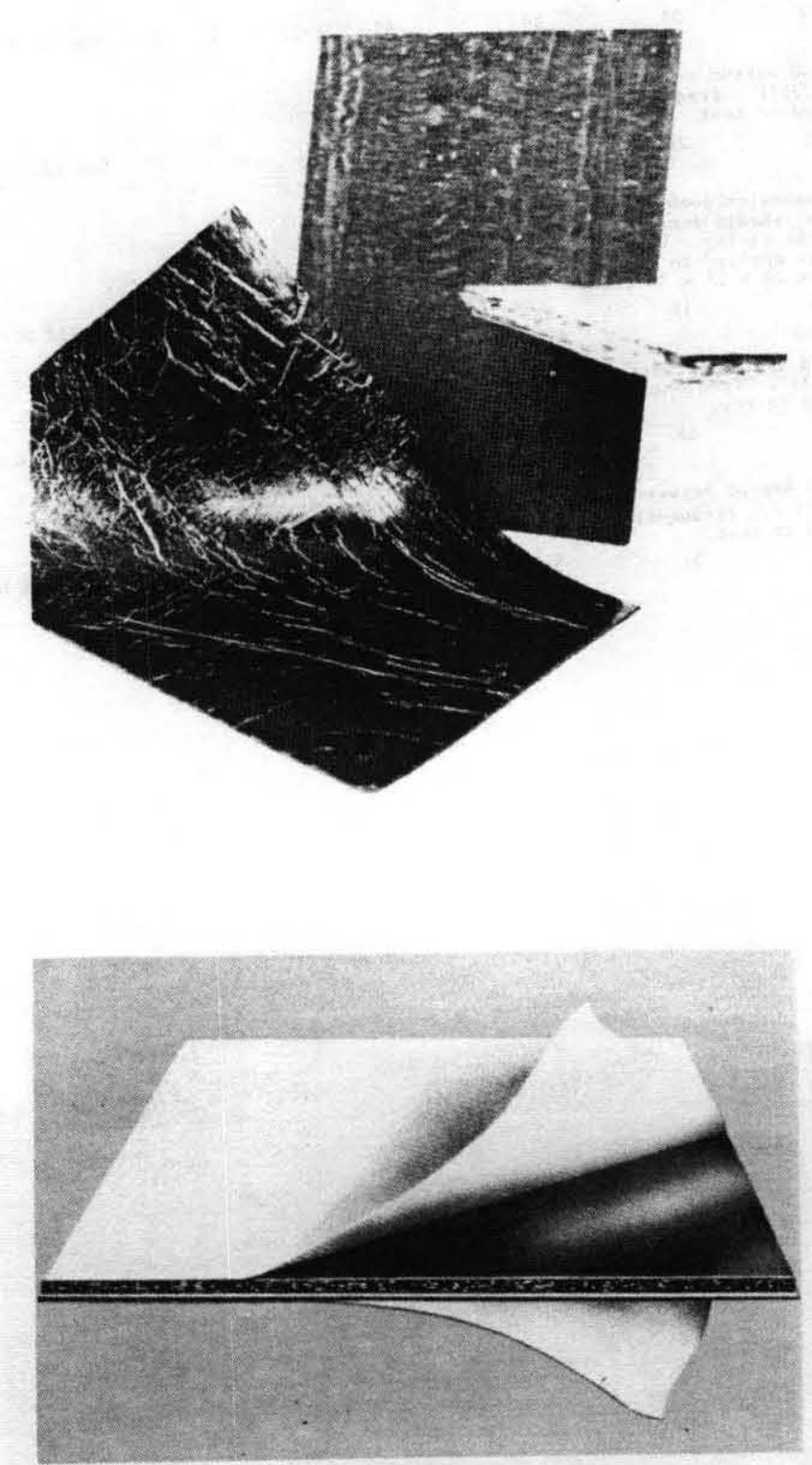


\section{CATEGORY 9. MASTICS}

Mastics are normally quick-drying cements which are used for sound barrier applications. They are usually dense, flexible, asphaltic products with reliability varying from elastic to semirigid. Mastics are applicable as barrier, deadening, or damping materials used in vehicles, doors, appliances, metal enclosures, etc.

The following data include absorption, insertion loss and transmission loss qualities of different mastics. Organizations contributing data to this table are: $28,40,65,73$, and 81 .

\begin{tabular}{l} 
CAUTION \\
NOTE THAT BARRIER VALUES SHOWN ON PAGE 204 ARE TRANSMISSION \\
LOSSES AND THOSE SHOWN ON PAGE 205 ARE INSERTION LOSSES. \\
REFER TO PAGES 70 AND 94 FOR DISCUSSION. \\
\hline
\end{tabular}

GLOSSARY

Facing: The outside surface of the specimen. In general the side facing the sound source

Backing: The other outside surface of the specimen. In general the side not facing the sound source

Core: The region between the facing and the backing

Creped Kraft: Crinkled, strong paper

Mastic: Any of various quick-drying pasting cements. For sound barrier application this is usually a dense flexible asphalted product. 
Table 9A. Absorption properties of mastic.

\begin{tabular}{|c|c|c|c|c|c|c|c|c|c|c|c|c|}
\hline \multirow{3}{*}{ NRC } & \multicolumn{6}{|c|}{ Absorption Coefficients } & \multirow{3}{*}{ 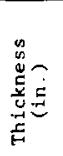 } & \multirow{3}{*}{ 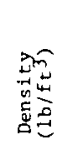 } & \multirow{3}{*}{ 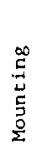 } & \multirow{3}{*}{ 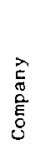 } & \multirow{3}{*}{ Product } & \multirow{3}{*}{ Reference } \\
\hline & $\stackrel{N}{x}$ & $\stackrel{N}{\simeq}$ & $\stackrel{N}{ \pm}$ & $\stackrel{N}{\simeq}$ & $\stackrel{N}{ \pm}$ & \pm & & & & & & \\
\hline & $\cong$ & $\stackrel{\circ}{~}$ & 品 & @ & $\stackrel{\circ}{\circ}$ & 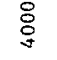 & & & & & & \\
\hline \multirow[t]{2}{*}{ (c) } & \multicolumn{12}{|c|}{$\begin{array}{l}\text { Formulared asphalt with inert fillers between } \\
\text { selected skin covering layers. }\end{array}$} \\
\hline & .02 & .02 & .02 & .10 & .12 & .02 & -. & - & $-\cdot$ & 28 & Mastic (asphait) & CR 6011 \\
\hline \multirow{2}{*}{ (c) } & \multicolumn{6}{|c|}{ G-60P mastic core with $28 \mathrm{gram}$ cotton padding. } & & & & & & $C R \quad D-6-1.76$ \\
\hline & .04 & .06 & .20 & .42 & .60 & .68 & -. & $\cdots$ & $-\cdot$ & 40 & dba damp-"G" & Test 1 \\
\hline \multirow[t]{2}{*}{$\left(\begin{array}{ll}30 \\
(c)\end{array}\right.$} & \multicolumn{12}{|c|}{$\begin{array}{l}\text { Three ply, paper facing on pressure sensitive adhe- } \\
\text { sive, } 11 \mathrm{~b} / \mathrm{ft} \text { mastic, and } 28 \text { gram resinated cotton } \\
\text { padding } 1 / 4 \text { inch thick. Refer to insertion loss }\end{array}$} \\
\hline & .04 & .07 & .20 & 41 & .61 & .68 & -. & -- & $\cdots$ & 65 & $\begin{array}{l}\text { Acoustigard } \\
\text { L24-60(100) }\end{array}$ & $\begin{array}{l}\text { GSAH } \\
\text { CR } 25-6-75\end{array}$ \\
\hline \multirow{2}{*}{$\begin{array}{l}60 \\
(\mathrm{c})\end{array}$} & \multicolumn{12}{|c|}{ G-75P mastic core with 85 gram cotton padding. } \\
\hline & .06 & .20 & .55 & .83 & .85 & 82 & -- & $\cdots$ & $-\cdot$ & 40 & dba damp-"G" & CR D-C-1-76 \\
\hline \multirow[t]{2}{*}{$\begin{array}{l}.60 \\
(c)\end{array}$} & \multicolumn{12}{|c|}{$\begin{array}{l}\text { Three ply, paper facing on pressure sensitive adhe- } \\
\text { sive, } 1 \text { ib/ft mastic. } 85 \text { gram resinated cotton } \\
\text { padding } 3 / 4 \text { inch thick. Refer to insertion loss }\end{array}$} \\
\hline & .07 & .20 & .55 & .83 & .85 & 82 & - & -. & $\cdots$ & 65 & $\begin{array}{l}\text { Acoustigard } \\
\text { L24-75(100) }\end{array}$ & ${ }_{\mathrm{CR}}^{G \delta \mathrm{H}} 25-6-75$ \\
\hline
\end{tabular}

Table 9B. Barrier properties of mastic (transmission loss).

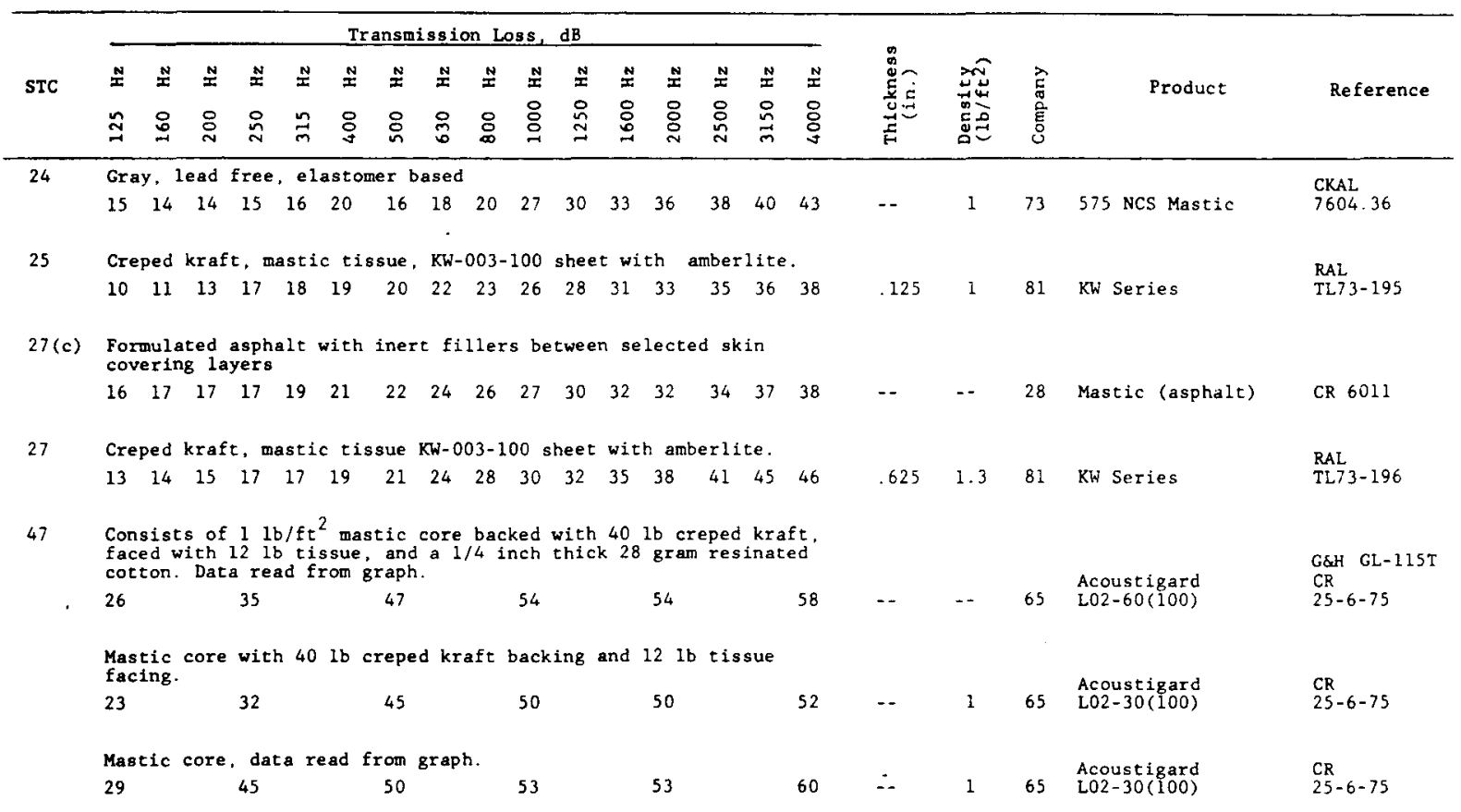


Table 9C. Barrier properties of mastic (insertion loss).

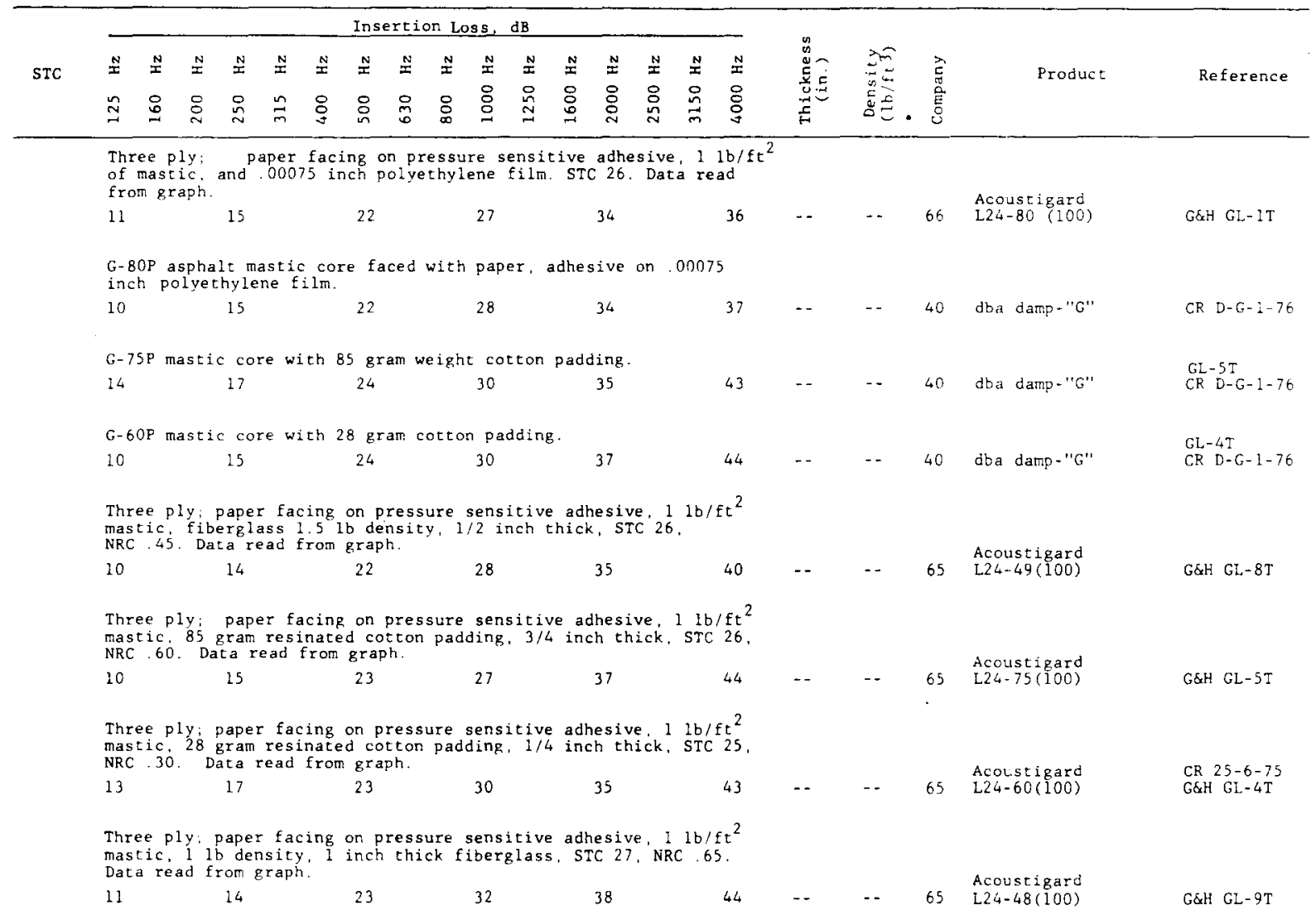


CATEGORY 10, QUILTED MATERIALS
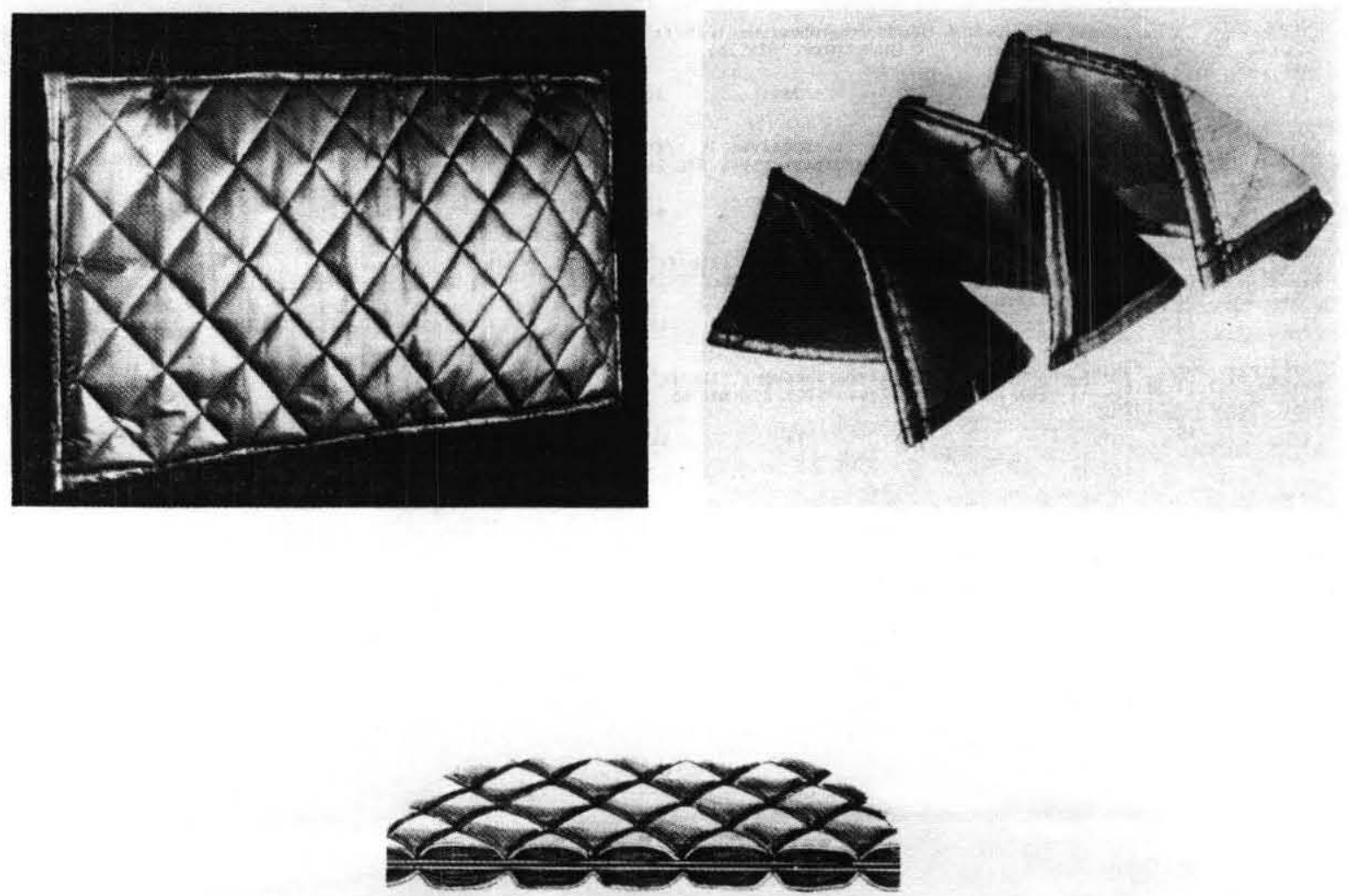
CATEGORY 10. QUILTED MATERIALS

With the availability of various sandwich type configurations, quilted materials are very versatile for sound control. They have good thermal properties and are resistant to moisture, many chemicals, and abrasion.

The facing material may be aluminized glass cloth, a fiberglass scrim type cloth, or other impervious facing materials. The absorption material can be foam but usually consists of a glass fiber material to achieve higher fire ratings. The quilt composite may be simply a facing material encapsulating an absorption material. It may include a barrier septum (usually lead) or a barrier-type backing (lead vinyl) for improved transmission loss properties.

This pliable composite can be used for barriers or enclosures, equipment or wall liners, duct or pipe covering, machinery quieting, or source isolation. Both absorption and sound transmission data are supplied. Organizations contributing data to this table are: 4, 20, 73, and 93. For related sections, see curtains and unit absorbers. 
Table 10A. Absorption properties of quilted materials.

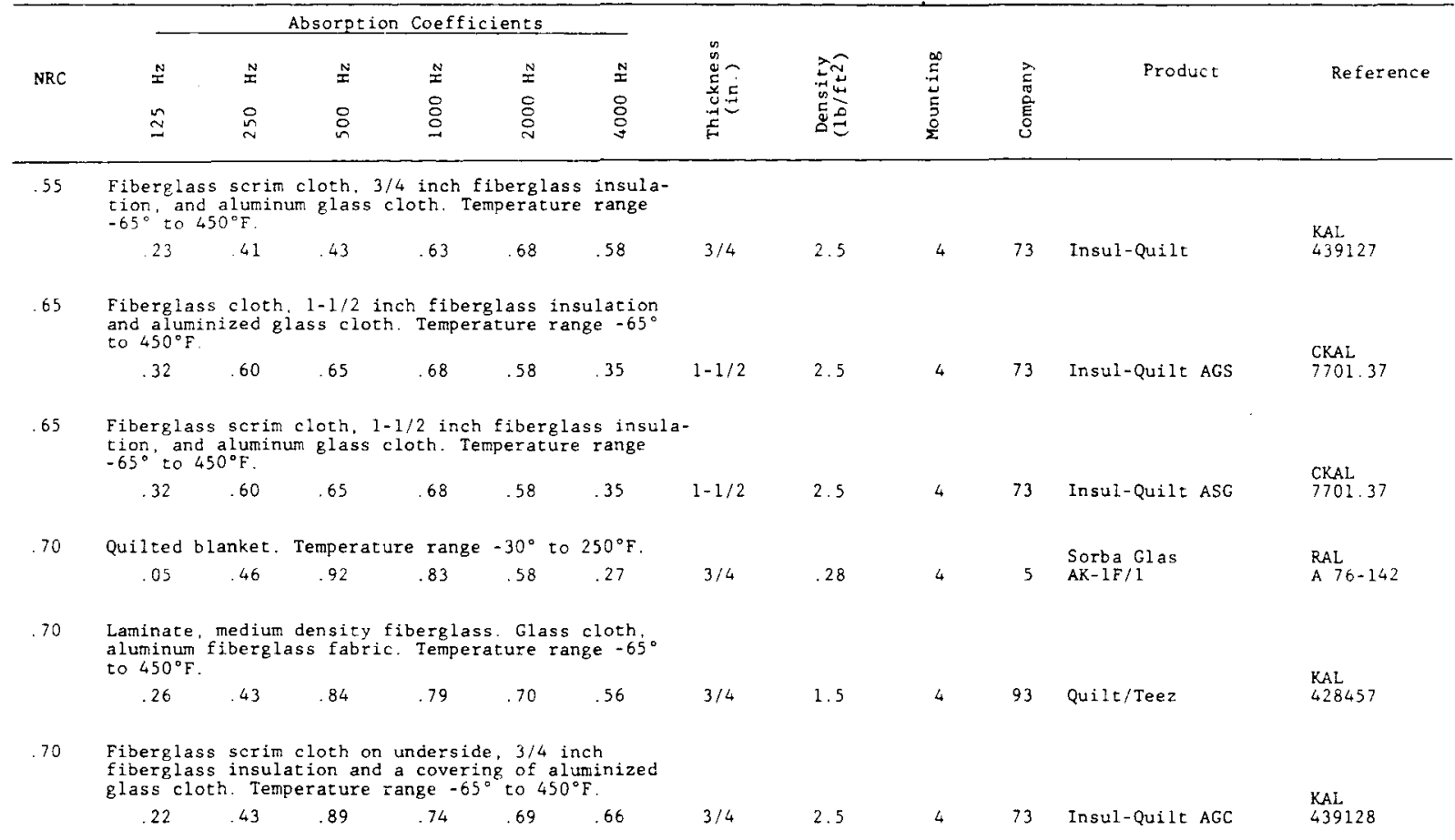

Table 10B. Barrier properties of quilted materials.

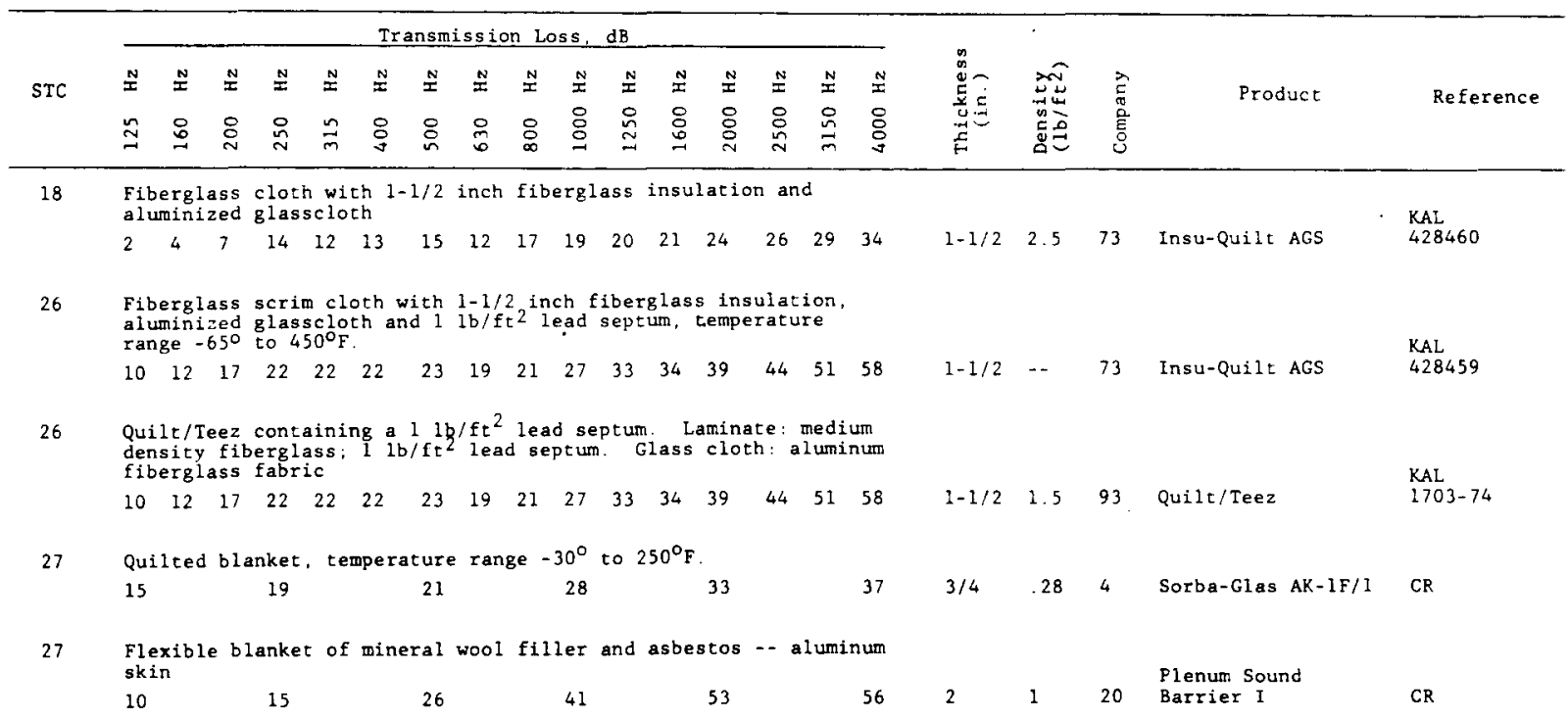




\section{CATEGORY 11. PLAIN AND MASS LOADED PLASTICS}
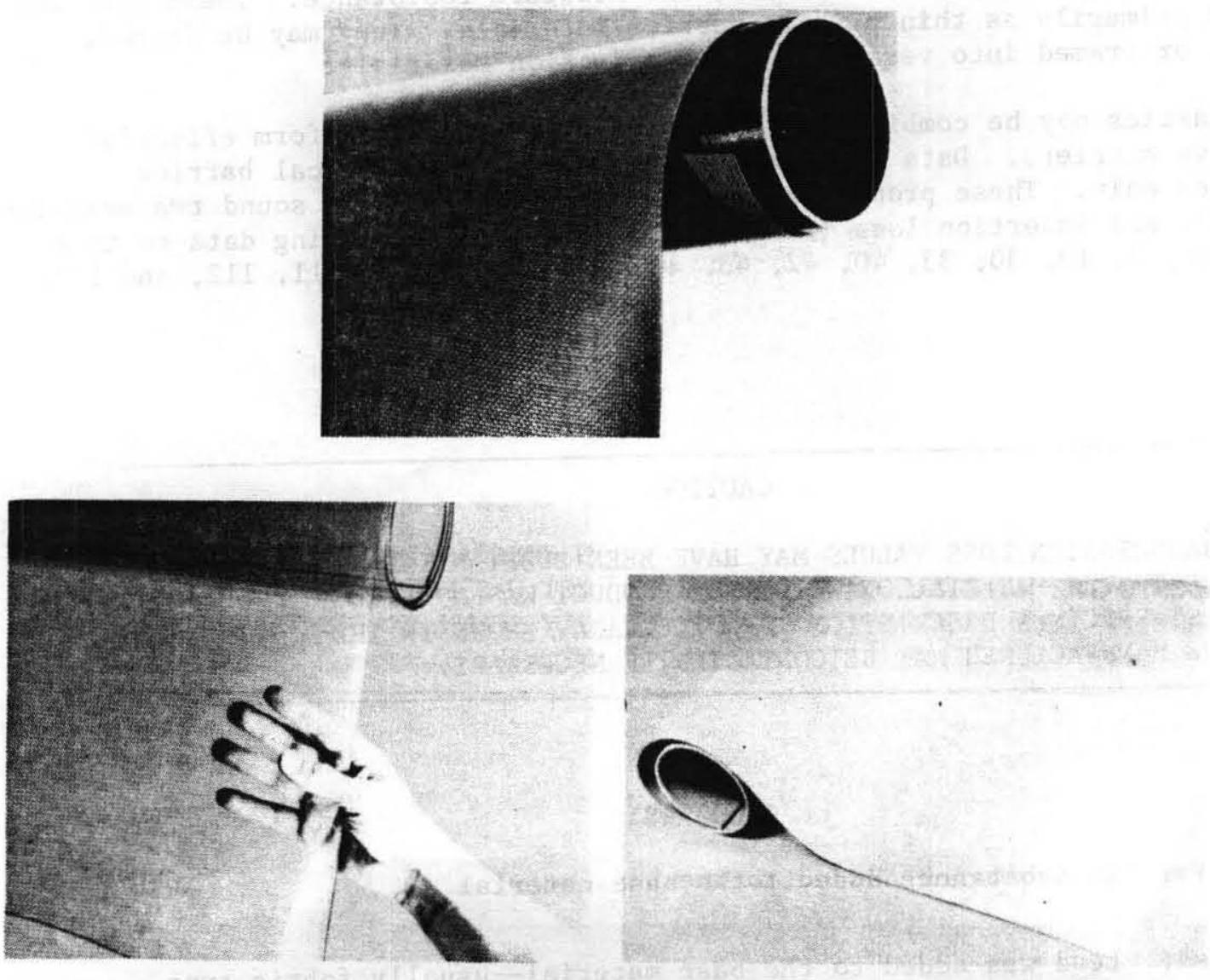
CATEGORY 11. PLAIN AND MASS-LOADED PLASTICS

Mass-loaded plastics are formulated from lead or nonlead fillers and vinyl in order to increase noise reduction capabilities. The composition may include a reinforcing material such as fiberglass to increase toughness. Such materials offer flame, oil, chemical, and moisture resistance. These plastics are used primarily as thin pliable barrier materials. They may be draped, wrapped, or framed into versatile noise reduction materials.

These plastics may be combined with absorptive materials to form effective absorptive barriers. Data in this section relate to acoustical barrier properties only. These properties are noise reduction (NR), sound transmission loss (TL), and insertion loss (IL). Organizations contributing data to this table are: 5, 13, 30, 33, 40, 42, 43, 48, 53,60, 78, 96, 111, 112, and 117 .

\title{
CAUTION
}

TRANSMISSION LOSS VALUES MAY HAVE BEEN SUBSTANTIALLY INCREASED DUE TO THE MATERIAL ON WHICH THE PRODUCT WAS MOUNTED. WHEN THE TEST SPECIMEN DESCRIPTION IS NOT CLEARLY SHOWN IN THE TABLE, THE MANUFACTURER MAY BE CONTACTED IF NECESSARY.

\author{
GLOSSARY \\ Loaded: Foreign substance added to the base material \\ Leaded or \\ Lead Loaded: Lead was added to the base material--usually fabric type \\ materials--to increase the sound transmission loss
}


Table 11. Plain and mass-loaded plastics.

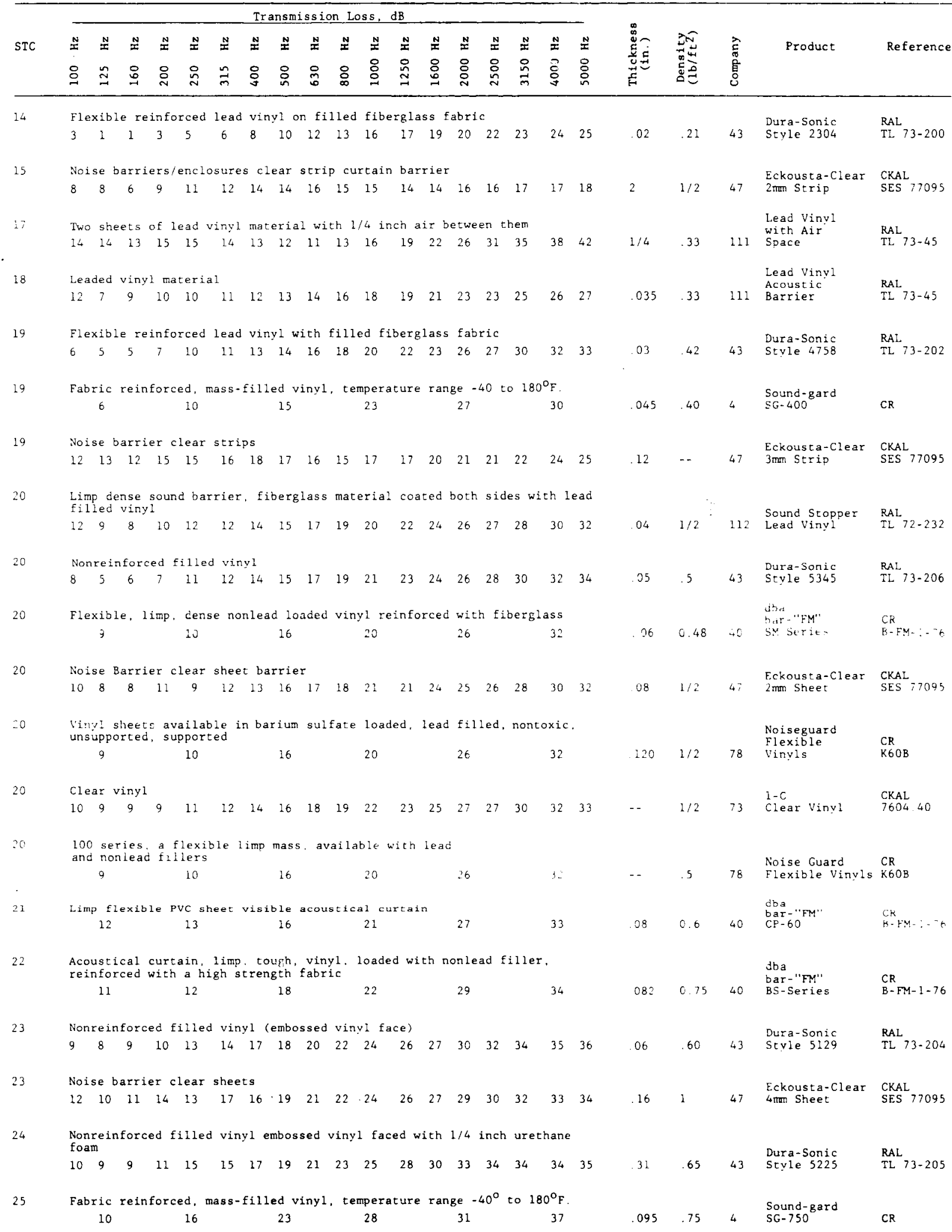


Table 11. Plain and mass-loaded plastics continued.

Transmission Loss, $d B$

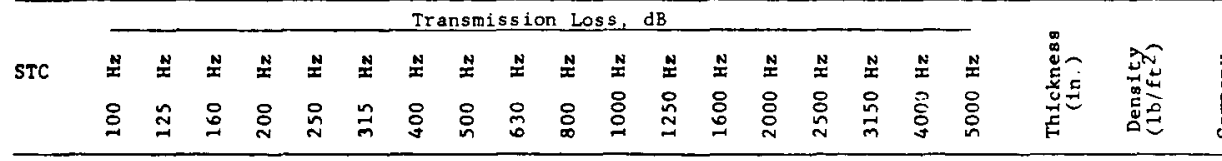

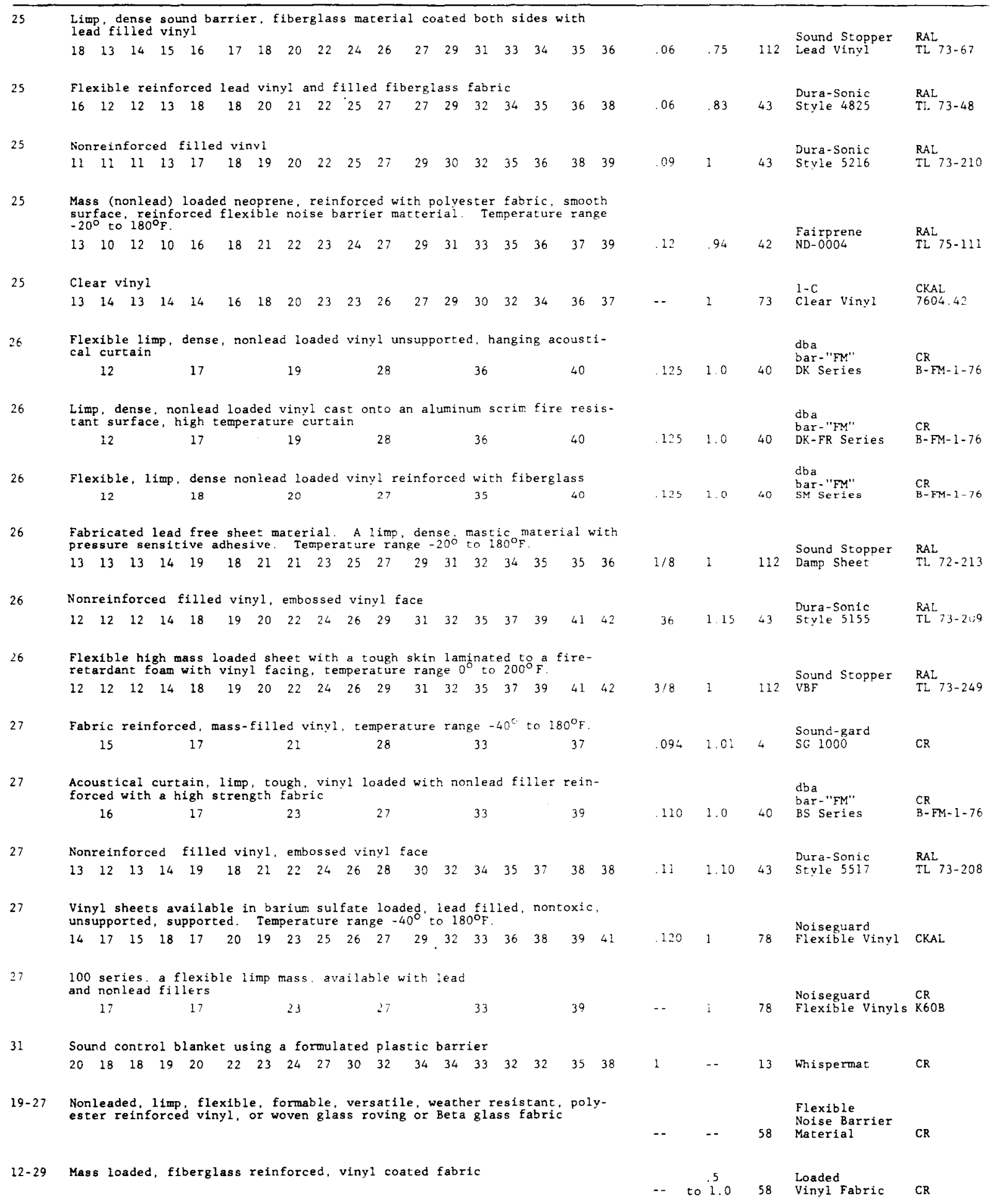


Table 11. Plain and mass-loaded plastics concluded.

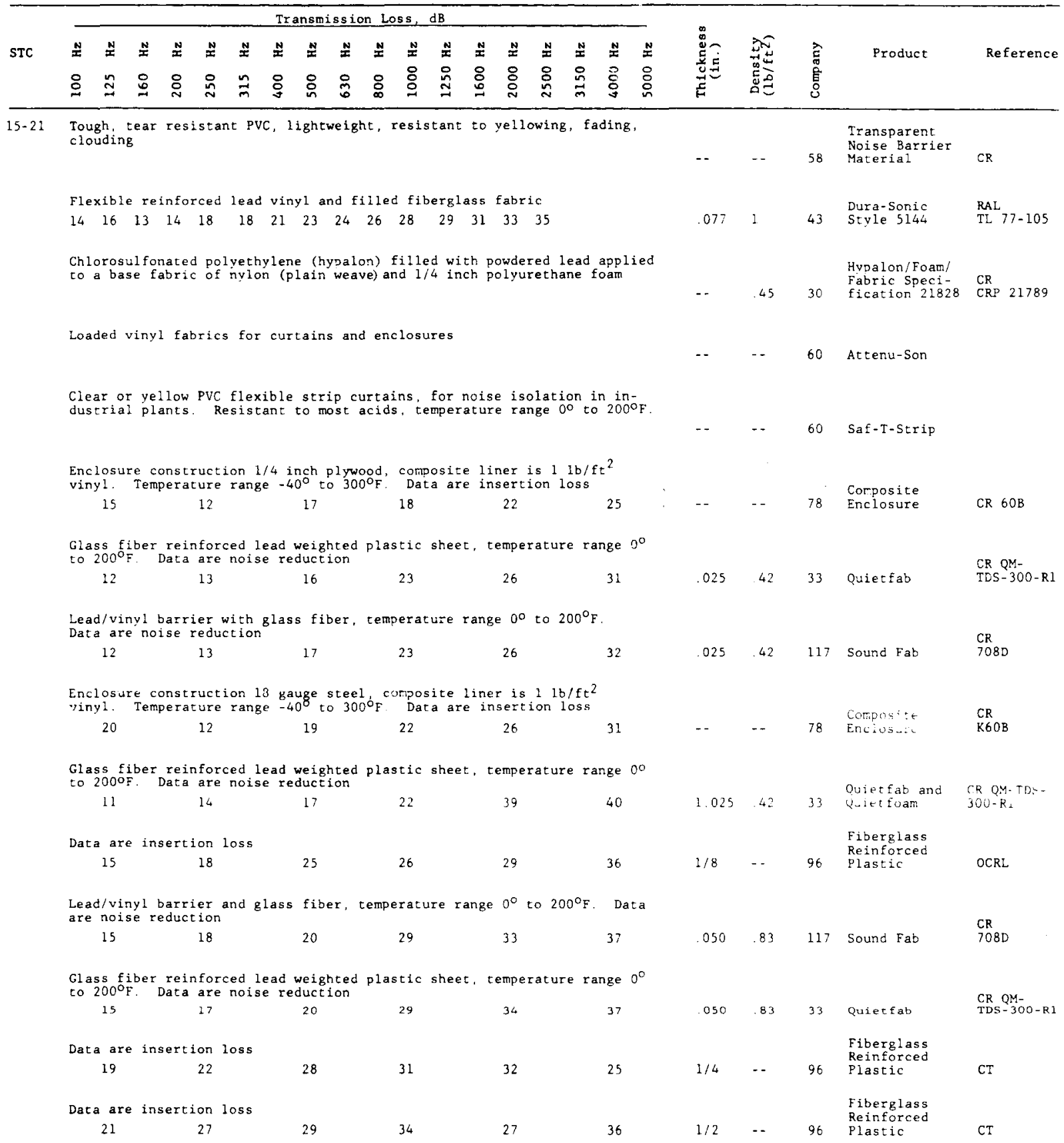


CATEGORY 12. GLASS AND PLASTIC SHEETS

\begin{abstract}
A broad category of materials which are linked because they are available as transparent sheet materials. They can exist as independent or as composite barrier systems. Their usefulness is augmented whenever visibility plus noise control is desired. Structurally, they can be rigid or flexible. Glass or plastic barriers are usually mounted in a fixed location.

Composite panels of glass separated by a plastic type layer, such as polyvinyl butyral are frequently used. In some cases, an air space is also provided. This total combination offers increased thermal and acoustical isolation.

Other related sections are curtains, panels, operable partitions, windows and enclosures. Organizations contributing data to this table are: $46,64,79$, $89,107,110$, and 140 .
\end{abstract}


Table 12. Glass and plastic sheets.

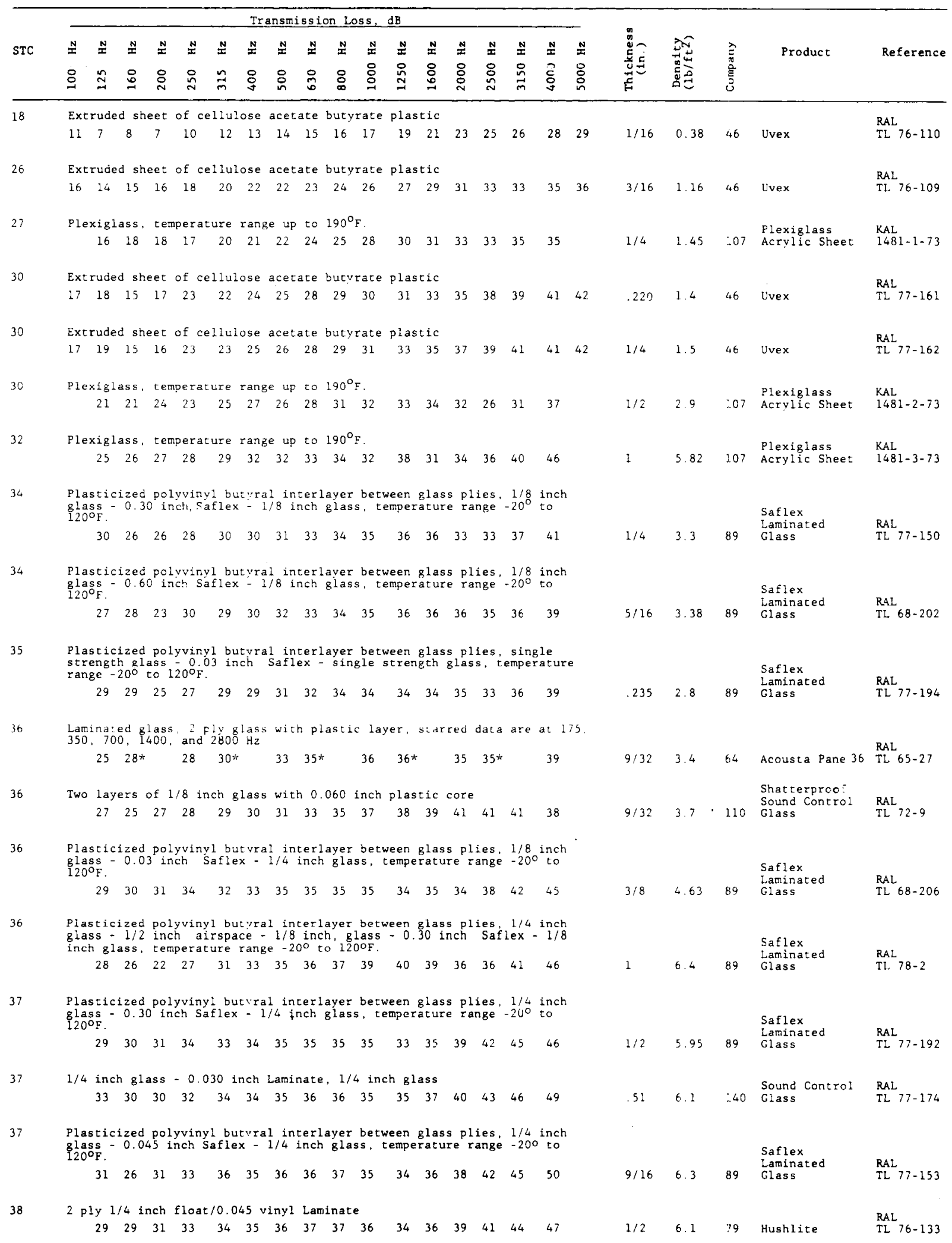


Table 12. Glass and plastic sheets concluded.

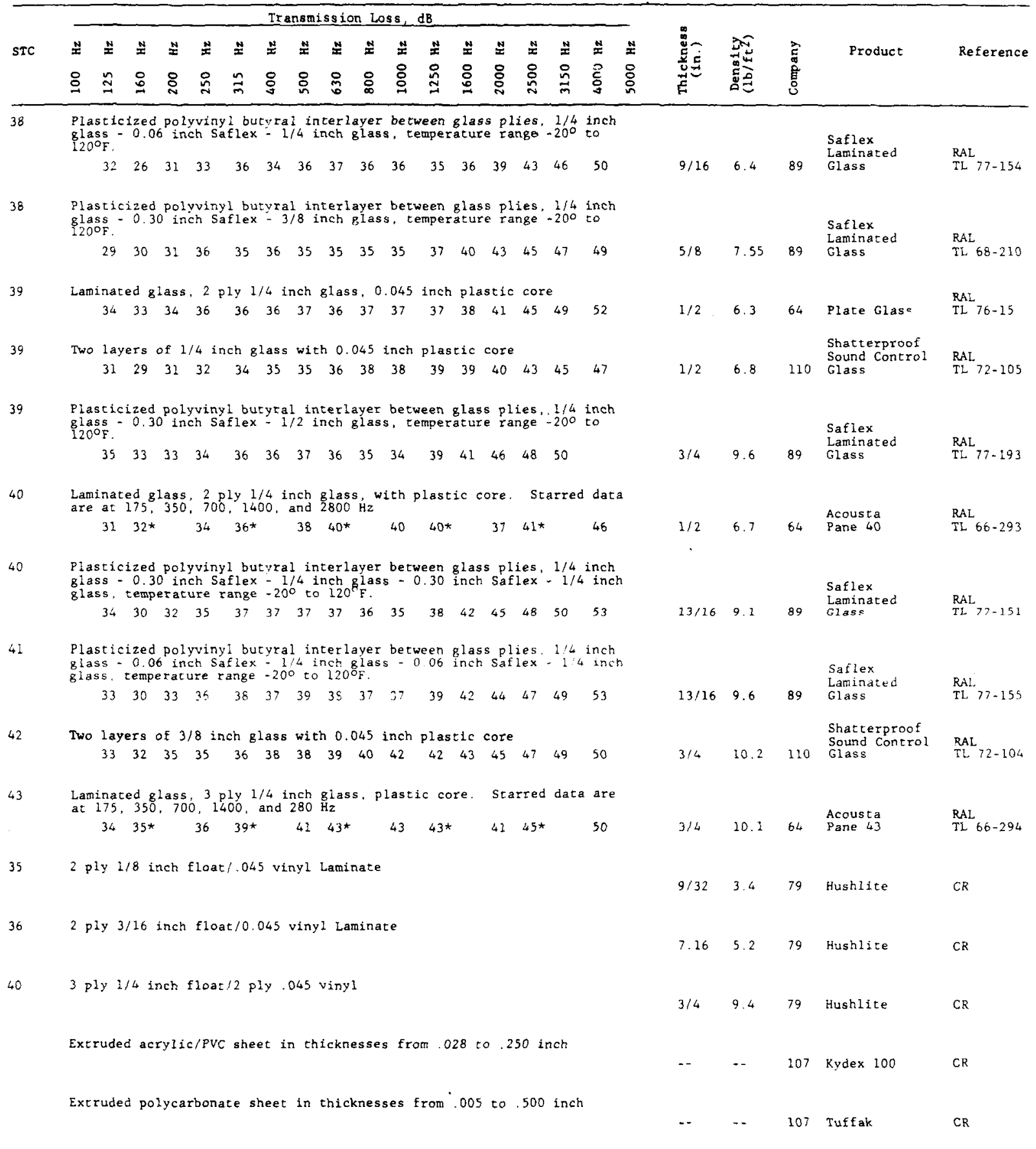


CATEGORY 13. OTHER BARRIER MATERIALS

Items listed in this category are separated from specific categories because of designated purpose, special application, or slight fabrication changes. - These items as well as all items listed in other categories should be considered with respect to particular acoustical performance and not limited to the designated use.

Organizations contributing data to this table are: $13,30,66,90,97$, and 117 . 
Table 13. Other barrier materials.

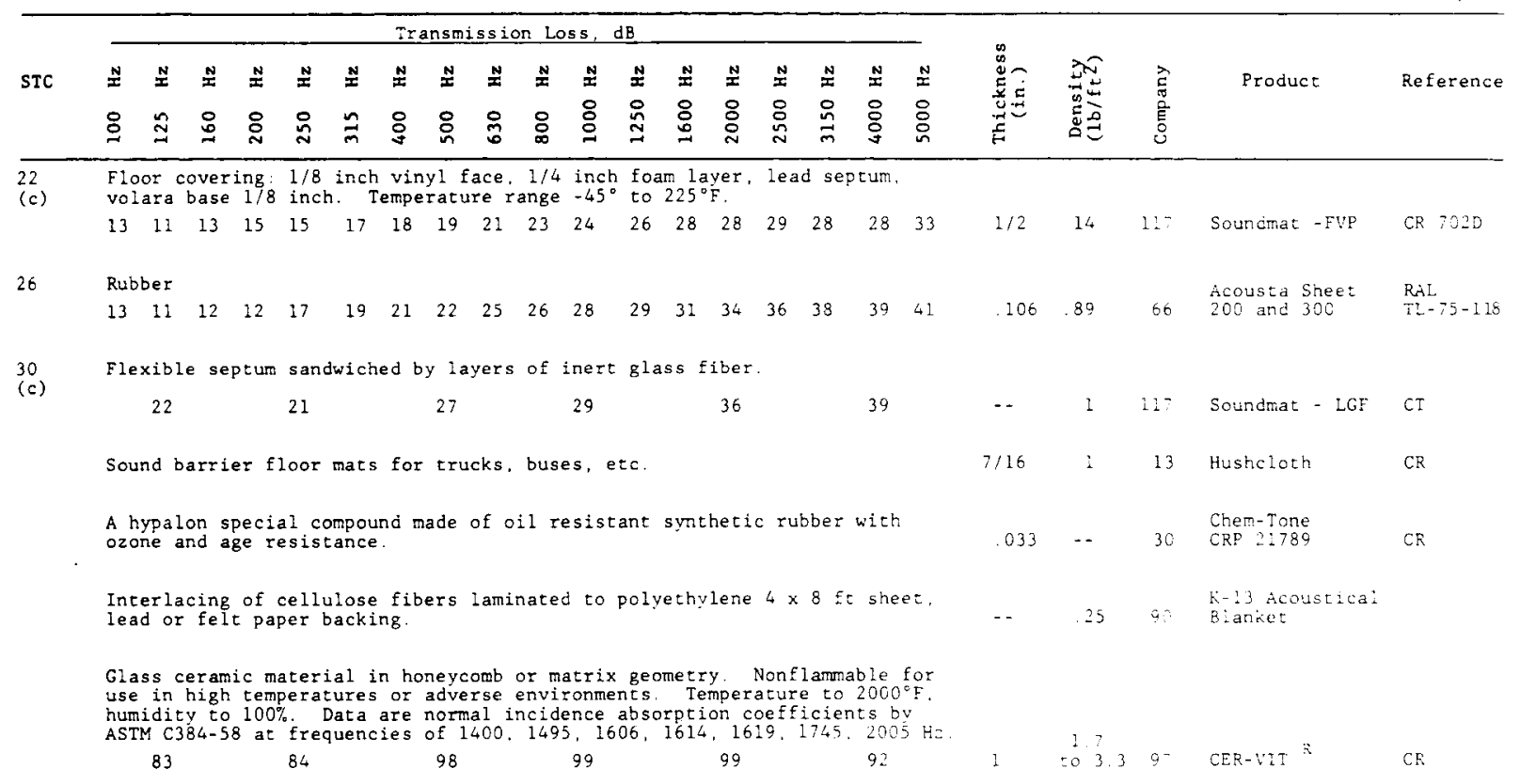




\section{CATEGORY 14. CEILING TILES}
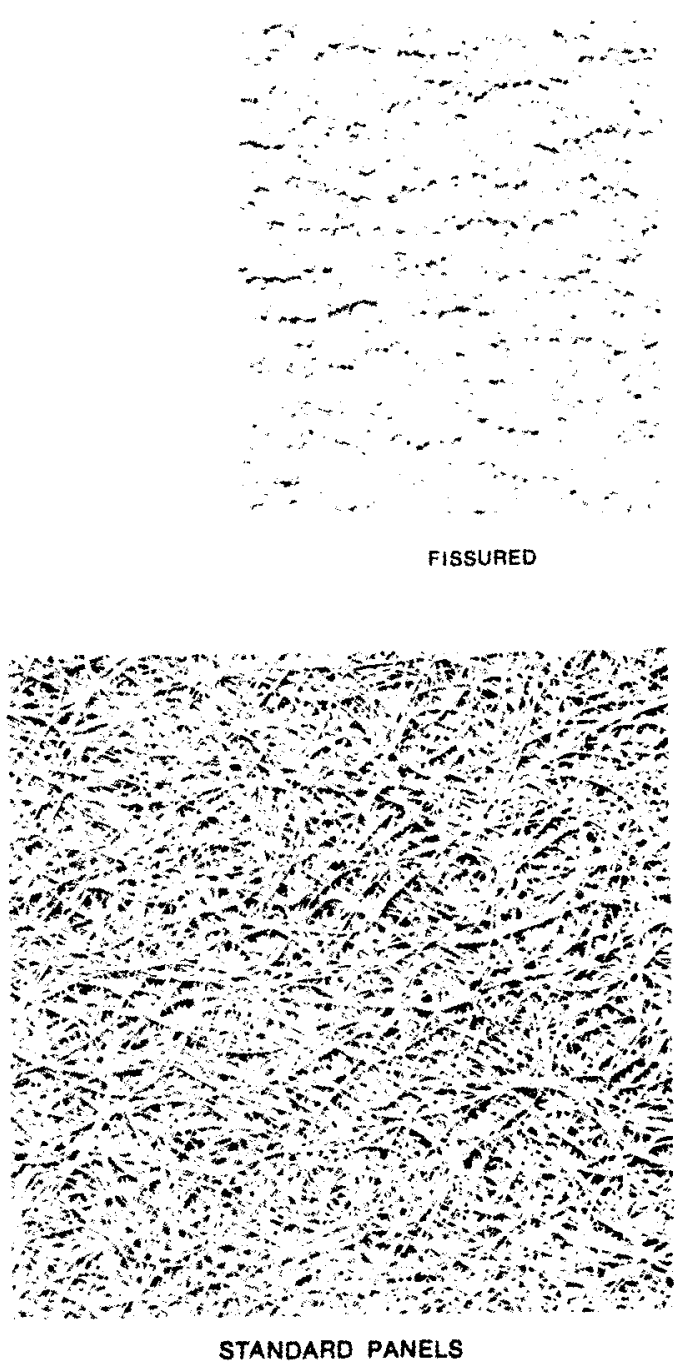

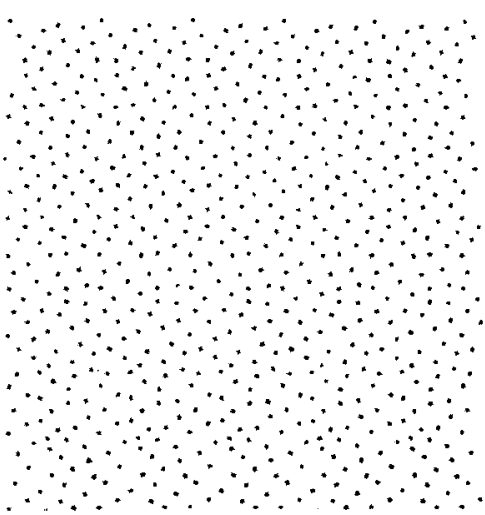

RANDOM PEAFORATED

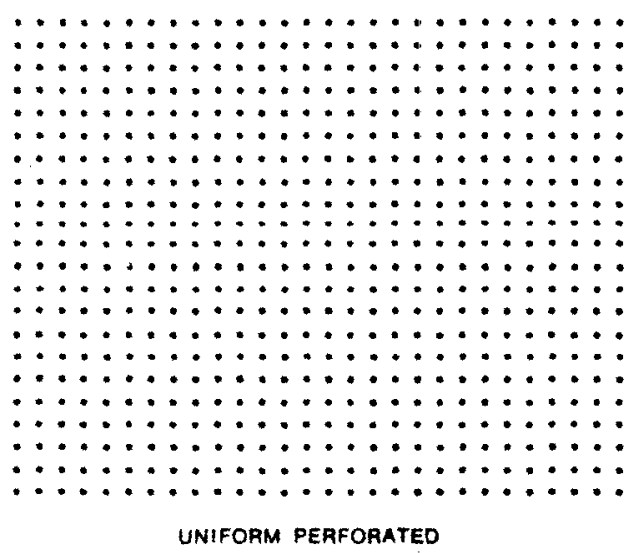

UNIFORM PERFORATED 


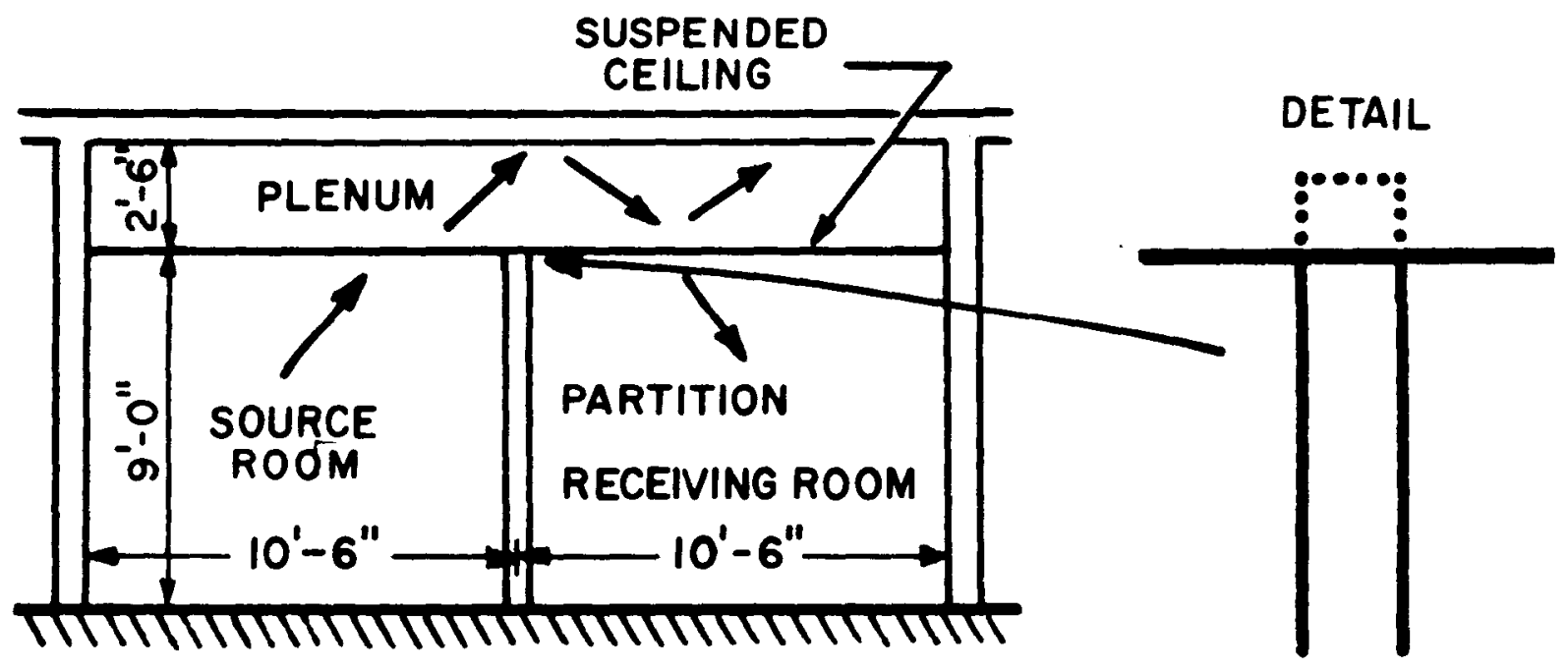

SECTION THROUGH TWO-ROOM TEST

CHAMBER. THE FACILITY IS 15'-6" WIDE.

Test Configuration for AMA-1-II 


\section{CATEGORY 14. CEILING TILES}

Ceiling tiles vary acoustically from highly reflective to very absorbent and can have from poor to good barrier properties. Typical tile parameters include texture, type of perforation, pattern, structural integrity, and appearance. Descripters such as embossed, fissured, plain, facing type, backing material, edge type (beveled, rabbeted, square, etc.), light reflectance, fire rating, moisture resistance, and asthetic value are usually included with the overall acoustical performance. The well-designed acoustical ceiling is an essential part of sound control.

Organizations contributing data to this table are: $4,5,15,28,34,74,85$, 92, 96, and 113. Related categories are panels, unit absorbers, and open plan systems.

\section{CAUTION}

1. ABSORPTION COEFFICIENTS MAY EXCEED 1.0. FOR A COMPLETE DISCUSSION OF THESE VALUES SEE PAGE 51.

2. THE NUMBERS LISTED UNDER THE "MOUNTING" COLUMN REFER TO THE AIMA STANDARD MOUNTINGS DESCRIBED ON PAGE 53.

\section{GLOSSARY}

Facing: The outside surface of the specimen. In general the side facing the sound source

Backing: The other outside surface of the specimen. In general the side not facing the sound source

Core: The region between the facing and the backing 
Table 14A. Absorption properties of ceiling tile.

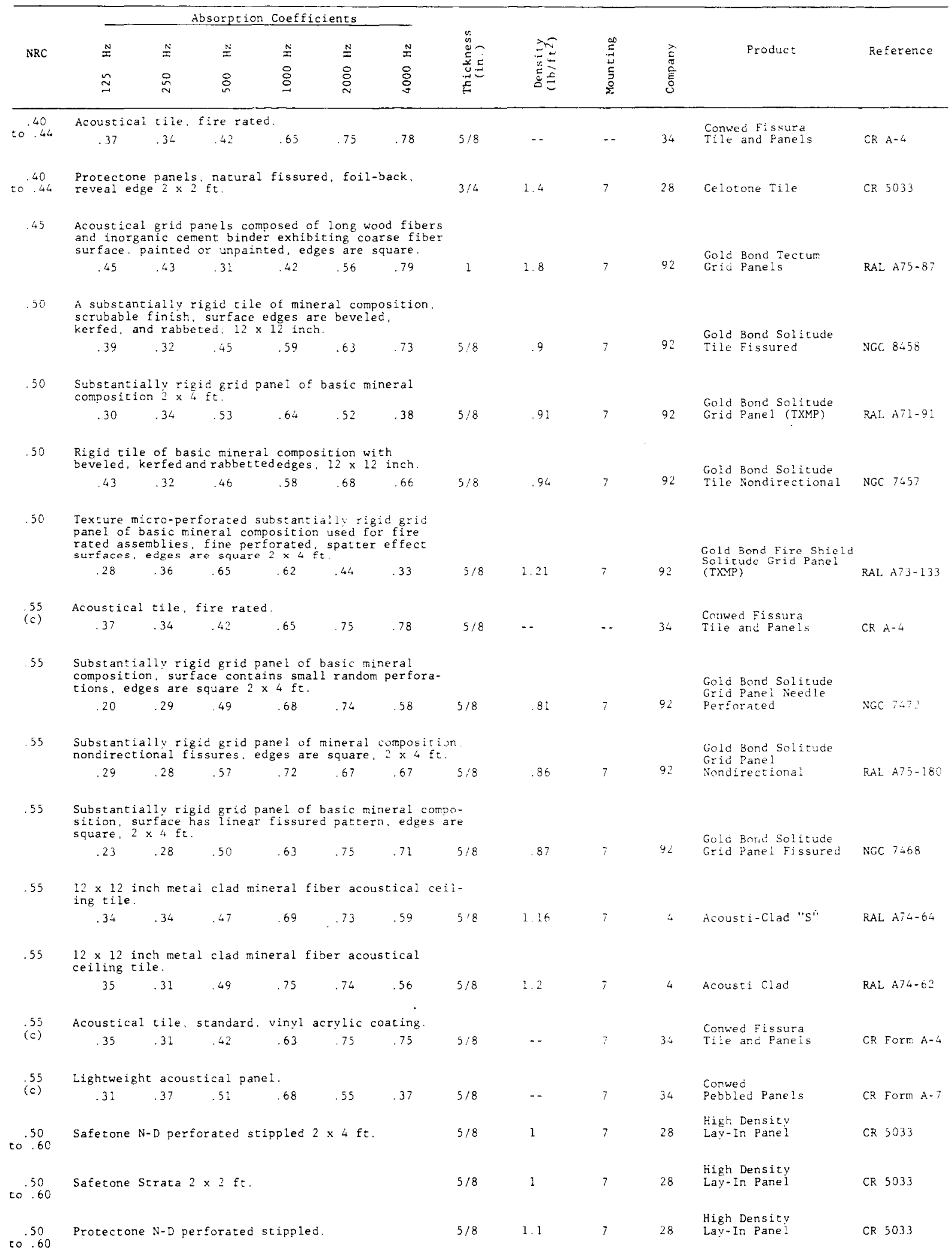


Table 14A. Absorption properties of ceiling tile continued.

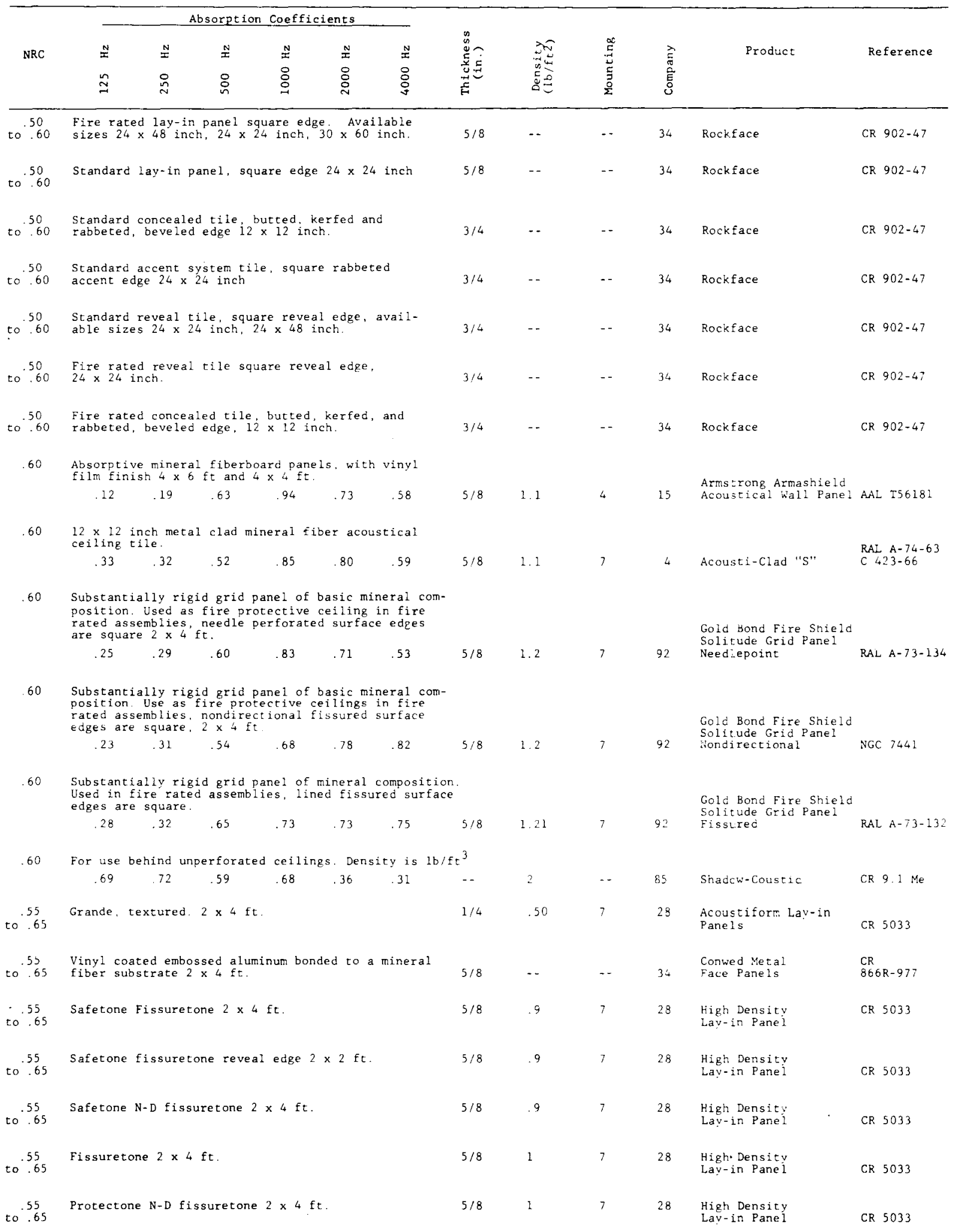


Table 14A. Absorption properties of ceiling tile continued.

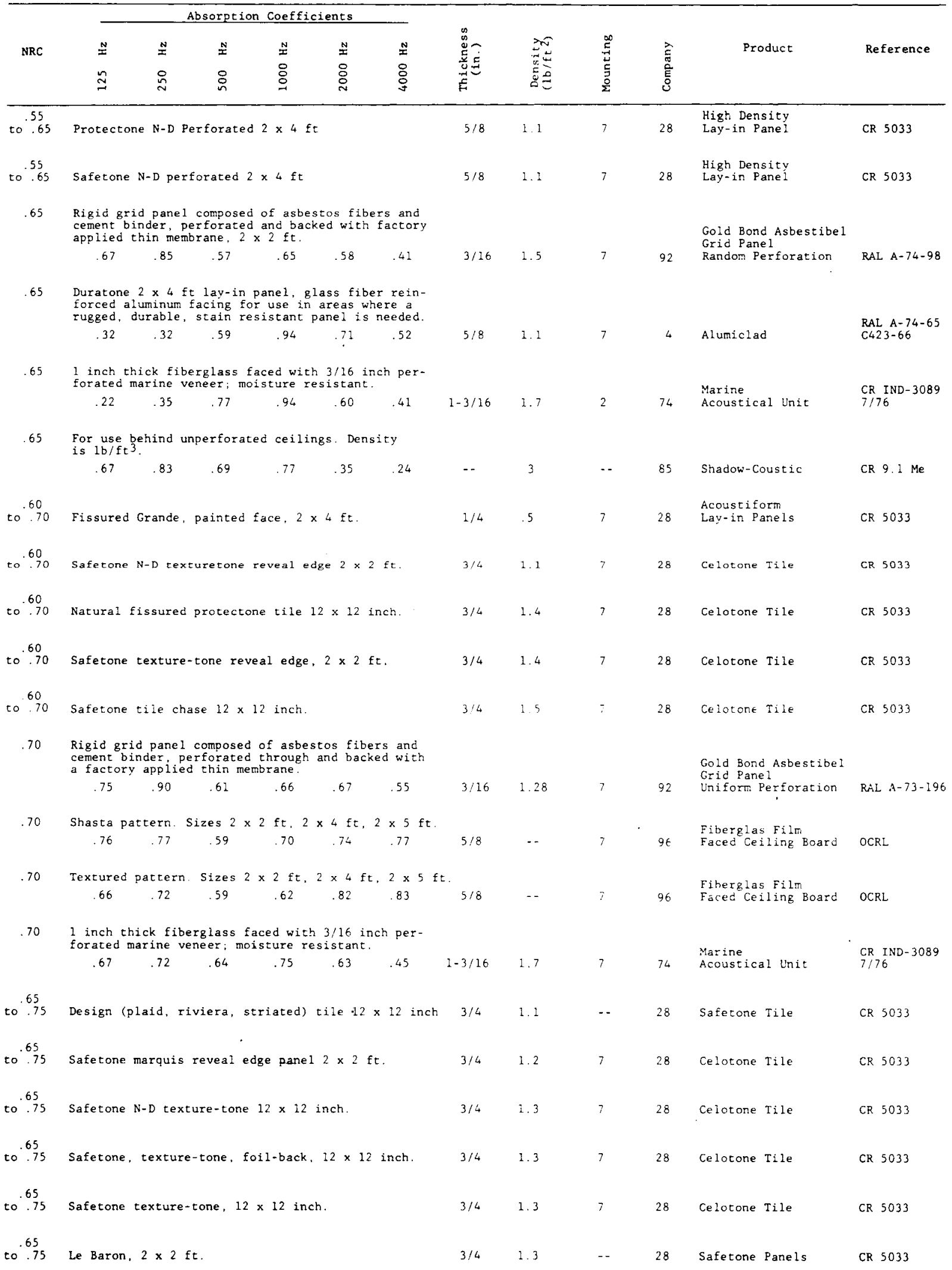


Table 14A. Absorption properties of ceiling tile continued.

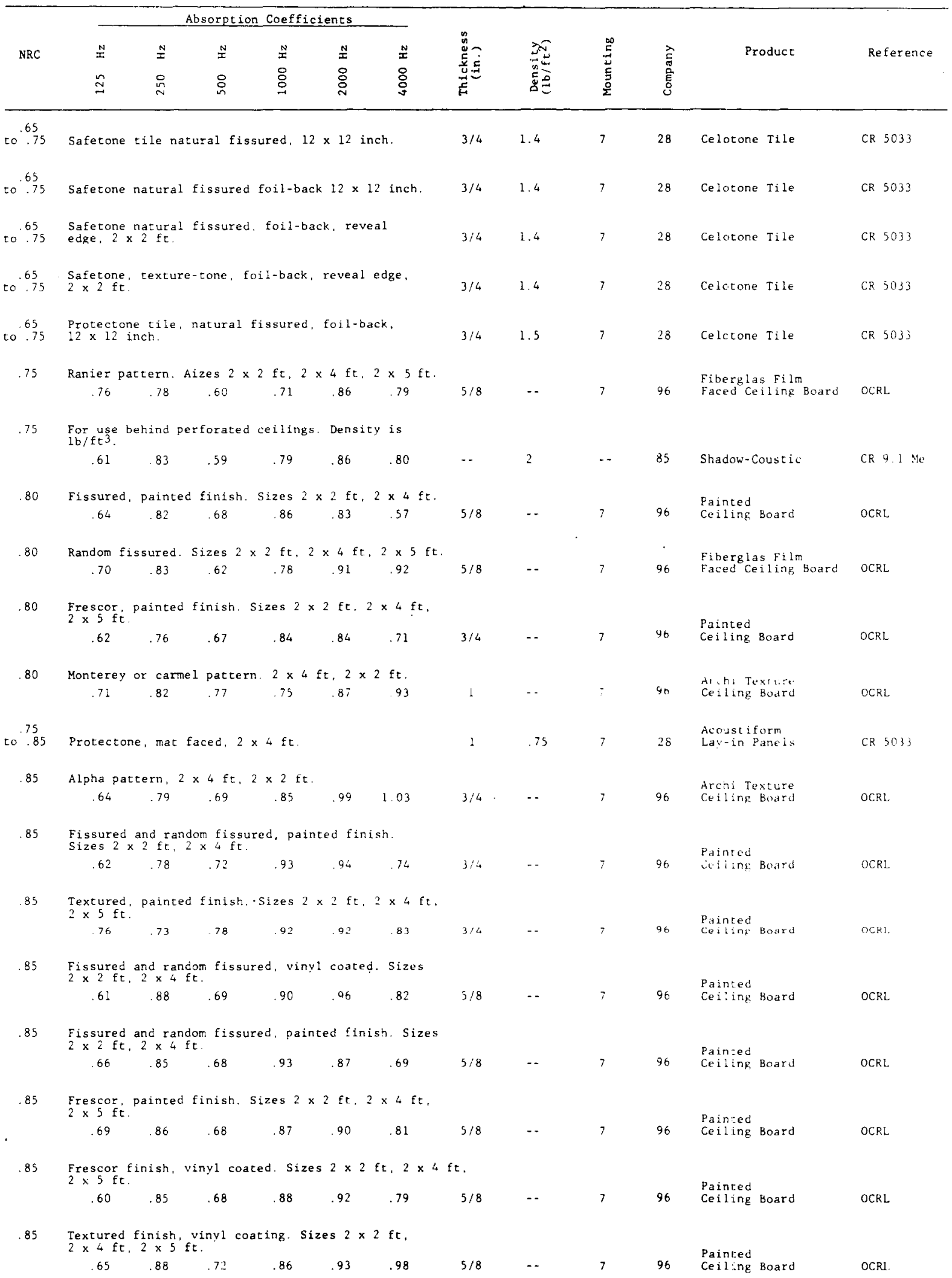


Table 14A. Absorption properties of ceiling tile concluded.

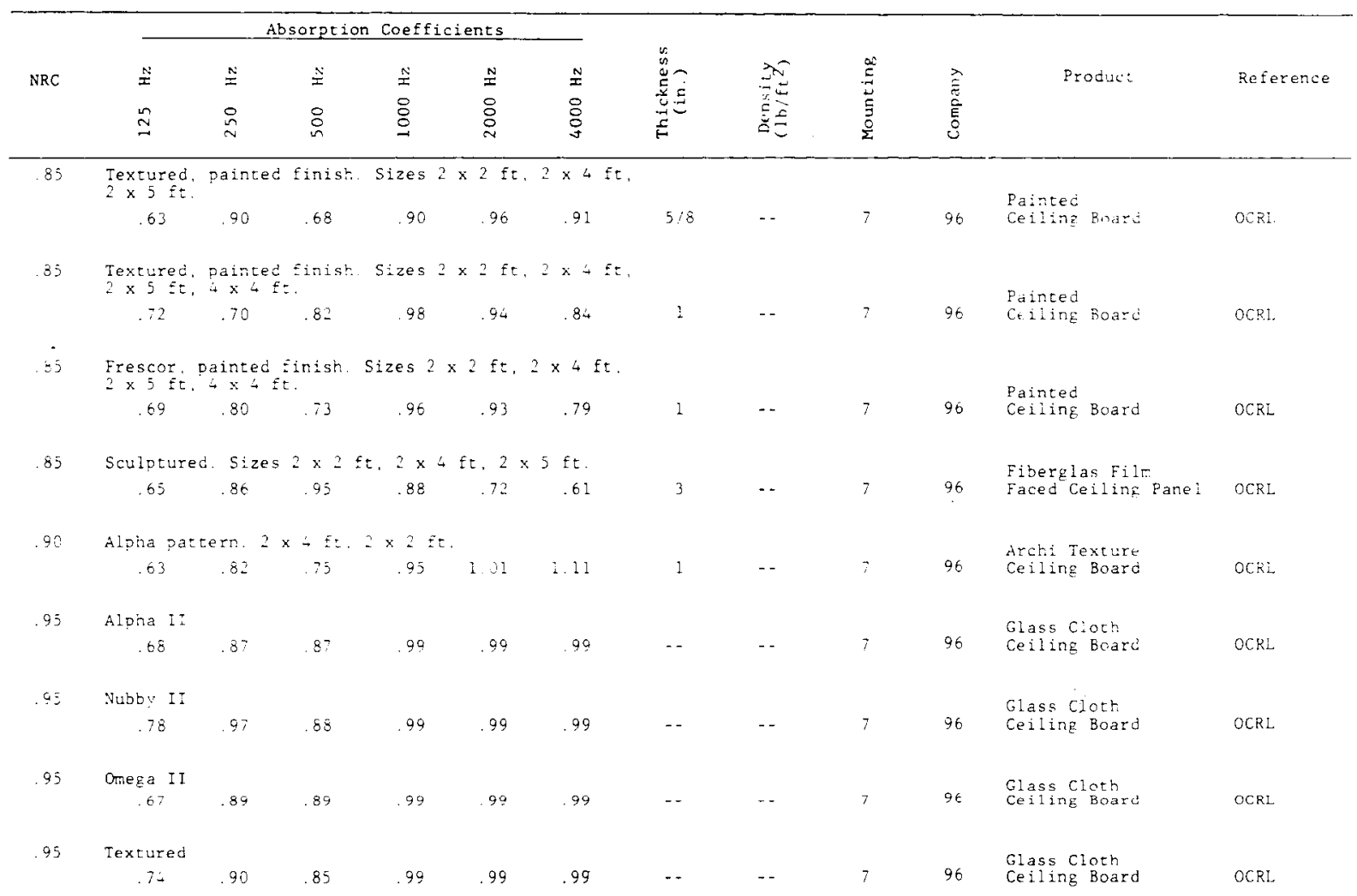


Table 14B. Barrier properties of ceiltng tile.

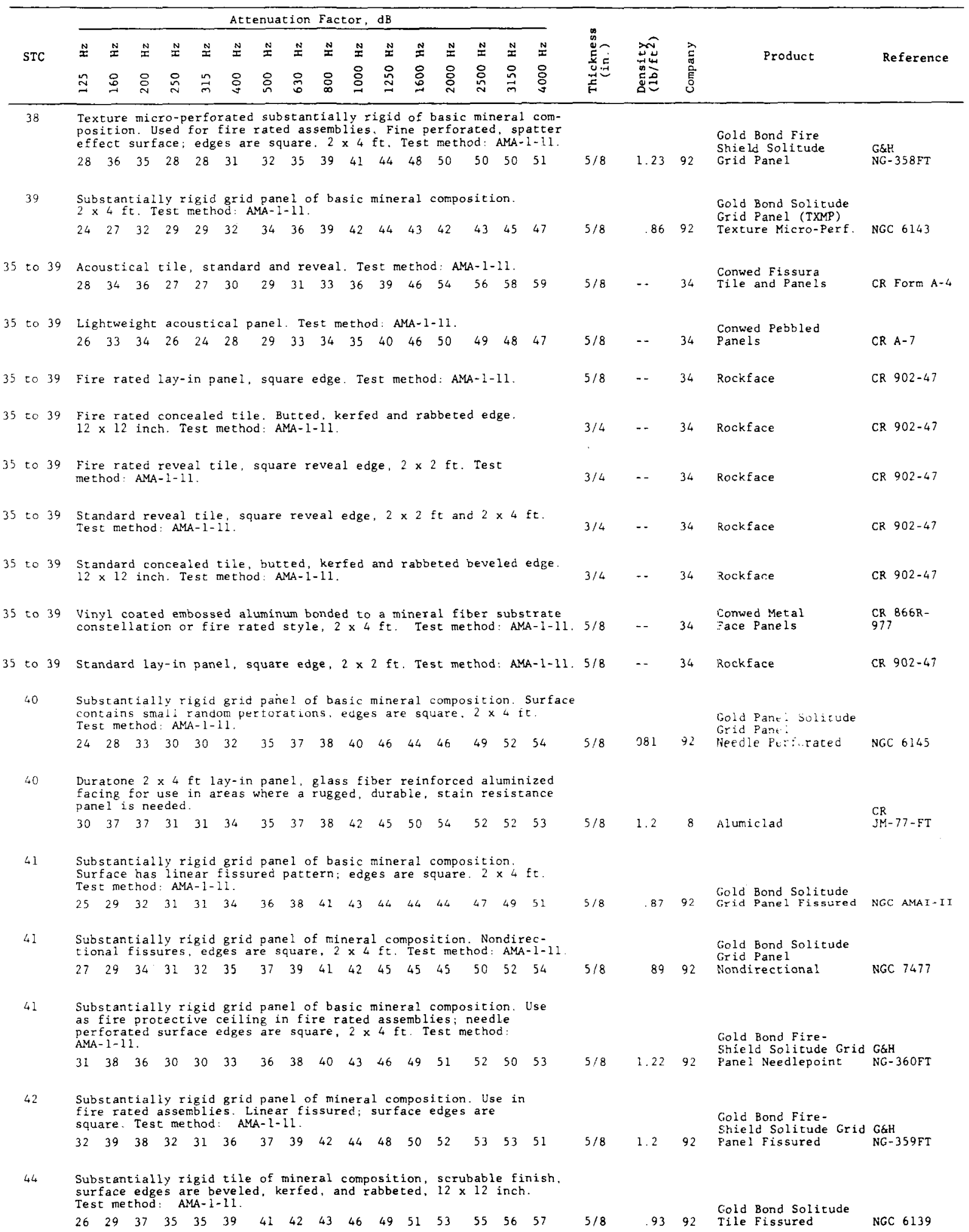


Table 14B. Barrier properties of ceiling tile concluded.

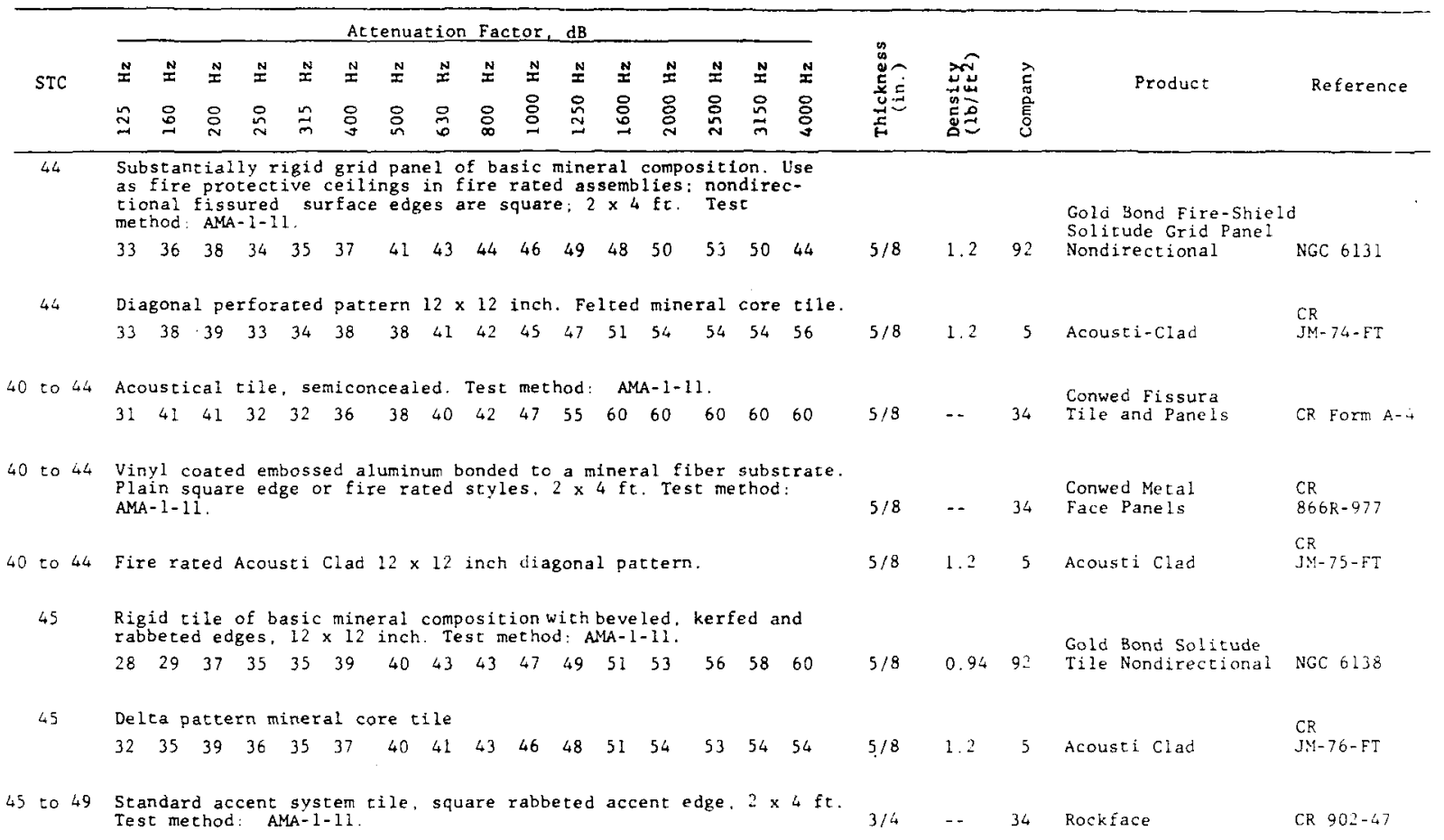


CATEGORY 15. CURTAINS

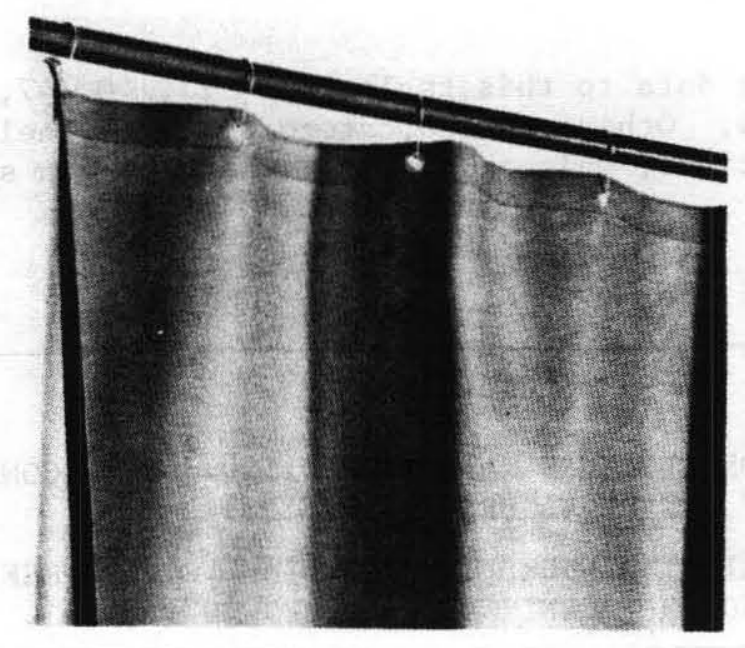




\section{CATEGORY 15. CURTAINS}

The acoustical properties of curtains are dependent upon the curtain material, surface texture, backing material and placement. All these factors produce variation in curtain acoustical performance. Curtains may contain a thick absorptive material for added absorption or simply be mass-loaded for barrier use only. Curtains may overlap and rely only on surface contact for scaling or may use mastic sealing agents. They may be hung as combined overlapping units or as a single acoustical curtain. Guide rails for variable placement are also used.

Organizations contributing data to this table are: $23,40,47,58,76,82$, $86,104,112,116$, and 119 . Other related categories are panels, quilted materials, operable partitions, unit absorbers, and open plan systems.

\section{CAUTION}

1. ABSORPTION COEFFICIENTS MAY EXCEED 1.0. FOR A COMPLETE DISCUSSION OF THESE VALUES SEE PAGE 51.

2. THE NUMBERS LISTED UNDER THE "MOUNTING" COLUMN REFER TO THE AIMA STANDARD MOUNTINGS DESCRIBED ON PAGE 53.

\section{GLOSSARY}

Facing: The outside surface of the specimen. In general the side facing the sound source

Backing: The other outside surface of the specimen. In general the side not facing the sound source

Core: The region between the facing and the backing

Lead Loaded: Lead was added to the fabric type material to increase its sound transmission loss. 
Table 15A. Absorption properties of curtain systems.

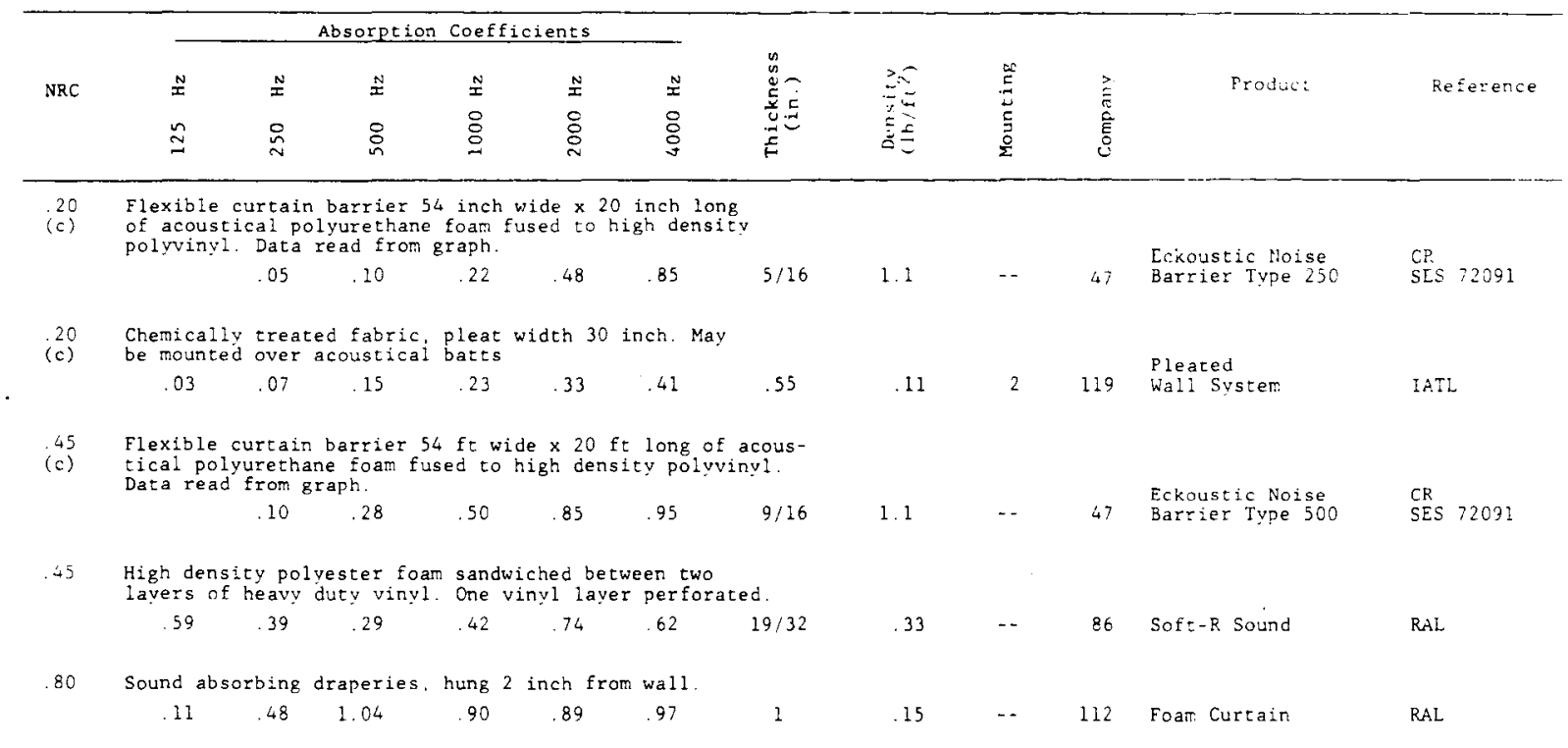


Table 15B. Barrier properties of curtain systems.

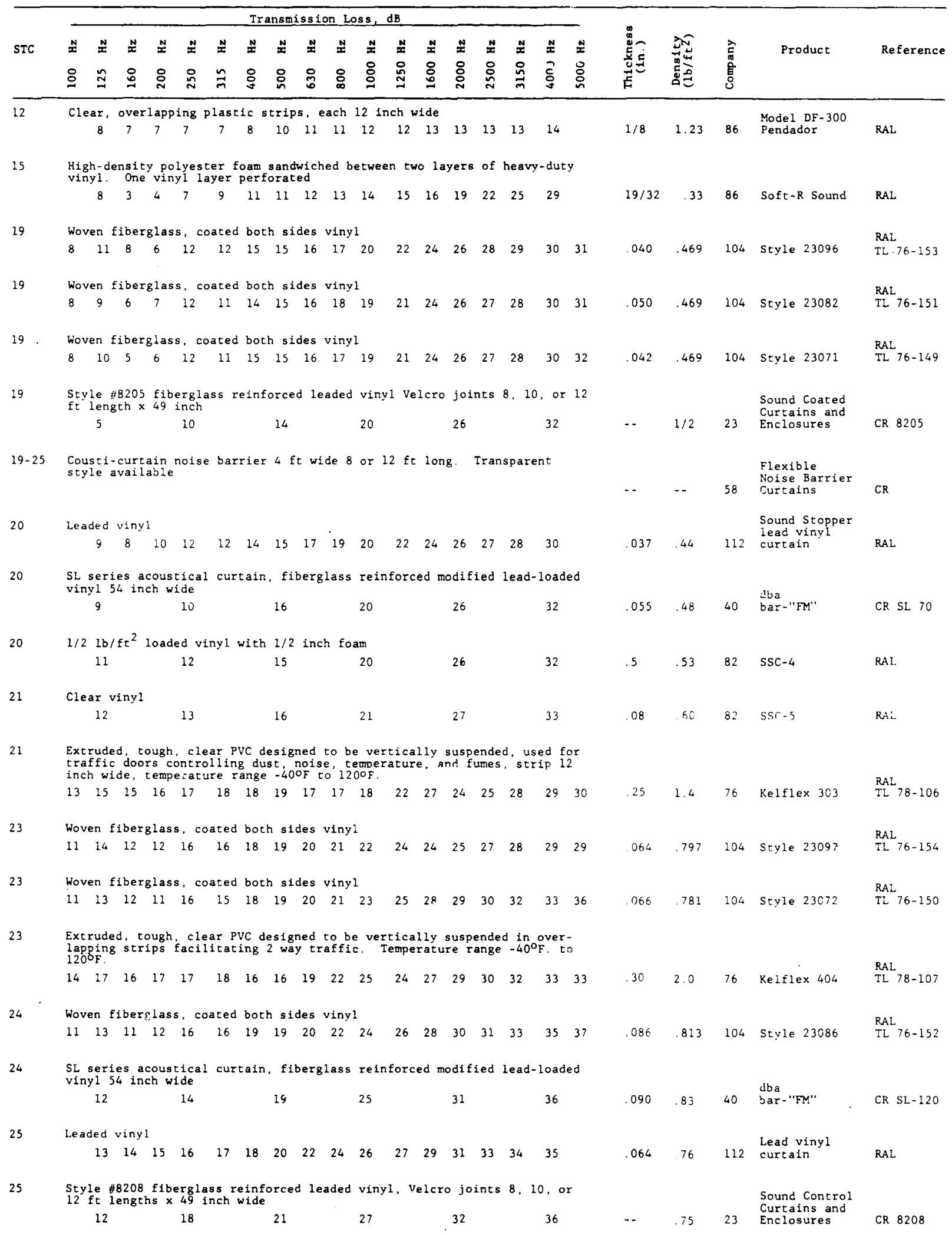




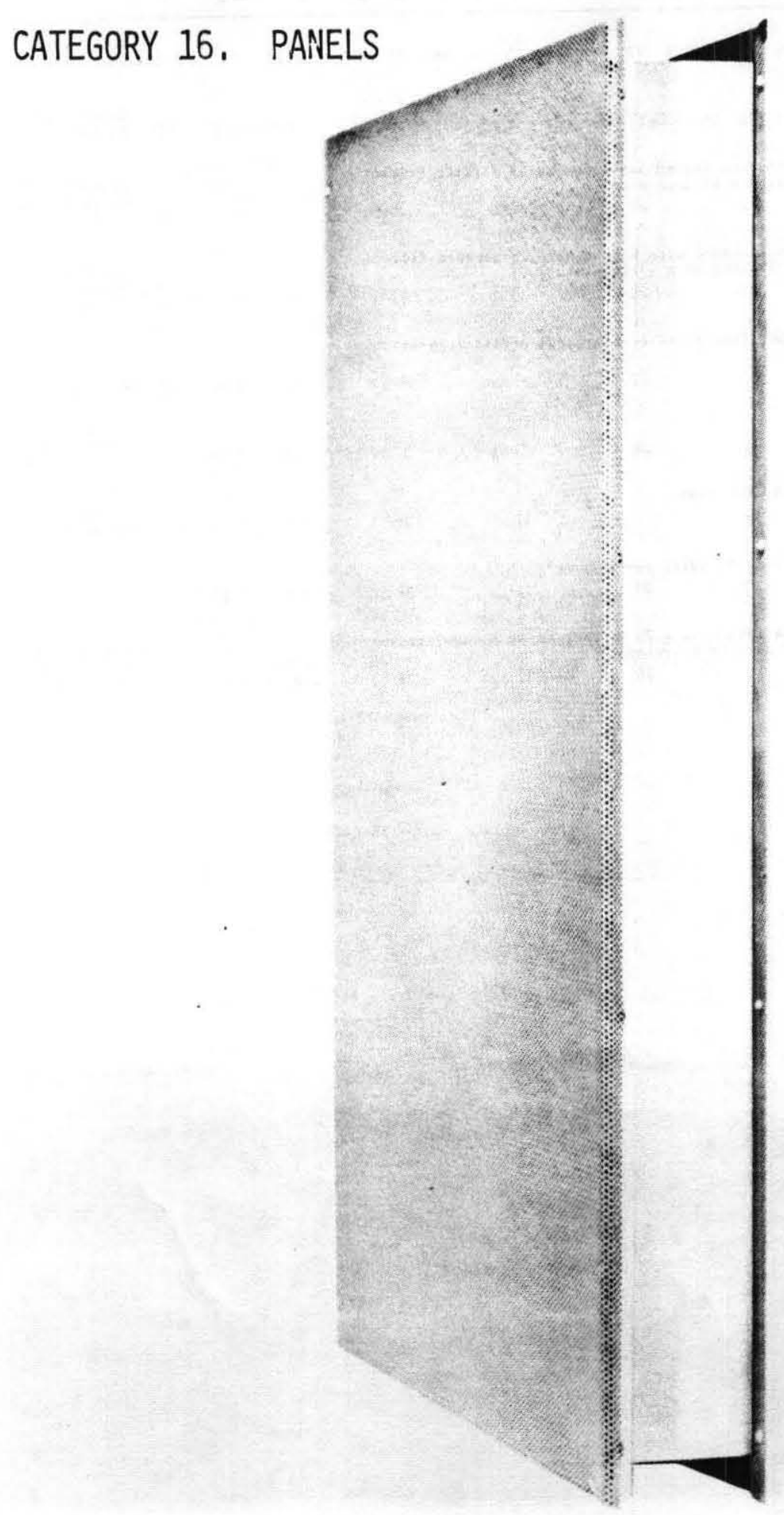

234 
Table 15B. Barrier properties of curtain systems concluded.

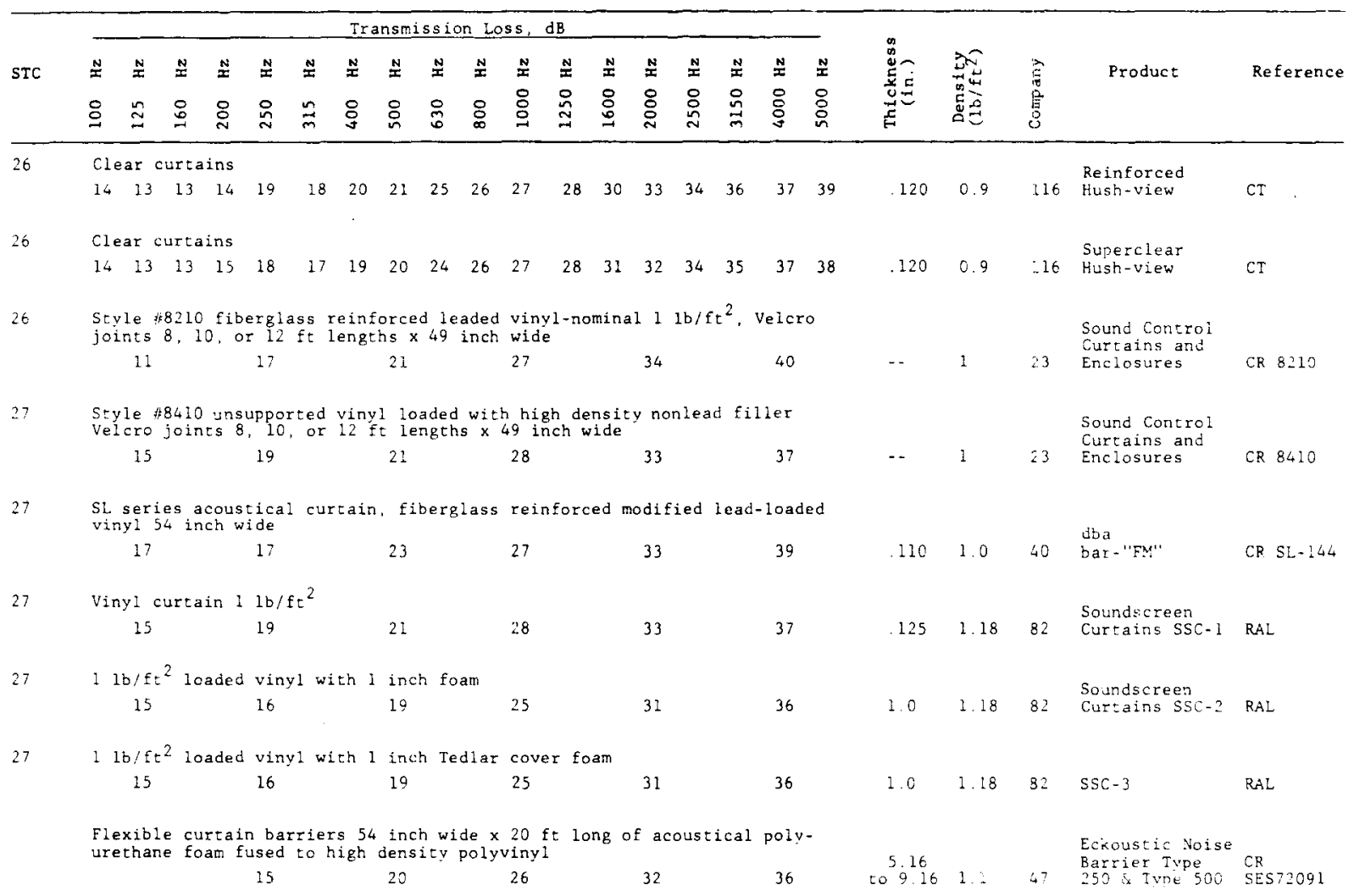




\section{CATEGORY 16. PANELS}

Prefabricated sound barrier panels can be used in machinery enclosures, walls, facings, etc. They are usually composite products using sound barrier materials for facing and backing and a sound absorbent material in the core. The exposed surfaces of the panels are available in different colors, textures, and materials to suit the requirements of a specific application.

The organizations contributing data to this table are: $2,4,5,7,11,12$, $21,40,47,49,50,52,61,70,71,77,78,82,120,125,128,131$, and 142 . Other related categories are walls, barrier materials, and enclosures.

\section{GLOS SARY}

Facing: The outside surface of the specimen. In general the side facing the sound source

Backing: The other outside surface of the specimen. In general the side not facing the sound source

Core: The region between the facing and the backing

Septum: A layer that separates two surfaces 
Table 16A. Absorption properties of panels.

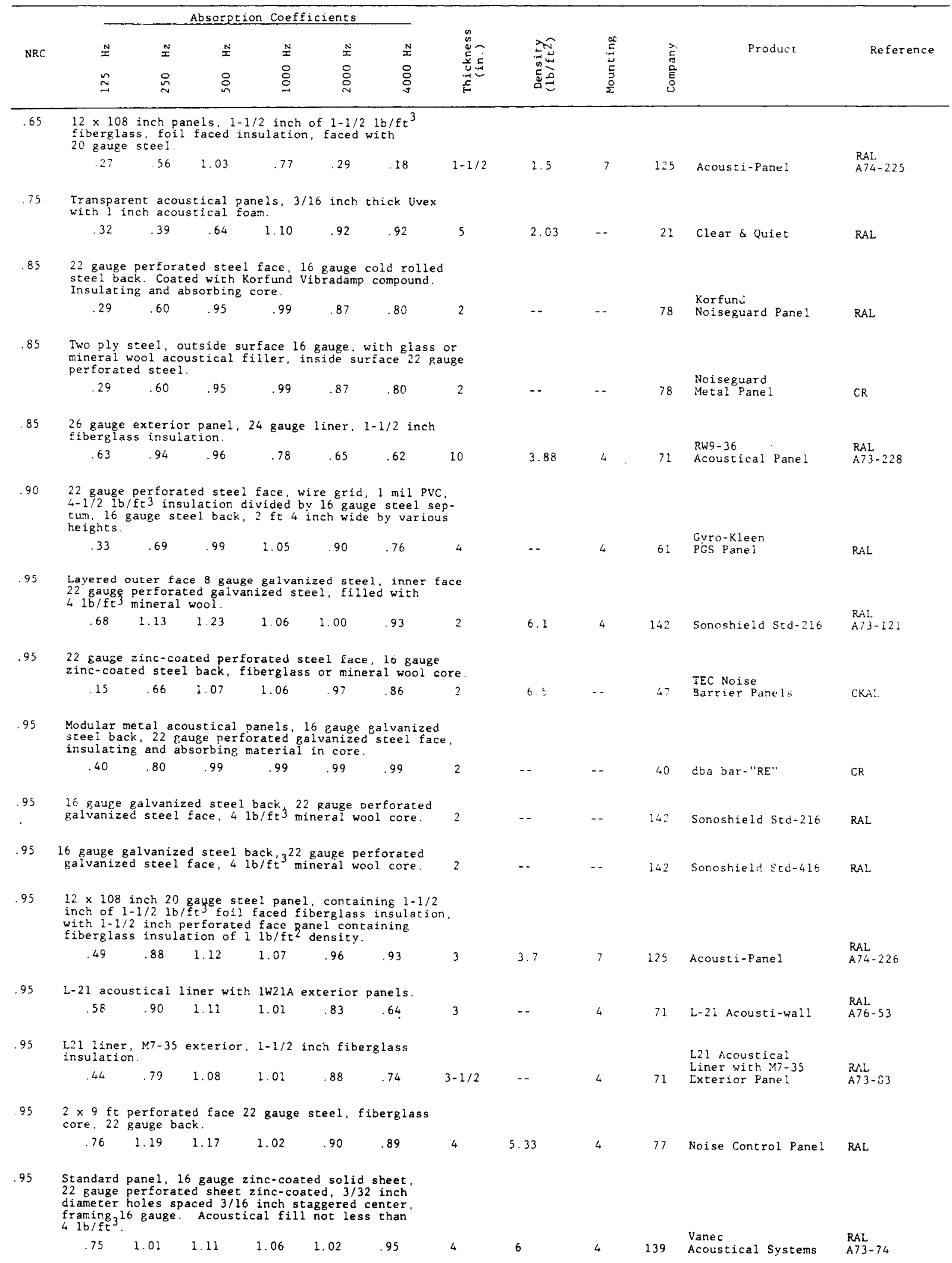


Table 16A. Absorption properties of panels continued.

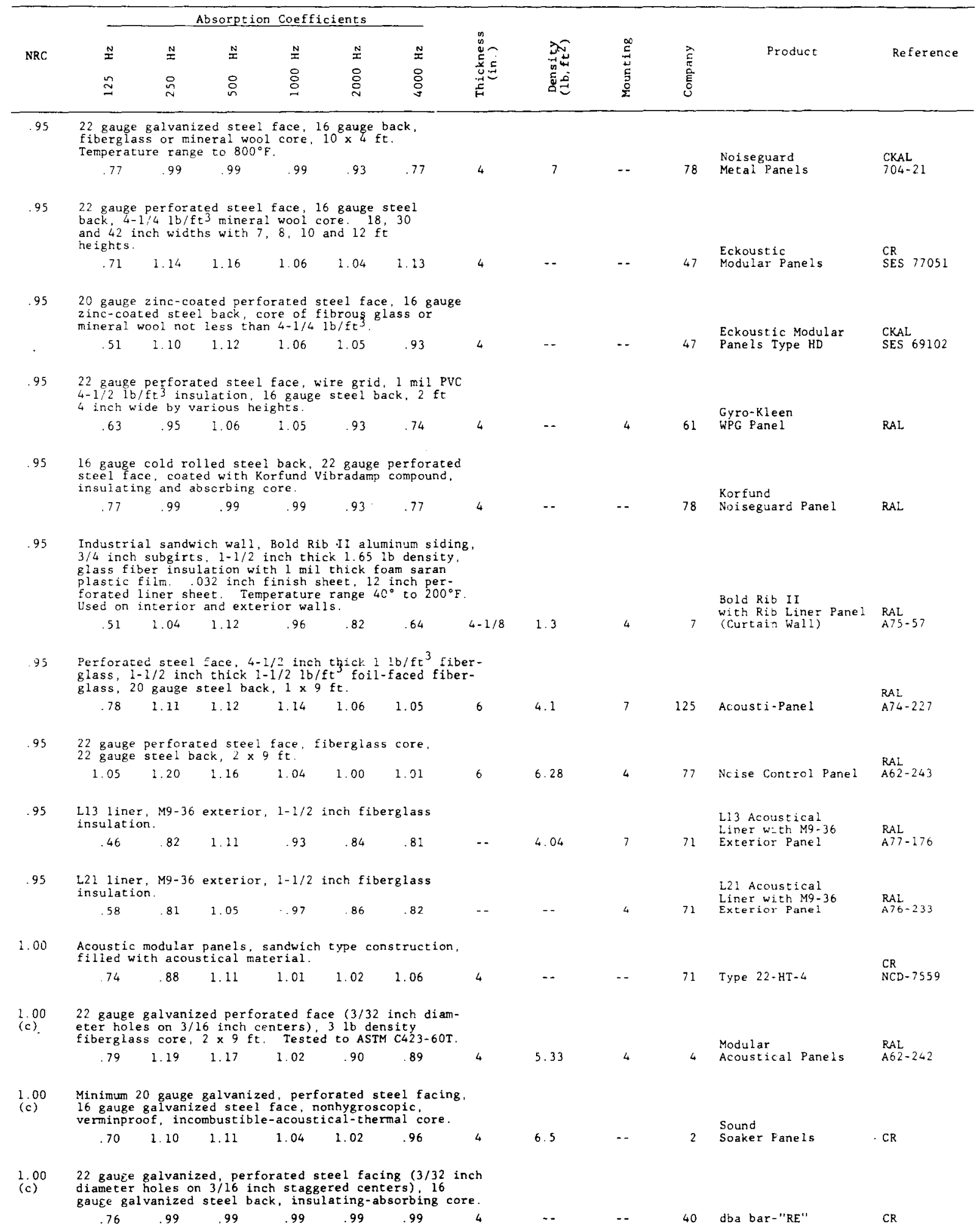


Table 16A. Absorption properties of panels concluded.

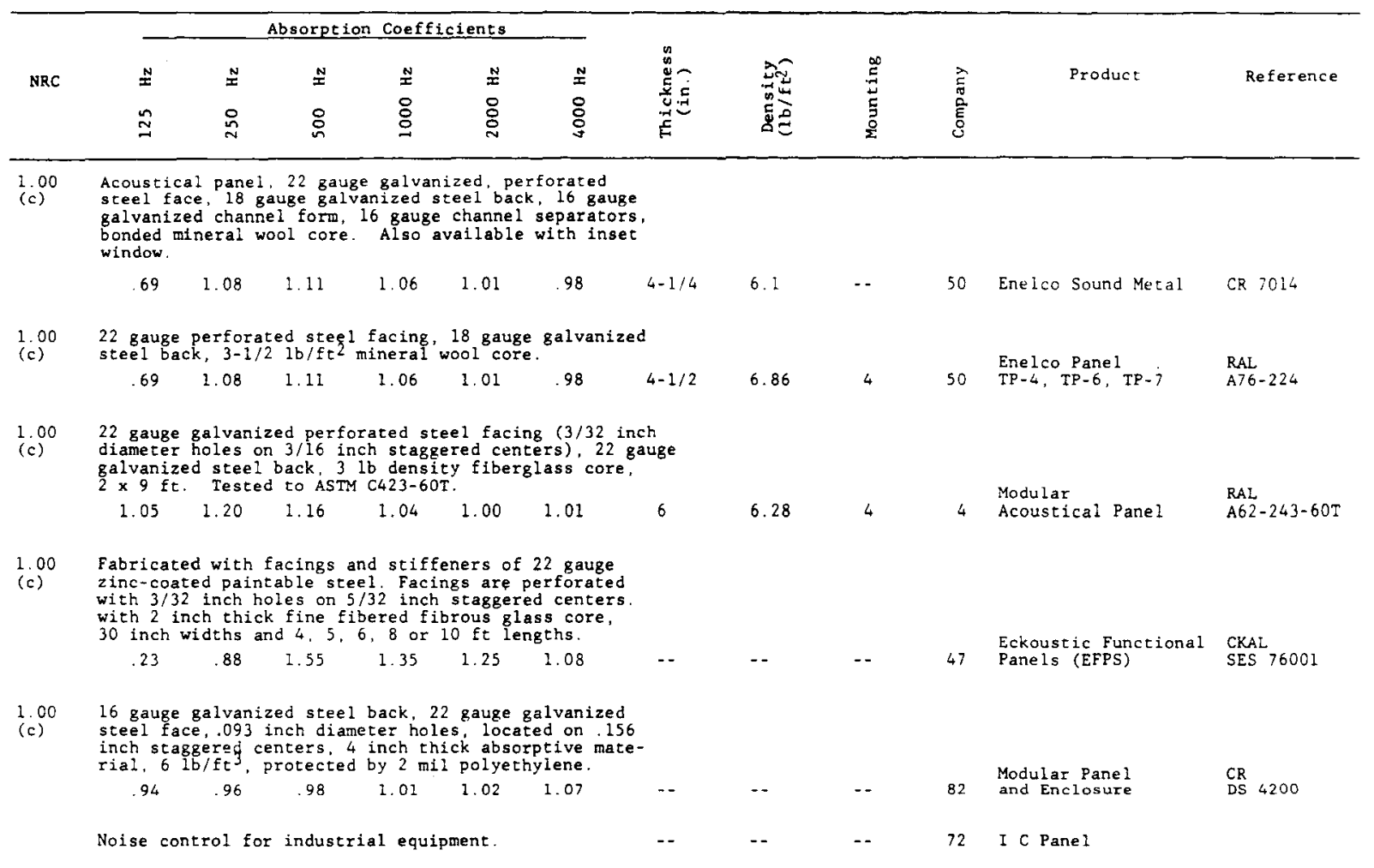


Table 16B. Barrier properties of panels.

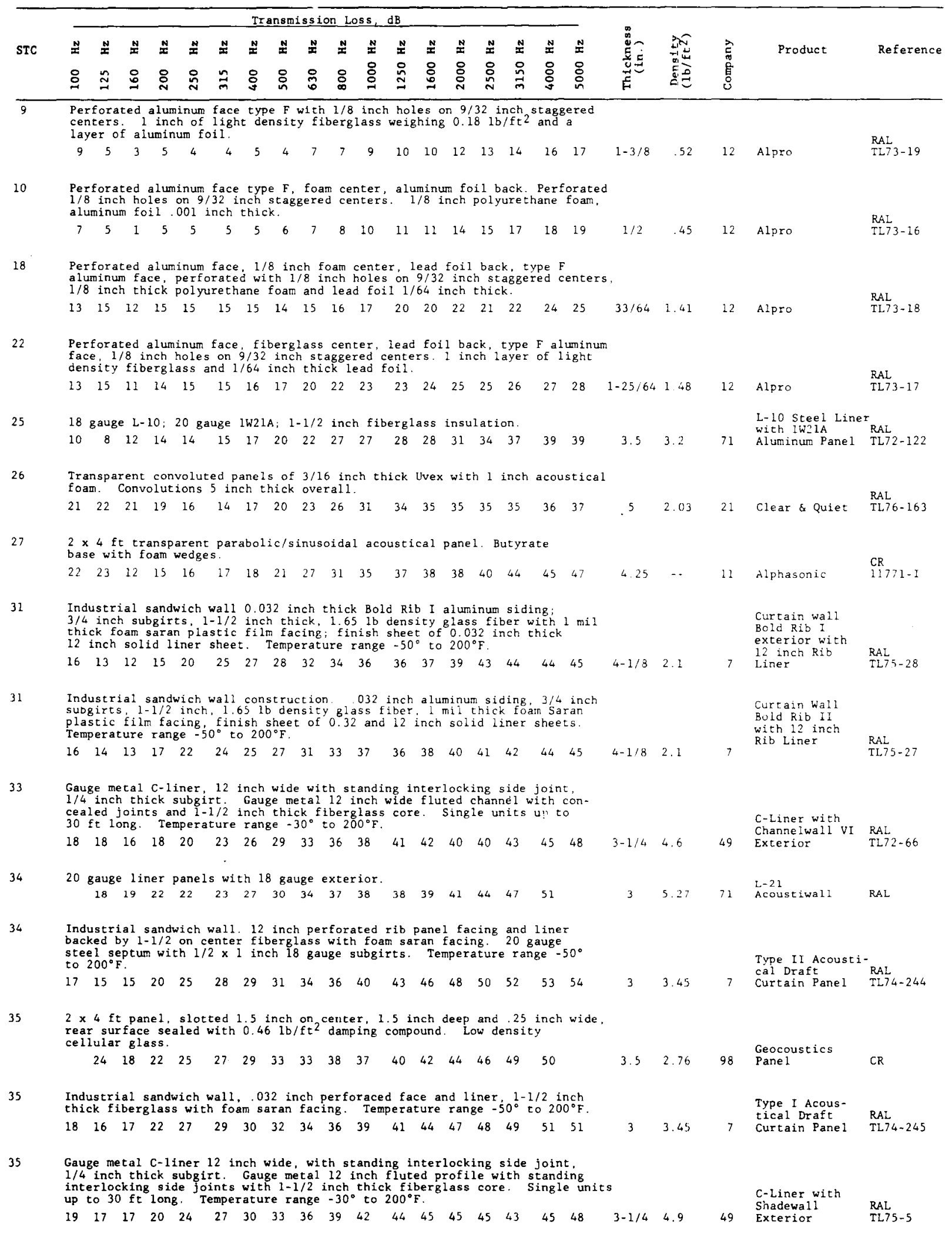


Table 16B. Barrier properties of panels continued.

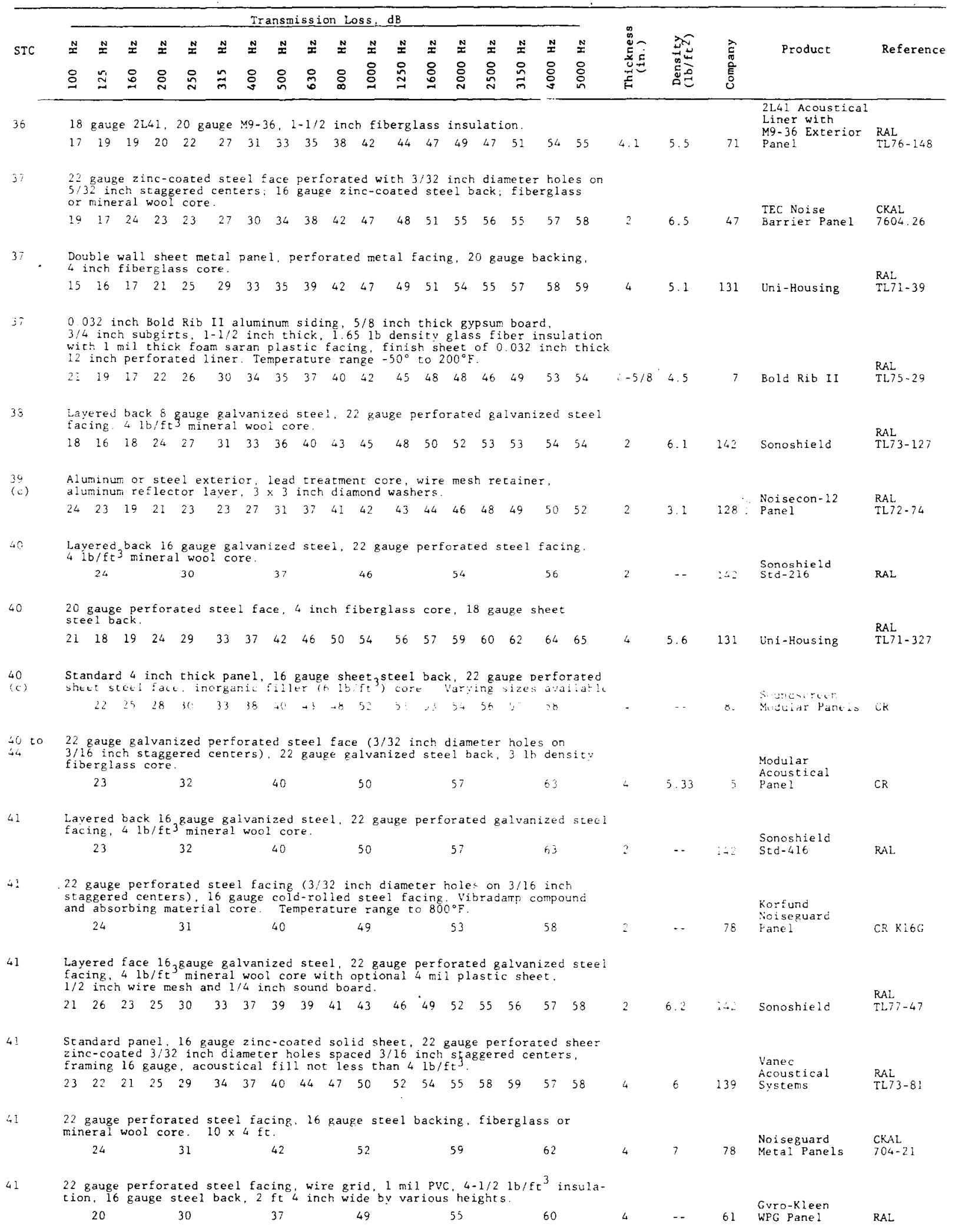


Table 16B. Barrier properties of panels continued.

\begin{tabular}{|c|c|c|c|c|c|c|c|c|c|c|c|c|c|c|c|c|c|c|c|c|c|c|c|}
\hline \multirow{3}{*}{ sTC } & \multicolumn{18}{|c|}{ Transmission Loss, $\mathrm{dB}$} & \multirow{3}{*}{ 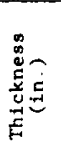 } & \multirow{3}{*}{ 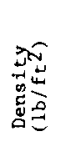 } & \multirow{3}{*}{ 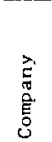 } & \multirow{3}{*}{ Product } & \multirow{3}{*}{ Referen } \\
\hline & N & $\stackrel{N}{x}$ & $\stackrel{N}{x}$ & $\stackrel{N}{x}$ & $\stackrel{N}{ \pm}$ & $\stackrel{N}{x}$ & $\stackrel{N}{x}$ & $\stackrel{N}{\mathbb{N}}$ & $\stackrel{N}{x}$ & $\stackrel{N}{x}$ & $\stackrel{N}{x}$ & $\stackrel{N}{x}$ & $\stackrel{N}{x}$ & $\stackrel{N}{ \pm}$ & $\stackrel{N}{\simeq}$ & $\stackrel{N}{ \pm}$ & $N$ & $\stackrel{N}{x}$ & & & & & \\
\hline & 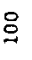 & $\underset{\sim}{\approx}$ & $\stackrel{8}{0}$ & 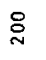 & $\stackrel{ }{ }$ & $\stackrel{m}{m}$ & : & 品 & 융 & ঃ & 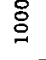 & $\stackrel{\mathscr{N}}{\cong}$ & $\begin{array}{l}8 \\
8 \\
0\end{array}$ & ¿̊̀ & : & m & : & : & & & & & \\
\hline
\end{tabular}

4122 gauge perforated steel face $(1 / 16$ inch holes on $3 / 16$ inch staggered

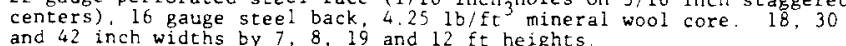
19
30
3950
58
60

Eckoustic

Modular panels CR

42 Panel 18 gauge galvanized steel back, perforated 22 gauge steel face
$3.51 \mathrm{f} / \mathrm{ft}$ mineral wool core.

$\begin{array}{llllllllllllllllllllllll}21 & 25 & 22 & 24 & 29 & 34 & 38 & 41 & 45 & 48 & 52 & 54 & 56 & 58 & 61 & 64 & 66 & 67 & 4 & 6.3 & 53 & \text { Ene } 3 \text { Pane } 1 & \text { RAL } & \end{array}$

$42 \quad 22$ gauge galvanized perforated steel facing, 18 gauge galvanized steel back. mineral wool core.
$22 \quad 27$
41
51
58
66
$4 \times 1 / 4 \quad 6$
Enelco
Soundmetal CR 7014

42 Minimum 20 gauge galvanized perforated steel facing. minimum 16 gauge

Malvanized steel back, nonhygroscopic, verminproof. incombustible absorbing core.
22
32
$40 \quad 50$
60
62
Sound Soaker
$C R$

$42 \quad 16$ gauge galvanized steel back, 22 gauge galvanized perforated steel face

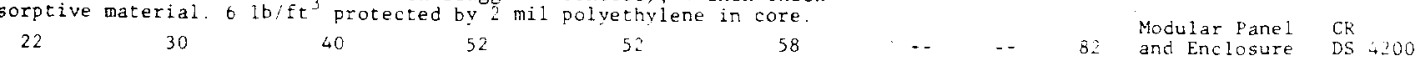
43 Acoustic modular panels, sandwich type construction, filled with acoustical
26
32
38
47
49
57

- 70 Type $22-\mathrm{HT}-4 \quad$ CR $\quad$ NCD 7559

44

16 gauge steel back, 22 gauge perforated steel face, $4.251 \mathrm{~b} / \mathrm{ft}^{3}$ mineral
wool core. Available with $3-5 / 8$ inch double glaze windows.

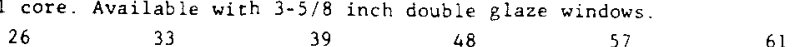

44

Gauge metal C-liner 12 inch wide with standing interlocking joint, 4 inch

thick subgirt, trimwall 12 inch wide with flush surface and interiocking

joints. Gauge metal with glass fiber insulation $\mathrm{l} f \mathrm{t}$ wide to any width

and up to $30 \mathrm{ft}$ long as single lengths any height with laps. Temperature

$\begin{array}{llllllllllllllllll}22 & 22 & 23 & 28 & 35 & 37 & 39 & 41 & 45 & 49 & 52 & 54 & 54 & 52 & 52 & 52 & 55 & 55\end{array}$

C-Liner
Trimball
$3-49 \quad 40 \quad$ Exterior

Eckoustis

$\begin{array}{ll}\text { Modular Panels } & \text { CR } \\ \text { Series CD } & \text { SES } 7705\end{array}$

44 Gauge metal c-liner 12 inch wide. with standing interlocking side joint

$1 / 4$ inch thick subgirt, gauge metal 12 inch wide fluted profile with stand

ing interlocking side joints with mineral fiber insulation. Single units
$1 \mathrm{ft}$ wide by $30 \mathrm{ft}$ long to any height with Lap. Temperature $-30^{\circ}$ to $200^{\circ} \mathrm{F}$

$\begin{array}{lllllllllllllllllllllll}21 & 20 & 23 & 30 & 35 & 39 & 44 & 48 & 50 & 53 & 54 & 55 & 54 & 52 & 51 & 51 & 53 & 55 & 3-1 / 4 & t .2 & 4 C & \text { Exterior } & \text { RAL }\end{array}$

44 Gauge metal c-liner 12 inch wide with standing interlocking side joint,

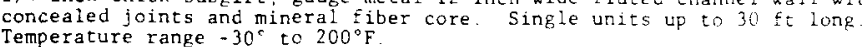

$\begin{array}{lllllllllllllllll}22 & 20 & 25 & 31 & 36 & 39 & 42 & 45 & 49 & 51 & 52 & 54 & 56 & 57 & 59 & 59 & 60\end{array}$

C-Liner
Channelwa

C-Liner

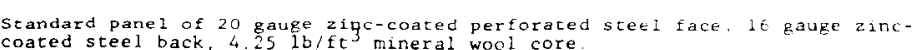

Eckoustic
25
32
38
49
56
62
Modular Pan

$[272-8]$

4420 gauge L21, $1-1 / 2$ inch fiberglass core, firewall raced

$\begin{array}{llllllllllllllllllllll}19 & 22 & 25 & 27 & 32 & 37 & 43 & 48 & 54 & 57 & 60 & 61 & 60 & 60 & 63 & 60 & 68 & 70 & 5-1: 8 & 9.2 & 71 & \text { Exterior Panel }\end{array}$

45 to 22 gauge galvanized steel face ( $3 / 32$ inch diameter holes or $3: 16$ inch

staggered centers), 22 gauge galvanized steel hack, $3 \mathrm{lb} / \mathrm{ft}^{3}$ fiberglass core. Modular

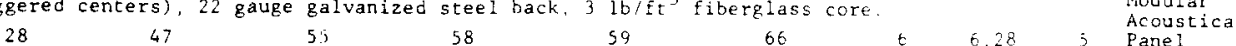

46 Gauge metal $\mathrm{C}-2$ iner 12 inch wide, with standing interlocking joint,

$1 / 4$ inch thick subgirt. Gauge metal 12 inch fluted profile with staneing

interlocking side joints with $1-1 / 2$ inch thick fiberglass core and two

$\begin{array}{lllllllllllllllllllllll}22 & 24 & 25 & 31 & 36 & 39 & 44 & 49 & 53 & 54 & 55 & 55 & 56 & 57 & 57 & 57 & 58 & 58 & 4-3 / 4 & 11 & 49 & 1 \text { Exterior } & \end{array}$

22 gauge perforated steel face, wire grid, 1 mil PVC, $4-1 / 21 \mathrm{~b} / \mathrm{ft}^{3}$ insulation
divided by 16 gauge steel septum, 16 gauge steel back, $2 \mathrm{ft} 4$ inch wide by various heights.
41
49
56
$60 \quad 50$

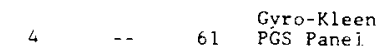
RAL 
Table 16B. Barrier properties of panels concluded. Transmission Loss, $d B$

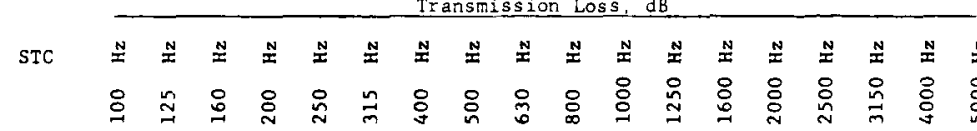

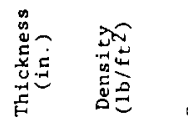

60 Paneling applied to $3 / 16$ inch steel plate, $2 \times 6$ inch channel stiffeness on 42 inch centers. Paneling: aluminum or steel exterior, lead treatment core. wire mesh retainer, aluminum reflector laver. Weight given includes backing plate.

$\begin{array}{llllllllllllllllll}40 & 42 & 44 & 46 & 51 & 53 & 54 & 56 & 58 & 01 & 64 & 68 & 69 & 68 & 68 & 68 & 70 & 72\end{array}$

$2 \times 4$ ft transparent convoluted butyrate panels with mylar sealed foam wedges attached along convolutions. Temperature to $150^{\circ} \mathrm{F}$, humidity co
in place, covering $57 \%$ of machine. Data cited are noise reduction.
10
14
15
17
18
19
- - 11 Alphasonic
$\mathrm{CR}$

22 gauge galvanized perforated steel face ( $3 / 32$ inch diameter holes on $3 / 16$ inch staggered centers), If gauge galvanized steel back, absorbing core.
13
23
32
44
52
53
2
-. 40 dba bat - "RE"
$C R$

22 gauge galvanized perforated steel face (3/32 inch diameter holes on $3 / 16$

inch staggered centers), 16 gauge galvanized steel back. absorbing core.
25
30
41
51
58
61
$4 \quad-\quad 40$ dba bar-"RE"
$C R$

Steel back, perforated galvanized face, sound absorbing core is moisture. vermin, and fireproof, chemically iner

$-\quad \quad+\quad 70$

CR 7 CD 7554

Galvanized steel, primed or finish-painted. 4 to 30 ft lengths. Density range 2 to $4 \mathrm{ib} / \mathrm{ft}^{2}$. Application: sound barrier for wall construction.

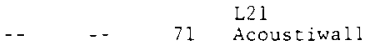

$\mathrm{CR}$ 
CATEGORY 17. ROOF DECKS

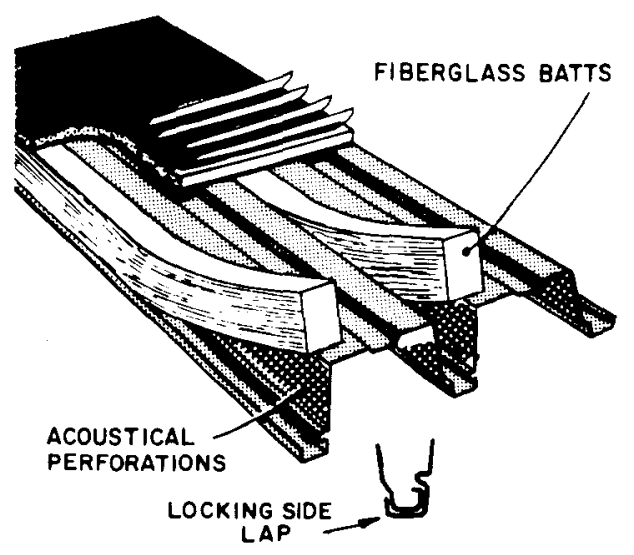

Perforated Facing and Fiberglass Core
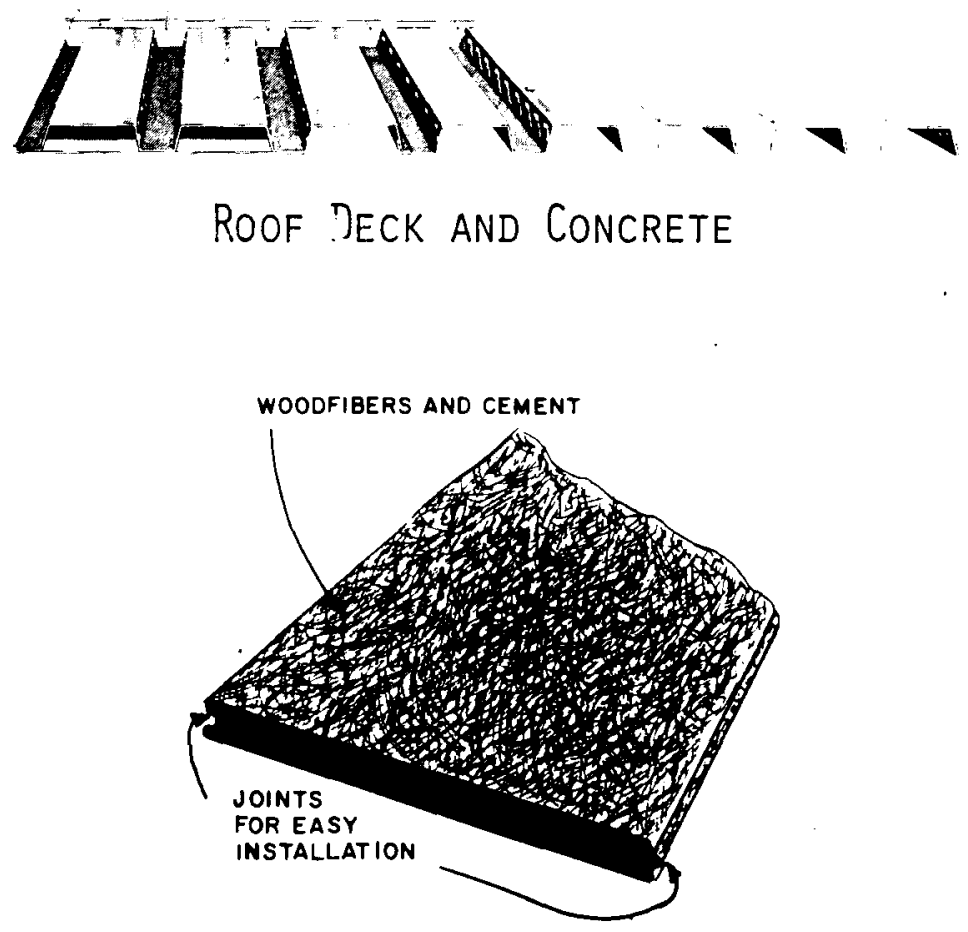

Roof Deck Panel for Absorption 
A roof deck is structurally designed to support dynamic loads and to provide the base for a roof system. Acoustically, roof decks act as a sound barrier or as an absorptive barrier system. Roof decks are usually arranged in an interlocking sandwich array consisting of prefinished, prefabricated, modular type panels. Basically, these panels include a backing layer (solid), a facing material (perforated metal) and a core area. The core area incorporates an integral channeling network which enhances overall structural rigidity, and eliminates self-excitation (vibrating panel). The geometry permits addition of an absorptive insulation material (fillers, batts, etc) for improved sound absorption.

Thickness may vary but usually range from 1 to 10 inches. Large offices, schools, churches, factories, etc, typically use a primary roof deck system. Modified roof decking can also be used in existing areas where improved thermal and acoustical properties are needed. Organizations contributing data to this table are: $45,51,71,84,87,108,113,134$, and 138.

\section{CAUTION}

1. ABSORPTION COEFFICIENTS MAY EXCEED 1.0. FOR A COMPLETE DISCUSSION OF THESE VALUES SEE PAGE 51.

2. THE NUMBERS LISTED UNDER THE "MOUNTING" COLUMN REFER TO THE AIMA STANDARD MOUNTINGS DESCRIBED ON PAGE 53.

\section{GLOSSARY}

Facing: The outside surface of the specimen. In general the side facing the sound source

Backing: The other outside surface of the specimen. In general the side not facing the sound source

Core: The region between the facing and the backing

Roof Deck: A platform or a surface covering the structural framework to form a roof

Reverberation Time: Defined as the time required for the sound pressure level of a room to decay 60 decibels, this quantity is an indirect measure of the total sound absorption provided by the room. 
Table 17A. Absorption properties of roof deck.

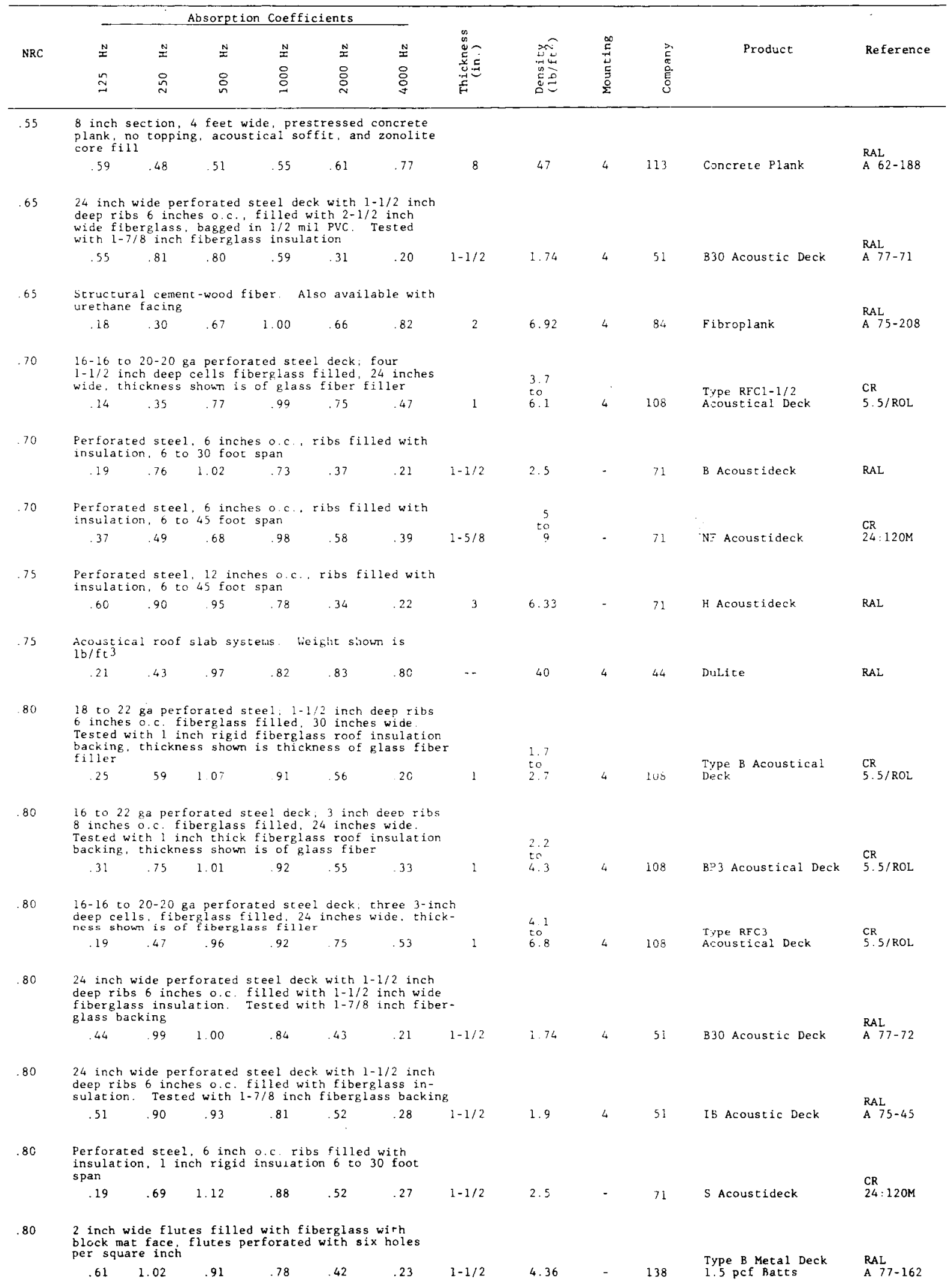


Table 17A. Absorption properties of roof deck continued.

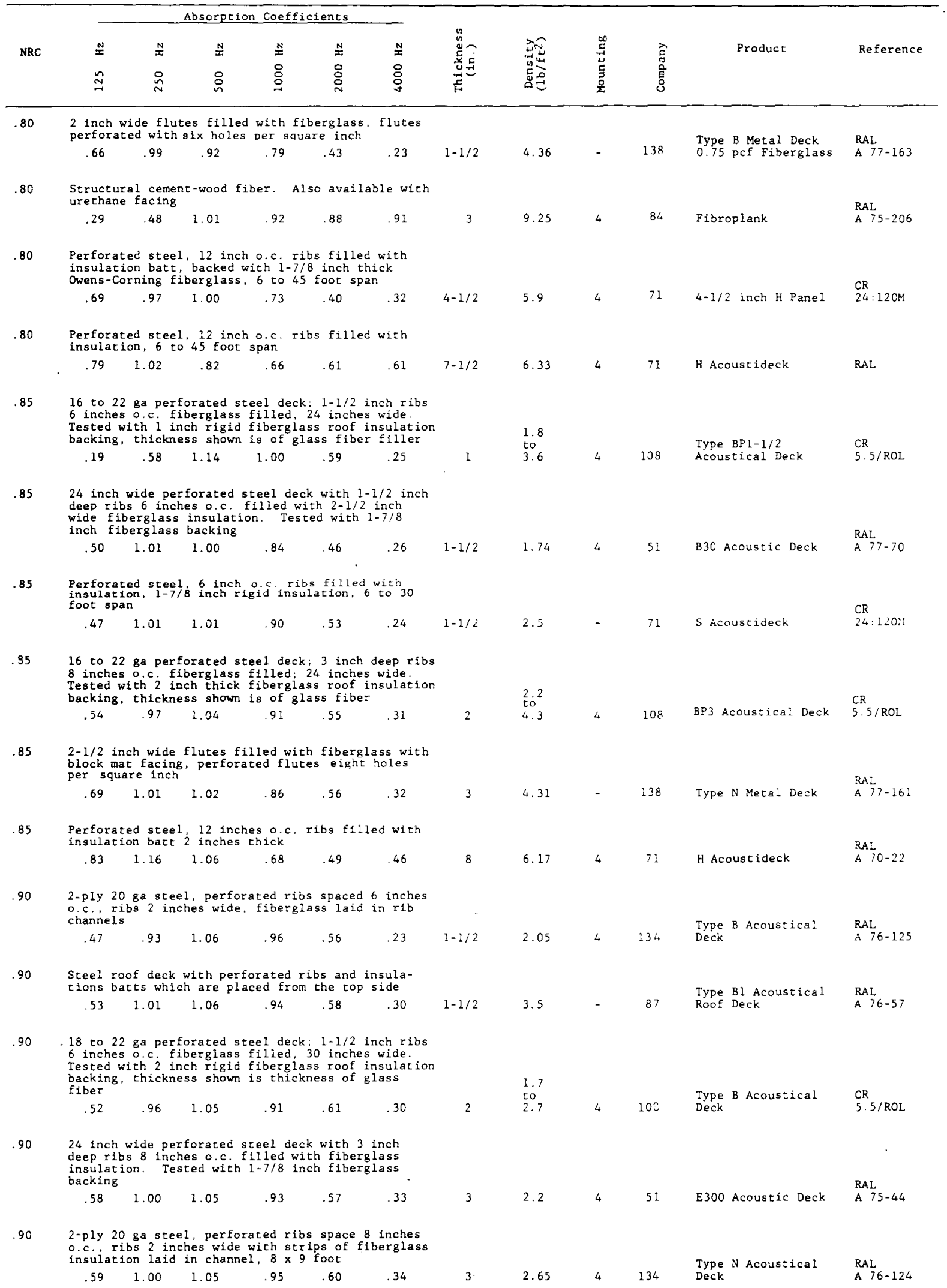


Table 17A. Absorption properties of roof deck concluded.

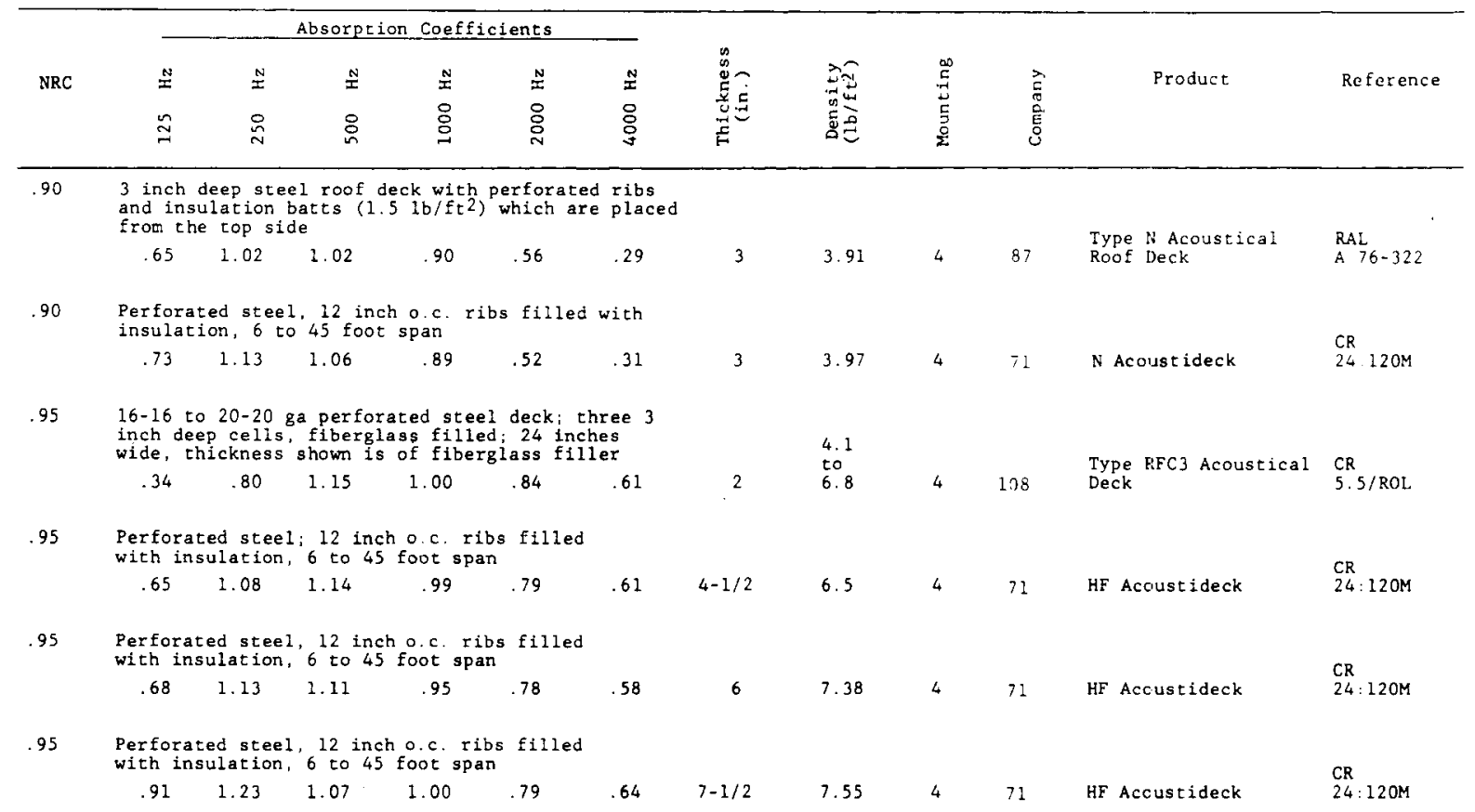


Table 17B. Barrier properties of roof deck.

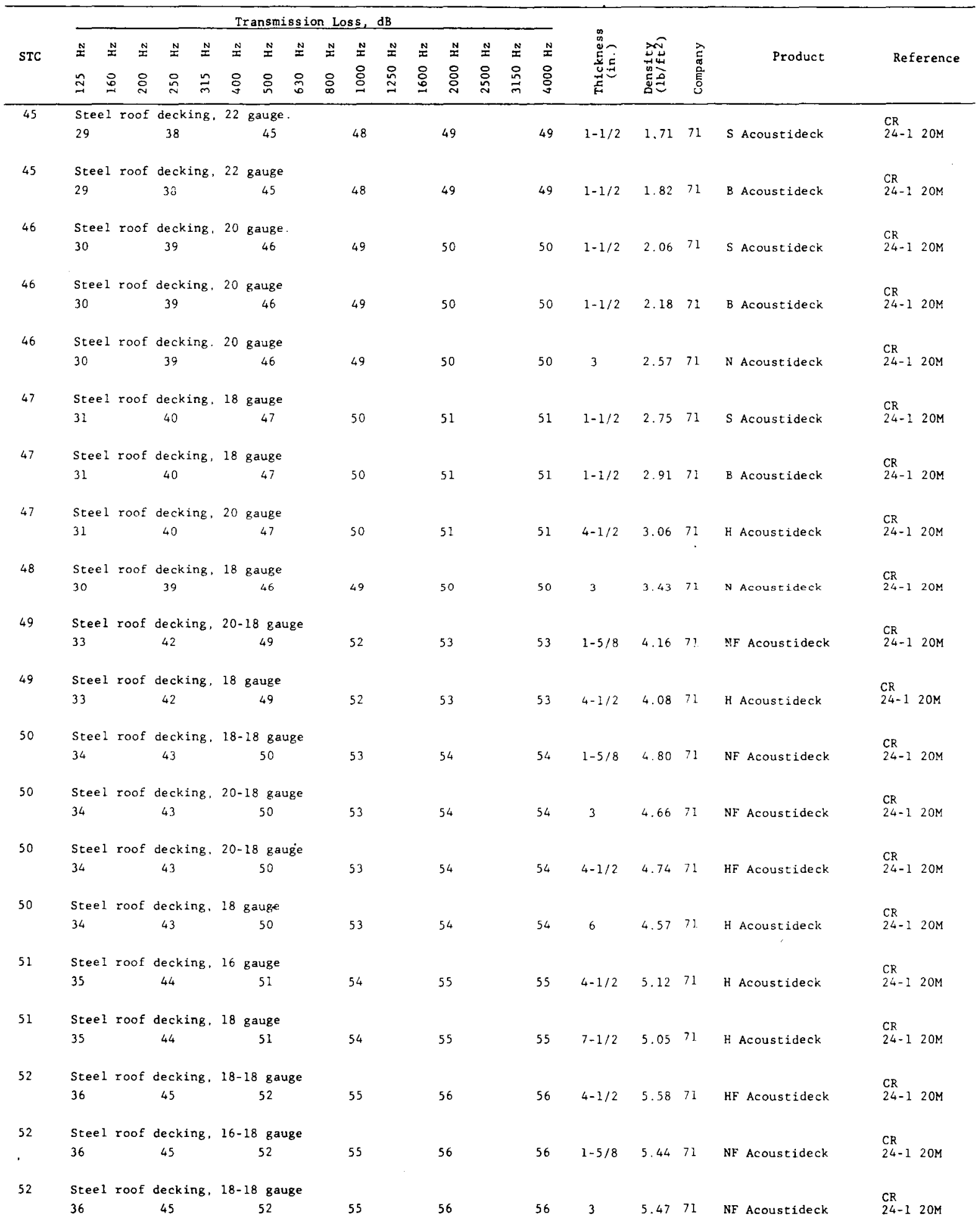


Table 17B. Barrier properties of roof deck concluded.

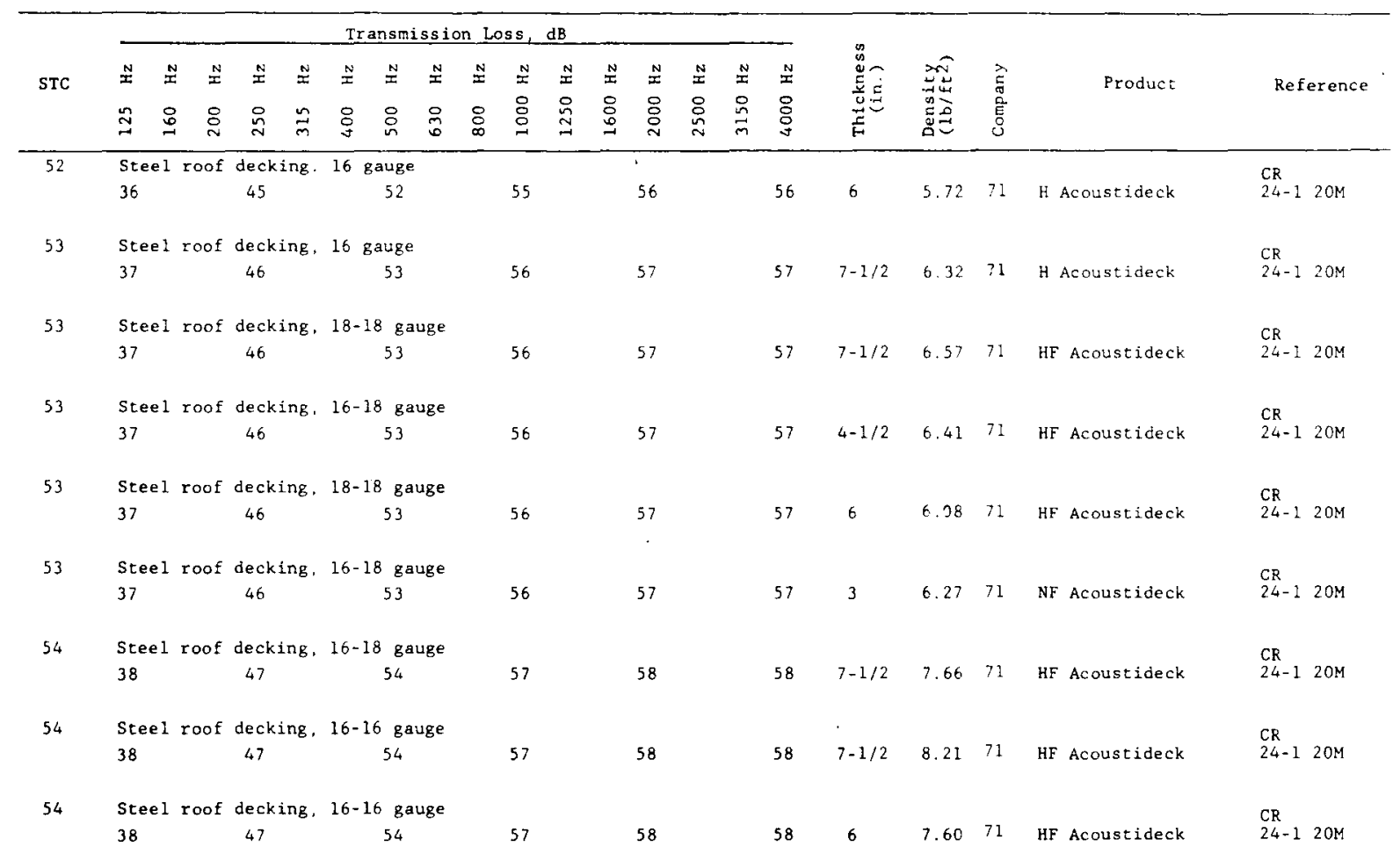


CATEGORY 18, UNIT ABSORBERS

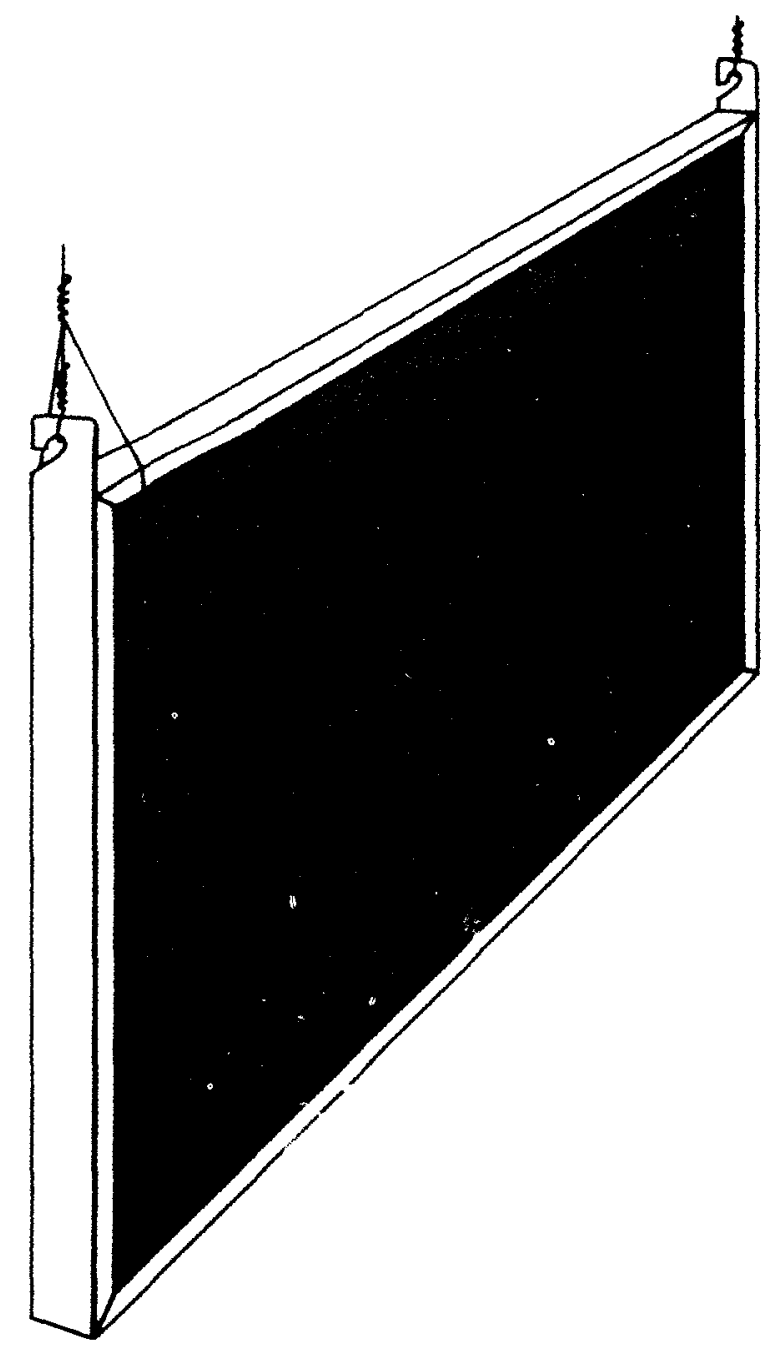


Sound absorption in a room can be increased by adding unit absorbers. They are easy to install and available in various shapes and sizes. The amount of absorption that can be obtained depends on the unit absorber spacing. The amount of sound energy absorbed by a particular unit absorber is proportional to the area exposed to the incident sound energy. For this reason, many absorbers are suspended from ceilings using wires to expose all surfaces to the sound. For efficient usage unit absorbers should be placed as close to the noise source as practical.

Organizations contributing data to this table are: $4,15,20,40,73,82,85$, $90,96,98,101,115$, and 133 .

\section{CAUTION}

ABSORPTION DATA PRESENTED ARE TOTAL ABSORPTION FOR EACH ITEM (SABINS/UNIT). THE TERM UNIT REFERS TO THE MANUFACTURER'S STANDARD SIZE UNIT AS DESCRIBED IN THE TABLE. FOR EXPLANATION OF SABINS SEE PAGE 50 . 
Table 18. Unit absorbers.

\begin{tabular}{|c|c|c|c|c|c|c|c|c|c|c|c|c|}
\hline \multirow{3}{*}{ NRC } & \multicolumn{6}{|c|}{ Absorption, sabins/unit } & \multirow{3}{*}{ 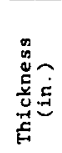 } & \multirow{3}{*}{ 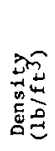 } & \multirow{3}{*}{$\begin{array}{l}\stackrel{\infty}{\Xi} \\
\stackrel{ \pm}{ \pm} \\
\stackrel{5}{\Sigma}\end{array}$} & \multirow{3}{*}{$\begin{array}{l}\overrightarrow{\mathrm{c}} \\
\text { o. } \\
\text { 兽 }\end{array}$} & \multirow{3}{*}{ Product } & \multirow{3}{*}{ Reference } \\
\hline & $\stackrel{N}{ \pm}$ & $\stackrel{N}{ \pm}$ & $\stackrel{N}{2}$ & $\stackrel{N}{I}$ & $\stackrel{N}{X}$ & $\stackrel{N}{N}$ & & & & & & \\
\hline & $\stackrel{n}{\cong}$ & 음 & 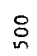 & 8 & 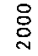 & 只 & & & & & & \\
\hline
\end{tabular}

Perforated $12 \times 18$ inch low density cellular glass block

(1)

Tedlar covered $12 \times 18$ inch low density cellular blocks with $1 / 8$ inch diameter holes side by side.

Testing strung on cables
$.94 \quad 1.00 \quad 1.15$
$.96 \quad 1.01$
I. 35

2

Perforated $12 \times 18$ inch low density cellular glass

blocks

$\begin{array}{llllll}1.07 & 1.18 & 1.26 & 1.23 & 1.21 & 1.37\end{array}$

$12 \times 18$ inch low density cellular glass block,

spaced $1 / 2$ inch apart in both directions on

cables

$\begin{array}{llllll}.95 & 1.18 & 1.12 & 1.28 & 1.36 & 1.14\end{array}$

1

$12 \times 18$ inch low densicy cellular glass block

cables

$1.03 \quad 1.16 \quad 1.20 \quad 1.31=1.45$

Perforated $12 \times 18$ inch low density cellular glass

blocks, spaced 2 inches apart

$\begin{array}{llllll}.93 & 1.39 & 1.33 & 1.47 & 1.28 & 1.33\end{array}$

$12 \times 18$ inch low density cellular glass blocks.
spaced 2 feet $0 . c$. both directions on cables

$\begin{array}{llllll}1.15 & 1.16 & 1.22 & 1.31 & 1.56 & 1.66\end{array}$

16 inch o.c., $11-1 / 2 \times 16 \times 1 / 8$ inch resonant
cavity in Dack. Low density cellular glass

$\begin{array}{llllll}2 & .8 & 2.0 & 2.2 & 1.8 & 1.2\end{array}$

$12 \times 18$ inch low density cellular glass blocks.

spaced 3 feet o.c. in both directions on cables

$\begin{array}{lllllll}1.17 & 1.34 & 1.28 & 1.51 & 1.1 & 1.68\end{array}$

Low density cellular glass block, $11-1 / 2 \times 16$

inch with $1 / 8$ inch resonant cavity in back.

spaced 24 inches 0 .

Perforated $12 \times 18$ inch low density cellular glass

blocks spaced 6 inches low

$\begin{array}{llllll}1.14 & 1.53 & 1.53 & 1.40 & 1.63 & 1.71\end{array}$

Tedlar covered $12 \times 18$ inch low density cellular

glass blocks with $1 / 8$ inch diameter holes. Spaced

glass blocks with $1 / 8$ inch diameter holes. Spact

2 feet $0 . c$ one

$\begin{array}{llllll}1.07 & 1.45 & 1.55 & 1.43 & 1.69 & 1.87\end{array}$

Slotted $12 \times 18$ inch low density cellular glass

blocks

$\begin{array}{cccccc}1.23 & 1.50 & 1.59 & 1.70 & 1.65 & 1.70\end{array}$

$12 \times 18$ inch low densicy cellular glass, Tedlar

12 18 inch low densicy cellular glass, Tedlar cables

$\begin{array}{llllll}1.24 & 1.30 & 1.63 & 1.63 & 1.72 & 1.91\end{array}$

$12 \times 18$ inch low density cellular glass blocks

spaced 2 feet o.c. both directions on cables

$\begin{array}{llllll}1.27 & 1.38 & 1.55 & 1.56 & 1.77 & 2.02\end{array}$

Perforated $12 \times 18$ inch low density cellular glass

blocks spaced 2 inches apart

$\begin{array}{llllll}1.24 & 1.59 & 1.82 & 1.61 & 1.60 & 1.74\end{array}$

$2 \quad 8 \quad 4 \quad 98$

Geocoustic Blocks $\quad \begin{aligned} & \text { KAL } \\ & 2141-77\end{aligned}$

Geocoustic Blocks $\quad$ KAL $2088-77$

Geocoust1c Blocks $\quad$ KAL $2141-77$ 
Table 18. Unit absorbers continued.

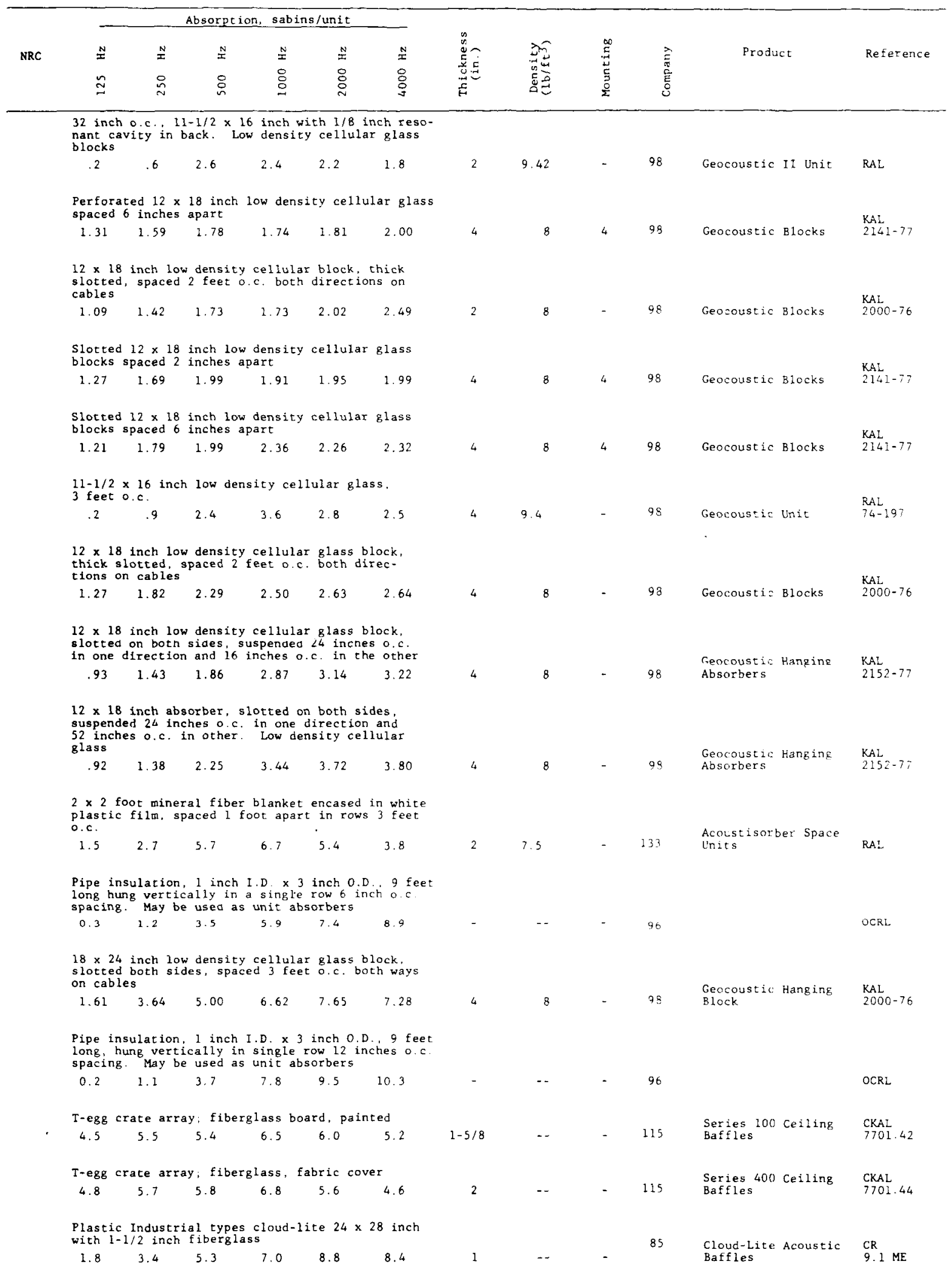


Table 18. Unit absorbers continued.

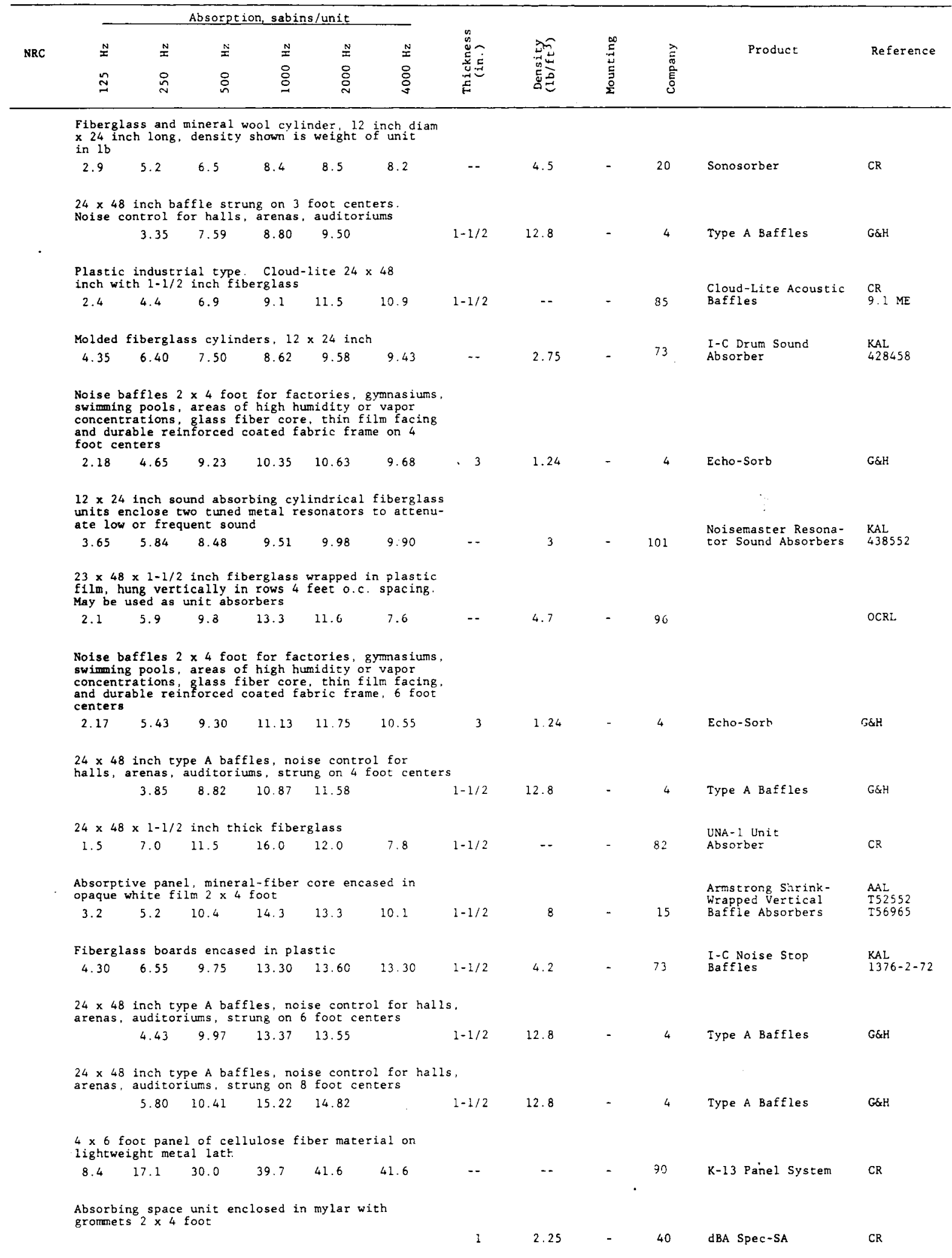


Table 18. Unit absorbers concluded.

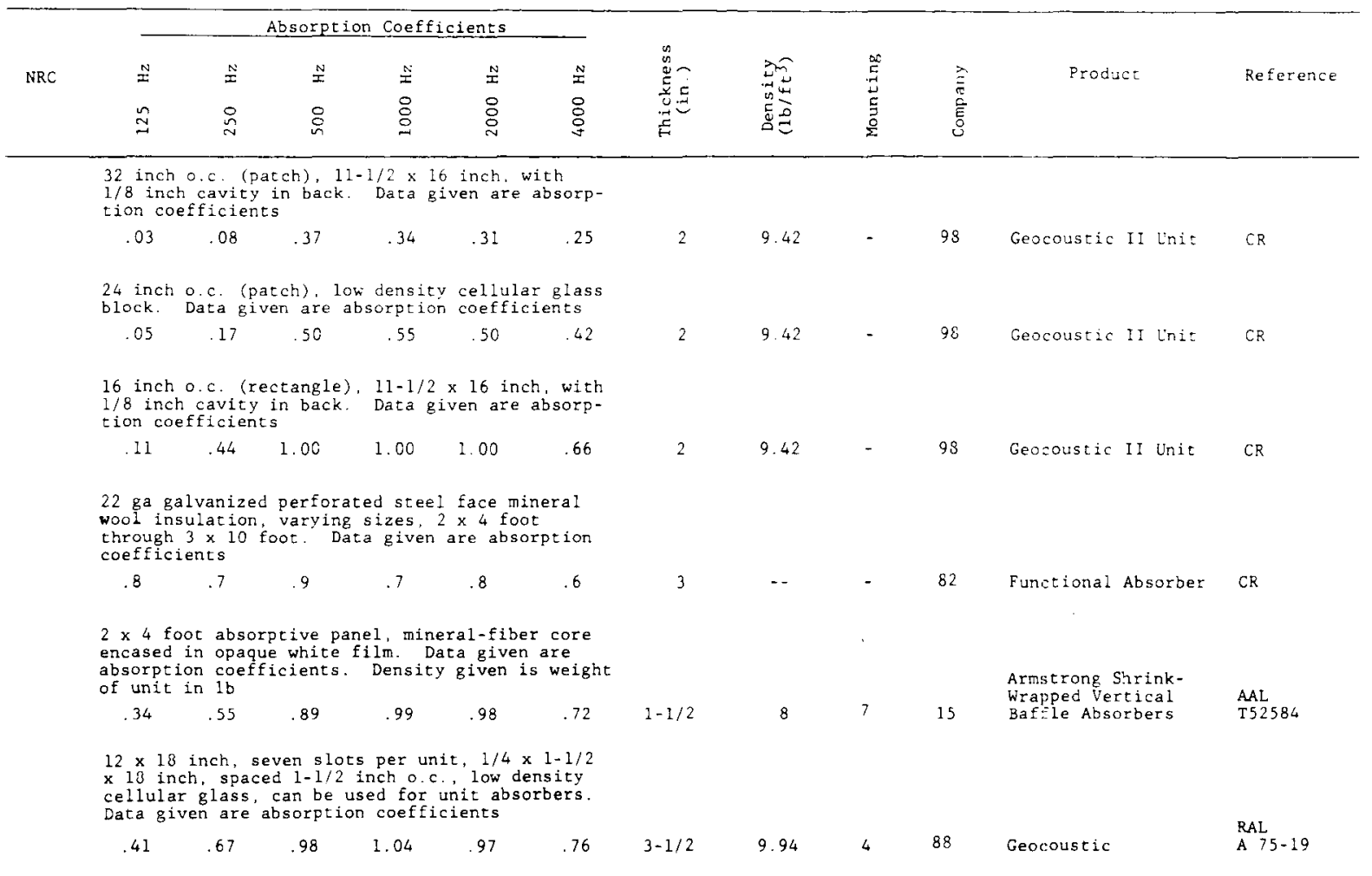


CATEGORY 19, ENCLOSURES

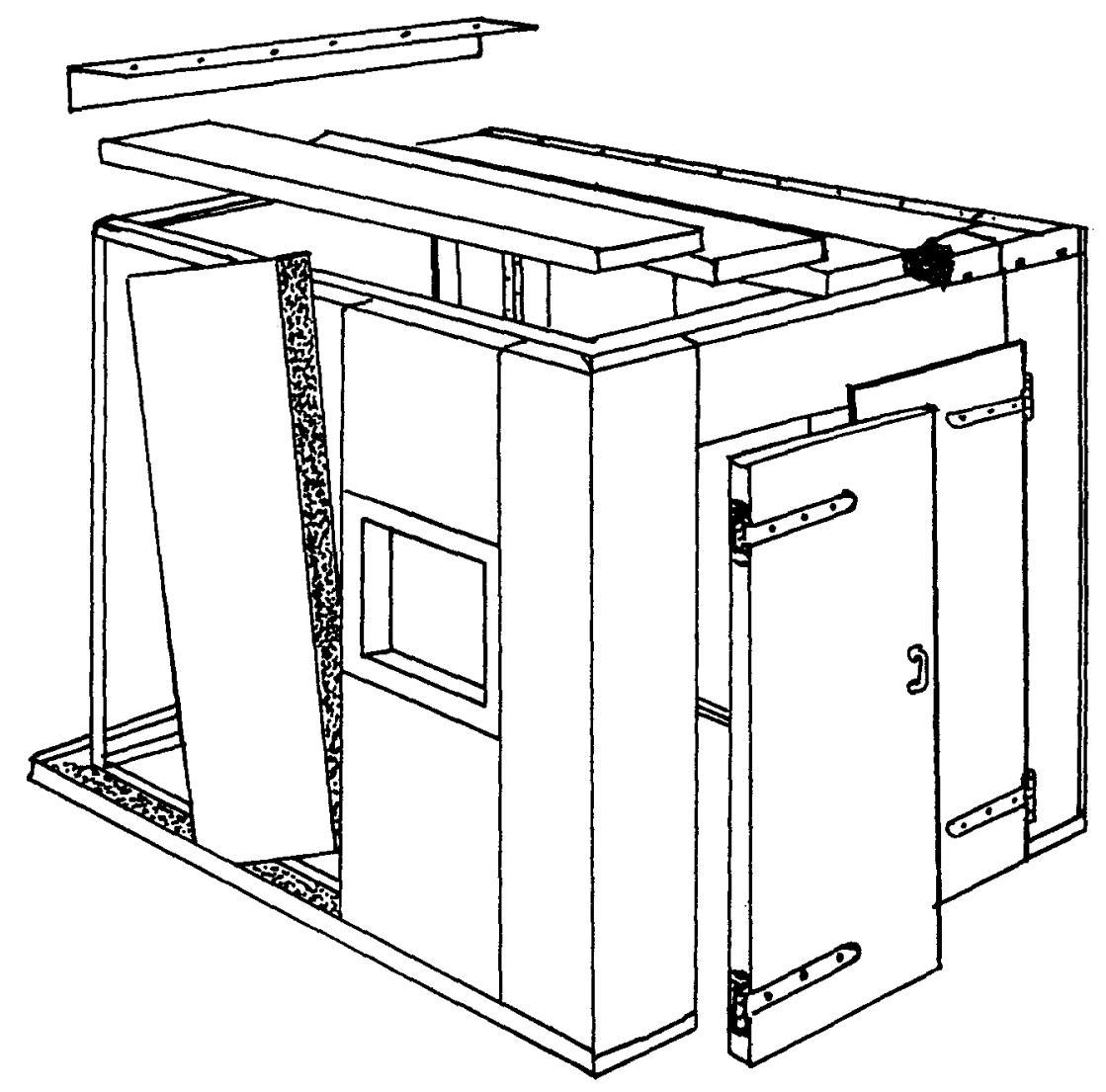


Quiet rooms are either constructed as complete units or prefabricated modular sections. Uses for Quiet rooms include viewing stations, study areas, audiometric testing rooms, music practice areas, recording studios, supervisory control centers, etc. Quiet room data are related to the finished product or a prefabricated section.

Enclosures are usually configured for a particular piece of equipment or machinery. Designs for enclosures are influenced by operator accessibility, thermal environment, chemical and moisture resistance, and overall maintenance. Data are presented for fabricated materials which can be used for enclosures. Since many installations are unique, a detailed analysis is required in determining the effectiveness of a proposed enclosure system.

Organizations contributing data to this table are: $5,32,47,70,72,77,78$, $82,112,114,120,125,127$, and 139 . Other related categories are: pane1s, unit absorbers, walls, and operable partitions.

\section{CAUTION}

1. NOISE REDUCTION DATA ARE SOMETIMES OBTAINED BY COMPUTATIONS BASED ON DATA FOR INDIVIDUAL PANELS WHICH ARE USED TO CONSTRUCT THE ROOM. ALSO, SPECIAL CUSTOMER OPTIONS (WINDOWS, VENTS, ETC.) MAY AFFECT THE PERFORMANCE OF A ROOM.

2. ABSORPTION COEFFICIENTS MAY EXCEED 1.0. FOR A COMPLETE DISCUSSION OF THESE VALUES SEE PAGE 51.

3. VALUES PRESENTED ON PAGE 260 ARE TRANSMISSION LOSSES AND THOSE PRESENTED ON PAGE 262 ARE NOISE REDUCTIONS. SEE PAGE 70 FOR EXPLANATION OF DIFFERENCES. 


\section{GLOSSARY}

Facing: The outside surface of the specimen. In general the side facing the sound source

Backing: The other outside surface of the specimen. In general the side not facing the sound source

Core: The region between the facing and the backing

Anechoic: Echo free

Anechoic Wedges: Wedge-shaped sound absorbing units commonly used to create a free field type environment 
Table 19A. Absorption properties of enclosure systems.

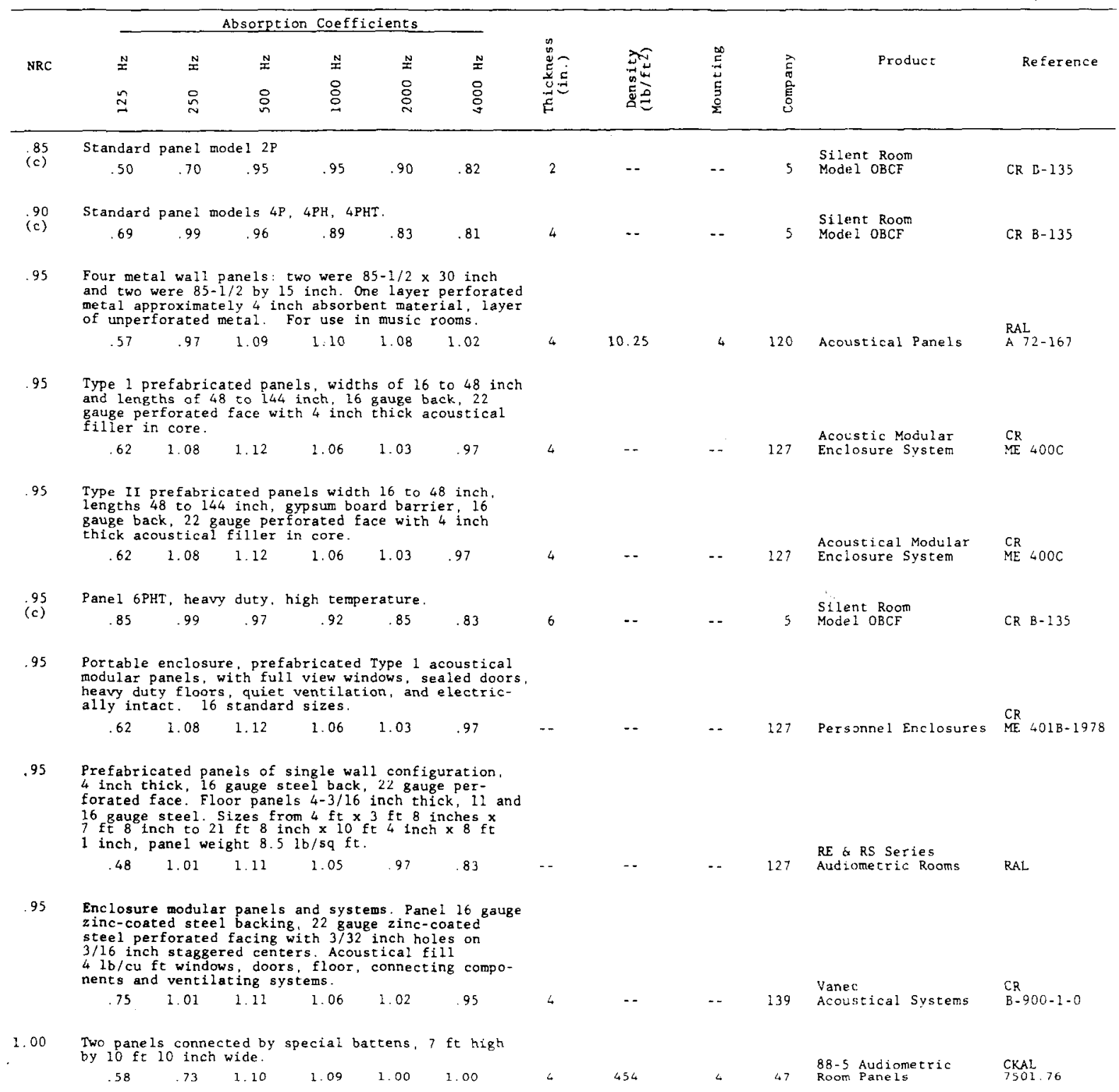


Table 19B. Barrier properties of enclosure systems (transmission 1oss).

\begin{tabular}{|c|c|c|c|c|c|c|c|c|c|c|c|c|c|c|c|c|c|c|c|c|c|c|c|}
\hline \multirow[b]{2}{*}{ sTC } & \multicolumn{18}{|c|}{ Iransmission Loss, dB } & \multirow[b]{2}{*}{ 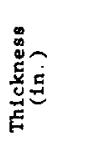 } & \multirow[b]{2}{*}{ 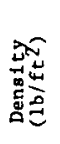 } & \multirow[b]{2}{*}{ 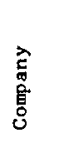 } & \multirow[b]{2}{*}{ Product } & \multirow[b]{2}{*}{ Reference } \\
\hline & $\begin{array}{l}\mathbf{N} \\
\stackrel{\mathbf{x}}{ }\end{array}$ & $\begin{array}{l}\cong \\
\cong\end{array}$ & $\begin{array}{l}\stackrel{N}{x} \\
\stackrel{8}{0}\end{array}$ & $\begin{array}{l}\mathbf{X} \\
\stackrel{N}{\mathbf{N}}\end{array}$ & $\begin{array}{l}\mathbf{N} \\
\stackrel{ }{\sim}\end{array}$ & $\begin{array}{l}\mathbf{x} \\
\stackrel{n}{n}\end{array}$ & $\begin{array}{l}\text { 보 } \\
\stackrel{8}{8}\end{array}$ & $\begin{array}{l} \pm \\
8 \\
8\end{array}$ & $\begin{array}{l}\text { N } \\
\stackrel{0}{0}\end{array}$ & $\begin{array}{l}\mathbf{N} \\
\underset{\infty}{8}\end{array}$ & \begin{tabular}{l}
$\mathbf{y}$ \\
$\varnothing$ \\
\hdashline
\end{tabular} & $\begin{array}{l}\stackrel{N}{x} \\
\stackrel{0}{D} \\
\text { I }\end{array}$ & $\begin{array}{l}\text { N⿱一土丷 } \\
8 \\
0 \\
-\end{array}$ & $\begin{array}{l}\mathbf{N} \\
8 \\
\stackrel{8}{8}\end{array}$ & $\begin{array}{l}\text { N } \\
8 \\
\stackrel{\circ}{ }\end{array}$ & 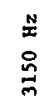 & $\begin{array}{l}\mathbf{N} \\
\text { ?े } \\
\text { ¿ }\end{array}$ & $\begin{array}{l}\stackrel{N}{x} \\
\stackrel{8}{8} \\
\stackrel{n}{n}\end{array}$ & & & & & \\
\hline \multirow[t]{2}{*}{$23(c)$} & \multicolumn{21}{|c|}{$\begin{array}{l}\text { Sliding or bi-fold door, covered with } 26 \text { gauge steel, urethane core, } \\
14 \times 17 \text { inch double paned window. For use in Soundscreen modular systems }\end{array}$} & \multirow{2}{*}{$\begin{array}{l}\text { Soundscreen } \\
\text { Doors }\end{array}$} & \multirow{2}{*}{$\begin{array}{l}\mathrm{CR} \\
\mathrm{GP}-4200\end{array}$} \\
\hline & 15 & 17 & 22 & 21 & 22 & 23 & 24 & 25 & 25 & 25 & 24 & 19 & 22 & 30 & 34 & 36 & 37 & 38 & 2 & -- & 82 & & \\
\hline \multirow[t]{2}{*}{$23(c)$} & Air & oper & ning & $6 \times$ & $14 \mathrm{i}$ & inch, & duct & $t 1 i$ & ned & with & fibe & rgla & ss & $4 \mathrm{ft}$ & lon & $g$ ven & it $P$ & nel & & & & \multirow{2}{*}{$\begin{array}{l}\text { Soundscreen } \\
\text { Ventilation } \\
\text { Panels }\end{array}$} & \multirow{2}{*}{$\begin{array}{l}C R \\
G P-4200\end{array}$} \\
\hline & 9 & 10 & 11 & 12 & 13 & 14 & 17 & 19 & 21 & 23 & 24 & 29 & 35 & 48 & 46 & 44 & 43 & 40 & 4 & -- & 82 & & \\
\hline \multirow[t]{2}{*}{30} & \multicolumn{7}{|c|}{$\begin{array}{l}12 \times 108 \text { inch } 20 \text { gauge steel } \\
\text { glass foll faced }\end{array}$} & \multicolumn{3}{|c|}{ containing 1} & $1-1 / 2$ & \multicolumn{2}{|c|}{ inch of } & \multicolumn{3}{|c|}{$1-1 / 2 \mathrm{lb} / \mathrm{ft}^{3}$} & \multicolumn{2}{|c|}{ fiber- } & & & & \multirow{4}{*}{$\begin{array}{l}\text { Soundscreen } \\
\text { Ventilation } \\
\text { Panel }\end{array}$} & \multirow{2}{*}{$\begin{array}{l}\text { RAL } \\
\text { TL } 74-238\end{array}$} \\
\hline & 17 & 15 & 18 & 20 & 22 & 22 & 21 & 25 & 28 & 32 & 36 & 39 & 40 & 41 & 41 & 40 & 43 & & $1-1 / 2$ & 1.5 & 125 & & \\
\hline \multirow[t]{2}{*}{$30(c)$} & 65 & t 10 r & ng ve & ent $p$ & panel & & & & & & & & & & & & & & & & & & \multirow{2}{*}{$\begin{array}{l}\text { CR } \\
G P-4200\end{array}$} \\
\hline & 12 & 13 & 14 & 15 & 16 & 20 & 25 & 30 & 32 & 34 & 36 & 40 & 44 & 50 & 54 & 56 & 57 & 53 & 4 & -- & 82 & & \\
\hline \multirow[t]{2}{*}{$31(c)$} & \multicolumn{9}{|c|}{$\begin{array}{l}\text { Swinging single door, } 34 \times 76 \text { inch, } \\
\text { perforated steel, with } 18 \times 18 \text { inch }\end{array}$} & $16 g$ & auge & $\begin{array}{l}\text { stee } \\
\text { nel }\end{array}$ & wind & dow & & 228 & e & & & & & \multirow{2}{*}{$\begin{array}{l}\text { Soundscreen } \\
\text { Doors }\end{array}$} & \multirow{2}{*}{$\begin{array}{l}C R \\
G P-4200\end{array}$} \\
\hline & 19 & 21 & 20 & 23 & 25 & 27 & 30 & 30 & 28 & 29 & 31 & 33 & 32 & 32 & 33 & 35 & 38 & 41 & 4 & $\cdots$ & 82 & & \\
\hline \multirow[t]{2}{*}{$31(c)$} & Sta & indar & US & elnat & ne & els & $v a$ & ryin & & izes & & & & & & & & & & & & \multirow{2}{*}{$\begin{array}{l}\text { Soundscreen } \\
\text { Modular } \\
\text { Panels }\end{array}$} & $\mathrm{CR}$ \\
\hline & 22 & 27 & 25 & 24 & 24 & 24 & 23 & 23 & 28 & 38 & 43 & 45 & 47 & 49 & 50 & 53 & 56 & 57 & 4 & - & 82 & & $G P-4200$ \\
\hline
\end{tabular}

33 Acoustical enclosure and wall system providing transmission loss quali-

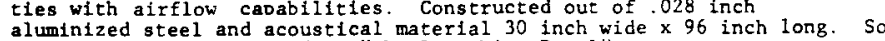
aluminized steel and acoustical material 30 inch wide x 96 inch long. So
12
22
$32 \quad 47$
58
59

34(c) B ft long vent panel

$\begin{array}{llllllllllllllllll}13 & 15 & 17 & 19 & 21 & 23 & 31 & 40 & 43 & 46 & 47 & 48 & 50 & 52 & 55 & 56 & 58 & 56\end{array}$

$2 \quad-\quad 32 \quad$ Muffl-wall

CKAL
7804.19

Soundscreen

Ventilation $\quad \mathrm{CR}$

$3612 \times 108$ inch 20 gauge steel, containing $1-1 / 2$ inch of $1-1 / 21 \mathrm{~b} / \mathrm{ft}^{3}$

fiberglass and $1 / 2$ inch gypsum board

$\begin{array}{llllllllllllllllll}21 & 22 & 23 & 24 & 25 & 28 & 28 & 29 & 32 & 35 & 39 & 42 & 44 & 44 & 43 & 44 & 46 & 48\end{array}$

$\begin{array}{lllll}1-1 / 2 & 3.5 & 125 \text { Acousti Panel } & \text { RAL } \\ \text { TL } 74-239\end{array}$

$3612 \times 100$ inch 20 gauge steel, containing $1 / 2$ inch gypsum board $1-1 / 2$ inch of $1-1 / 2 \mathrm{lb} / \mathrm{cu} \mathrm{ft}$ fiberglass and another $1 / 2$ inch gypsum board

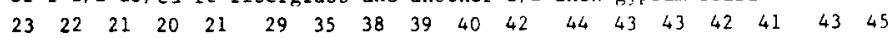

$1-1 / 2 \quad 5.5 \quad 125$ Acousti Panel $\quad \stackrel{\text { RAL }}{\text { Ii }} 74-240$

36(c) $2 \times 4 \mathrm{ft}$ parel, two $18 \times 30$ inch acrylic windows $1 / 4$ inch thick $\begin{array}{llllllllllllll} & & & \text { Soundscreen } & \text { CR } \\ \text { Modular Panels } & 6 P-4200\end{array}$

38 (c) $10 \mathrm{ft}$ long vent panel

$\begin{array}{llllllllllllllllll}15 & 16 & 18 & 22 & 25 & 30 & 38 & 40 & 43 & 48 & 51 & 52 & 52 & 53 & 54 & 55 & 58 & 58\end{array}$

42 Type I prefabricated panels, widths of 16 to 48 inch with lengths of 48 to 144 inch. 16 gauge back, 22 gauge perforated face with 4 inch thick
acoustical filler in core
22
28
40
49
54
57

Acoustic Modular

$\begin{array}{ll}\text { Enclosure } & \text { CR } 1974 \\ \text { System } & \text { ME }-4000\end{array}$

44 Type II prefabricated panels, width 16 to 48 inch, lengths 48 to 144 inch gypsum board barrier, 16 gauge back, 22 gauge perforated face with 4 inch hick acoustical filier in core
24
31
41
50
56
57

Acoustic Morilar $\begin{array}{ll}\text { Enclosure } & \mathrm{CR} \\ \text { System } & \mathrm{ME}-400\end{array}$

Standard panels made of steel and fiberglass (Model $2 \mathrm{P}$ ), $4 \times 6 \mathrm{ft}$ up in
25
31
46

$11 \mathrm{ft} 6$ inch long $\times 8$ ft 2 inch wide $\times 8$ ft 11 inch high enclosure with four double-wing doors 3 ft wide
26
36
40
44
50
50

Heavy duty panel Model $4 \mathrm{PH}$, and high temperature panel Model $4 \mathrm{PHT}$ temp-
erature to $1000 \mathrm{~F}^{\mathrm{F}} \mathrm{4} \times 6 \mathrm{ft}$ up in $1 \mathrm{ft}$ increments - all 78 inch high inside, 100 inch outside
26
33
41
46
52
55

$\begin{array}{lllll}4 & 5 & \begin{array}{l}\text { Silent Room } \\ \text { Model OBCF }\end{array} & \text { CR } \\ \text { B-135 }\end{array}$ 
Table 19B. Barrier properties of enclosure systems (transmission loss) concluded.

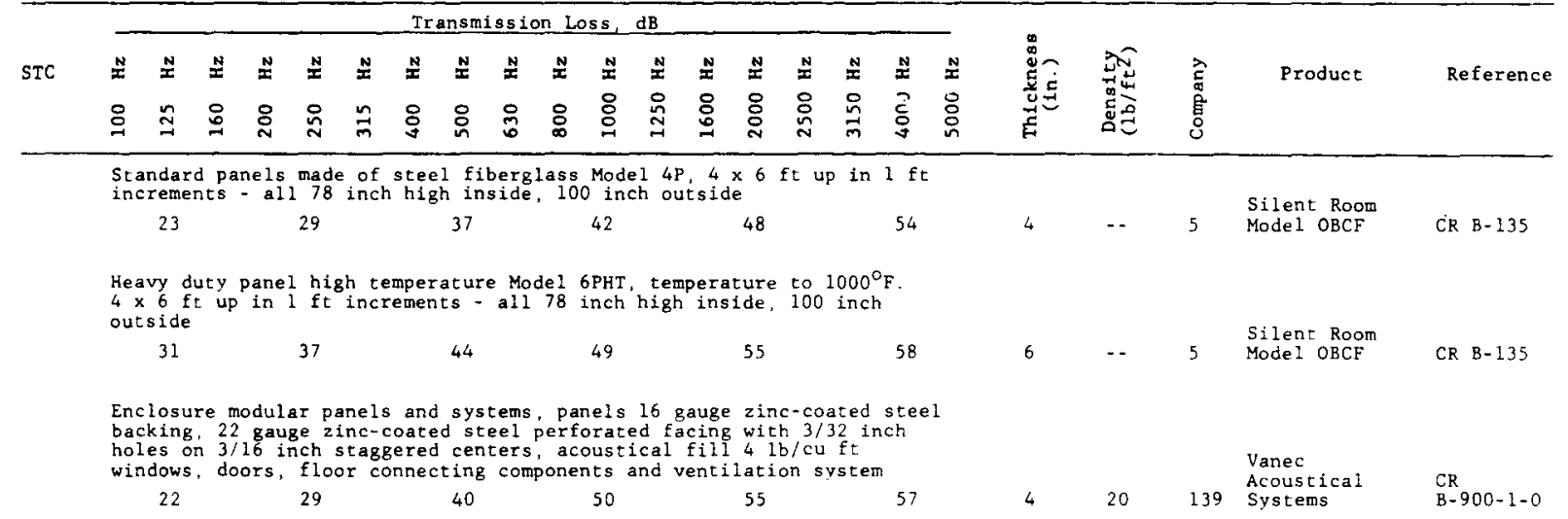


Table 19C. Barrier properties of enclosure systems (noise reduction).

Noise Reduction, $d B$

STC

ำ

○

Free standing enclosure $72 \times 96 \times 84$ inch high. Leaded vinyl supported by metal frame

$\begin{array}{llllllllllllllll}9 & 6 & 6 & 7 & 9 & 11 & 13 & 16 & 19 & 21 & 21 & 19 & 21 & 23 & 26 & 26\end{array}$

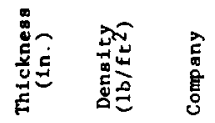

Free standing enclosure $72 \times 96 \times 84$ inch high. Leaded vinyl supported by wetal frame

$\begin{array}{llllllllllllllll}11 & 8 & 7 & 10 & 10 & 14 & 16 & 19 & 19 & 20 & 20 & 21 & 22 & 22 & 22 & 23\end{array}$

\begin{tabular}{|c|c|c|c|c|}
\hline & - & 112 & $\begin{array}{l}\text { Sound Stopper } \\
\text { free standing } \\
\text { enclosure }\end{array}$ & RAL \\
\hline & -- & 112 & $\begin{array}{l}\text { Sound Stopper } \\
\text { free standing } \\
\text { enclosure }\end{array}$ & RAL \\
\hline & -- & 78 & $\begin{array}{l}\text { Noise Guard } \\
\text { Portable office } \\
\text { Enclosure }\end{array}$ & \\
\hline
\end{tabular}

Enclosure with inside dimensions of $80 \times 80 \times 84$ inch high, outside di-

mens $84 \times 84 \times 89$ inch high. 16 gauge steel back, 22 gauge perfora

Door, window, ventilation, and electrical supolied

24

25

29

34

37

22 gauge galvanized steel back, 22 gauge galvanized perforated face, 6 $\mathrm{lb} / \mathrm{cu} \mathrm{ft}$ absorption material core, $1 / 8$ inch structural steel flant. (i 350 1b): Outside dimensions 6 ft 4 inch $x 6$ ft 4 inch $x 7$ ft 6 inch
S.V.R. -2 : outside dimensions 6 ft 6 inch $x 10$ ft 4 inch 8 ft 0 inch $(2300$ ib)
19
21
26
32
36
38

OCBF labyrinth models, $4 \times 6 \mathrm{ft}$ up in $1 \mathrm{ft}$ increments, all 78 inch high Inside, 100 inch outside
16
21
28
36
36
35

OCBF door model $4 \times 6 \mathrm{ft}$ up in $1 \mathrm{ft}$ increments, all 78 inch high inside 100 inch outside

$20 \quad 23$

$28 \quad 36$

36

35

Prefabricated, acoustically treated room designed for maximum visibility and personnel safety. Constructed from tracoustics 2 inch panels. suge galvanized steel outer and
olid steel floor with rubber mat
1730
39
42
45

Portable prefabricated type 1 acoustical module panels with full view windows, sealed doors, heavy duty floors, quiet ventilation. 16 standard sizes

25

17

30

39

42

45

$53 \times 38 \times 88$ inch outside, $45 \times 30 \times 80$ inch inside, onc $30 \times 24$ inch

$\begin{array}{llllllllllllllllll}\text { window, three perforated walls, carpeted floor } \\ 21 & 23 & 22 & 29 & 32 & 36 & 36 & 36 & 36 & 37 & 39 & 41 & 41 & 41 & 39 & 39 & 41 & 42\end{array}$

Outside is $83 \times 113 \times 91$ inch, inside is $75 \times 105 \times 86$ inch, with one 30 $x 86$ inch windo

$\begin{array}{llllllllllllllllll}24 & 23 & 24 & 26 & 29 & 34 & 36 & 38 & 39 \cdot 37 & 37 & 40 & 42 & 40 & 38 & 42 & 45 & 46\end{array}$

4 Inch thick panels, outer surface 16 gauge CRS, CRS perforated $3 / 22$ inch on 3/16 inch staggered centers, 10 gauge inner surface; floor is one piece with top surface and 16 gauge lower, booth dimensions $38 x$

$21 \quad 2322 \quad 2932 \quad 36 \quad 36 \quad 36 \quad 36 \quad 37 \quad 3941 \quad 4142 \quad 4141$

Audiometric booth $6 \mathrm{ft} 10$ inch high $\times 3$ ft 4 inch wide $x 3$ ft 6 inch deep

with isolators on casters, windows, jack panel, ventilator. 2 inch thick panel construction, 22 gauge perforated zinc coated steel face mineral wool filler, 16 gauge steel back

$\begin{array}{llllllllllllllllll}27 & 24 & 16 & 27 & 31 & 30 & 32 & 34 & 39 & 40 & 43 & 46 & 49 & 52 & 52 & 53 & 54 & 53\end{array}$

All steel construction, outside dimensions $32 \times 42 \times 71$ inch, inside $28 \times$
$38 \times 60$ inch. Available in several variations and models

$\begin{array}{cccccc}20 & 32 & 38 & 44 & 52 & 53\end{array}$

Portable audiometric booth $29-1 / 2$ inch wide $\times 40$ inch deep and 62 inch

high with isolators or casters. Also window, jack panel, ventilation. 2
inch thick panel construction, perforated inside of 22 gauge zinc coated

steel, outside of 16 gauge steel mineral wool core

$\begin{array}{llllllllllllllllll}13 & 15 & 24 & 24 & 35 & 35 & 38 & 40 & 43 & 44 & 44 & 47 & 52 & 52 & 53 & 52 & 53 & 51\end{array}$

Prefabricated panels of single wall configurations 4 inch thick. 16

gauge outer surface and 22 gauge perforated inner surface. Floor panels.

$4-3 / 16$ inch thick of 11 and 16 gauge steel. Sizes from 4 ft $x 3$ ft 8

inch $x 7 \mathrm{ft} 8$ inch to $21 \mathrm{ft} 8$ inch $x 10 \mathrm{ft} 4$ inch $x 8 \mathrm{ft} l$ inch. Panel

$\begin{array}{llllllllllllllllll}24 & 24 & 23 & 28 & 31 & 34 & 39 & 44 & 46 & 48 & 52 & 55 & 57 & 58 & 60 & 59 & 59 & 59\end{array}$

$\begin{array}{lllll}2 & - & 82 & \begin{array}{l}\text { Versacoustic } \\ \text { Rooms }\end{array} & \begin{array}{l}\text { CR } \\ \text { DS4202 }\end{array} \\ & & & \begin{array}{l}\text { Silent Room } \\ \text { Portabie }\end{array} & \text { CR } \\ \text { B-135 }\end{array}$

$\begin{array}{llll}\text {-. } & \text {-. } 5 & \begin{array}{l}\text { Silent Room } \\ \text { Portable }\end{array} & \text { CR } \\ \text { B-135 }\end{array}$

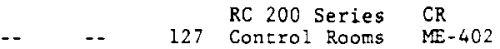

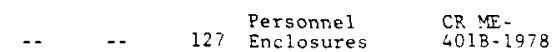

$8 \quad--\quad 120 \begin{array}{ll}\text { 25M Hearing } & \text { RAL } \\ \text { Nest Booth } & \text { NR } 76-8\end{array}$

$8 \quad$-- $\quad 120 \begin{aligned} & \text { Model } 802 \\ & \text { Practice Module NR } 76-7\end{aligned}$

$\begin{array}{llll}\text { Hearing } & \\ \text { Test Booth } & \text { RAL }\end{array}$

$\begin{array}{lllll} & & & & \\ \text { CKAL } & \text {-. } & 47 & \text { Model } 442 & 738-02\end{array}$

$2 \quad \ldots \quad 114$ Mini Booth $\quad$ V7 IC3

$\begin{array}{llll} & & & \\ - & - & \text { AB20OHD } & \text { CKAL } \\ \text { Type 1 } & 77-08.01\end{array}$ 
Table 19C. Barrier properties of enclosure systems (noise reduction) concluded.

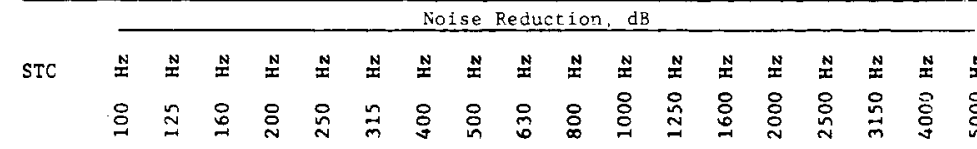

Model 885 prefabricated panels, final assembly at location

$\begin{array}{lllllllllllllllll}20 & 20 & 15 & 28 & 31 & 36 & 42 & 46 & 50 & 52 & 54 & 55 & 55 & 58 & 58 & 59 & 59\end{array}$

Enclosure with inside dimensions of $76 \times 76 \times 84$ inch high and $84 \times 84 \times$ 91 inch high. 16 gauge steel back, 22 gauge perforated steel face with core of $4-3 / 416$. density. Door, window, ventilation, and electrical supplied

$$
27
$$

50

55

16 gauge steel back, 22 gauge steel perforated face, nonflamable mineral wool core, dimensions $29 \times 39 \times 74$ inch

$$
40 \quad 47
$$

47

52

56

Inside $72 \times 76 \times 78$ inch, vent sealed, 16 gauge CR steel outside, 22
gauge CR steel inside, one wall contained a double glazed window $24 \times 30$ inch
32
36
46
58
64
66

Two model 802 practice modules. The measurement was made from module to module

$\begin{array}{llllllllllllllllll}38 & 42 & 45 & 51 & 51 & 56 & 56 & 57 & 61 & 68 & 74 & 81 & 84 & 78 & 85 & 90 & 92 & 95\end{array}$

Model $88 \mathrm{D}$, inner room was a model $88-5$ audiometric room, the outer was
assembled from 4 inch thick panels connected together by special battens, 4 inch air space

$\begin{array}{llllllllllllllllll}36 & 34 & 39 & 50 & 62 & 71 & 80 & 85 & 89 & 90 & 90 & 88 & 90 & 92 & 89 & 87 & 84 & 79\end{array}$

Prefabricated panels of double wall configuration, 4 inch thick, 16 gauge back and 22 gauge perforated face. Floor panels $4-3 / 16$ inch thick 11 and
16 gauge steel. Sizes from $4 \mathrm{ft} \times 3 \mathrm{ft} 8$ inch $7 \mathrm{ft} 8$ inch to $21 \mathrm{ft} 8$ inch gauge steel. Sizes from $4 \mathrm{ft} \times 3 \mathrm{ft} 8$ inch $\times 7 \mathrm{ft} 8$ inch

$\begin{array}{llllllllllllllllll}41 & 49 & 46 & 55 & 61 & 71 & 73 & 74 & 82 & 84 & 87 & 90 & 90 & 92 & 92 & 98 & 98 & 98\end{array}$

Inside is $72 \times 76 \times 70$ inch and outside is $96 \times 100 \times 94$ inch

49

36

70

100

$>107$

$>100$

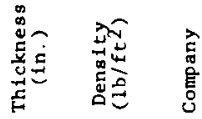

Product

Reference

Single Wall
Examination
Room

Noise Guard

$\begin{array}{ll}\text { Portable office } & \\ \text { Enclosure } & \end{array} 44$

Model AR-18

RR

$\begin{array}{ll}\text { Rooms } & \text { DS } 4203\end{array}$

Single Walled

Audiometric

Rooms NR $71-56$

Model 802

Practice

$\begin{array}{ll}\text { Modules } & \text { RAL } \\ \text { NR } 76-6\end{array}$

Double Wall

$\begin{array}{llll} & & & \text { Audiometric } \\ \text { Room } & \text { CKAL } & \text { 75-08-03 }\end{array}$

RE \& RS Series

Audiometric RAL
Rooms

Double valled

$\begin{array}{ll}\text { Audiometric } & \text { RAL } \\ \text { Room } & \text { NR71-58 }\end{array}$

- $\quad$ - $\quad 7$ Portable $\quad$ Shop office - 
CATEGORY 20, DOORS

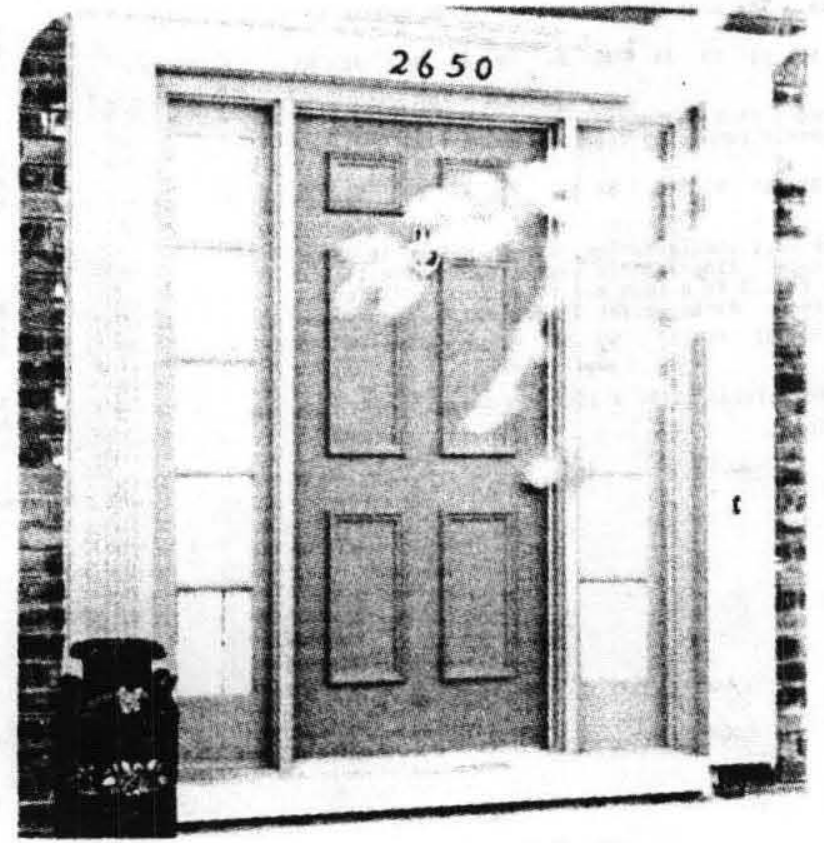




\section{CATEGORY 20. DOORS}

A door is basically an operable partition used for privacy and security purposes. Acoustically, it is primarily a noise barrier. There may be instances where a door has a perforated side and has absorptive qualities. Absorption materials may also be applied to a surface. The data presented are primarily sound transmission values.

The acoustical performance of a door is dependent upon surface material, filler material in the cavity area, and the sealing capability. The cavity area may be hollow, but for improved barrier results different mass related configurations are used. The seal design is the critical parameter for doors. Various seals and sealing techniques are available which can be pressure sensitive, magnetic, spring loaded, or contact type. Organizations contributing data to this table are: $4,8,35,52,54,95,105,122,126$, and 145.

Facing: The outside surface of the specimen. In general, the sound source side

Backing: The surface of the specimen opposite the facing. In genera1, the side opposite the sound source

Core: The region between the facing and the backing. 
Table 20. Doors.

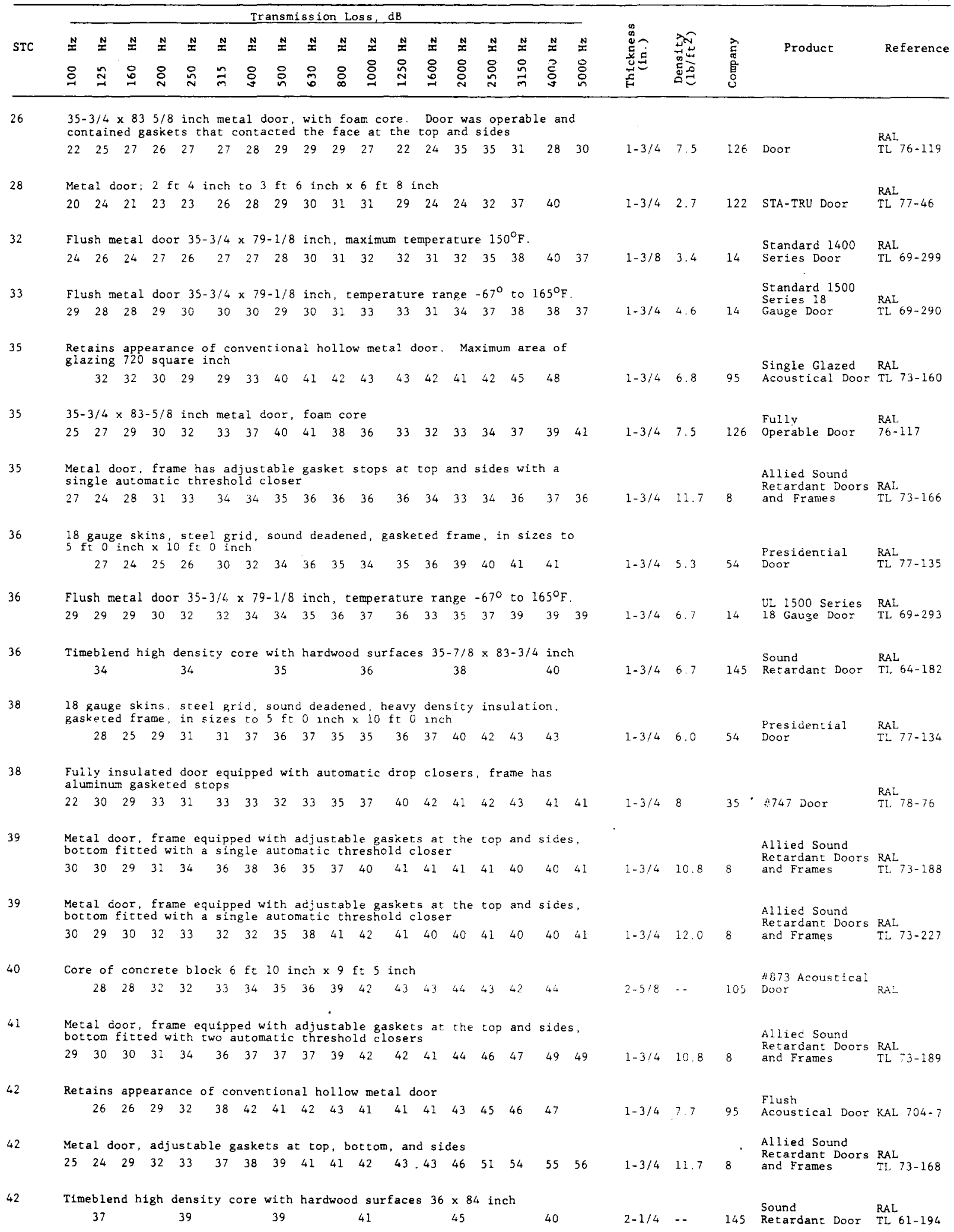


Table 20. Doors concluded.

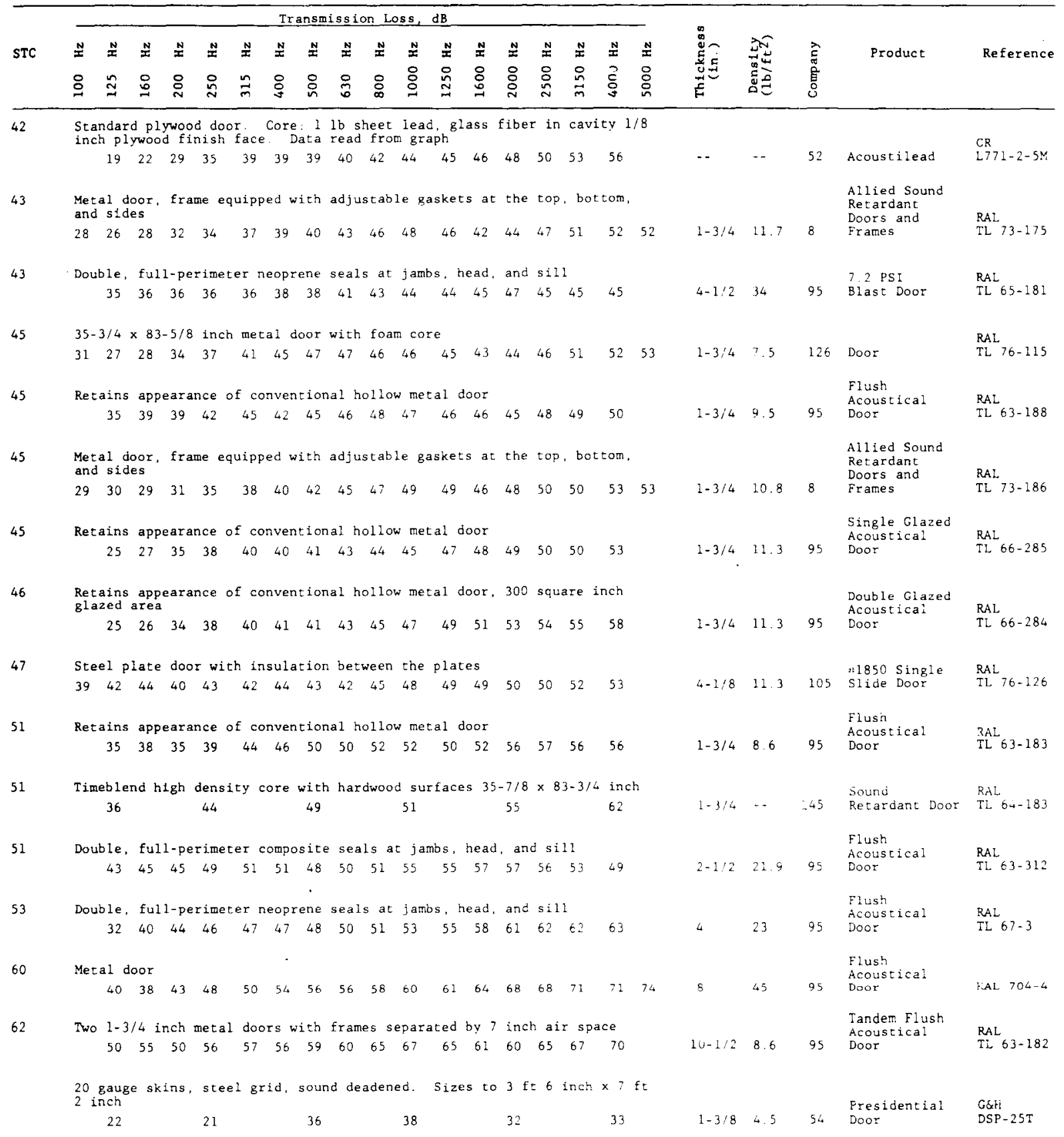




\section{CATEGORY 21. FLOORS}

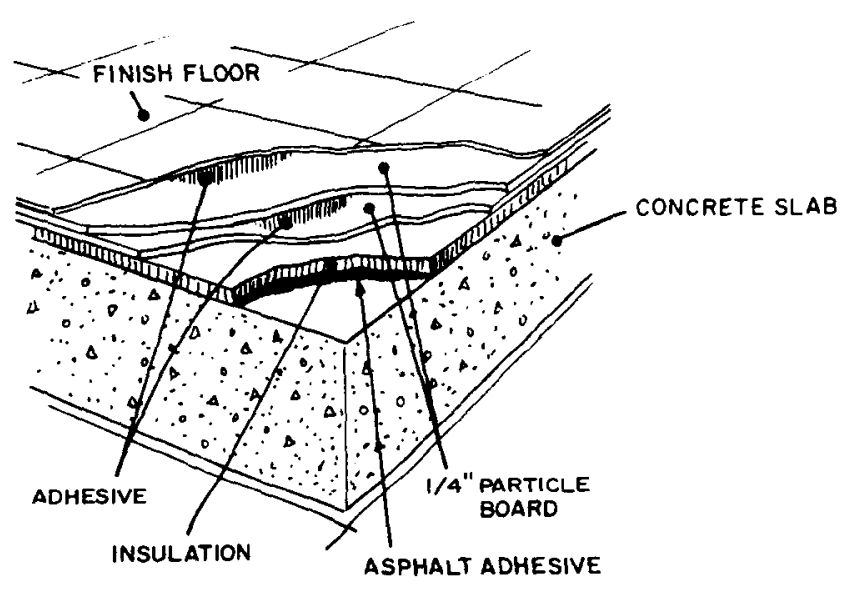

Concrete Subfloor

with a Finish Floor Cover

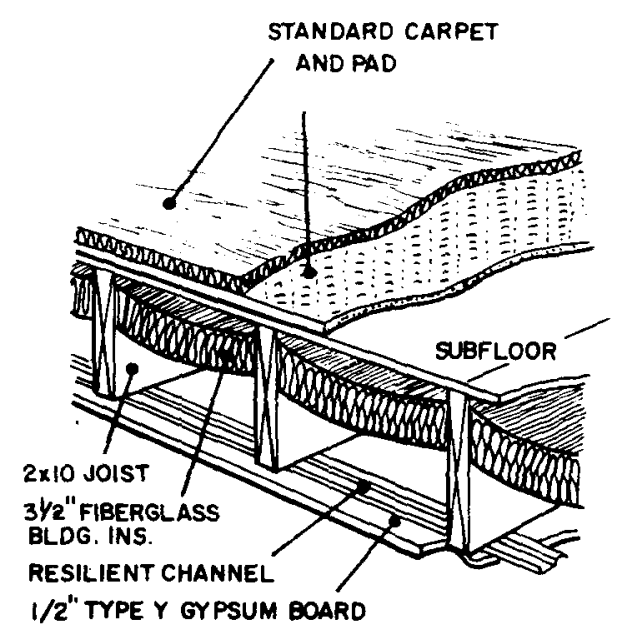

A. Floor with Wood Support Structure and a Carpet Cover 


\section{CATEGORY 21. FLOORS}

Materials used for basic floor structures are concrete, wood and metal. Floor coverings include tile, wood, or carpet. Acoustic measurements on floors are either sound transmission (STC or NR) or sound impact (INR or IIC) tests. The latter procedure is performed with a calibrated tapping machine.

Concrete floors are typically heavy and provide a good transmission barrier, but they are efficient transmitters of tapping sounds. The tapping sound transmission can be reduced significantly by using carpets, pads, and insulation filled cavities.

Organizations contributing data to this table are: $55,75,103,109,113$, 129,144 , and 145 .

\section{CAUTION}

1. THE PRODUCT LISTED IN THE TABLE MAY ONLY BE A FLOOR ACCESSORY BUT IT WAS TESTED IN A FLOOR SYSTEM AND, HENCE IS LISTED IN THIS TABLE.

2. FOR IMPACT DATA, THE VALUES SHOWN ARE SOUND PRESSURE LEVELS GENERATED IN A ROOM BELOW WHEN THE STANDARD TAPPING MACHINE WAS OPERATED ON THE FLOOR COVERING. SEE PAGE 88 FOR FURTHER EXPLANATION.

\section{GLOSSARY}

Wood Joists: Parallel timbers that support the planks of a floor Standard Carpet and Pad: $44 \mathrm{oz}$ per square yard Gro-Point carpet with $40 \mathrm{oz}$ per square yard hair felt pad (see page 66).

Floor Deck: A platform or a surface covering the structural framework to form a floor. 
Table 2lA. Floors (transmission and impact).

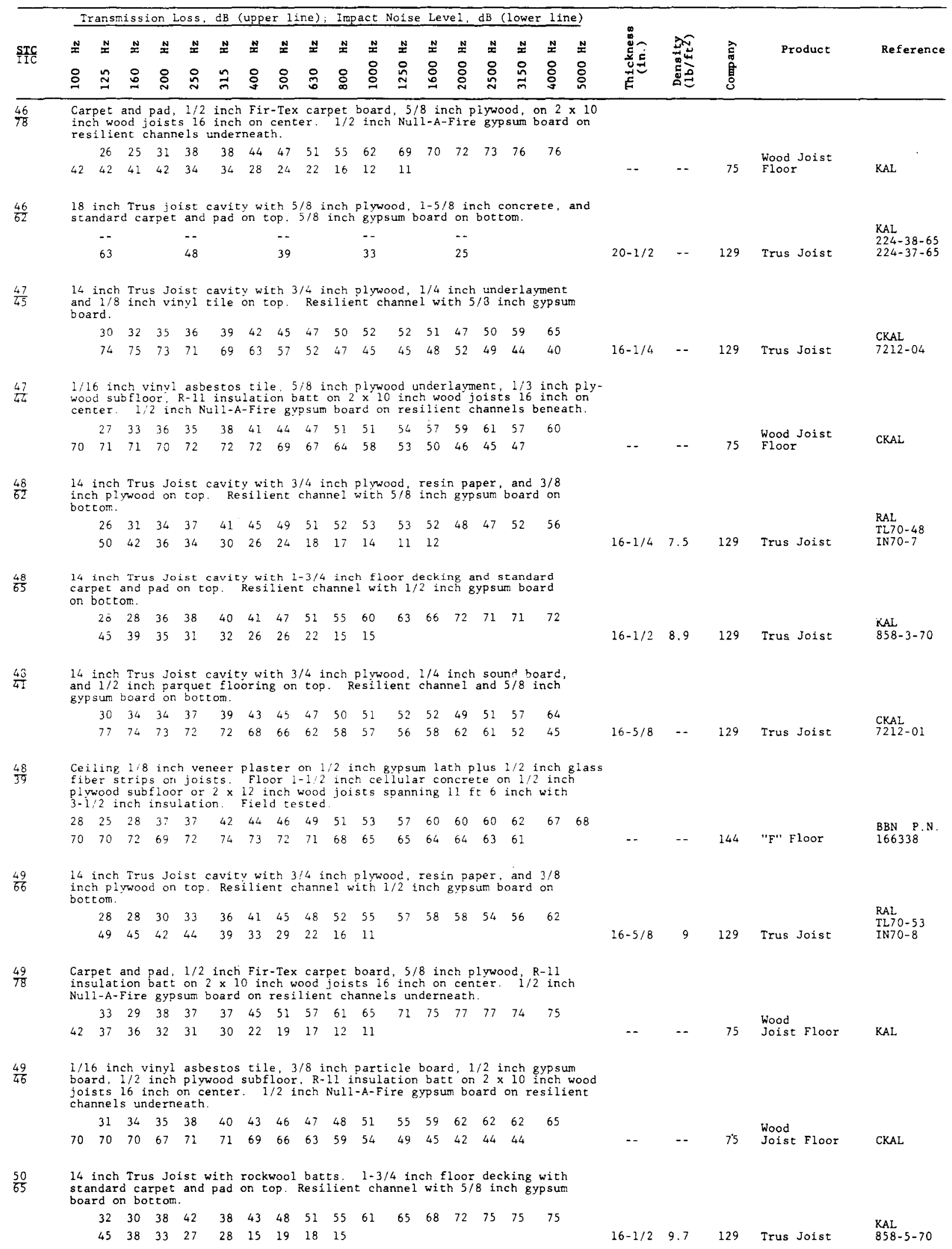


Table 21A. Floors (transmission and impact) continued.

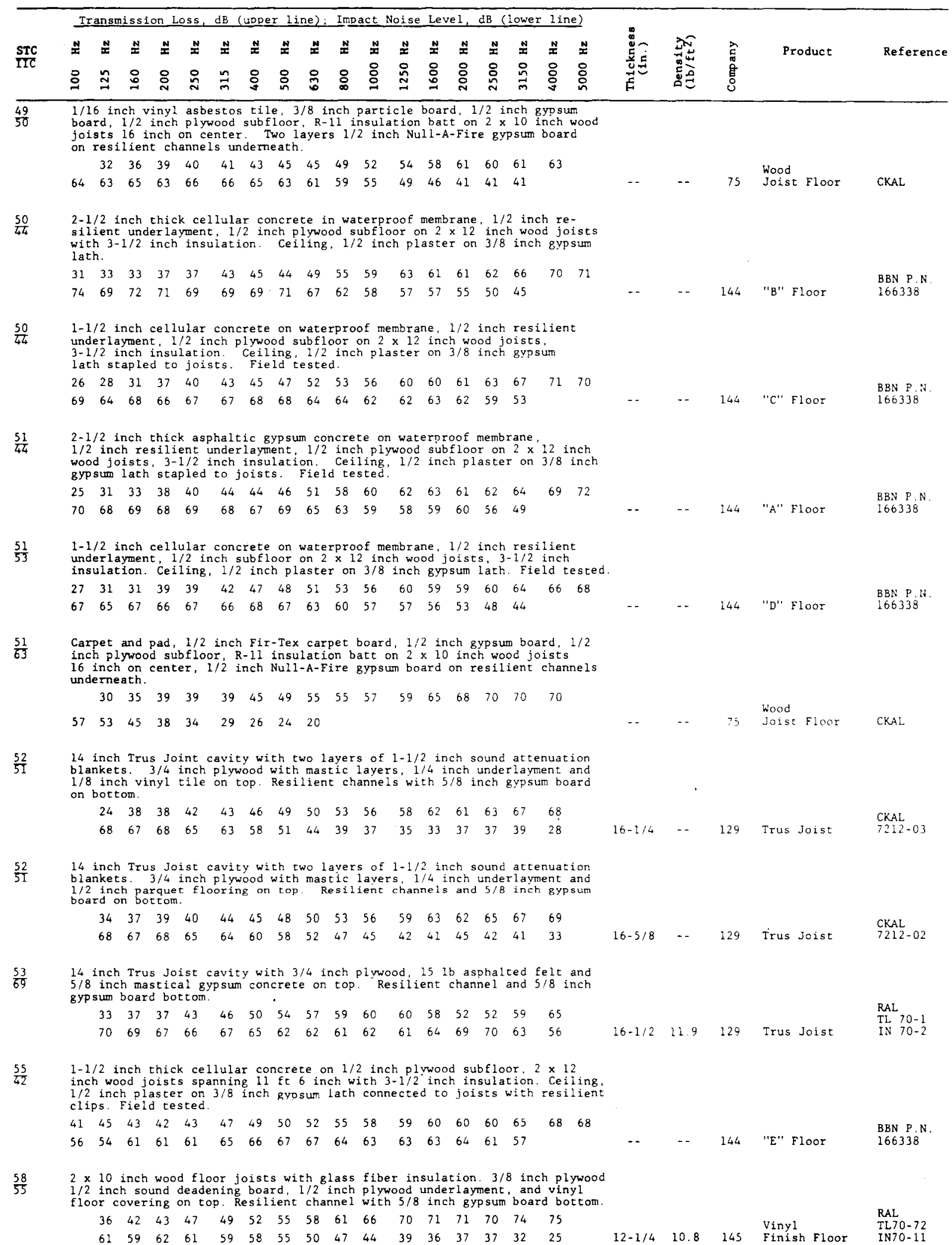


Table 2lA. Floors (transmission and impact) concluded.

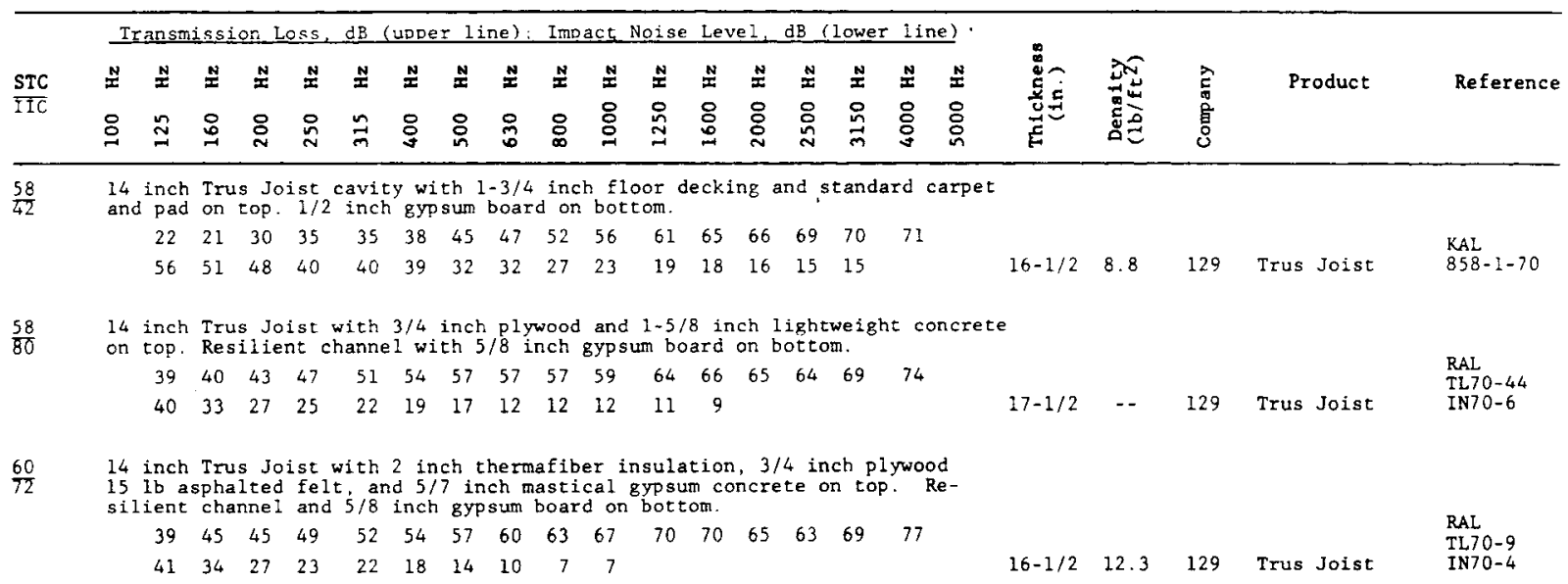

Table 21B. Floors (transmission loss).

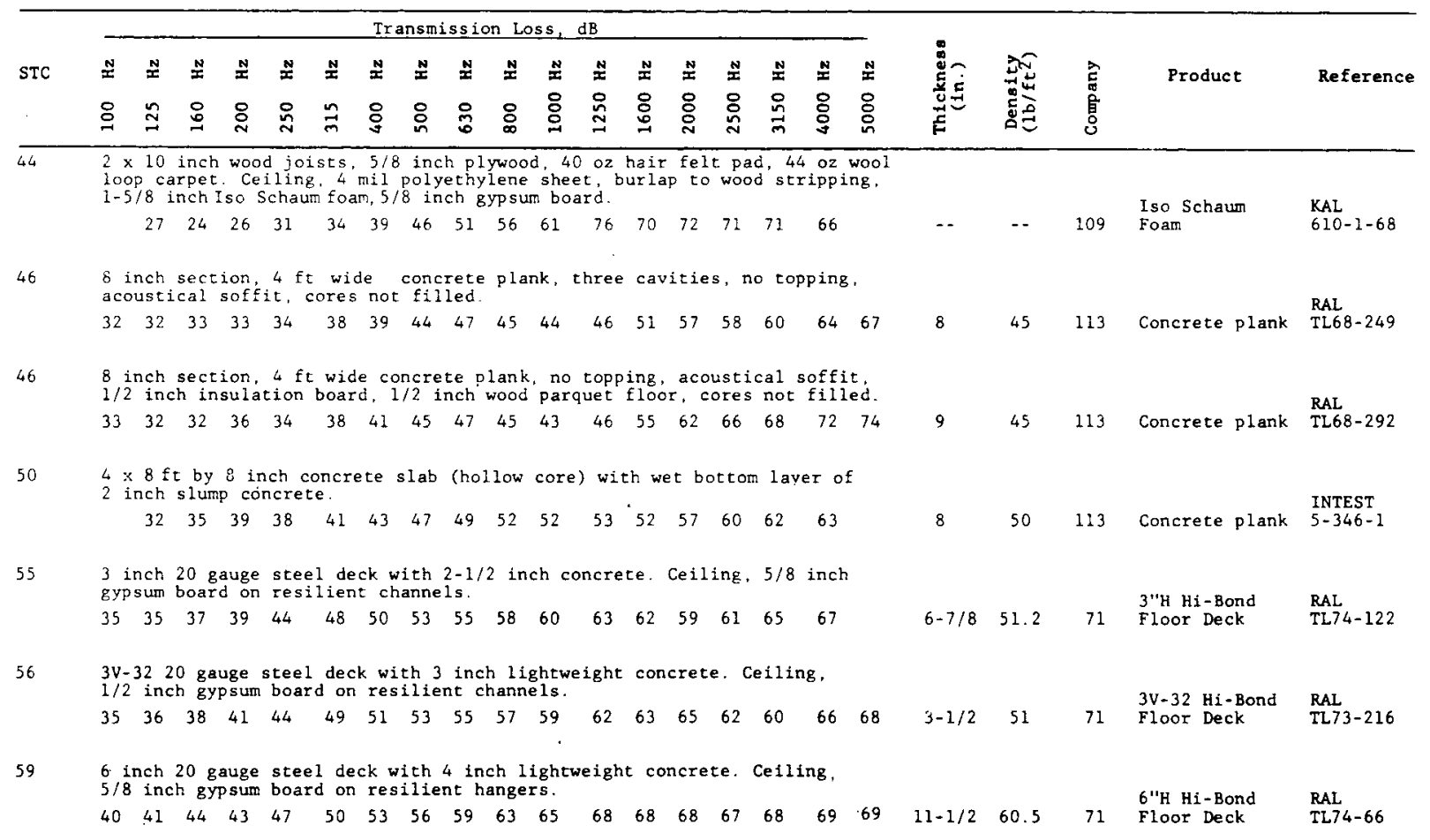


Table 2lC. Floors (impact level).

Impact Noise Level, $\overline{d B}$

\begin{tabular}{|c|c|c|c|c|c|c|c|c|c|c|c|c|c|c|c|c|c|c|c|c|c|c|c|}
\hline \multirow{3}{*}{ IIC } & \multicolumn{18}{|c|}{ Impact Noise Level, as } & \multirow{3}{*}{ 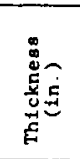 } & \multirow{3}{*}{ 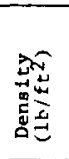 } & \multirow{3}{*}{ 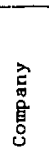 } & \multirow{3}{*}{ Product } & \multirow{3}{*}{ Reference } \\
\hline & $\underline{x}$ & 쏘 & $\stackrel{\text { N }}{x}$ & Nㅗㄴ & 폴 & $\stackrel{N}{x}$ & 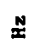 & $\underline{x}$ & Nㅗㄴ & $\stackrel{N}{x}$ & $\stackrel{N}{\mathbf{N}}$ & $\stackrel{N}{x}$ & $\stackrel{N}{x}$ & $\stackrel{N}{x}$ & 쏲 & $\underline{x}$ & $\stackrel{N}{x}$ & $\stackrel{N}{x}$ & & & & & \\
\hline & ¿ & $\cong$ & $\stackrel{\circ}{0}$ & 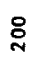 & 号 & $\stackrel{m}{m}$ & $\stackrel{8}{q}$ & $\stackrel{8}{n}$ & 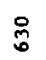 & : & $\stackrel{\circ}{\circ}$ & $\stackrel{\stackrel{0}{N}}{\text { I }}$ & 吕 & 衣 & 品 & 总 & ষ্ু & 吕 & & & & & \\
\hline
\end{tabular}

428 inch section, $4 \mathrm{ft}$ wide prestressed concrete plant, no topping, acoustical soffit $1 / 2$ inch insulation board, $1 / 2$ inch wood parquet floor, cores not filled, botcom painted. $\begin{array}{lllllllllllllllllllllllll}71 & 70 & 72 & 75 & 76 & 75 & 74 & 71 & 68 & 65 & 64 & 62 & 52 & 44 & 42 & 37 & 32 & 30 & 9 & 45 & 113 & \text { Concrete plank } & \text { IN68-4 }\end{array}$

$48 \quad 1-1 / 2$ inch cellular concrete on waterproof membrane, $1 / 2$ inch resilient underlayment, $1 / 2$ inch plywood subfloor on $2 \times 12$ inch wood joists with $3-1 / 2$ inch insulation and covering of 07 inch thick vinyl/foam/felt, 2 Ceiling, $1 / 2$ inch plaster on $3 / 8$ inch gypsum lath stapled to

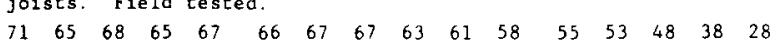
$\begin{array}{lllll}-- & - & 144 & \text { "C" Floor } & \text { BBN } \\ 166338\end{array}$

$48 \quad 1-1 / 2$ inch cisular concrete on waterproof membrane, $1 / 2$ inch resilient underlayment, $1 / 2$ inch subfloor on $2 \times 10$ inch wood joists with $3-1 / 2$ inch insulation, with covering .07 inch thick vinyl/foam/ lath. Field tested. $\begin{array}{llllllllllllllll}62 & 62 & 69 & 58 & 68 & 68 & 67 & 68 & 65 & 60 & 56 & 53 & 48 & 41 & 33 & 26\end{array}$ 49 2-1/2 inch thick asphaltic gypsum concrete on a waterproof membrane, wood joists with $3-1 / 2$ inch insulation and covered with .07 inch thick vinyl/foam/felt $2.4 \mathrm{lb} / \mathrm{yd}^{2}$. Ceiling. $1 / 2$ inch plaster on $3 / 8$ inch gypsum
lath stapled to joists. Field tested. $\begin{array}{llllllllllllllll}68 & 66 & 67 & 66 & 67 & 66 & 65 & 65 & 61 & 59 & 54 & 50 & 48 & 44 & 37 & 25\end{array}$

49 1-1/2 inch cellular concrete on waterproof membrane, $1 / 2$ inch resilient underlayment, $1 / 2$ inch plywood subfloor on $2 \times 12$ inch wood joists with ling 2.8 inch insulation. to joists. Field tested.

$\begin{array}{llllllllllllllll}68 & 64 & 67 & 66 & 66 & 65 & 65 & 65 & 58 & 56 & 51 & 45 & 40 & 30 & 23 & 16\end{array}$

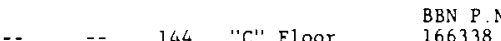

49 1-1/2 inch cellular concrete on waterproof wembrane, $1 / 2$ inch resilient underlayment, $1 / 2$ inch plywood subfloor on $2 x 12$ inch wood joists with

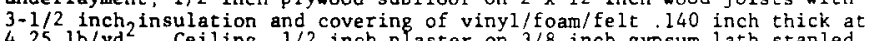
$4.25 \mathrm{lb} / \mathrm{yd}^{2}$ Ceiling.

$\begin{array}{llllllllllllllll}67 & 65 & 68 & 66 & 66 & 65 & 65 & 65 & 60 & 56 & 51 & 45 & 40 & 32 & 25 & 18\end{array}$

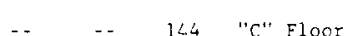

BBN P.N

$50 \quad 1-1 / 2$ inch cellular concrete on waterproof membrane, $1 / 2$ inch resilient under layment, $1 / 2$ inch plywood subfloor on $2 x 12$ inch wood joists with Ceiling. $1 / 2$ Field tested.

$\begin{array}{llllllllllllllll}70 & 67 & 69 & 68 & 64 & 60 & 56 & 54 & 47 & 40 & 34 & 26 & 24 & 21 & 19 & 17\end{array}$

- $\quad$ - $\quad 144 \quad$ "C" FloO

BBN P. N
166338

$50 \quad 1 / 1-2$ inch cellular concrete on waterproof membrane, $1 / 2$ inch resilient underlayment, $1 / 2$ inch plywood subfloor on $2 \times 12$ inch wood joists with 3-1/2 inch insulation, vinyl covering of viny $1 /$ foam 25 inch thick at
$3.5 \mathrm{lb} / \mathrm{yd}^{2}$. Ceiling. I/2 inch plaster on $3 / 8$ inch gypsum lach stapled to joists. Field tested.

$\begin{array}{llllllllllllllll}70 & 65 & 67 & 62 & 59 & 54 & 45 & 38 & 33 & 27 & 22 & 16 & 16 & 13 & 8 & 6\end{array}$

$1-1 / 2$ inch cellular concrete on waterproof membrane, $1 / 2$ inch resilient underlayment, $1 / 2$ inch subfloor on $2 \times 12$ inch joists with $3 / 1-2$ inch insulation and with covering of 105 inch chick vinyl f $f$ an $f$ elc at $2.8 \mathrm{lb} / \mathrm{yd}^{2}$. Ceiling, $1 / 2$ inch piaster on $3 / 8$ inch gypsum lath. Field tested.

$\begin{array}{llllllllllllllll}62 & 63 & 67 & 66 & 66 & 66 & 65 & 64 & 59 & 53 & 47 & 39 & 33 & 27 & 21 & 17\end{array}$

1-1/2 inch cellular concrete on $1 / 2$ inch plywood subfloor, $2 \times 12$ inch wood joists spanning $11 \mathrm{ft} 6$ inch with $3-1 / 2$ inch insulation between joists and with a covering of 07 inch thick vinyl/foam/felt at 2.4 $1 \mathrm{~b} / \mathrm{yd}^{2}$ Ceiling, $1 / 2$ inch plaster on gypsum lath connected to joists
via resilient clips. Field tested. $\begin{array}{llllllllllllllll}53 & 53 & 60 & 60 & 62 & 63 & 63 & 64 & 64 & 61 & 59 & 56 & 54 & 51 & 44 & 38\end{array}$

.14 inch foam-backed vinvl sheet, $3 / 8$ inch particle board, $1 / 2$ inch
gypsum board, $1 / 2$ inch plywood subfloor. R-11 insulatinn batt on $2 \times 10$ gupsum board, $1 / 2$ inch plywood subfloor. R-11 insulation batt on $2 \times 10$
inch wood joists 16 inch on center. Two lavers $1 / 2$ inch Nulf-A-Fire gypsum board on resilient channels underneath.

$\begin{array}{llllllllllllllll}63 & 64 & 65 & 62 & 64 & 63 & 60 & 52 & 44 & 39 & 32 & 27 & 25 & 19 & 19 & 18\end{array}$

- $\quad$ - $\quad 75 \quad \begin{aligned} & \text { Wood } \\ & \text { Joist Floor }\end{aligned}$

CKAL 
Table 21C. Floors (impact level) concluded.

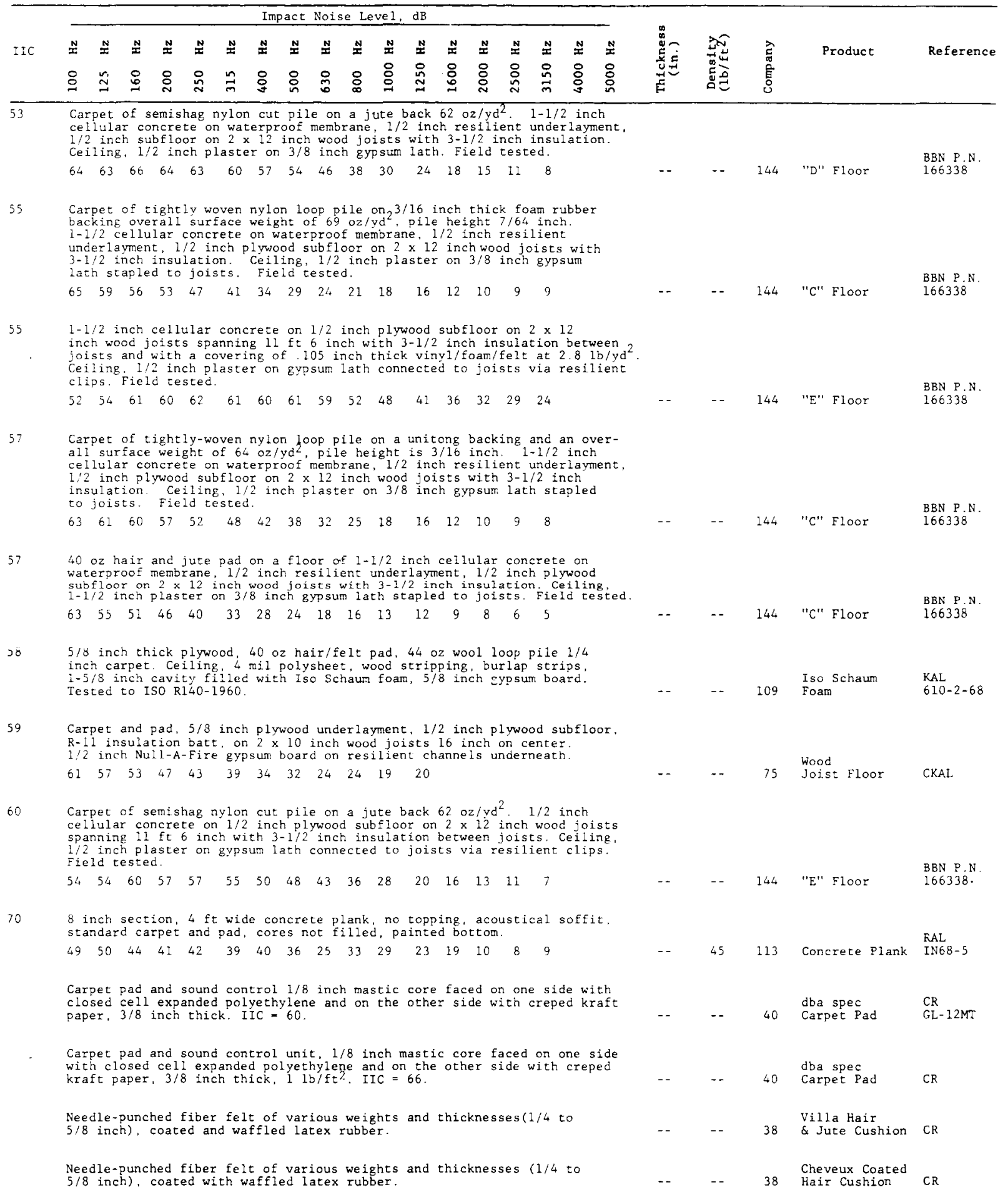




\section{CATEGORY 22, WALLS}

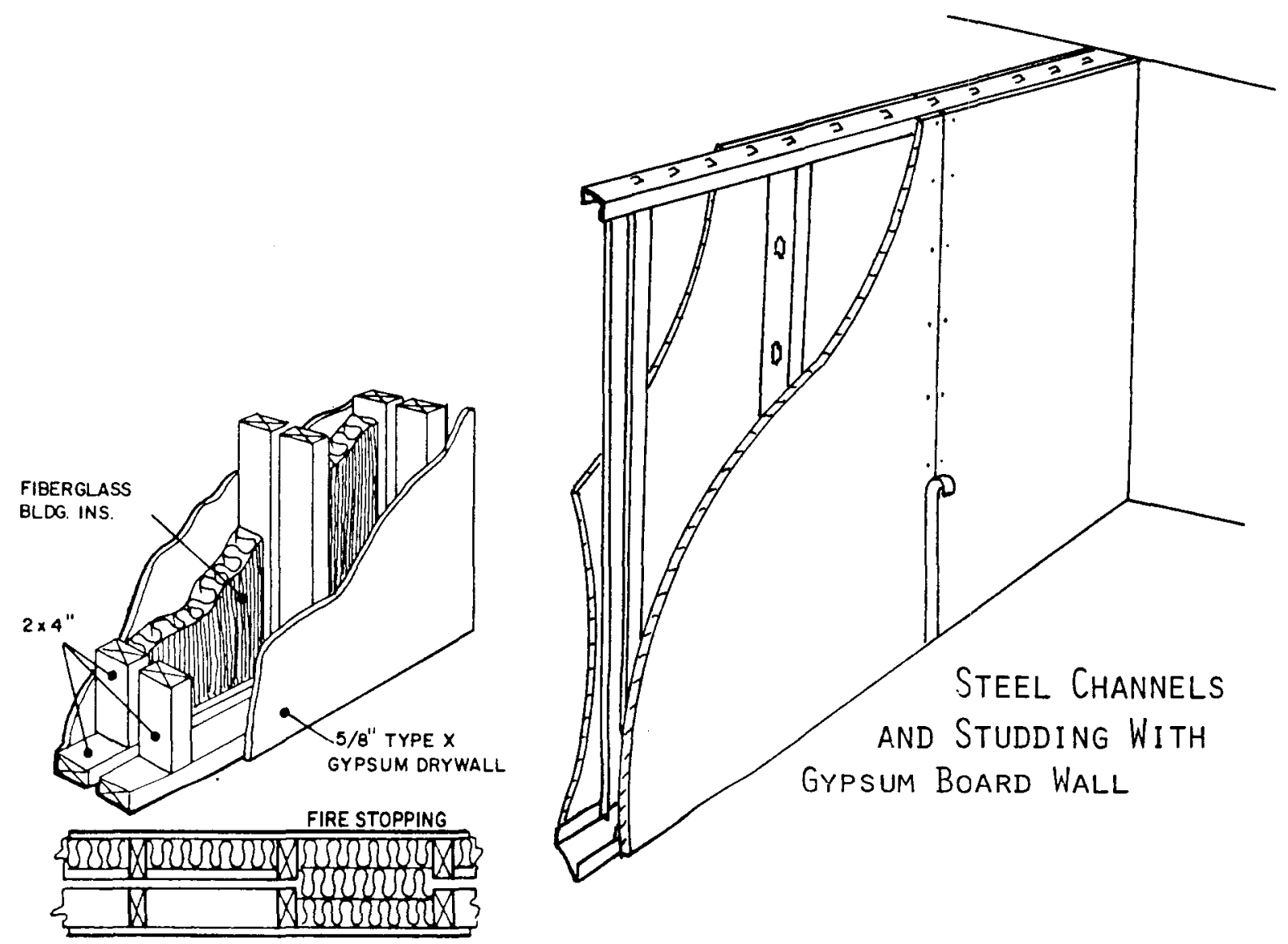

Gypsum Board Wall with Twin Stud Support and Insulation 
CATEGORY 22. WALLS

Walls are primarily gypsum board, masonry, wood, aluminum, or steel. Walls can be used as load carrying structures or area separation barriers. The many variations of construction offer a wide range of acoustical barrier performance.

Gypsum is the most commonly used wall material; however, walls using gypsum boards of approximately the same thicknesses (say $1 / 2$ inch) can be erected in a variety of ways with each wall construction providing a different sound transmission loss. Most common variables in such wall construction are the number of gypsum boards, thickness of the insulation added in the cavity, additional sound deadening boards, and different stud materials and construction. Organizations contributing data to this table are: $52,55,59,69,75$, 90, 91, 109, 132, 144, and 145. Related categories are panels, enclosures, operable partitions, and open plan systems.

\section{GLOSSARY}

Facing: The outside surface of the specimen. In general the side facing the sound source

Backing: The other outside surface of the specimen. In general the side not facing the sound source

Core: The region between the facing and the backing

Batt: Fiber wadded in sheets

Fiberglass bolt: Fiberglass roll of a given length

Furring: The creating of air spaces with thin strips of wood or metal before adding wall bonds or plaster

Gypsum: A hydrated sulfate of calcium. $\mathrm{CaSO}_{4} \cdot 2 \mathrm{H}_{2} \mathrm{O}$. Used for making wallboards, plaster of Paris, etc.

Lath: Thin, lightweight structure used as groundwork for plastering, mounting tiles, etc. It may be in a form of gypsum board, perforated metal wire cloth, thin wood strips, etc.

Screw Stud: Studs on which the wall boards are attached by screws

Stud: An upright piece in a frame to which boards or laths are applied 
Table 22A. Gypsum board walls (ASTPI E90-70 or equivalent).

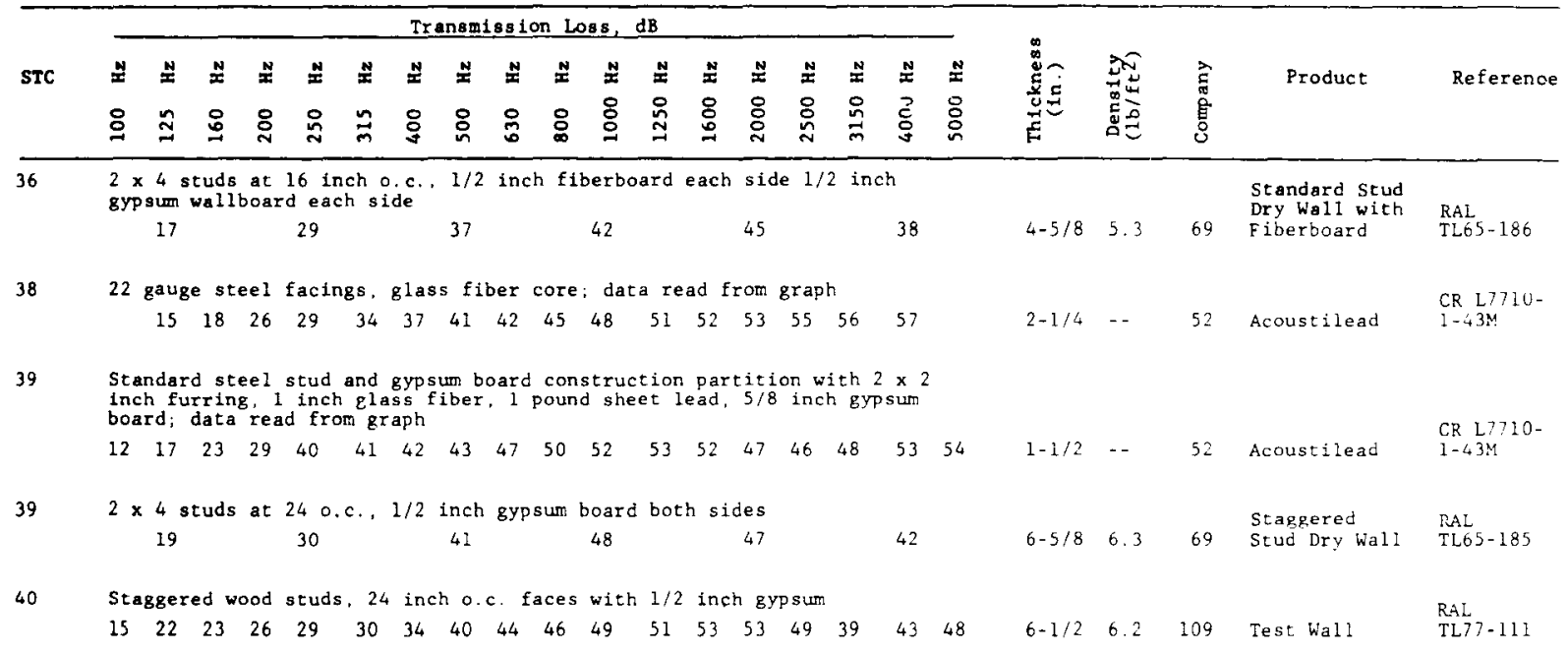

40 Wall of $5 / 8$ inch gypsum board, both sides on $2 \times 4$ studs, 16 inch $0 . c$ filied with Ino schaum foam

$\begin{array}{llllllllllllllll}21 & 23 & 28 & 34 & 35 & 34 & 36 & 40 & 41 & 46 & 48 & 49 & 45 & 41 & 44 & 49\end{array}$ 40 Cellulose fibers sprayed between $5 / 8$ inch layer gypsum board and $1 / 2$ inch
plywood with $5 / 8$ inch gypsum board other side

$\begin{array}{llllllllllllllllll}23 & 23 & 22 & 29 & 38 & 34 & 35 & 40 & 44 & 46 & 49 & 49 & 42 & 43 & 48 & 51\end{array}$

Standard steel stud and gypsum board construction partition with $1 \times 2$
inch furring, 1 inch glass fiber, I pound sheet lead. $5 / 8$ inch gypsum
board; data read from graph

Standard steel stud and gypsum board construction partition with $1 \times 2$
inch furring, 1 inch glass fiber, I pound sheet lead. $5 / 8$ inch gyp sum
board; data read from graph

Standard steel stud and gypsum board construction partition with $1 \times 2$
inch furring, 1 inch glass fiber, I pound sheet lead. $5 / 8$ inch gyp sum
board; data read from graph

$\begin{array}{llllllllllllllllll}13 & 20 & 29 & 36 & 39 & 38 & 42 & 41 & 44 & 48 & 49 & 52 & 50 & 44 & 43 & 45 & 48 & 5\end{array}$

41

Cellulose fibers sprayed between layers of $1 / 2$ inch gypsum board

$\begin{array}{llllllllllllllll}21 & 20 & 26 & 33 & 37 & 38 & 40 & 44 & 45 & 49 & 52 & 54 & 53 & 51 & 52 & 54\end{array}$

$\begin{array}{llll}\text {-. } & 6.4 & 109 & \text { Iso Schaum Foam NCI } 68-7\end{array}$

$\begin{array}{llll}\text { RAL } & \text { R } 90 & \mathrm{~K}-13 & \text { TL } 70-118\end{array}$

44

3-5/8 inch metal stud with $5 / 8$ inch gypsum board each side and urea

$\begin{array}{llllllllllllllll}23 & 24 & 30 & 32 & 39 & 40 & 46 & 49 & 54 & 58 & 60 & 59 & 49 & 46 & 50 & 56\end{array}$ $5 / 8$ inch type $x$ gypsum wallboard - vertical joints, 3-5/8 inch metal

$\begin{array}{llllllllllllllll}20 & 28 & 33 & 35 & 39 & 43 & 44 & 48 & 48 & 50 & 50 & 51 & 47 & 42 & 43 & 48\end{array}$

Facine of two layers of $1 / 2$ inch gypsum board, core of $3-5 / 8$ inch screw uds and backing of two layers of $1 / 2$ inch gypsum board

$\begin{array}{llllllllllllllll}28 & 31 & 33 & 35 & 4 & 43 & 44 & 49 & 52 & 55 & 55 & 56 & 53 & 44 & 45 & 50\end{array}$

Staggered wood studs. 24 inch $0 . c$. faced with $1 / 2$ inch gypsum with Rapco $\begin{array}{llllllllllllllllll}23 & 23 & 28 & 30 & 34 & 38 & 42 & 45 & 49 & 51 & 54 & 56 & 57 & 57 & 54 & 52 & 56 & 59\end{array}$

Staggered stud, wood frame partition, $2 \times 4$ inch studs 16 inch $0 . c$. on $2 \times 6$ plate, one layer of $5 / 8$ inch gypsum board each side, spray-in

$\begin{array}{llllllllllllllll}30 & 32 & 36 & 40 & 41 & 42 & 45 & 47 & 47 & 47 & 48 & 48 & 45 & 42 & 47 & 53\end{array}$

2 inch thick mineral fiber tested as batts inside wall: $5 / 8$ inch rypsum
board, both sides of $2-1 / 2$ inch stagpered metal studs 24 inch

$\begin{array}{llllllllllllllll}23 & 33 & 38 & 42 & 47 & 50 & 53 & 55 & 56 & 57 & 57 & 56 & 51 & 48 & 50 & 53\end{array}$

Single row wood stud, cavity insulation, gypsur board with resilient channels facing 5/8 inch gyp sum board, direct attached core, $2 \times 4$ wood studs 16 inch $0 . c$. With $2-1 / 4$ inch glass fiber absorption. backing $5 / 8$

$\begin{array}{llllllllllllllllll}24 & 25 & 29 & 34 & 40 & 43 & 45 & 47 & 50 & 51 & 52 & 54 & 52 & 46 & 44 & 40 & 53 & 53\end{array}$

47

$2 \times 8$ inch wood joists on 16 inch centers; Upper side: $1-1 / 2$ inch con-

crete over $1 / 2$ fnch plywood sheathing; Lower side: $5 / 8$ inch gypsum wall-
board $1.1 / 2$ inch Energy Guard cellulose spray insulation in joist cavity

\begin{tabular}{|c|c|c|c|c|}
\hline $1 / 4$ & $\cdots$ & 52 & Acoustilead & $\begin{array}{l}\text { CR L77 } 1 C- \\
1-43 \mathrm{M}\end{array}$ \\
\hline-- & 6.3 & 90 & $k-13$ & $\begin{array}{l}\text { RAL } \\
\text { TL69-131 }\end{array}$ \\
\hline- & 5.1 & 109 & & KÁL \\
\hline-- & 5.4 & 109 & $\begin{array}{l}\text { Test wall } \\
\text { with Foam }\end{array}$ & $\begin{array}{l}\mathrm{CR} \\
\mathrm{NCI} \quad 6 \delta-8\end{array}$ \\
\hline $5-5 / 8$ & 9 & 145 & $\begin{array}{l}\text { Gyosurn } \\
\text { Wa1lboard }\end{array}$ & $\mathrm{CR}$ \\
\hline $6-1 / 2$ & 6.5 & 109 & Test liall & $\begin{array}{l}\text { RAL } \\
\mathrm{TL} 77-145\end{array}$ \\
\hline - & -- & 55 & $\begin{array}{l}\text { Fibron A-100 } \\
\text { Spray-in Wall } \\
\text { Insulation }\end{array}$ & $\begin{array}{l}\text { CR SRC } \\
75-120-1 \mathrm{~A}\end{array}$ \\
\hline $3-3 / 4$ & 5.9 & 59 & Acoustifiber & $\begin{array}{l}\text { RAL } \\
\text { TL73-107 }\end{array}$ \\
\hline $5-9 / 32$ & 6.36 & 132 & $\begin{array}{l}\text { USDA WA11 } \\
\text { (B)FPL } 242\end{array}$ & $\begin{array}{l}\text { RAL } \\
\text { TL73-72 }\end{array}$ \\
\hline- & -- & 55 & Energy Guard & $\mathrm{CR}$ \\
\hline
\end{tabular}


Table 22A. Gypsum board walls (ASTM E90-70 or equivalent) continued.

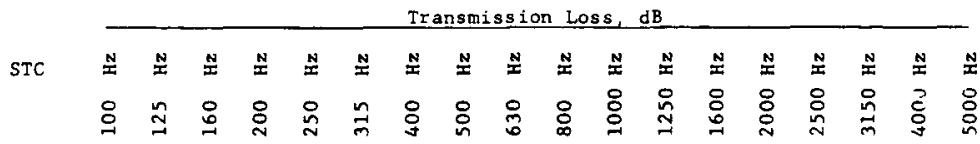

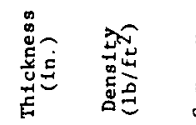

Cellulose fibers sprayed on interior of gypsum board partition, 1-5/8
inch metal studs, faced both sides with $5 / 8$ inch gypsum board

$\begin{array}{llllllllllllllll}24 & 31 & 35 & 36 & 39 & 43 & 47 & 50 & 52 & 53 & 55 & 55 & 52 & 51 & 53 & 55\end{array}$

$3 \quad 6.3 \quad 90 \quad \mathrm{~K}-13$

RAL

$5 / 8$ gypsum board, 1 pound sheet lead, 2 inch glass fiber, $5 / 8$ inch gypsum
board on $2-1 / 2$ inch steel studs; datá read from graph

$\begin{array}{lllllllllllllllllllll}24 & 29 & 38 & 40 & 43 & 45 & 48 & 52 & 53 & 54 & 55 & 55 & 52 & 50 & 52 & 60 & 3-3 / 4 & -- & 52 & \text { Acoustilead } & \mathrm{CR}\end{array}$

48 Facing of $5 / 8$ inch gypsum board with $1 / 2$ inch sound deadening board lining, core of wood studs and backing of $5 / 8$ inch gypsum board with $1 / 2$ inch
sound deadening board lining

$\begin{array}{llllllllllllllll}24 & 28 & 34 & 37 & 42 & 47 & 51 & 55 & 58 & 61 & 62 & 64 & 63 & 60 & 61 & 64\end{array}$

$\begin{array}{lllll} & & \text { Partition } & \text { RAL } \\ & 7.7 & 145 & \text { WaIl System } & \text { TL70-3 }\end{array}$

49 Cellulose fibers sprayed between layers of $5 / 8$ inch gypsum board on 3-5/8 inch metal studs

$\begin{array}{llllllllllllllll}29 & 35 & 38 & 41 & 41 & 44 & 45 & 49 & 52 & 52 & 53 & 53 & 51 & 50 & 53 & 55\end{array}$

$5 \quad 6.6 \quad 90 \quad x-13$

RAL $99-173$

$492 \times 4$ studs ls inch o.c. $2 / 2$ inch fiber board each side, outer facing was $1 / 2$ inch gypsum wall board
27
38
48
57
59
55

$\begin{array}{lllll}5-3 / 4 & 7.3 & 69 & \text { Standard } & \text { RAL } \\ \text { Stud Dry wall } & \text { TL65-233 }\end{array}$

Staggered stud, wood frame partition, $2 \times 4$ inch studs 16 inch $0 . c$. on $\begin{array}{llllllllllllllll}34 & 38 & 41 & 43 & 45 & 44 & 48 & 49 & 50 & 49 & 50 & 51 & 48 & 46 & 50 & 55\end{array}$

$5 / 8$ inch gypsum board, $3-5 / 8$ inch steel stubes with cavities filled with 2 inch fiberglass and $5 / 8$ inch gypsum board
$\begin{array}{llllllllllllllll}30 & 37 & 28 & 41 & 53 & 51 & 56 & 50 & 41 & 52 & 58 & 58 & 55 & 59 & 58 & 59\end{array}$

$2 \times 4$ studs 24 inch o.c., $1 / 2$ inch fiber board each side, $1 / 2$ inch

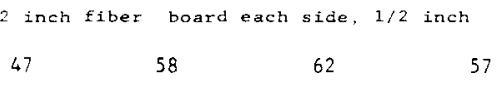

29

$40 \quad 47$

57

Facing of $5 / 8$ inch gypsum board with $1 / 2$ inch sound deadening board, core of wood studs and backing of $5 / 8$ inch gypsum board with $1 / 2$ inch ound deadening board

$\begin{array}{llllllllllllllll}27 & 30 & 34 & 39 & 42 & 47 & 52 & 56 & 59 & 59 & 60 & 60 & 61 & 61 & 60 & 60\end{array}$

50. $2 \times 4$ wood studs - 16 inch o.c. with separate stud plates on concrete lloor, gypsum board - two $5 / 8$ inch layers each side, one layer sound deadening board, $1 / 2$ inch Fircex Staggered stud, wood frame partition, $2 \times 4$ inch studs, 16 inch $0 . c$. on
$2 \times 6$ plate, two layers of $5 / 8$ inch gypsum board

$\begin{array}{llllllllllllllll}38 & 41 & 44 & 46 & 46 & 47 & 49 & 51 & 50 & 50 & 51 & 52 & 50 & 50 & 54 & 59\end{array}$ Facing of $5 / 8$ inch gypsum board with $1 / 2$ inch Homosole sound deadening,
board, core of wood studs and backing of $5 / 8$ inch gypsum board with $1 / 2$ inch sound deadening board

$\begin{array}{llllllllllllllll}28 & 32 & 39 & 43 & 46 & 56 & 55 & 57 & 59 & 62 & 63 & 65 & 64 & 61 & 62 & 63\end{array}$

Cellulose fibers sprayed into interior of gypsum board wall

$\begin{array}{llllllllllllllll}32 & 36 & 37 & 42 & 47 & 48 & 51 & 52 & 55 & 57 & 58 & 57 & 54 & 54 & 56 & 59\end{array}$

$2 \times 4$ wood studs, 16 inch $0 . c$. with separate stud plates on concrete floor, gypsum board, two layers $5 / 8$ inch each side. $1 / 2$ inch Firtex layer sound deadening board and $1-1 / 2$ inch Fibron crey spray-on insulation

S4 Cellulose fiber sprayed between wood frame wall: two layers $5 / 8$ inch Cellulose fiber sprayed between wood frame wall: two layers $5 / 8$ inch
gypsum board, staggered wood studs, single layer $5 / 8$ inch gypsum board $\begin{array}{llllllllllllllll}34 & 38 & 41 & 45 & 48 & 51 & 52 & 53 & 55 & 56 & 58 & 58 & 57 & 57 & 58 & 60\end{array}$ $5 / 8$ inch gypsum board, $3-5 / 8$ inch steel studs with the cavity filled with

$\begin{array}{llllllllllllllll}53 & 50 & 51 & 48 & 52 & 52 & 48 & 55 & 54 & 56 & 52 & 53 & 60 & 53 & 61 & 61\end{array}$

Double row wood stud, cavity insulaticn, gypsum board; Facing: 1/2 inch

gypsum board, core double row $2 \times 3$ studs, 16 inch $0 . c ., 2-1 / 2$ inch plate separation, two

$\begin{array}{llllllllllllllllll}28 & 31 & 35 & 40 & 46 & 49 & 52 & 54 & 57 & 59 & 61 & 63 & 64 & 64 & 62 & 59 & 61 & 63\end{array}$

$\begin{array}{ll}\text { Fibron A-I00 } & \\ \text { Spray-In Wall }\end{array}$

Spray-In wall CR SRC

-. $\quad 109$ Rapco-Foam WLI 22100

$\begin{array}{lllll}7-3 / 4 & 8.0 & 69 & \begin{array}{l}\text { Staggered } \\ \text { StudDry Wall }\end{array} & \text { RAL } \\ \text { TL } 65-200\end{array}$

$\begin{array}{llll}7-7 / 8 & 8.5 \quad 145 & \begin{array}{l}\text { Wall with } \\ \text { Sound Deaden- } \\ \text { ing Boards }\end{array} & \text { RAL } 70-4\end{array}$

-. $\quad$ - $\quad 55 \quad$ Energy Guard $\quad$ CR

$\begin{array}{llll} & & \text { Fibron A-100 } & \text { CR SRC } \\ \text { - } & 55 & \text { Spray-on Wall } & 75-120-1 C\end{array}$

$\begin{array}{lllll}5-7 / 8 & 7.8 & 145 & \begin{array}{l}\text { Partition } \\ \text { Wall System }\end{array} & \text { RAL } 70-2\end{array}$

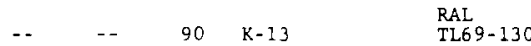

-- $\quad$-- $\quad 55 \quad \begin{aligned} & \text { Fibron Grey } \\ & \text { Spray-on }\end{aligned}$

$\begin{array}{lllll}8 & 12.2 & 90 & K-13 & \text { RAL }\end{array}$

-- -- 109 Rapco-Foam WLI 22100

$\begin{array}{lllll}8.5 & 6.4 & 132 & \begin{array}{l}\text { USDA Wal1 } \\ \text { (A)FPL 309 }\end{array} & \text { RAL } \\ \text { TL75-84 }\end{array}$ 
Table 22A. Gypsum board walls (ASTM E90-70 or equivalent) concluded.

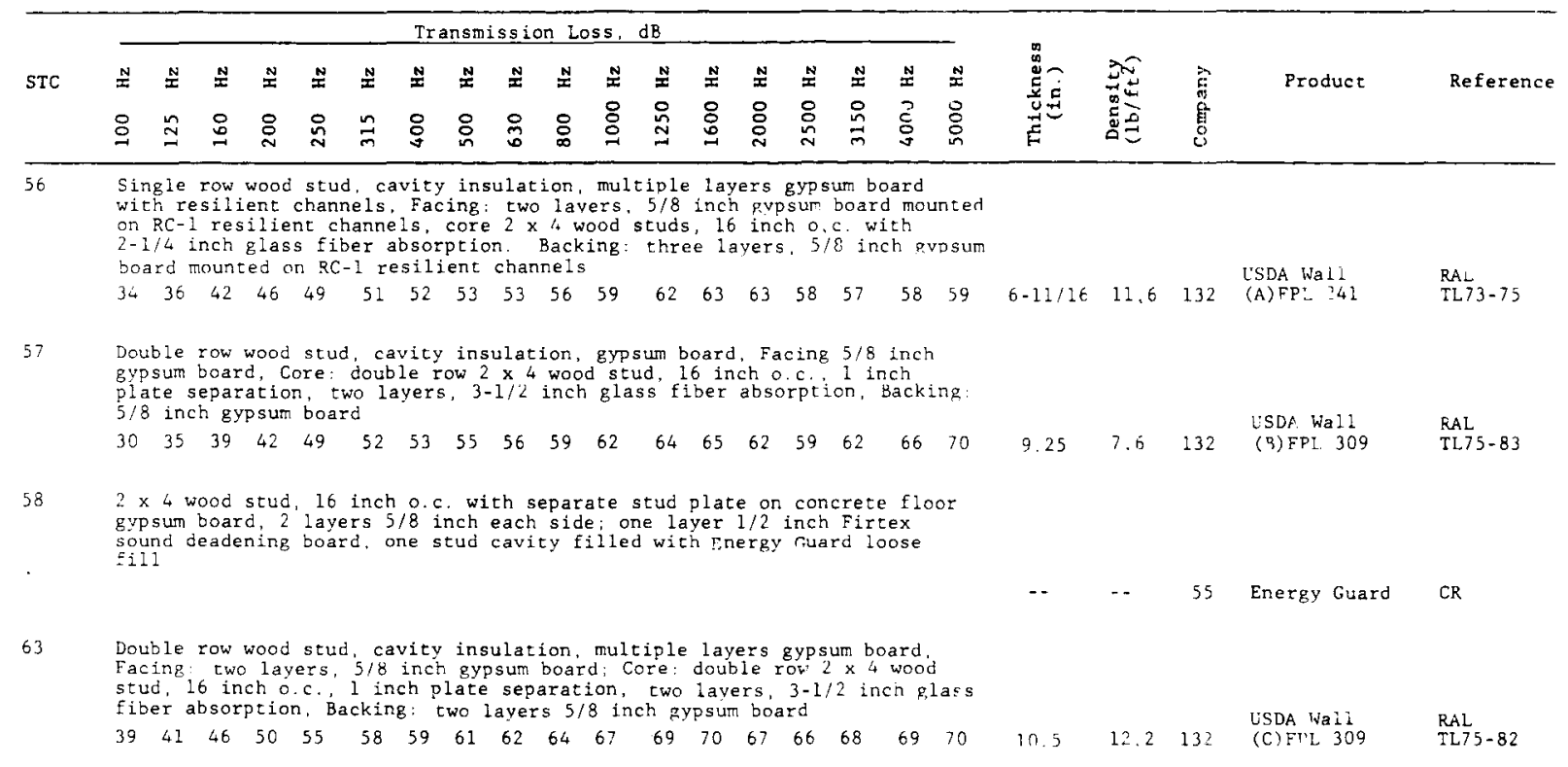


Table 22B. Gypsum board walls (AMA-1-11).

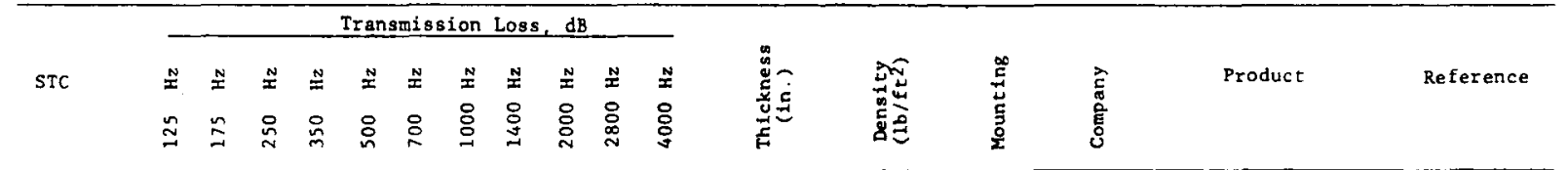

35 Facing of $1 / 2$ inch gypsum board, core of $2 \times 4$ inch wood studs 16 inch on center, and backing of $1 / 2$ inch

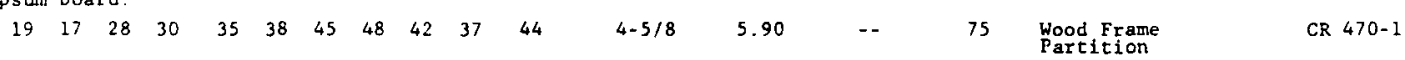

36 Facing of $5 / 8$ inch Nul1-A-Fire gypsum board, core of $2 \times 4$ inch wood studs 16 inch on center and backing

$\begin{array}{lllllllllllllllll}30 & 22 & 31 & 30 & 37 & 39 & 44 & 43 & 39 & 45 & 52 & 4-7 / 8 & 7.10 & -- & 75 & \begin{array}{l}\text { Wood Frame } \\ \text { Partition }\end{array}\end{array}$

37 Facing of $5 / 8$ inch Null-a-Fire gypsum board, core of KWS-158 speed studs 24 inch on center and backing of same as facing.

$\begin{array}{llllllllllllllllll}17 & 20 & 30 & 35 & 43 & 46 & 49 & 47 & 37 & 37 & 46 & 2-7 / 8 & 5.6 & \ldots & 75 & \begin{array}{l}\text { Metal Frame } \\ \text { Partition }\end{array} & \text { CR } 476\end{array}$ Facing of $5 / 8$ inch Nu11-A-Fire gypsum board, core of
KIVS-250 speed studs 24 inch on center and backing of same as facing.

$\begin{array}{lllllllllllllllll}23 & 27 & 33 & 35 & 42 & 45 & 50 & 49 & 39 & 36 & 41 & 3-1 / 4 & 5.2 & \ldots & 75 & \begin{array}{c}\text { Metal Frame } \\ \text { Partition }\end{array}\end{array}$

$40 \quad$ Facing of $5 / 8$ inch Null-A-Fire gypsum board, core of
KWS-358 speed studs 24 inch on center and backing of same as facing.

$\begin{array}{lllllllllllllllll}20 & 29 & 35 & 38 & 44 & 48 & 51 & 50 & 30 & 39 & 44 & 4-7 / 8 & 5.4 & \ldots & 75 & \text { Metal Frame }\end{array}$

CR 476

41 Facing of $5 / 8$ inch Nu11-A-Fire gypsum board, core of

blanket in space and backing of same as facing.

$27 \quad 34 \quad 39 \quad 42 \quad 45 \quad 48 \quad 51 \quad 51 \quad 34 \quad 38 \quad 43 \quad 4-7 / 8 \quad 5.445$ Metal Frame

CR 476

42 Facing of $5 / 8$ inch Null-A-Fire gypsum board, core of

KWS- 250 speed studs 24 inch on center with insulation

blanket in space and backing of same as facing.

$\begin{array}{lllllllllllllll}25 & 32 & 38 & 43 & 48 & 50 & 51 & 51 & 43 & 39 & 44 & 3-1 / 4 & 5 & & \end{array}$

43 Facing of two layers $3 / 8$ inch and $1 / 2$ inch gypsum board core of KWS- 158 speed studs 24 inch on cencer and backing of same as facing.

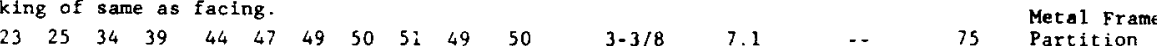

44 Facing of two layers $3 / 8$ and $5 / 8$ inch gypsum board, core of KWS- 158 speed studs 24 inch on center and backing of same as facing.

$\begin{array}{llllllllllll}24 & 26 & 39 & 42 & 49 & 49 & 52 & 52 & 35 & 52 & 57 & 3-5 / 8\end{array}$

$-5 / 8$

8.4

$-$

Metal Frame

CR 476

44 Facing of $1 / 2$ inch gypsum board, core of $2 \times 3$ inch wood

studs staggered at 8 inch on center and backing of $1 / 2$ inch gypsum board.

$\begin{array}{llllllllllllllllll}36 & 31 & 36 & 40 & 40 & 46 & 47 & 50 & 52 & 41 & 45 & 6-5 / 8 & 6.2 & -- & 75 & \text { Wood Frathe }\end{array}$

NBS 242

$44 \quad$ Facing of two layers $5 / 8$ inch gypsum board, core of same as facing.

$\begin{array}{llllllllllllllll}23 & 29 & 38 & 38 & 40 & 44 & 48 & 51 & 51 & 46 & 53 & 6-1 / 8 & 10.93 & \ldots & 75 & \text { Wood Frame }\end{array}$

44 Facing of 5/8 inch gypsum board, core of $2 \times 3$ inch

wood studs staggered at 8 inch on center and backing

of $5 / 8$ inch gypsum board.

$\begin{array}{llllllllllllllll}43 & 44 & 37 & 38 & 40 & 46 & 48 & 47^{\circ} & 41 & 44 & 50 & 6-7 / 8 & 7.7 & \ldots & 75 & \begin{array}{l}\text { Wood Frame } \\ \text { Partition }\end{array}\end{array}$

NBS 243

45 Facing of two layers $1 / 2$ inch gypsum board, core of

same

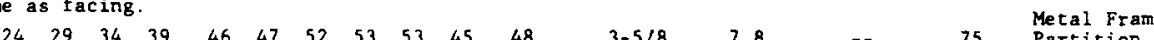

Partition

CR 476

45 Facing of two layers $1 / 2$ inch Null-A-Fire gypsum board, core of KWS- 250 speed studs 24 inch on center, and backing of same as facing.

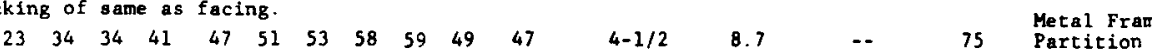

CR 476 Facing of two layers $1 / 2$ inch gypsum board, core of
$2 \times 4$ inch wood studs 16 inch on center and backing of same as facing. 41464905153780 Wood Frame 
Table 22B. Gypsum board walls (AMA-1-11) continued.

Transmission Loss, $\mathrm{dB}$

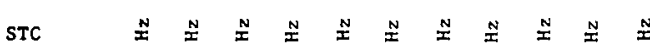

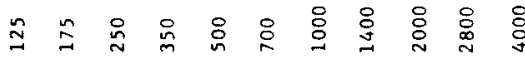

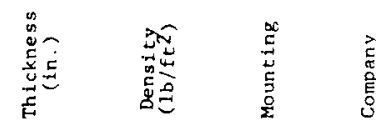

Reference

45 Facing of two layers $3 / 8$ and $1 / 2$ inch gypsum board, core of $2 \times 4$ inch wood studs 16 inch on center. and backing of same as facing.
$\begin{array}{lllllll}25 & 33 & 39 & 39 & 41 & 47 & 49\end{array}$
$5-3 / 8$
8. 10
75 Wood Frame
$\mathrm{CR} 470$

45 Facing of two layers $1 / 2$ and $5 / 8$ inch gypsum board, core of $2 \times 4$ inch wood studs 16 inch on center.

and backing of same as facing.

$\begin{array}{lllllllllllllllll}22 & 31 & 39 & 41 & 42 & 47 & 49 & 52 & 53 & 50 & 55 & 5-7 / 8 & 9.88 & \ldots & 75 & \begin{array}{l}\text { Wood Frame } \\ \text { Partition }\end{array}\end{array}$

46 Facing of two layers $1 / 2$ and $5 / 8$ inch gyp sum board, core of KWS- 158 speed studs 24 inch on center and

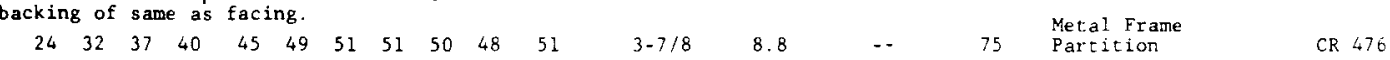

46 Facing of two layers $5 / 8$ inch gypsum board, core of KWS-158 speed studs 24 inch on center and backing

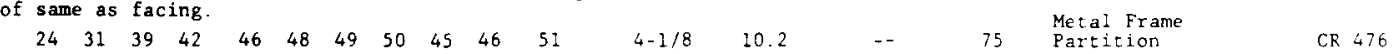

46 Facing of two layers $3 / 8$ and $1 / 2$ inch gypsum board, core of kwS -250 speed studs 24 inch on center and

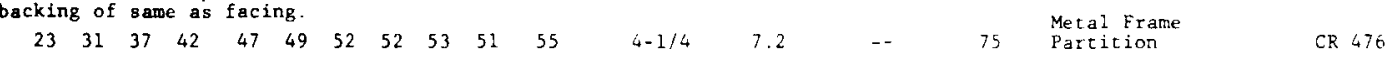

46 Facing of two layers $3 / 8$ and $5 / 8$ inch gypsum board, core of KWS -250 speed studs 24 inch on center and backing of same as facing.

$\begin{array}{lllllllllllllll}24 & 31 & 37 & 41 & 45 & 49 & 50 & 53 & 52 & 53 & 53 & 4-1 / 2 & 8 & 5 & \ldots\end{array}$

CR 476

46 Facing of two layers $3 / 8$ and $1 / 2$ inch 8 ypsum board, core of $2 \times 4$ inch wood studs 16 inch on center with insulacing.

blanket in space and backing of same as

$\begin{array}{llllllllllllllll}26 & 36 & 38 & 40 & 44 & 48 & 51 & 53 & 53 & 55 & 52 & 5-3 / 8 & 8.26 & \ldots & 75 & \text { Wocd Frame }\end{array}$

CR 470

46 Facing of $1 / 2$ inch gypsum board, $1 / 2$ inch Fir Tex sound deadening board, 6 inch strip of laminat ing $2 x 4$ inch wod studs 24 inch on center and backin of same as facing.

$\begin{array}{lllllllllll}31 & 34 & 36 & 40 & 46 & 48 & 51 & 53 & 55 & 55 & 53\end{array}$ $5-218$

GSH $1 B 1$.

46 Facing of 1/2 inch gypsum board, 1/2 inch Fir-Tex rated sound deadening board.. 6 inch strip of

laminating compound 24 inch on center between layers, core of $2 \times 4$ inch wood studs 16 inch on center and backing of same as facing.

$\begin{array}{lllllllllll}23 & 31 & 37 & 43 & 49 & 54 & 55 & 55 & 55 & 56 & 55\end{array}$

46 Facing of two layers $1 / 2$ inch gypsum board. core

insularion blanket in space and backing of same

insulation

$\begin{array}{llllllllll}24 & 31 & 38 & 42 & 43 & 46 & 49 & 51 & 52 & 48\end{array}$

$5-5 / 8 \quad 8.82 \quad \ldots \quad 75$ Wood Frame

46 Facing of two layers $1 / 2$ and $5 / 8$ inch gypsum board, core of $2 \times 4$ inch wood studs 16 inch on center
with insulation blanket in space and backing of

$\begin{array}{llllllllllllllll}23 & 32 & 39 & 42 & 43 & 46 & 49 & 52 & 54 & 52 & 56 & 5-7 / 8 & 10 & \ldots & 75 & \begin{array}{l}\text { Wood Frame } \\ \text { Partition }\end{array}\end{array}$

Partition

CR 470

47 Facing of two layers $1 / 2$ inch gypsum board, core of WS -250 speed studs 24 inch on center and backing

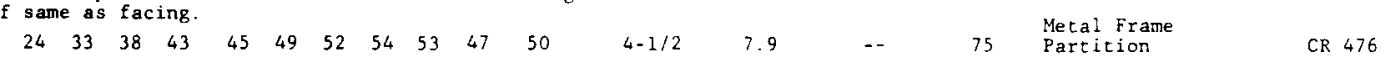

47 Facing of two layers $5 / 8$ and $3 / 8$ inch gypsum board, core of $2 \times$ with insulation blanket in space and backing of ame as facing.

$\begin{array}{llllllllllllllll}24 & 35 & 39 & 41 & 44 & 48 & 50 & 51 & 48 & 49 & 45 & 5-1 / 2 & 9.28 & \ldots & 75 & \begin{array}{l}\text { Woof Frame } \\ \text { Partition }\end{array}\end{array}$

CR 470 
Table 22B. Gypsum board walls (AMA-1-11) continued.

\begin{tabular}{|c|c|c|c|c|c|c|c|c|c|c|c|c|c|c|c|c|c|}
\hline \multirow{3}{*}{ STC } & \multicolumn{11}{|c|}{ Transmission Loss, $d B$} & \multirow{3}{*}{ 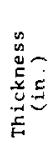 } & \multirow{3}{*}{ 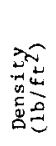 } & \multirow{3}{*}{ 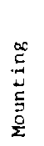 } & \multirow{3}{*}{$\begin{array}{l}\widehat{\widehat{c}} \\
\frac{\pi}{\pi} \\
\stackrel{0}{0} \\
8\end{array}$} & \multirow{3}{*}{ Product } & \multirow{3}{*}{ Reference } \\
\hline & N & $\stackrel{\Xi}{ \pm}$ & $\underline{x}$ & $\stackrel{N}{I}$ & $\stackrel{N}{\geq}$ & $\underline{x}$ & $\stackrel{N}{x}$ & $\stackrel{N}{I}$ & $\stackrel{N}{I}$ & $\stackrel{N}{x}$ & $\stackrel{N}{x}$ & & & & & & \\
\hline & $\cong$ & $\cong$ & $\stackrel{8}{\stackrel{0}{N}}$ & 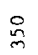 & 吕 & $\stackrel{8}{\circ}$ & $\stackrel{8}{\square}$ & $\begin{array}{l}8 \\
\stackrel{9}{9}\end{array}$ & $\stackrel{8}{8}$ & $\begin{array}{l}8 \\
\stackrel{8}{8} \\
\text { 品 }\end{array}$ & $\stackrel{8}{8}$ & & & & & & \\
\hline
\end{tabular}

47 Facing of $1 / 2$ inch gypsum board, $1 / 2$ inch Fir-Tex

sound deadening board, core of $2 \times 3$ inch wood

studs staggered at

$\begin{array}{lllllllllllllllll}34 & 35 & 37 & 41 & 44 & 48 & 50 & 52 & 54 & 53 & 52 & 5-5 / 8 & 7.72 & - & 75 & \begin{array}{l}\text { Wood Frame } \\ \text { Partition }\end{array}\end{array}$

48 Facing of two layers $3 / 8$ and $1 / 2$ inch gypsurn board,

core of KWS- 158 speed studs 24 inch on center with

insulation blanket in space and backing of same a

facing.

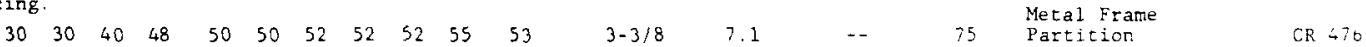

48 Facing of two layers $1 / 2$ and $5 / 8$ inch gypsum board,

core of KWS- 250 speed studs 24 inch on center and

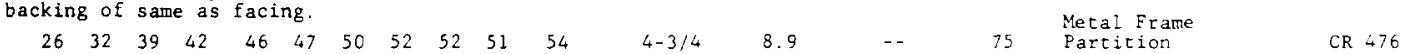

48 Facing of two layers $5 / 8$ inch gypsum board, core of

KWS-250 speed studs 24 inch on center and backing of

same as facing.

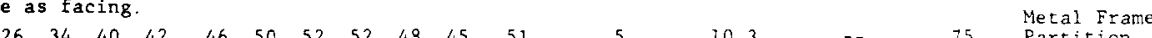

CR 476

48 Facing of two layers $3 / 8$ and $1 / 2$ inch gyp sum board,

backing of same as facing.

$\begin{array}{lllllllllllllllll}29 & 35 & 42 & 42 & 46 & 48 & 52 & 58 & 55 & 53 & 55 & 5-3 / 8 & 7.3 & \ldots & 75 & \begin{array}{l}\text { Metal Frame } \\ \text { Partition. }\end{array} \text { CR 476 }\end{array}$

48 Facing of two layers $5 / 8$ and $3 / 8$ inch gypsum board,

inch wood studs 16 inch on center and backing of same as facing.

$25 \quad 3340 \quad 42 \quad 45 \quad 48 \quad 52 \quad 55 \quad 54 \quad 54 \quad 56 \quad 5-1 / 2 \quad 9,15 \quad--\quad$ wood Frame

48 Facing of two layers $5 / 8$ inch gypsum board, core of same as facing.

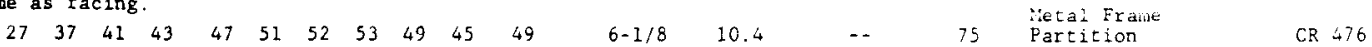

49 Facing of two layers $1 / 2$ and $5 / 8$ inch gypsum board,

core of kWS-158 speed studs 24 inch on center with

insulation blanket in space and backing of same

as facing

$\begin{array}{lllllllllllllllllll}28 & 39 & 44 & 47 & 49 & 48 & 48 & 50 & 50 & 49 & 49 & 3-7 / 8 & 8.8 & \text { Metal Frame } & 75 & \text { Partition }\end{array}$

49 Facing of two layers $5 / 8$ inch gypsum board, core of

blanket in space and backing of same as facing.

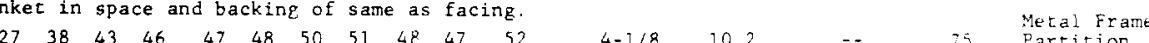

49 Facing of two layers $3 / 8$ and $5 / 8$ inch gypsum board,

backing of same as facing.

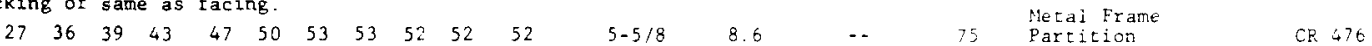

49 Facing of $5 / 8$ inch gypsum board, $1 / 2$ inch Fir-Tex sound deadening board, 6 inch strip of laminating

compound 24 inch on center between layers, core of

$2 \times 4$ inch wood studs 24 inch on center and backing

of same as facing.

$\begin{array}{lllllllllll}36 & 38 & 42 & 43 & 49 & 52 & 53 & 54 & 54 & 55 & 57\end{array}$

$5-7 / 8 \quad 7.58 \quad-5 \quad$ Wood Frame

Girh $1 B 1-$
$10 F T-(2)$

49 Facing of two layers $1 / 2$ and $5 / 8$ inch gypsum board.

backing of same as facing.

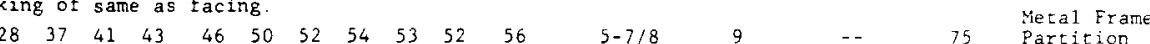

CR 476

50 Facing of two layers $1 / 2$ inch Null-A-Fire gypsum board. core of KWS-250 speed studs 24 inch on center with insulation bianket in space and backing of

same as facing.

$\begin{array}{lllllllllllllllll}27 & 36 & 42 & 47 & 48 & 50 & 53 & 55 & 54 & 50 & 51 & 4-1 / 2 & 8.7 & -- & 75 & \begin{array}{l}\text { Metal Frame } \\ \text { Partition }\end{array}\end{array}$

50 Facing of two layers $5 / 8$ inch gypsum board, core of blanket in space and backing of same as facing.

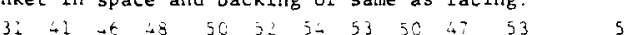

103 Metal Frame

$C_{R} 476$ 
Table 22B. Gypsum board walls (AMA-1-11) continued.

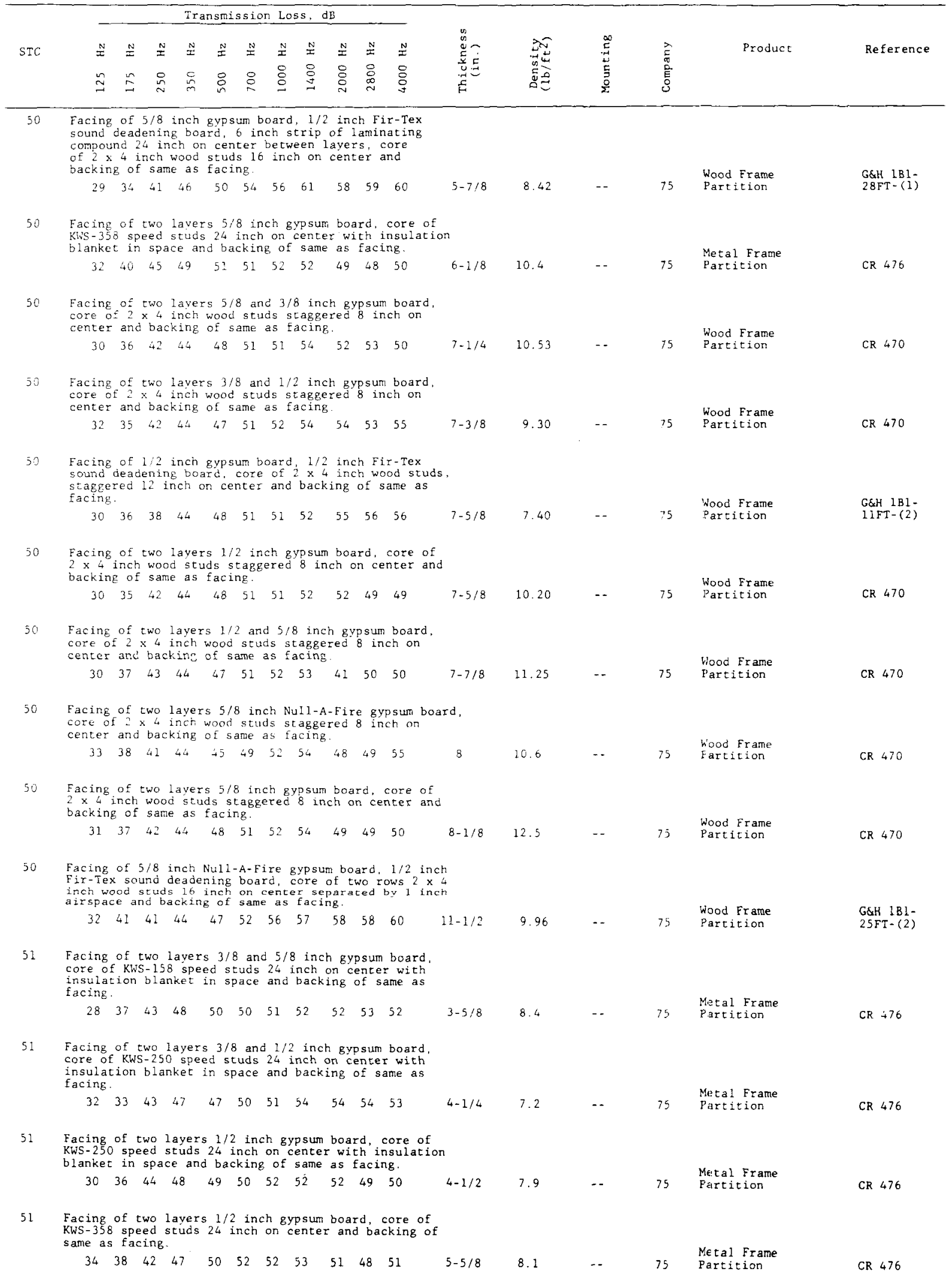


Table 22B. Gypsum board walls (AMA-1-11) continued.

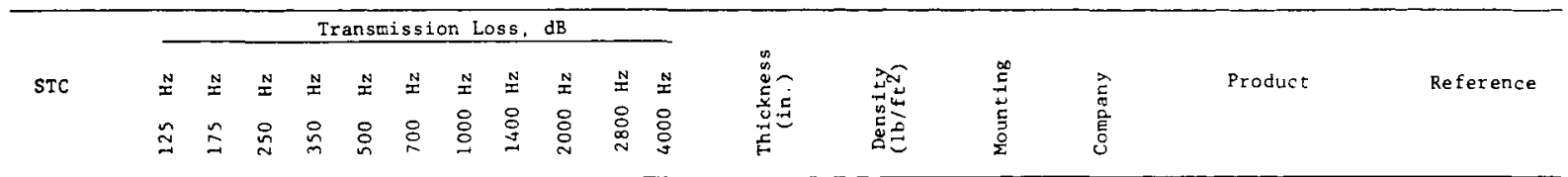

51 Facing of two layers $1 / 2$ and $5 / 8$ inch gypsum board,

core of KWS -358 speed studs 24 inch on center with

insulation blanket in space and backing of same a

$\begin{array}{llllllllllllllllll}28 & 38 & 43 & 45 & 48 & 48 & 51 & 53 & 53 & 51 & 53 & 5-7 / 8 & 9 & -- & 75 & \begin{array}{l}\text { Metal Frame } \\ \text { Partition }\end{array}\end{array}$

51 Facing of two layers $1 / 2$ inch gypsum board, core

of $2 \times 4$ inch wood studs staggered 8 inch on center

with insulation blanket in space and backing of

ame as facing.

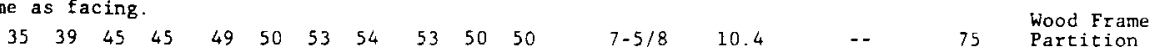

$\mathrm{CR} 470$

51 Facing of $5 / 8$ inch gypsum board, $1 / 2$ inch Fir-Tex

sound deadening board, 6 inch strip laminating

compound 24 inch on center beckeen layers, core

of $2 \times 4$ inch wood stud staggered 8 inch on cente

acking of same as facing.

$\begin{array}{lllllllllll}38 & 39 & 43 & 45 & 48 & 55 & 58 & 57 & 58 & 58 & 59\end{array}$

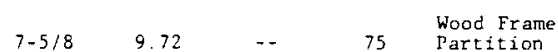

G\&H $1 \mathrm{~B} 1-$

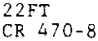

51 Facing of two layers $1 / 2$ and $5 / 8$ inch gypsum board,

core of $2 \times 4$ inch wood studs staggered 8 inch on

center with insulation blanket in space and backing

same as facing.

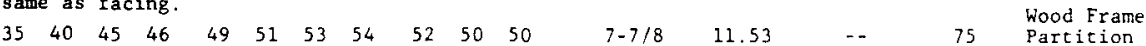

CR 470

51 Facing of two layers $5 / 8$ inch Null-A-Fire gypsum board,

core of $2 \times 4$ inch wood

center with insulation blanket in space and backing

same as facing.

$\begin{array}{lllllllllll}38 & 44 & 44 & 47 & 46 & 49 & 52 & 54 & 49 & 50 & 54\end{array}$

$10.7 \quad$-. $\quad 75$ Wood Frame

CR 470

52 Facing of two layers $1 / 2$ and $5 / 8$ inch gypsum board,

core of his-250 speed studs 24 inch on center with

insulation blanket in space and backing of same as

facing.

Partition

CR 476

52 Facing of two layers $3 / 8$ and $1 / 2$ inch gypsum board.

king of same as

acing.

$\begin{array}{lllllllllll}32 & 37 & 42 & 46 & 51 & 51 & 54 & 53 & 53 & 52 & 51\end{array}$

$5-3 / 8$

Metal Frame

$\mathrm{CR} 476$

52 Facing of two layers $5 / 8$ and $3 / 8$ inch gypsum board,

core of $2 \times 4$ inch wood studs staggered 8 inch on

center with insulation blanket in sp

same as facing.

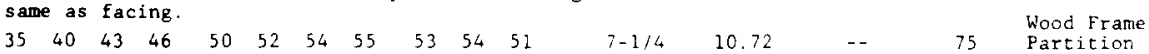

$\operatorname{CR} 470$

53 Facing of two layers $3 / 8$ and $5 / 8$ inch gypsum board,

core of KWS- 250 speed wood studs staggered 8 inch on cente

insulation blanket in space and backing of same as

facing.

$\begin{array}{lllllllllll}34 & 37 & 44 & 48 & 49 & 50 & 52 & 53 & 54 & 54 & 55\end{array}$

8.5 $\quad-2 \quad 75 \quad \begin{aligned} & \text { Metal Frame } \\ & \text { Partition }\end{aligned}$

CR 470

53 Facing of $5 / 8$ inch Null-A-Fire gypsum board, $1 / 2$ inch

Fir-Tex sound deadening board, core of two rows $2 \times 3$

inch wood studs separated by $i$ inch air space and

backing of same as $f$ acing.

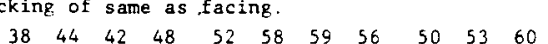

$8-1 / 2$

9.4

Wood Frame

$8 \mathrm{FT}-(1)$
$\mathrm{CR} 470-9$

54 Facing of two layers $3 / 8$ and $5 / 8$ inch gypsum board,

core of KWS- 358 speed stud

facing.

$\begin{array}{lllllllllll}35 & 38 & 47 & 49 & 52 & 51 & 53 & 55 & 58 & 55 & 57\end{array}$

54 Facing of two layers $3 / 8$ and $1 / 2$ inch gypsum board,

core of $2 \times 4$ inch wood studs staggered 8 inch on

of same as facing.

$\begin{array}{lllllllllll}31 & 41 & 46 & 48 & 49 & 51 & 53 & 55 & 56 & 55 & 56\end{array}$

$7-318$

$9.42 \quad--\quad 75 \quad \begin{aligned} & \text { Wood Frame } \\ & \text { Partition }\end{aligned}$

CR 470

54 Facing of two layers $1 / 2$ inch gypsum board, core of

two rows $2 \times 4$ inch wood studs 16 inch on center with

and backing of same as facing.

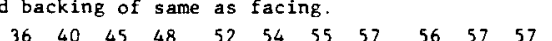

1

$13.6 \quad--\quad 75 \quad \begin{aligned} & \text { Wood Frame } \\ & \text { Partition }\end{aligned}$

CR 470 
Table 22B. Gypsum board walls (AMA-1-11) concluded.

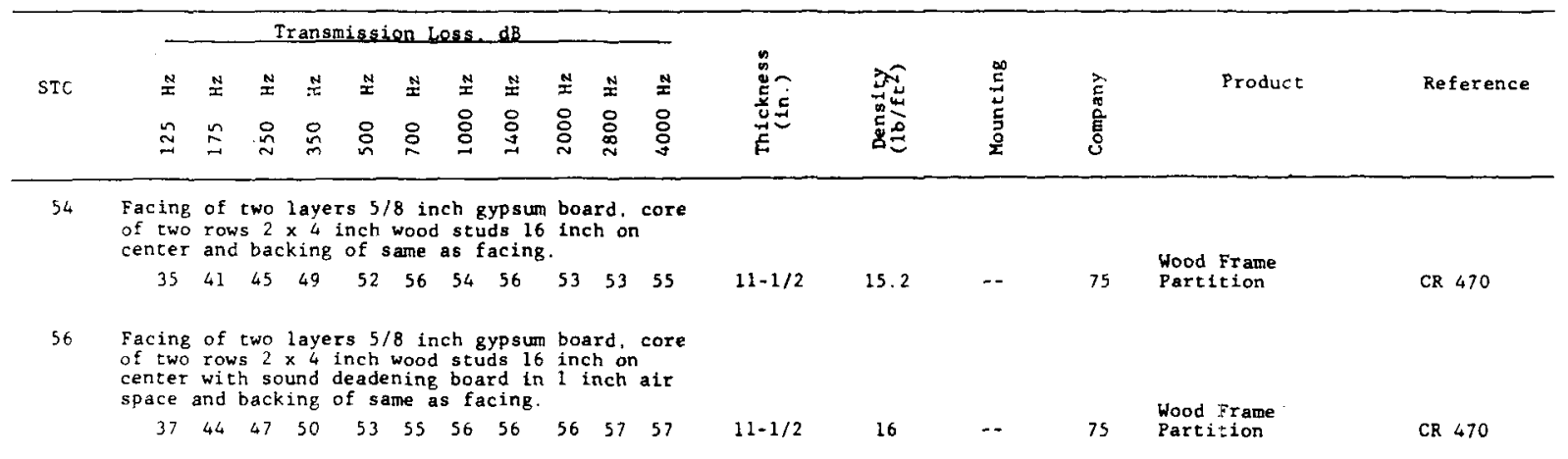


Table 22C. Plaster, concrete, steel, and other walls.

Transmission Loss, $\mathrm{dB}$

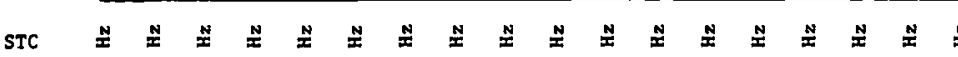

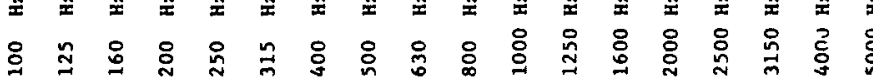

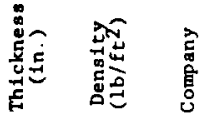

Product

Reference

40 Ext. Wall: outdoor side, $7 / 8$ inch portland cement plastef on 17 gauge

wire lath, rockwool insulation with vapor barrier, $1 / 2$ inch veneer base and veneer finish $1 / 16$ inch

$\begin{array}{llllllllllllllllll}29 & 28 & 28 & 32 & 38 & 35 & 35 & 38 & 39 & 39 & 39 & 41 & 41 & 41 & 43 & 45 & 47 & 48\end{array}$

$5-1 / 4 \quad 13.7 \quad 144$

RAL
TL $77-41$

41 Typical block configuration two or three core concrete, temperature range

-20 to $1500^{\circ} \mathrm{F}$. Data read from graph

$\begin{array}{lllllllllllllllllllll}25 & 26 & 27 & 31 & 33 & 35 & 37 & 39 & 42 & 45 & 45 & 46 & 47 & 47 & 47 & 47 & 4 & 4 & 20 & 91 & \text { Concrete }\end{array}$

41 Ext. wal1, outdoor side $7 / 8$ inch, portland cement plaster on 17 gauge

wire lath, paper base, rockwool insulation, $3 / 8$ inch gypsum lath,

$\begin{array}{lllllllllllllll}30 & 29 & 26 & 29 & 38 & 38 & 38 & 39 & 40 & 40 & 40 & 41 & 41 & 43 & 44\end{array}$

$5-1 / 2 \quad 17.7 \quad 144$

RAL
TL $7-43$

Standard stee 1 office partition with $1 \times 2$ inch furring. 1 inch glass
fiber, 1 pound sheet lead, $1 / 4$ inch plywood; data read from graph

$\begin{array}{llllllllllllllll}17 & 22 & 26 & 32 & 36 & 42 & 45 & 46 & 48 & 51 & 52 & 57 & 60 & 62 & 65 & 66\end{array}$

$1-1 / 8$

52

Acoustilead

$\operatorname{CK}_{1-43 \mathrm{M}} \operatorname{Li10}$

4322 gauge steel facings, glass fiber core, 1 pound sheet lead; data read from graph

$\begin{array}{llllllllllllllll}18 & 23 & 28 & 34 & 40 & 40 & 44 & 45 & 47 & 49 & 52 & 53 & 55 & 56 & 57 & 58\end{array}$

2-1/4 -. 52 Acoustilead

CR L $71 \mathrm{iO}$

43 Ext. wall: outdoor side: $7 / 8$ inch portland cement plaster on $1 / 2$ inch

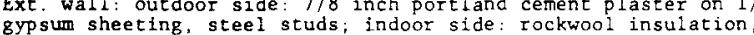

$1 / 2$ inch veneer base and veneer finish

$\begin{array}{lllllllllllllllllllllllll}25 & 30 & 40 & 41 & 39 & 40 & 40 & 41 & 42 & 41 & 41 & 42 & 43 & 43 & 45 & 46 & 48 & 49 & 3 & 14.4 & 144 & \text { RAL } & & & \end{array}$

43 Ext. wall: outdoor side $7 / 8$ inch portland cement plaster on 17 inch wire

lath, on 1 inch polystyrene sheeting 24 studs $(16$ inch 0.0 .) ; indoor

single 2 × 4 sole plate and a double cap plate, fire stop

$\begin{array}{lllllllllllllllll}25 & 27 & 23 & 26 & 37 & 35 & 41 & 45 & 50 & 49 & 43 & 45 & 43 & 49 & 54 & 58 & 60\end{array}$

$6-1 / 4 \quad 17.7 \quad 144$

RAL
TL78 -93

44 Partition steel stud metal lath and plaster with urea-formaldehyde foam fil

$\begin{array}{llllllllllllllll}26 & 24 & 27 & 35 & 40 & 42 & 46 & 50 & 52 & 52 & 51 & 58 & 45 & 46 & 47 & 48\end{array}$

$3 \quad 18 \quad 109$

KAL

44 Exterior wall: outdoor side: $7 / 8$ inch portland cement plaster on wire

lath, 17 gauge, $1 / 2$ inch gypsum sheathing, 2 x 4 wood studs; indoor

side: rockwool insulation, $1 / 2$ inch veneer base and finish, $2 \times 4$ inch

single sole plate, double cap plate

$\begin{array}{llllllllllllllllll}23 & 24 & 23 & 30 & 38 & 37 & 43 & 46 & 49 & 51 & 50 & 50 & 44 & 44 & 49 & 56 & 60 & 6\end{array}$

$5-3 / 4 \quad 12.9 \quad 144$

RAL
TL $78-91$

45

4 inch cinder block, with $1 \times 2$ inch furring, 1 inch glass fiber

1 pound sheet lead, $1 / 4$ inch plywood, data read from graph

$\begin{array}{llllllllllllllll}33 & 28 & 29 & 32 & 35 & 39 & 42 & 46 & 50 & 52 & 55 & 58 & 59 & 60 & 60 & 60\end{array}$

22 gauge steel facings, glass fiber core, 2 pound sheet lead; data read from graph

$\begin{array}{lllllllllllllll}25 & 27 & 30 & 37 & 41 & 42 & 45 & 47 & 48 & 51 & 53 & 54 & 56 & 57 & 58\end{array}$

$$
\text { (1) }
$$$$
1 \quad \text {-. } 52 \text { Acoustilead } \quad C R \quad 27710-
$$$$
\begin{array}{llll}
2-1 / 4 \quad \cdots \quad 52 \text { Acoustilead } & \text { CR L77lí } \\
1-43 M
\end{array}
$$

Standard steel office partition with $1 \times 2$ inch furring, 1 inch glass

ber, 1 pound sheet lead, $1 / 2$ inch gypsum board; data read from graph

$\begin{array}{llllllllllllllll}23 & 29 & 32 & 39 & 43 & 45 & 47 & 49 & 51 & 53 & 54 & 56 & 58 & 60 & 62 & 64\end{array}$

$1 / 4$ inch plywood, 1 pound sheet lead, $1-1 / 2$ inch glass fiber, 1 pound

sheet lead, $1 / 4$ inch plywood; data read from graph

$\begin{array}{lllllllllllllllllll}21 & 24 & 25 & 30 & 36 & 40 & 47 & 48 & 50 & 52 & 52 & 53 & 54 & 56 & 58 & 58 & 60 & 57\end{array}$

Ext wall: outdoor side $-7 / 8$ inch portland cement plaster on 17 gauge
wire lath, paper base, $2 \times 4$ wood studs: indoor side of rockwool insula-

$t$ ion, vapor barrier, resilient clips, $3 / 8$ inch thick gypsum lath, $1 / 2$

inch thick sanded gypsum plaster and putty finish

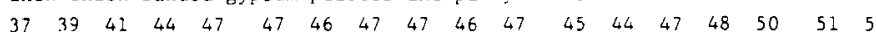

47 Exterior wall : outdoor side $-7 / 8$ inch portland cement plaster on 17

gauge wire lath paper backed, $25 / 32$ inch insulated sheeting.

gauge wire lath, paper backed, $25 / 32$ inch insulated sheeting,

fire strip, $3 / 8$ inch gypsum lath, $1 / 2$ inch sanded and plaster finish

$\begin{array}{llllllllllllllllll}25 & 31 & 26 & 33 & 43 & 45 & 46 & 49 & 52 & 51 & 49 & 51 & 51 & 52 & 56 & 62 & 64 & 66\end{array}$

\begin{tabular}{|c|c|c|c|c|}
\hline $1-1 / 4$ & -- & 52 & Acoustilead & $\begin{array}{l}C R \quad L>710- \\
l=43 \mathrm{M}\end{array}$ \\
\hline 2 & - & 52 & Acoustilead & $\begin{array}{l}\text { CR } L 7710- \\
1-43 M\end{array}$ \\
\hline 6 & 21.1 & 144 & & $\begin{array}{l}\text { RAL } \\
\text { TL } 77-40\end{array}$ \\
\hline
\end{tabular}

RAL
TL $77-40$

RAL
TL $78-90$ 
Table 22C. Plaster, concrete, steel, and other walls concluded.

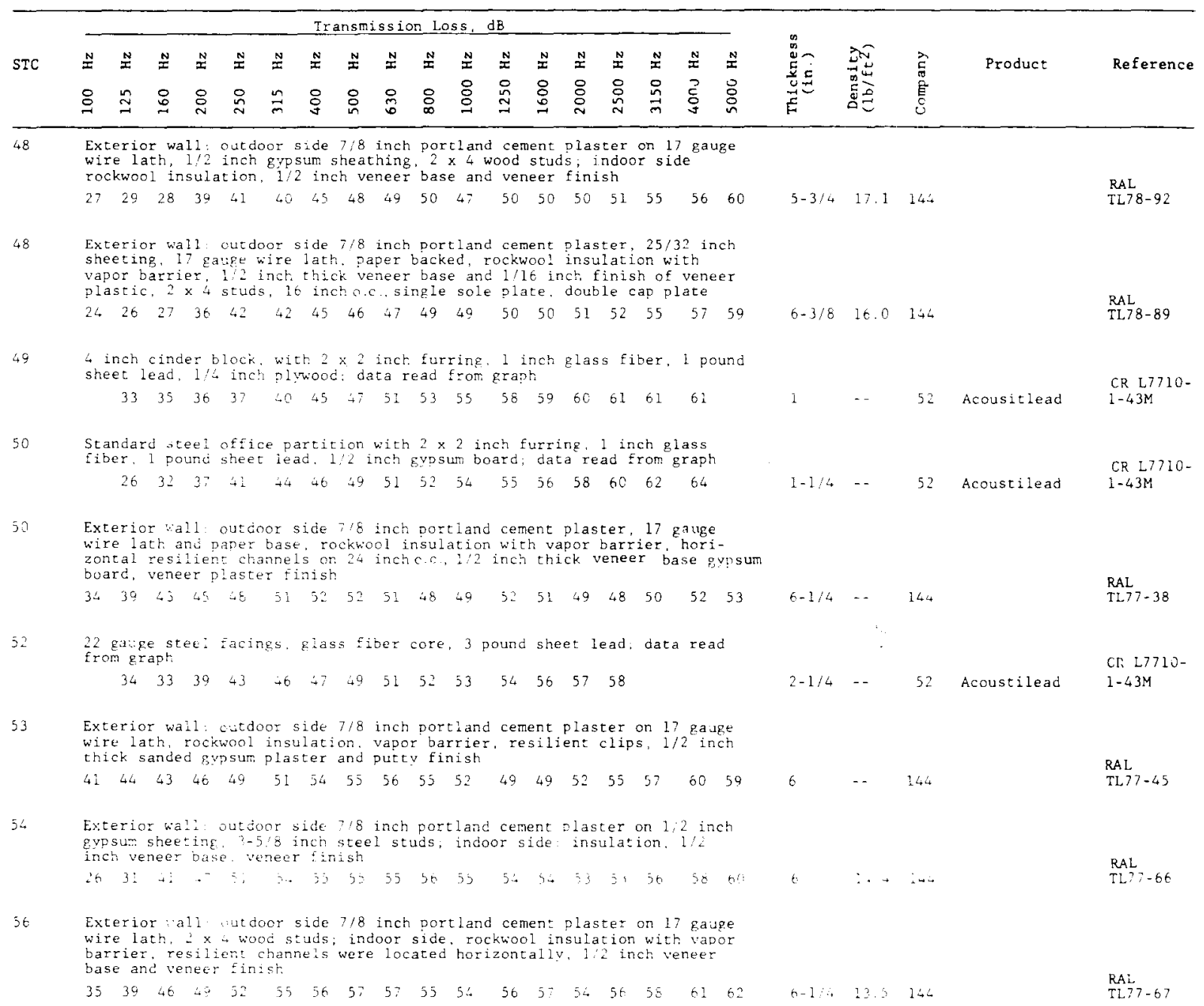




\section{CATEGORY 23. WINDOWS}

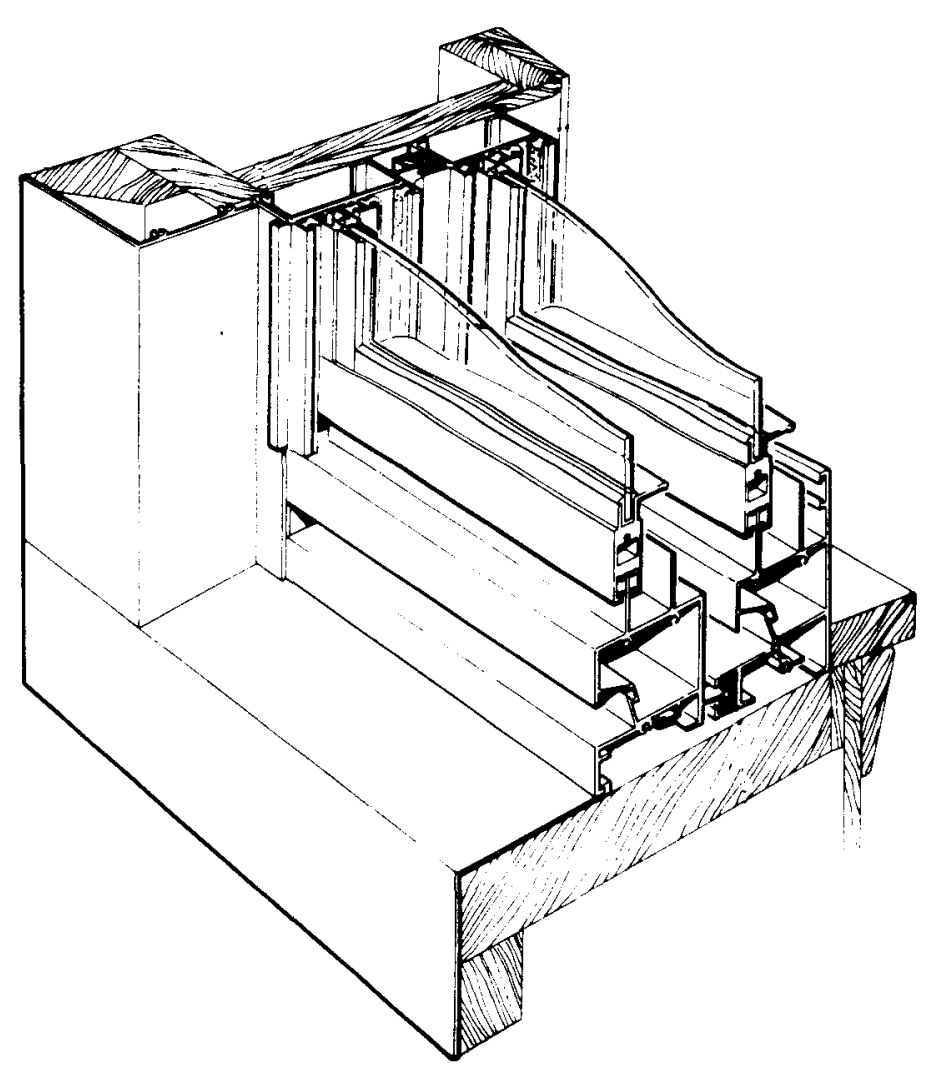




\title{
CATEGORY 23. WINDOWS
}

\begin{abstract}
Sound transmission losses of window assemblies are listed. Various types of windows, e.g., pivoted, dual glazed, laminated glass, venetian blind, and plastic windows, etc, are presented. Simple windows are usually the "weak links" in the sound isolation of rooms and buildings, but it is possible to select windows with high sound transmission losses to make the interiors of the buildings reasonably quiet. In the buildings at airports the selection of windows will determine to a large extent the interior noise levels. In such instances entirely sealed, dual glazed windows with a large airspace between the plates provide acceptable sound attenuation. Thickness, sealing, transparent barrier material and spacing are all important in the acoustic performance of a window.

Organizations contributing data to this table are: $37,64,73$, and 88 .
\end{abstract}

\section{GLOSSARY}

Facing: The outside surface of the specimen. In general the side facing the sound source

Backing: The other outside surface of the specimen. In general the side not facing the sound source

Core: The region between the facing and the backing

Glazed Window: A window furnished with glass

Dual Glazed Window: A window furnished with two glass panes 
Table 23. Windows.

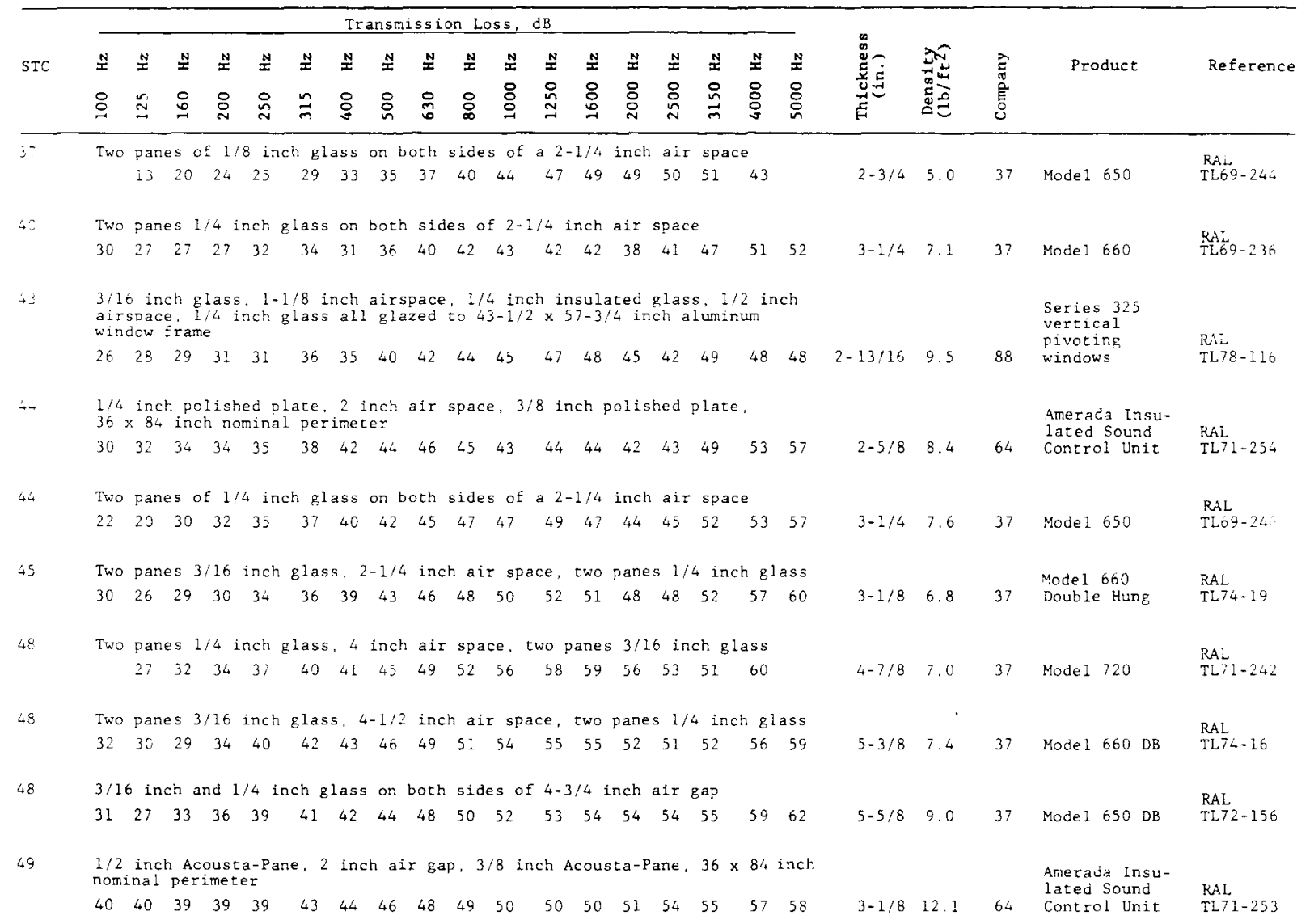


CATEGORY 24. OPERABLE PARTITIONS

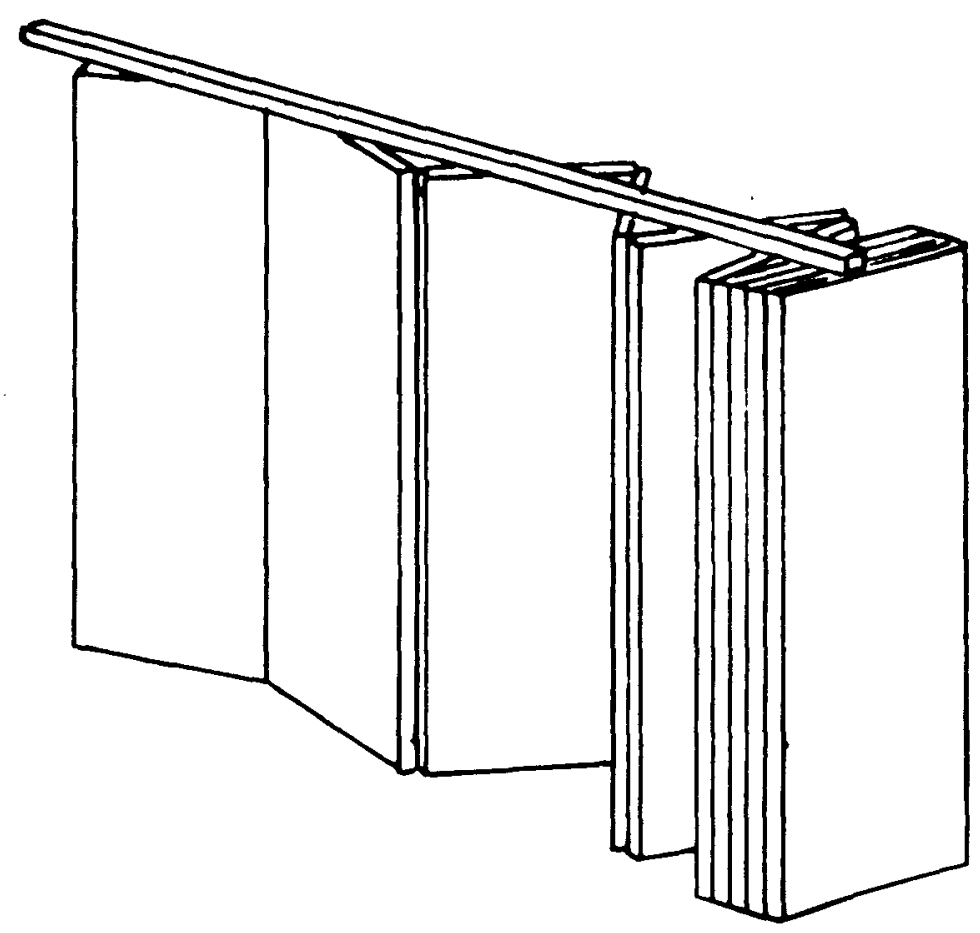




\section{CATEGORY 24. OPERABLE PARTITIONS}

Operable partitions are used as room dividers which are more rigid than flexible curtains. They are usually suspended from the ceiling on an overhead track. These partitions are often mounted on rollers for ease of operation and are opened in an accordianlike fashion. For individual access, smaller exit doors may be included; especially where the partitions are used for large areas such as gymnasiums, shops, hangers, auditoriums, etc.

Sealing is one of the main design parameters for acoustical performance. Various techniques are used in maintaining an acoustical seal at each fold and around the perimeter when the partition is closed. Organizations contributing data to this table are: 68, 99, and 105 . 
Table 24. Operable partitions.

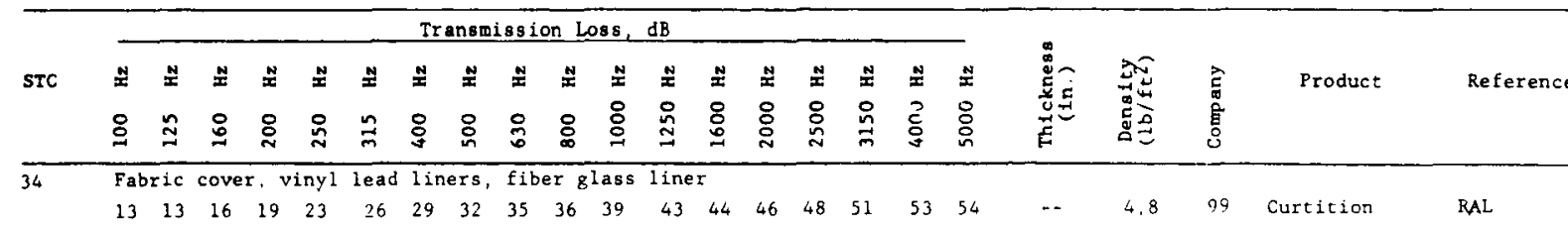

37 3-1/4 inch 26 gauge steel slats backed by 13 ounce per 54 inch vinyl

$\begin{array}{llllllllllllllllllllllll}\text { impregnated linet faced by } 48 & \text { ounce per } 54 \text { inch vinyl fabric } \\ 16 & 15 & 19 & 23 & 24 & 29 & 33 & 36 & 36 & 39 & 42 & 45 & 46 & 48 & 49 & 50 & 51 & 50 & -- & 4 & 68 & \text { Sounaguard } X-8 & \text { TL } 71-316\end{array}$

38 \#240 vinyl covering panels hinged to operate as a single-unit. Standard
aluminum base

$\begin{array}{llllllllllllllllllllll}14 & 19 & 28 & 32 & 33 & 35 & 37 & 37 & 40 & 41 & 41 & 43 & 43 & 43 & 44 & 40 & 3 & \ldots & 105 & \text { \#240 Panels } & \text { RAL }\end{array}$

38 Center-hung bi-fold wall with \#2540V vinyl covered panels

$\begin{array}{llllllllllllllllllllllll}15 & 21 & 26 & 36 & 35 & 37 & 37 & 37 & 39 & 39 & 40 & 40 & 39 & 36 & 34 & 37 & 38 & 39 & 3 & 5.9 & 105 & \text { Folding Wall } & \text { RAL } & 76-10\end{array}$

595 inch wide 22 gauge steel slat backed by 18 ounce per 54 inch vinyl
impregnated liner faced by 48 ounce per 54 inch vinyl fabric

$\begin{array}{lllllllllllllllllllllll}15 & 18 & 21 & 25 & 28 & 31 & 34 & 37 & 42 & 43 & 43 & 45 & 48 & 49 & 52 & 53 & 53 & 55 & - & 5.9 & 58 & \text { Foldoor Super } & \text { RAL } \\ \text { Soundguard X24 } & \text { TL71-38 }\end{array}$

$39 \quad 3-1 / 4$ inch wide 22 gauge steel slat backed by 18 ounce per 54 inch vinyl impregnated liner faced by 48 ounce per 54 inch vinyl fabric

$\begin{array}{llllllllllllllllll}19 & 19 & 24 & 27 & 28 & 30 & 31 & 35 & 41 & 47 & 49 & 50 & 48 & 49 & 50 & 51 & 51 & 51\end{array}$ $\underset{\text { Facing } 3 / 8 \text { inch particle board, } 2-1 / 21 \mathrm{~b} / \mathrm{ft}^{3} \text { mineral wool, with laminated }}{\text { Facs }}$

$\begin{array}{llllllllllllllllll}16 & 17 & 26 & 29 & 32 & 34 & 36 & 37 & 40 & 41 & 39 & 42 & 43 & 45 & 46 & 46 & 47 & 46\end{array}$

$$
\begin{array}{lllll}
\text { - } & 6.1 & 58 & \begin{array}{l}
\text { Super Sound- } \\
\text { guard X16 } \\
\text { Fully Operable }
\end{array} & \text { KLL } 71-256 \\
2-1 / 4 & 4.9 & 68 & \begin{array}{l}
\text { Foldoor } \\
\text { Series } 1
\end{array} & \text { KAL } \\
1 L 70-225
\end{array}
$$

$40 \quad 5-1 / 4$ inch wide 24 gauge steel slat backed by 28 ounce per 54 inch vinyl impregnated liner faced by 48 ounce per 54 inch vinyl fabric

$\begin{array}{llllllllllllllllll}17 & 20 & 23 & 26 & 28 & 30 & 34 & 38 & 44 & 48 & 48 & 48 & 50 & 51 & 53 & 53 & 54 & 53\end{array}$

$415-1 / 4$ inch wide 22 gauge steel slat backed by 18 ounce per 54 inch vinyl impregnated liner faced by 48 ounce per 54 inch vinyl fabric

$\begin{array}{llllllllllllllllll}23 & 22 & 24 & 26 & 29 & 32 & 34 & 37 & 42 & 45 & 46 & 48 & 49 & 51 & 52 & 54 & 55 & 56\end{array}$

$$
\begin{array}{lllll}
- & 5.8 & 68 & \begin{array}{l}
\text { Foldoor Super } \\
\text { Soundguard X12 }
\end{array} & \begin{array}{l}
\text { RAL } \\
\text { TL72-23 }
\end{array} \\
& & \begin{array}{l}
\text { Super Sound } \\
\text { guard X24 } \\
\text { Folding Door }
\end{array} & \text { RAL TL71-210 }
\end{array}
$$

Facing $1 / 4$ inch particle board fabric covered filled with $2-1 / 2 \mathrm{lb} / \mathrm{ft}^{3}$ rockwool three ll-gauge strips 5 inch wide laminated to back of

particle board

$\begin{array}{lllllllllllllllll}21 & 22 & 27 & 31 & 34 & 34 & 36 & 40 & 41 & 42 & 42 & 44 & 47 & 49 & 50 & 48 & 49\end{array}$

42

Center-hung bi-fold wall with \$2540 V vinyl covered panels

$\begin{array}{llllllllllllllll}21 & 27 & 36 & 38 & 38 & 38 & 39 & 41 & 41 & 42 & 43 & 45 & 47 & 46 & 46 & 44\end{array}$

$3 / 8$ inch particle board faces (fabric covered), 2-1/2 lb/ft ${ }^{3}$ rockwool and steel dampers

$\begin{array}{llllllllllllllllll}20 & 24 & 30 & 32 & 36 & 37 & 39 & 41 & 41 & 42 & 43 & 44 & 46 & 47 & 47 & 46 & 45 & 44\end{array}$ \#245 vinyl covered panels, hinged to operate as a single unit. Standard

$\begin{array}{llllllllllllllll}25 & 30 & 36 & 41 & 39 & 40 & 40 & 41 & 44 & 44 & 44 & 45 & 46 & 46 & 45 & 41\end{array}$

\#245 vinyl covered panels, standard aluminum base, automatic bottom

$\begin{array}{llllllllllllllll}22 & 31 & 36 & 40 & 41 & 43 & 45 & 46 & 47 & 45 & 44 & 44 & 45 & 47 & 49 & 50\end{array}$

$3 / 8$ inch flakeboard faces (fabric covered), $6 \mathrm{lb} / \mathrm{ft}^{3}$ rockwool, steel dampers

$\begin{array}{llllllllllllllllll}28 & 32 & 38 & 38 & 41 & 40 & 43 & 45 & 47 & 48 & 49 & 51 & 53 & 52 & 52 & 49 & 50 & 52\end{array}$

Steel panels bonded to fabric, with perforated Iuftex-360 fabric

Partition has an NRC value of 0.75

Foidoor

Series? $\quad$ TL72-210

$$
\begin{array}{llll} 
& & \begin{array}{l}
\$ 2500 \text { Series Fold- } \\
\text { ing Wall with Rat }
\end{array} \\
3 & 5.9 & 105 & \text { Compression Unit OT76-9 }
\end{array}
$$$$
\begin{array}{llll} 
& 5.5 & \text { Foldoor } & \text { RAL } \\
\text { Series } 3 & \text { TL76-103 }
\end{array}
$$

\#380 Foldiuls

380 Foldil

W245 panel

RAL

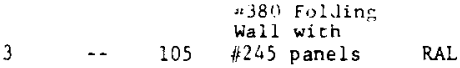

$\begin{array}{lllll}3-3 / 4 & 8.7 & 68 & \begin{array}{l}\text { Foldoor } \\ \text { Series } 4\end{array} & \text { RAL } \\ \text { TL7 } 7-69\end{array}$

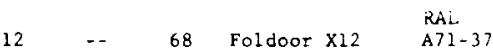


CATEGORY 25. OPEN PLAN SYSTEMS

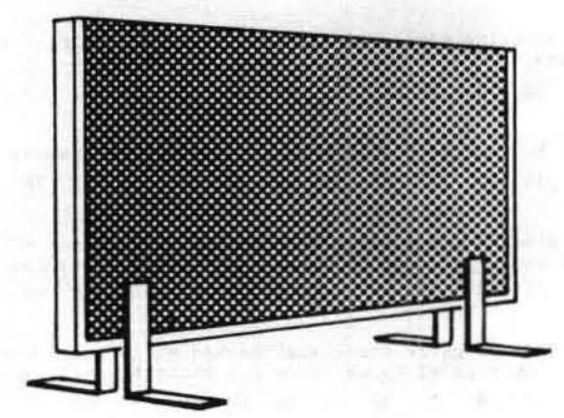

OFFICE LANDSCAPE SCREEN

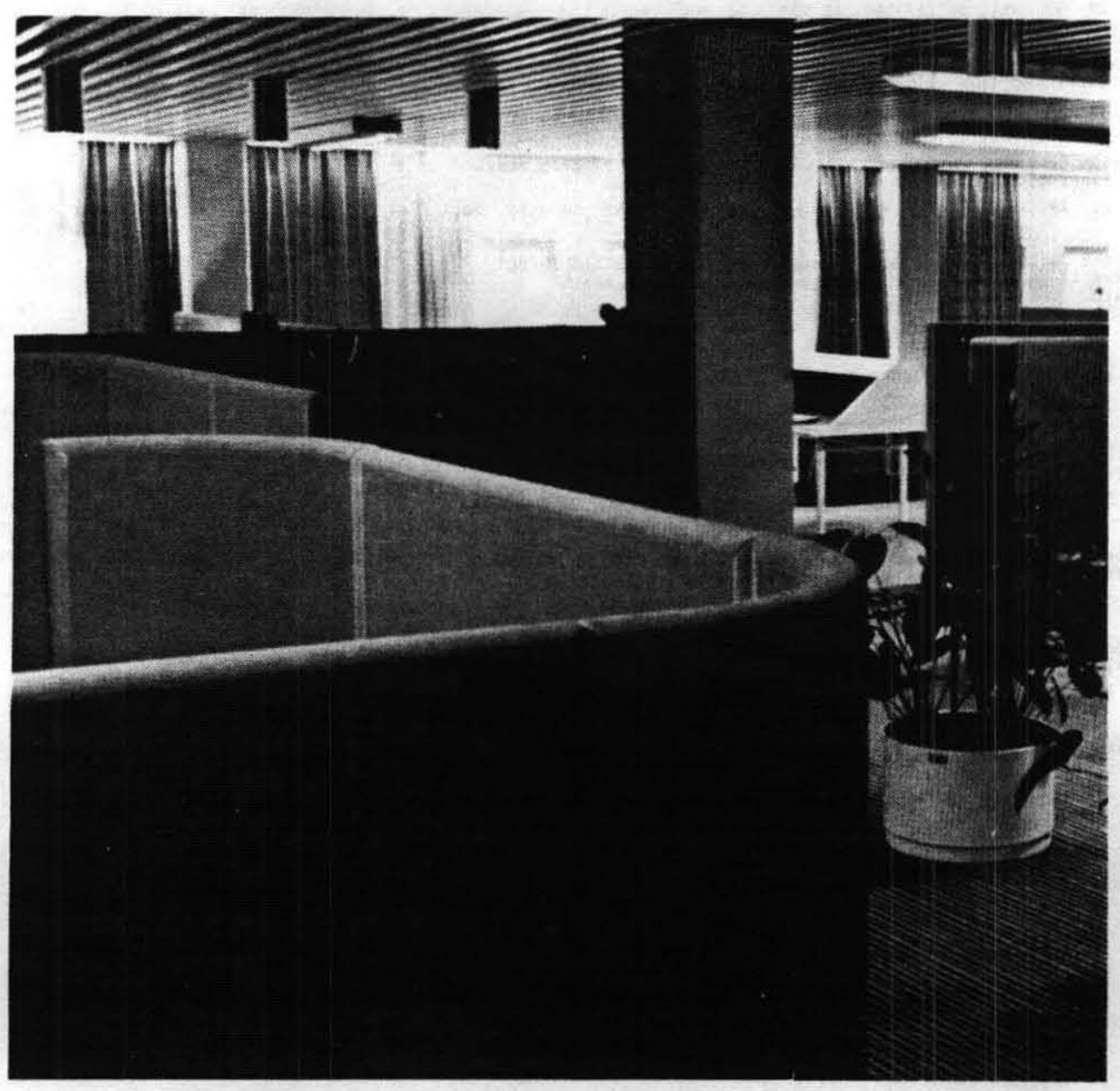


CATEGORY 25. OPEN PLAN SYSTEMS

Open plan systems refer to products and materials which are used in open plan offices, buildings, or educational areas. The room configuration for open plan areas has no interior floor to ceiling partitions. Basically, there is one, large open area which is subdivided into working modules using movable partitions. These movable partitions are generally free standing, partial height barriers. They are often called landscape screens and are typically 5 to $6 \mathrm{ft}$ high. These screens have absorptive and barrier properties so that speech privacy can be obtained between modules. Acoustically, these screens may be rated according to absorptive (NRC), transmission loss (STC), or noise isolation class (NIC') properties. The two other major elements of open plan systems are in absorptive ceiling and a sound masking system. In order to achieve adequate speech privacy, all three elements must have good acoustic performance.

Organizations contributing data to this table are: $4,67,77,96,118,133$, 136 , and 141 .

\section{CAUTION}

1. ABSORPTION COEFFICIENTS MAY EXCEED 1.0. FOR A COMPLETE DISCUSSION OF THESE VALUES SEE PAGE 51.

GLOSSARY

Landscape screen: A partial height, movable partition with absorptive and barrier properties.

NIC': $\quad$ Noise isolation class referred to open plan system performance. Higher numbers indicate better acoustic isolation. 
Table 25A. Absorption properties of upen plan office systems.

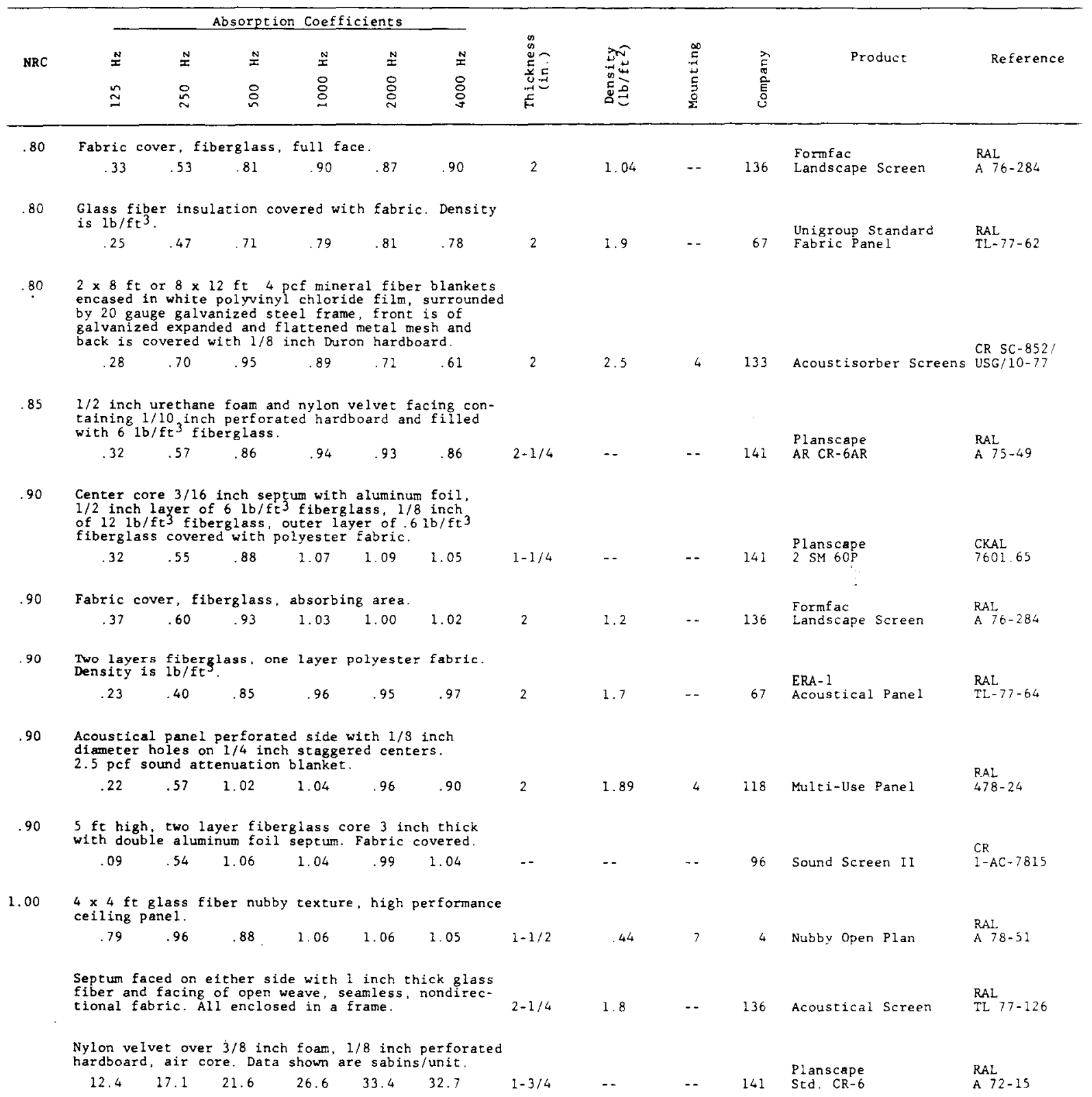


Table 25B. Barrier properties of open plan office systems.

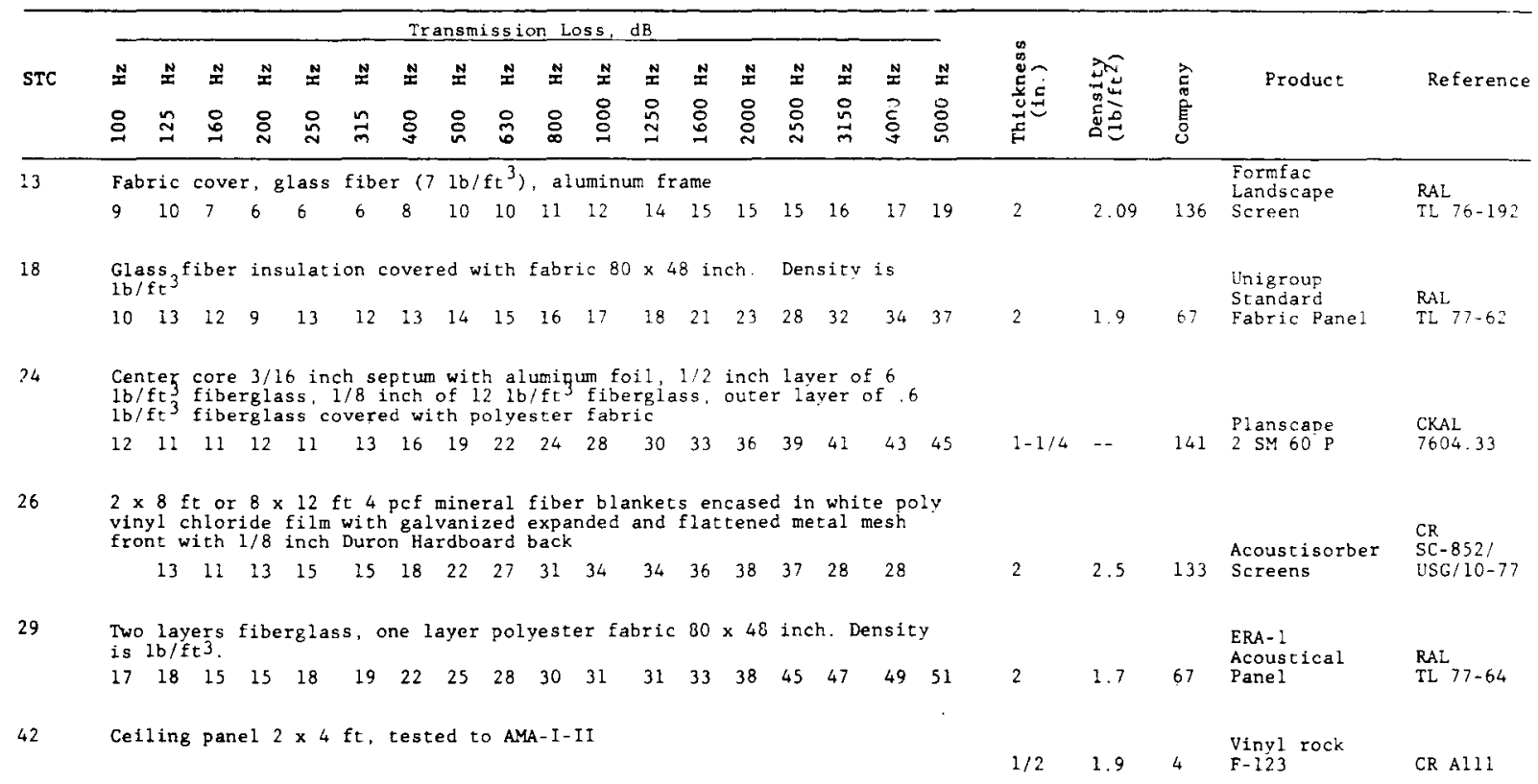

Table 25C. Speech privacy potential of open plan office systems.

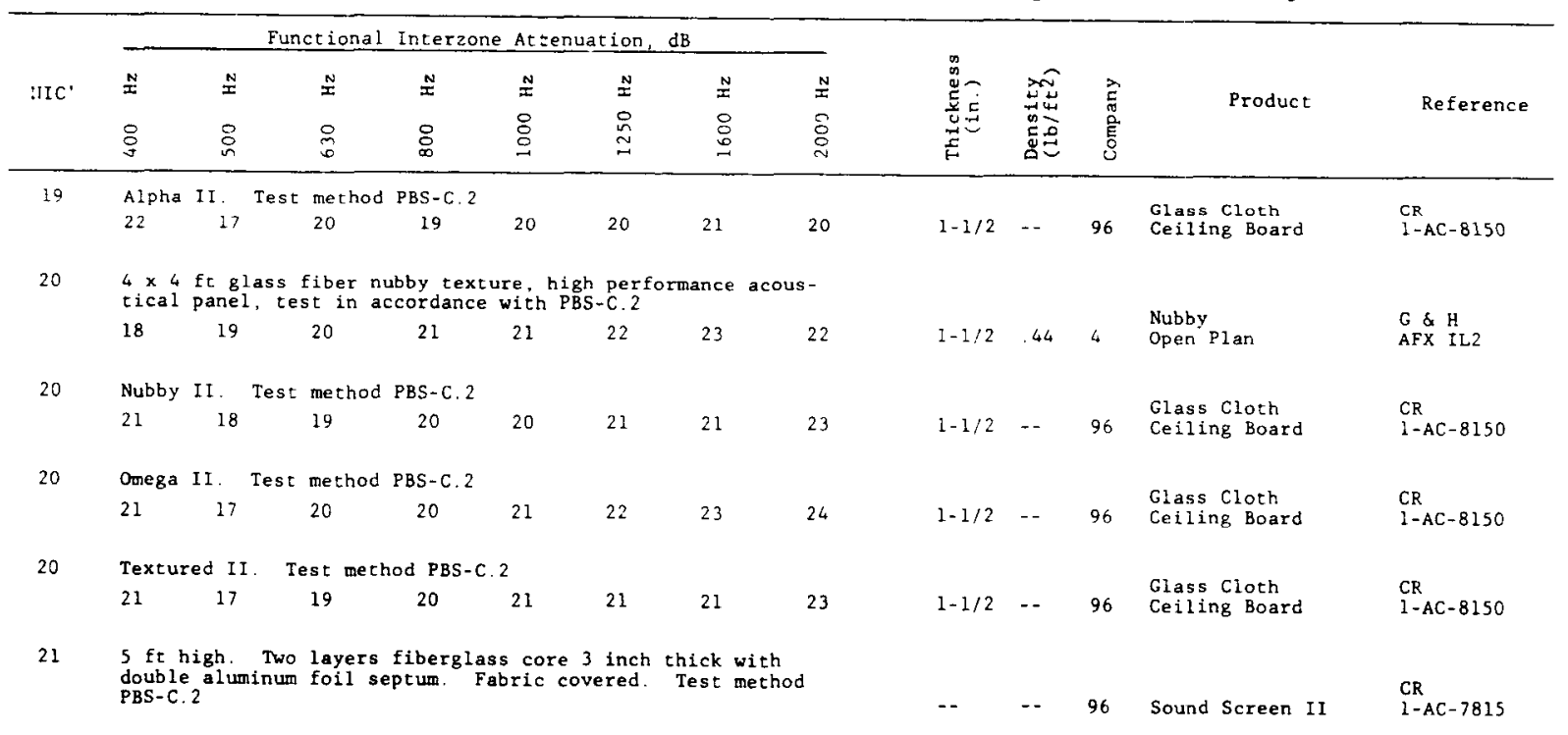


CATEGORY 26. WALL TREATMENTS

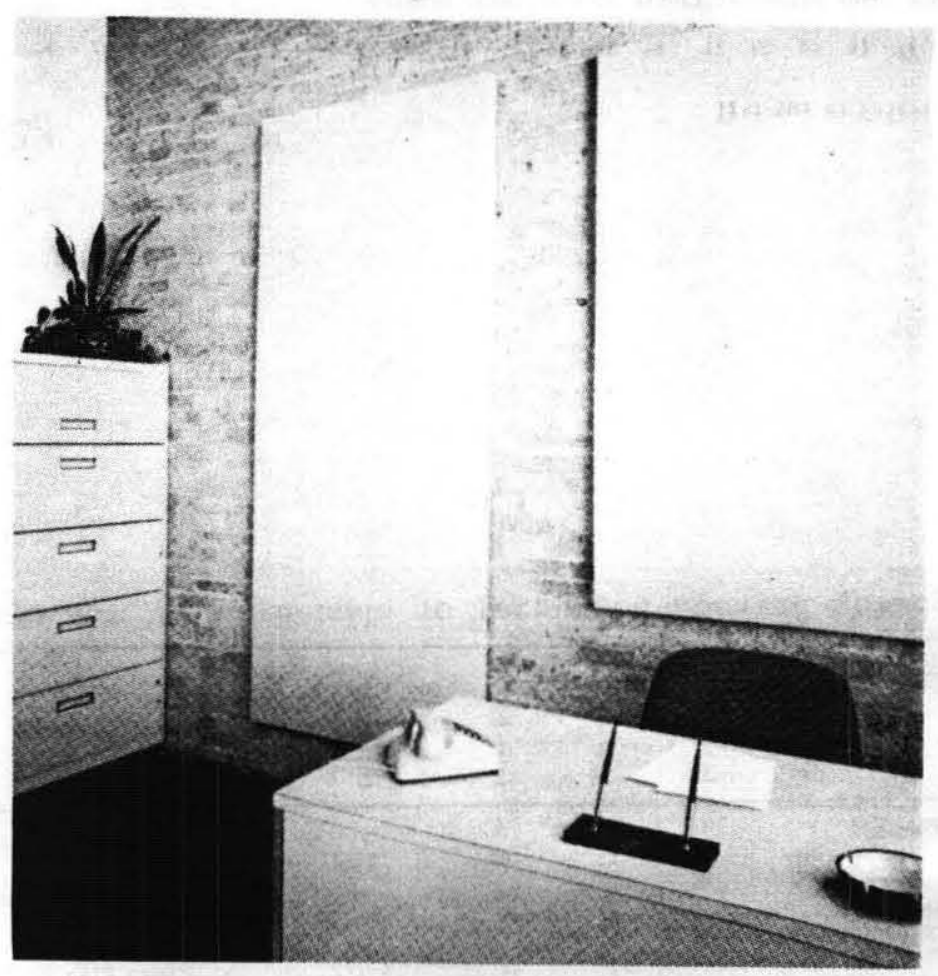


CATEGORY 26. WALL TREATMENTS

Facings in the form of panels, boards, and coverings which can be mounted on walls are used to improve acoustic performance. Wall treatments are made from a variety of materials and are available in various designs, colors, and surface textures. Aesthetic value plus sound control are major criteria for selection of wall treatments.

Organizations contributing data to this table are: 4, 11, 15, 73, 85, 92, 96, 106, 115, and 133. Related categories are walls, unit absorbers, panels, ceiling tile, and open plan systems.

\section{CAUTION}

1. ABSORPTION COEFFICIENTS MAY EXCEED 1.0. FOR A COMPLETE DISCUSSION OF THESE VALUES SEE PAGE 51.

2. THE NUMBERS LISTED UNDER THE "MOUNTING" COLUMN REFER TO THE AIMA STANDARD MOUNTINGS DESCRIBED ON PAGE 54.

\section{GLOSSARY}

Facing: The outside surface of the specimen. 'In general the side facing the sound source

Backing: The other outside surface of the specimen. In general the side not facing the sound source

Core: The region between the facing and the backing

Lath: Thin lightweight structure used as groundwork for plastering, mounting tiles, etc. It may be in a form of gypsum board, perforated metal wire cloth, thin wood strips, etc. 
Table 26. Wall treatment.

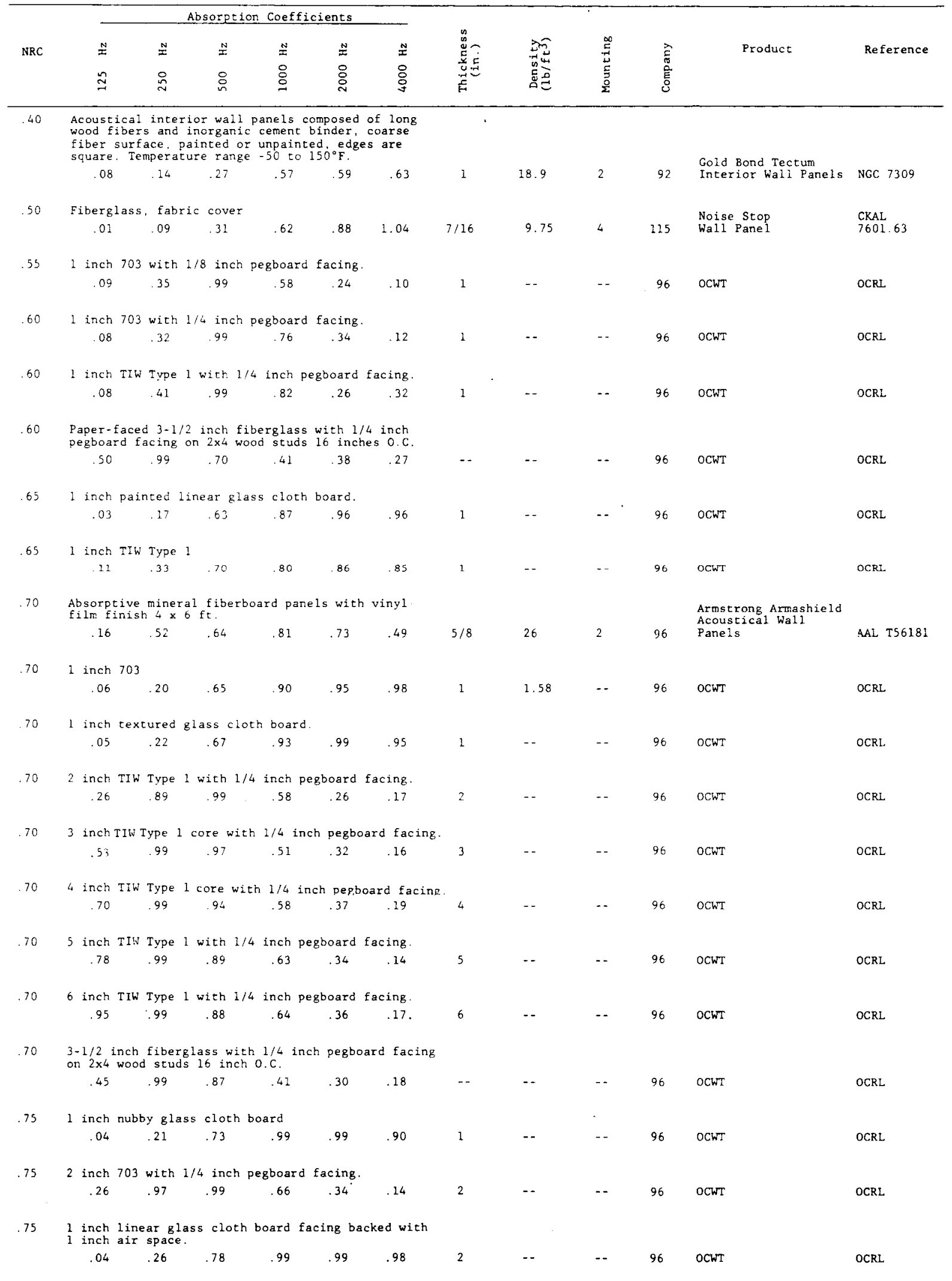


Table 26. Wal1 treatment continued.

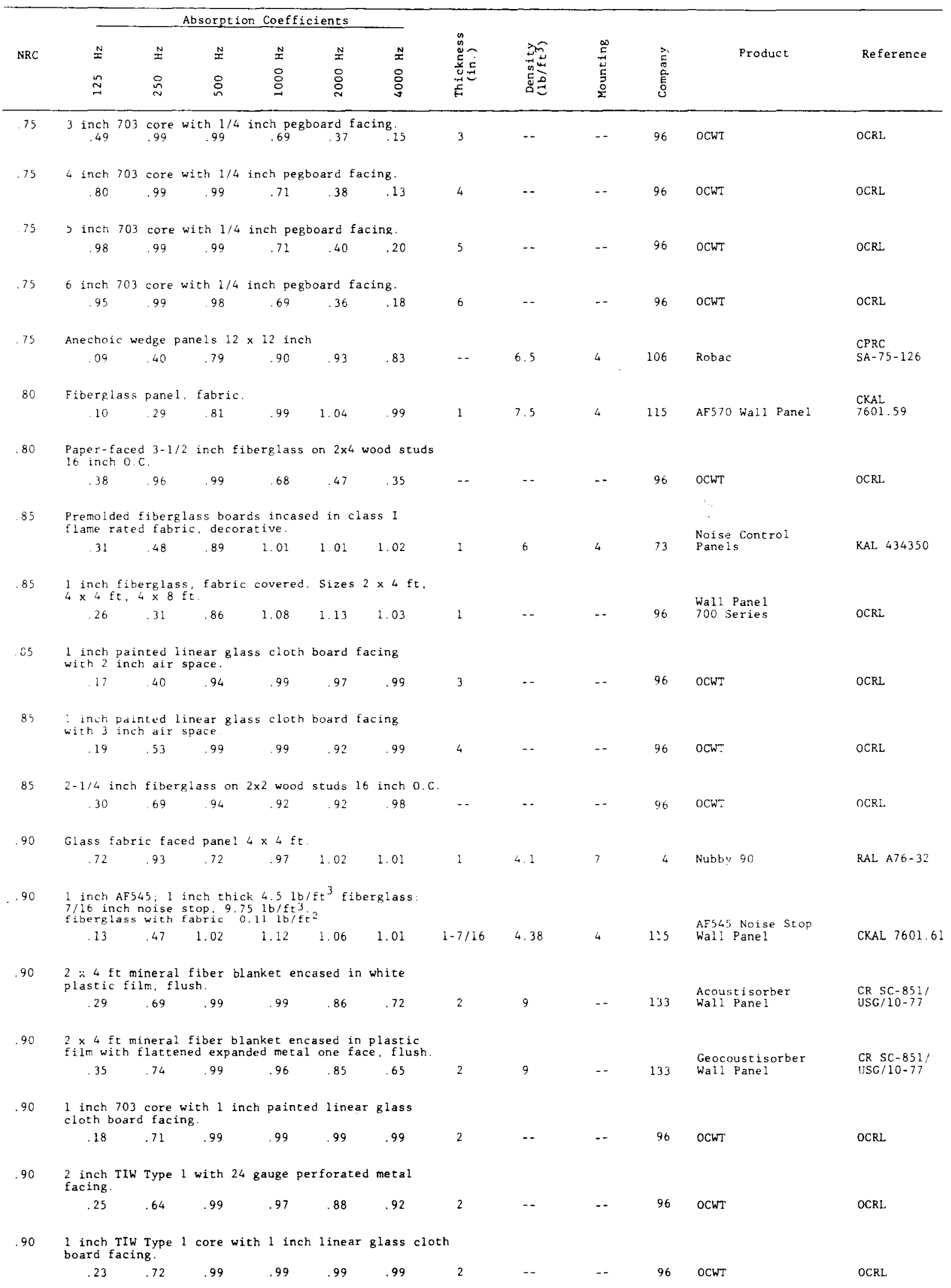


Table 26. Wall treatment continued.

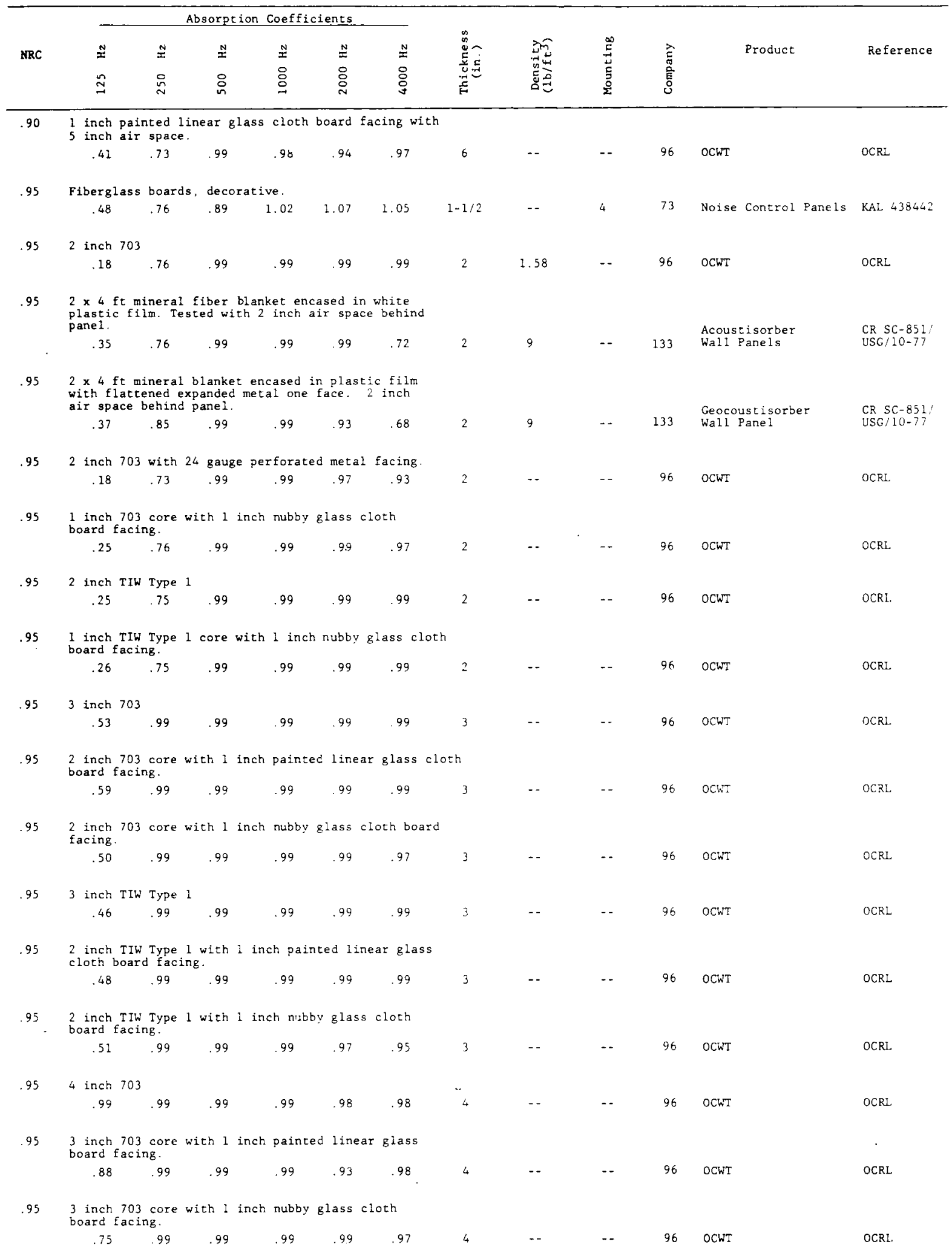


Table 26. Wall treatment continued.

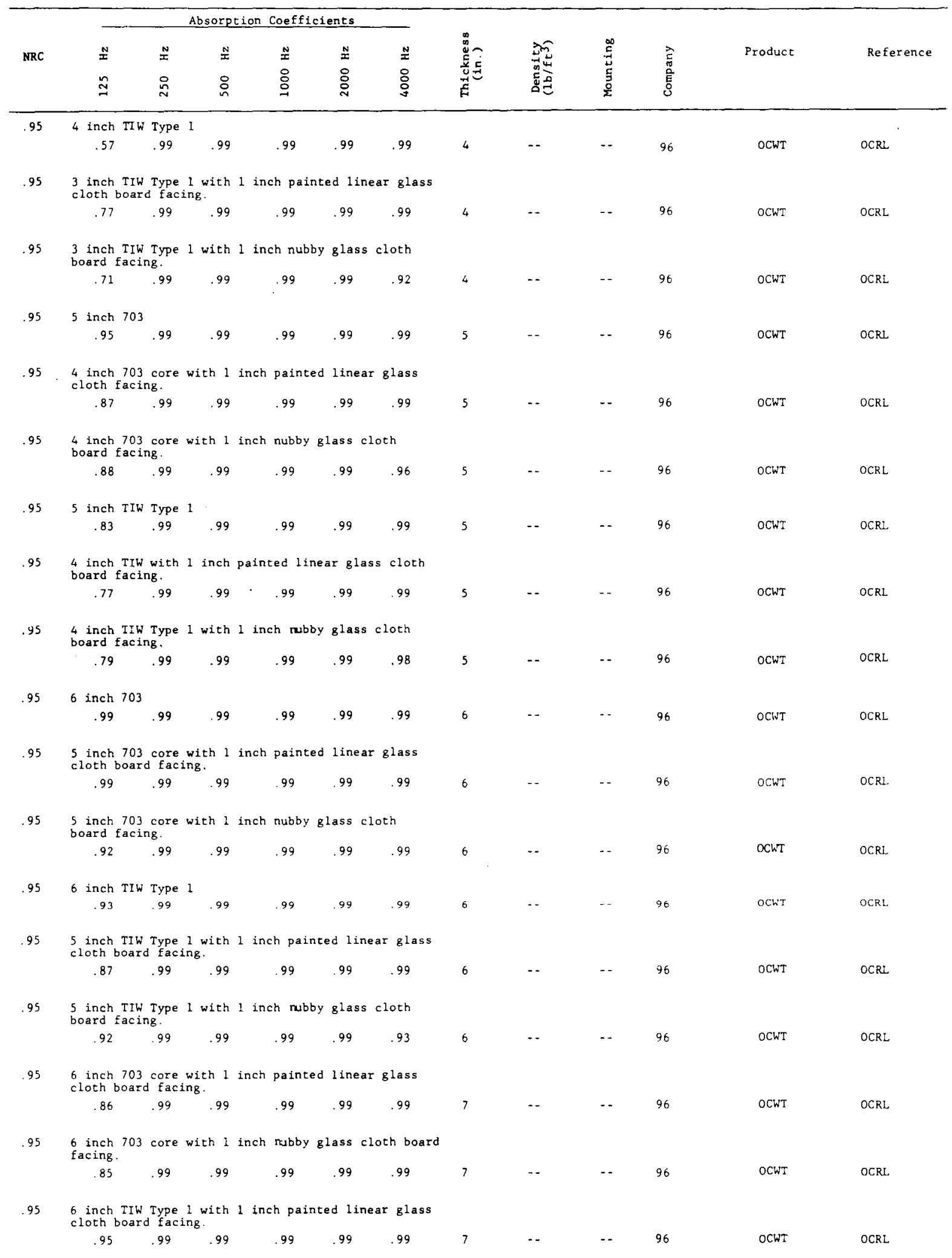


Table 26. Wall treatment concluded.

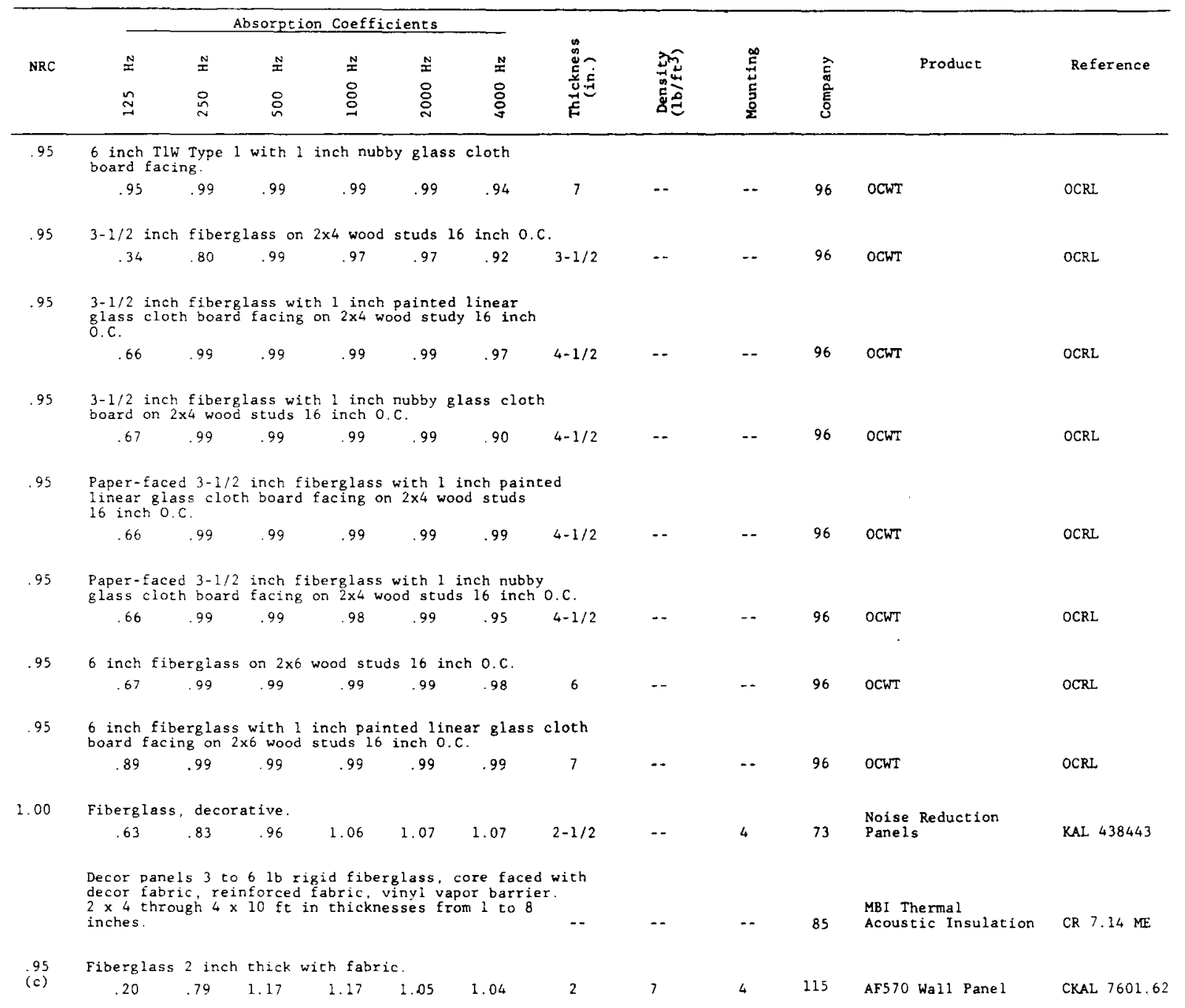




\section{CATEGORY 27. PIPE LAGGINGS}

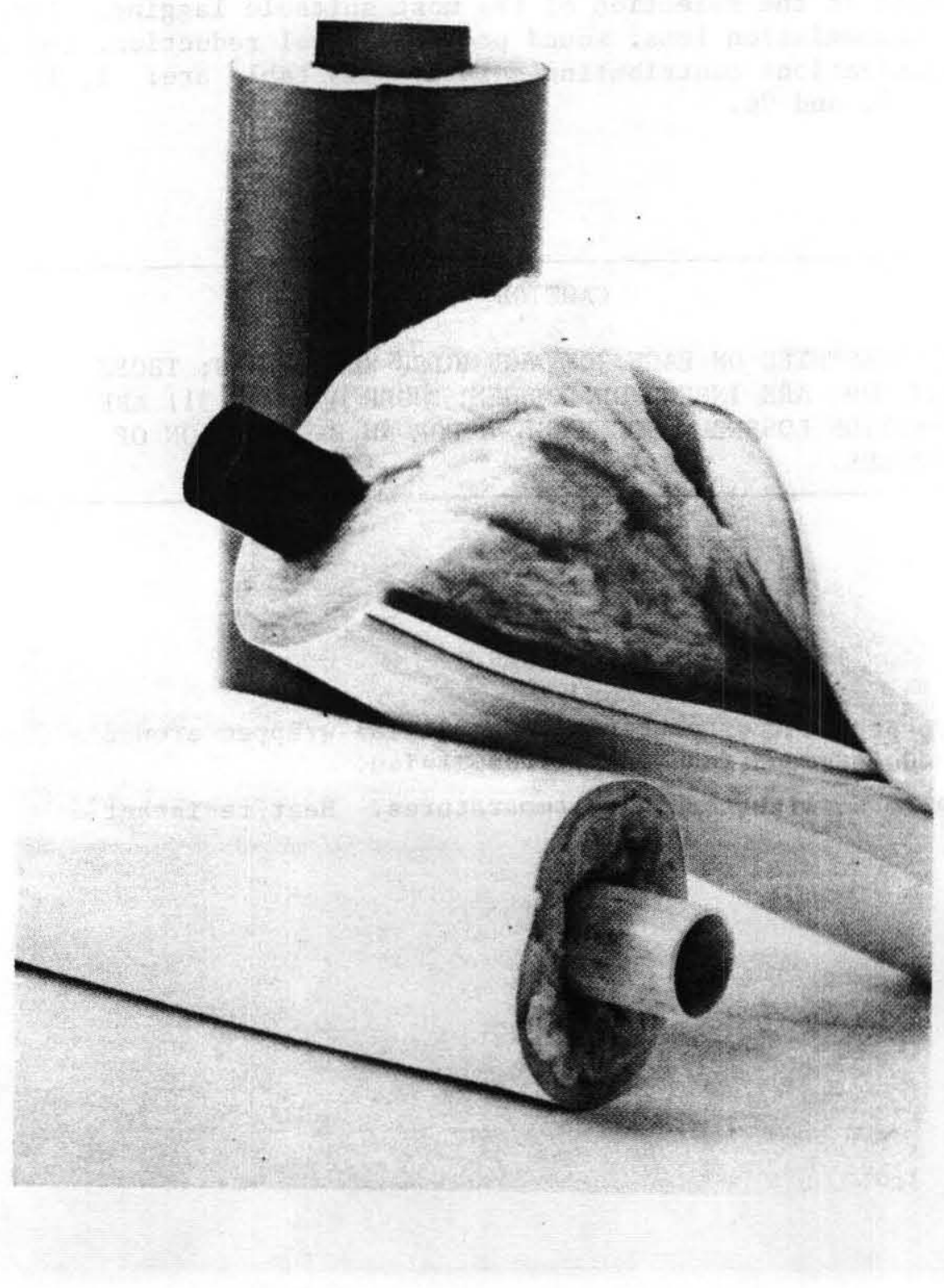


Pipe laggings can effectively reduce the ambient noise levels if the pipe and fluid generated noise is of high amplitude compared to other ambient noise. Pipe laggings consist essentially of a decoupling element and a "floating" barrier where the decoupling element stops the pipe vibrations from driving the barrier material. Thermal properties and ease of application are the important criteria in the selection of the most suitable lagging. Data shown may consist of transmission loss, sound pressure level reduction, and noise reduction. Organizations contributing data to this table are: $1,18,32,40$, $45,66,73,74,90$, and 96 .

VALUES PRESENTED ON PAGE 307 ARE NOISE REDUCTIONS; THOSE ON PAGE 309, ARE INSERTION LOSSES; THOSE ON PAGE 311 ARE TRANSMISSION LOSSES. SEE PAGE 94 FOR AN EXPLANATION OF DIFFERENCES.

\section{GLOSSARY}

Lagging: Strip or sheet of nonconducting material wrapped around a pipe to reduce sound (and heat) transmission.

Refractory: Able to withstand high temperatures. Heat resistant. 
Table 27A. Pipe lagging (noise reduction).

\begin{tabular}{|c|c|c|c|c|c|c|c|c|c|c|c|c|c|c|c|c|c|c|c|c|c|c|}
\hline & & & & & & & Noi & se $R_{e}$ & ducti & on, d & & & & & & & & & & & & \\
\hline$\stackrel{N}{x}$ & $\underline{x}$ & $\stackrel{N}{I}$ & $\stackrel{N}{=}$ & $\stackrel{N}{I}$ & $\stackrel{N}{x}$ & $\stackrel{N}{I}$ & $\stackrel{N}{=}$ & $\stackrel{N}{x}$ & $\stackrel{N}{=}$ & $\stackrel{N}{x}$ & $\stackrel{N}{I}$ & N & $\stackrel{N}{I}$ & $\stackrel{N}{\mathbf{N}}$ & $\stackrel{N}{I}$ & $\stackrel{N}{I}$ & $\stackrel{N}{x}$ & $\stackrel{\infty}{\mathbb{E}} ?$ & 20 & $\widehat{E}$ & Product & Referenc \\
\hline$\underset{-}{8}$ & $\stackrel{\sim}{\approx}$ & $\stackrel{8}{\stackrel{9}{-}}$ & $\underset{\sim}{8}$ & $\stackrel{\circ}{\sim}$ & $\stackrel{n}{m}$ & ᄋ & $\stackrel{8}{\circ}$ & రิ & $\underset{\infty}{\stackrel{8}{\infty}}$ & $\stackrel{8}{\circ}$ & $\stackrel{ }{\stackrel{n}{二}}$ & 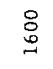 & 옹 & 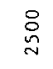 & $\begin{array}{l}0 \\
\stackrel{0}{9} \\
\Rightarrow\end{array}$ & $\stackrel{8}{8}$ & $\begin{array}{l}8 \\
8 \\
8\end{array}$ & 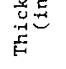 & 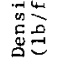 & $\begin{array}{l}\bar{\pi} \\
\stackrel{0}{E} \\
\bar{\delta}\end{array}$ & & \\
\hline Cor & rugate & d all & minum & and & lead & lami & ate. & & & & & & & & & & & & & & Acous & \\
\hline & & & & 14 & & & 16 & & & 26 & & & 37 & & & 41 & & $5 / 16$ & 1.2 & 73 & $\mathrm{~N}-\mathrm{C}-$ & 7604,222 \\
\hline 0.5 & inch & foam & .106 & inch & rub & & & & & & & & & & & & & & & & & \\
\hline & & & 1 & 6 & 5 & 4 & 9 & 12 & 14 & 15 & 21 & 22 & 20 & 17 & 24 & 21 & 24 & .606 & 1.03 & 66 & Sheet 500 & RAL \\
\hline & $\begin{array}{l}\text { dard } \\
\text { ts }\end{array}$ & $\begin{array}{l}\text { convo } \\
\text { ed fo } \\
0^{\circ} \text { to }\end{array}$ & $\begin{array}{l}\text { uted } \\
\text { the } \\
220^{\circ}\end{array}$ & $\begin{array}{l}\text { foam } \\
\text { rmal } \\
\text { F foar }\end{array}$ & $\begin{array}{l}n . \text { A. } \\
\text { and } \\
\text { an, - }\end{array}$ & $\begin{array}{l}040 \mathrm{i} \\
\text { acous } \\
20^{\circ} \mathrm{t}\end{array}$ & $\begin{array}{r}\text { ical } \\
150\end{array}$ & $\begin{array}{l}n y 1 \\
\text { insu } \\
\text { F ja }\end{array}$ & $\begin{array}{l}\text { atio } \\
\text { ket. }\end{array}$ & $\begin{array}{c}{\left[\begin{array}{l}\text { lam } \\
\text { on } \\
\text { Dens }\end{array}\right.}\end{array}$ & ip & $\begin{array}{l}\text { to } \\
\text { and } \\
\text { ven } i\end{array}$ & $\begin{array}{l}\text { flex } \\
\text { tank } \\
\text { s lin }\end{array}$ & $\begin{array}{r}\text { Te } \\
\mathrm{r} \text { we }\end{array}$ & npe & $c e$ & & & & & & \\
\hline 0 & 0 & 0 & 0 & 0 & 0 & 3 & 5.1 & 8.4 & 9.9 & 13.8 & 18.6 & 20.4 & 23.9 & 25.1 & 26.9 & 28.5 & 29.5 & 1 & 1.47 & 1 & Acoustazip & $78-11$ \\
\hline
\end{tabular}

High temperature insulation (up to $2300^{\circ} \mathrm{F}$ ). Flow velocity $30 \mathrm{ft} / \mathrm{sec}$. Available in $2 \times 45$ and $4 \times 25 \mathrm{ft}$ rolls. Available in $1 / 4,1 / 2,1,1-1 / 2$ and 2 inch thicknesses
and $3,4,6$ and 8 lb densities.

$\begin{array}{llllllllllllllllllll}0 & 1 & 0 & 0 & 1.8 & 0 & 0 & 1 & 4.3 & 9 & 8 & 11.5 & 13.8 & 17.5 & 17 & 19.5 & 18 & 23\end{array}$

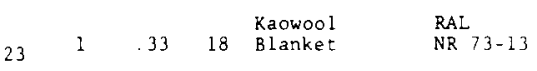

Barium-filled vinyl, 1 inch convoluted foam. Temperature range 0 to $150^{\circ} \mathrm{F}$ barium-filled vinyl, $-60^{\circ}$ to $220^{\circ} \mathrm{F}$ foam. Used as thermal and acoustical insulation on pipes. Density vinyl, $-60^{\circ}$ to $220^{\circ} \mathrm{F}$ foam. Used as thermal and acoustical insulation on pipes. Density
given is linear weight in $1 \mathrm{~b} / \mathrm{ft}$. $\begin{array}{lllllllllllllllllllllll}0 & 0 & 9 & 8 & 2.2 & 6.6 & 7.6 & 10.3^{15.3} & 13.4 & 20.8 & 23.7 & 24.7 & 25.3 & 30.7 & 31.2 & 33 & 33\end{array}$ High temperature insulation (up to $2300^{\circ} \mathrm{F}$ ). Flow velocity $30 \mathrm{ft} / \mathrm{sec}$. Available in
$2 \times 45$ and $4 \times 25 \mathrm{ft}$ rolls. Avaliable in $1 / 4,1 / 2,1,1-1 / 2$ and 2 inch thicknesses and $3,4,6$ and 8 ib densities.

$\begin{array}{llllllllllllllllllll}0 & 1 & 1 & 1.8 & 3 & .5 & 1 & 4 & 6 & 9.8 & 11 & 13.5 & 17.3 & 21.8 & 22 & 25 & 23 & 29.4\end{array}$

High temperature insulation (up to $2300^{\circ} \mathrm{F}$ ). Flow velocity $30 \mathrm{ft} / \mathrm{sec}$. Availabie in and $3,4,6$ and 8 1b densities.

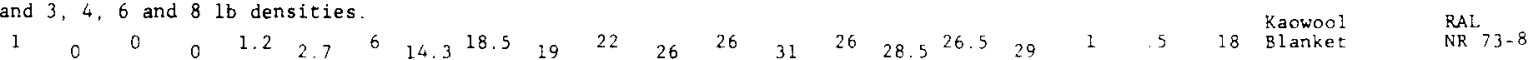

High cemperature insulation (up to $2300^{\circ} \mathrm{F}$ ). Flow velocity $30 \mathrm{ft} / \mathrm{sec}$. Available in and $3,4,6$ and 8 lb densities.

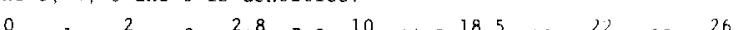

High temperature insulation (up to $2300^{\circ} \mathrm{F}$ ). Flow velocicy $30 \mathrm{ft} / \mathrm{sec}$. Available in $2 \times 45$ and $4 \times 25$ ft rolls.

$\begin{array}{lllllllllllllllllllllllll}0 & 1.5 & 0 & 1.8 & 2.5 & 3.5 & 5.5 & 13.5 & 17.8 & 18.8 & 23.5 & 26 & 27 & 32.3 & 27.8 & 29 & 29.5 & 33 & 1 & .66 & 18 & \text { KaOwool } & \text { RAL } & & \end{array}$

High temperature insulation (up to $2300^{\circ} \mathrm{F}$ ). Flow velocity $30 \mathrm{ft} / \mathrm{sec}$. Available in

$2 \times 45$ and $4 \times 25 \mathrm{ft}$ rolls. Available in $1 / 4,1 / 2,1,1-1 / 2$ and 2 inch thicknesses

$\begin{array}{llllllllllllllllll}0 & 0 & 0 & 0 & .5 & 0 & 0 & 5.5 & 6.5 & 10 & 13 & 20 & 21 & 27 & 24 & 27 & 27 & 29.5\end{array}$

High temperature insulation (up to $2300^{\circ} \mathrm{F}$ ). Flow velocitv $30 \mathrm{ft} / \mathrm{sec}$. Available in

$2 \times 45$ and $4 \times 25 \mathrm{ft}$ rolls. Available in $1 / 4,1 / 2,1,1-1 / 2$ and 2 inch thicknesse

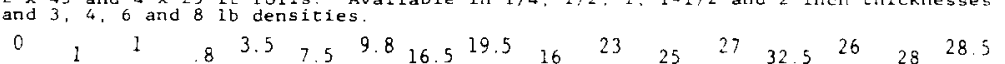

Cellulose fiber blanket in two layers, 1 inch total thickness, $4 \times 8 \mathrm{ft}$ sheets

RAL

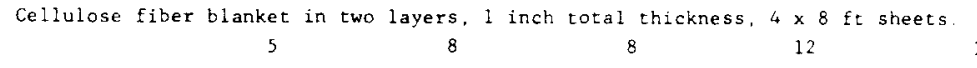

K-1

K-13 5 - BMC

Mineral wool, a $1200^{\circ} \mathrm{F}$ mineral Eiber batt.

$\begin{array}{llllllllllllllllllllll}0 & 0 & 0 & 0 & 0 & 0 & 0 & 0 & 2.2 & 3.1 & 5.5 & 7.8 & 8 & 10 & 8.6 & 10 & 10 & 10.3 & 1.5 & .38 & 18 & \text { Flexwhite }\end{array}$

Barium-filled vinyl, $1 / 2$ inch foam, 1 inch fiberglass. Temperature range barium-

filled vinvi 0 to $150^{\circ} \mathrm{F}$ fiberglass 0 to $450^{\circ} \mathrm{F}$; foam $-60^{\circ}$ to $220^{\circ} \mathrm{F}$. Used as thermal

and acoustical insulation on pipes. Density given is lineat weight in lb/ft.

$\begin{array}{llllllllllllllllllllllll}.5 & 2 & 2.5 & 3.3 & 5.2 & 6.9 & 9.7 & 11.6 & 18.1 & 14.2 & 22.4 & 26 & 24.7 & 28.3 & 33 & 33 & 32.8 & 34.5 & 1.5 & 5.7 & 1 & \text { Acoustazip } & \text { NR } & 78-12\end{array}$

Mineral wool insulation, a $1200^{\circ} \mathrm{F}$ mineral fiber batt.

$\begin{array}{lllllllllllllllllllllll}0 & 0 & 0 & 0 & 0 & 5 & 1.6 & 1.2 & 2.5 & 4.2 & 6.2 & 9.1 & 9.1 & 11.5 & 10.5 & 12 & 12 & 12 & 1.5 & 75 & 18 & \text { Flexwhite } & \end{array}$ 
Tab1e 27A. Pipe lagging (noise reduction) concluded.

\begin{tabular}{|c|c|c|c|c|c|c|c|c|c|c|c|c|c|c|c|c|c|c|c|c|}
\hline & & & & & & & Noise & E Reductio & $\mathrm{n}, \mathrm{d}$ & & & & & & & & & & & \\
\hline 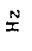 & $\stackrel{N}{x}$ & $\cong$ & $\stackrel{N}{2}$ & $\stackrel{N}{ \pm}$ & $\stackrel{n}{x}$ & $\cong$ & $\stackrel{N}{=}$ & $\stackrel{N}{=}$ & $\stackrel{N}{I}$ & $\stackrel{N}{=}$ & $\stackrel{N}{ \pm}$ & $\stackrel{N}{x}$ & $\stackrel{N}{I}$ & $\stackrel{N}{I}$ & $\stackrel{\Perp}{\Xi}$ & 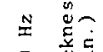 & $\underset{0=0}{20}$ & $\overrightarrow{\tilde{\varpi}}$ & Product & Reference \\
\hline$D_{-1}^{8}$ & $\approx$ & $\stackrel{8}{\circ}$ & $\stackrel{i}{\sim}$ & $\stackrel{0}{n}$ & $\cong$ & $\stackrel{8}{9}$ & 品 & \begin{tabular}{ll}
0 \\
\hdashline
\end{tabular} & 吕 & $\stackrel{\stackrel{0}{\cong}}{\cong}$ & : & : & 品 & $\stackrel{\circ}{m}$ & $\underset{\Xi}{\stackrel{\Xi}{\sigma}}$ & 总总 & 跣 & 总 & & $\cdot$ \\
\hline
\end{tabular}

Mineral wool, a $1200^{\circ} \mathrm{F}$ mineral fiber batt.

$\begin{array}{llllllllllllllllllllllll}2 & 5 & 1 & 5 & 3 & 4 & 7 & 9 & 13 & 14 & 14.3 & 18.5 & 14.5 & 19 & 16 & 19 & 18.2 & 19.5 & 2 & .5 & 18 & \text { Mineral Wool } & \text { RAL } 75-10\end{array}$

High temperature insulation (up to $2300^{\circ} \mathrm{F}$ ). Flow velocity $30 \mathrm{ft} / \mathrm{sec}$. Available in

$2 \times 45$ and $4 \times 25 \mathrm{ft}$ rolis. Available in $1 / 4,1 / 2,1,1-1 / 2$ and 2 inch thicknesses

and $3,4,6$ and $8 \mathrm{lb}$ densities.

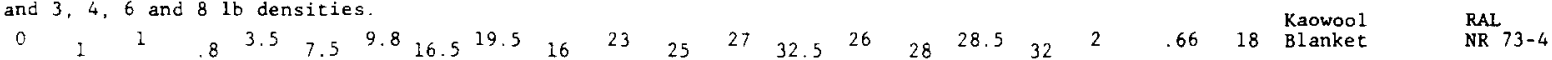

High temperature insulation (up to $2300^{\circ} \mathrm{F}$ ). Flow velocity $30 \mathrm{ft} / \mathrm{sec}$. Available in

$2 \times 45$ and $4 \times 25 \mathrm{ft}$ rolls. Available in $1 / 4,1 / 2,1,1-1 / 2$ and 2 inch thicknesses

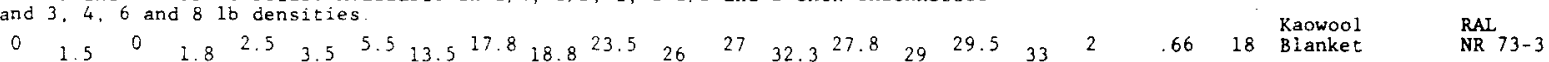

High temperature insulation (up to $2300^{\circ} \mathrm{F}$ ). Flow velocity $30 \mathrm{ft} / \mathrm{sec}$. Available in

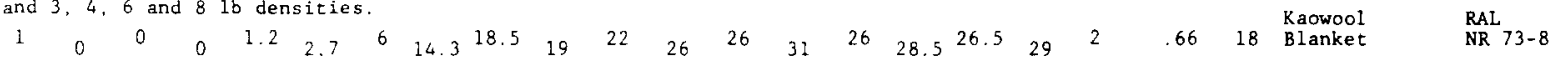

High temperature insulation (up to $2300^{\circ} \mathrm{F}$ ). Flow velocity $30 \mathrm{ft} / \mathrm{sec}$. Available in

$2 \times 45$ and $4 \times 25 \mathrm{ft}$ rolls. Available in $1 / 4,1 / 2,1,1-1 / 2$ and 2 inch thicknesses

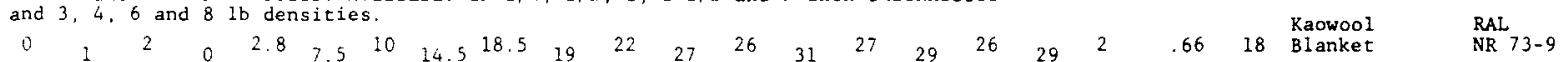

High temperature insulation (up to $2300^{\circ} \mathrm{F}$ ). Flow velocity $30 \mathrm{ft} / \mathrm{sec}$. Available in

$2 \times 45$ and $4 \times 25 \mathrm{ft}$ rolls. Available in $1 / 4.1 / 2,1,1-1 / 2$ and 2 inch thicknesses

$\begin{array}{cccccccccccccc}0 & 0 & & & & & & \end{array}$

Mineral wool insulation, a $1200^{\circ} \mathrm{F}$ mineral fiber batt.

$\begin{array}{llllllllllllllllllllllllllll}2 & 0 & 1.5 & 2 & 2.5 & 5 & 7 & 9.8 & 12.5 & 14 & 13.5 & 18.8 & 14 & 19.8 & 16.8 & 19.5 & 18.5 & 21.2 & 2 & 1 & 18 & \text { Mineral Wool } & \text { NAR } 75-12\end{array}$

High temperature insulation (up to $2300^{\circ} \mathrm{F}$ ). Flow velocity $30 \mathrm{ft} / \mathrm{sec}$. Available in

$2 \times 45$ and $4 \times 25 \mathrm{ft}$ rolls. Available in $1 / 4,1 / 2,1,1-1 / 2$ and 2 inch thicknesse

$\begin{array}{llllllllllllllllll}1.5 & 0 & 1 & 3 & 3.8 & 3.5 & 6 & 13.3 & 14 & 19.8 & 21.5 & 25.5 & 28 & 35.5 & 29 & 30.8 & 25\end{array}$

(1)

High temperature insulation (up to $2300^{\circ} \mathrm{F}$ ). Flow velocity $30 \mathrm{ft} / \mathrm{sec}$. Availabie in

$2 \times 45$ and $4 \times 25 \mathrm{ft}$ rolls. Available in $1 / 4,1 / 2,1,1-1 / 2$ and 2 inch thicknesses

and $3,4,6$ and 8 ib densities.

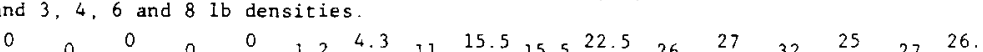

Cellulose fiber blanket in two layers, $2-1 / 2$ inch total thickness, $4 \times 4 \mathrm{ft}$ sheets.

$$
\begin{array}{ccccc}
5 & 10 & 15 & 22 & \text { inch total thickness, } 4 \times 4 \text { sheets. }
\end{array}
$$
and $3,4,6$ and $8 \mathrm{lb}$ densities.

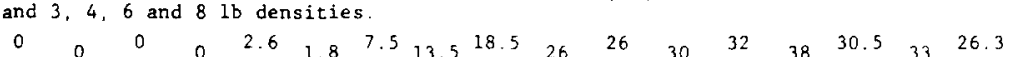

High temperature insulation (up to $2300^{\circ} \mathrm{F}$ ). Flow velocits $30 \mathrm{ft} / \mathrm{sec}$. Available in $2 \times 45$ and $4 \times 25 \mathrm{ft}$ rolls. Available in $1 / 4,1 / 2,1,1-1 / 2$ and 2 inch thicknesses

$\begin{array}{llllllllllllllll}1.8 & 3 & 2 & 5 & 10 & 16.5 & 22.8 & 27.5 & 26 & 29.5 & 33 & 38 & 30 & 33 & 26.5\end{array}$

High temperature insulation (up to $2300^{\circ} \mathrm{F}$ ). Flow velocity $30 \mathrm{ft} / \mathrm{sec}$. Available in

$2 \times 45$ and $4 \times 25 \mathrm{ft}$ rolls. Available in $1 / 4,1 / 2,1,1-1 / 2$ and 2 inch thicknesses

and $3,4,6$ and 8 ib densities.

$\begin{array}{llllllllllllllllllllll}0 & 0 & 0 & 1.8 & 1 & 4.3 & 7 & 15.5 & 21.5 & 17.5 & 24.5 & 27.5 & 28 & 33.8 & 26.5 & 27.5 & 27.5 & 30\end{array}$

Cellulose fibers laminated to polyethylene combined with lead felt, available in

$$
6
$$

20

23

39

42 Cellulose fibers laminated to polyethylene combined with lead, felt, etc. Available in
$4 \times 8 \mathrm{ft}$ sheets. Desntiy given is volume density in $\mathrm{bb} / \mathrm{ft}$.

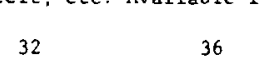

Cellulose fiber blanket in two layers, $1-1 / 2$ inch total thickness, $4 \times 8 \mathrm{ft}$ sheets. 
Table 27B. Pipe lagging (insertion loss).

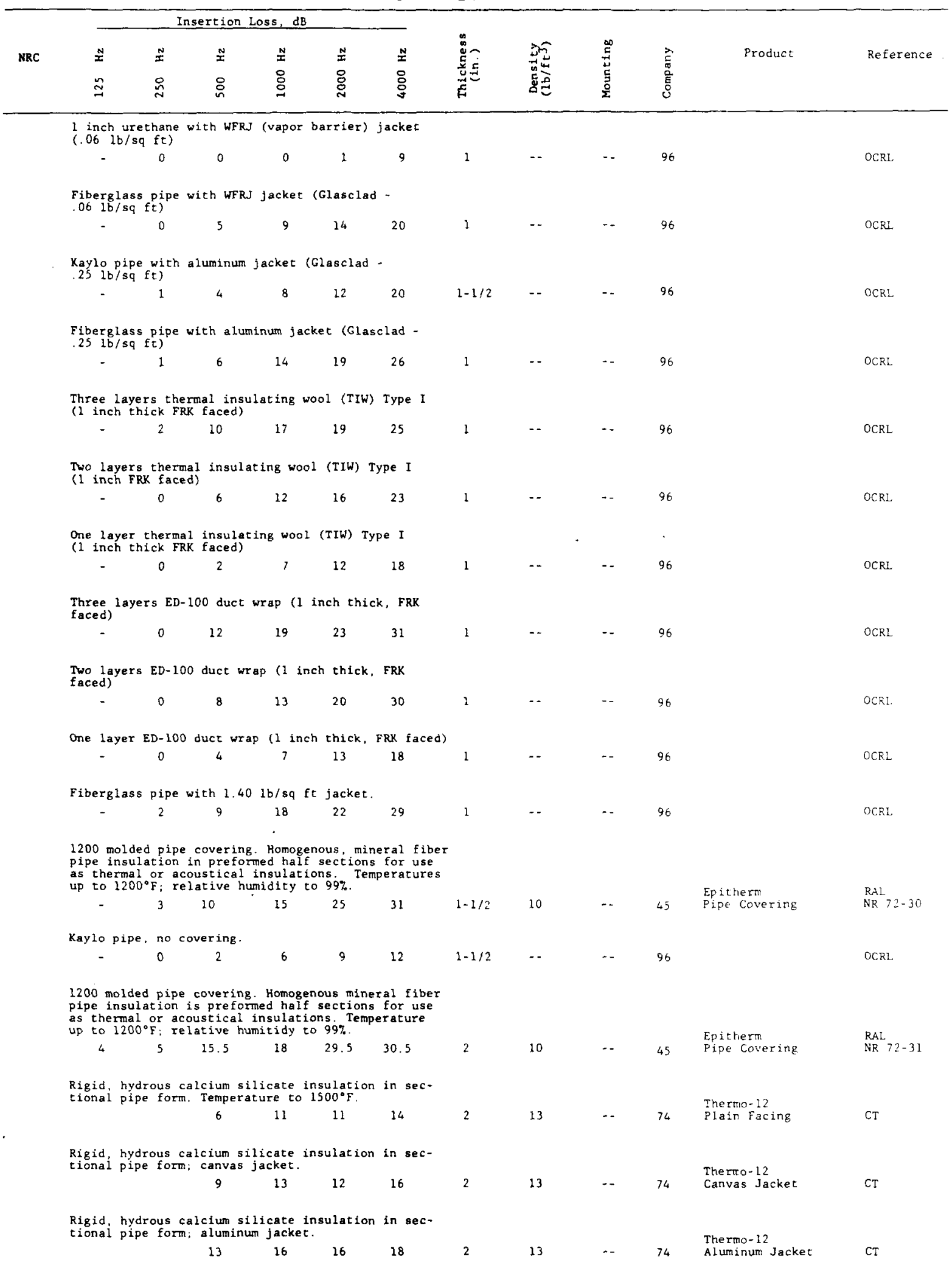


Table 27B. Pipe lagging (insertion loss) concluded.

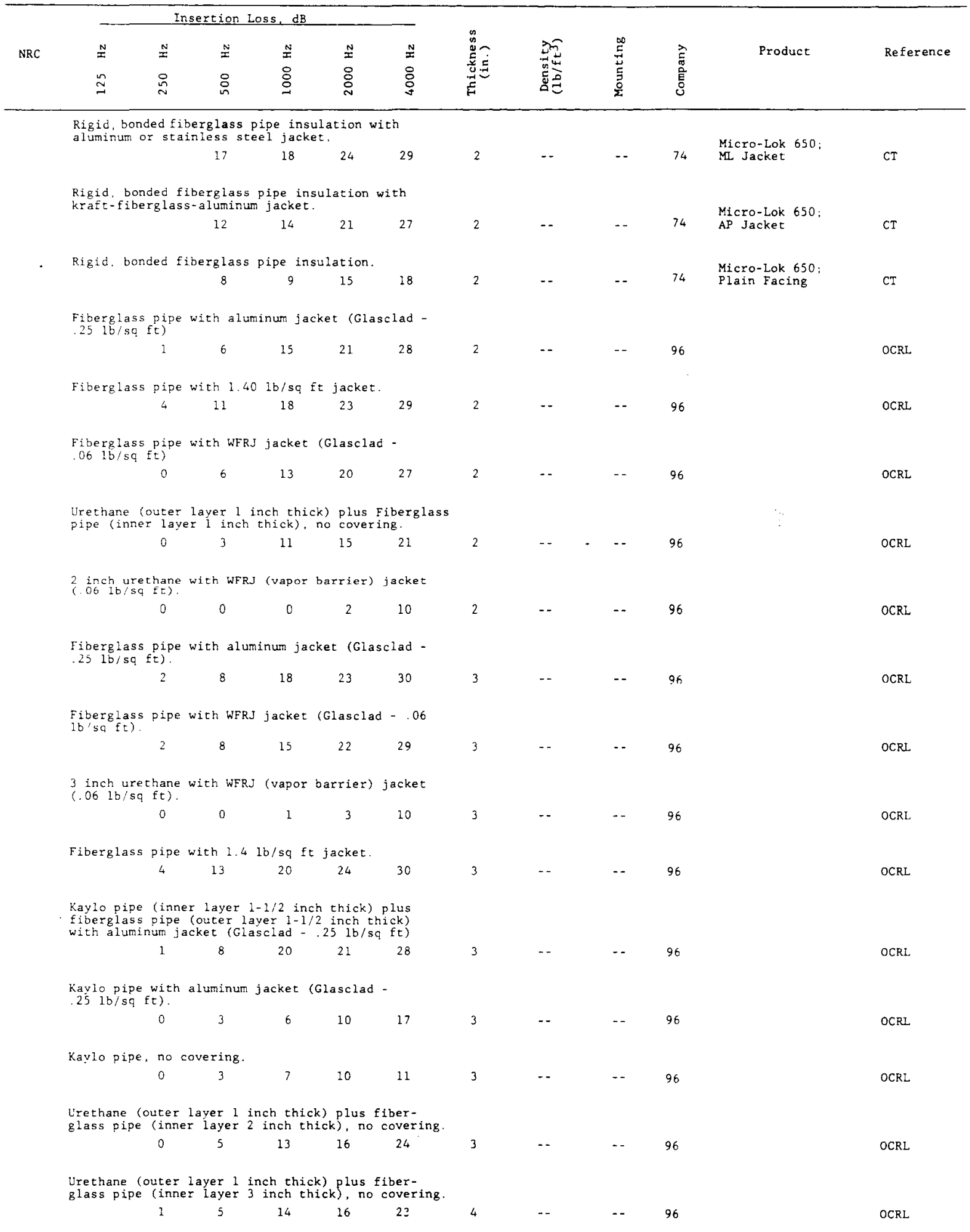


Table 27C. Pipe lagging (transmission loss).

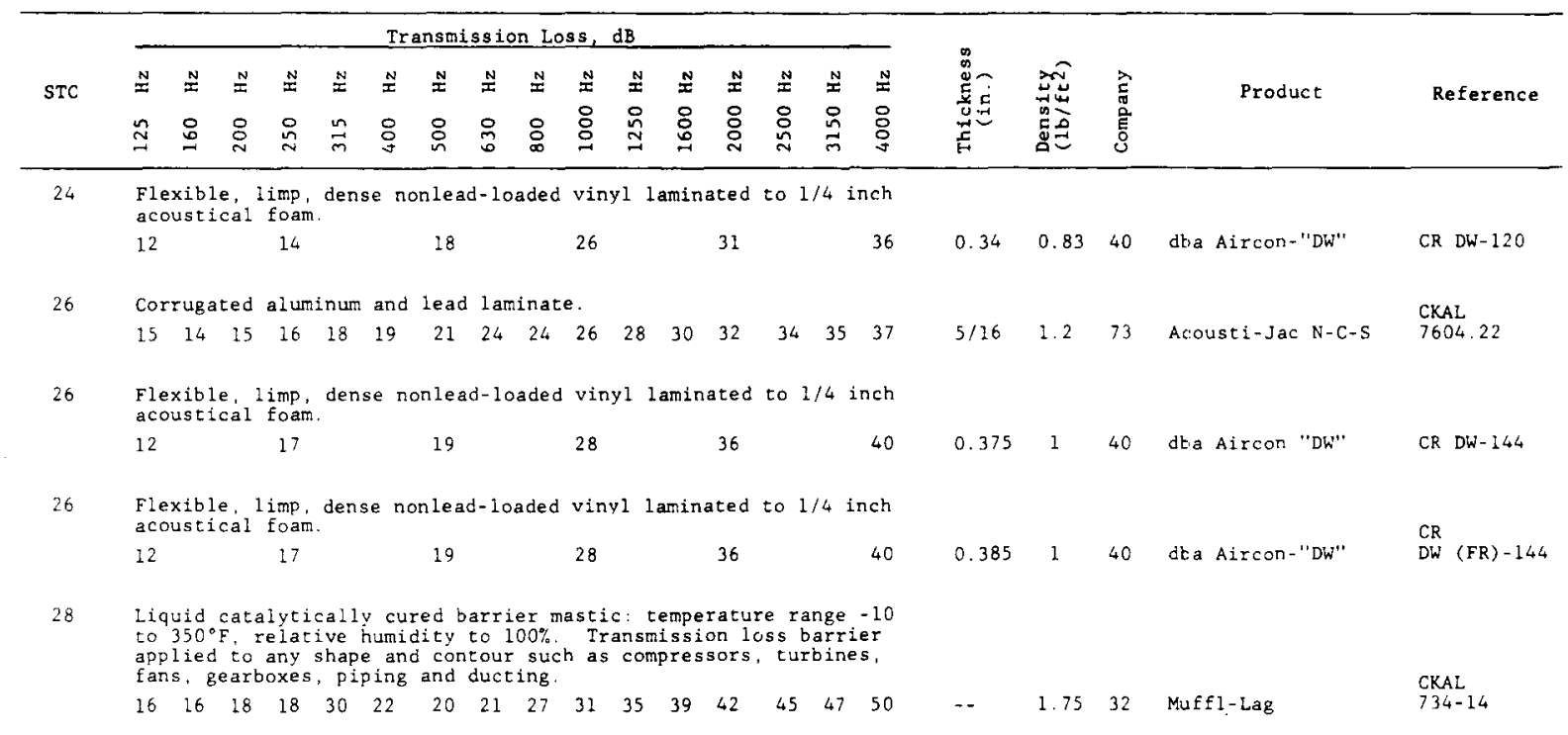




\section{CATEGORY 28, GENERAL INDUSTRIAL SILENCERS}

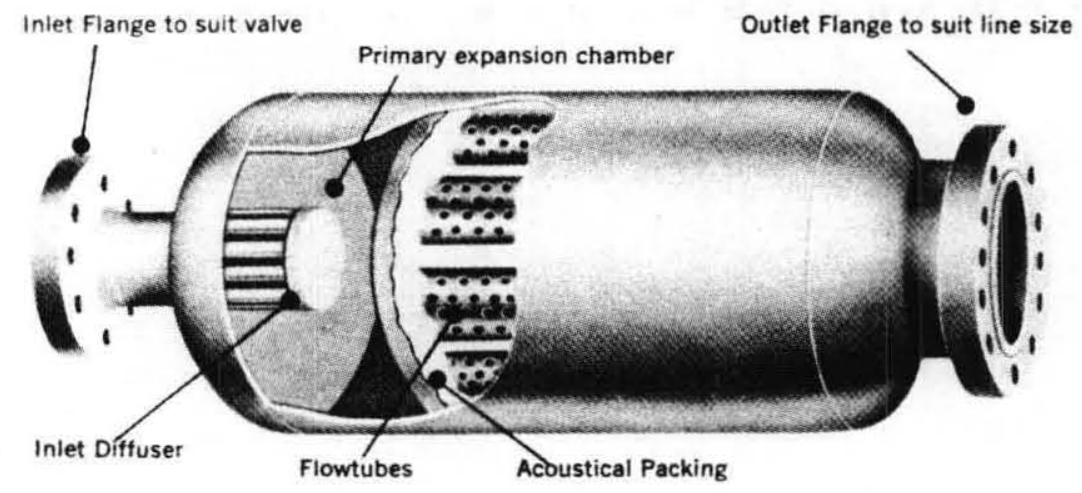


Information in this category is limited to products used in industrial rather than vehicle applications. These silencers are used to quiet gas flows in a variety of applications from high volume airflow to high temperature steam outlets. These units may have reactive or absorptive components or a combination of both. Materials are specified for heavy duty, industrial applications. Organizations contributing data to this table are: $2,5,40,70,102,135$, and 139 .

\section{CAUTION}

1. SILENCER PERFORMANCE FIGURES OFTEN DO NOT CONFORM TO STANDARD REFERENCE MEASUREMENTS. FOR SPECIFIC APPLICATIONS, SEE MANUFACTURER'S PRODUCT LITERATURE.

2. IN MANY CASES, ONLY REPRESENTATIVE INFORMATION IS PRESENTED FOR A GIVEN PRODUCT LINE. SEE MANUFACTURER'S LITERATURE FOR COMPLETE LISTINGS OF SIZES AND PERFORMANCE DATA. 
Table 28A. General industrial silencers (attenuation).

\begin{tabular}{|c|c|c|c|c|c|c|c|c|c|c|}
\hline \multicolumn{8}{|c|}{ Attenuation, $\mathrm{dB}$} & \multirow{3}{*}{ Company } & \multirow{3}{*}{ Product } & \multirow{3}{*}{ Reference } \\
\hline$\stackrel{N}{I}$ & $\stackrel{N}{I}$ & $\stackrel{N}{I}$ & $\stackrel{N}{I}$ & $\stackrel{N}{I}$ & $\stackrel{N}{I}$ & $\stackrel{N}{=}$ & $\stackrel{N}{=}$ & & & \\
\hline$\hat{b}$ & $\stackrel{\sim}{\approx}$ & $\stackrel{\circ}{\sim}$ & 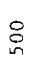 & $\stackrel{8}{8}$ & $\stackrel{8}{\stackrel{\sim}{2}}$ & $\underset{8}{8}$ & $\begin{array}{l}\stackrel{8}{8} \\
\stackrel{\infty}{\infty}\end{array}$ & & & \\
\hline
\end{tabular}

Standard panel filters, fabricated steel sheet and plate, welded. Nominal
capacity 1750 to $63,000 \mathrm{cfm}$.

$\begin{array}{cccccccc}2 & 3 & 4 & 5 & 8 & 13 & 14 & 13 \\ & & & & & & & \end{array}$

$\begin{array}{ccccccccc}\text { capacity } & 1750 & \text { to } & 35,500 & \mathrm{cfm} . & & & & \\ 2 & 3 & 4 & 5 & 8 & 13 & 14 & 13\end{array}$

FSH Series
135 Filter Silencer

CR 241

Unit constructed of heavy duty steel sheet and plate welded throughout

Nominal capacity 1750 to $35,500 \mathrm{cfm}$. Used on centrifugal compressors. blowers and gas turbines.
2
58
$14 \quad 13$

$$
3
$$$$
4
$$

13

3

Heavy duty, compact unit, dry pleated paper element, used on engines,
compressors and blowers. Sizes vary from $7-1 / 2$ inch diameter to $6-1 / 2$ inch compressors and blowers. Sizes vary from $7-1 / 2$ inch diameter to $6-1 / 2$ inch
long with pipe size $1 / 2$ to 20 inch diameter $\times 28-1 / 2$ inch long with 6 inch
5
$8 \quad 10.5$
$12.5 \quad 14$
14
$14 \quad 13$

CCS Series
Intake Filter

CR $34-3002$

Absorption silencer, straight through design, all welded construction

Pipe size 5 to 30 inch, sizes range from 11 inch diameter to 36 inch iong

$\begin{array}{cccccccc}20 & 36 & \text { inch diameter } x & \text { i } 89 & \text { inch long. } & & & \\ 2 & 3 & 5 & 8 & 15 & 22 & 23 & 20\end{array}$

Heavy duty, all welded, explosion resistant, flange type, straight through design, and exterior surfaces prime coated. Pipe size 4 to 36 inch, various sizes from: 10 inch diameter $x 33$ inch long to 54 inch diameter $\times 227$ inch long Vertical or horizontal mounch
17
$18 \quad 17$
$17 \quad 16 \quad 13$
1187

Air intake silencer, pipe sizes from 22 to 36 inch, and size varies from inch diameter $x 57$ inch long to 40 inch diameter $x 93$ inch long.
45
$5 \quad 7$
$11 \quad 17$
22
$22 \quad 19$

135 SL3H Series

CR $12-3003$

Heavy duty assembly with a weather hood, employs an oil wetted polyurethane foam filter element for use on small blowers, compressors, and engines.
Rated capacity 15 to $1050 \mathrm{cfm}$.
14
17
19
18
$15 \quad 14$
$13 \quad 12$

FS Series

CR 242

Exhaust silencers for turbo charged engines, welded steel, exterior surfaces prime coated. gas flows through a ported tube and attenuating chambers.
12
$23.5 \quad 24$
16.5
10.5
$10.5 \quad 10.5$

Mode 1 A4

CR $\mathrm{A}^{4 / 9 / 74}$

Intake filter/silencer for reciprocating engines, compressors, blowers, for low and midfrequency noise reduction. Welded steel, exterior surfaces are prime coated. Internal surfaces are cleaned and coated with a rust inhibitor

19

$22.5 \quad 19$

$15 \quad 12$

$10.5 \quad 10.5$

Mode 1 AIO

CR Al0/9/74

Intake and exhaust silencers for reciprocating engine blowers, compressors Welded steel. exterior faces prime coated. gas flows through ported tubes and at tenuating chambers.
17
212
$17.5 \quad 15 \quad 14$
$13 \quad 12$

Mode 1 Al

CR Al/9/74

Spark arrester/exhaust silencer for reciprocating engines, welded steel, .

exterior surfaces are prime coated. The spark collector box is provided with a plugged outlet which can be led to any convenient point. Gas flow through ported tubes and attenuating chambers. Vertical mounting.
$17.5 \quad 21$
20.5
$\begin{array}{lll}18 & 15.5 & 14.5\end{array}$
$13.5 \quad 13$
Mode $1 \mathrm{~A}$ ?
CR A7/9/74

Heavy duty all welded construction with spark traps, explosion resistant, exterior surface prime coated, standard silencing. Pipe sizes 4 to 30 inch
Various sizes 14 inch diameter $x 35$ inch long to 66 inch diameter $x 146$ inch long. Vertical or horizontal mounting.
17
19
$15 \quad 14$

18

16

Noncritical silencer, industrial usages, pipe size 1 to 30 inch. Various
sizes from 5 inch diameter $x 21$ inch long to 72 inch diameter $\times 229$ inch

sizes
long.

CR 224B 
Table 28A. General industrial silencers (attenuation) concluded.

\begin{tabular}{|c|c|c|c|c|c|c|c|c|c|c|}
\hline \multicolumn{8}{|c|}{ Attenuation, $\mathrm{dB}$} & \multirow{3}{*}{ Company } & \multirow[b]{2}{*}{ Product } & \multirow{3}{*}{ Referenc } \\
\hline$\stackrel{N}{x}$ & $\stackrel{N}{x}$ & $\stackrel{N}{ \pm}$ & $\stackrel{N}{x}$ & N & $\stackrel{N}{x}$ & $\cong$ & $\stackrel{N}{x}$ & & & \\
\hline 8 & 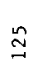 & $\stackrel{0}{\sim}$ & 吕 & $\stackrel{8}{\circ}$ & $\stackrel{8}{8}$ & : & ¿ & & & \\
\hline
\end{tabular}
A heavy duty, welded unit constructed of carbon steel sheet plate used
for critical pLV applications. Pipe size from 1 to 30 inch, diameter versus length from $8 \times 27$ inch to $66 \times 206$ inch

$\begin{array}{cccccccccc}17 & 21 & 24 & 26 & 27 & 26 & 25 & 21\end{array}$

RIS Group,

135 Type Inlet Silencer

CR 244

Intake and exhaust silencers for reciprocating engines, blowers, compressors. Welded steel, exterior surfaces prime coated, gas flows through series of ported tubes, and attenuating chambers.

Reactive chamber type silencer, for large slow speed reciprocating or positive displacement machinery, Nominal capacity 1875 to 26,000 cfn.

$\begin{array}{llllllll}28 & 29 & 29 & 28 & 26 & 25 & 24 & 28\end{array}$

Maximum silencing, nontuned, multichambered: pipe size 1 to 30 inch various sizes from 5 inch diameter $x 21$ inch long to 72 inch diameter $\times 265$ inch long

Heavy duty, welded unit, constructed of carbon steel sheet and plate Used for subcritical PLV apolications. Pipe size 1 to 30 inch size range 5 inch diameter $x 21$ inch long to 72 inch diameter $\times 304$ inch iong.

28

27

26

$25 \quad 24$

Heavy duty, welded unit. constructed of carbon steel sheet and plate. Used for companion silencer with UCD series, pipe size 10 to 30 inch. size ranges 30 inch diameter $\times 54-1 / 2$ inch long to 72 inch diameter $\times 133$ inch long.

$\begin{array}{llllllll}21 & 26 & 23 & 32 & 32 & 30 & 26 & 21\end{array}$

Heavy duty, welded unit, constructed of carbon steel sheet and plate. Used for critical PLV applications pipe size to 30 inch. size ranges
6 inch diameter $x 29$ inch long to 60 inch diameter $x 276$ inch long.

$$
\begin{array}{llllllll}
22 & 26 & 30 & 32 & 32 & 30 & 27 & 21
\end{array}
$$

Application intake and exhaust silencers for blowers compressurs noise reduction ovar a wide frequency range, welded steel, exterior surface prtenuating hampers and up to groular airway ined through a series of material which is retained by perforated sheet steel and woven fabric.

16 which is retained by perforated sheet steel and woven fabric.

take and exhaust silencers for reciprocating engines, compressors,

Intake and exhaust silencers for reciprocating engines, compressors, blowers, exhausters, pumps. Welded steel, exterior surface prime coated. sound absorbent materiai which is retained by perforated sheet steel and layers of woven fabric.
6,5
il 20.5
$46 \quad 41 \quad 24$

Aluminum exhaust silencer, pipe sizes 2-1/2 to 54 inch. Varied sizes range from 10 inch diameter $x 41$ inch long to 114 inch diameter $x$ so inch long.
34
35.5
32
31.
30 .
29

Heavy duty, welded unit, constructed of carbon steel sheet and plate,

used for critical PLV applications. Pipe size 1 to 30 inch, size ranges

8 inch diameter $x 33$ inch long to 72 inch diameter $\times 304$ inch $10 n 8$.

$\begin{array}{llllllll}28 & 32 & 35 & 36 & 37 & 36 & 27 & 26\end{array}$

Engine exhaust muffler for reciprocating encines, various sizes, carbon stee 1.

$\begin{array}{lllllllll}34 & 36 & 37 & 36 & 34 & 32 & 30 & 28\end{array}$

Intake and exhaust silencers for blowers, compressors; high noise reduc

tion over a wide frequency range. All welded steel, exterior surfaces prime

coated. Temperature up to

chambers and a circular airway lined

is retained by a perforated sheet steel and woven fabric.

$2207.532 .5037 .5-43043.5038 .5$

29.5

2

Absorptive-type silencer, heavy duty, welded steel construction with acoustical packing. Pipe size $1 / 2$ to 48 inch, with $3-1 / 2$ inch diameter $x 10$ inch long to

Carbon steel, one coat primer sizes 4 to 24 inch diameter inlet. Broadband silencing for specific flow. Model $P$ (intake lexhaust silencer) pulsating flow resonator design; Model PB suitable for high-pressure, high velocity flow, continuous or intermittent; Model PE, for high velocity flow with low pressure

arop requirements
Model A14

CR. A14/9/74

Quietflo

Silencer CIS-DCS

UR AND URD

Chamber Type

WBM Series

lower Mounted SD Group Combination Discharge Silence

Model A13

CR Al3/9/74

RD Group, Combination Chamber Absorptive Type 244

dba aircon- "M"

CR Models P, PB, PE
Silencers

CR NCD-7553 
Table 28B. General industrial silencers (insertion loss).

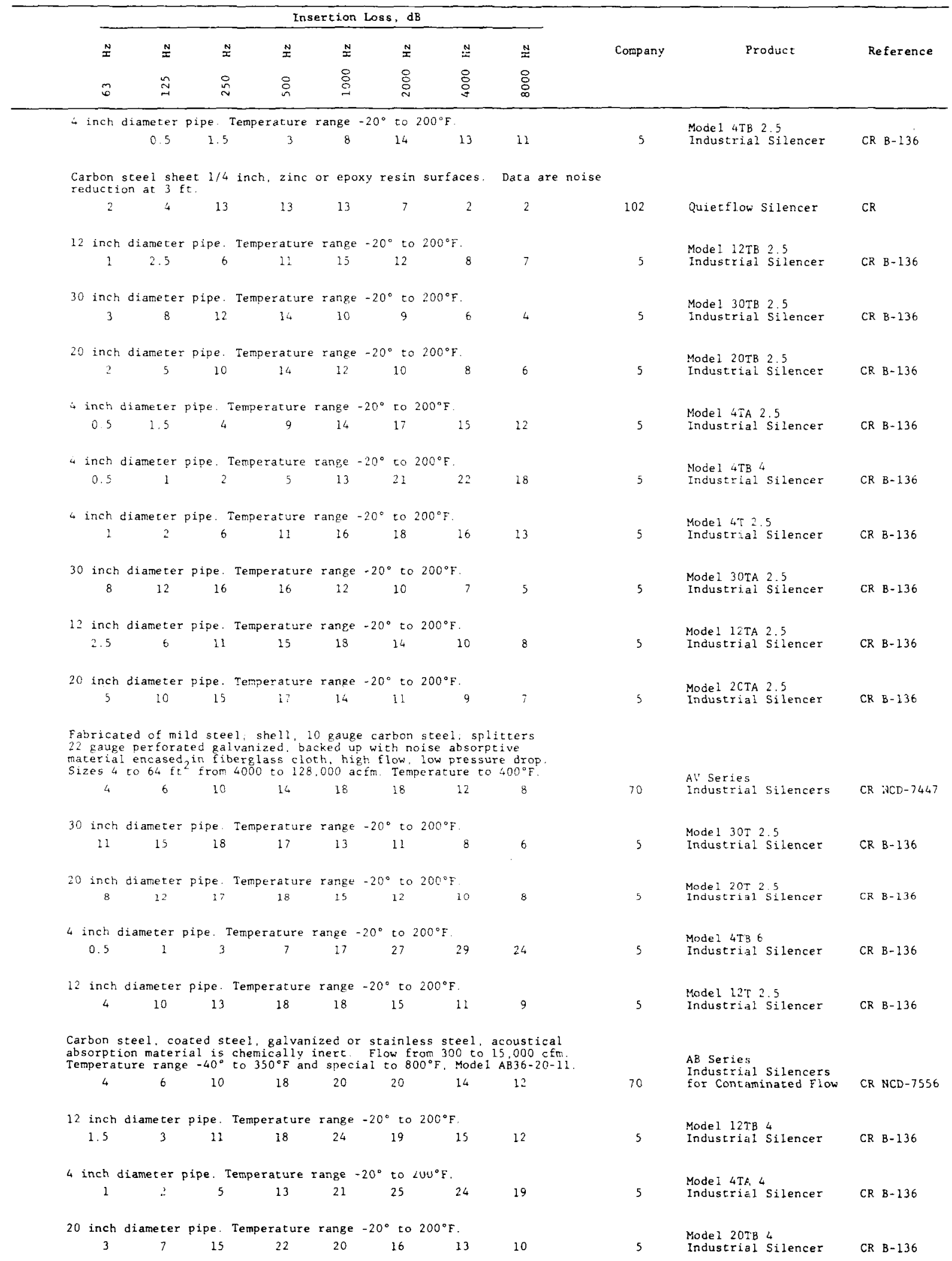


Table 28B. General industrial silencers (insertion loss) continued.

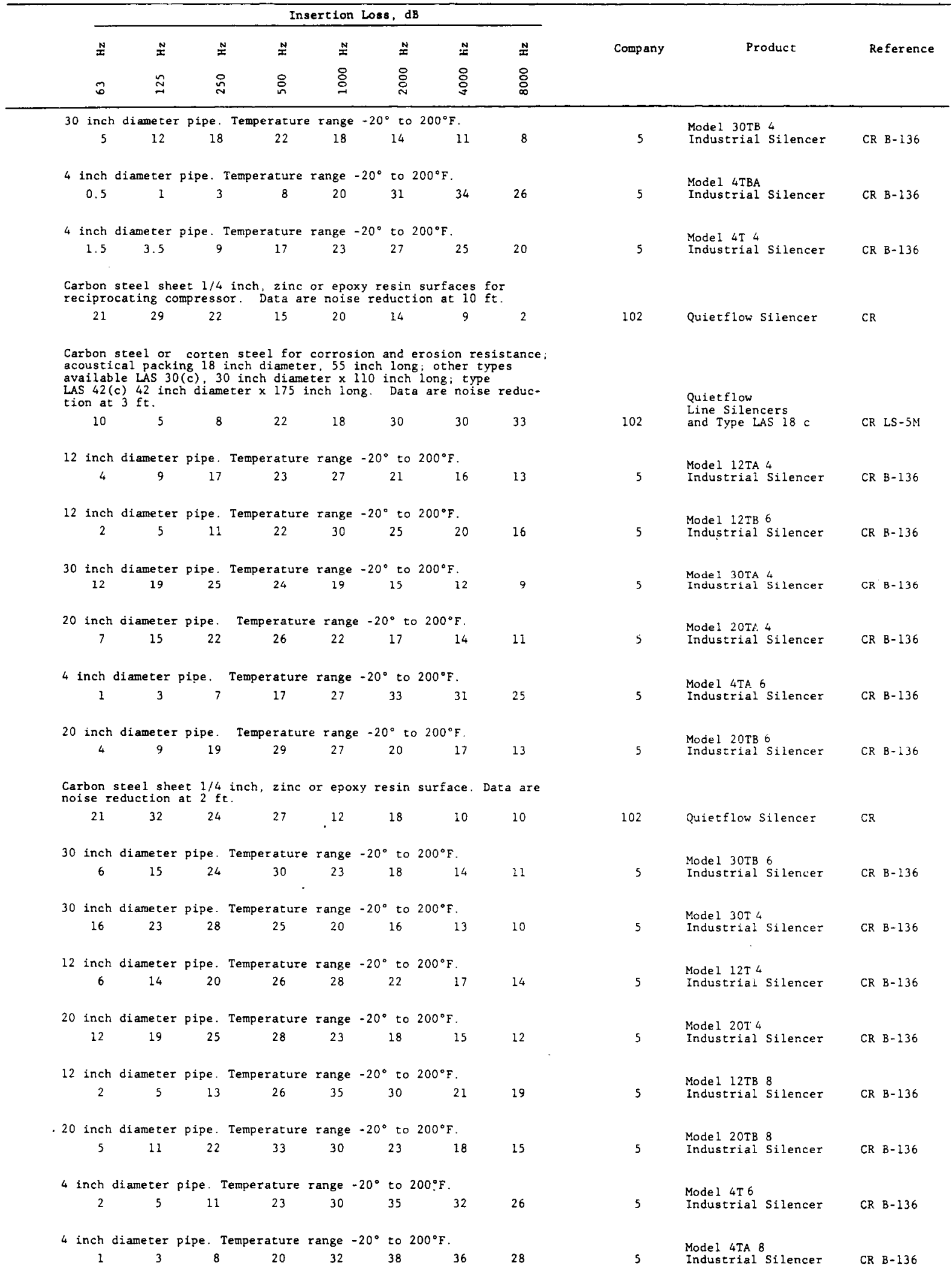


Table 28B. General industrial silencers (insertion loss) concluded.

\begin{tabular}{|c|c|c|c|c|c|c|c|c|c|c|c|c|}
\hline & \multicolumn{8}{|c|}{ Insertion Loss, $\mathrm{dB}$} & \multirow{3}{*}{ Company } & \multirow{3}{*}{ Product } & \multirow{3}{*}{\multicolumn{2}{|c|}{ Reference }} \\
\hline \multirow{2}{*}{\multicolumn{2}{|c|}{$\begin{array}{l}\stackrel{N}{x} \\
m \\
m\end{array}$}} & \multirow{2}{*}{$\begin{array}{l}\mathbb{N} \\
\stackrel{n}{N}\end{array}$} & \multirow{2}{*}{$\begin{array}{l}= \\
2 \\
2\end{array}$} & \multirow{2}{*}{$\begin{array}{l}\underset{N}{2} \\
\stackrel{8}{8}\end{array}$} & \multirow{2}{*}{ 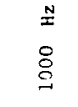 } & \multirow{2}{*}{$\begin{array}{l}\text { N } \\
\stackrel{8}{8} \\
\stackrel{8}{0}\end{array}$} & \multirow{2}{*}{$\begin{array}{l}\stackrel{N}{=} \\
\text { ㅇ } \\
\stackrel{O}{9}\end{array}$} & \multirow{2}{*}{$\begin{array}{l}\text { N } \\
8 \\
8 \\
8\end{array}$} & & & & \\
\hline & & & & & & & & & & & & \\
\hline & $\begin{array}{l}\text { low tub } \\
\text { orten } \\
\text { elded }\end{array}$ & $\begin{array}{l}\text { ibes, acous } \\
\text { stee } 1 \text { for } \\
\text { constructi }\end{array}$ & $\begin{array}{l}\text { stic pa } \\
\text { flow } \\
\text { ion. D }\end{array}$ & $\begin{array}{l}\text { acking. explo } \\
\text { tubes. heavy } \\
\text { Data are nois }\end{array}$ & $\begin{array}{l}\text { osion } \\
\text { wall } \\
\text { se redu }\end{array}$ & $\begin{array}{l}\text { chamber, } \\
\text { carbon s } \\
\text { uction. }\end{array}$ & $\begin{array}{l}\text { construc } \\
\text { steel for }\end{array}$ & $\begin{array}{l}\text { on includes } \\
\text { shell, all }\end{array}$ & & \multirow{2}{*}{$\begin{array}{l}\text { Quiet flo } \\
\text { Vent Silencers } \\
\text { Type Vs } 108\end{array}$} & \multirow{2}{*}{\multicolumn{2}{|c|}{$C R$}} \\
\hline & 7 & 7 & 20 & 22 & 26 & 33 & 36 & 36 & 102 & & & \\
\hline \multirow[t]{2}{*}{12} & 2 inch & diameter & pipe. & Temperature & range & $-20^{\circ}$ to & $200^{\circ} \mathrm{F}$ & & & Mode 12 TA 6 & & \\
\hline & 5 & 11 & 22 & 30 & 35 & 27 & 21 & 17 & 5 & Industrial Silencer & $C R$ & B-136 \\
\hline \multirow[t]{2}{*}{30} & inch & diameter & pipe. & Temperature & range & $-20^{\circ}$ to & $200^{\circ} \mathrm{F}$ & & & Mode 1 30TA 6 & & \\
\hline & 15 & 24 & 32 & 32 & 25 & 19 & 15 & 12 & 5 & Industrial Silencer & $C R$ & $B-136$ \\
\hline \multirow[t]{2}{*}{30} & inch & diameter & pipe. & Temperature & range & $-20^{\circ}$ to & $0200^{\circ} \mathrm{F}$ & & & Mode $130 \mathrm{~TB} 8$ & & \\
\hline & 7 & 18 & 28 & 35 & 28 & 22 & 18 & 13 & 5 & Industrial Silencer & $C R$ & $B+136$ \\
\hline \multirow[t]{2}{*}{20} & inch & diameter & pipe. & Temperature & range & $-20^{\circ}$ to & - $200^{\circ} \mathrm{F}$ & & & Model 20TA 6 & & \\
\hline & 9 & 20 & 29 & 34 & 29 & 22 & 18 & 14 & 5 & Industrial Silencer & $C R$ & $B-136$ \\
\hline \multirow[t]{2}{*}{4} & inch 0 & diameter $\mathrm{P}$ & pipe. I & Temperature $r$ & fange - & $-20^{\circ}$ to & $200^{\circ} \mathrm{F}$ & & & Model 4 T 8 & & \\
\hline & 2 & 5 & 16 & 26 & 35 & 40 & 37 & 30 & 5 & Industrial Silencer & $C R$ & $B-136$ \\
\hline \multirow[t]{2}{*}{30} & inch & diameter & pipe. & Temperature & range & $-20^{\circ}$ to & - $200^{\circ} \mathrm{F}$. & & & Model 30- 6 & & \\
\hline & 21 & 30 & 36 & 33 & 26 & 20 & 16 & 13 & 5 & Industrial silencer & $C R$ & $8-136$ \\
\hline \multirow[t]{2}{*}{20} & inch & diameter & pipe. & Temperature & range & $-20^{\circ}$ to & $0200^{\circ} \mathrm{F}$. & & & Model $20 \tau 6$ & & \\
\hline & 15 & 24 & 32 & 36 & 30 & 23 & 19 & 15 & 5 & Indust tial Silencer & $C R$ & $B-136$ \\
\hline \multirow[t]{2}{*}{12} & 2 inch & diameter & pipe. & Temperature & range & $-20^{\circ}$ to & $200^{\circ} \mathrm{F}$ & & & Model $12 T 6$ & & \\
\hline & 8 & 18 & 26 & 34 & 36 & 28 & 22 & 18 & 5 & Industrial Silencer & $C R$ & $B-136$ \\
\hline \multirow[t]{2}{*}{12} & inch & diameter & pipe. & Temperature & range & e $-20^{\circ} \mathrm{t}$ & to $200^{\circ} \mathrm{F}$. & & & Model $22 \mathrm{TA} 8$ & & \\
\hline & 5 & 13 & 26 & 35 & 40 & 32 & 23 & 20 & 5 & Industrial silencer & $\mathrm{CK}$ & $5-: 30$ \\
\hline 30 & inch & diameter & pipe. & Temperature & range & $-20^{\circ}$ to & - $200^{\circ} \mathrm{F}$ & & & Mode 1 30TA 8 & & \\
\hline & 18 & 28 & 38 & 37 & 29 & 23 & 19 & 14 & 5 & Industrial Silencer & $C R$ & $5-136$ \\
\hline 20 & inch & diameter & pipe. & Temperature & range & $-20^{\circ}$ to & - $200^{\circ} \mathrm{F}$ & & & Model 20TA 8 & & \\
\hline & 11 & 23 & 33 & 40 & 33 & 25 & 20 & 16 & 5 & Industrial silencer & $C R$ & $B-136$ \\
\hline 30 & inch & diameter & pipe. & Temperature & range & $-20^{\circ}$ to & - $200^{\circ} \mathrm{F}$ & & & Mode 1 \OT 8 & & \\
\hline & 24 & 35 & 42 & 38 & 30 & 24 & 19 & 15 & 5 & Industrial Silencer & $C R$ & $8 \cdot 136$ \\
\hline 12 & inch & diameter & pipe. & Temperature & range & $-20^{\circ}$ <0 & $0200^{\circ} \mathrm{F}$ & & & Model $12 T A$ & & \\
\hline & 9 & 22 & 30 & 40 & 41 & 33 & 25 & 21 & 5 & Industrial silencer & $C R$ & $B-136$ \\
\hline 20 & inch & diameter & pipe. & Temperature & range & $-20^{\circ}<0$ & C $200^{\circ} \mathrm{F}$ & & & & & \\
\hline & 18 & 28 & 38 & 42 & 35 & 27 & 22 & 17 & 5 & Industrial silencer & $C R$ & $8-136$ \\
\hline $\begin{array}{l}\text { Int } \\
\text { sta }\end{array}$ & $\begin{array}{l}\text { take } 0 \\
\text { rainles }\end{array}$ & $\begin{array}{l}\text { or dischar } \\
\text { ss steel s }\end{array}$ & $\begin{array}{l}\text { rge sil } \\
\text { screen }\end{array}$ & $\begin{array}{l}\text { lencer, carbor } \\
\text { and fibergla }\end{array}$ & $\begin{array}{l}\text { on stee } \\
\text { ass clo }\end{array}$ & $\begin{array}{l}\text { el, fibe } \\
\text { oth. }\end{array}$ & erglass $p$ & & & & & \\
\hline & 11 & 18 & 32 & 42 & 48 & 50 & 49 & 37 & 40 & dba aircon-"S" & $C R$ & \\
\hline Ino & dustri & ial silenc & cers fo & or various nee & eds. & & & & 139 & Vanec Silencers & $C R$ & \\
\hline
\end{tabular}


CATEGORY 29, HIGH PRESSURE DISCHARGE SILENCERS
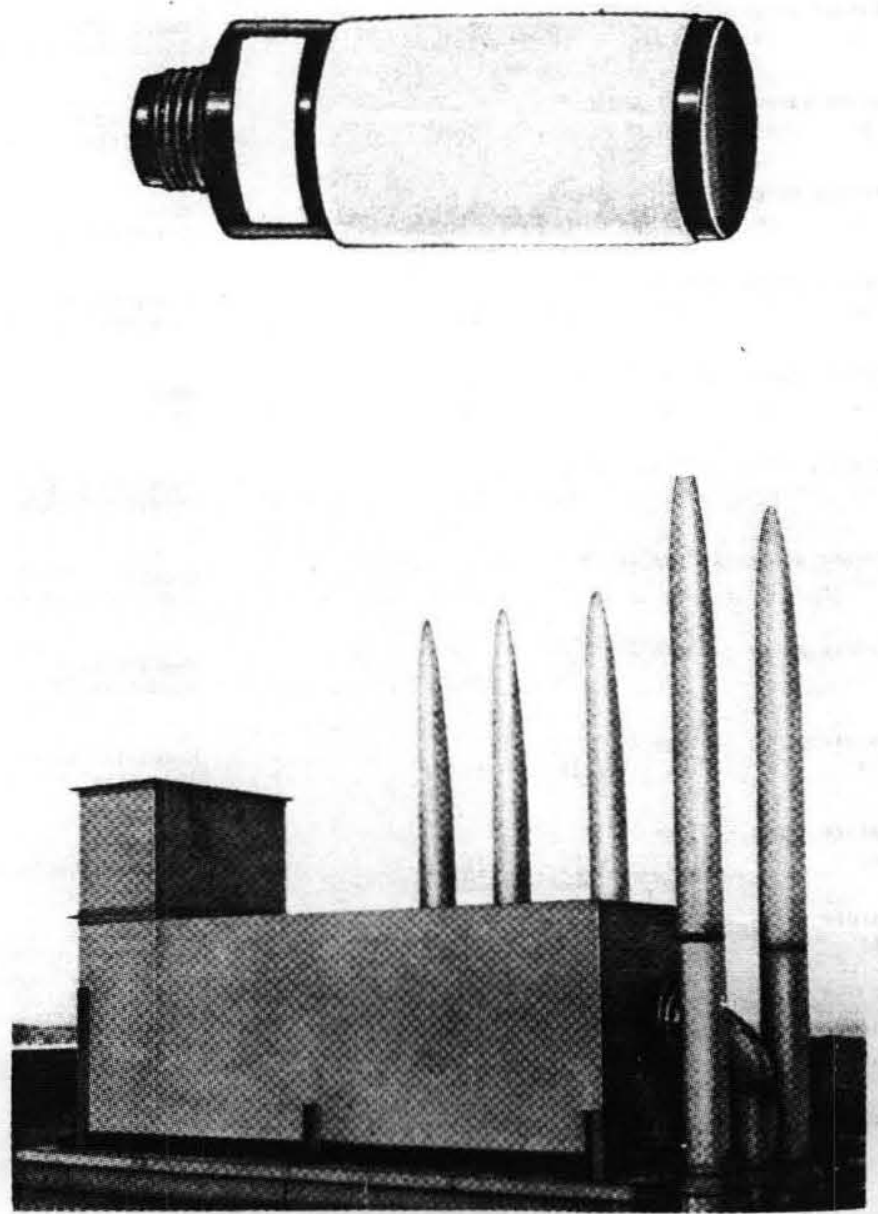
These silencers range in size from less than 1 inch in diameter to several feet in diameter. They are used to quiet high pressure gas or steam discharges. The simplest application is for noise reduction of shop air discharge lines. Large geometries are used in exhaust or industrial discharge stack applications. Organizations contributing data to this table are: 2, 5, $9,16,17,19,40,56,63,80$, and 124 .

\section{CAUTION}

1. SILENCER PERFORMANCE FIGURES OFTEN DO NOT CONFORM TO STANDARD REFERENCE MEASUREMENTS. FOR SPECIFIC APPLICATIONS, SEE MANUFACTURER'S PRODUCT LITERATURE.

2. IN MANY CASES, ONLY REPRESENTATIVE INFORMATION IS PRESENTED FOR A GIVEN PRODUCT LINE. SEE MANUFACTURER'S LITERATURE FOR COMPLETE LISTINGS OF SIZES AND PERFORMANCE DATA. 
Table 29. High pressure discharge silencers.

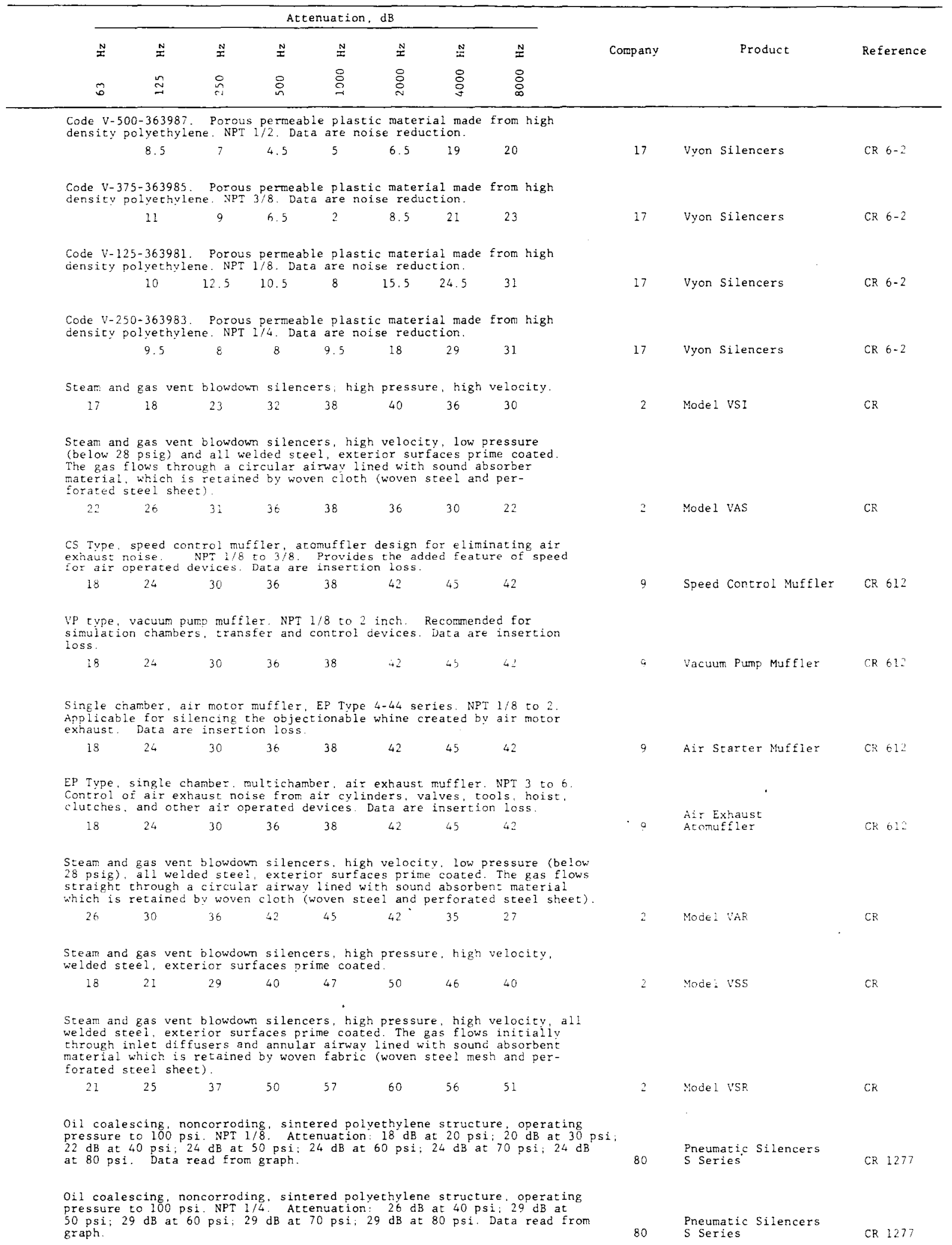


Table 29. High pressure discharge silencers continued.

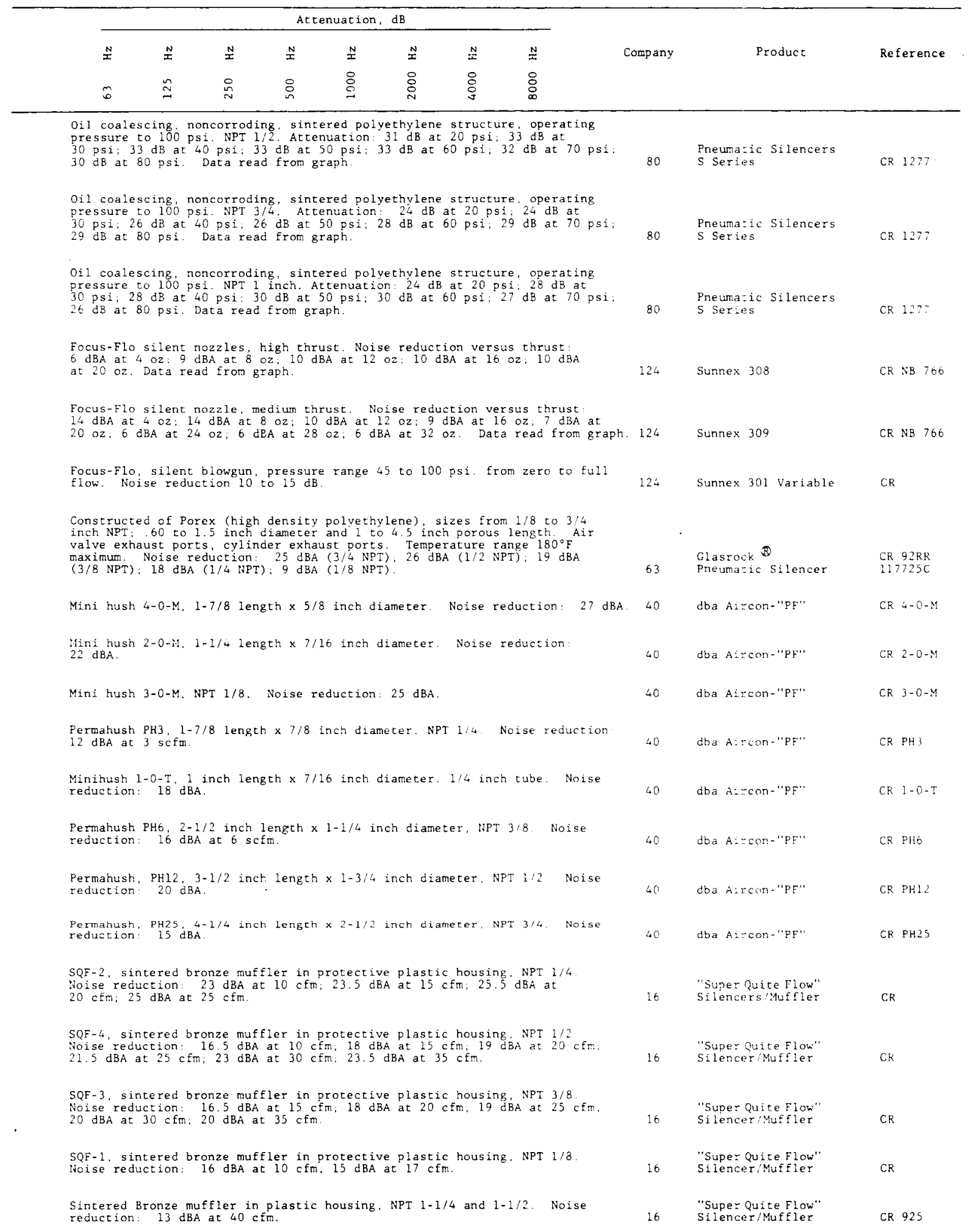


Table 29. High pressure discharge silencers concluded.

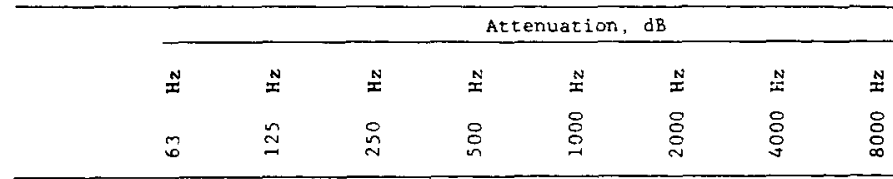

Model SBL. 25 to $30 \mathrm{dBA}$ reduction when used on $100 \mathrm{psi}$ air.

Blowoff silencers

CR B-32R3

Water-resistant acoustic packing for use with steam. Noise reduction $37 \mathrm{dBA} .5$

Model HBS Silencer

Water-resistant acoustic packing for use with steam. Noise reduction $46 \mathrm{dBA} .5$

Model RBS Silencer

Model TSN-125, metal construction, can be used for stationary air cleaning applications, NPT $1 / 8,78 \mathrm{dBA}$ at $3 \mathrm{ft}$ and $0.5 \mathrm{lbf}$

19

Model QE-125. metal construction, NPT $1 / 8$. dBA at $3 \mathrm{ft}: 61.5$ at $10 \mathrm{scfm}$;

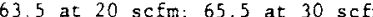

Model TSN-250, metal construction, can be used for stationary air cleaning applications. NPT $1 / 4.80 \mathrm{dBA}$ at $3 \mathrm{ft}$ and $0.5 \mathrm{lbf} ; 85 \mathrm{dBA}$ at $3 \mathrm{ft}$ and $1 \mathrm{bf}$ Model QE-250, metal construction. $\mathrm{IPT} 1 / 4$. dBA at $3 \mathrm{ft} .62 .5$ at $10 \mathrm{scfm}$; 65 at 20 scfm: 67 at $30 \mathrm{scfm} ; 68.5$ at $40 \mathrm{scfm}$.

Model QE-375, metal construction, NPT $3 / 8$. dBA at $3 \mathrm{ft}: 69$ at $10 \mathrm{scfm} ; 72$ at $20 \mathrm{ct}$

Model QE-500, metal construction. NPT 1/2. dBA at $3 \mathrm{ft}: 74$ at $20 \mathrm{sefm}$;

Model QE-500. metal construction, NPT 150 . dBA at 3 ft: 74 at 2

Hush-flo silencer nozzle, metal construction. Sizes up to NPT $1 / 2$. dBA at

Hush-Flo silencer nozzle, metal construction. Sizes up to NPT $1 / 2$
$3 \mathrm{ft}: 59$ at $10 \mathrm{scfm} ; 63$ at $20 \mathrm{scfm} ; 68$ at $30 \mathrm{scfm} ; 73$ at $40 \mathrm{scfm}$

Mape micro-miniature tuffler. compact, lightweipht, radial flow discharge. NPT $1 / 8$ and $1 / 4$ inch. Use on pneumatic circuit applications such as control. pilor limit, zone and relay values.

PM Type, model P, porous metal iilter and muffler compact, applicable limited space intake filcering crvogenic phase separation, pressure or vactum equalization. MNPT $1 / 8$ to 2 inch.

PC Type. model $C$, porous metal adjustable flow filter and muffler, controls air cycle speeds. regulates airflow, adjustable flow. $1 / 8$ to 1 inch MNPT

AE Type, air ejector muffler, adaptable to any compressed air ejector presentiy used for the ejection of parts. $1 / 8$ to 1 inch NPT.

B:: Type, bantam muffler, compact, applicable limited space, corrosionresistant metal, disperses exhaust air over a 360 deg pattern. $1 / 8$ to 2 inch NPT.

FS Type, filter silencer, dual-stage depeh filtration, noise attenuation, perform at high or low velocities, NPT $1 / 8$ to 2 inch and 3 to 6 inch

TF Type, Thru-Flow muftler, constructed of corrosion-resistant material, for Tp Tications where compressed air is being used on heavy slurries.

AE Type, model $T$. tube type air ejector, pinpoints noise-free parts ejection AE Type, model $T$. tube type air ejectoz, pinpoints
size $1 / 4$ and $3 / 4$ inch diameter $x 12$ inch length.

DF Type, end flow muffler, lightweight, single direction exhaust airflow, small in size, $1 / 8$ to 2 inch $\mathrm{NPT}$

SM Type, steam exhaust muffler, compact, lightweight, corrosion resistant has coating for resistance to alkalis, heavy duty metal cylinder wall dis

Carbon steel, low alloy corrosion resistant material, glass fiber or scovia acoustic pack. heavy gauge sheet acoustic facing, steel bar supports, steel acoustic pack, heavy
ThrustR

CR PC-78

Quiek

CR PC-78

19

Thrust R

CR PC -78

Quiek:

CR PC -78

Quiek

CR PC-78

Quiek

CR PC-78

19 Hush-F1o Nozzle

CR PC-78

Micro-Miniature

Puffler

CR 612

Porous Metal

Filter $\&$ Muffler

CR 612

Adjustable Flow

CR

9 Air Ejector Muffler

CR 612

Bantam Muffler

CR

9 Filter Silencer

CR 612

Thru-Flow Muffler

CR

Tube Type
Air Ejector Muffler

CR

End Flow Muffler

CR 612

Steam Exhaust Muffler

CR 612 
CATEGORY 30, FAN SILENCERS

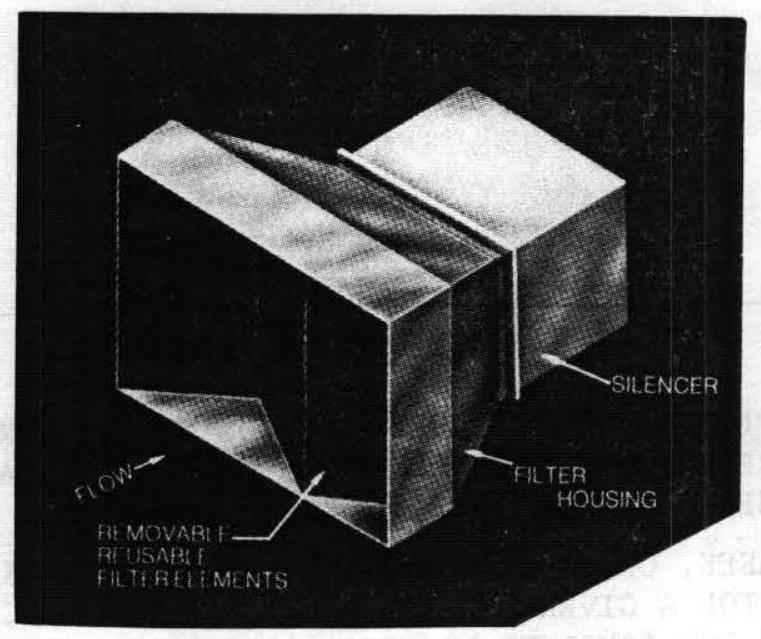




\section{CATEGORY 30. FAN SILENCERS}

Silencers in this group may be used on either fan inlet or discharge plenums. Characteristic dimensions are difficult to identify since length, width, and height are all variables. These silencers often include filters, transition sections, and plenum volumes. Interior splitter or baffle geometries are usually used as primary noise reduction methods. Organizations contributing data to this table are: 5 and 50.

\section{CAUTION}

1. SILENCER PERFORMANCE FIGURES OFTEN DO NOT CONFORM TO STANDARD REFERENCE MEASUREMENTS. FOR SPECIFIC APPLICATIONS, SEE MANUFACTURER'S PRODUCT LITERATURE.

2. IN MANY CASES, ONLY REPRESENTATIVE INFORMATION IS PRESENTED FOR A GIVEN PRODUCT LINE. SEE MANUFACTURER'S LITERATURE FOR COMPLETE LISTINGS OF SIZES AND PERFORMANCE DATA. 
Table 30. Fan silencers (insertion 1oss).

\begin{tabular}{|c|c|c|c|c|c|c|c|c|c|c|}
\hline \multicolumn{8}{|c|}{ Insertion Loss, dB } & \multirow{3}{*}{ Company } & \multirow{3}{*}{ Product } & \multirow{3}{*}{ Reference } \\
\hline$\stackrel{N}{I}$ & 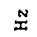 & $\stackrel{N}{I}$ & N & 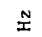 & $\stackrel{N}{X}$ & $\stackrel{N}{=}$ & $\mathbb{N}$ & & & \\
\hline$\hat{b}$ & $\stackrel{\cong}{\approx}$ & 怘 & in & 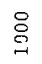 & 용 & $\begin{array}{l}8 \\
8 \\
9\end{array}$ & $\stackrel{8}{\circ}$ & & & \\
\hline
\end{tabular}

For use when fan inlet is connected to process, discharge to atmosphere.

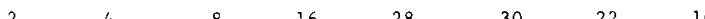

Mode 1 DF-5-1 Fan

CR

For use when fan inlet is connected to process, discharge to atmosphere.

$\begin{array}{cccccccc}\text { Dimensions, WxHxl:* } & 24 & \times & 36 & \times & 24 & \text { inch, } & \text { 9000 rated } \\ 2 & 4 & 8 & 16 & 28 & 30 & 22 & 10\end{array}$

For use when fan inlet is connected to process, discharge to atmosphere.

$\begin{array}{cccccccc}\text { Dimensions, WxHxl } & 48 \times & 30 \times 24 & \text { inch, } & 18,000 & \text { rated } & \text { cfm?x } & \\ 2 & 4 & 8 & 16 & 28 & 30 & 22 & 10\end{array}$ For use when fan inlet is connected to process, discharge to atmosphere

$\begin{array}{lllllll}2 & 4 & 8 & 16 & 28 & 30 & 22\end{array}$

(atnoser

For use when fan inlet is connected to process, discharge to atmosphere.

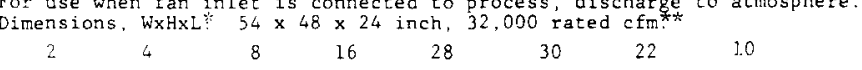
For use when fan inlet is connected to process, discharge to atmosphere.

mensions, WXHXL: $60 \times 78 \times 48$ inch, 60.000 rated cfm:

ischarge Silencer $\quad \mathrm{B}-22$

For use when fan inlet is connected to process, discharge to atmosphere.
Dimensions, WxHKL $72 \times 102 \times 48,110,000$ rated cfm:

ilencer includes

fan inlet flange. Silencer lncludes

with one or two removable plates to allow access to the bolts. Dimensions.

WhHL $30 \times 24 \times 30$ inch, 5000 rated $\mathrm{cfm}$.

$\begin{array}{llllll}10 & 12 & 13 & 13 & 13 & 11\end{array}$

11

Designed to bolt directly onto the fan inlet filange. Silencer includes

an inlet bell mouth and silencing element, followed by a plenum section

With one or two removable plates to allow acces
WxHXL $44 \times 44 \times 34$ inch, 18,000 rated cfots

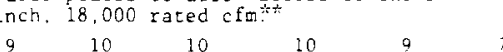

Model DF-9-1, Fan

$\mathrm{CR}$
$\mathrm{B}-229$

7

Jesigned to bolt directly onto the fan inlet flange. Silencer includes an inlet bell mouth and silencing element, followed by a plenum section
with one or two removable plates to allow access to the bolts. Dimensions, with one or two removable plates to allow access to the bolts. Dimensions,
WxHxL $52 \times 52 \times 42$ inch, 32,000 rated $\mathrm{cfm}$ ?

$\begin{array}{llllllll}7 & 8 & 11 & 16 & 17 & 17 & 15 & 12\end{array}$

Designed to bolt directly onto the fan inlet flange. Silencer includes an inlet be 11 mouth and silencing element, followed by a plenum section
with one or two removable plates to allow access to the bolts. Dimensions.
WxHxL

$\begin{array}{lllllll}8 & 8 & 10 & 14 & 19 & 20 & 20\end{array}$

Designed to bolt directly onto the fan inlet flange. Silencer includes

an inlet beli mouth and siletcing element, followed by a plenum section
with one or two removable plates to allow access to the bolts. Dimensions, with one or two removable plates to allow access to the bolts. Dimensions
$96 \times 12$
$26 \quad 27$
22
1613

18

13

For single inlet fans without inlet boxes, 90 deg inlet. Designed to bolt directly to the far inlet flange. Dimensions, lixhlyL $15.5 \times 36 \times 49$ inch,

8

$9 \quad 10$

I2

16

18

$1 \% \quad 16$ For single inlet fans without inlet boxes, 90 deg inlet. Designed to bolt
directly to the fan inlet flange. Dimensions, WxHxL: $19 \times 60 \times 73$ inch, , 000 rated cfm
910
19
21
21
17
15

For single inlet fans without inlet boxes, $90 \mathrm{deg}$ inlet. Designed to bolt 24.000 rated cfm th
8
9
$10 \quad 18$
$21 \quad 20$
17

15

*Dimensions without flanges. Add 4 to 6 inch to allow for flanges

* Maximum allowable flow is $10 \%$ higher than rated flow. 
Table 30. Fan silencers (insertion loss) continued.

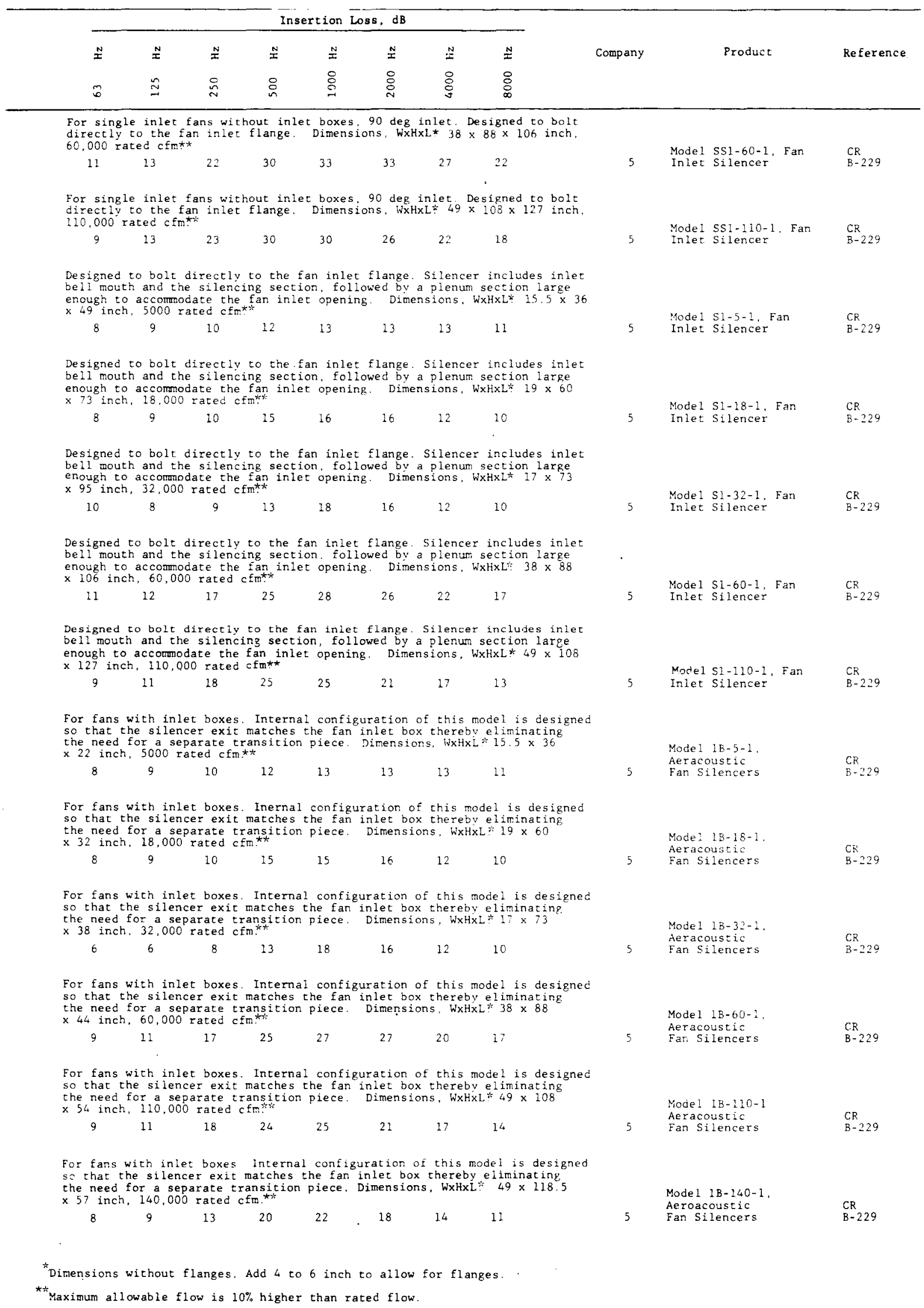


Table 30. Fan silencers (insertion loss) concluded.

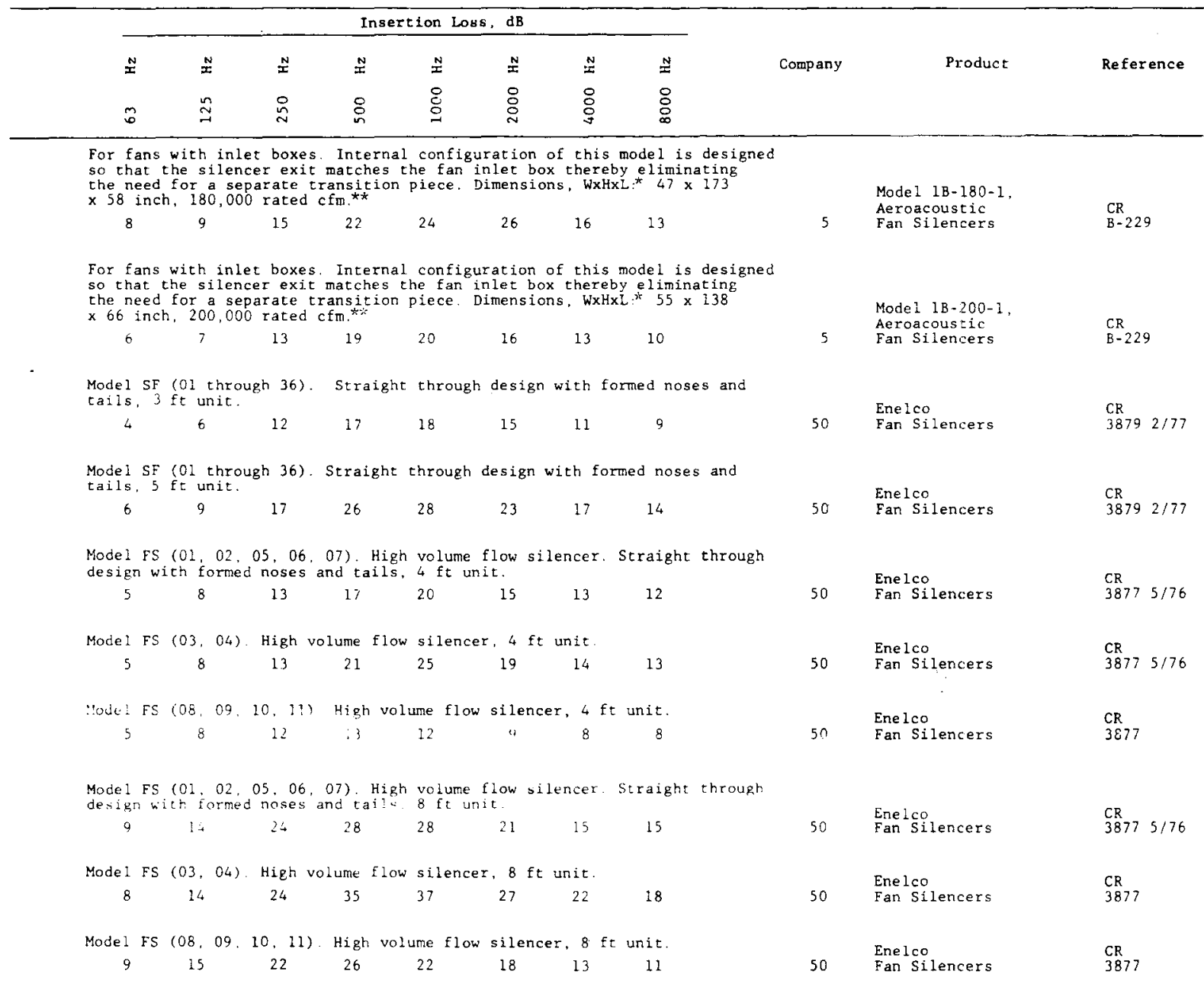

*Dimensions without flanges. Add 4 to 6 inch to allow for flanges

** Maximum allowable flow is $10 \%$ higher than rated flow. 
CATEGORY 31. INLET AND EXHAUST SILENCERS
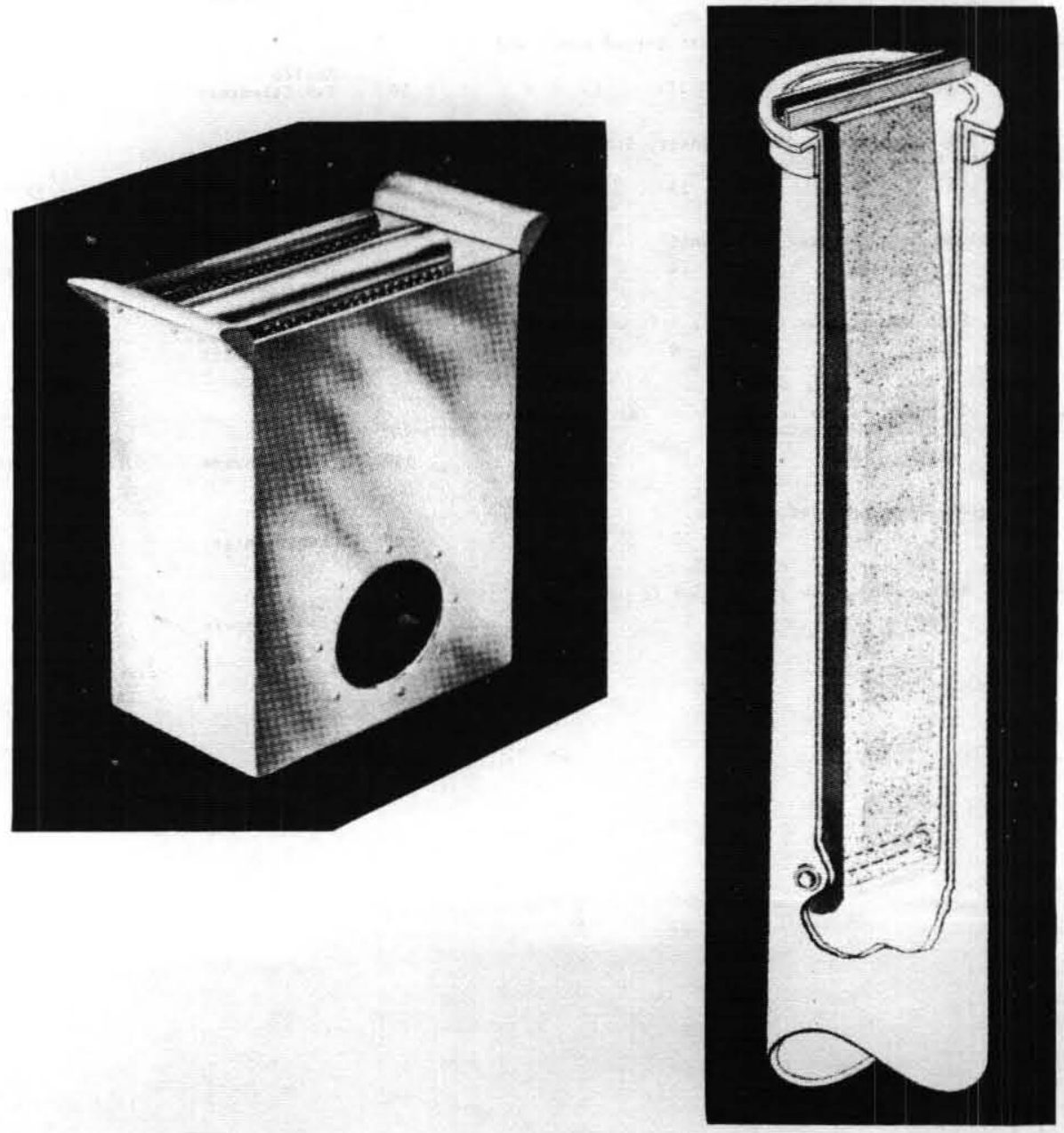
This category includes a wide range of silencer geometries. These units are only used for industrial applications. Deformation is presented on silencers for large exhaust stacks and chimneys. Also, exhaust systems for large plenums are included. Materials vary for ambient to high temperature gas installations. For related infomation see general industrial silencers and high pressure discharge silencers. Organizations contributing data to this table are: $6,50,62$, and 121 .

\section{CAUTION}

1. SILENCER PERFORMANCE FIGURES OFTEN DO NOT CONFCRM TO STANDARD REFERENCE MEASUREMENTS. FOR SPECIFIC APPLICATIONS, SEE MANUFACTURER'S PRODUCT LITERATURE.

2. IN MANY CASES, ONLY REPRESENTATIVE INFORMATION IS PRESENTED FOR A GIVEN PRODUCT LINE. SEE MANUFACTURER'S LITERATURE FOR COMPLETE LISTINGS OF SIZES AND PERFORMANCE DATA. 
Table 31. Inlet and exhaust silencers.

Insertion Loss, dB

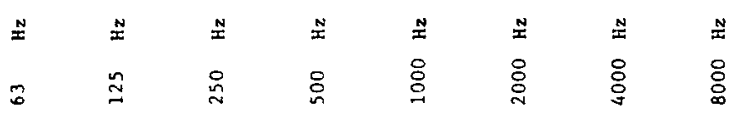

Company

Product

Reference

Silencers for up to $625 \mathrm{cfm}$. For intake or discharge of centrifugal
compressors or blowers. Temperature range 0 to $1000^{\circ} \mathrm{F}$. 5 inch size.

$$
\begin{array}{llllll}
3.5 & 7 & 17 & 21.5 & 11.5 & 10.5
\end{array}
$$

Silencers for up to $1600 \mathrm{cfm}$. For intake or discharge of centrifugal
compressors or blowers. Temperature range 0 to $1000^{8} \mathrm{~F}$. 8 inch size.

$$
\begin{array}{llllll}
5 & 10.5 & 23 & 16 & 13.5 & 12
\end{array}
$$

Silencers for up to $400 \mathrm{cfm}$. For intake or discharge of centrifuga

$$
\begin{array}{llllll}
5.5 & 10 & 22.5 & 27.5 & 16.5 & 11
\end{array}
$$
Silencers for up to $900 \mathrm{cfm}$. For intake or discharge of centrifugal
compressors or blowers. Temperature range 0 to $1000^{\circ} \mathrm{F} .6$ inch size.

$$
\begin{array}{llllll}
7 & 12.5 & 25 & 23 & 14 & 12
\end{array}
$$

Compact silencer for air conditioning equipment. Deep sound attenuator nondirectional for air and sound, and construction of 062 inch thick aluminum and fiberglass. Used in return air grilles and transfer grilles. 24 inch long $\times 24$ inch wide. Other sizes available.

$\begin{array}{llllllll}7 & 12 & 12 & 12 & 19 & 25 & 25 & 20\end{array}$ Silencers for up to $2500 \mathrm{cfm}$. For intake or discharge of centrifugal
compressors or blowers. Temperature range 0 to $1000^{\circ} \mathrm{F}$. 10 inch size

$$
\begin{array}{rrrrr}
6.5 & 13.5 & 27 & 22.5 & 14
\end{array}
$$
Silencers for up to $6500 \mathrm{cfm}$. For intake or discharge of centrifugal
compressors or blowers. Temperature range 0 to $1000^{\circ} \mathrm{F}$. I6 inch size.

$$
\begin{array}{llllll}
14.5 & 24 & 29.5 & 13.5 & 9 & 9.5
\end{array}
$$

Silencers for up to $4800 \mathrm{cfm}$. For intake or discharge of centrifugal compressors or blowers. Temperature range 0 to $1000^{\circ} \mathrm{F}$. 14 inch size.

$$
\begin{array}{llllll}
10.5 & 25.5 & 27.5 & 18 & 12 & 9
\end{array}
$$

Silencers for up to 3500 efm. For intake or discharge of centrifugal
compressors or blowers. Temperature range 0 to $1000^{\circ} \mathrm{F}$. 12 inch size.

$$
\begin{array}{llllll}
7 & 14 & 31.5 & 28 & 20 & 5.5
\end{array}
$$

Silencers for up to $230 \mathrm{cfm}$. For intake or discharge of centrifugal compressors or blowers. Tetiperature range 0 to $1000^{\circ} \mathrm{F}, 3$ inch size.

$$
\begin{array}{llllll}
9.5 & 10.5 & 22.5 & 21.5 & 28 & 18.5
\end{array}
$$

Model Cv04, intermediate volume flow silencer. Constructed of carbon steel with acoustically lined shell and a center acoustic bubble.

$\begin{array}{llllllll}13 & 15 & 19 & 34 & 33 & 36 & 33 & 26\end{array}$
Model CVO6 through CV10, intermediate volume flow silencer. Constructed
of carbon steel with acoustically lined she 11 and a center acoustic bubble
14

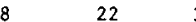
$36 \quad 36$
$34 \quad 33$
25

50

Model CV12 through CV16, intermediate volume flow silencer. Constructed of carbon steel with acoustically lined shell and a center acoustic bubble.
16
$28 \quad 36$
3638
$35.33-25$

Model HV08 silencer, $3 / 16$ inch carbon steel shell, panel is of 16 gauge thick steel with fibergl

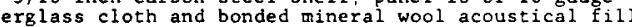
mperature up to $450^{\circ}$$$
16
$$$$
3240
$$

40

$40 \quad 34^{\cdot} 28$

50

Enelco

Vent Silencer

CR
$300 D$

Model HV12 silencer. $3 / 16$ inch carbon steel shell, panel is of 16 gauge
thick steel with fiberglass cloth and bonded mineral wool acoustical fill thick steel with fiberg

$\begin{array}{ccccccccc}20 & 26 & 39 & 49 & 50 & 40 & 33 & 29\end{array}$

Model CV27 through CV4O intermediate volume flow silencer. Constructed of

Model CV 27 through CV40 intermediate volume flow silencer. Constructed of
carbon steel with acoustically lined shell and a center acoustic bubble.

$36 \quad 37$

78

33

3126

Model CV18 through CV25 intermediate volume flow silencer. Constructed of Model CV18 through. CV25 intermediate volume flow silencer. Constructed of

$\begin{array}{lllllrr}19 & 25 & 33 & 39 & 38 & 34 & 33\end{array}$

Model C11905, shell material 14 gauge cold rolled steel, fire retardant acoustical material. Vent is painted with inorganic zinc-rich primer.

\begin{abstract}
19
\end{abstract}
$33 \quad 37$
46

43

48

Enelco

Vent Silencer

$\mathrm{CR}$
1889

Enelco
Vent Silencer

CR
$3884 \quad 5 / 76$

Enelco

Vent Silencer

CR
$3884 \quad 5 / 76$

Weatherproof

$\begin{array}{ll}\text { Inlet and } & \text { CR } \\ \text { Exhaust Air Silencer } & 154-75 \quad 8-76\end{array}$ 


\section{CATEGORY 32. SPLITTER/LOIJVR SILENCERS}

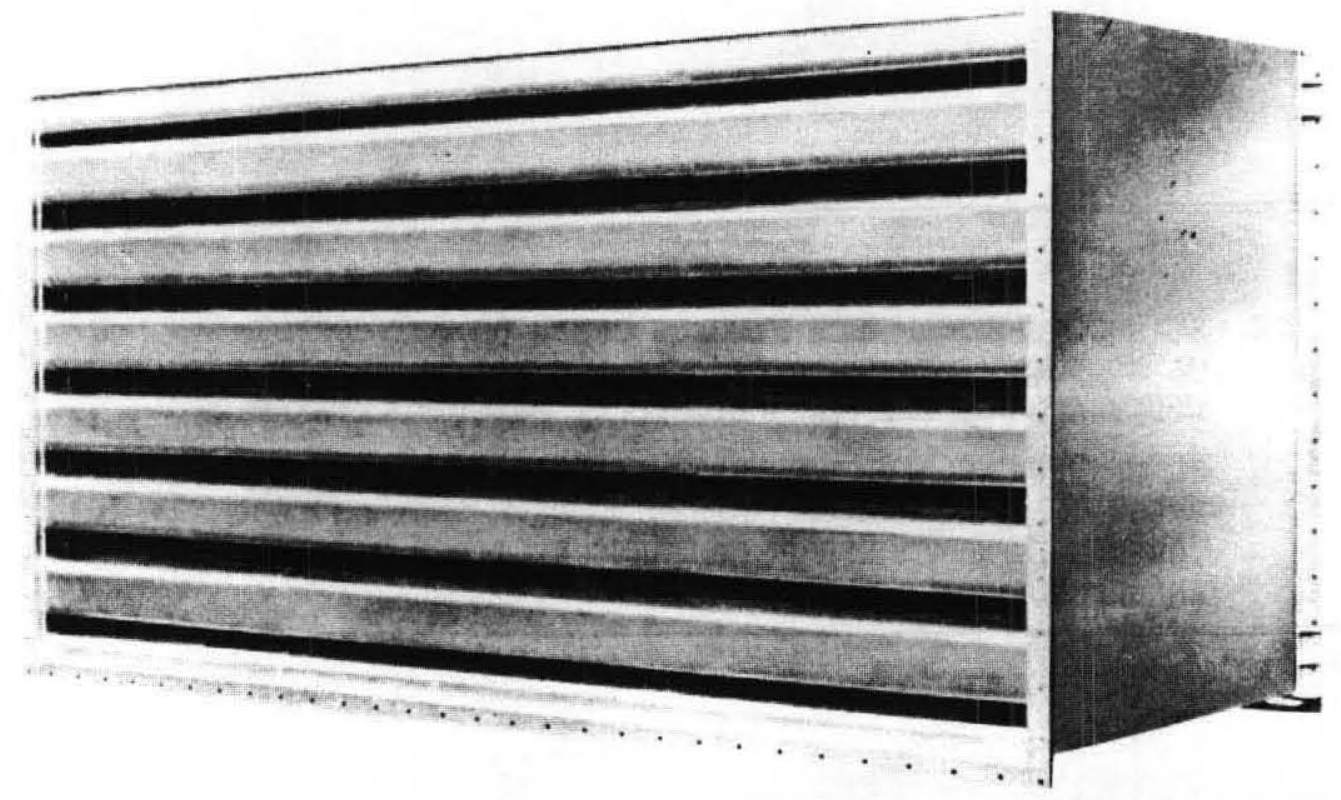




\section{CATEGORY 32. SPLITTER/LOUVER SILENCERS}

A splitter or louver geometry indicates that a large area of uniformly flowing gas is divided into smaller, narrower passages. Sometimes the main flow direction is altered by the splitter or louver. These geometries generally block direct line of sight noise transmission from an interior noise source to the ambient environment. Absorptive materials are of ten installed within a splitter or louver to improve sound absorption performance. Organizations contributing data to this table are: 5, 6, and 50 .

\section{CAUTION}

1. SILENCER PERFORMANCE FIGURES OFTEN DO NOT CONFORM TO STANDARD REFERENCE MEASUREMENTS. FOR SPECIFIC APPLICATIONS, SEE MANUFACTURER'S PRODUCT LITERATURE.

2. IN MANY CASES, ONLY REPRESENTATIVE INFORIIATION IS PRESENTED FOR A GIVEN PRODUCT LINE. SEE MANUFACTURER'S LITERATURE FOR COMPLETE LISTINGS OF SIZE'S AND PERFORMANCE DATA. 


\section{CATEGORY 32. SPLITTER/LOIJVR SILENCERS}

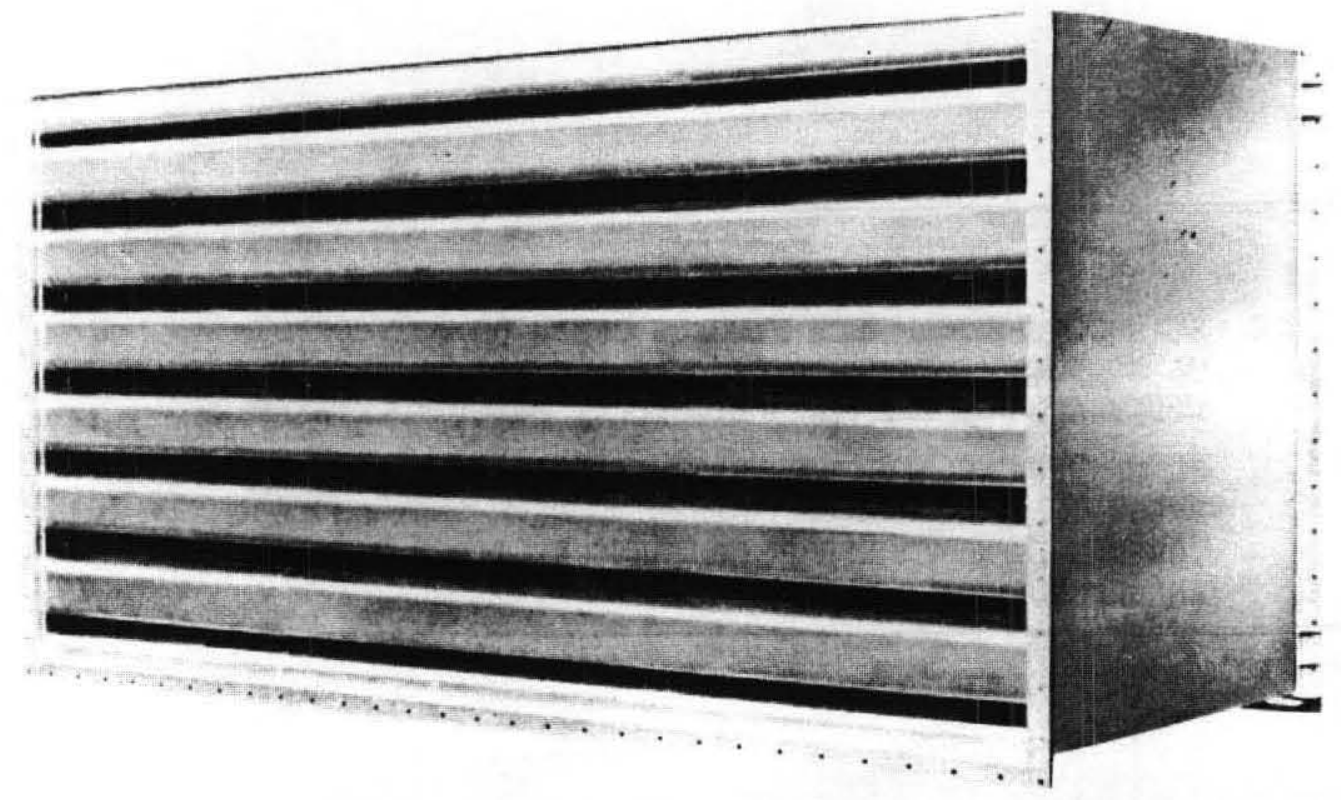




\section{CATEGORY 32. SPLITTER/LOUVER SILENCERS}

A splitter or louver geometry indicates that a large area of uniformly flowing gas is divided into smaller, narrower passages. Sometimes the main flow direction is altered by the splitter or louver. These geometries generally block direct line of sight noise transmission from an interior noise source to the ambient environment. Absorptive materials are of ten installed within a splitter or louver to improve sound absorption performance. Organizations contributing data to this table are: 5, 6, and 50 .

\section{CAUTION}

1. SILENCER PERFORMANCE FIGURES OFTEN DO NOT CONFORM TO STANDARD REFERENCE MEASUREMENTS. FOR SPECIFIC APPLICATIONS, SEE MANUFACTURER'S PRODUCT LITERATURE.

2. IN MANY CASES, ONLY REPRESENTATIVE INFORIIATION IS PRESENTED FOR A GIVEN PRODUCT LINE. SEE MANUFACTURER'S LITERATURE FOR COMPLETE LISTINGS OF SIZE'S AND PERFORMANCE DATA. 
Table 32. Splitter/louver silencers.

\begin{tabular}{|c|c|c|c|c|c|c|c|c|c|c|c|}
\hline & \multicolumn{8}{|c|}{ Insertion Losa, $\mathrm{dB}$} & \multirow{3}{*}{ Company } & \multirow{3}{*}{ Product } & \multirow{3}{*}{ Reference } \\
\hline & $\stackrel{N}{I}$ & $\stackrel{N}{\mathbf{N}}$ & $\stackrel{N}{x}$ & $\stackrel{N}{x}$ & $\stackrel{N}{I}$ & $\stackrel{N}{I}$ & $\stackrel{N}{\Sigma}$ & $\stackrel{N}{ \pm}$ & & & \\
\hline & $\hat{b}$ & 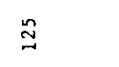 & $\stackrel{\circ}{\sim}$ & in & $\stackrel{8}{\circ}$ & $\stackrel{8}{\stackrel{一}{\sim}}$ & $\stackrel{8}{8}$ & $\stackrel{8}{\circ}$ & & & \\
\hline \multirow[t]{2}{*}{ sS } & Series, & aluminum, & , sta & nless and & galvanized & d av & lable & 24 inch & size. & Stack-Stuffer & CR Bull \\
\hline & 3 & 6 & 12 & 22 & 27 & 20 & 12 & 8 & 5 & Silencers, SSA3 & $B-38$ \\
\hline \multirow[t]{2}{*}{ ss } & Series. & Al uminum. & . $s t a$ & nless and & galvanized & ave & lable. & 48 inch & size. & Stack-Stuffer & CR Bull. \\
\hline & 6 & 12 & 22 & 27 & 20 & 12 & 8 & 4 & 5 & Silencers, SSA3 & B- 38 \\
\hline \multirow[t]{2}{*}{ ss } & Series, & aluminum, & , sta & nless and & galvanized & d ave & lable. & 96 inch & size. & Stack-Stuffer & CR Bull \\
\hline & 12 & 22 & 27 & 20 & 12 & 8 & 4 & 2 & 5 & Silencers, SSA 3 & $E-38$ \\
\hline \multicolumn{12}{|c|}{$\begin{array}{l}\text { Acoustical louvers, top surfaces solid, bottom surface absorptive, water } \\
\text { stops on upper surface, outer casings i6 gauge galvanized steel, internals } \\
22 \text { gage galvanized steel. }\end{array}$} \\
\hline & & 6 & 11 & 15 & 18 & 18 & 16 & 12 & 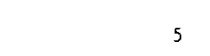 & $\begin{array}{l}\text { Aeroacoustic } \\
\text { Silentflow Lotivers }\end{array}$ & $\begin{array}{l}\text { CR Bull } \\
B-46\end{array}$ \\
\hline \multicolumn{12}{|c|}{ Splitter silencers, Model A8, 6 inch modules, available in several models. } \\
\hline & 7 & 15 & 30 & 54 & 65 & 68 & 60 & 45 & 5 & $\begin{array}{l}\text { Aeroacoustic } \\
\text { Splitter Silencers }\end{array}$ & $B-133$ \\
\hline \multicolumn{10}{|c|}{ Splitter silencers, Model F2, 12 inch modules. } & & \\
\hline & 5 & 10 & 17 & 23 & 24 & 20 & 16 & 12 & 5 & $\begin{array}{l}\text { Aeroacoustic } \\
\text { Splitter Silencer }\end{array}$ & $\begin{array}{l}\text { CR Bu11. } \\
\text { B-133 }\end{array}$ \\
\hline \multicolumn{10}{|c|}{ Splitter silencers, Model Q10, 15 inch modules. } & & \\
\hline & 9 & 17 & 29 & 41 & 43 & 27 & 22 & 17 & 5 & Splitcer Silencers & $\begin{array}{l}\text { CR Bul1 } \\
B-133\end{array}$ \\
\hline \multicolumn{10}{|c|}{ Splitter silencers, Model v3, is inch modules. } & Aerocoustis & \\
\hline & 5 & 8 & 13 & 18 & 15 & 12 & 9 & 7 & 5 & Splitter Silencer & $B-133$ \\
\hline \multicolumn{12}{|c|}{$\begin{array}{l}\text { Airfoil shaped turning vane for noise and directional air control, } 14 \text { gauge } \\
\text { aluminum extrusion, acoustically treated with fiberglass, which is protected } \\
\text { by an open protective metal facing. Temperature range } 290^{\circ} \mathrm{F} \text {, humidity, no } \\
\text { limit, maximum velocity } 4000 \mathrm{fpm} \text {. Standard available length } 10 \mathrm{ft} \text {. }\end{array}$} \\
\hline & & 6 & 8 & 11 & 18 & 25 & 28 & 20 & 6 & Acoustiturn & $\mathrm{CR}$ \\
\hline \multicolumn{12}{|c|}{$\begin{array}{l}\text { Sound absorption louver, available in } 54 \text { standard sizes, for use in control- } \\
\text { ling fan noises, air intakes, cooling tower inlets. (Reported values are } \\
\text { transmission loss.) }\end{array}$} \\
\hline & 3 & 6 & 7 & 10 & 14 & 13 & 12 & 10 & so & Acoustilouve & \\
\hline \multicolumn{12}{|c|}{$\begin{array}{l}\text { Sound absorption louver available in } 54 \text { standard sizes for use in controlling } \\
\text { fan noises, air. intakes, cooling tower inlets. (Reported values are transmission } \\
\text { loss.) }\end{array}$} \\
\hline & 4 & 7 & 8 & 11 & 16 & 17 & 13 & 10 & 50 & $\begin{array}{l}\text { Eneled Acoustillouvre } \\
\text { Model } \mathrm{AL}-1\end{array}$ & $\begin{array}{l}\text { CR Form } \\
858 \text { ALl }\end{array}$ \\
\hline
\end{tabular}




\section{CATEGORY 33， VEHICULAR MUFFLERS}

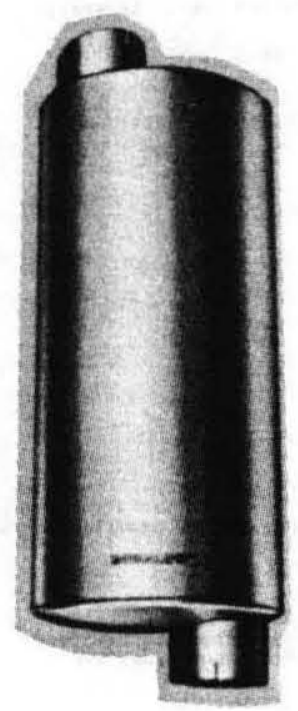


The muffler products listed in this category are only applicable to heavy equipment and trucks. No information is presented for automotive use. Single and dual muffler configurations are presented. The required exhaust noise level at $50 \mathrm{ft}$ from the vehicle is often the determining factor in muffler selection. For low noise requirements, muffler shell noise becomes a major contributing factor so that double wrapping or high temperature insulation may be added to the basic muffler design. The organization contributing data to this table is company 39.

\section{CAUTION}

1. MUFFLER PERFORMANCE FIGURES OFTEN DO NOT CONFORM TO STANDARD REFERENCE MEASUREMENTS. FOR SPECIFIC APPLICATIONS, SEE MANUFACTURER'S PRODUCT LITERATURE.

2. IN MANY CASES, ONLY REPRESENTATIVE INFORMATION IS PRESENTED FOR A GIVEN PRODUCT LINE. SEE MANUFACTURER'S LITERATURE FOR COMPLETE LISTINGS OF SIZES AND PERFORMANCE DATA.

3. SEVERAL MANUFACTURERS WERE SOLICITED FOR VEHICULAR MUFFLER INFORMATION, BUT ONLY ONE COMPANY PROVIDED DATA FOR THIS TABLE. 
Table 33. Vehicular mufflers.

\begin{tabular}{|c|c|c|c|c|c|c|}
\hline Sound Measurem & Criteria & $\begin{array}{l}\text { Engine } \\
\text { Mode 1 }\end{array}$ & Application & Company & $\begin{array}{l}\text { Product } \\
\text { Model } \\
\text { Number }\end{array}$ & Reference \\
\hline $\begin{array}{l}\text { Exhaust Noise } \\
\text { (ABA at } 50 \mathrm{ft}) \\
\end{array}$ & $\begin{array}{l}\text { Back Pressure } \\
\text { Fu11 Load } \\
\text { (in. Hg) } \\
\end{array}$ & & & & & \\
\hline $\begin{array}{l}76 \\
72 \\
70\end{array}$ & $\begin{array}{l}1.2 \\
2.0 \\
1.6\end{array}$ & NTC- 230 & $\begin{array}{l}\text { Trucks, Cummins } \\
\text { turbocharged engines } \\
\text { cab side mount } \\
\text { Single 4" systems }\end{array}$ & 39 & $\begin{array}{r}\text { MUM09-0022 } \\
\text { or MPM09-0141 } \\
\text { or MKM10-0147 }\end{array}$ & $\begin{array}{l}\text { CR } \\
1200-192\end{array}$ \\
\hline $\begin{array}{l}75 \\
71 \\
69\end{array}$ & $\begin{array}{l}1.0 \\
1.7 \\
1.4\end{array}$ & Formula 230 & & & $\begin{array}{r}\text { MUMO9-0022 } \\
\text { or MPMO9-0141 } \\
\text { or MKM10-0147 }\end{array}$ & \\
\hline $\begin{array}{l}77 \\
73 \\
71\end{array}$ & $\begin{array}{l}1.5 \\
2.4 \\
1.9\end{array}$ & NTC -250 & & & $\begin{array}{r}\text { MLMO9-0022 } \\
\text { or MPMO9-0141 } \\
\text { or MKM10-0147 }\end{array}$ & \\
\hline $\begin{array}{l}76 \\
72 \\
70\end{array}$ & $\begin{array}{l}1.3 \\
2.0 \\
1.7\end{array}$ & Formula 250 & & & $\begin{array}{r}\text { MUMO9-0022 } \\
\text { or MPMO9-0141 } \\
\text { or MKM10-0147 }\end{array}$ & \\
\hline $\begin{array}{l}78 \\
74 \\
72\end{array}$ & $\begin{array}{l}1.3 \\
2.1 \\
1.7\end{array}$ & NTC- 270 & & & $\begin{array}{l}\text { MUMO9-0022 } \\
\text { or MPMO9-0141 } \\
\text { or MKM10-0147 }\end{array}$ & \\
\hline $\begin{array}{l}79 \\
73\end{array}$ & $\begin{array}{l}1.9 \\
2.4\end{array}$ & NTC-27OCT & & & $\begin{array}{r}\text { MUMO9-0022 } \\
\text { or MKM10-1047 }\end{array}$ & \\
\hline $\begin{array}{l}79 \\
73\end{array}$ & $\begin{array}{l}2.1 \\
2.8\end{array}$ & PT-270 & & & or MLMO9-0022 & \\
\hline $\begin{array}{l}77 \\
71\end{array}$ & $\begin{array}{l}2.2 \\
2.9\end{array}$ & NTC- 290 & & & $\begin{array}{r}\text { MMMO9-0022 } \\
\text { or MKM10-0147 }\end{array}$ & \\
\hline $\begin{array}{l}78 \\
74 \\
72\end{array}$ & $\begin{array}{l}1.4 \\
2.3 \\
1.8\end{array}$ & $\begin{array}{l}\text { NTC-290 } \\
\text { (pre 1976) }\end{array}$ & & & $\begin{aligned} & \text { MUMO9-0022 } \\
& \text { or MPMO9-0141 } \\
& \text { or MKM10-0147 }\end{aligned}$ & \\
\hline $\begin{array}{l}76 \\
70\end{array}$ & $\begin{array}{l}1.8 \\
2.4\end{array}$ & Formula 290 & & & $\begin{array}{r}\text { MUM09-0022 } \\
\text { or MKM10-0147 }\end{array}$ & \\
\hline $\begin{array}{l}78 \\
72\end{array}$ & $\begin{array}{l}2.3 \\
3.0\end{array}$ & PT - 330D & & & $\begin{array}{r}\text { MUMO9-0022 } \\
\text { or MKM10-0147 }\end{array}$ & \\
\hline $\begin{array}{l}78 \\
72\end{array}$ & $\begin{array}{l}1.9 \\
2.5\end{array}$ & NTC- 335 & & & $\begin{array}{r}\text { MUMO9-0022 } \\
\text { or MKMI0-0147 }\end{array}$ & \\
\hline 79 & 2.2 & NTC- 350 & & & MUMO9-0022 & \\
\hline $\begin{array}{l}78 \\
72\end{array}$ & $\begin{array}{l}1.8 \\
2.4\end{array}$ & Formula 335 & & & $\begin{array}{r}\text { MUMO9-0022 } \\
\text { or MKM10-0147 }\end{array}$ & \\
\hline $\begin{array}{l}78 \\
72\end{array}$ & $\begin{array}{l}1.8 \\
2.4\end{array}$ & NTC $-350-Y$ & & & $\begin{array}{r}\text { MUMO9-0022 } \\
\text { or MKM10-0147 }\end{array}$ & \\
\hline 80 & 2.6 & NTF - 365 & & & MUM09-0022 & \\
\hline $\begin{array}{l}78 \\
74 \\
72\end{array}$ & $\begin{array}{l}1.1 \\
1.8 \\
1.5\end{array}$ & VT-555 & & & $\begin{array}{r}\text { MUMO9-0022 } \\
\text { or MPMO9-0141 } \\
\text { or MKM10-0147 }\end{array}$ & \\
\hline $\begin{array}{l}78 \\
74 \\
72\end{array}$ & $\begin{array}{l}1.2 \\
1.9 \\
1.5\end{array}$ & VTF-555 & & & $\begin{array}{r}\text { MUM09-0022 } \\
\text { of MPMO9-0141 } \\
\text { of MKM10-0147 }\end{array}$ & \\
\hline $\begin{array}{l}79 \\
73\end{array}$ & $\begin{array}{l}2.2 \\
2.9\end{array}$ & $V T-903$ & & & $\begin{array}{r}\text { MMO9-0022 } \\
\text { or MKM10-0147 }\end{array}$ & \\
\hline $\begin{array}{l}78 \\
72\end{array}$ & $\begin{array}{l}1.9 \\
2.5\end{array}$ & Formula 903 & & & $\begin{array}{r}\text { MLM09-0022 } \\
\text { or MKM10-0147 }\end{array}$ & \\
\hline $\begin{array}{l}75 \\
73 \\
712 \\
69\end{array}$ & $\begin{array}{l}0.5 \\
0.9 \\
0.9 \\
1.5\end{array}$ & NTC- 230 & $\begin{array}{l}\text { Trucks, Cunmins } \\
\text { turbocharged engines } \\
\text { cab side mount } \\
\text { Single 5" systems }\end{array}$ & & $\begin{aligned} \text { MPMO9-0161 } \\
\text { or MPM09-0197 } \\
\text { or MPM10-0106 } \\
\text { Or MFM10-0165 }\end{aligned}$ & \\
\hline
\end{tabular}


Table 33. Vehicular mufflers continued.

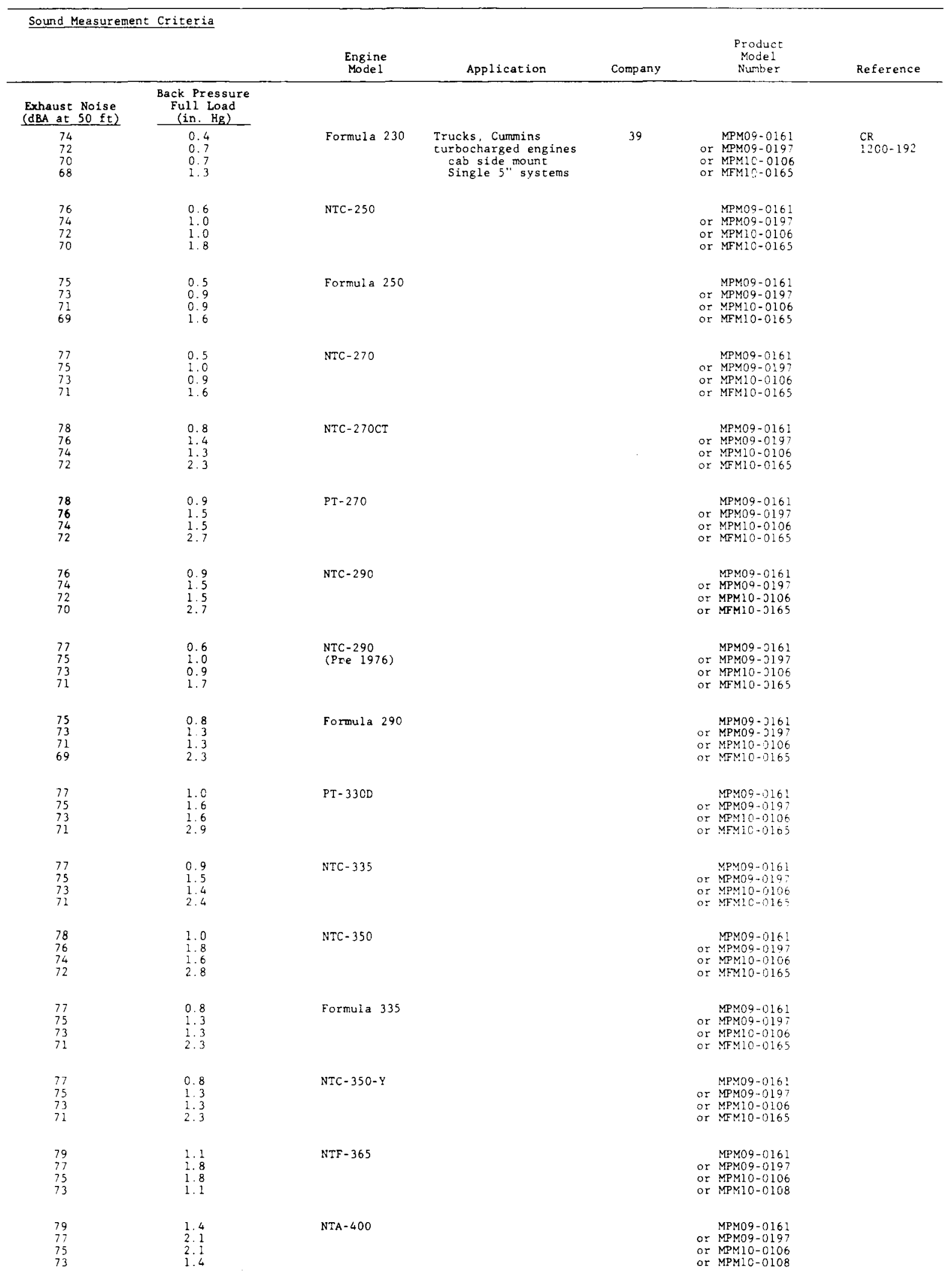


Table 33. Vehicular mufflers continued.

\begin{tabular}{|c|c|c|c|c|c|c|}
\hline \multicolumn{7}{|c|}{ Sound Measurement Criteria } \\
\hline & & $\begin{array}{l}\text { Engine } \\
\text { Model }\end{array}$ & Application & Company & $\begin{array}{l}\text { Product } \\
\text { Mode1 } \\
\text { Number }\end{array}$ & Reference \\
\hline $\begin{array}{l}\text { Exhaust Noise } \\
\text { (dBA at } 50 \mathrm{ft}) \\
\end{array}$ & $\begin{array}{c}\text { Back Pressure } \\
\text { Ful1 Load } \\
\text { (in. Hg) } \\
\end{array}$ & & & & & \\
\hline $\begin{array}{l}80 \\
78 \\
76 \\
74\end{array}$ & $\begin{array}{l}1.7 \\
2.4 \\
2.4 \\
1.6\end{array}$ & NTA -420 & $\begin{array}{l}\text { Trucks, Cummins } \\
\text { turbocharged engines } \\
\text { cab side mount } \\
\text { single 5" systems }\end{array}$ & 39 & $\begin{array}{l}\text { MPM09-0161 } \\
\text { or MPMO9-0197 } \\
\text { Or MPM10-0106 } \\
\text { or MPM10-0102 }\end{array}$ & $\begin{array}{l}C R \\
1200-192\end{array}$ \\
\hline $\begin{array}{l}80 \\
78 \\
76 \\
74\end{array}$ & $\begin{array}{l}1.5 \\
2.4 \\
2.4 \\
1.4\end{array}$ & $\mathrm{KT}-450$ & & & $\begin{array}{r}\text { MPM09-0161 } \\
\text { Or MPM09-0197 } \\
\text { or MPMO9-0106 } \\
\text { or MPM10-0108 }\end{array}$ & \\
\hline $\begin{array}{l}82 \\
74\end{array}$ & $\begin{array}{l}2.9 \\
2.8\end{array}$ & KTA- 525 & & & $\begin{array}{r}\text { MPM09-0161 } \\
\text { or MPM10-0108 }\end{array}$ & \\
\hline $\begin{array}{l}82 \\
74\end{array}$ & $\begin{array}{l}2.5 \\
2.4\end{array}$ & KTA-600 & & & $\begin{array}{r}\text { MPMO9-0161 } \\
\text { or MPM10-0108 }\end{array}$ & \\
\hline $\begin{array}{l}77 \\
75 \\
73 \\
71\end{array}$ & $\begin{array}{l}0.5 \\
0.9 \\
0.8 \\
1.4\end{array}$ & $V T-555$ & & & $\begin{array}{l}\text { MPMO9-0161 } \\
\text { or MPM09-0197 } \\
\text { or MPM10-0106 } \\
\text { or MFM10-0165 }\end{array}$ & \\
\hline $\begin{array}{l}77 \\
75 \\
73 \\
71\end{array}$ & $\begin{array}{l}0.6 \\
1.1 \\
0.9 \\
1.5\end{array}$ & VTF -555 & & & $\begin{array}{r}\text { MPMO9-0161 } \\
\text { or MPM09-0197 } \\
\text { or MPM10-0106 } \\
\text { or MFM10-0165 }\end{array}$ & \\
\hline $\begin{array}{l}78 \\
76 \\
74 \\
72\end{array}$ & $\begin{array}{l}1.0 \\
1.8 \\
1.8 \\
2.9\end{array}$ & VT -903 & & & $\begin{aligned} & \text { MPMO9-0161 } \\
& \text { or MPMO9-0197 } \\
& \text { Or MPM10-0106 } \\
& \text { or MFM10-0165 }\end{aligned}$ & \\
\hline $\begin{array}{l}77 \\
75 \\
73 \\
71\end{array}$ & $\begin{array}{l}0.9 \\
1.7 \\
1.6 \\
2.6\end{array}$ & Formula 903 & & & $\begin{array}{l}\text { MPMO9-0161 } \\
\text { or MPMO9-0197 } \\
\text { or MPM10-0106 } \\
\text { or MFM1n-0165 }\end{array}$ & \\
\hline $\begin{array}{l}70 \\
69 \\
71 \\
70 \\
72 \\
73 \\
73 \\
71 \\
72 \\
70 \\
72 \\
72 \\
73 \\
72 \\
72 \\
74 \\
74 \\
75 \\
75 \\
77 \\
72 \\
72 \\
73 \\
72\end{array}$ & $\begin{array}{l}0.6 \\
0.5 \\
0.7 \\
0.6 \\
0.6 \\
0.9 \\
1.1 \\
1.1 \\
0.7 \\
0.9 \\
1.2 \\
0.9 \\
1.1 \\
0.9 \\
0.9 \\
1.3 \\
1.4 \\
1.7 \\
1.8 \\
2.8 \\
0.6 \\
0.7 \\
1.1 \\
1.0\end{array}$ & 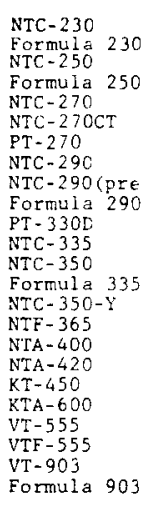 & $\begin{array}{l}\text { Trucks, Cummins } \\
\text { turbocharged engines } \\
\text { cab side mount } \\
\text { Split systems } 5 \times 4 \times 4 \\
\text { 1976) }\end{array}$ & & 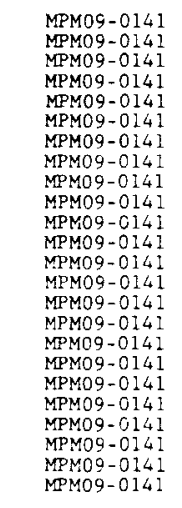 & \\
\hline $\begin{array}{l}70 \\
71 \\
71 \\
69 \\
70 \\
68 \\
70 \\
70 \\
69 \\
70 \\
70 \\
72 \\
71 \\
72 \\
73 \\
73 \\
70 \\
70 \\
71 \\
70\end{array}$ & $\begin{array}{l}0.4 \\
0.6 \\
0.7 \\
0.7 \\
0.5 \\
0.6 \\
0.8 \\
0.6 \\
0.8 \\
0.7 \\
0.7 \\
0.9 \\
1.0 \\
1.3 \\
2.2 \\
2.6 \\
0.4 \\
0.5 \\
0.7 \\
0.7\end{array}$ & 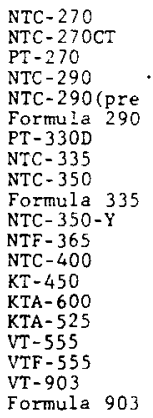 & $\begin{array}{l}\text { Trucks, Cummins } \\
\text { turbocharged engines } \\
\text { cab side mount } \\
\text { Split systems } 5 \times 5 \times 5 \\
\text { 1976) }\end{array}$ & & $\begin{array}{l}\text { MFM10-0172 } \\
\text { MFM10-0172 } \\
\text { MFM10-0172 } \\
\text { MFM10-0172 } \\
\text { MFM10-0172 } \\
\text { MFM10-0172 } \\
\text { MFM10-0172 } \\
\text { MFM10-0172 } \\
\text { MFM10-0172 } \\
\text { MFM10-0172 } \\
\text { MFM10-0172 } \\
\text { MFM10-0172 } \\
\text { MFM10-0172 } \\
\text { MFM10-0172 } \\
\text { MFM10-0172 } \\
\text { MFM10-0172 } \\
\text { MFM10-0172 } \\
\text { MFM10-0172 } \\
\text { MFM10-0172 } \\
\text { MFM10-0172 }\end{array}$ & \\
\hline
\end{tabular}


Table 33. Vehicular mufflers continued.

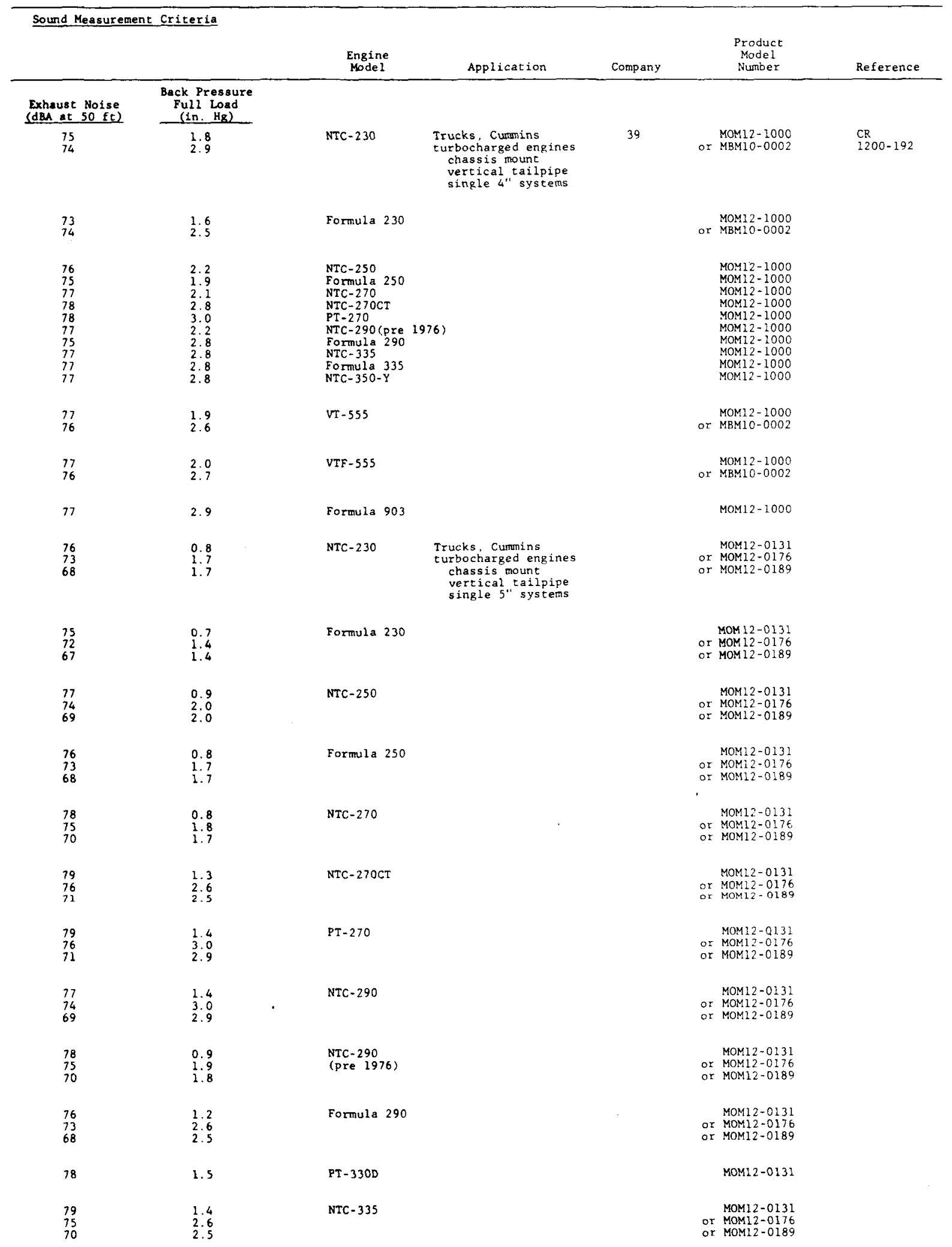


Table 33. Vehicular mufflers continued.

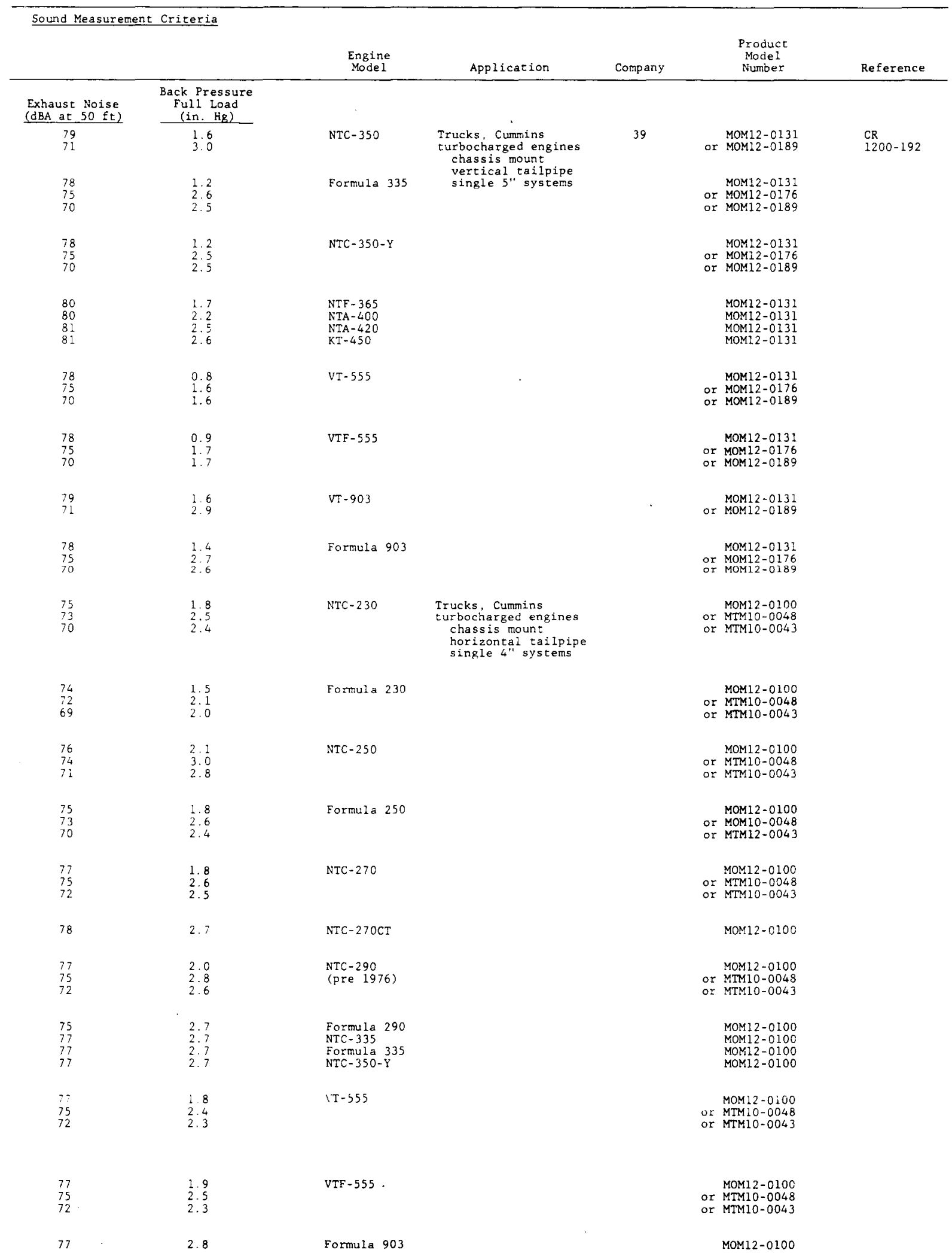


Table 33. Vehicular mufflers continued.

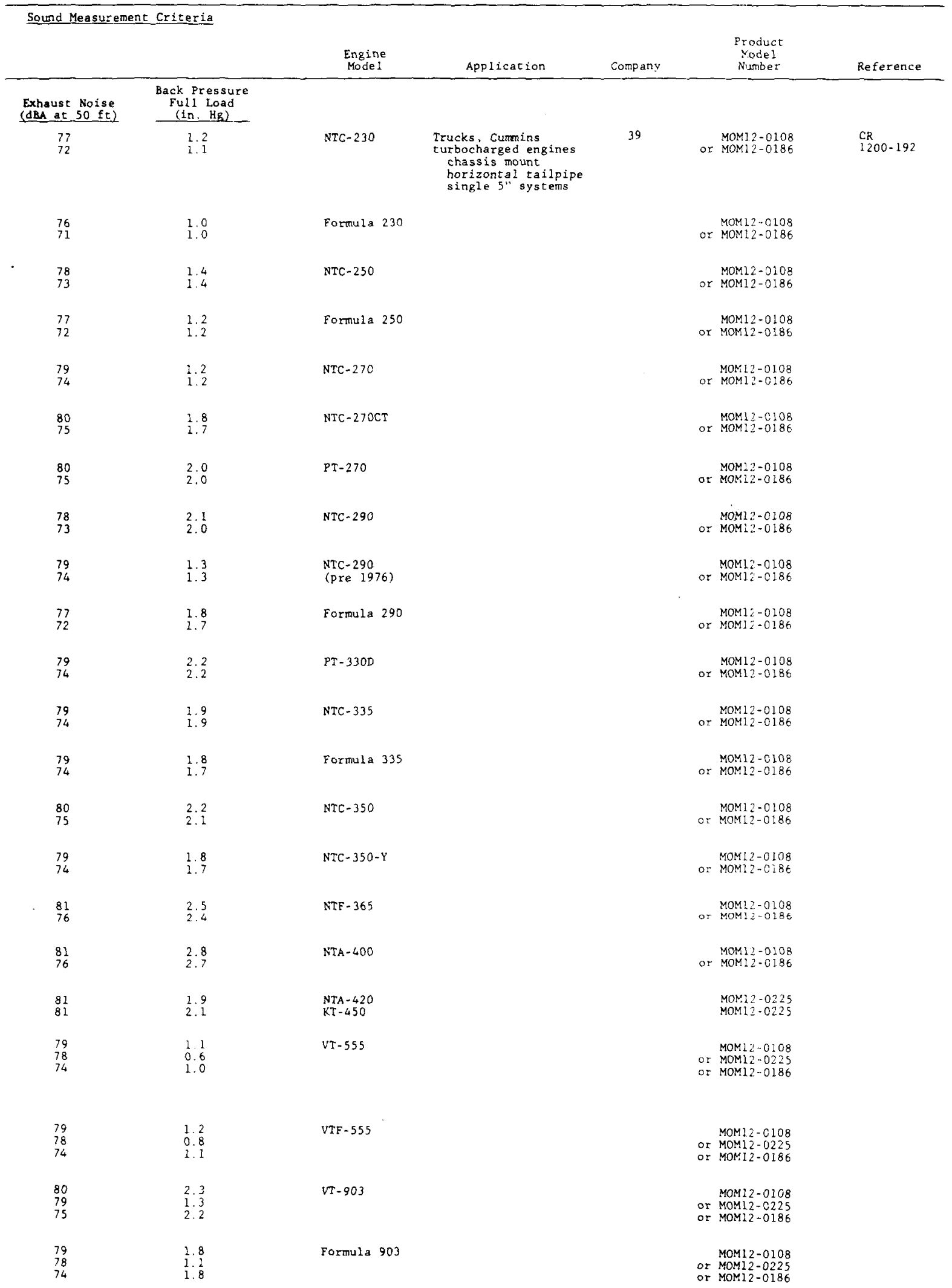


Table 33. Vehicular mufflers continued.

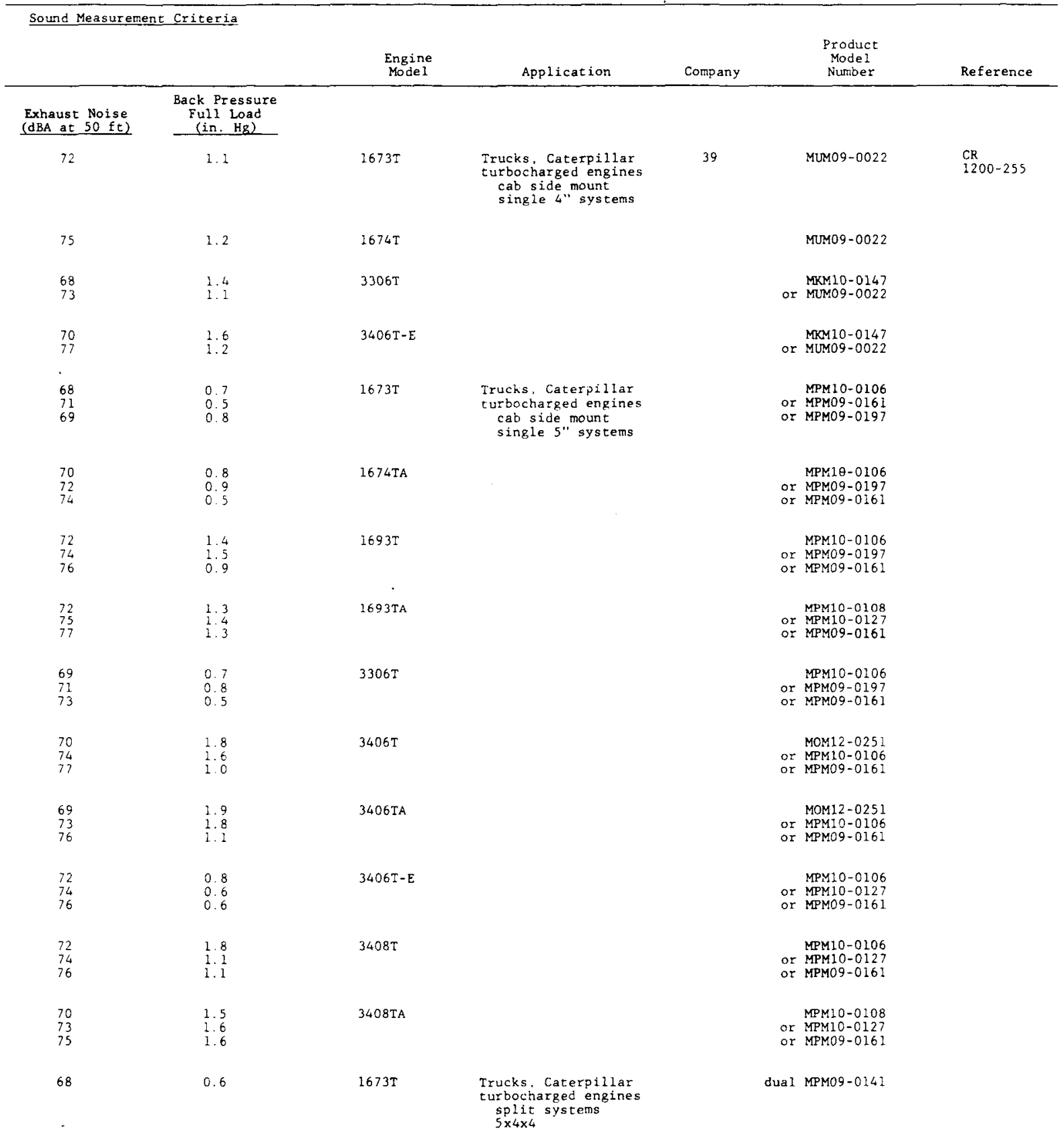


Table 33. Vehicular mufflers continued.

\begin{tabular}{|c|c|c|c|c|c|c|c|}
\hline \multicolumn{8}{|c|}{ Sound Measurement Criteria } \\
\hline & & $\begin{array}{l}\text { Engine } \\
\text { Model }\end{array}$ & Application & Company & & $\begin{array}{l}\text { Product } \\
\text { Mode 1 } \\
\text { Number }\end{array}$ & Reference \\
\hline $\begin{array}{l}\text { Exhaust Noise } \\
(\mathrm{dBA} \text { at } 50 \mathrm{ft}) \\
\end{array}$ & $\begin{array}{l}\text { Back Pressure } \\
\text { Ful1 Load } \\
\text { (in. Hg) } \\
\end{array}$ & & & & & & \\
\hline 71 & 0.2 & & $\begin{array}{l}\text { Trucks, Caterpillar } \\
\text { turbocharged engines } \\
\text { cab side mount } \\
\text { split systetis } \\
5 \times 5 \times 5\end{array}$ & 39 & dua 1 & MPM09-0161 & $\begin{array}{l}\mathrm{CR} \\
1200-255\end{array}$ \\
\hline 70 & 0.7 & $1674 \mathrm{TA}$ & $5 \times 4 \times 4$ & & dua 1 & MPM09-0141 & \\
\hline $\begin{array}{l}71 \\
73\end{array}$ & $\begin{array}{l}0.4 \\
0.2\end{array}$ & & $5 \times 5 \times 5$ & & or dual & $\begin{array}{l}\text { MPM09-0197 } \\
\text { MPM09-0161 }\end{array}$ & \\
\hline 72 & $\frac{1.3}{0.7}$ & $1693 \mathrm{~T}$ & $5 \times 4 \times 4$ & & or dual & $\begin{array}{l}\text { MPM09-0141 } \\
\text { MIMM09-0022 }\end{array}$ & \\
\hline $\begin{array}{l}71 \\
75\end{array}$ & $\begin{array}{l}0.5 \\
0.4\end{array}$ & & $5 \times 5 \times 5$ & & $\begin{array}{r}\text { dual } \\
\text { or dual }\end{array}$ & $\begin{array}{l}\text { MPM10-0106 } \\
\text { MPMO9-0161 }\end{array}$ & \\
\hline 76 & 1.2 & $1693 \mathrm{TA}$ & $5 \times 4 \times 4$ & & dual & MMO9-0022 & \\
\hline 72 & $\begin{array}{l}1.0 \\
0.9\end{array}$ & & $5 \times 5 \times 5$ & & or dual & $\begin{array}{l}\text { MFMID-0106 } \\
\text { MFM09-0197 }\end{array}$ & \\
\hline 69 & 0.6 & $3306 \mathrm{~T}$ & $5 \times 4 \times 4$ & & dua! & MPM09-0141 & \\
\hline 71 & 0.2 & & $5 \times 5 \times 5$ & & dual & MPM09-0161 & \\
\hline $\begin{array}{l}72 \\
76\end{array}$ & $\begin{array}{l}1.3 \\
0.9\end{array}$ & $3406 \mathrm{~T}$ & $5 \times 4 \times 4$ & & or dual & $\begin{array}{l}\text { MPMO9-0141 } \\
\text { MUMO9-0022 }\end{array}$ & \\
\hline $\begin{array}{l}70 \\
73\end{array}$ & $\begin{array}{l}1.2 \\
0.7\end{array}$ & & $5 \times 5 \times 5$ & & or dual & $\begin{array}{l}\text { MFM10-0165 } \\
\text { MPMO9-0197 }\end{array}$ & \\
\hline $\begin{array}{l}71 \\
75\end{array}$ & $\begin{array}{l}1.4 \\
0.9\end{array}$ & $3406 \mathrm{TA}$ & $5 \times 4 \times 4$ & & $\begin{array}{l}\text { dual } \\
\text { or dual }\end{array}$ & $\begin{array}{l}\text { MPYY09-0141 } \\
\text { MUY09-0022 }\end{array}$ & \\
\hline $\begin{array}{l}69 \\
72\end{array}$ & $\begin{array}{l}1.3 \\
0.8\end{array}$ & & $5 \times 5 \times 5$ & & $\begin{array}{l}\text { dual } 1 \\
\text { or dual }\end{array}$ & $\begin{array}{l}\text { MFM10-0165 } \\
\text { MPM09-0197 }\end{array}$ & \\
\hline 71 & 0.7 & $3406 \mathrm{~T}-\mathrm{E}$ & $5 \times 4 \times 4$ & & dual & MPYY09-0141 & \\
\hline $\begin{array}{l}69 \\
72\end{array}$ & $\begin{array}{l}0.7 \\
0.4\end{array}$ & & $5 \times 5 \times 5$ & & or dual & $\begin{array}{l}\text { MFM10-0165 } \\
\text { MPMO9-0197 }\end{array}$ & \\
\hline $\begin{array}{l}71 \\
75\end{array}$ & $\begin{array}{l}1.4 \\
0.9\end{array}$ & $3408 \mathrm{~T}$ & $5 \times 4 \times 4$ & & or dual & $\begin{array}{l}\text { MPMO9-0141 } \\
\text { MUMO9-0022 }\end{array}$ & \\
\hline $\begin{array}{l}69 \\
72\end{array}$ & $\begin{array}{l}1.2 \\
0.8\end{array}$ & & $5 \times 5 \times 5$ & & or dual & $\begin{array}{l}\text { MFM10-0165 } \\
\text { MPP109-0197 }\end{array}$ & \\
\hline $\begin{array}{l}70 \\
74\end{array}$ & $\begin{array}{l}1.9 \\
1.3\end{array}$ & $3408 \mathrm{TA}$ & $5 \times 4 \times 4$ & & $\begin{array}{l}\text { dual } \\
\text { or dual }\end{array}$ & $\begin{array}{l}\text { MPNO9-0141 } \\
\text { MUN09-0022 }\end{array}$ & \\
\hline $\begin{array}{l}70 \\
71\end{array}$ & $\begin{array}{l}1.1 \\
1.2\end{array}$ & & $5 \times 5 \times 5$ & & $\begin{array}{r}\text { dual } \\
\text { or dual }\end{array}$ & $\begin{array}{l}\text { MPN10-0106 } \\
\text { MPMO9-0197 }\end{array}$ & \\
\hline 72 & 0.8 & $1673 \mathrm{~T}$ & $\begin{array}{l}\text { Trucks, Caterpillar } \\
\text { turbocharged engines } \\
\text { chassis mount } \\
\text { vertical tailpipe } \\
\text { single 5" systems }\end{array}$ & & & MOM12-0131 & \\
\hline 75 & 0.9 & $1674 \mathrm{TA}$ & & & & MOM12-0131 & \\
\hline 77 & 1.4 & $1693 \mathrm{~T}$ & & & & MOM12-0131 & \\
\hline 73 & 0.8 & $3306 \mathrm{~T}$ & & & & $\operatorname{MOM12-0131}$ & \\
\hline 78 & 1.7 & $3406 \mathrm{~T}$ & & & & MOM12-0131 & \\
\hline 77 & 1.8 & $3406 \mathrm{TA}$ & & & & MOM12-0131 & \\
\hline
\end{tabular}


Table 33. Vehicular mufflers continued.

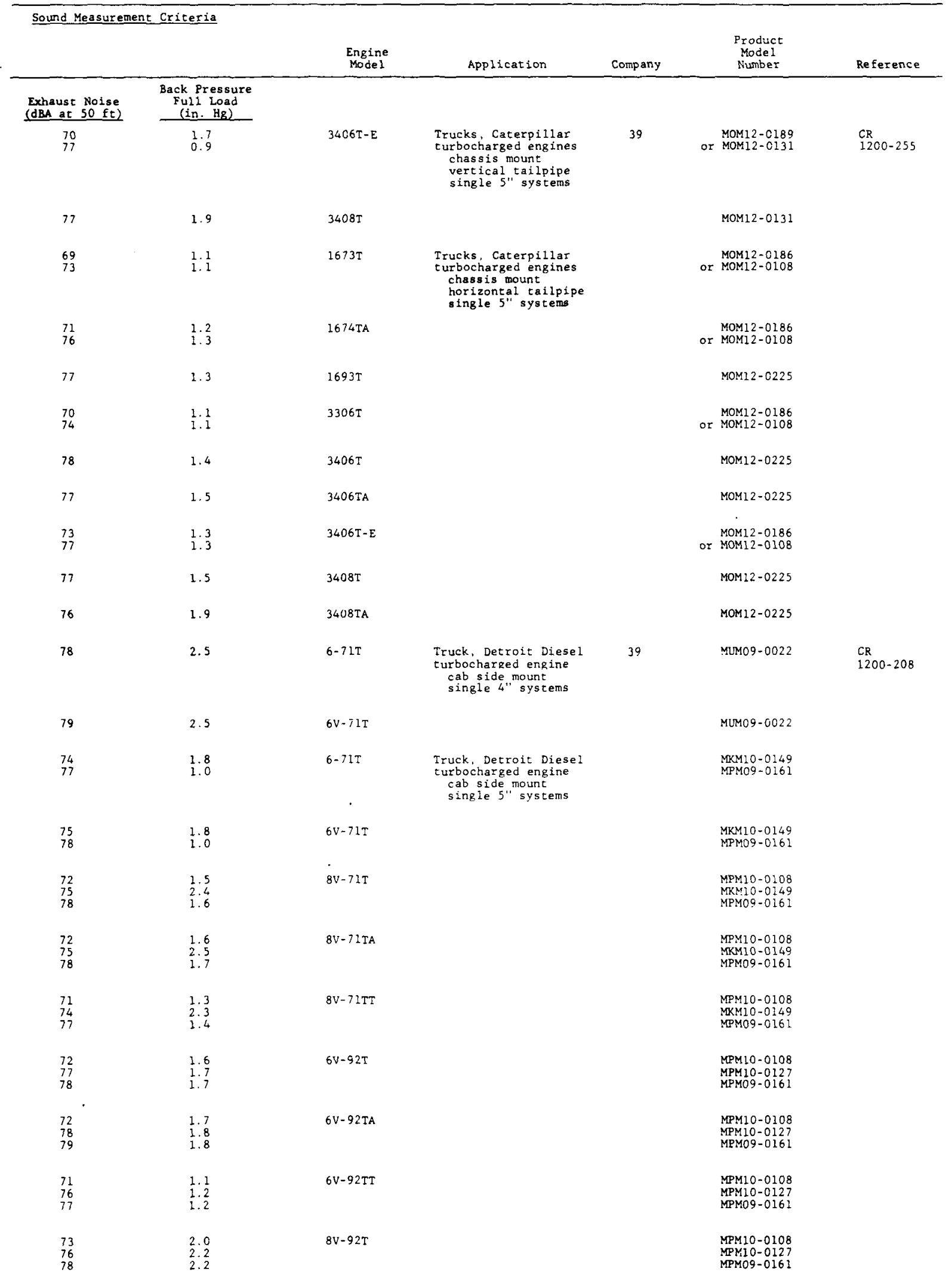


Table 33. Vehicular mufflers continued.

\begin{tabular}{|c|c|c|c|c|c|c|c|}
\hline \multicolumn{8}{|c|}{ Sound Measurement Cxiteria } \\
\hline & & $\begin{array}{l}\text { Engine } \\
\text { Model } \\
\end{array}$ & Application & Company & & $\begin{array}{c}\text { Product } \\
\text { Model } \\
\text { Number }\end{array}$ & Reference \\
\hline $\begin{array}{r}\text { Exhaust Noise } \\
\text { (dBA at } 50 \mathrm{fr}) \\
\end{array}$ & $\begin{array}{c}\text { Back Pressure } \\
\text { Ful Load } \\
\text { (in. Hg) } \\
\end{array}$ & & . & & & & \\
\hline $\begin{array}{l}73 \\
76 \\
78\end{array}$ & $\begin{array}{l}2.1 \\
2.3 \\
2.3\end{array}$ & $8 V-92 T A$ & $\begin{array}{l}\text { Truck, Detroit Diesel } \\
\text { turbocharged engine } \\
\text { cab side, mount } \\
\text { single } 5 \text { " systems }\end{array}$ & 39 & & $\begin{array}{l}\text { MPM10-0108 } \\
\text { MPM10-0127 } \\
\text { MPMO9-0161 }\end{array}$ & $\begin{array}{l}C R \\
1200-208\end{array}$ \\
\hline $\begin{array}{l}72 \\
75 \\
77\end{array}$ & $\begin{array}{l}1.7 \\
1.8 \\
1.8\end{array}$ & $8 \mathrm{~V}-92 \mathrm{TT}$ & & & & $\begin{array}{l}\text { MPM10-0108 } \\
\text { MPM10-0127 } \\
\text { MPM09-0161 }\end{array}$ & \\
\hline 80 & 2.5 & $12 \mathrm{~V}-71 \mathrm{~T}$ & $\begin{array}{l}\text { Truck, Detroit Diese1 } \\
\text { turbocharged engine } \\
\text { cab side mount } \\
\text { dual 4" systems }\end{array}$ & & dua 1 & MLMO 9-0022 & \\
\hline $\begin{array}{l}72 \\
76 \\
79\end{array}$ & $\begin{array}{l}1.0 \\
1.8 \\
1.0\end{array}$ & $12 \mathrm{~V}-71 \mathrm{~T}$ & $\begin{array}{l}\text { Truck, Detroit Diesel } \\
\text { turbocharged engine } \\
\text { cab side mount } \\
\text { dual } 5 " \text { systems }\end{array}$ & & $\begin{array}{l}\text { dual } \\
\text { or dual } \\
\text { or dual }\end{array}$ & $\begin{array}{l}\text { MPM10-0108 } \\
\text { MKM10-0149 } \\
\text { MPM09-0161 }\end{array}$ & \\
\hline $\begin{array}{l}69 \\
73\end{array}$ & 2.1 & $6.71 \mathrm{~T}$ & $\begin{array}{l}\text { Truck, Detroit Diesel } \\
\text { turbocharged engine } \\
\text { cab side mount } \\
\text { split systems } \\
5 \times 4 \times 4\end{array}$ & & or dua 1 & $\begin{array}{l}\text { MSMO9-0142 } \\
\text { MPMO9-0141 }\end{array}$ & \\
\hline $\begin{array}{l}89 \\
73\end{array}$ & $\begin{array}{l}1.2 \\
0.8\end{array}$ & & $5 \times 5 \times 5$ & & or dual 1 & $\begin{array}{l}\text { MFM10-0165 } \\
\text { MPMO9-0197 }\end{array}$ & \\
\hline $\begin{array}{l}70 \\
76\end{array}$ & $\begin{array}{l}2.1 \\
1.3\end{array}$ & $6 \mathrm{~V}-71 \mathrm{~T}$ & $5 \times 4 \times 4$ & & $\begin{array}{r}\text { dual } 1 \\
\text { or dual }\end{array}$ & $\begin{array}{l}\text { MSM09-0142 } \\
\text { MPMO9-0141 }\end{array}$ & \\
\hline $\begin{array}{l}70 \\
74\end{array}$ & $\begin{array}{l}1.2 \\
0.8\end{array}$ & & $5 \times 5 \times 5$ & & or dual & $\begin{array}{l}\text { MFM10-0165 } \\
\text { MPM09-0197 }\end{array}$ & \\
\hline $\begin{array}{l}70 \\
74\end{array}$ & $\begin{array}{l}1.8 \\
2.1\end{array}$ & $8 \mathrm{~V}-71 \mathrm{~T}$ & $5 \times 4 \times 4$ & & or dual & $\begin{array}{l}\text { MKM 10-0147 } \\
\text { MPM09-0141 }\end{array}$ & \\
\hline $\begin{array}{l}70 \\
75\end{array}$ & $\begin{array}{l}1.8 \\
1.3\end{array}$ & & $5 \times 5 \times 5$ & & $\begin{array}{l}\text { dual } \\
\text { or dual }\end{array}$ & $\begin{array}{l}\text { MPM10-0165 } \\
\text { MPM09-0197 }\end{array}$ & \\
\hline 70 & $\begin{array}{l}1.9 \\
2.2\end{array}$ & $8 \mathrm{~V}-71 \mathrm{TA}$ & $5 \times 4 \times 4$ & & or dual & $\begin{array}{l}\text { MRM10-0147 } \\
\text { MPM09-0141 }\end{array}$ & \\
\hline $\begin{array}{l}70 \\
75\end{array}$ & $\begin{array}{l}2.0 \\
1.4\end{array}$ & & $5 \times 5 \times 5$ & & $\begin{array}{l}\text { dual } \\
\text { or dual }\end{array}$ & $\begin{array}{l}\text { MFM10-0165 } \\
\text { MPMO9-0197 }\end{array}$ & \\
\hline $\begin{array}{l}69 \\
73\end{array}$ & $\begin{array}{l}1.6 \\
1.8\end{array}$ & $8 \mathrm{~V}-71 \mathrm{TT}$ & $5 \times 4 \times 4$ & & $\begin{array}{l}\text { dual } \\
\text { o: dual }\end{array}$ & $\begin{array}{l}\text { YKM10-0147 } \\
\text { MPM09-0141 }\end{array}$ & \\
\hline $\begin{array}{l}69 \\
74\end{array}$ & $\begin{array}{l}1.6 \\
1.1\end{array}$ & & $5 \times 5 \times 5$ & & or dual & $\begin{array}{l}\text { VFM10-0165 } \\
\text { MPM09-0197 }\end{array}$ & \\
\hline $\begin{array}{l}71 \\
74\end{array}$ & $\begin{array}{l}1.8 \\
2.1\end{array}$ & $6 V-92 T$ & $5 \times 4 \times 4$ & & or dual & $\begin{array}{l}\text { MKM10-0147 } \\
\text { MPMO9-0141 }\end{array}$ & \\
\hline $\begin{array}{l}71 \\
75\end{array}$ & $\begin{array}{l}1.9 \\
1.3\end{array}$ & & $5 \times 5 \times 5$ & & $\begin{array}{l}\text { dual } \\
\text { or dual }\end{array}$ & $\begin{array}{l}\text { IPM10-0165 } \\
\text { IAPM09-0197 }\end{array}$ & \\
\hline $\begin{array}{l}71 \\
74\end{array}$ & $\begin{array}{l}2.0 \\
2.3\end{array}$ & $6 \mathrm{~V}-92 \mathrm{TA}$ & $5 \times 4 \times 4$ & & or dual & $\begin{array}{l}\text { :1KM2O-014? } \\
\text { MPMO9-0141 }\end{array}$ & \\
\hline $\begin{array}{l}71 \\
75\end{array}$ & $\begin{array}{l}2.1 \\
1.4\end{array}$ & & $5 \times 5 \times 5$ & & or dua 1 & $\begin{array}{l}\text { MFM10-0165 } \\
\text { MPMO9-0197 }\end{array}$ & \\
\hline $\begin{array}{l}70 \\
73\end{array}$ & $\begin{array}{l}1.3 \\
1.5\end{array}$ & $6 \mathrm{~V}-92 \mathrm{TT}$ & $5 \times 4 \times 4$ & & or dual & $\begin{array}{l}\text { MKM10-0147 } \\
\text { MPM09-0141 }\end{array}$ & \\
\hline $\begin{array}{l}70 \\
74\end{array}$ & $\begin{array}{l}1.3 \\
0.9\end{array}$ & & $5 \times 5 \times 5$ & & or dual & $\begin{array}{l}\text { NFM10-0165 } \\
\text { MPMO9-0197 }\end{array}$ & \\
\hline $\begin{array}{l}71 \\
78\end{array}$ & $\begin{array}{l}2.3 \\
2.0\end{array}$ & $8 \mathrm{~V}-92 \mathrm{~T}$ & $5 \times 4 \times 4$ & & $\begin{array}{l}\text { dual } \\
\text { or dual }\end{array}$ & $\begin{array}{l}\text { MIKM10-0147 } \\
\text { MUMO9-0022 }\end{array}$ & \\
\hline
\end{tabular}


Table 33. Vehicular mufflers continued.

\begin{tabular}{|c|c|c|c|c|c|c|c|}
\hline Sound Measuren & Criteria & $\begin{array}{l}\text { Engine } \\
\text { Model }\end{array}$ & Application & Company & & $\begin{array}{l}\text { Product } \\
\text { Mode1 } \\
\text { Number }\end{array}$ & Reference \\
\hline $\begin{array}{l}\text { Exhaust Noise } \\
\text { (ABA at } 50 \mathrm{ft})\end{array}$ & $\begin{array}{c}\text { Back Pressure } \\
\text { Fuli Load } \\
\text { (in. Hg) } \\
\end{array}$ & & & & & & \\
\hline 71 & $\begin{array}{l}2.3 \\
1.7\end{array}$ & $8 V-92 T$ & $\begin{array}{l}\text { Truck, Detroit Diesel } \\
\text { turbocharged engine } \\
\text { cab side mount } \\
\text { spitit systems } \\
5 \times 5 \times 5\end{array}$ & 39 & $\begin{array}{r}\text { dual } \\
\text { or dual }\end{array}$ & $\begin{array}{l}\text { MFM10-0165 } \\
\text { MPM09-0197 }\end{array}$ & $\begin{array}{l}C R \\
1200-208\end{array}$ \\
\hline $\begin{array}{l}71 \\
78\end{array}$ & $\begin{array}{l}2.4 \\
2.0\end{array}$ & $8 \mathrm{~V}-92 \mathrm{TA}$ & $5 \times 4 \times 4$ & & $\begin{array}{r}\text { dual } \\
\text { or dual }\end{array}$ & $\begin{array}{l}\text { MKM10-0147 } \\
\text { MUM09-0022 }\end{array}$ & \\
\hline $\begin{array}{l}71 \\
75\end{array}$ & $\begin{array}{l}2.4 \\
1.8\end{array}$ & & $5 \times 5 \times 5$ & & or dual & $\begin{array}{l}\text { MFM10-0165 } \\
\text { MPMO9-0197 }\end{array}$ & \\
\hline $\begin{array}{l}70 \\
74\end{array}$ & $\begin{array}{l}2.0 \\
2.3\end{array}$ & $8 V-92 T T$ & $5 \times 4 \times 4$ & & or dual & $\begin{array}{l}\text { MKM10-0147 } \\
\text { MPM09-0141 }\end{array}$ & \\
\hline $\begin{array}{l}70 \\
74\end{array}$ & $\begin{array}{l}2.0 \\
1.4\end{array}$ & & $5 \times 5 \times 5$ & & or dual & $\begin{array}{l}\text { MFM10-0165 } \\
\text { MPM09-0197 }\end{array}$ & \\
\hline 77 & 1.7 & $6-71 T$ & $\begin{array}{l}\text { Truck. Detroit Diesel } \\
\text { turbocharged engine } \\
\text { chassis mount } \\
\text { verticai tailpipe } \\
\text { single 5" system }\end{array}$ & & & MOM12-0131 & \\
\hline 78 & 1.7 & $6 \mathrm{~V}-71 \mathrm{~T}$ & & & & MOM12-0131 & \\
\hline 79 & 2.4 & $8 V-71 T$ & & & & MOM12-0131 & \\
\hline 79 & 2.5 & $8 \mathrm{~V}-71 \mathrm{TA}$ & & & & MOM12-0131 & \\
\hline 78 & 2.2 & $8 \mathrm{~V}-71 \mathrm{TT}$ & & & & MOM12-0131 & \\
\hline 81 & 2.5 & $6 V-92 T$ & & & & Мом12-0131 & \\
\hline 79 & 2.1 & $6 \mathrm{~V}-92 \mathrm{TT}$ & & & & MOM12-0131 & \\
\hline 79 & 1.7 & $12 \mathrm{~V}-71 \mathrm{~T}$ & $\begin{array}{l}\text { Truck, Detroit Diese } \\
\text { turbocharged engine } \\
\text { chassis mount } \\
\text { vertical tailpipe } \\
\text { dual 5" systems }\end{array}$ & & dua 1 & MOM12-0131 & \\
\hline $\begin{array}{l}74 \\
79\end{array}$ & $\begin{array}{l}2.4 \\
2.4\end{array}$ & $6-71 \mathrm{~T}$ & $\begin{array}{l}\text { Truck, Detroit Diese } 1 \\
\text { turbocharged engine } \\
\text { chassis mount } \\
\text { horizontal tailpipe } \\
\text { single 5" systems }\end{array}$ & & or & $\begin{array}{l}\text { MOM12-0186 } \\
\text { MOM12-0108 }\end{array}$ & \\
\hline $\begin{array}{l}75 \\
80\end{array}$ & $\begin{array}{l}2.4 \\
2.4\end{array}$ & $6 \mathrm{~V}-71 \mathrm{~T}$ & & & & $\begin{array}{l}\text { MOM12-0186 } \\
\text { MOM12-0108 }\end{array}$ & \\
\hline $\begin{array}{l}77 \\
82\end{array}$ & $\begin{array}{l}2.4 \\
2.4\end{array}$ & $12 \mathrm{~V}-71 \mathrm{~T}$ & $\begin{array}{l}\text { Truck, Detroit Diesel } \\
\text { turbocharged engine } \\
\text { chassis mount } \\
\text { horizontal taipipe } \\
\text { dual 5" systems }\end{array}$ & & or dual & $\begin{array}{l}\text { MOM12-0186 } \\
\text { МOM12-0108 }\end{array}$ & \\
\hline
\end{tabular}


Table 33. Vehicular mufflers continued.

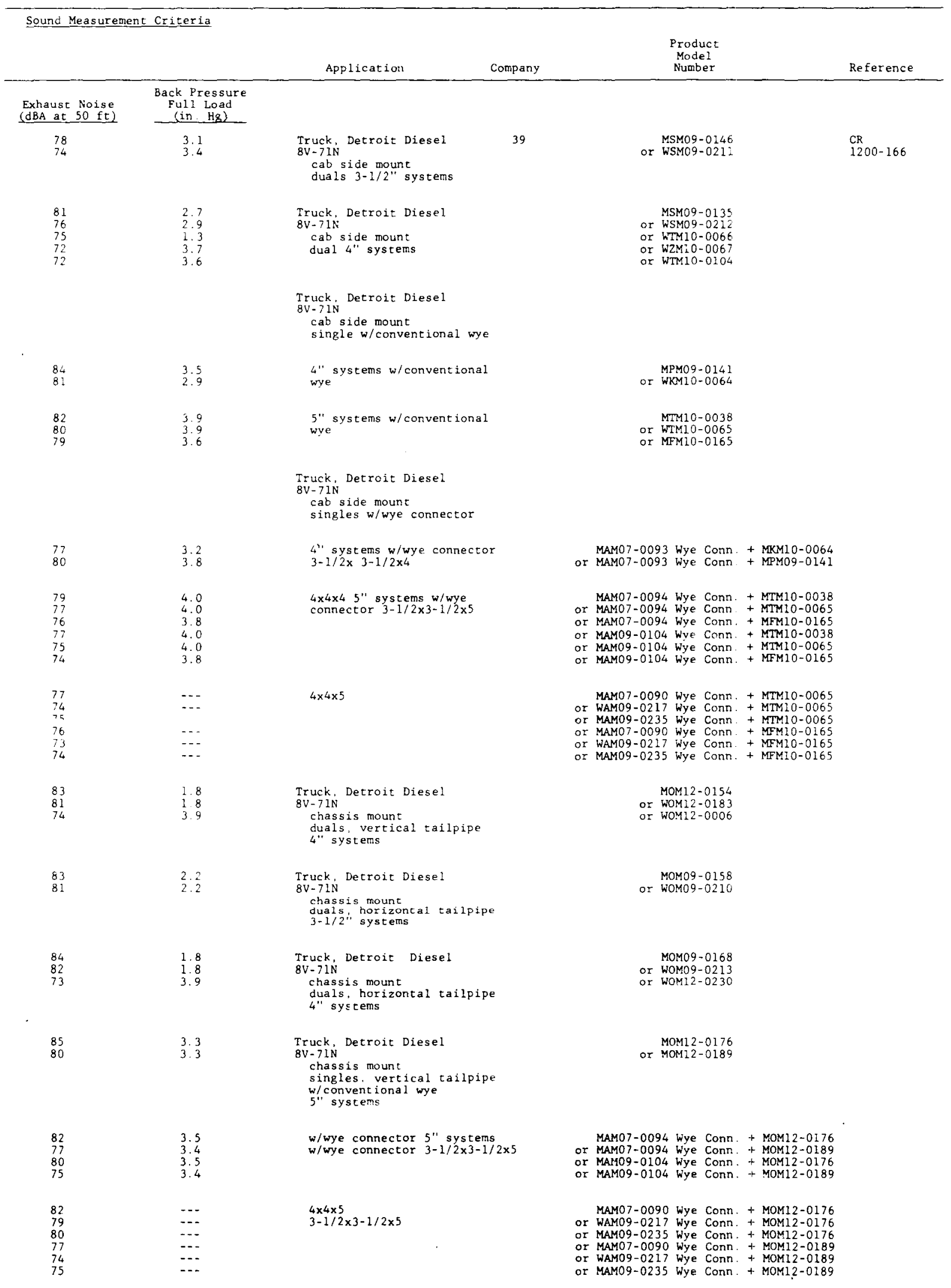


Table 33. Vehicular mufflers continued.

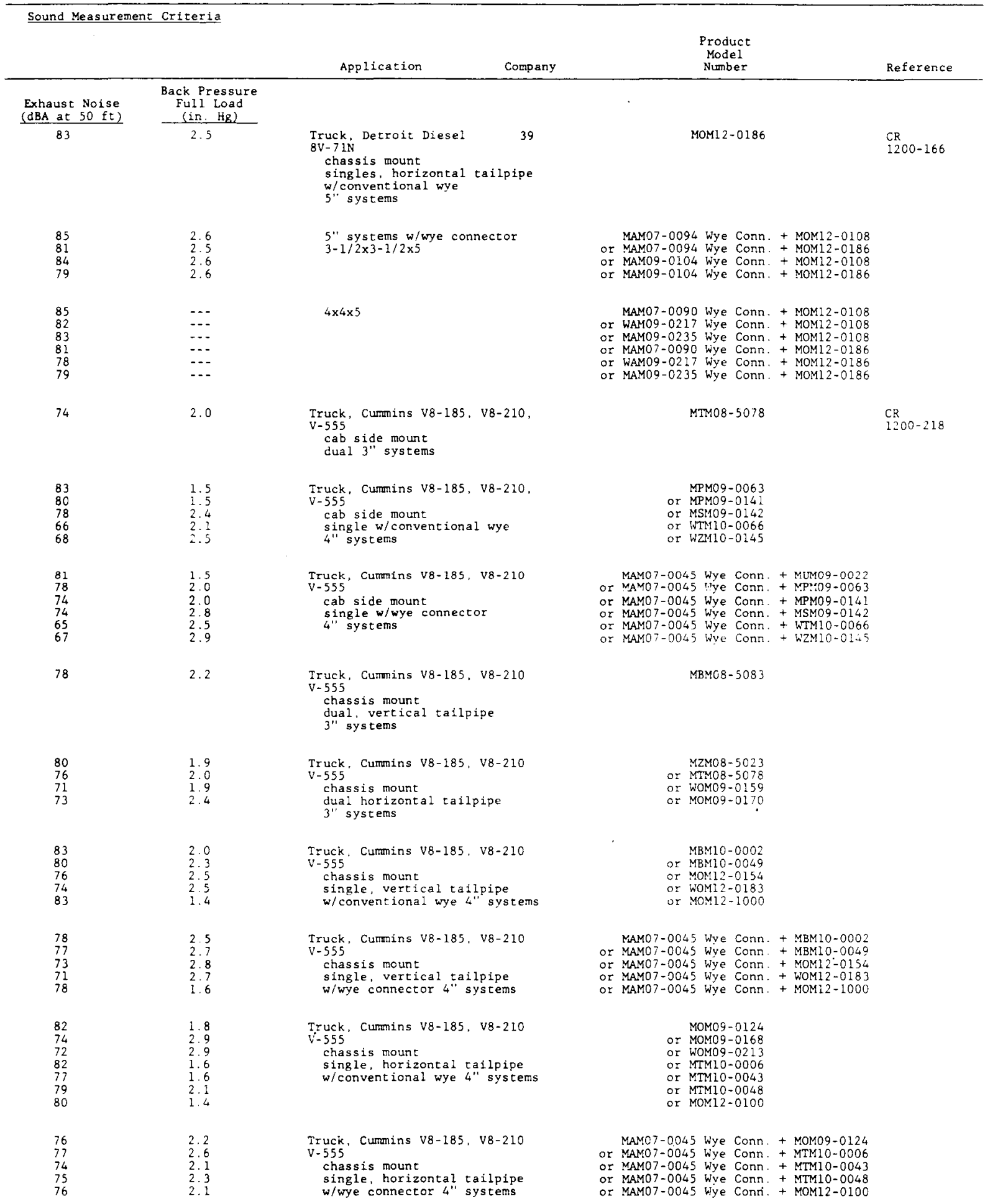


Table 33. Vehicular mufflers concluded.

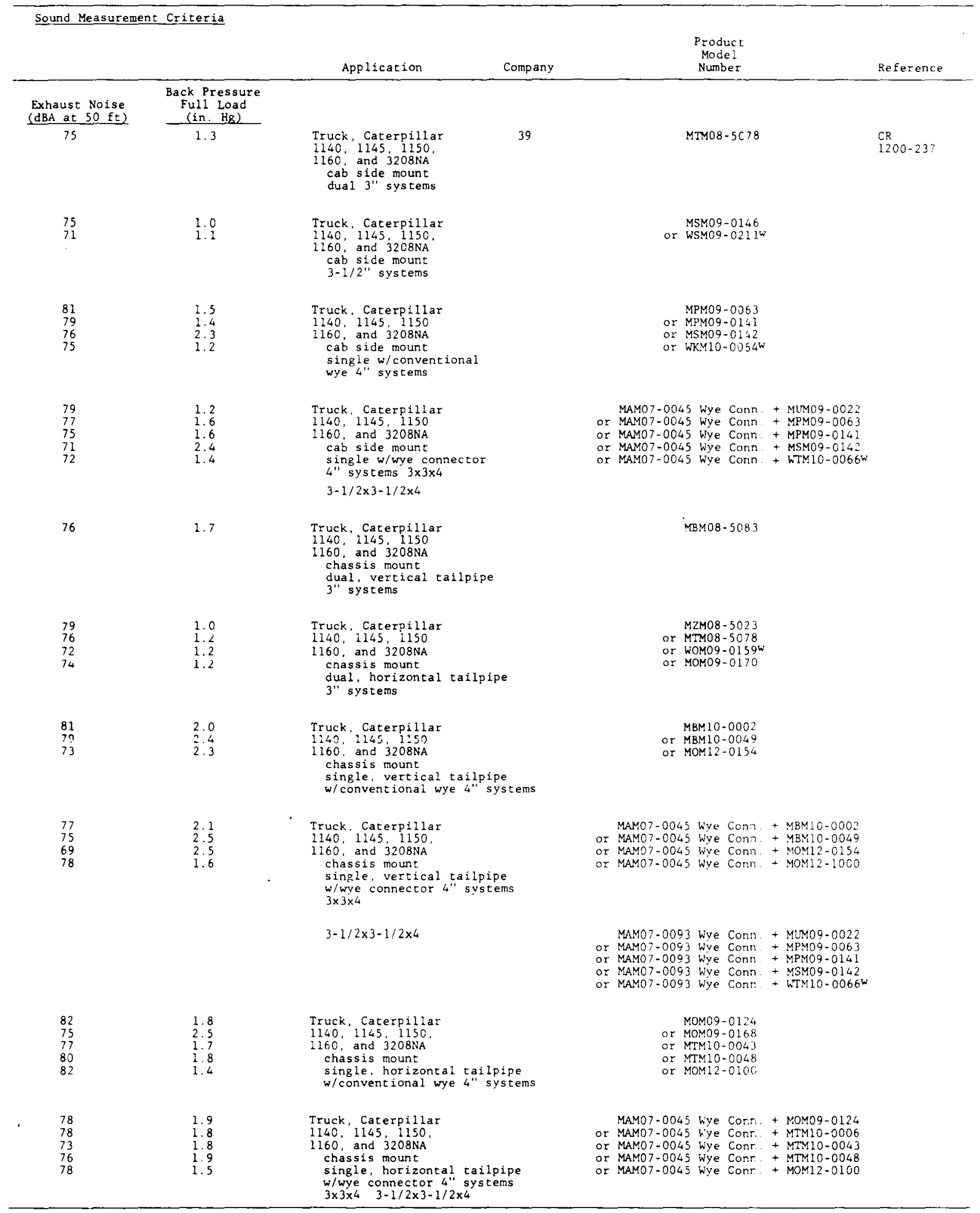

"Muffler has double-wrapped body to reduce "shell" noise. 


\section{CATEGORY 34, DUCT SILENCERS}
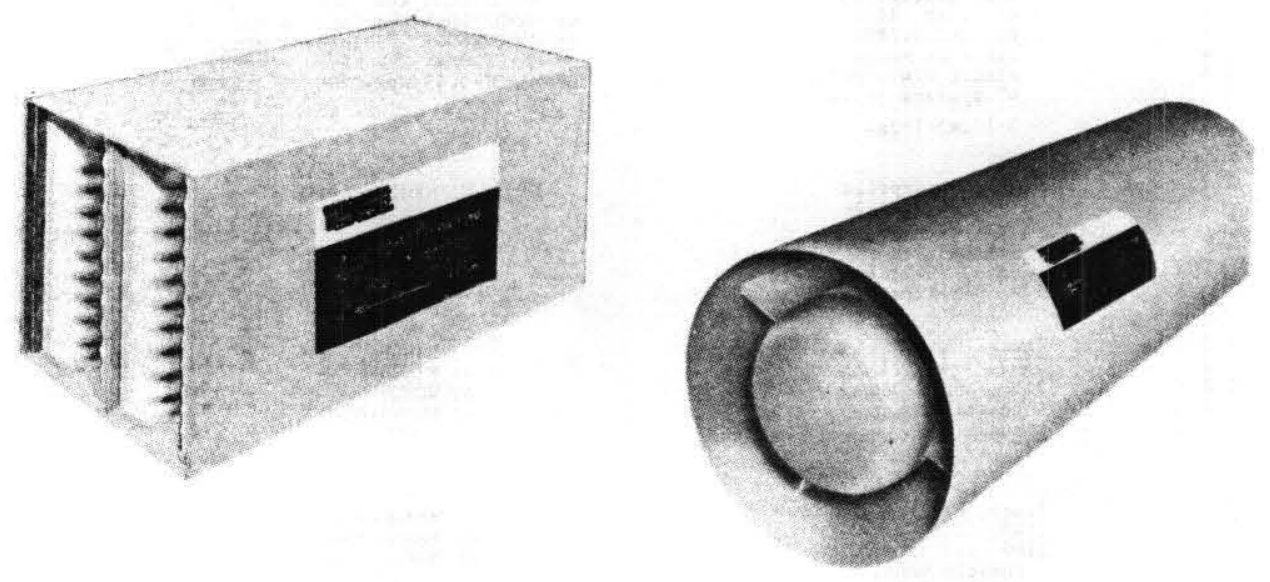
Duct silencers are inserted into round or rectangular ducts to reduce external noise levels. These silencers include structural elements which conform to the duct size. Internal splitters, bullets, louvers, and turning vanes are often included in these designs. They are mainly used for lower gas velocities. Organizations contributing data to this table are: 5, 50, and 78 .

\section{CAUTION}

1. SILENCER PERFORMANCE FIGURES OFTEN DO NOT CONFORM TO STANDARD REFERENCE MEASUREMENTS. FOR SPECIFIC APPLICATIONS, SEE MANUFACTURER'S PRODUCT LITERATURE.

2. IN MANY CASES, ONLY REPRESENTATIVE INFORMATION IS PRESENTED FOR A GIVEN PRODUCT LINE. SEE MANUFACTURER'S LITERATURE FOR COMPLETE LISTINGS OF SIZES AND PERFORMANCE DATA. 
Table 34. Duct silencers.

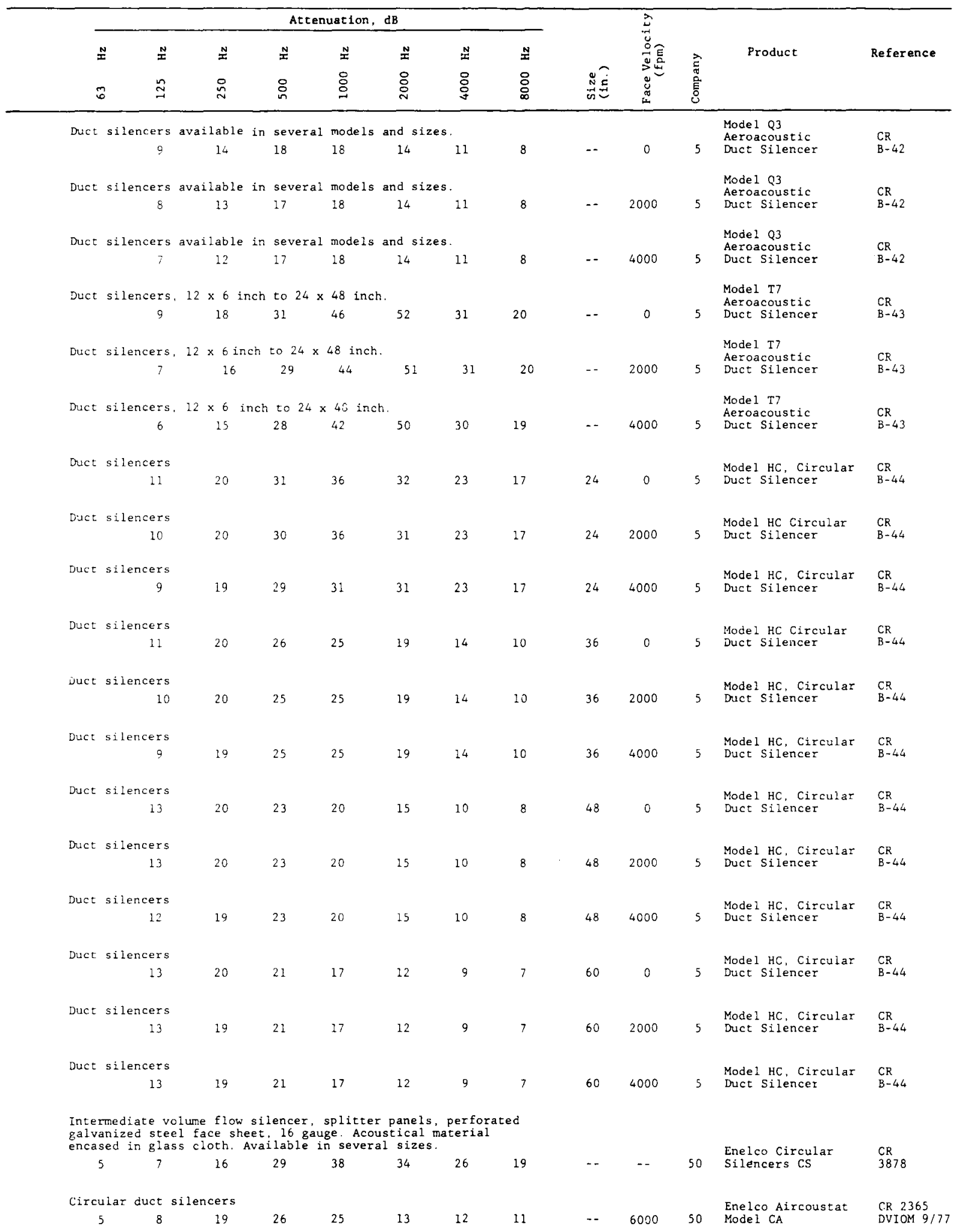


Table 34. Duct silencers continued.

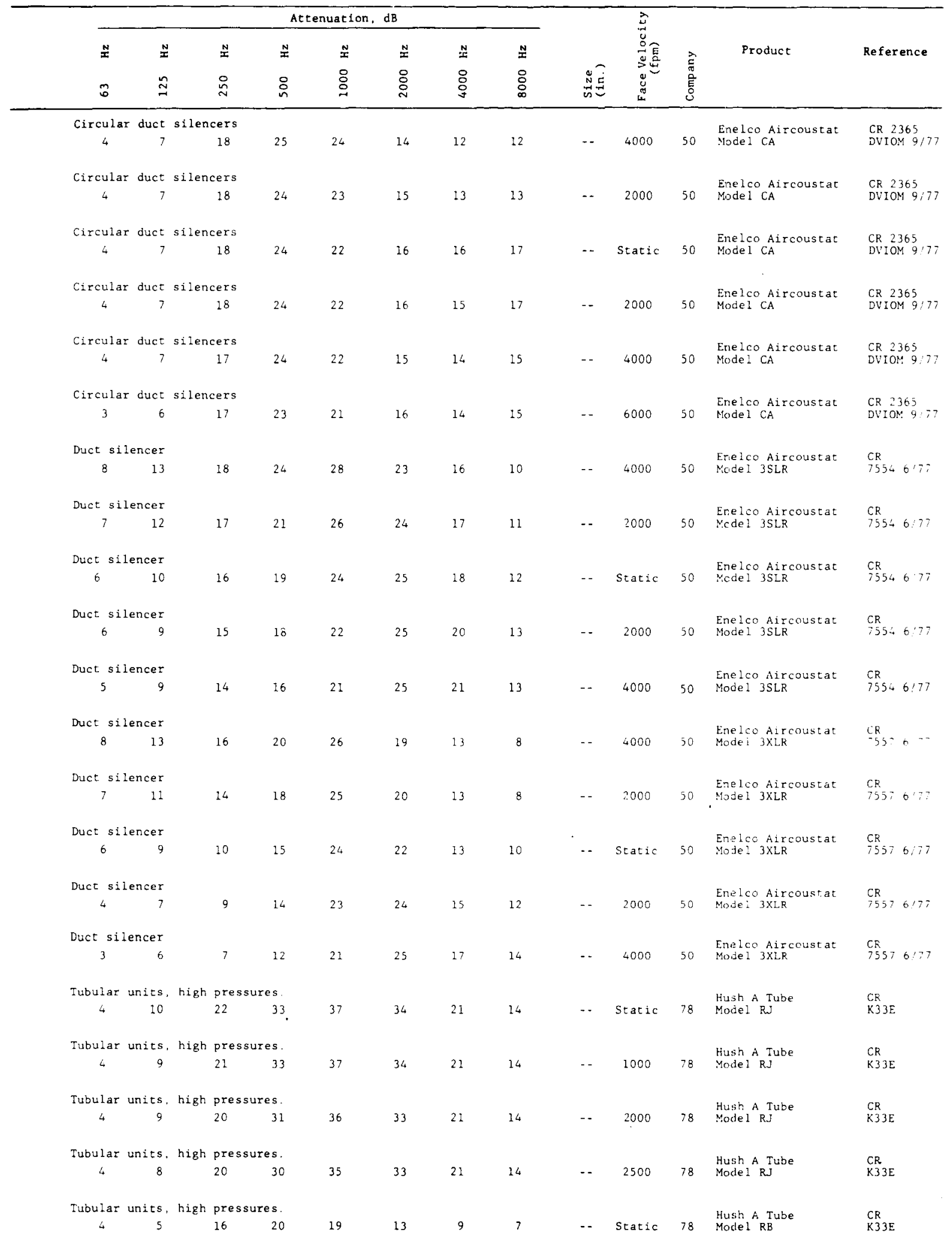


Table 34. Duct silencers concluded.

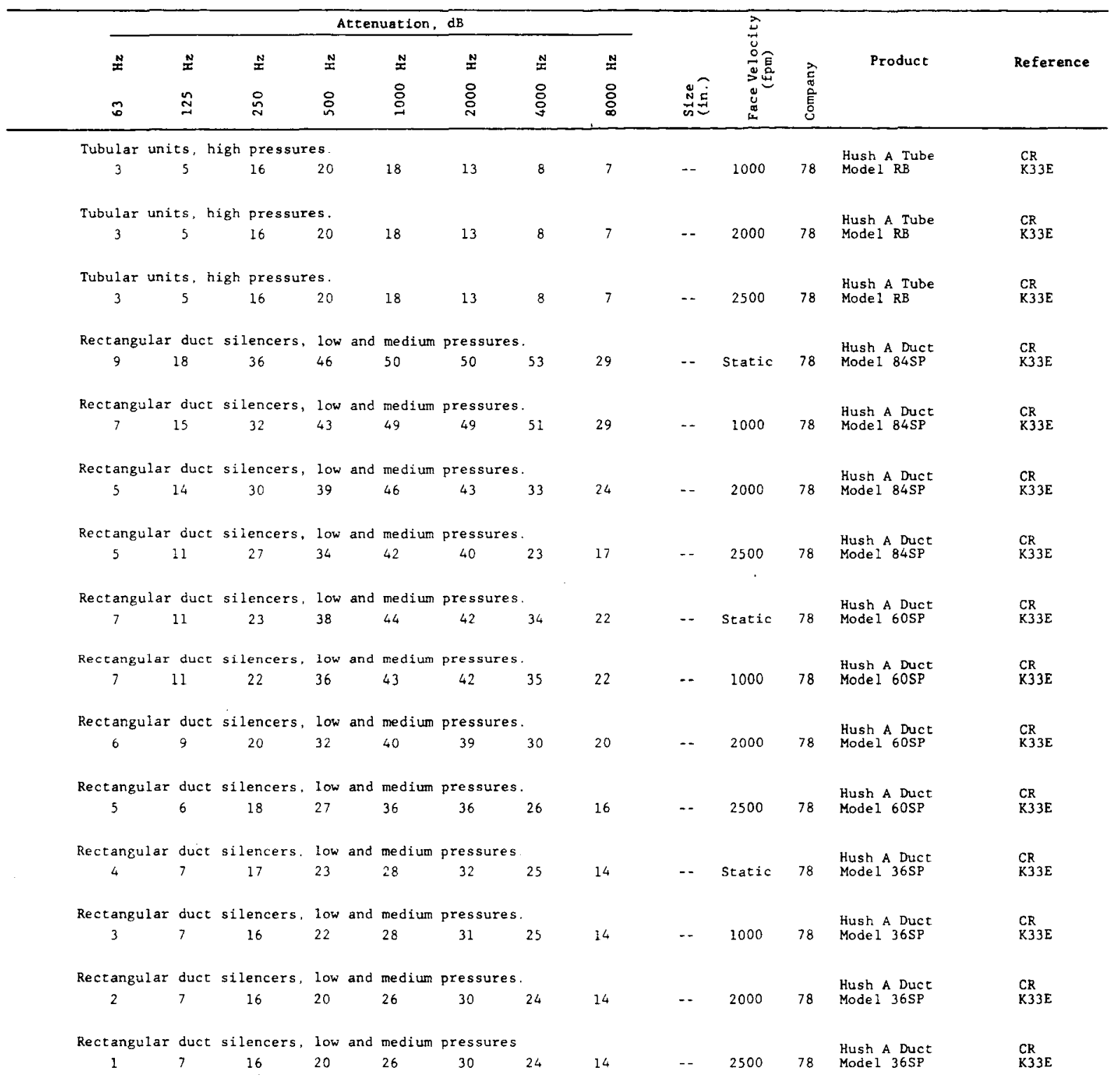


CATEGORY 35. DUCTING MATERIALS
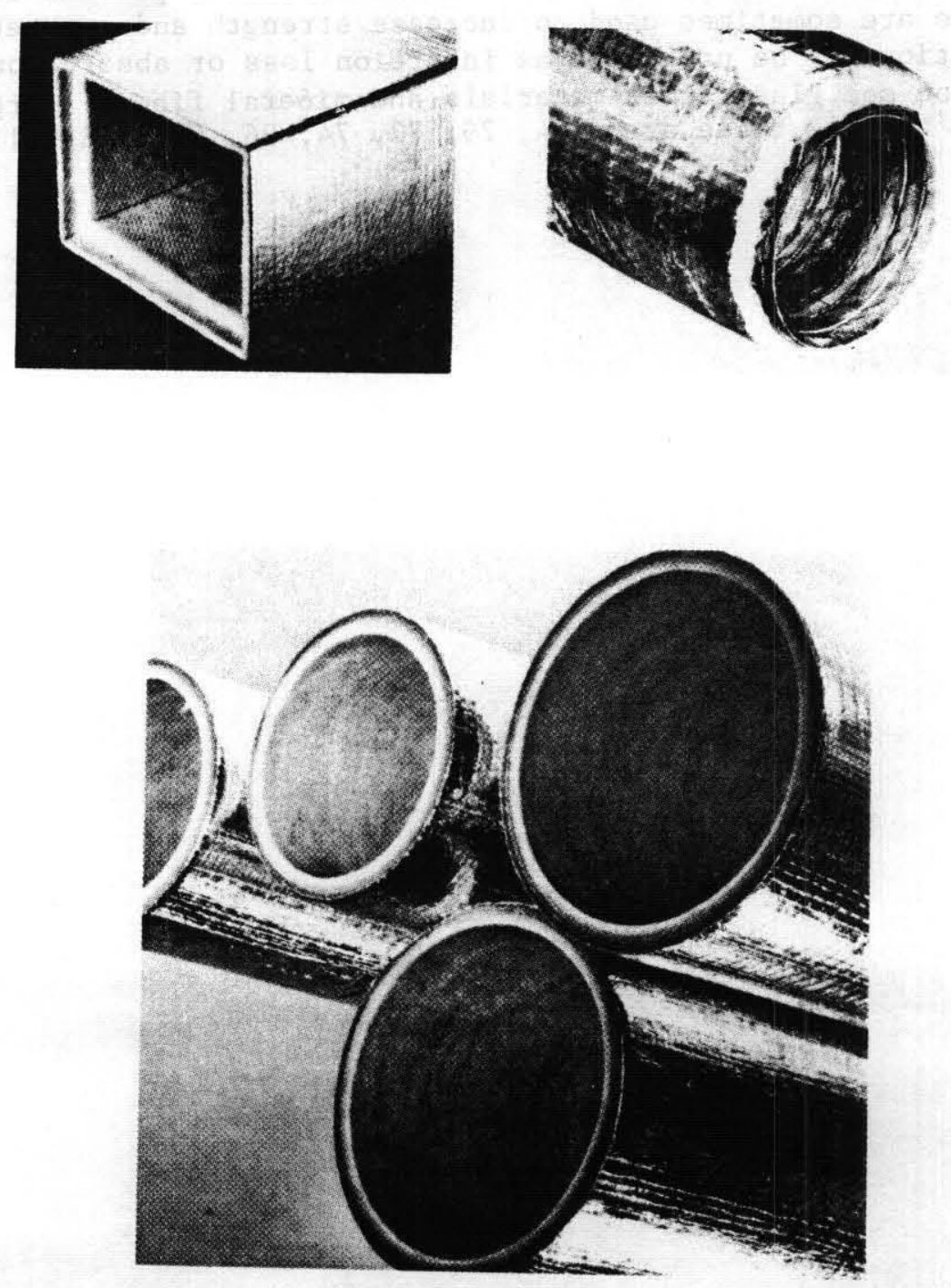
CATEGORY 35. DUCTING MATERIALS

The materials listed in this category are generally used to form air conditioning and heating ducts. Common elements are formed fiberglass boards (in round or rectangular shapes) covered with an aluminized fabric or plastic skin. Circular wire rods are sometimes used to increase strength and yet retain flexibility. Information may be presented as insertion loss or absorption. For related information see glass fiber materials and mineral fibers. Organizations contributing data to this table are: $24,29,73,74,96,98$, and 131 . 
Table 35A. Absorption properties of ducting.

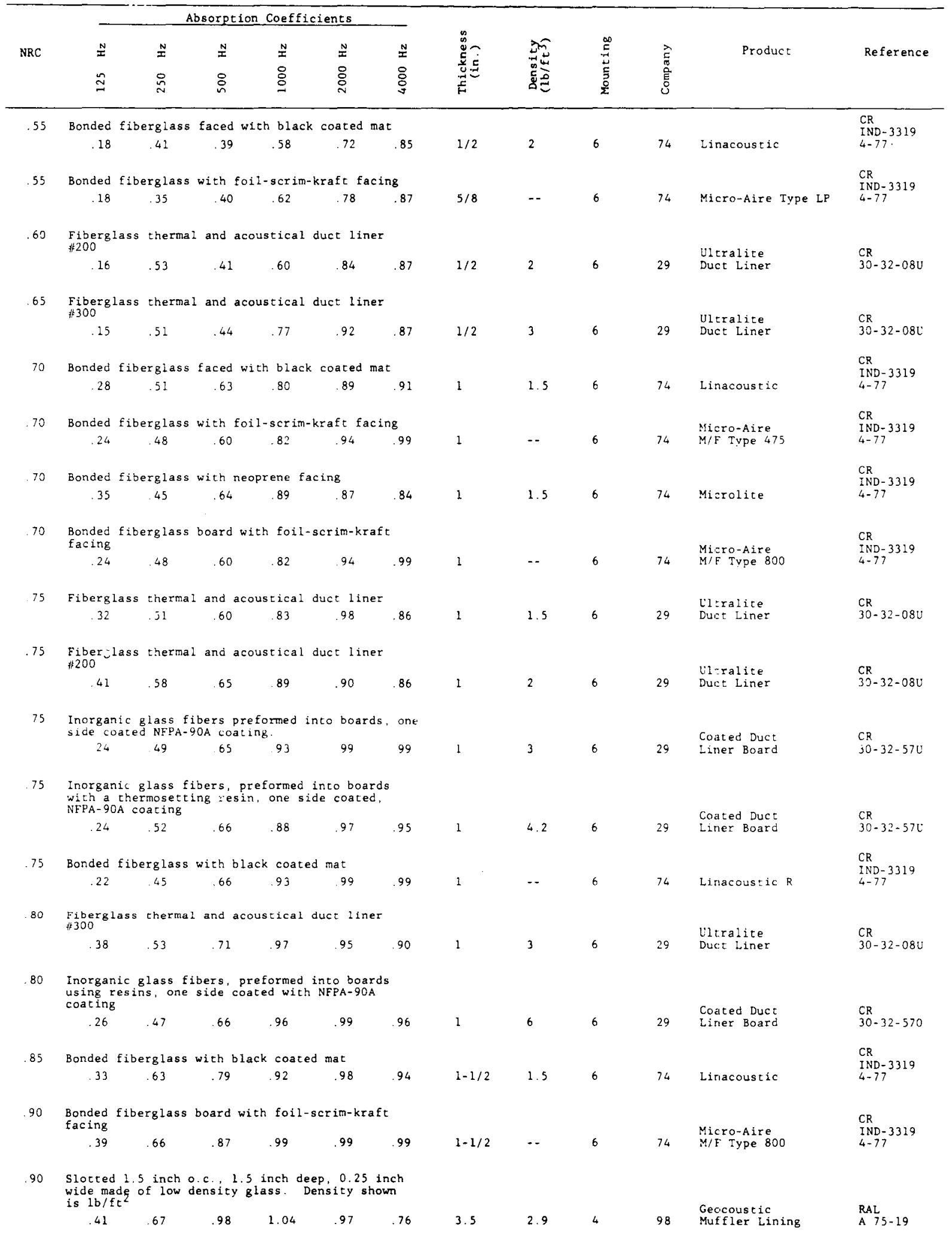


Table 35A. Absorption properties of ducting concluded.

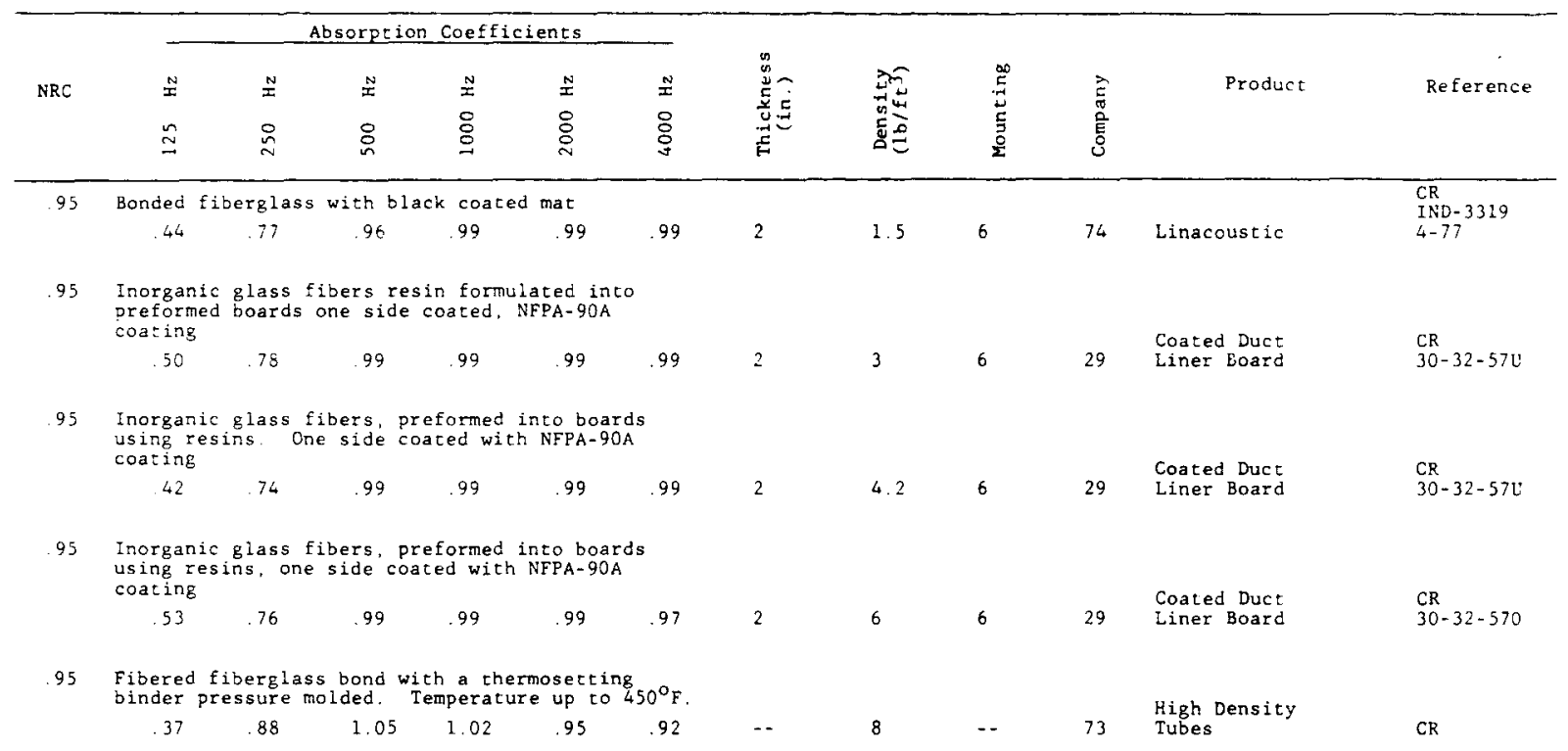


Table 35B. Barrier properties of ducting (insertion loss).

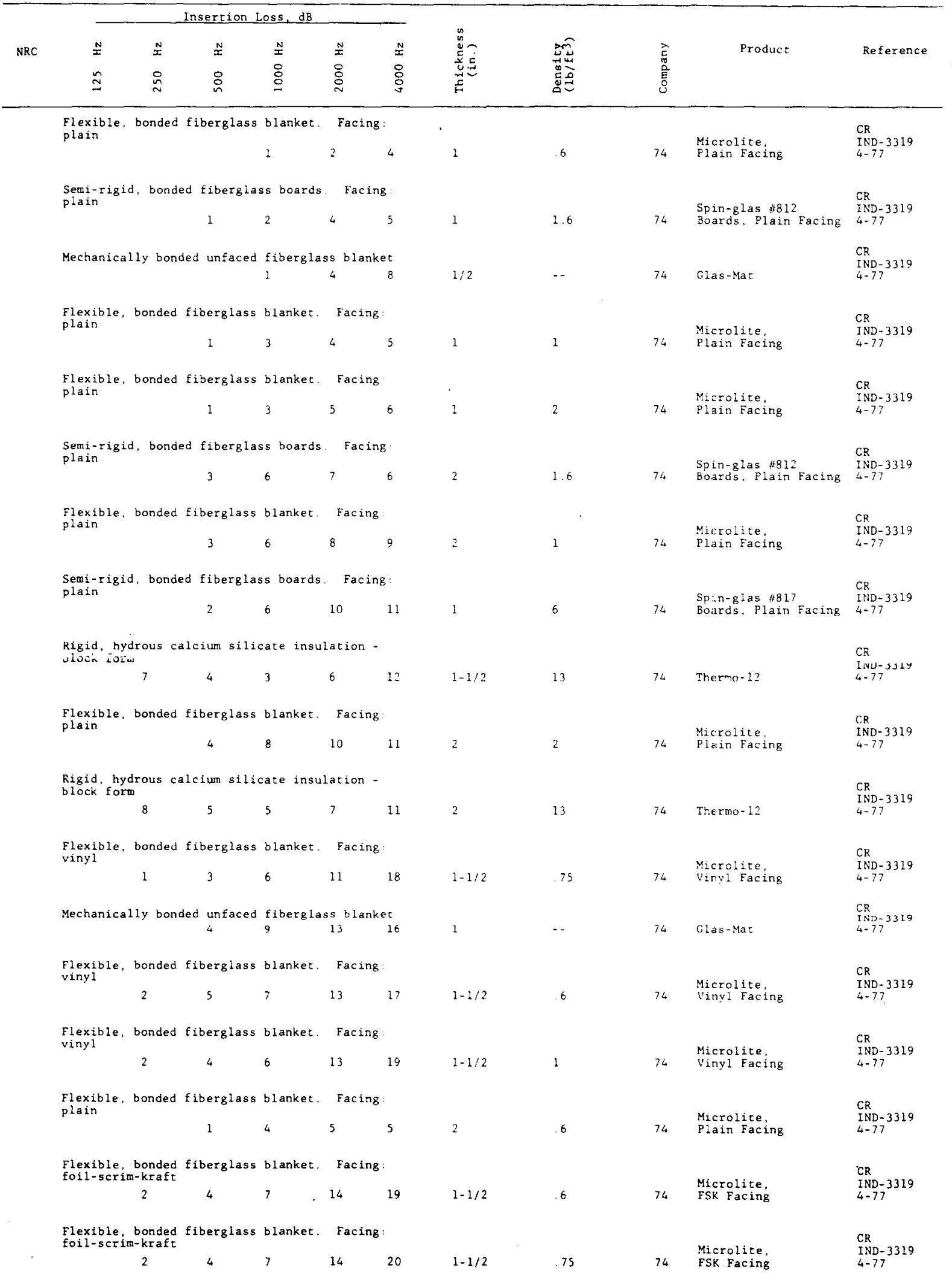


Table 35B. Barrier properties of ducting (insertion loss) continued.

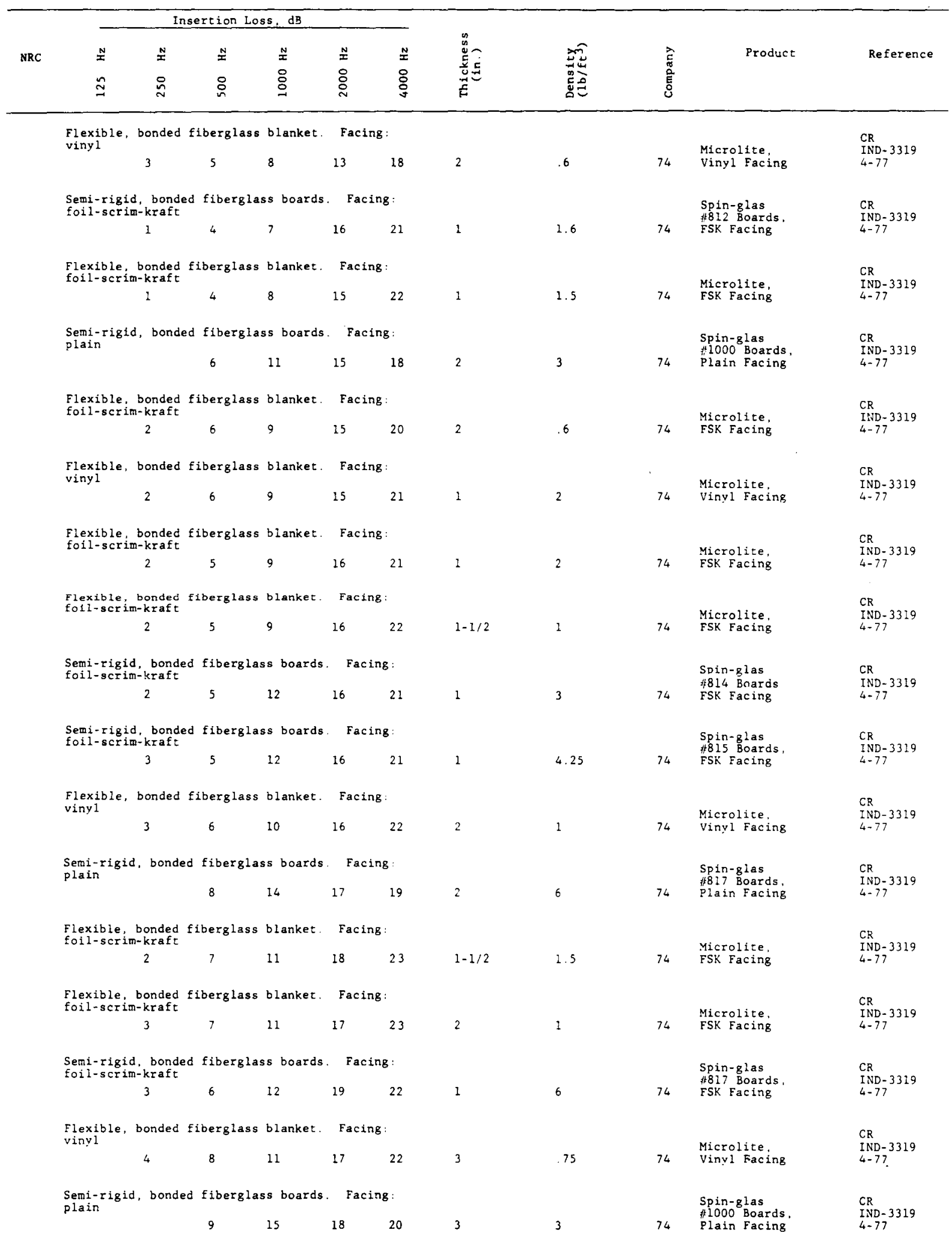


Table 35B. Barrier properties of ducting (insertion loss) concluded.

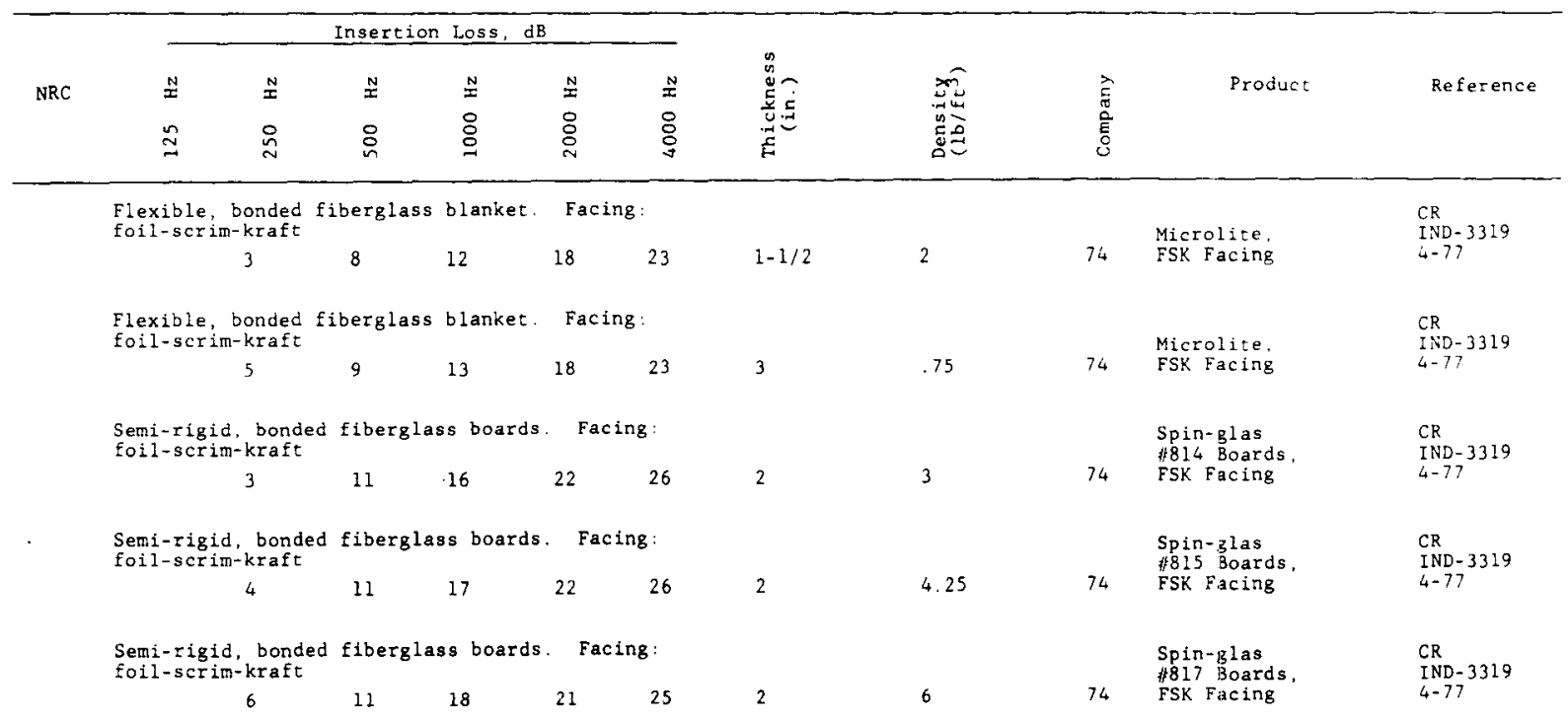


Table 35C. Attenuation properties of ducting.

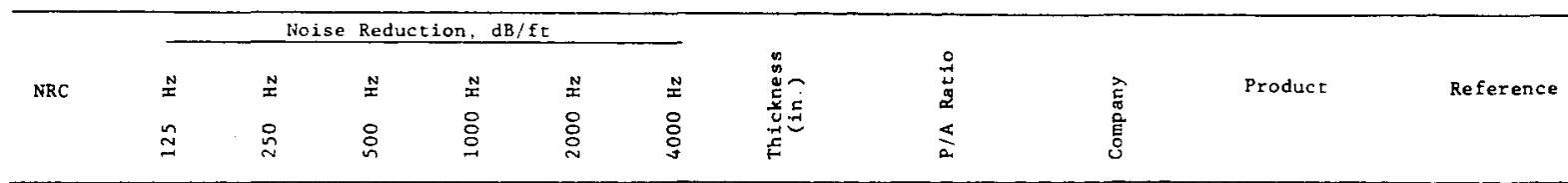

Cylindrical muffler, Iining I.D. 30 inch nominal

$\begin{array}{llcclll}4 & .9 & 1 & 1 & 1 & 1\end{array}$

3.5

$\begin{array}{lll}\text {-- } & 98 \quad \begin{array}{l}\text { Geocoustic Muffler } \\ \text { Lining }\end{array} \quad \text { CR }\end{array}$

Rectangular muffler Iining $25 \times 25$ inch low den-

sity cellular glass

4

Glass fiber with fire-rated coating tested at

$\begin{array}{cccccc}\text { air velocity of } & 2000 & \mathrm{fpm}_{\mathrm{P}} & & \\ 5 & .5 & 1.5 & 2.8 & 4 & 2.7\end{array}$

Glass fiber with fire-rated coating tested at

$\begin{array}{cccccc}\text { air velocity of } & 2000 \mathrm{fpm} & & \\ .7 & .6 & 1.7 & 2.9 & 4.1 & 2.8\end{array}$

Rectangular muffler lining $16 \times 16$ inch low den-

Rectangular muf fler
sity cellular glass

$\begin{array}{lllll}7 & 1 & 3 & 3 & 3\end{array}$

3.5

$\begin{array}{lll}\text { Geocoustic Muffler } & \\ \text { Lining } & \text { CR }\end{array}$

Cylindrical muffler, lining I.D. 16 inch nominal,
16 inch actual. Low density cellular glass

$\begin{array}{lllllll}7 & 1 & 3 & 3 & 3 & 2\end{array}$

Fiberglass board with scrim-reinforced foil vapor barrier facing

$\begin{array}{llllll}1.1 & 9 & 2.3 & 3.3 & 3.8 & 2.1\end{array}$

Glass fiber with Eire-rated coating rested at air

$\begin{array}{llllll}4 & .5 & 1.7 & 4.4 & 3.8 & 2.2\end{array}$

einforced foil vapor Fiberglass board
barrier facing

$\begin{array}{lllllll}1 & .8 & 2.4 & 3.4 & 3.9 & 2.2\end{array}$

Glass fiber with fire-rated coating tested at air

$\begin{array}{lllllll}.6 & 8 & 2 & 3.4 & 3.9 & 3.6\end{array}$ Glass fiber with fire-rated coating tested at air

$\begin{array}{lrrrrr}6 & .1 & 2 & 3.4 & 4.1 & 3.7\end{array}$

Glass fiber with fire-rated coating tested at air velocity of $2000 \mathrm{fpm}$

$\begin{array}{llllll}.3 & 1 & 2.4 & 3.4 & 3.8 & 3.4\end{array}$

Glass fiber with fire-rated coating tested at ait velocity of $2000 \mathrm{fpm}$

$\begin{array}{llllll}2 & 1.1 & 2.4 & 3.5 & 3.9 & 3.7\end{array}$ Glass fiber with fire-rated coating tested at air
velocity of 2000 fpm

$\begin{array}{llllll}4 & 1.3 & 3.1 & 3.6 & 3.9 & 3.5\end{array}$

Glass fiber with fire-rated coating tested at air velocity of $2000 \mathrm{fpm}$

$\begin{array}{lllll}9 & 3.2 & 4.6 & 3.5 & 2.6\end{array}$

Glass fiber with fire-rated coating tested at air velocity of $2000 \mathrm{fpm}$

ass fiber with fire-rated coating tested at air velocity of $2000 \mathrm{fpm}$

$\begin{array}{llllll}.6 & 1 & 3.8 & 4.7 & 3.6 & 2.3\end{array}$

Glass fiber with fire-rated coating tested at air velocity of $2000 \mathrm{fpm}$

$\begin{array}{llllllll}. ? & 1.1 & 2.1 & 3.5 & 5.3 & 3.8 & 1\end{array}$

Aeroflex Duct Liner

96 Aeroflex Duct Liner, CR

96 Aeroflex Duct Liner.

Geocoustic Muffler

Lining

CR

Geocoustic Muffler Lining

CR

96 Type 475 FR

$C R$

6 Duct Liner Board CR

96 Type $800 \mathrm{FR}$

$\mathrm{CR}$

Aeroflex Duct Liner. Trpe 150

CR

Aeroflex Duct Liner.

Type 200 .

$\mathrm{CR}$

Aeroflex Duct liner.

Type 200

CR

Aeroflex Duct Liner.

Type 150

CR

eroflex Duct Liner.

Type 150

CR 
Table 35C. Attenuation properties of ducting continued.

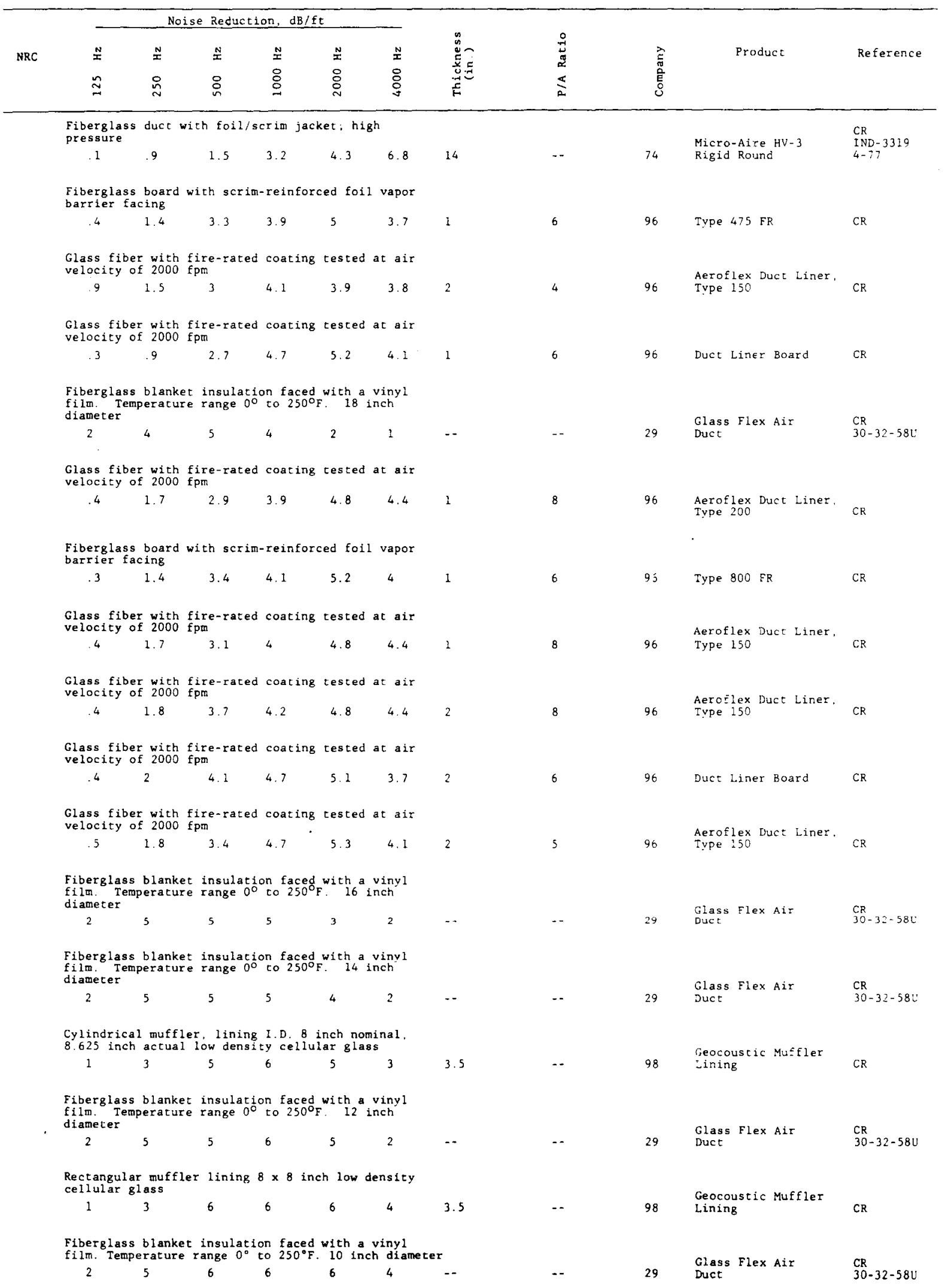


Table 35C. Attenuation properties of ducting concluded.

\begin{tabular}{|c|c|c|c|c|c|c|c|c|c|c|c|}
\hline \multirow{3}{*}{ NRC } & \multicolumn{6}{|c|}{ Noise Reduction, $\mathrm{dB} / \mathrm{ft}$} & \multirow{3}{*}{ 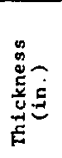 } & \multirow{3}{*}{$\begin{array}{l}0 \\
\vdots \\
2 \\
2 \\
\leq \\
\vdots\end{array}$} & \multirow{3}{*}{ 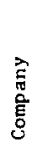 } & \multirow{3}{*}{ Product } & \multirow{3}{*}{ Reference } \\
\hline & 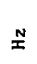 & $\stackrel{N}{x}$ & $\stackrel{N}{I}$ & $\mathbf{N}$ & I & $\stackrel{2}{2}$ & & & & & \\
\hline & $\stackrel{\approx}{\approx}$ & $\stackrel{\circ}{N}$ & 용 & $\stackrel{8}{\circ}$ & $\stackrel{\text { ㅇ }}{\mathrm{O}}$ & \& & & & & & \\
\hline
\end{tabular}

Fiberglass blanket insulation faced with a vinyl
film. Temperacure range 00 to $250^{\circ} \mathrm{F}$. \& inch

$\begin{array}{lllll}2 & 5 & 7 & 7 & 7\end{array}$

Fiberglass duct with foil-scrim jacket; high

.

$$
\text { 1. } 2
$$

2.5

$12.2 \quad 16$

10

Flexible round ducting of fiberglass helix wrapped with fiberglass insulation and covered wrapped with fiber
with plastic skin

$\begin{array}{lllllll}5.2 & 6.7 & 6.3 & 6 & 9.2 & 5.8\end{array}$ Fiberglass blanket insulation faced with a vinyl
film. Temperature range 00 to $250^{\circ} \mathrm{F}$. 6 inch

$$
2
$$$$
2
$$$$
\text { (n) }
$$

$$
87
$$

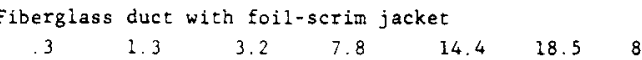

Cylindrical muffler lining of geocoustic material

irominal 4 inch, actual 4.5 inch, muffler lining$$
10
$$$$
11
$$

Flexible round ducting of fiberglass helix wrapped in fiberglass insulation and covered with plastic

$$
\begin{array}{llllll}
6.5 & 7.7 & 7.7 & 8.2 & 10.5 & 6.3
\end{array}
$$
Fiberglass blanket insulation faced with a vinyl
film. Temperature range 00 to $250 \% \mathrm{~F} .4$ inch

$$
3
$$

3

$$
89
$$

11

$10 \quad--$

Flexible round ducting of fiberglass helix wrapped with fiberglass insulation and covered with plas-
6.5
$10.5 \quad 10.7$

Rectangular muffler lining $4 \times 4$ inch, low density cellular glass
3
$7 \quad 12$
$12 \quad 13$
12
$8 \quad 3.5$

Fiberglass duct with foil-scrim jacket: high

pressure

$$
\begin{array}{lllll}
5.3 & 11.4 & 18.6 & 29 & 5
\end{array}
$$

Rectangular muffler lining $2 \times 2$ inch, low density cellular glas$$
6
$$

$$
14
$$

$$
24 \quad 26
$$

24

Cylindrical muffler lining I.D., nominal 2 inch. Cylindrical muffler lining I. D., nomina
actual 2.375 inch, low density glass

$$
\begin{array}{llllll}
16 & 28 & 30 & 28 & 19
\end{array}
$$

3.5 Double wall duct, filled with insulation, inside
wall perforated up co $150^{\circ} \mathrm{F}$.

$$
\begin{array}{llllllll}
82 & 1 & 15 & 8 & 8 & 217 & 2 &
\end{array}
$$

\begin{tabular}{|c|c|c|c|}
\hline & 29 & $\begin{array}{l}\text { Glass Flex } \\
\text { Air Duct }\end{array}$ & $\begin{array}{l}\text { CR } \\
30-32-58 \mathrm{U}\end{array}$ \\
\hline & 74 & $\begin{array}{l}\text { Micro-Aire HV-3 } \\
\text { Rigid Round }\end{array}$ & $\begin{array}{l}\text { CR } \\
\text { IND-3319 } \\
4-77\end{array}$ \\
\hline & 74 & Micro-Aire FLX & $\begin{array}{l}\mathrm{CR} \\
\text { IND-3319 } \\
4-77\end{array}$ \\
\hline & 29 & $\begin{array}{l}\text { Glass Flex } \\
\text { Air Duct }\end{array}$ & $\begin{array}{l}\mathrm{CR} \\
30-32-58 \mathrm{U}\end{array}$ \\
\hline & 74 & $\begin{array}{l}\text { Micro-Aire } \\
\text { Rigid Round }\end{array}$ & $\begin{array}{l}\text { CR } \\
\text { IND-3319 } \\
4-77\end{array}$ \\
\hline & 98 & $\begin{array}{l}\text { Geocoustic Muffler } \\
\text { Lining }\end{array}$ & $\mathrm{CR}$ \\
\hline & 74 & Micro-Aire FLX & $\begin{array}{l}\text { CR } \\
\text { IND-3319 } \\
4=77\end{array}$ \\
\hline & 29 & $\begin{array}{l}\text { Glass Flex } \\
\text { Air Duct }\end{array}$ & $\begin{array}{l}C R \\
30-32-58 \mathrm{U}\end{array}$ \\
\hline & 74 & Micro-Aire FLX & $\begin{array}{l}\text { CR } \\
\text { IND-3319 } \\
4-77\end{array}$ \\
\hline & 98 & $\begin{array}{l}\text { Geocoustic Muffler } \\
\text { Lining }\end{array}$ & $C R$ \\
\hline & 74 & $\begin{array}{l}\text { Micro-Aire } 4 V-3 \\
\text { Rigid Round }\end{array}$ & $\begin{array}{l}\text { CR } \\
\text { IND-3319 } \\
4=77\end{array}$ \\
\hline & 98 & $\begin{array}{l}\text { Geocoustic Muffler } \\
\text { Lining }\end{array}$ & $\mathrm{CR}$ \\
\hline & 98 & $\begin{array}{l}\text { Geocoustic Muffler } \\
\text { Lining }\end{array}$ & $C R$ \\
\hline & 131 & $\begin{array}{l}\text { Acousti } \mathrm{K}-27 \\
\text { Duct }\end{array}$ & $C R$ \\
\hline & 24 & Brunscoustic Plate & $C R$ \\
\hline & 24 & Feltmetal & $\mathrm{CR}$ \\
\hline
\end{tabular}

Porous sheet material of sintered metal fibers bonded to perforated sheet. Used as a viscous absorber lining separated from a duct wall by an air gap. Used in limited space silencers high pressure, temperature, or velocity gas streams; chemically hostile environments

Porous sheet material made from sintered metal fibers in a variety of materials and a wide range of acoustic flow resistances. Used as $v$ iscous absorber lining separated from a duct wall by an air space. Used in limited space

weers, high pressure, cenperature, or velo- 
CATEGORY 36. SEALS

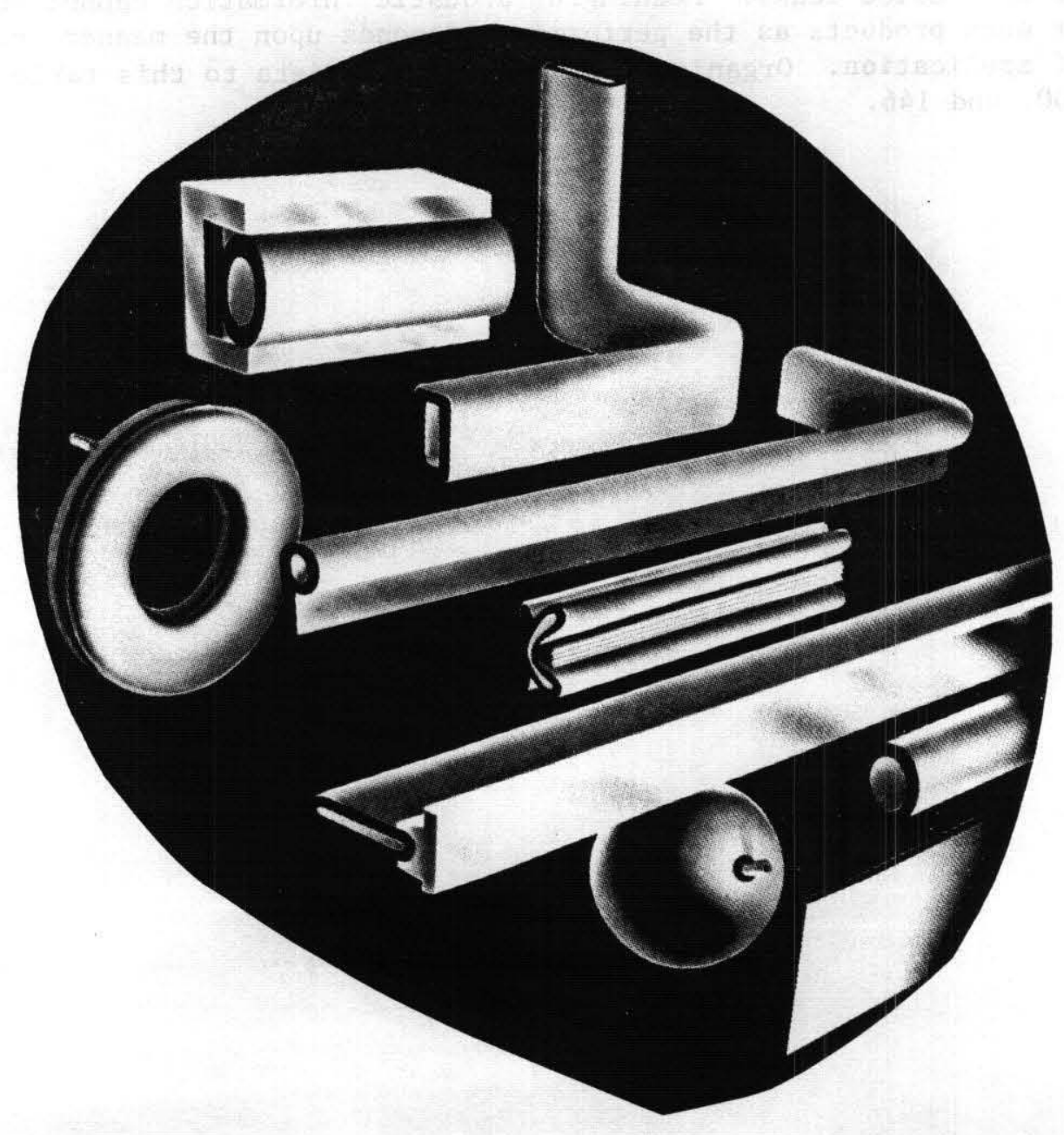




\section{CATEGORY 36. SEALS}

A very good sound barrier system would be rendered ineffective by a small noise leak. The products listed in the table can be used in a variety of ways to stop such noise leaks. Meaningful acoustic information cannot be provided for such products as the performance depends upon the manner and the place of application. Organizations contributing data to this table are: 25,100 , and 146 . 
Table 36. Transmission loss properties of seals.

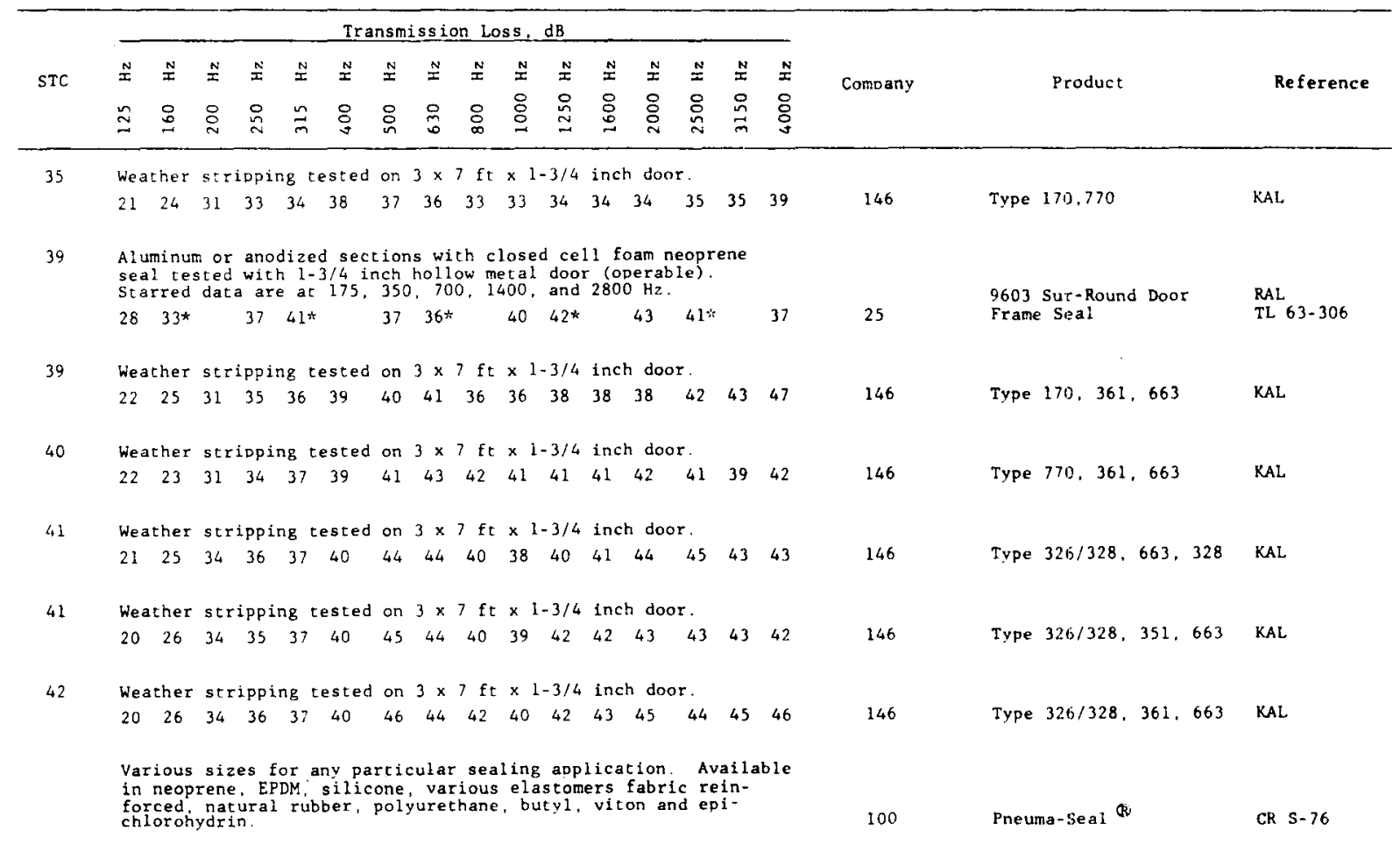


CATEGORY 37. DAMPING, DEADENERS, AND PADDING MATERIALS

The materials in this category are primarily used for decreasing vibration. A material may do this by absorbing, restricting, or changing the frequency characteristics of the vibrating structure. The material performance is usually mass related. In most cases where an absorptive material is used, its function is that of a cushioning device or deadener to limit vibration rather than as a sound absorber.

The information presented is not consistent between companies as that comparative evaluation of materials is not possible. Therefore, products are listed in alphabetical order by organization.

Organizations contributing data to this table are: $13,22,32,33,36,38$, $40,47,78,81,82$, and 117 . 
Table 37. Damping material.

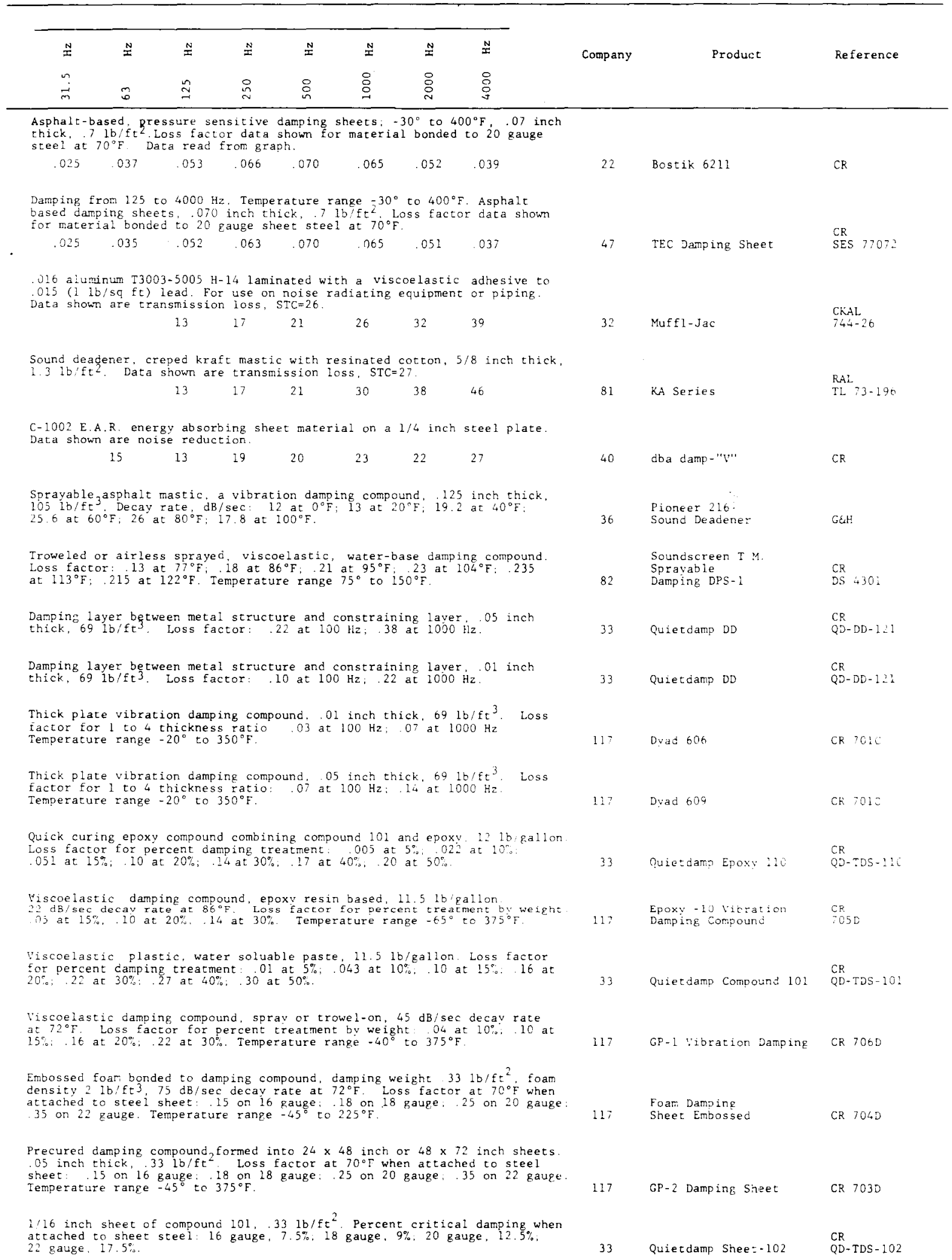


Table 37. Damping material concluded.

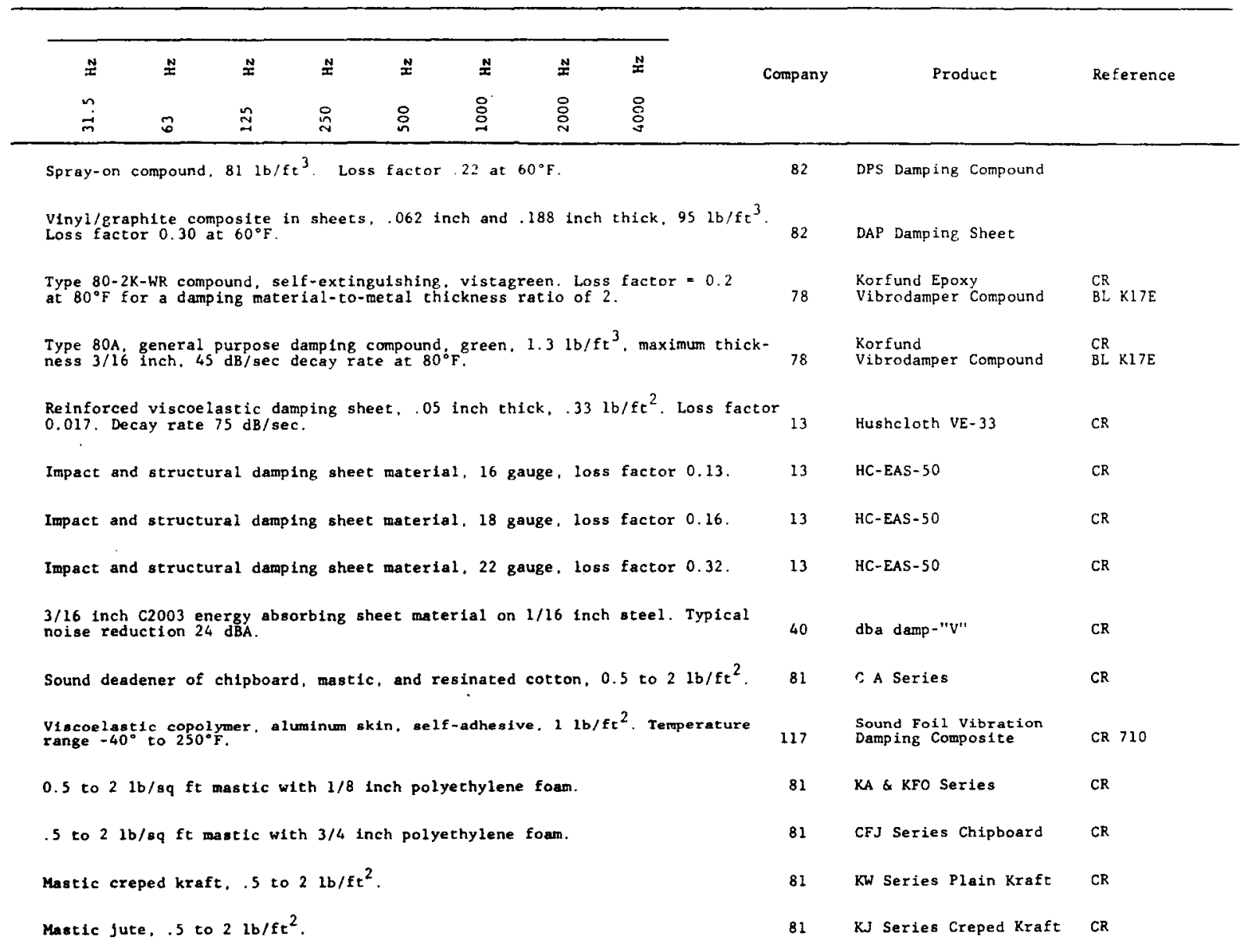




\section{CATEGORY 38. SPECIAL APPLICATIONS}

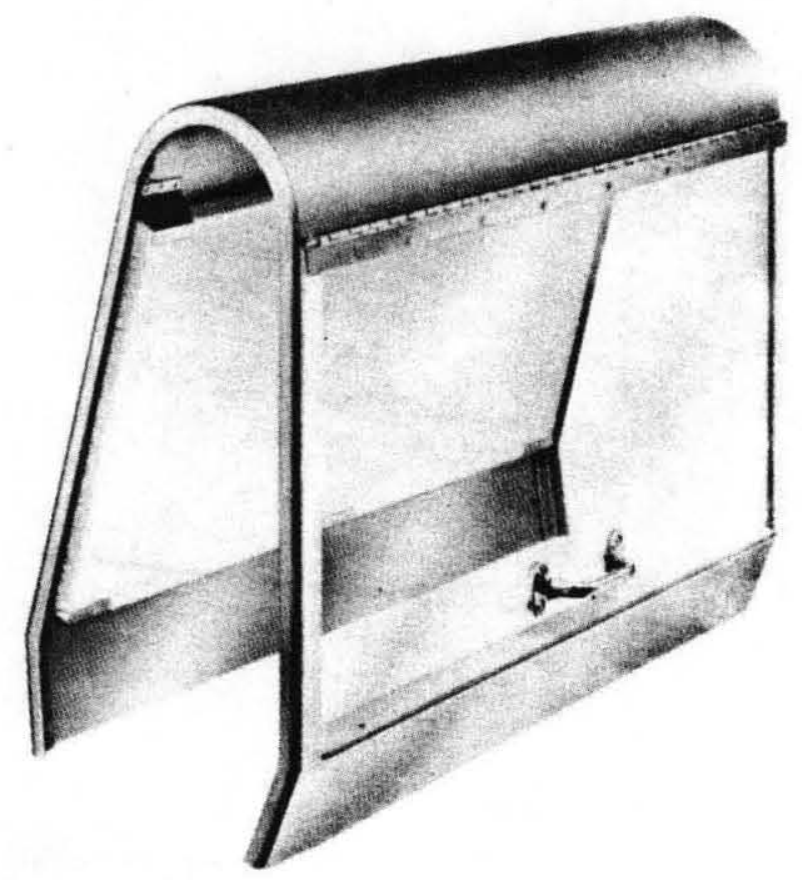


CATEGORY 38. SPECIAL APPLICATIONS

\begin{abstract}
Several products are presented here which have unique acoustical features not included in other categories. Some examples are ear plugs and ear protectors, special covers or enclosures, and partial barriers. Many of these products do not have appropriate acoustic data so that specific information must be requested from the manufacturer or distributor. Organizations contributing data to this table are: 3, 20, 40, 41, 48, 53, 82, and 137.
\end{abstract}


Table 38. Special applications.

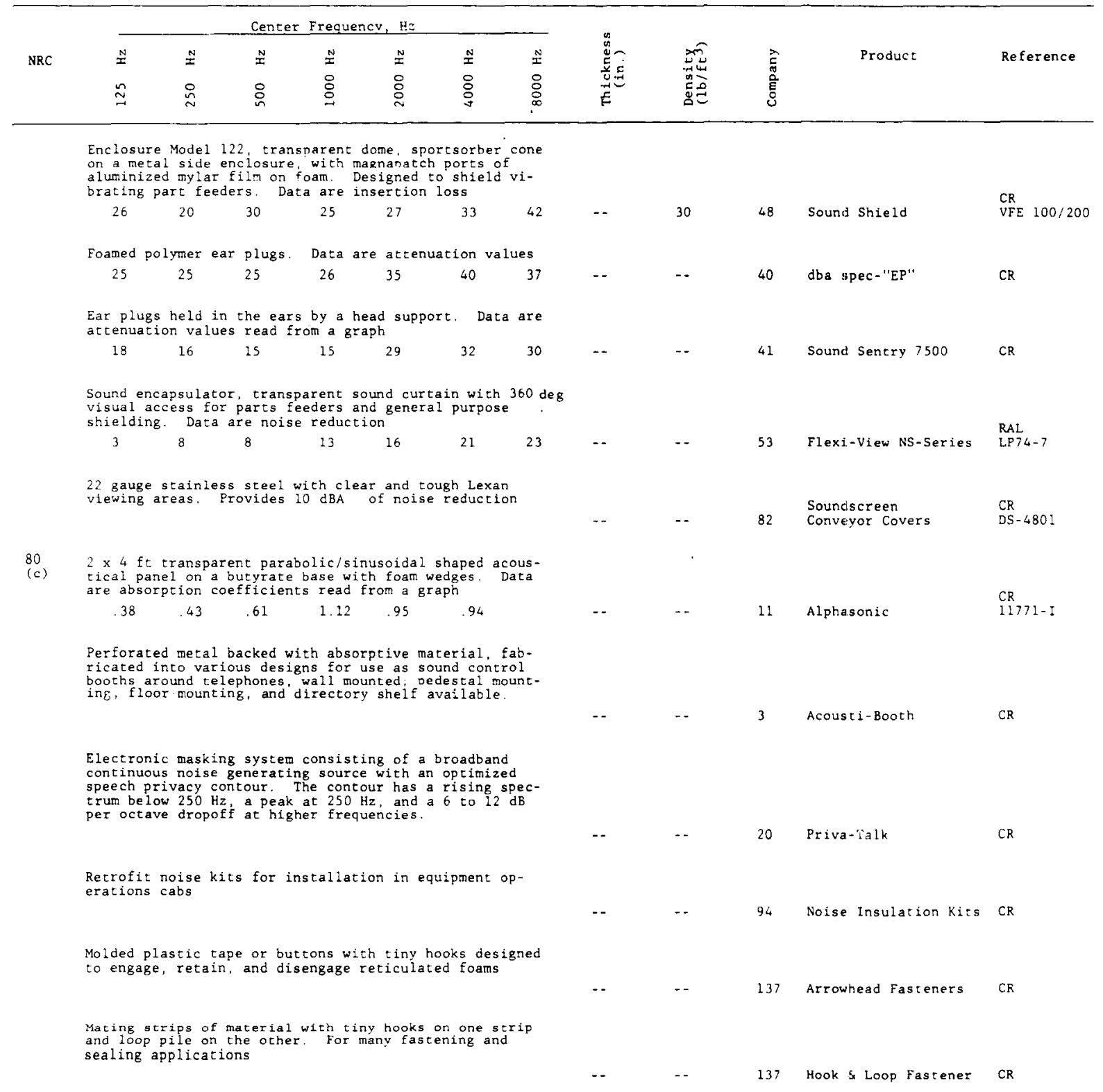





\section{Description}

Absorptive Block

Barrier/Fiberglass Composites

Barrier/Foam Composites

Ceiling Tiles

Curtains

Damping/Deadeners/Padding

Doors

Ducting Materials

Duct Silencers

Enclosures

Fan Silencers

Felt

Floors

Foam

General Industrial Silencers

Glass Fiber Materials
Table/Type

1

7A (absorption)

7B (barrier)

8A (absorption)

8B (barrier/TL)

8C (barrier/IL)

8D (barrier/NR)

$14 \mathrm{~A}$ (absorption)

14B (barrier)

15A (absorption)

15B (barrier)

37

20

35A (absorption)

35B (barrier/IL)

35C (attenuation)

34

19A (absorption)

19B (barrier/TL)

19C (barrier/NR)

30

3A (absorption)

3B (barrier)

21A (TL and impact)

21B (TL)

$21 \mathrm{C}$ (impact)

2

$28 \mathrm{~A}$ (attenuation)

28B (IL)

4A (absorption/number $4 \mathrm{mtg}$ )

4B (absorption/number $6 \mathrm{mtg}$ )

4C (absorption/number $7 \mathrm{mtg}$ )

4D (absorption/number $7 \mathrm{mtg} \bmod$.

4E (absorption/other $\mathrm{mtg}$ )

4F (barrier/other $\mathrm{mtg}$ )
Page

Number

159

193

194

198

199

200

201

222

227

231

232

371

266

359

361

364

354

259

260

262

327

170

170

270

272

273

163

314

317

173

176

180

183

184

185 
$\underline{\text { Description }}$

Glass and Plastic Sheets

High Pressure Discharge Silencers 29

Inlet and Exhaust Silencers 31

Mastics

Mineral Fiber Materials

Open Plan Systems

Operable Partitions

Other Barrier Materials

Panels

Pipe Laggings

Plain and Mass-Loaded Plastics

Quilted Materials

Roof Decks

Seals

Special Applications

Splitter/Louver Silencers

Spray On Materials

Unit Absorbers

Vehicular Mufflers

Walls

Wa11 Tratments

Windows

12

24

13
Table/Type

Page

Number

215

322

332

9A (absorption)

9B (barrier/TL)

204

204

205

188

$\begin{array}{ll}5 \mathrm{~A} \text { (absorption) } & 188 \\ 5 \mathrm{~B} \text { (barrier) } & 188\end{array}$

25A (absorption) 296

25B (barrier) 297

25C (speech, privacy) 297

293

218

$16 \mathrm{~A}$ (absorption) 236

16B (barrier) 239

$27 \mathrm{~A}$ (NR) 307

27B (IL) 309

$27 \mathrm{C}$ (TL) 311

112211

$10 \mathrm{~A}$ (absorption) 208

10B (barrier) 208

$17 \mathrm{~A}$ (absorption) 245

$17 \mathrm{~B}$ (barrier) 248

$36 \quad 369$

$38 \quad$. $\quad 375$

$32 \quad 335$

6190

$18 \quad 252$

$33 \quad .338$

22A (gypsum board/E90-70) 277

22B (gypsum board/AMA I-11) 280

$22 \mathrm{C}$ (other) 286

$26 \quad 300$

$23-290$ 
PHOTOGRAPHIC CREDITS

Courtesy of

Category

American Acoustical Products

Celotex Corporation

Top: American Acoustical Products

Bottom: Johns Manville

4

Celotex Corporation

Left: Canada Metal Company Ltd.

Right: Globe Industries Inc.

Tube-Lok Products

Top: Celotex Corporation

Bottom: Globe Industries Inc.

Top: Foam Design Inc.

Bottom: Acoustiflex Corporation

Top: Foam Design Inc.

Bottom: Korfund Dynamics

National Gypsum

Foam Design Inc.

Koch

Middle: Inryco

Bottom: Concrete Products Inc.

Lord All Force Acoustics

Acoustiflex Corporation

Stanley Door

Owens/Corning Fiberglass Corporation

National Gypsum

DeVac Inc.

Hough Manufacturing Corporation

Top: L. E. Carpenter \& Company

Bottom: Upstate Precision

Açoustiflex Corporation 
Accessible Products

Quietflo

Top: Lehigh Corporation

Bottom: Aeroacoustic Corporation

29

Aeroacoustic Corporation

30

Aeroacoustic Corporation

31

Aeroacoustic Corporation

32

Donaldson Corporation

33

Environmental Elements Corporation

34

Top: Certainteed Corporation

Bottom: Johns Manville Corporation

35

Presray

36

All Force Acoustics

38 